\title{
Application of digital infrared thermography for nondestructive evaluation of composite bridge components
}

Archana Vasudevan

West Virginia University

Follow this and additional works at: https://researchrepository.wvu.edu/etd

\section{Recommended Citation}

Vasudevan, Archana, "Application of digital infrared thermography for nondestructive evaluation of composite bridge components" (2004). Graduate Theses, Dissertations, and Problem Reports. 1470. https://researchrepository.wvu.edu/etd/1470

This Thesis is protected by copyright and/or related rights. It has been brought to you by the The Research Repository @ WVU with permission from the rights-holder(s). You are free to use this Thesis in any way that is permitted by the copyright and related rights legislation that applies to your use. For other uses you must obtain permission from the rights-holder(s) directly, unless additional rights are indicated by a Creative Commons license in the record and/ or on the work itself. This Thesis has been accepted for inclusion in WVU Graduate Theses, Dissertations, and Problem Reports collection by an authorized administrator of The Research Repository @ WVU. For more information, please contact researchrepository@mail.wvu.edu. 


\title{
APPLICATION OF DIGITAL INFRARED \\ THERMOGRAPHY FOR NONDESTRUCTIVE \\ EVALUATION OF COMPOSITE BRIDGE COMPONENTS
}

\author{
By \\ ARCHANA VASUDEVAN \\ THESIS \\ Submitted to the \\ College of Engineering and Mineral Resources \\ West Virginia University
}

In partial fulfillment of the requirements for the degree of

Master of Science in Civil Engineering

Udaya B. Halabe, Ph.D., P.E., Chair

Hota V. S. GangaRao, Ph.D., P.E.

Powsiri Klinkhachorn, Ph.D.

Department of Civil and Environmental Engineering

Morgantown, West Virginia

2004

Keywords: Composites, Defects, Debonds, Delaminations, FRP, Digital Infrared Thermography, Temperature-Time Analysis, Aging, Fatigue, Wraps 


\section{ABSTRACT \\ APPLICATION OF DIGITAL INFRARED THERMOGRAPHY FOR NONDESTRUCTIVE EVALUATION OF COMPOSITE BRIDGE COMPONENTS}

\section{ARCHANA VASUDEVAN}

The objective of this research is to evaluate the applicability of digital infrared thermographic system to detect subsurface defects such as debonds and delaminations in Fiber Reinforced Polymer (FRP) bridge decks and other composite bridge components such as beams and columns wrapped with steel or FRP jacket.

Infrared thermography is one of the nondestructive evaluation (NDE) techniques that are being used for testing field bridges and ensuring continued structural integrity of bridge components. The infrared technique allows rapid data collection and interpretation in the field. Also, recent advances in digital infrared imaging has opened the door for using more advanced image enhancement techniques, which can lead to better sensitivity and reliability in the detection of subsurface defects.

This thesis investigates the use of digital infrared thermography on FRP bridge decks both under laboratory and field conditions. Air-filled and water-filled debonds were inserted between the wearing surface and the underlying FRP deck. Also, simulated subsurface delaminations (of various sizes and thickness) were created at the flange-to-flange junction between two FRP deck modules. The infrared technique was used to detect these embedded subsurface defects. Also, the use of various heating and cooling methods was explored. The effect of distance on the detectability of debonds and delaminations were considered. Surface temperature-time curves were established for different sizes of delaminations and debonds. As a part of this research two infrared field tests were conducted. One of the field trips was conducted to locate debonds in an FRP bridge deck. The other field trip involved inspecting and locating debonds in FRP wrapped timber railroad bridge components. Other types of bridge components considered in the laboratory studies included steel-concrete composite columns with embedded debonds and FRP wrapped wooden members for debonds or cracks.

The results show that infrared thermography is a useful tool for defect detection in composite decks. Therefore, the technique can be used for several applications such as quality control during pultrusion of new decks (in factories), during field construction, and field inspection of in-service decks. The technique was also successful in detecting subsurface defects in various other composite components considered in this study. 


\section{ACKNOWLEDGEMENTS}

I would like to express my deep sense of gratitude to my advisor Dr. Udaya B. Halabe, for his valuable guidance, encouragement and support that I received during my Master of Science in Civil Engineering (M.S.C.E.) degree program at West Virginia University, Morgantown, WV. I would like to thank Dr. Hota. V. S. GangaRao for his kind support and help during my research and studies. I would also like to thank Dr. Powsiri Klinkhachorn for serving on my thesis committee and providing valuable help.

I extend my thanks to Dr. P. V. Vijay for providing information related to accelerated aging tests. I wish to thank Mr. Samer H. Petro for helping me in connection with my field trips on testing of timber railroad bridge. I would also like to convey my thanks to Mr. Dana Humberson and Mr. David Turner for their laboratory assistance. I would also like to thank all the other staff members of Constructed Facilities Center (CFC) at West Virginia University for providing their timely help.

I would like to acknowledge the funding for this research as a part of the research grants from the U. S. Department of Transportation - Federal Highway Administration (USDOT-FHWA) - CFC Center of Excellence program and the U.S.D.O.T - Federal Railroad Administration (USDOT-FRA). Also, the help provided by West Virginia Division of Highways (WVDOH) during field testing of a composite bridge deck in Monroe County, WV is greatly appreciated.

I wish to thank my parents, sister and brother-in- law for their love, constant encouragement and support. Finally, I wish to thank all my friends for their help directly or indirectly in my research work. 
Description

Page No.

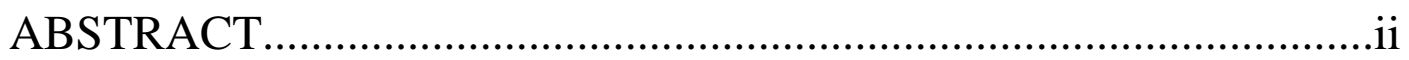

ACKNOWLEDGEMENTS.........................................................ii

CHAPTER 1 - INTRODUCTION 1

1.1 BACKGROUND 1

1.1.1 Bridge status 1

1.1.2 Strategies for Repair/Rehabilitation Using FRP 2

1.1.3 Typical NDE Techniques 3

1.2 RESEARCH OBJECTIVES 4

1.3 SCOPE 5

1.4 ORGANIZATION

CHAPTER 2 - REVIEW OF THEORY AND APPLICATIONS OF INFRARED THERMOGRAPHY 6

2.1 INFRARED BASICS AND TESTING METHODOLOGY 6

2.1.1 Heat Transfer 6

2.1.2 Electromagnetic Spectrum $\quad 8$

2.1.3 Infrared Measurement $\quad 8$

2.1.4 Active and Passive Thermography 9

2.1.5 Testing Procedure 9

2.1.6 Advantages and Disadvantages 10

2.2 PRINCIPLES OF THERMOGRAPHY AND RADAR FOR BRIDGE DECK ASSESSMENT (MASER AND RODDIS 1990) 11

2.2.1 Summary 11 
2.2.3 Physical Basis for Thermography 12

2.2.4 Physical Thermal Model of Delamination 12

2.2.5 Cases Analyzed and the Results from Thermal Model 13

2.2.6 Analysis Results from the Thermal Model 14

2.2.7 Ground Penetrating Radar $\quad 17$

2.2.8 Results from Field Studies $\quad 17$

2.2.9 Conclusions 17

2.3 NONDESTRUCTIVE EVALUATION OF FRP COMPOSITE MEMBERS USING INFRARED THERMOGRAPHY (BANGALORE 2002) 18

2.3.1 Laboratory Experimental Setup 18

2.3.2 Specimens Setup 19

2.3.3 Infrared Tests and Results $\quad 20$

2.3.4 Conclusions 22

2.4 DETECTION OF SUBSURFACE ANOMALIES IN COMPOSITE BRIDGE DECKS USING INFRARED THERMOGRAPHY (ALQENNAH 2000) 22

2.4.1 Laboratory Experiments 22

2.4.1.1 Experimental Setup 22

2.4.1.2 Specimen Setup 22

2.4.1.3 Infrared Results 23

2.4.1.4 Conclusions 25

2.4.2 Field Studies 25

2.4.2.1 Field Setup and Tests $\quad 26$

2.4.2.2 Conclusions 29

2.5 HEALTH MONITORING OF FRP BRIDGE DECKS

(MICELI ET AL. 2001) 29

2.5.1 Summary 29

2.5.2 Background 29

2.5.3 Experimental Procedure $\quad 30$

2.5.4 Results and Discussions 31

2.5.5 Conclusions 34 
2.6 TEMPORAL TREATMENT OF A THERMAL RESPONSE FOR DEFECT DEPTH ESTIMATION (PLOTNIKOV AND WINFREE 1999) 34

2.6.1 Introduction 34

2.6.2 Processing of Thermal Response in Time Domain 34

2.6.3 Comparison of Algorithms (Computational Approach) 35

2.6.4 Comparison of Algorithms (Experimental Approach) 39

2.6.5 Conclusions

CHAPTER 3 - INFRARED MONITORING SYSTEMS

AND EQUIPMENT 43

3.1 INFRARED CAMERAS

3.1.1 The FSI Prism Single Point (SP) Infrared Camera 43

3.1.2 ThermaCAM ${ }^{\text {TM }}$ S60 44

3.2 HEATING SOURCES 46

3.2.1 Quartz Tower Heater 46

3.2.2 Heating Blankets $\quad 47$

3.2.3 Solar Radiation $\quad 48$

3.3 COOLING SOURCES $\quad 48$

3.3.1 Liquid Carbon Dioxide $\left(\mathrm{CO}_{2}\right) \quad 49$

3.3.2 Cold Water $\quad 50$

CHAPTER 4 - LABORATORY EXPERIMENTS, ANALYSIS AND RESULTS 51

4.1 INTRODUCTION 51

4.2 PREPARATION OF DEBONDS AND DELAMINATIONS 52

4.3 EXPERIMENTAL SETUP 54

4.4 DETECTION OF DEBONDS BENEATH THE WEARING SURFACE 56

4.4.1 Description of Specimens 56

4.4.2 Infrared Tests and Results $\quad 60$ 
4.4.3 Conclusions

4.5 DETECTION OF DELAMINATIONS WITHIN THE FLANGE-FLANGE JUNCTION

4.5.1 Description of Specimens $\quad 64$

4.5.2 Infrared Tests and Results 65

4.5.3 Conclusions 69

4.6 SURFACE TEMPERATURE-TIME CURVES AND

ANALYSIS FOR DEBONDS AND DELAMINATIONS 70

4.6.1 Bridge deck Specimens $\quad 70$

4.6.2 Infrared Tests and Results $\quad 70$

4.6.3 Conclusions 83

4.7 INFRARED TESTS ON DECKS SUBJECTED

TO FATIGUE LOADING $\quad 84$

4.7.1 Bridge Deck Specimens $\quad 84$

4.7.2 Fatigue Loading Setup $\quad 86$

4.7.3 Infrared Tests and Results $\quad 88$

4.7.4 Conclusions 98

4.8 INFRARED TESTS ON DECKS SUBJECTED TO

ACCELERATED AGING 99

4.8.1 Description of Specimens and their Conditioning 102

4.8.2 Infrared Tests and Results 105

4.8.3 Conclusions 112

4.9 EFFECT OF DISTANCE ON DETECTABILITY OF DEFECTS 112

4.9.1 Description of Specimens 113

4.9.2 Infrared Tests and Results 113

4.9.3 Conclusions 120

4.10 INFRARED TESTS CONDUCTED UNDER SOLAR RADIATION 120

4.10.1 Description of Specimens 121

4.10.2 Infrared Tests and Results 121

4.10.3 Conclusions 131

4.11 INFRARED TESTS USING COOLING SOURCES 132 
4.11.1 Liquid Carbon Dioxide $\left(\mathrm{CO}_{2}\right) \quad 132$

4.11.2 Cold Water 134

$\begin{array}{ll}\text { 4.11.3 Conclusions } & 136\end{array}$

4.12 INFRARED TESTS ON STEEL-CONCRETE $\begin{array}{ll}\text { COMPOSITE COLUMNS } & 136\end{array}$

$\begin{array}{ll}\text { 4.12.1 Description of Specimens } & 137\end{array}$

4.12.2 Infrared Tests and Results 138

$\begin{array}{ll}\text { 4.12.3 Conclusions } & 140\end{array}$

4.13 INFRARED TESTS ON FRP WRAPPED TIES 140

4.13.1 Description of Specimens 141

4.13.2 Infrared Tests and Results 141

4.13.3 Conclusions 144

4.14 CONTRAST PARAMETER 145

$\begin{array}{ll}4.15 \text { OVERALL CONCLUSIONS } & 147\end{array}$

CHAPTER 5 - FIELD TESTING AND EVALUATION OF TIMBER RAILROAD BRIDGE COMPONENTS 149

$\begin{array}{ll}5.1 \text { INTRODUCTION } & 149\end{array}$

$\begin{array}{ll}5.2 \text { DESCRIPTION OF THE BRIDGES } & 149\end{array}$

5.3 LABORATORY EXPERIMENTS 152

5.3.1 Experimental Setup 152

5.3.2 Test Specimens 154

5.3.3 Experimental Results 154

5.3.3.1 Results with Quartz Tower Heater 154

5.3.3.2 Results with Solar Radiation 156

5.3.3.3 Results with Greenhouse effect 156

$\begin{array}{ll}5.4 \text { FIELD TESTS } & 157\end{array}$

5.4.1 Summer 2001 Testing 157

5.4.1.1 Experimental Setup 157

5.4.1.2 Infrared Testing and Results 158

5.4.2 Summer 2002 Testing 162 
5.4.2.1 Experimental Setup $\quad 162$

5.4.2.2 Infrared Testing and Results 163

5.4.3 Summer 2003 Testing 173

5.4.3.1 Experimental Setup $\quad 173$

5.4.3.2 Infrared Testing and Results 174

$\begin{array}{ll}\text { 5.4.4 Conclusions } & 189\end{array}$

CHAPTER 6 - FIELD TESTING OF FRP BRIDGE DECK 191

6.1 INTRODUCTION 191

6.2 DESCRIPTION OF THE BRIDGE 191

6.3 EXPERIMENTAL SETUP 193

6.4 INFRARED TESTING AND RESULTS 193

6.5 CONCLUSIONS 206

CHAPTER 7 - CONCLUSIONS AND RECOMMENDATIONS 207

7.1 CONCLUSIONS 207

7.1.1 Literature Review 207

7.1.2 Laboratory Experiments and Analysis 208

7.1.3 Field Testing and Evaluation 210

7.2 RECOMMENDATIONS FOR FUTURE RESEARCH 211

REFERENCES 213 


\section{Chapter 1}

\section{INTRODUCTION}

\subsection{BACKGROUND}

\subsubsection{Bridge Status}

The transportation infrastructure is the backbone of the United States. As per the National Bridge Inventory (NBI) 2003 report (National Bridge Inspection Programs conducted by the United States Department of Transportation (USDOT) - Federal Highway Administration (FHWA)), as of February 2003 about 25\% of the total numbers of bridges (includes U.S. Highways, Nation's Interstate Highways, State and County Roads, and other routes of national significance) in the US are classified as structurally deficient or functionally obsolete, with the estimated cost for replacement and rehabilitation running into billions of dollars.

A structurally deficient bridge is one that has been restricted to light vehicles only, is closed, or requires rehabilitation for remaining open to traffic. On the other hand, a functionally obsolete bridge is one in which some of the criteria for deck geometry, load carrying capacity (comparing original design load to the current state legal load), clearance or approach roadway alignment, for the bridge are no longer met. Although a bridge can be classified into any or both of these categories, these percentages are additive because any bridge classified as structurally deficient is not included in the functionally obsolete category (Dunker and Rabbat 1990).

Table 1.1 Statistics on the Nation's Bridges (National Bridge Inventory 2003)

\begin{tabular}{|c|c|c|c|c|c|c|}
\hline $\begin{array}{c}\text { Month - } \\
\text { Year }\end{array}$ & $\begin{array}{c}\text { \# of } \\
\text { Bridges }\end{array}$ & $\begin{array}{c}\text { \# Not } \\
\text { deficient }\end{array}$ & $\begin{array}{c}\text { Structurally } \\
\text { deficient }\end{array}$ & $\begin{array}{c}\text { Functionally } \\
\text { Obsolete }\end{array}$ & $\begin{array}{c}\text { \# Total } \\
\text { Deficient }\end{array}$ & $\begin{array}{c}\% \\
\text { Deficient }\end{array}$ \\
\hline Dec 98 & 582,984 & 410,387 & 93,076 & 79,506 & 172,582 & 29.6 \\
\hline Dec 99 & 585,542 & 415,492 & 88,150 & 81,900 & 170,050 & 29.0 \\
\hline Dec 00 & 587,458 & 419,877 & 86,692 & 80,889 & 167,581 & 28.5 \\
\hline Dec 01 & 590,066 & 424,967 & 83,630 & 81,469 & 165,099 & 28.0 \\
\hline Dec 02 & 594,220 & 431,210 & 81,437 & 81,573 & 163,010 & 27.4 \\
\hline
\end{tabular}


Though we see from the table that the number of deficient bridges has been decreasing over the years, there are still a large number of bridges that require some repair, major rehabilitation or replacement. One of the major reasons for bridge deficiency is the deterioration of the deck due to fatigue loading and harsh environments. Most of the existing bridges are made of concrete that are over 30 to 50 years old. Deterioration of concrete members, primarily the decks, has been one of the major problems. Apart from concrete bridges, there are wooden bridges (mainly rail road bridges, some over 100 years old) which are subjected to decay and deterioration over time.

\subsubsection{Strategies for Repair/Rehabilitation Using FRP}

Repair or replacement of the bridges with new innovative materials have been studied and tested over the past decade. The USDOT-FHWA and several state DOTs (e.g., CA, NY, OH, WV) are focusing on advancing the Fiber Reinforced Polymer (FRP) composite technology to rebuild the American transportation infrastructure in terms of new bridge construction as well as the rehabilitation and maintenance of the existing bridge inventory.

Researchers around the world have demonstrated the use of (FRP) composite as a space age technology for bridge construction. New breeds of this high performance and innovative materials are making headway into the civil and bridge infrastructures. FRP bridge decks are being considered for replacing old concrete bridge decks because of the higher strength-to-weight ratio, better durability and better corrosion resistance properties offered by FRP deck systems. A 8" (203mm) thick concrete deck weighs about 100 to $110 \mathrm{lb} / \mathrm{ft}^{2}$ (488 to $537 \mathrm{~kg} / \mathrm{m}^{2}$ ), whereas a 8” (203mm) thick composite deck weighs only about 20 to $25 \mathrm{lb} / \mathrm{ft}^{2}$ (98 to $122 \mathrm{~kg} / \mathrm{m}^{2}$ ) (Shekar et al.2002). A light-weight 8” (203mm) thick composite deck weighs about $15 \mathrm{lb} / \mathrm{ft}^{2}\left(73 \mathrm{~kg} / \mathrm{m}^{2}\right)$ and a low-profile $4 "(102 \mathrm{~mm})$ thick composite deck weighs about $10 \mathrm{lb} / \mathrm{ft}^{2}\left(49 \mathrm{~kg} / \mathrm{m}^{2}\right)$. Also, FRP modular decks allow easy and rapid installation during field construction. FRP materials are also being used by the Federal Railroad Administration (FRA) to rehabilitate old timber bridges. FRP jacketing (wrapping) is a technique primarily being used for rehabilitating deteriorating structural members (e.g., concrete beams and columns, wooden piles and pile caps) in 
existing concrete bridges and timber railroad bridges. These FRP jackets, when properly bonded to the underlying structural members, increase their load carrying capacity. Also, some state DOTs (e.g., NY and CA) are using steel jacket to rehabilitate concrete columns which deteriorated as a result of in-service loads (including earthquake loads) and environmental conditions.

Use of innovative materials such as FRP requires utilization of new types of field testing and evaluation methods in order to ensure construction quality and continued structural integrity. For example, there may be areas with debonds between the composite jacket and the underlying structural member, in which case the enhanced load carrying capacity is not fully realized. Also, additional debonds may form during the life of the bridge, causing a loss of composite action and further reducing the load carrying capacity of the members. The FRP bridge decks, on the other hand, are susceptible to subsurface debonds (between the wearing surface and the underlying deck) and delaminations (within the flanges of the composite deck), which can adversely affect the ride quality and load carrying capacity, respectively. Therefore, periodic monitoring of the bridge components is necessary for timely detection of subsurface defects such as debonds and delaminations.

\subsubsection{Typical NDE Techniques}

Nondestructive testing and evaluation (NDE\&T) techniques are increasingly being considered for the condition assessment of aging infrastructures (National Bridge Inventory 2003). NDT techniques are used for materials evaluation and defect detection in various structural components (like, beams, columns, slabs, etc.) without impairing their future usefulness. Some of the NDE techniques used in evaluating bridges and other aging infrastructure are Infrared Thermography, Ground Penetrating Radar (GPR), Elastic Wave Propagation (e.g., ultrasonics and acoustic emission), Fiber Optics, etc. Infrared thermography is emerging as one of the promising NDE techniques for the evaluation and defect detection in bridge components. It utilizes the heat energy radiated by an object to characterize its subsurface conditions. The subsurface defects affect the rate of heat transfer through the thickness of the structural member and hence result in surface temperature differentials with respect to defect-free areas. The surface 
temperatures are recorded by the infrared camera in the form of real-time color or black and white images (thermograms) that can be interpreted easily to reveal the location and size of subsurface defects in the bridge components. Some of the major advantages of the infrared thermography technique are that the equipment is portable, the data acquisition can be done rapidly and interpretation of the infrared images is relatively easy. Advanced digital infrared cameras and image processing techniques can be used to enhance the quality of the images.

\subsection{RESEARCH OBJECTIVES}

The objective of this research is to investigate the use of digital infrared thermography for detecting subsurface defects in composite bridge members. The specific sub-objectives are:

- Review literature on recent developments in the processing and analysis of infrared thermography.

- Create debonds (between the wearing surface and the underlying FRP deck specimens) and delaminations (within the flanges of FRP deck specimens) with different lateral dimensions and thicknesses and investigate the detectability of such subsurface defects using digital infrared thermography.

- To compare the thermal contrasts in the infrared images obtained using different heat sources like solar heating, quartz tower heater, heating blanket, and also cooling sources like cold water and liquid carbon dioxide (which is equivalent of negative heat).

- To investigate the detectability of debonds and delaminations over different distances using infrared thermography.

- To establish surface temperature-time curves for different sized debonds and delaminations in FRP bridge deck members using digital infrared thermography.

- To conduct field study on a FRP bridge deck to detect debonds between the wearing surface and the underlying deck.

- To conduct field studies to detect debonds and assess the effectiveness of the wrapping method and for periodic monitoring of bond integrity in FRP wrapped timber components on rehabilitated railroad bridges. 
- Provide recommendations for future testing using digital infrared thermography along with the different methods of heating and cooling.

\subsection{SCOPE}

Literature review on infrared thermography technique and its applications have been carried out. This research involved the extensive usage of the state-of-the art digital infrared camera and the associated software. Laboratory investigations were conducted on many Glass Fiber Reinforced Polymer (GFRP) composite bridge deck specimens with embedded debonds and delaminations using the digital infrared camera. The scope also included the study of different heating as well as cooling methods used in conjunction with infrared thermography to detect debonds/delaminations in the GFRP bridge deck specimens. Tables and graphs for the surface temperature-time analysis of debonds and delaminations are provided. Laboratory experiments for debond detection in other types of composite bridge components like steel-concrete composite column and FRP wrapped wooden ties are included. The scope also includes infrared testing and evaluation of a FRP bridge deck and FRP wrapped components (e.g., timber piles and pile caps) in timber railroad bridges.

\subsection{ORGANIZATION}

This thesis is organized into seven chapters. Chapter 1 presents the background, scope and objective of the research. Chapter 2 reviews the literature on the infrared thermography technique, recent developments and applications on various bridge components. Chapter 3 gives a detailed description of the digital infrared camera and the associated software used for this research. This chapter also includes the various heating and cooling methods used in the study. Chapter 4 presents the laboratory tests conducted on various bridge components like FRP bridge decks, FRP wrapped timber ties and steelconcrete composite columns. Field tests conducted for the condition assessment of FRP wrapped timber railroad bridge components are discussed in Chapter 5. Field tests conducted on a FRP bridge deck and the corresponding results are presented in Chapter 6. Conclusions of this research and recommendations for future studies are included in Chapter 7 , followed by a listing of all the references cited in this study. 


\section{Chapter 2 \\ REVIEW OF THEORY AND APPLICATIONS OF INFRARED THERMOGRAPHY}

The Infrared NDT technique is used for the condition assessment of various structural components and materials. Many researchers have demonstrated the use of this technique on composite materials and components. The theory behind the technique and the testing methodology is discussed in the sections below. Applications of the infrared technique for evaluation of various composite bridge components are also reviewed. The other sections include studies and evaluation of various composite materials based on the aging and fatigue behaviors.

\subsection{INFRARED BASICS AND TESTING METHODOLOGY}

\subsubsection{Heat Transfer}

Heat transfer in a medium or material occurs in three different ways: Conduction, Convection and Radiation. Conduction in a stationery media is the propagation of heat energy from one molecule to another, generally from higher temperature regions to lower temperature regions. The heat flow through a medium is directly proportional to the temperature difference (between hot and cold regions) and the thermal conductivity of the medium. Convection is the heat transfer that takes place due to the motion of a fluid medium (like air) over the solid structural material. The main parameters that determine the convective heat transfer are: the temperature of the solid surface, temperature of the surrounding air and wind speed. Radiation is the heat transfer caused by the emission of electromagnetic waves. It is characteristic of all matter at temperatures higher than absolute zero. The energy transferred due to radiation is directly proportional to the fourth power of the temperature difference between the objects. Thermography measures the temperature differences on the surface of an object by measuring the radiant emission (Kaplan 1999). The heat transfer also depends on the thermal property of the material. Table 2.1 gives the thermal properties of some materials. 
Table 2.1 Thermal properties of materials (Maldague 1993)

\begin{tabular}{|c|c|c|c|c|c|}
\hline Material & $\begin{array}{c}\text { Specific Heat } \\
\mathrm{C} \\
\left(\mathrm{J} \mathrm{kg}^{-1}{ }^{\circ} \mathrm{C}^{-1}\right)\end{array}$ & $\begin{array}{c}\text { Mass } \\
\text { Density } \\
\rho \\
\rho \\
\left(\mathrm{kg} \mathrm{m}^{-3}\right) \\
\end{array}$ & $\begin{array}{c}\text { Heat Capacity } \\
\rho \mathrm{C} \\
\left(\mathrm{J} \mathrm{m}^{-3} \mathrm{C}^{-1}\right) \\
\end{array}$ & 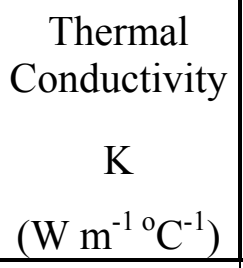 & $\begin{array}{c}\text { Thermal } \\
\text { Diffusivity } \\
\delta \\
\left(\mathrm{m}^{2} \mathrm{~s}^{-1}\right)\end{array}$ \\
\hline Air (as defect) & 700 & 1.2 & $0.0008 \times 10^{6}$ & 0.024 & $33 \times 10^{-6}$ \\
\hline Aluminium & 880 & 2700 & $2.4 \times 10^{6}$ & 230 & $95 \times 10^{-6}$ \\
\hline $\begin{array}{l}\text { Brass }(65 \% \mathrm{Cu} \text { and } \\
35 \% \mathrm{Zn})\end{array}$ & 380 & 8400 & $3.2 \times 10^{6}$ & 130 & $32 \times 10^{-6}$ \\
\hline $\operatorname{CFRP}^{\mathrm{b}}\left(_{\mid}\right.$fibers $)$ & 1200 & 1600 & $1.9 \times 10^{6}$ & 0.8 & $0.42 \times 10^{-6}$ \\
\hline $\operatorname{CFRP}^{\mathrm{b}}$ (\| fibers $)$ & 1200 & 1600 & $1.9 \times 10^{6}$ & 7 & $3.7 \times 10^{-6}$ \\
\hline Concrete & 800 & 2400 & $1.9 \times 10^{6}$ & 1 & $0.53 \times 10^{-6}$ \\
\hline Copper & 380 & 8900 & $3.4 \times 10^{6}$ & 380 & $110 \times 10^{-6}$ \\
\hline Epoxy resin & 1700 & 1300 & $2.2 \times 10^{6}$ & 0.2 & $0.09 \times 10^{-6}$ \\
\hline Glass & 670 & 2600 & $1.7 \times 10^{6}$ & 0.7 & $0.41 \times 10^{-6}$ \\
\hline $\operatorname{GFRP}^{\mathrm{c}}$ ( $\_$fibers $)$ & 1200 & 1900 & $2.3 \times 10^{6}$ & 0.3 & $0.13 \times 10^{-6}$ \\
\hline $\operatorname{GFRP}^{\mathrm{c}}$ (\| fibers) & 1200 & 1900 & $2.3 \times 10^{6}$ & 0.38 & $0.17 \times 10^{-6}$ \\
\hline Lead & 130 & 11300 & $1.5 \times 10^{6}$ & 35 & $23 \times 10^{-6}$ \\
\hline Nickel & 440 & 8900 & $3.9 \times 10^{6}$ & 91 & $23 \times 10^{-6}$ \\
\hline Plexiglass ${ }^{\mathrm{TM}}$ & - & 1200 & - & 0.2 & $0.25 \times 10^{-6}$ \\
\hline Porcelain & 1100 & 2300 & $2.5 \times 10^{6}$ & 1.1 & $0.43 \times 10^{-6}$ \\
\hline Steel (mild) & 440 & 7900 & $3.5 \times 10^{6}$ & 46 & $13 \times 10^{-6}$ \\
\hline Steel (stainless) & 440 & 7900 & $3.5 \times 10^{6}$ & 25 & $7.1 \times 10^{-6}$ \\
\hline Teflon $^{\mathrm{TM}}$ & - & 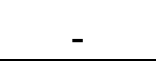 & - & 0.42 & $1.59 \times 10^{-6}$ \\
\hline Titanium & 470 & 4500 & $2.1 \times 10^{6}$ & 16 & $7.6 \times 10^{-6}$ \\
\hline Uranium & 120 & 18700 & $2.2 \times 10^{6}$ & 27 & $12 \times 10^{-6}$ \\
\hline Water & 4180 & 1000 & $4.2 \times 10^{6}$ & 0.6 & $0.14 \times 10^{-6}$ \\
\hline Zircaloy 2 & 280 & 6600 & $1.8 \times 10^{6}$ & 13 & $11 \times 10^{-6}$ \\
\hline
\end{tabular}

(Vavilov 1980, p 182; Reynolds and Wells 1984, p 43; Tretout 1987, p 49; Touloukian and DeWitt 1970)

${ }^{a}$ Defined as $\delta=\mathrm{K} / \rho \mathrm{C}$, where $\mathrm{K}$ is the thermal conductivity, $\rho$ is mass density, $\mathrm{C}$ is the specific heat, and $\rho \mathrm{C}$ is the heat capacity.

${ }^{\mathrm{b}}$ Carbon fiber reinforced polymer.

${ }^{\mathrm{c}}$ Glass fiber reinforced polymer. 


\subsubsection{Electromagnetic Spectrum}

The essential property, which distinguishes infrared from visible light, is its wavelength. The electromagnetic spectrum is shown in the Figure 2.1. Radiative heat transfer takes place in the infrared portion of the spectrum, from $0.75 \mu \mathrm{m}$ to about $100 \mu \mathrm{m}$, although most practical measurements can be made to about $20 \mu \mathrm{m}$ (Kaplan 1999).

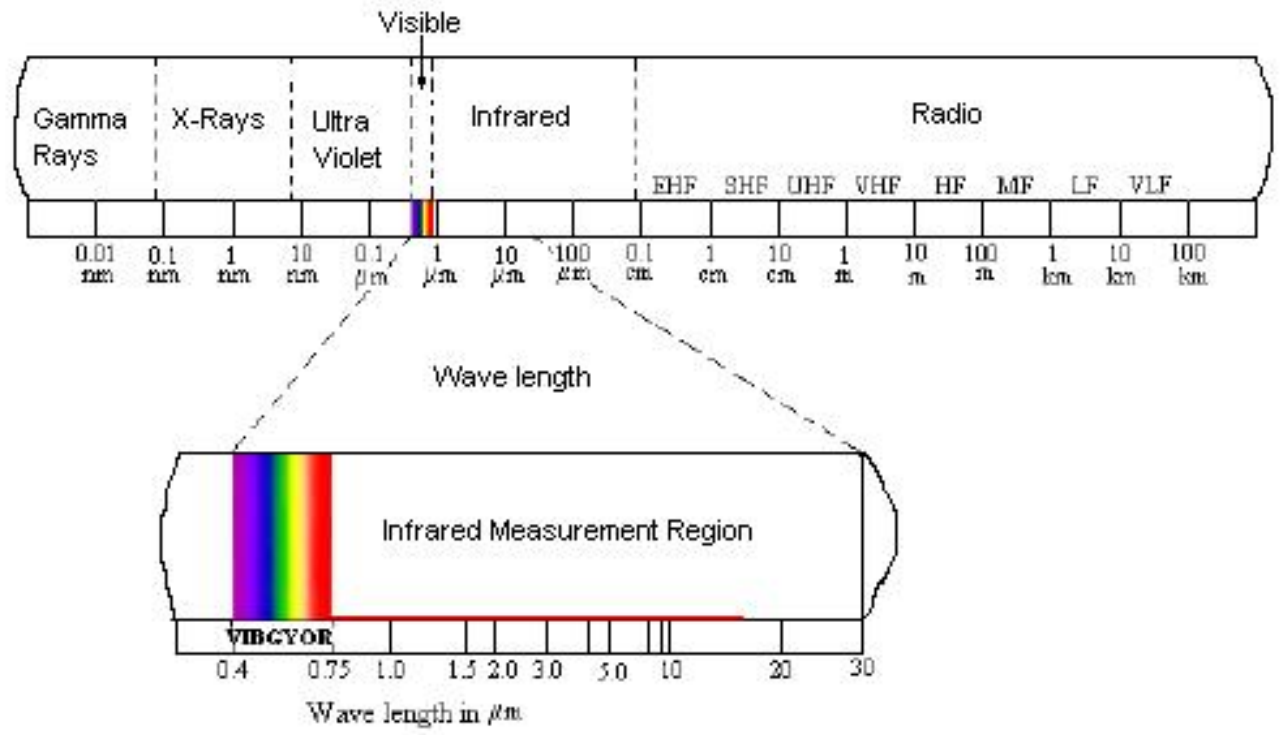

Figure 2.1. Electromagnetic spectrum showing the infrared measurement region (Kaplan 1999)

All objects radiate electromagnetic waves at any temperature above absolute zero $\left(-273^{\circ} \mathrm{C}\right)$, but the amount emitted and its distribution with wavelength depend on the temperature and emissivity of the body. The emissivity of any object is defined as the ratio of the actual emission from the object to that from a hypothetical source called a "black body" at the same temperature.

\subsubsection{Infrared Measurement}

All objects radiate energy in the infrared spectrum. The hotter the area, the more the energy radiated. Infrared detectors can sense the infrared radiant energy and produces useful electrical signals proportional to the temperature of the object surface. They are capable of measuring temperatures down to sensitivities of $0.1^{\circ} \mathrm{C}$ (or even better with newer generation infrared cameras/imagers) and with response times in the microsecond 
range. The instruments called the infrared thermal imagers can produce thermal maps (or thermograms) with a color or black and white intensity scale which is representative of the temperature of the surface being focused (Kaplan 1999).

\subsubsection{Active and Passive Thermography}

Thermal NDE is conducted using the active or passive approaches. In active thermography, heat flows are produced with external heating or cooling of the structure being tested. With such thermal perturbation, the subsurface defects may produce surface temperature differentials that can be measured by the thermographic system detectors. In the passive approach, no external heating or cooling is applied. It relies on the existing temperature differences within the structure being evaluated or between the structure and its surroundings to establish the necessary temperature patterns. This approach is commonly used to assess or monitor the state of industrial processes or in the manufacturing stage (Maldague and Moore 2001).

\subsubsection{Testing Procedure}

Infrared thermography is an NDE technique that utilizes the heat energy emitted by an object to characterize its subsurface conditions. The method is based on the principle that subsurface voids will affect the rate of heat flow through a structure, thereby resulting in surface temperature differentials. By measuring the surface temperatures under known heat flow conditions the subsurface defects can be located (Weil 1991 and Halabe et al.1995).

A typical setup of the measurement system is shown in the Figure 2.2. The thermographic inspection typically involves two phases. The first phase is the development of the thermal gradient through the thickness of the specimen and the second is monitoring the surface temperature and development of the image (Hawkins et al. 1999). The thermal gradient is developed either using a heating or a cooling source. Some examples of heating sources are heating gun, quartz heaters, solar radiation, warm water, heating blankets etc. Examples of cooling sources are cold water, liquid nitrogen, liquid carbon dioxide etc. Infrared detectors or cameras detect the surface temperature 
profiles of the structure under study. Infrared detectors that measure radiation over different wavelengths are commercially available (Kaplan 1999).

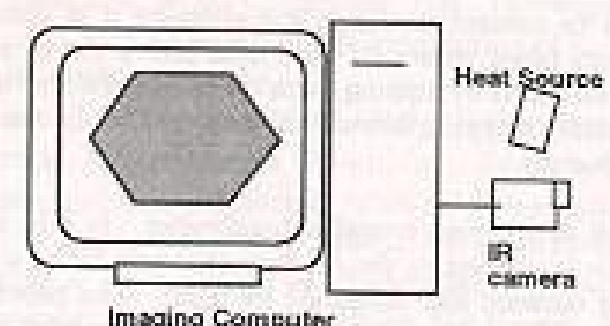

Imsging Computer
Develop thermal gradient
Structure

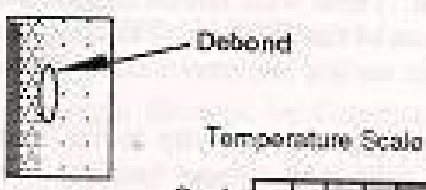

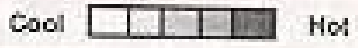

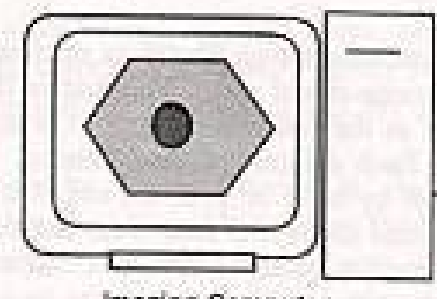

lmoging Computer

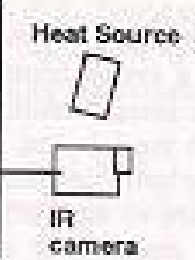

camora

Image development

Strueture

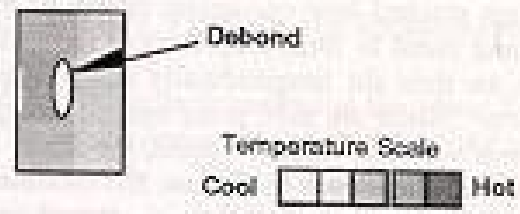

Figure 2.2. Thermographic inspection phases (Hawkins et al. 1999)

\subsubsection{Advantages and Disadvantages}

Infrared (IR) NDT is a non-contact technique and does not use any external wire connections or sensors. As no external sensors are required, there are no problems related to the wear and tear and replacement of sensors in the field environment. The results can be interpreted with relative ease, as compared with the Ground Penetrating Radar (GPR) and Ultrasonic Techniques (Halabe et al. 1995). IR thermography is an extremely fast inspection technique that can be used to survey a large area in a very short time. For example, an IR scanning conducted on a concrete bridge column from over 50 feet away, took less than a minute. To inspect the same area( $\sim 27 \mathrm{sq} . \mathrm{ft})$ using ultrasonic technique would require over an hour to complete exclusive of time which might be required to prepare (clean and sand) the column (Hawkins et al. 1999).

Detection of micro-cracks or very small defects using the infrared technique is almost impossible. Usually it cannot detect the depth or the thickness of a defect, though some recently published computational algorithms have made important strides in depth 
estimation from the analysis of the infrared images. The measurement of the surface temperature profile by an infrared camera is highly influenced by environmental parameters such as solar radiation, air temperature, wind, rain, surface stains and patches and shadows of adjacent structures and trees (Halabe et al. 1995).

\subsection{PRINCIPLES OF THERMOGRAPHY AND RADAR FOR BRIDGE DECK ASSESSMENT (MASER AND RODDIS 1990)}

\subsubsection{Summary}

Traditional methods of bridge deck condition assessment are slow, labor intensive and unreliable and hence new technologies like ground penetrating radar and infrared thermography are used for producing rapid and accurate condition assessment of these decks. Models to predict the radar and infrared techniques response to moisture, chloride, delamination and deck geometry are presented. The techniques have shown to predict area of deterioration to within 5\% of total deck area.

\subsubsection{Background}

Bridge deck deterioration is a major problem for highway agencies. It is difficult to evaluate the actual condition of an in-service concrete bridge deck. The two major mechanisms of concrete deck deterioration are the corrosion-induced spalling and the concrete disintegration. Nondestructive testing methods like infrared thermography and ground penetrating radar have been used for determining the deck condition. The nondestructive techniques are mainly attractive because the condition of the in-service decks is not impaired in any way. Also, the techniques are rapid and non-contact, and hence a large area can be surveyed and the traffic is not excessively constricted.

The infrared thermographic technique is straightforward and the interpretation of the results is easy. However, conditions of the deck can potentially complicate the identification of delaminations. Surface emissivity variations due to surface texture, spalls, patches, polishing in wheel paths and oil staining will result in apparent anomalies. Thermography is also affected by atmospheric conditions such as cloud cover, wind speed, moisture, as well as season of year and time of day. Ground-penetrating radar, on 
the other hand, is less sensitive to ambient conditions. However, radar produces complex signals and hence improved signal interpretation and automation of data analysis are needed to make radar a routinely acceptable technique (it should be noted that significant strides have been made in the late 1990s to improve radar data analysis and display software).

\subsubsection{Physical Basis for Thermography}

Thermography directly senses the emitted infrared radiation and detects the differences in surface temperature of the top of the deck. Heat flows into and out of the deck by radiation, conduction and convection. The deck's internal thermal behavior of heat conduction and absorption must balance its radiant and convective interactions with its surroundings. The net radiant flow is a function of the incident solar radiation, the energy radiated from air to the deck and that from the deck to air. The convective flow depends on temperature difference between the air and deck, and the air velocity. Since both the solar radiation and ambient air temperature vary on a daily cycle, the deck's thermal behavior will also fluctuate. The physical parameters determining the emitted infrared radiation are thus: deck emissivity, deck volumetric heat, thickness of the heated layer, intensity of incident solar radiation and air velocity.

\subsubsection{Physical Thermal Model of Delamination}

A thermal model of a delaminated bridge deck is shown in Figure 2.3. The deck is split into three layers: cover layer of sound concrete of thickness $\mathrm{d}_{1}$; a delaminated layer of thickness $d_{d}$; and a lower layer of sound concrete of thickness $d_{b}$.

The top and bottom layers have thermal properties characteristic of structural concrete, where as the delaminated layer is a damaged zone and would have altered thermal properties. The delaminated area (about $1 / 4$ " or $6 \mathrm{~mm}$ thick) may be composed of one or more crack planes that are under the weight of the overlaying concrete and traffic loads. The thermal effects of these crack planes are assumed to be equivalent to uniform thickness horizontal thin open crack, filled with air or water. The thermal conductivity $k_{d}$, and volumetric heat $\mathrm{v}_{\mathrm{d}}$ of the damaged layer are computed based on this type of crack 


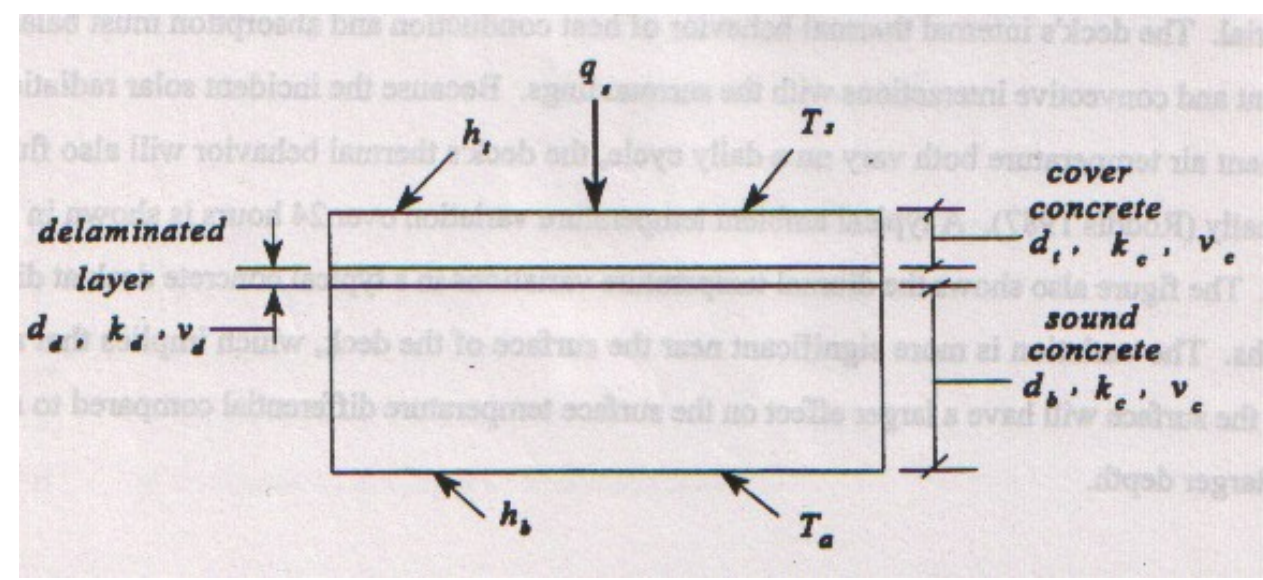

Figure 2.3. Thermal model of a bridge deck (Maser and Roddis 1990)

assumption. The other deck properties for each of the corresponding layers are shown in the Figure 2.3.

The thermal model is driven by an input solar radiation function, $\mathrm{q}_{\mathrm{s}}$ and by the ambient temperature. The effects due to heat transfer (conduction, convection and radiation) have been combined using the concept of a heat transfer coefficient as follows:

$$
\mathrm{q}=\mathrm{h}\left(\mathrm{T}_{\mathrm{s}}-\mathrm{T}_{\mathrm{a}}\right)
$$

where $\mathrm{q}$ is heat transferred between the deck and its surroundings $\left(\mathrm{W} / \mathrm{m}^{2}\right)$; $\mathrm{h}$ is heat transfer coefficient $\left[\mathrm{W} /\left(\mathrm{m}^{2}{ }^{\circ} \mathrm{C}\right)\right] ; \mathrm{T}_{\mathrm{s}}$ is surface temperature $\left({ }^{\circ} \mathrm{C}\right)$ and $\mathrm{T}_{\mathrm{a}}$ is ambient temperature $\left({ }^{\circ} \mathrm{C}\right)$. The linear approximation is valid to within $\pm 5 \%$ for the temperature differences encountered in typical bridge deck applications.

\subsubsection{Cases analyzed and the results from thermal model}

Many deck example cases were analyzed. To allow deck to reach steady periodicity, all cases were run for three-day duration and only the final 24 hours of data were used. Figure 2.4 shows the thermal cases in a sound thick slab (15" thickness). 


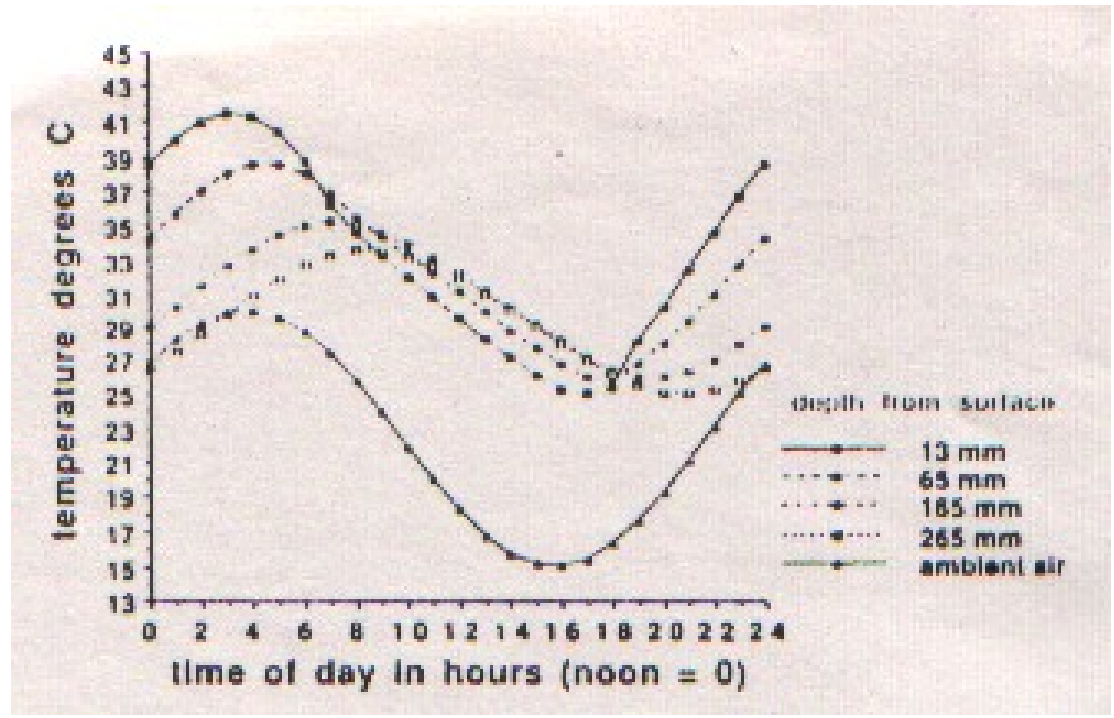

Figure 2.4. Thermal data for sound thick slab (Maser and Roddis 1990)

Case 1, was a 15 " $(381 \mathrm{~mm})$ sound deck with no delamination damage, to verify the results of the analytical model by comparison with reported actual field conditions. Case 2, a 7.5" (190 mm) thin sound deck with no delamination damage, established a base case for comparison with the modeled defect case. Cases 3, 4 and 5 were cases of air-filled delaminations and all assumed a thin deck with 1.5" (38 mm) cover. The equivalent crack width for cases 3,4 , and 5 were 0.01 " $(0.25 \mathrm{~mm}), 0.03$ " $(0.76 \mathrm{~mm}), 0.05$ " $(1.27 \mathrm{~mm})$ respectively. Case 6 represented a water-filled crack a thickness of 0.05 " $(1.27 \mathrm{~mm})$. Cases 7 and 8 investigated the effect of varying thickness of the cover over the delamination.

\subsubsection{Analysis Results from the Thermal Model}

The model was found to be in general agreement with the already published field studies and data (Manning and Holt 1983). The shape and characteristics of the field and model temperature curves were similar, so the model did appear to capture the basic physical behavior. A 7.5” (190mm) sound deck was analyzed in case 2 to set a baseline for an undamaged slab of typical thickness. Cases 3, 4 and 5 modeled a delamination as a damaged zone having thermal properties equivalent to the presence of a thin air filled crack. The results of case $5(0.05$ " or $1.7 \mathrm{~mm}$ thick air-filled crack) shown in Figure 2.5 
(a) were compared to the previously conducted field data (Figure 2.5 (b)), which shows the case of delaminated concrete.
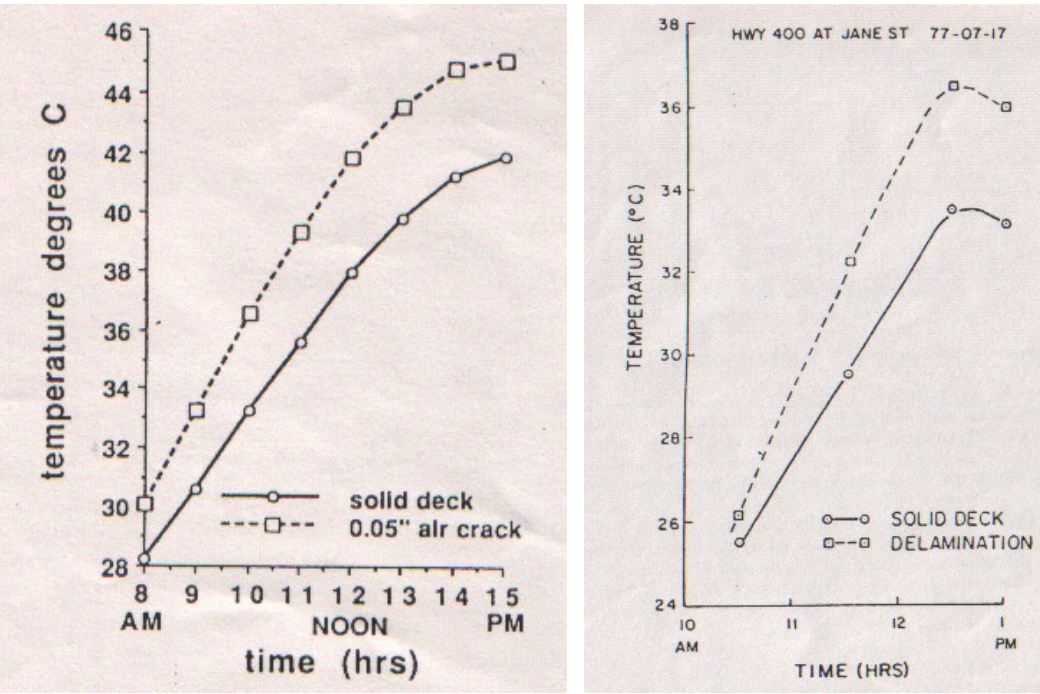

Figure 2.5. Thermal variation of surface temperature on a bridge deck based on (a) model analysis (Maser and Roddis 1990) (b) previously established field studies (Manning and Holt 1983)

The surface temperature difference between the solid and delaminated area reached a maximum of $3{ }^{\circ} \mathrm{C}$ for the field data and $4{ }^{\circ} \mathrm{C}$ for the analytical data. The analytical model was found to be in general agreement with the behavior shown by the field data.

The width of the air-filled crack influenced the magnitude of the temperature difference (shown in Figure 2.6). Increasing crack width by a factor of five increased the maximum surface temperature difference by a factor of four. Case 6 explored the results of $0.05 "(1.27 \mathrm{~mm})$ thick water-filled crack and the results showed that there were no significant differences (only $0.14^{\circ} \mathrm{C}$ ) in the deck temperatures when compared to that of a solid deck. Cases 7 and 8 that investigated the effect of varying cover thickness (for an air-filled delamination) showed that increasing cover thickness reduced the value of temperature difference between solid and delaminated area (Figure 2.7). The results from all the eight cases showed that this was a promising physical model for the thermal behavior of the delaminated slab. 


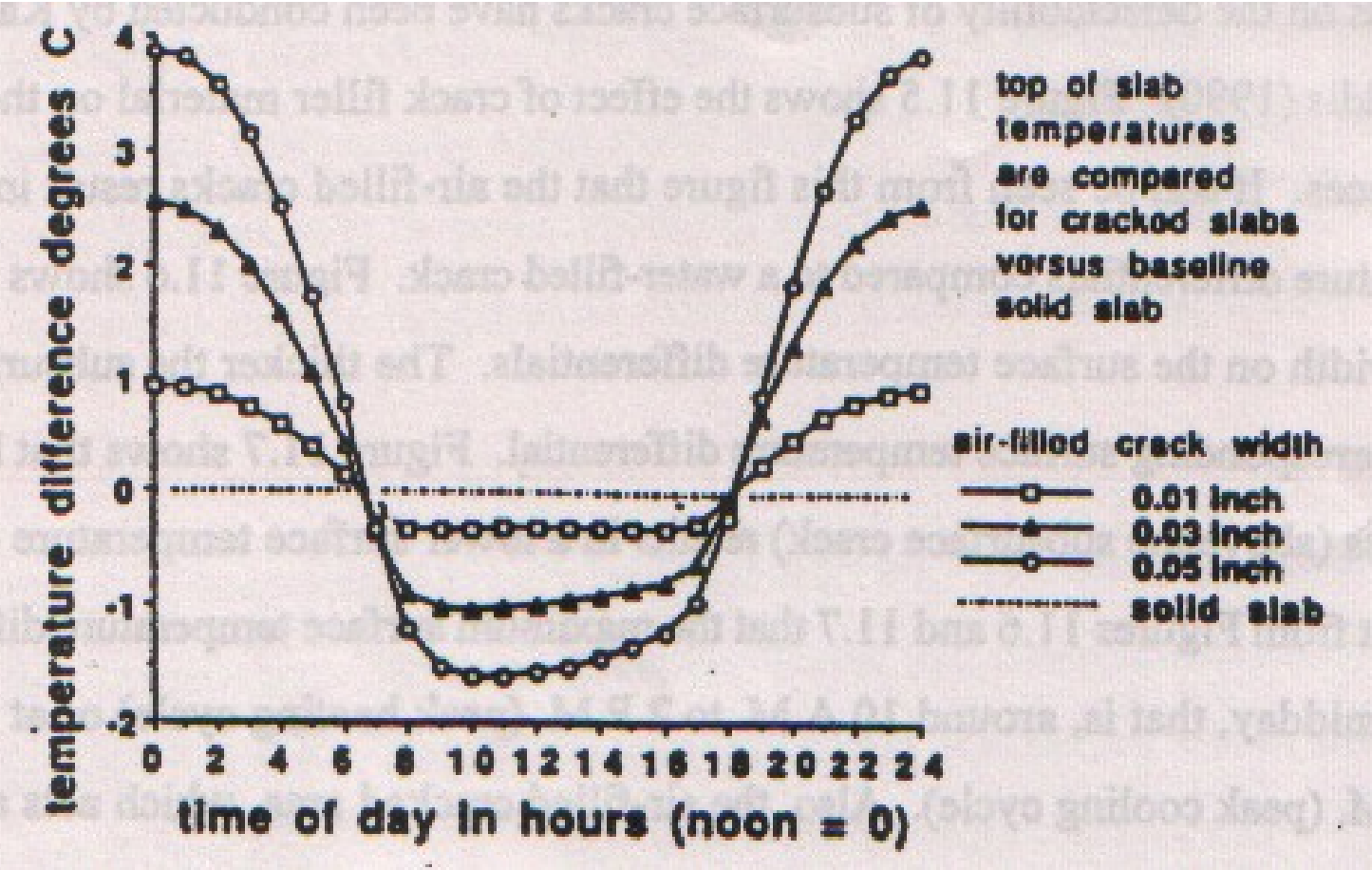

Figure 2.6. Effect of crack width on thermal cases 2, 3, 4, 5 (Maser and Roddis 1990)

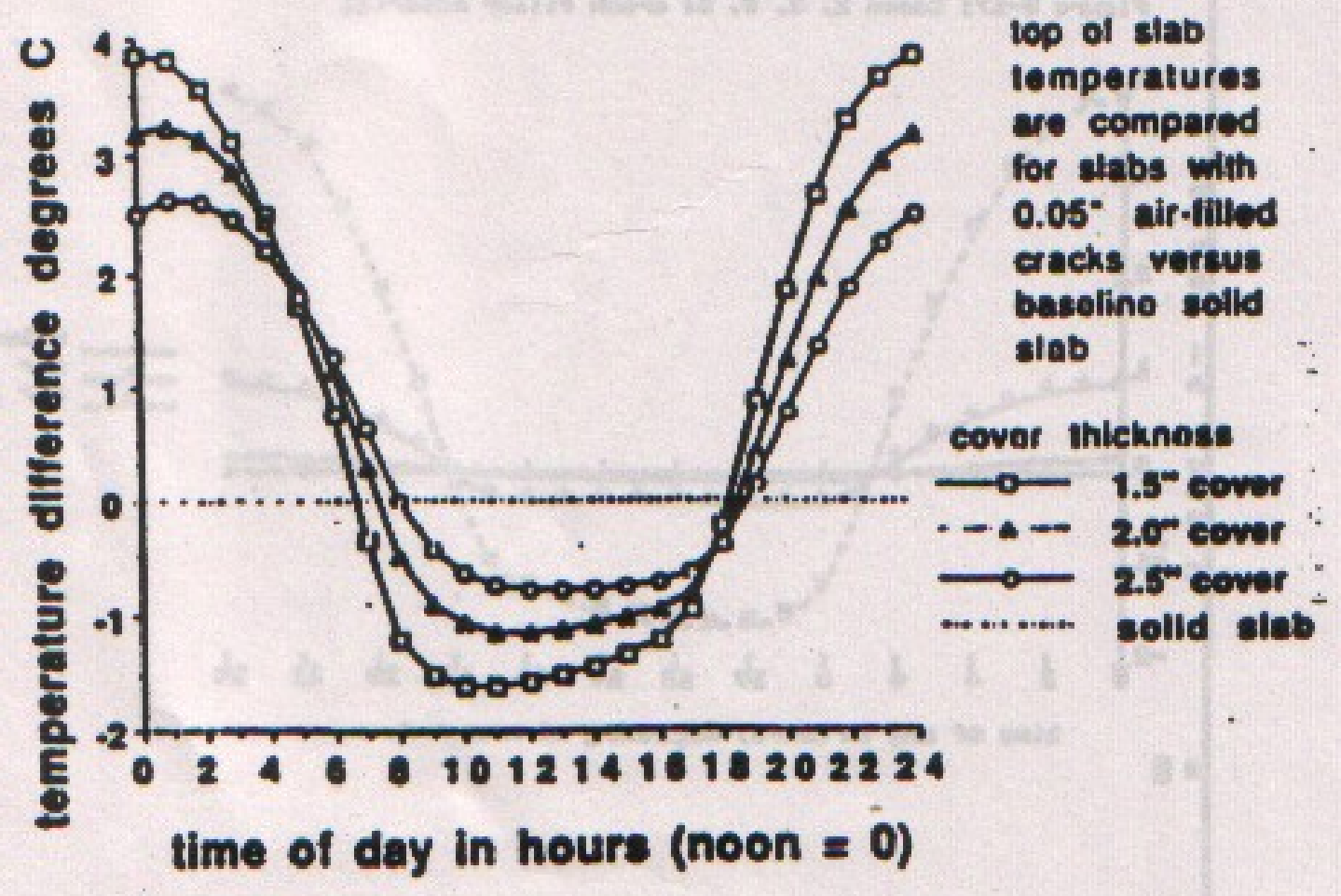

Figure 2.7. Effect of cover thickness on thermal cases 2, 5, 7, 8 (Maser and Roddis 1990) 
Parametric studies and research were conducted on another model with an asphalt overlay. The studies showed that the relationship between the maximum predicted thermal anomaly and the asphalt thickness, delamination width and depth were too small to be reliably measured.

\subsubsection{Ground Penetrating Radar}

Radar technique transmits short pulses of electromagnetic energy from an antenna into a dielectric medium and receives the reflected pulses through a receiving antenna. Based on the received pulses and echoes it produces a voltage versus time record called the "radar waveforms" which gives information on the location of the material boundaries and significant material properties like permittivity and conductivity. Numerical studies with respect to three conditions relevant to deck deterioration chloride content, moisture content and rebar cover were conducted. Physical models to study radar response to the above mentioned conditions in the deck were developed.

\subsubsection{Results from Field Studies}

The objectives of the field studies were to collect infrared and radar data for asphalt-overlaid decks that were scheduled for maintenance and rehabilitation. The results showed that the best prediction of deteriorated deck area was obtained by combining the results from both ground penetrating radar and infrared thermography techniques. Radar detected moisture and chloride content associated with the deterioration but could not detect the delamination directly. Infrared thermography, on the other hand, detected the delaminations directly but the presence of subsurface moisture and asphalt thickness affected the infrared images.

\subsubsection{Conclusions}

Physical models were developed to predict responses of infrared thermography and ground penetrating radar techniques from delaminated decks. Studies showed that infrared thermography was capable of detecting delaminations but did not give satisfactory results when the delaminations were small, when the defect depth was large, and when asphalt thickness was too large. Radar was sensitive to moisture and chloride 
conditions but could not directly sense the delaminations. However when both the techniques are used in parallel more reliable field data can be collected.

\subsection{NONDESTRUCTIVE EVALUATION OF FRP COMPOSITE MEMBERS USING INFRARED THERMOGRAPHY (BANGALORE 2002)}

This section presents the results from past laboratory experiments conducted at West Virginia University on composite specimens using infrared thermography.

\subsubsection{Laboratory Experimental Setup}

The thermal images were recorded using FSI Prism SP (Single Point) infrared camera, which was capable of detecting the infrared radiation in the medium wavelength (3 to $5 \mu \mathrm{m}$ ) spectral region and displaying a real-time image showing relative intensity of the radiation. The video output can be set to either Gray scale image mode or Color image mode. A TV monitor with built-in VCR was used to view and record the real time thermal images. The images were recorded on a VHS tape and were later transferred as still images into a personal computer using a video snapshot software. The heating source used in the laboratory was a quartz tower heater. The experimental setup used in the laboratory is shown in Figure 2.8.

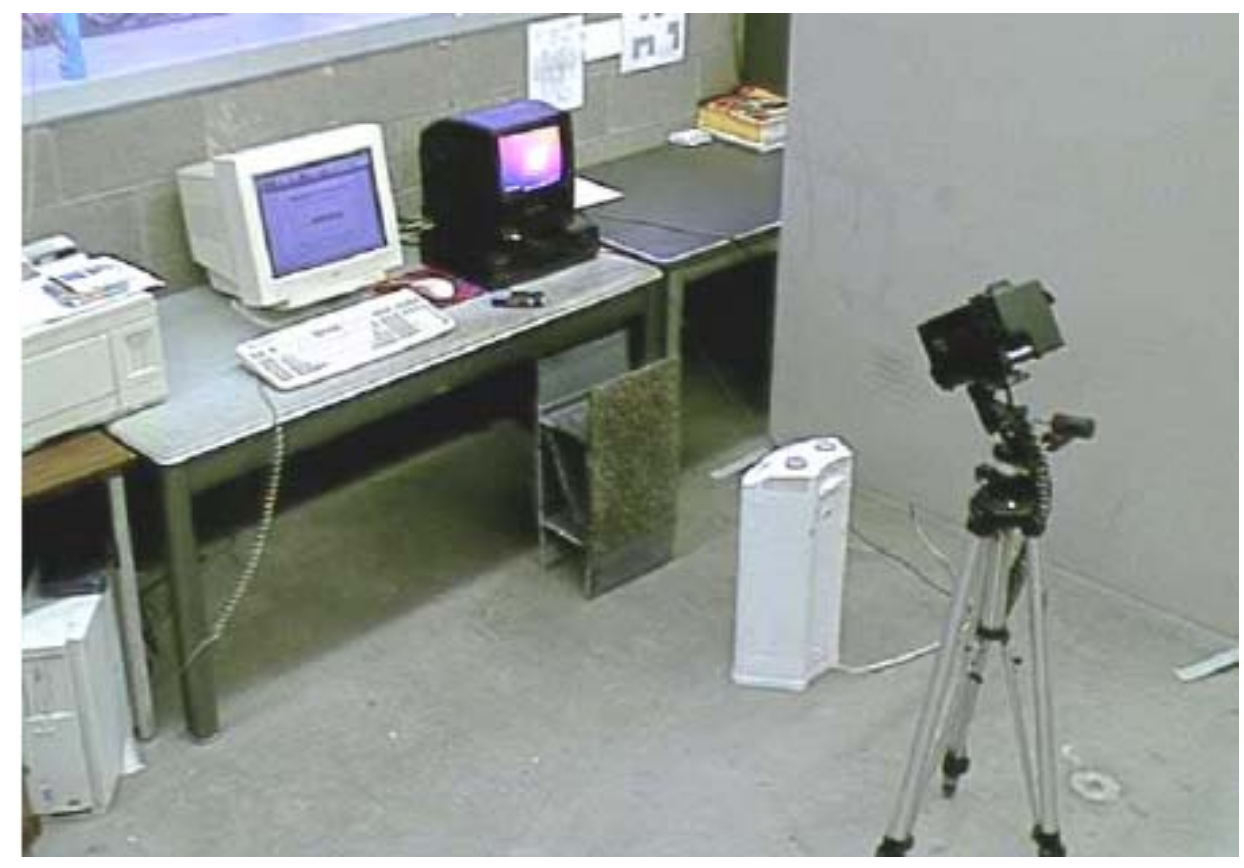

Figure 2.8. Experimental setup (Bangalore 2002) 


\subsubsection{Specimens Setup}

Two types of glass fiber reinforced polymer (GFRP) composite sections were tested. The first type that was tested consisted of box sections with sizes 2 " x 5 " $(51 \mathrm{~mm}$ x $127 \mathrm{~mm})$ and thickness $3 / 16 "(5 \mathrm{~mm})$ and contained delaminations of different sizes. These delaminations were made by entrapping air between two polypropylene sheets. The delaminations were inserted in the specimens during the pultrusion process. In some of the sections the 3 " x 3 " $(76 \mathrm{~mm} \times 76 \mathrm{~mm})$ and 2" x 2 " $(51 \mathrm{~mm}$ x $51 \mathrm{~mm})$ delaminations (both $1 / 16$ " or $1.5 \mathrm{~mm}$ thick) were seen on the surface (Figure 2.9(a)). One of the box sections had its surface painted, so that the delamination was not visible on the surface (Figure 2.9(b)).
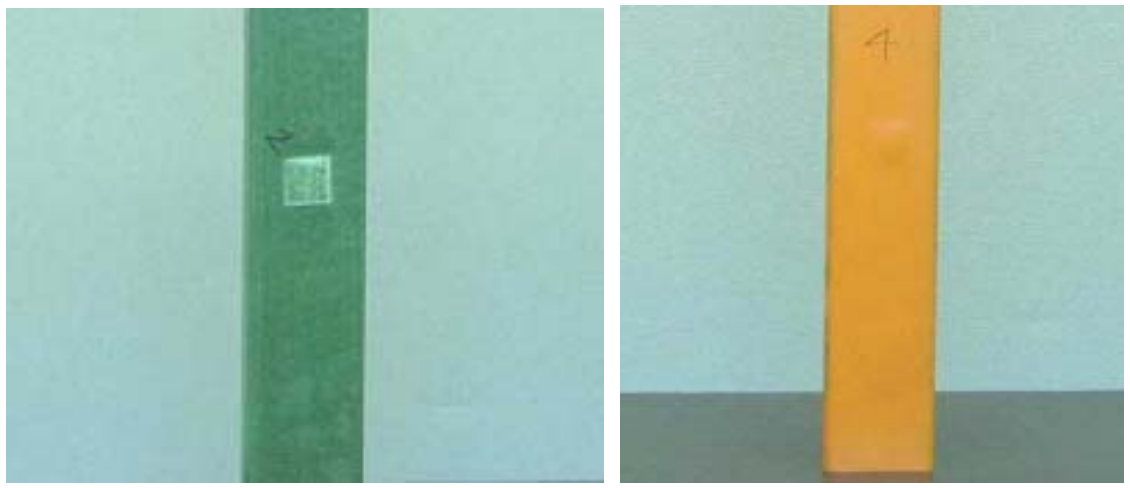

Figure 2.9. Photograph of box sections with (a) unpainted surface showing 2 " $\mathrm{x} 2$ " $\mathrm{x} 1 / 16$ " delamination (b) painted surface having 2" x 2" x 1/16" and 3" x 3"x 1/16" delaminations (Bangalore 2002)

The second type of section consisted of bridge deck modules of size 24" x 12 " $(0.6 \mathrm{~m} \times 0.3 \mathrm{~m})$ and $8 "(0.2 \mathrm{~m})$ deep. Specimen BD1 (Figure 2.10(a)) had two delaminations of sizes 3"x 3" x 1/16" (76mm x 76mm x 1.6mm) and 2"x 2" x 1/16" $(51 \mathrm{~mm} \times 51 \mathrm{~mm} \times 1.6 \mathrm{~mm})$, that were inserted within the joint between the two modules. BD2 was a bridge deck module (Figure 2.10(b)) that had two debonds (of same size and thickness as that of the delaminations in BD1) placed between the $3 / 8$ " $(9.5 \mathrm{~mm})$ thick wearing surface layer and the underlying FRP deck. These debonds and delaminations were made by entrapping air between two polypropylene sheets as mentioned earlier. 

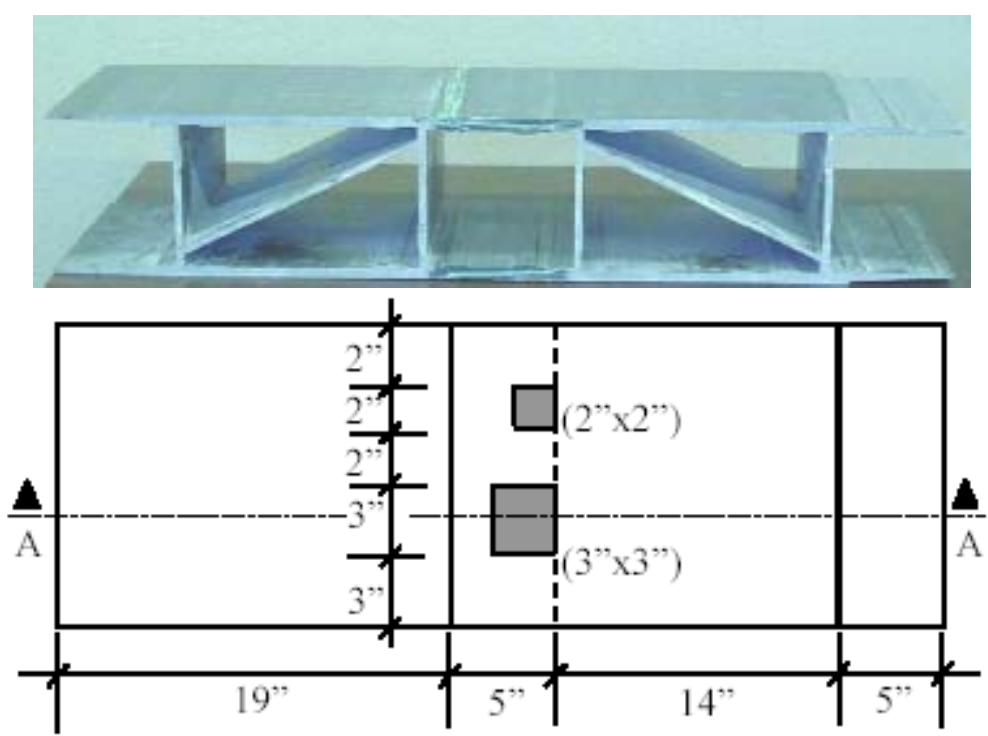

(a)
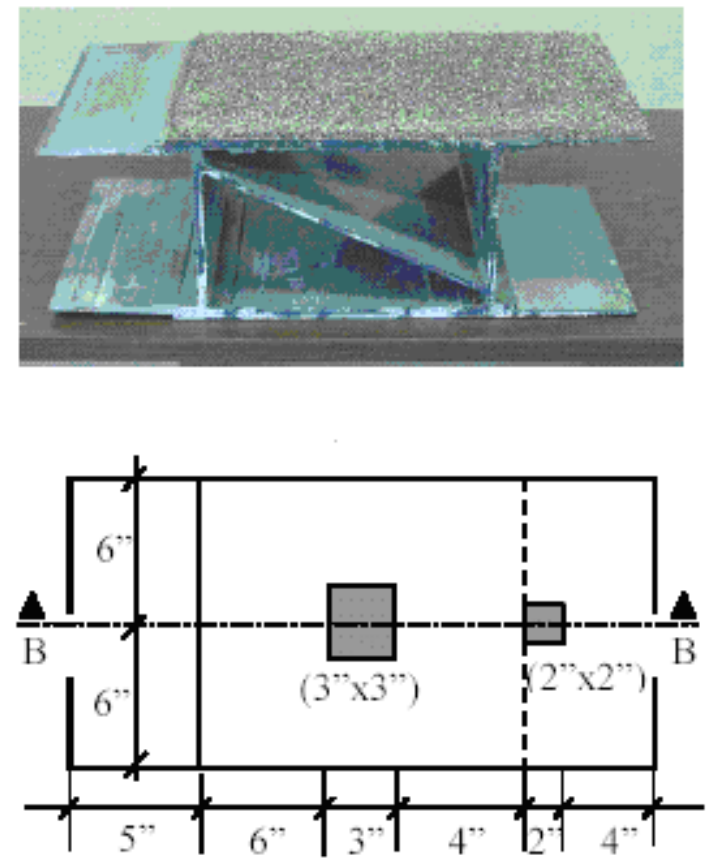

(b)

Figure 2.10. Photographs and schematic views of bridge deck specimen (a) BD1 (b) BD2 (Bangalore 2002)

\subsubsection{Infrared Tests and Results}

The specimens were heated by placing the quartz heater at a distance of 6-8 inches $(0.15-0.2 \mathrm{~m})$ from the surface. The surface temperature profiles were observed using the infrared camera and were recorded on a VHS tape. Figure 2.11 (a) and (b) shows the infrared images of the delaminations in the box sections that had unpainted and 
painted surfaces. As seen in the images, the bright spot on the specimen indicates the delamination.
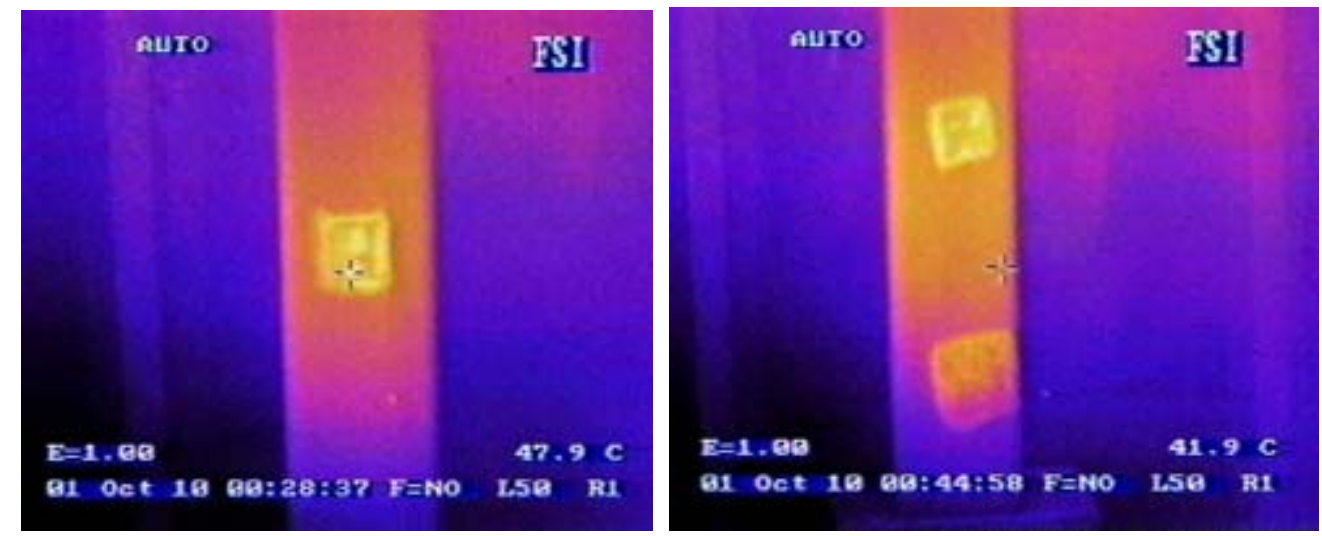

Figure 2.11. Infrared images of box sections with (a) unpainted surface showing a delamination (b) painted surface with two delaminations (Bangalore 2002)

Figure 2.12 (a) and (b) shows the infrared images of the bridge deck specimens BD1 and BD2. The infrared image of BD1 (Figure 2.12(a)) showed some differential temperature zones, but the shapes of the patches were different from what was expected and hence could not be categorically judged as delaminations.
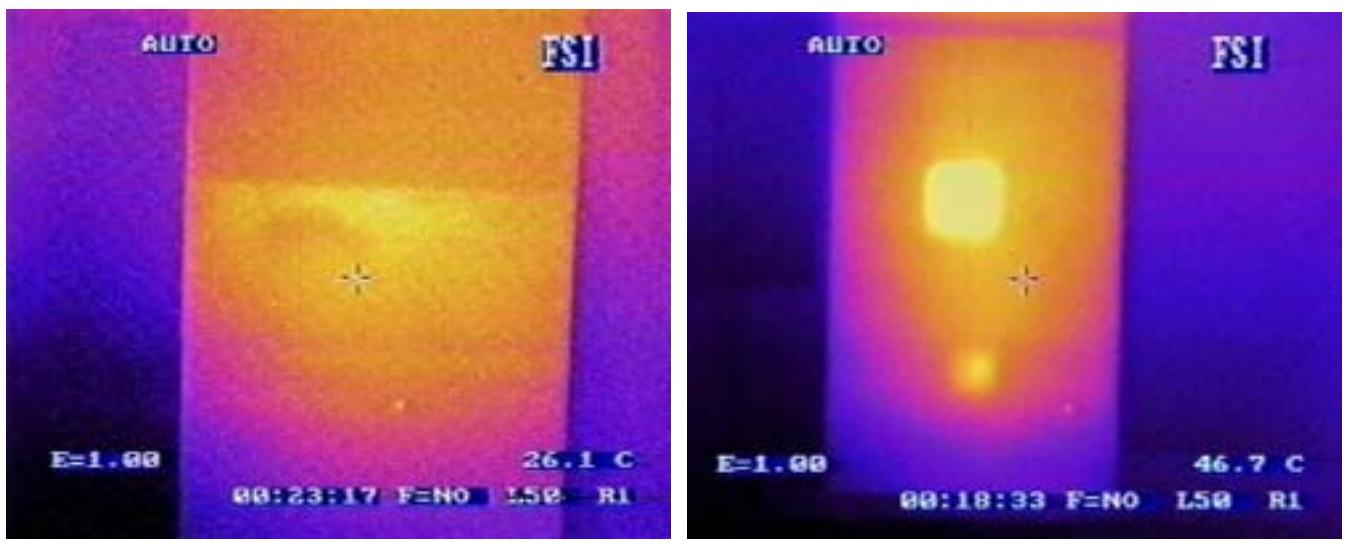

Figure 2.12. Infrared images of bridge deck specimens (a) BD1 (b) BD2 (Bangalore 2002)

Figure 2.12(b) shows infrared image of deck BD2 with the debonds (seen as bright yellow/white regions) of sizes 3"x 3" (76mm x 76mm) and 2"x 2" (51mm x $51 \mathrm{~mm}$ ) in plan (with $1 / 16$ " or $1.6 \mathrm{~mm}$ thickness) present in between the $3 / 8$ " $(9.5 \mathrm{~mm})$ thick wearing surface and the underlying deck. Infrared thermography was very 
successful in predicting the locations as well as the shapes and relative sizes of the two debonds.

\subsubsection{Conclusions}

Infrared thermography can be used as an effective tool for detecting subsurface delaminations in members built with FRP materials. The delaminations in the box sections were easily located and this may be due to the fact that the delaminations were very close to the surface. The delaminations embedded within the flange-flange junction between two adjacent sections in the bridge deck specimen BD1 could not be detected. However, in specimen BD2, the debonds between the wearing surface and the bridge deck surface could be easily detected. This is possibly due to the higher thermal conductivity of the wearing surface material (thermal conductivity of gravels $\approx 1 \mathrm{Wm}^{-1}$ ${ }^{\circ} \mathrm{C}^{-1}$ ) compared to the composite deck (thermal conductivity $\approx 0.3$ to $0.38 \mathrm{Wm}^{-1}{ }^{\circ} \mathrm{C}^{-1}$ ).

\subsection{DETECTION OF SUBSURFACE ANOMALIES IN COMPOSITE BRIDGE DECKS USING INFRARED THERMOGRAPHY (ALQENNAH 2000)}

This section presents laboratory experiments previously conducted on the FRP deck specimens at West Virginia University. It also includes some of the field tests conducted on FRP bridge decks in West Virginia.

\subsubsection{Laboratory Experiments}

\subsubsection{Experimental Setup}

Two infrared cameras, Insight 80 Series and FLIR Prism Single Point, with a resolution of 0.1 and $0.2^{\circ} \mathrm{C}$, respectively, were used to measure the temperature differences on the specimens' surface during the heating or cooling cycles. The monitor and the VCR are used to view, capture and record the thermal images that are produced from the specimen during the heating cycles. Quartz tower heater, heat gun, and solar radiation were different heat sources used to heat the specimens.

\subsubsection{Specimen Setup}

Four composite deck specimens with built-in debonds between the $3 / 8$ " thick wearing surface and the FRP deck were tested. The cross sectional dimensions of the 
specimens are shown in Figure 2.13. Sample 1 (Figure 2.14 (a)) was a 12" x 16" (0.3m x $0.4 \mathrm{~m})$ FRP composite deck specimen with a 2" x 2" (51mm x 51mm) debond created using a duct tape. Sample 2 (Figure 2.15) was a 12" x 24" $(0.3 \mathrm{~m}$ x $0.6 \mathrm{~m})$ composite deck specimen with several built in debonds. Sample 3 (Figure 2.16 (a)) was a specimen of size 12 "x $16 "(0.3 \mathrm{~m} \times 0.4 \mathrm{~m})$ in plan with an 11 "x 7.5 " $(0.28 \mathrm{~m} \times 0.19 \mathrm{~m})$ dimension air gap (of thickness 0.05 " or $1.27 \mathrm{~mm}$ ) built in between the wearing surface and the deck. For Sample 4 (Figure 2.16 (b)), a 12"x 16" (0.3m x 0.4m) FRP composite deck specimen with two air-filled subsurface debonds of plan sizes 3" x 2" (76mm x 51mm) and 1" x 1" $(25 \mathrm{~mm} \times 25 \mathrm{~mm})$ and thickness of $0.05 "(1.27 \mathrm{~mm})$ were constructed.

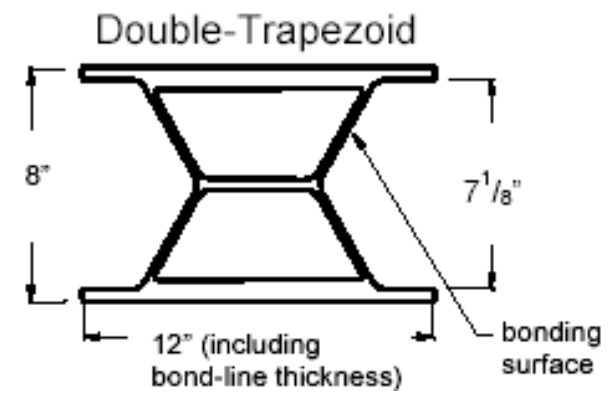

Figure 2.13. Cross section of composite bridge deck specimen (Alqennah 2000)

\subsubsection{Infrared Results}

Sample 1 was tested by the two infrared cameras and neither of them was able to detect the simulated debonding as the duct tape did not lead to any surface thermal differential (Figure 2.14 (b)). To heat sample 2 (Figure 2.15) different heating sources (quartz tower heater, heat gun, solar radiation and negative heating by using liquid $\mathrm{CO}_{2}$ ) were used. Many infrared images were taken, but none were able to show the debonds. Uniform heating could not be achieved with the heating gun. 


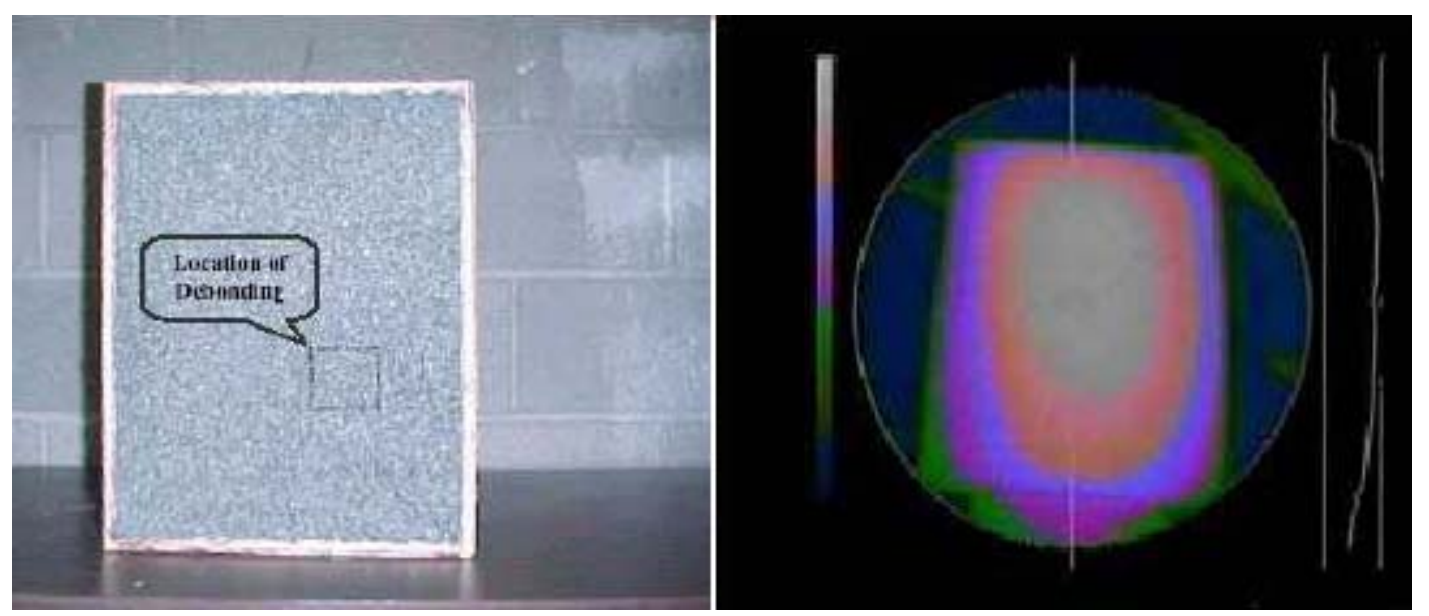

Figure 2.14. (a) Photograph and (b) infrared image of sample 1 (Alqennah 2000)

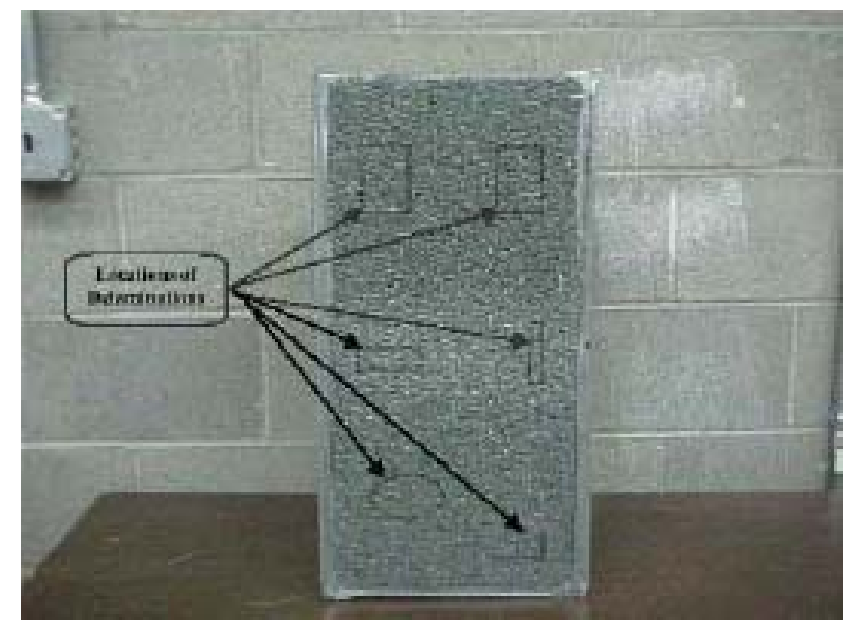

Figure 2.15. Photograph and of sample 2 (Alqennah 2000)

Sample 3 was heated between the temperature ranges of 45 to $75^{\circ} \mathrm{C}$ using quartz tower heater. The temperature difference between the sound area and debonded area was about $7^{\circ} \mathrm{C}$, clearly visible in the infrared image (Figure 2.16 (a)). Sample 4 was heated up to $82^{\circ} \mathrm{C}$ using quartz tower heater. The infrared image (Figure 2.16 (b)) showed good contrasts between the debonded and defect-free areas and hence the debonds were seen clearly. 


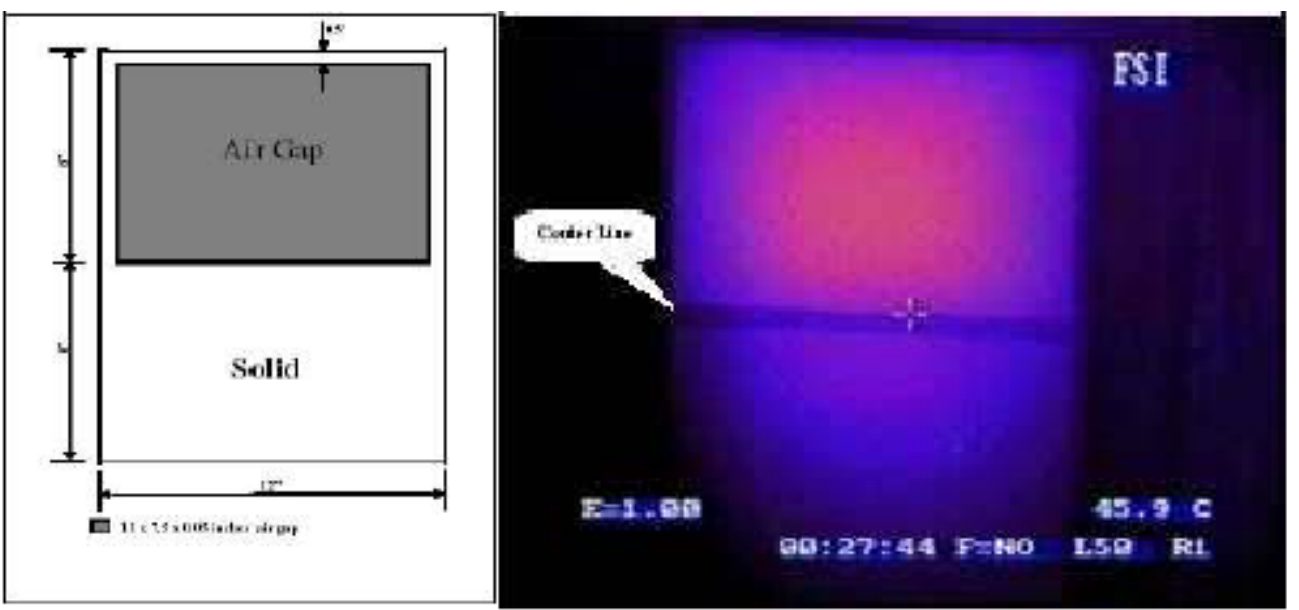

Figure 2.16. (a) Schematic view and infrared image of sample 3 (Alqennah 2000)

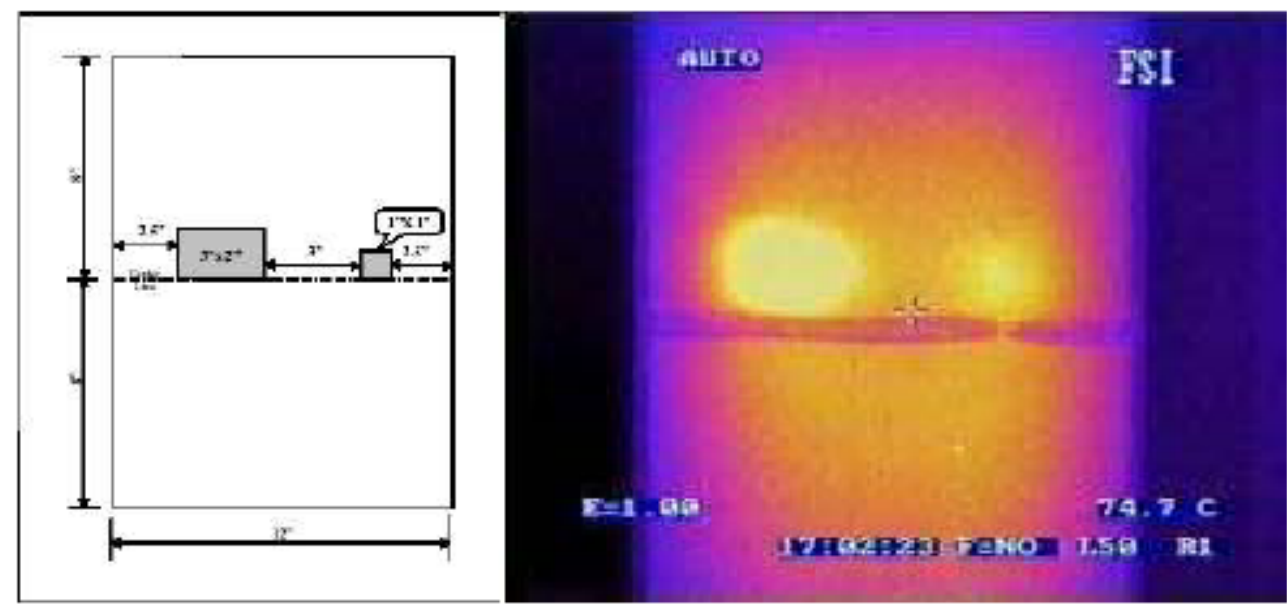

Figure 2.16. (b) Schematic view and infrared image of sample 4 (Alqennah 2000)

\subsubsection{Conclusions}

From the laboratory experiments conducted on the FRP composite bridge deck specimens it was concluded that the infrared thermography technique is able to detect subsurface debonds under the wearing surface. The minimum detectable debonded area was 1 square inch $(25 \mathrm{~mm} \times 25 \mathrm{~mm})$, with debond thickness as small as 0.05 ” $(1.27 \mathrm{~mm})$.

\subsubsection{Field Studies}

Field tests were conducted on the Laurel Lick and Wickwire Run bridge decks which were constructed using fiber reinforced polymer (FRP) composites and were located in West Virginia. The deck section is $8 "(0.2 \mathrm{~m})$ in depth, and made of full-depth hexagons and half depth trapezoids. A thin layer of polymer concrete overlay or wearing 
surface is applied on the deck. Infrared thermography was used for the condition assessment of these composite bridges.

\subsubsection{Field Setup and Tests}

The equipment used was same as the ones used in the laboratory studies, except for the heating source. Solar radiation was used as the heating source for the field studies. The ambient temperature was about $24^{\circ} \mathrm{C}$. The decks were divided into many lanes for testing. The infrared camera was mounted on a cart and the images were continuously recorded on a video tape (see Figure 2.17).

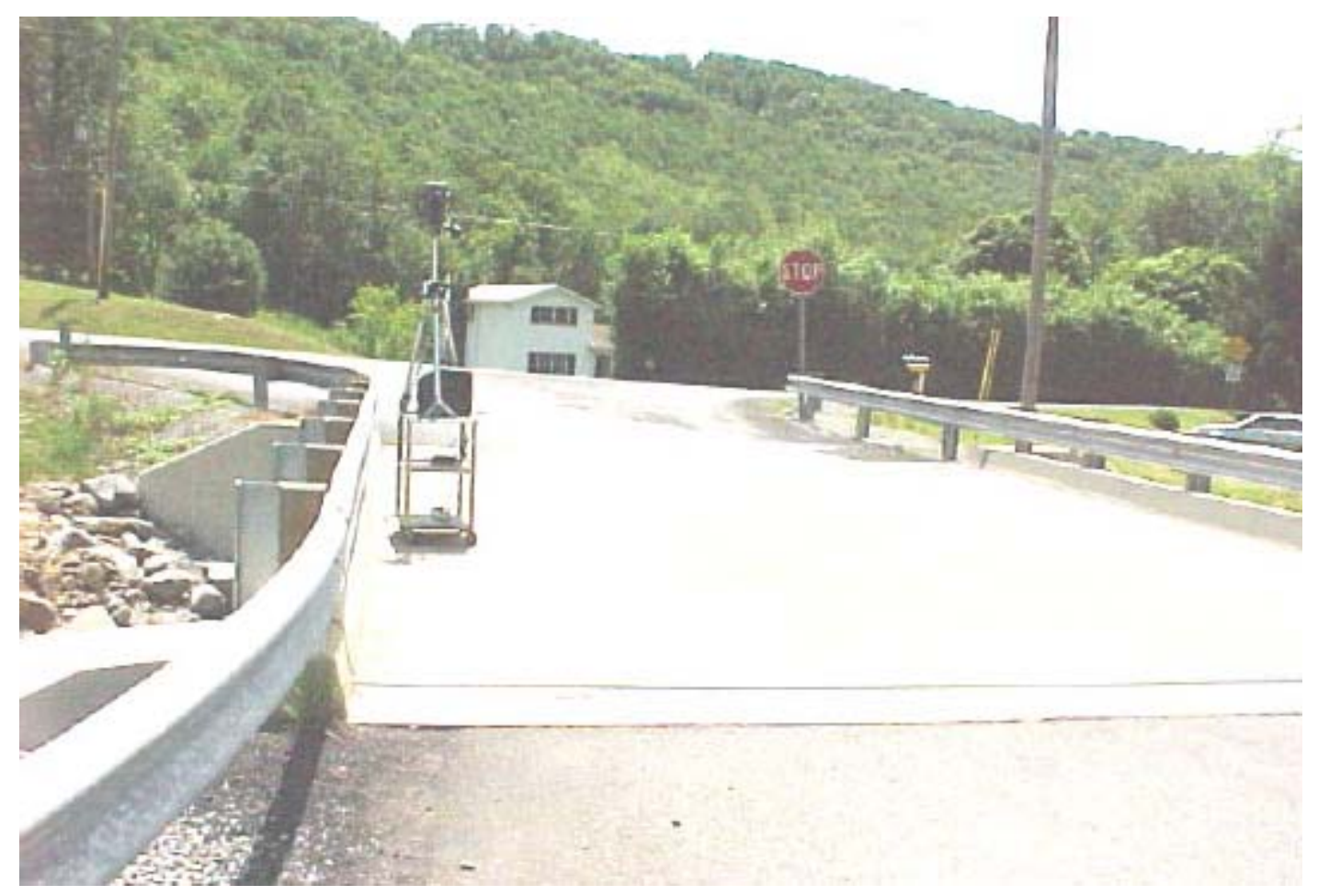

Figure 2.17. Photograph of Wickwire Run bridge with the infrared setup (Alqennah 2000)

The thermal images for the Laurel Lick bridge did not show debonds for any portion of the deck. However, some infrared images showed surface temperature differentials on certain portions of the bridge deck that were caused due to the shadows from the guard rails, surface irregularities and gravel. The infrared image (Figure 2.18 (a)) shows higher temperature areas caused by the guardrail and its reflection (of solar radiation) on portions of the deck. Another image (Figure 2.18 (b)) shows regions of 
lower temperatures caused by the shadow of the guardrail on the deck. Surface irregularities on the surface of the bridge deck also resulted in temperature differences in the thermal image (Figure 2.19).

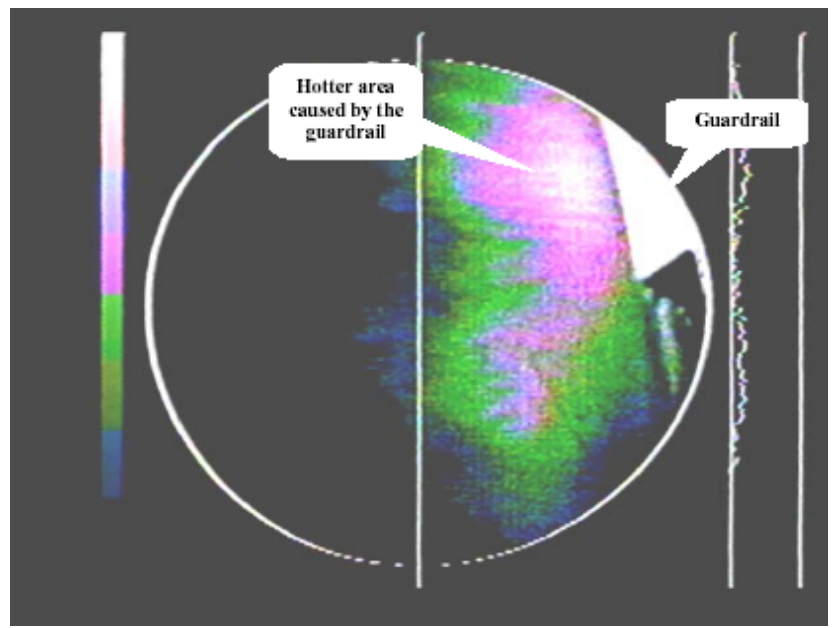

(a)

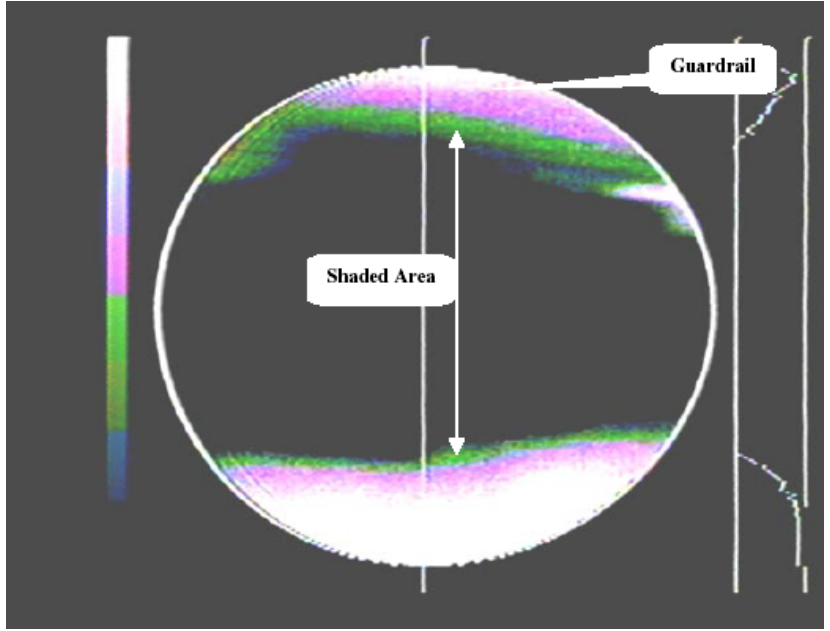

(b)

Figure 2.18. Infrared images showing (a) hotter areas caused due to reflection of solar rays by the guard rails, and (b) colder areas caused due to shadows from guard rails (Alqennah 2000) 


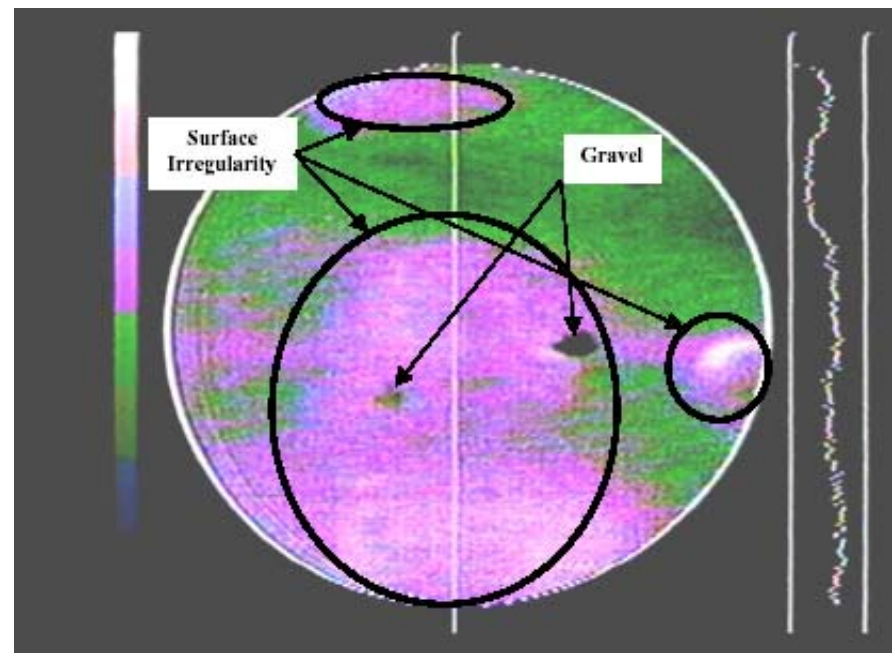

Figure 2.19. Infrared images showing presence of surface irregularities and gravel (Alqennah 2000)

Figures 2.20 and 2.21 shows the photographs and infrared images of portions of the Wickwire Run bridge that had surface cracks.
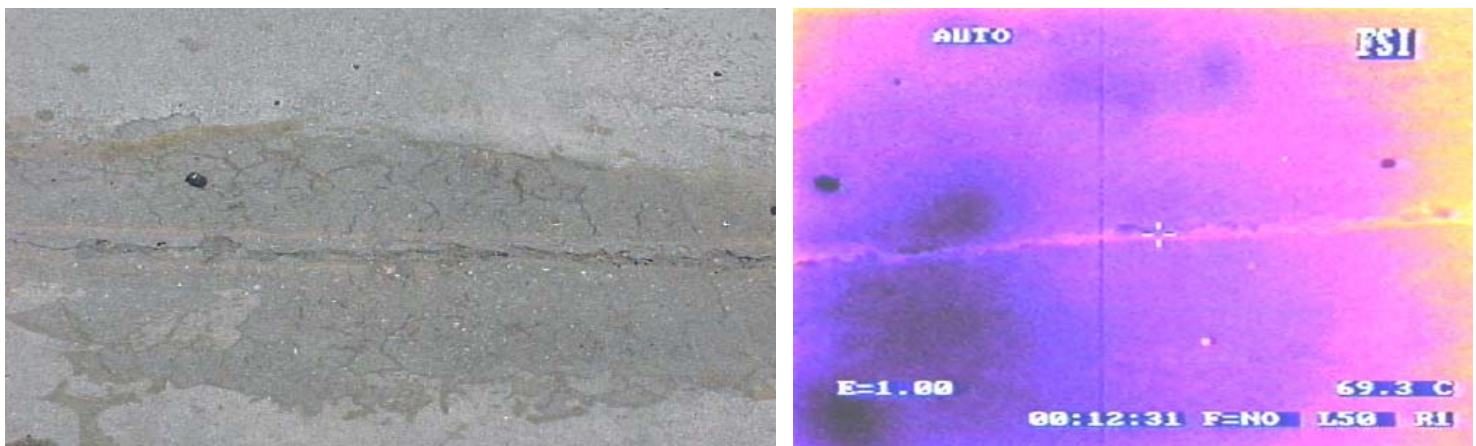

Figure 2.20. Photograph and infrared image of a surface crack (Alqennah 2000)
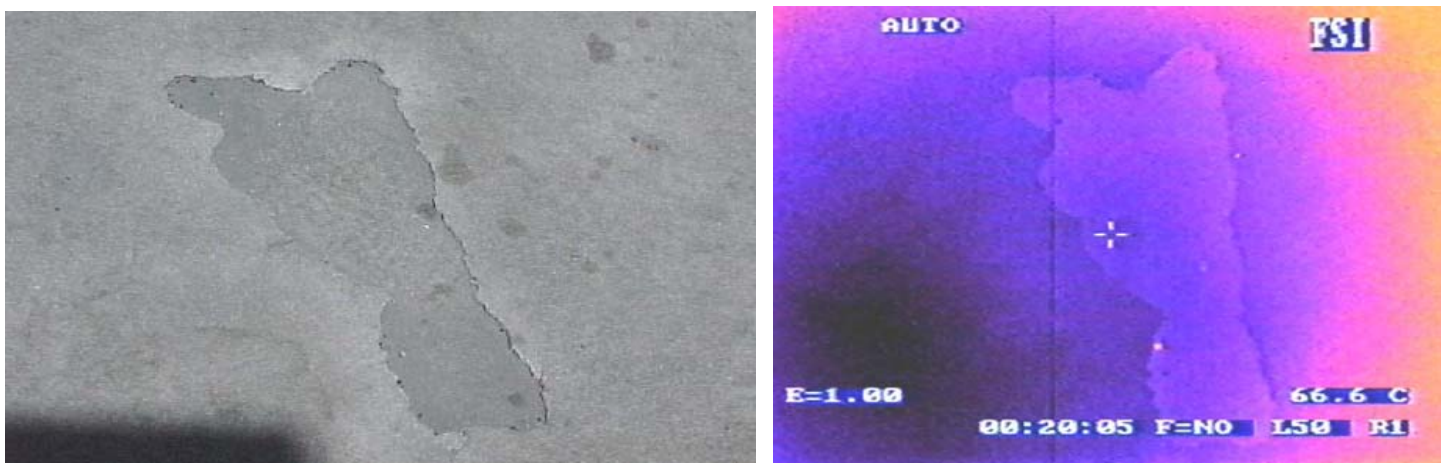

Figure 2.21. Photograph and infrared image of another surface crack (Alqennah 2000) 


\subsubsection{Conclusions}

From the field tests conducted on the two composite bridge decks, it was concluded that both the bridges did not have any subsurface debonds. However, there were surface cracks in the Wickwire Run bridge. Infrared thermography also detected some temperature differentials caused by the reflection from the guard rails, shadows of the guard rails, gravel and surface irregularities. Hence care must be exercised when interpreting these images.

\subsection{HEALTH MONITORING OF FRP BRIDGE DECKS (MICELI ET AL. 2001)}

\subsubsection{Summary}

A significant portion of the nation's bridges are classified as structurally deficient or functionally obsolete. To solve this problem, new materials such as glass fiber reinforced vinyl ester matrix composites are being explored for the use in bridge systems. These materials are less affected by the corrosive environmental conditions when compared to conventional concrete decks and provide a longer life span. These materials have additional benefits such as reduced dead loads. However, there is a lack of long term durability data concerning these material systems. Therefore, effective methods to monitor the health of the FRP systems are required. This paper discusses the use of infrared thermography for detecting the structural imperfections like delaminations, debonds, and voids caused both during fabrication and in the field.

\subsubsection{Background}

Many structurally deficient bridges may be restored back by replacing their decks with lighter materials. FRP is one such material used for the decking system and its usage increases the load rating of the bridge. The long-term durability aspects of such FRP materials are still unclear. Hence nondestructive evaluation (NDE) methods are required for the continuous condition assessment of the structures built with these materials. A prong had pursued use the infrared thermography technique for the study of initiation and development of deterioration in the laboratory. Another prong had endeavored to develop the capabilities of health monitoring in the field. 
Because of the rapidly evolving nature of these applications a full picture of the nature of the long-term deterioration of FRP materials is unknown. The faulty designs leading to structural damages have resulted in shifting the focus from the more important durability issues to fixing of the faulty design aspects.

In this research, an initial decking system was rejected after preliminary mechanical testing and nondestructive evaluation suggested that the fabrication issues were yet to be resolved. Another deck developed damages around the points of attachment to the substructure and was removed from the field. The third deck is presently being field-tested.

\subsubsection{Experimental Procedure}

The bridge decks were constructed of pultruded square cross section tubes sandwiched between an upper and lower pultruded plates with a layer of quartzite particles on an epoxy layer as a wearing surface at the top. The overall dimensions of one of the decks (that were pultruded by Strongwell, Inc. in Bristol, Virginia) were 15' x 5' and 7" deep (shown in Figure 2.22).

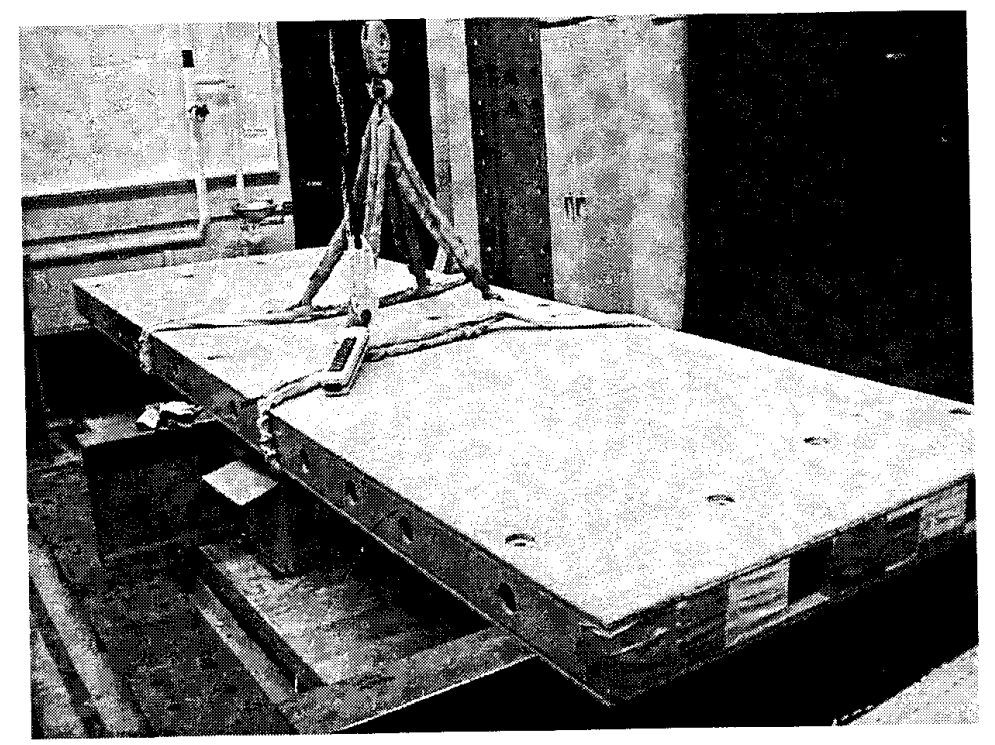

Figure 2.22. Deck section where openings of some of the tubes have been blocked (Miceli et al.2001)

Two major areas of concerns regarding condition of these decks were the presence of debonds in between the top plates and the tubes or between the tubes, and the 
absorption of moisture. Consequently it was determined that infrared thermography could be used to identify the debonds and allow for its rapid examination. However, the problem of assessing moisture absorption had not been developed.

A Raytheon Amber Radiance IT image system was used for the thermal imaging. Solar radiation could not be effectively used to heat the top surface, because of the fact that the quartzite wearing surface erodes in the wheel paths and the surface was subjected to staining from the chemicals that drip from the truck traffic which cause variation in the surface thermal absorption. Consequently another heating method that used forced hot air through the tubes was used as an effective method of heating the whole length of the tube. Since the disbonds disrupt the heat conduction through the structure, they could be detected in the thermal images.

\subsubsection{Results and Discussions}

In the laboratory experiments the first bridge deck was tested by forcing the hot air through individual tubes. There were temperature differentials in the images that possibly indicated the presence of the disbonds. But the differentials due to possible variations in the bond thickness and surface emissivity could not be ruled out. However, near the vicinity of the bolts connecting the deck to the beams below, there was a clear variation in the thermal image patterns before and after the application of the proof load. Figure 2.23 shows thermal images of the deck that was caused by forced hot air into the tubes.
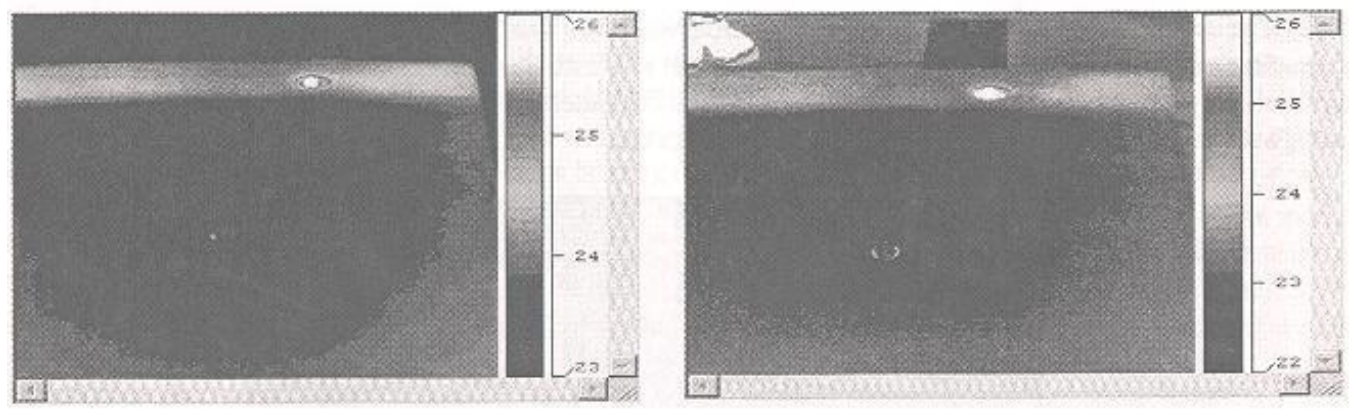

Figure 2.23. Thermal images before and after proof loading of the deck in the vicinity of a bolt

(Miceli et al. 2001)

Due to restricted access of the system in the field, a system for simultaneously forcing hot air into three different pairs of tubes was used. This could be done without 
disrupting the traffic. The testing was conducted prior to sunrise and after closing the weight station, to avoid the problems due to tire path wear of the quartzite surface and the staining. Figures 2.24 (a) and (b) show the thermal images of the same bridge deck over a period of one month. Due to space restrictions, hot air enters the tubes from the bottom side and impinges the top inside surface of the tubes, before flowing down the tube. The differences in the thermal patterns of the two figures were due to the damage to the hot air delivery system caused by the excessive vibration of the deck section. Nevertheless it was established that such a procedure was capable of producing thermal patterns under field conditions.
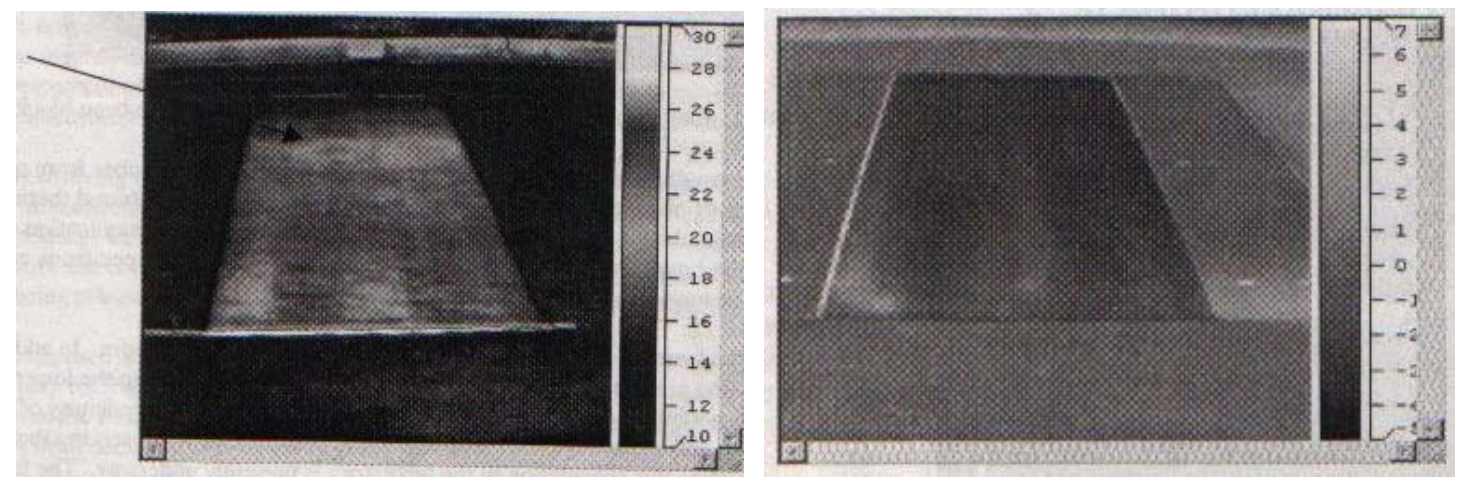

Figure 2.24. Thermal images of the bridge deck (a) initially, and (b) after one month (Miceli et al. 2001)

Further efforts to define the sensitivity of the infrared thermography technique to this type of disbond (delamination) imperfections were pursued using model deck in the laboratory. Figure 2.25 shows a schematic view of the model deck with a disbond created between the tubes and top plate. 


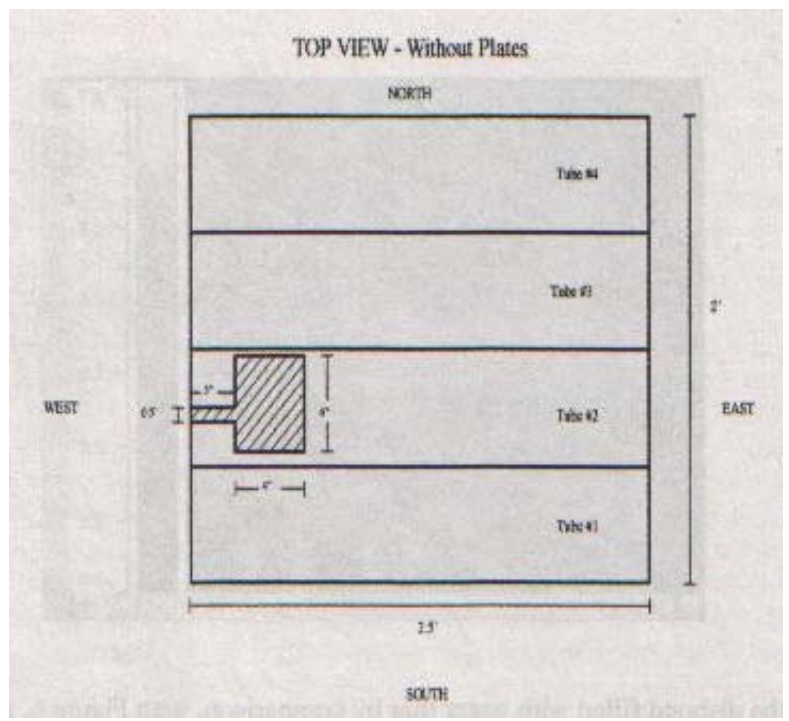

Figure 2.25. Schematic diagram of a model deck (Miceli et al.2001)

The model deck was tested using forced hot air. Mathematical modeling of the heat conduction associated with the convective heat transfer was in close agreement with experimental observations. To ascertain the effects of moisture on the detectability of the disbond, tests were conducted by filling the disbond with water through the channel, and the resulting thermal images are shown in Figure 2.26. Since the thermal conductivity of water is higher than that of air, water filled disbond is less disruptive on the heat conductivity and has a smaller effect on the thermal image.
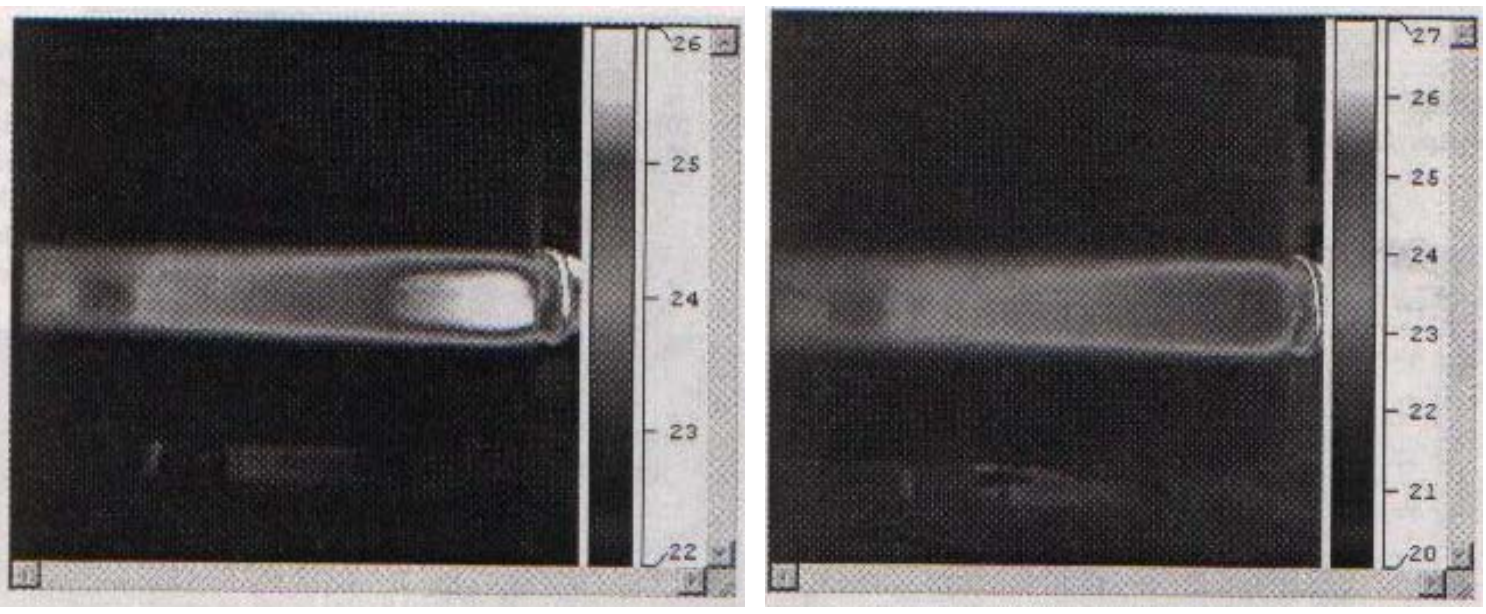

Figure 2.26. Thermal image of deck with (a) air filled disbond (b) water filled disbond (Miceli et al.2001) 


\subsubsection{Conclusions}

Infrared imaging can be used for monitoring the health of FRP structures with disbonds (delaminations). Surface anomalies due to staining and non-uniform wear can complicate image interpretation. Presence of moisture in a disbond (delamination) can cause its size to be underestimated.

\subsection{TEMPORAL TREATMENT OF A THERMAL RESPONSE FOR DEFECT DEPTH ESTIMATION (PLOTNIKOV AND WINFREE 1999)}

\subsubsection{Introduction}

Transient thermography is gaining wider acceptance, because of the rapidness and remoteness of this NDE technique. Flaws in a component may induce thermal contrast in surface thermograms. The quantitative ability of thermal evaluation can be improved by developing a methodology to estimate the depth of the flaws. It is possible to locate the flaw regions (due to corrosion) and their implications on the structural integrity from just one scan.

The research reviewed here focused on composite aircraft components with varying defect depths. A long square heating pulse and several minutes of observations are required to receive adequate thermal response for depth determination. A three dimensional finite difference model of heat propagation in solids in Cartesian coordinates was used to simulate the thermographic process.

\subsubsection{Processing of Thermal Response in Time Domain}

To estimate the defect depth, most of the algorithms use the temporal characteristics of the thermal response received from the exited surface. The algorithms parameterize the flaw depth in terms of a specified point on the thermal contrast curve or divergence point between two temperature evolution curves (one from an inspected area and another from a flawless area). For this application, first it is necessary to get smooth contrast curve for each pixel in the thermal image and secondly to locate the characteristic point. Calculating thermal contrast involves extracting two temperature time evolutions: for inspected area and for reference area. By locating the characteristic point on the thermal contrast curve, it was possible to construct a new image with 
improved defect characterization. Since there are several characteristic points on the contrast curve, it was possible to construct several characteristic images.

\subsubsection{Comparison of Algorithms (Computational Approach)}

Three temperature evolution functions of a thermal response, from different locations are shown in Figure 2.27(a). Signal $\operatorname{Tref}_{\mathrm{ref}}(\mathrm{t})$ is the average thermal response in a reference region as a function of time, $t T_{3}(t)$ and $T_{5}(t)$ are the averaged thermal response for the regions above flat bottomed holes located 3 and $5 \mathrm{~mm}$ under the specimen surface (see Figure 2.27(a)). The curves for 3 and $5 \mathrm{~mm}$ defect depths are noticeably different from the Tref. Since there was a sufficient thermal contrast, it was possible to quantitatively characterize those defects.

A common form of a thermal contrast function is given as follows:

$$
C(t)=\frac{T(t)-T_{\text {ref }}(t)}{T_{\text {ref }}(t)}
$$

Figure 2.27(b) shows the thermal contrast curve, $\mathrm{C}_{3}(\mathrm{t})$ obtained after smoothening with a low pass filter to reduce the noise. Several characteristic points on the contrast curve could be identified, which enabled defect depth determination. The point $t_{\text {div }}$, corresponds to the moment the temperature signal above the inspected point diverges from the reference signal. Establishing of a threshold level is required to identify this point on the time evolution curve (Karpez et al. 1994). Another point $t_{\mathrm{ps}}$, was the time corresponding to the point when the contrast curve had the peak slope (Favro et al. 1996). This point could be determined by seeking the first derivative of the thermal contrast time evolution function. Other time parameters commonly used for defect depth estimation are the time of maximum contrast - $t_{\max }$ and the time at which the contrast reaches 0.72 times the maximum contrast value $-\mathrm{t}_{07}$ which is reported as a more stable value. 

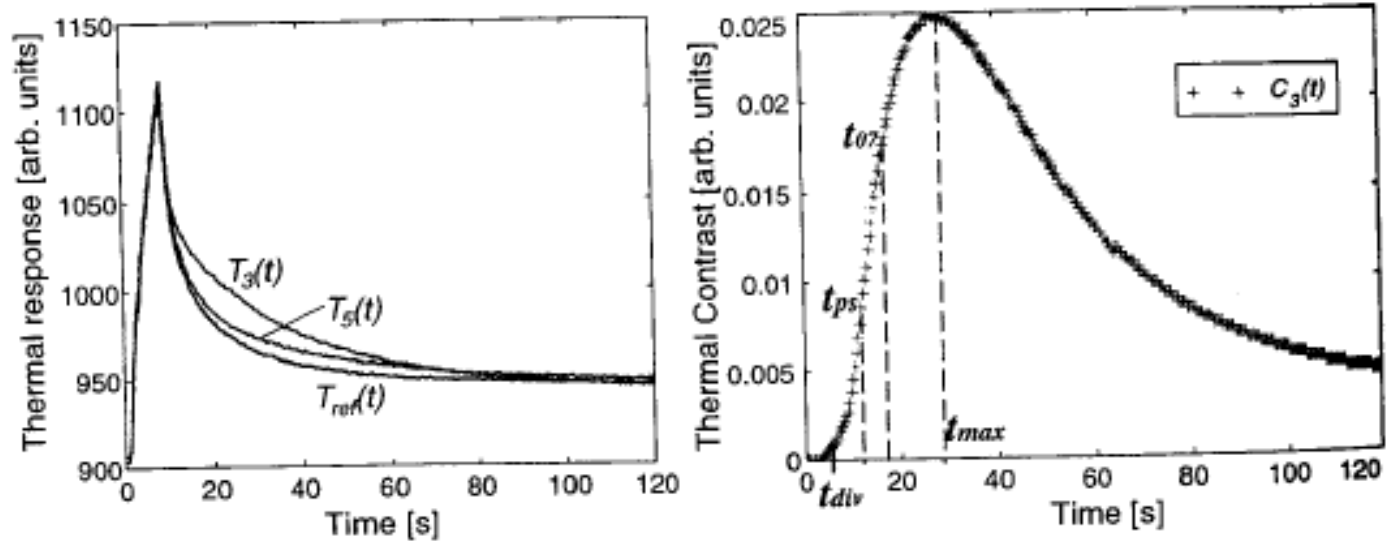

Figure 2.27. Time evolution functions of (a) thermal response and (b) thermal contrast (Plotnikov and Winfree 1999)

The objective of this work was to perform a fair comparison of the informative characteristics such as, the thermal contrast - time evolution plots and various points on these plots, and highlight their strengths and weaknesses. The thermal contrast extraction from noisy experimental data is a complicated procedure involving careful application of noise reduction techniques. Hence, it was informative to study general features of the characteristics points using noise-free simulated thermal contrast curves. This approach helped to assess their behavior in an unbiased way. The computed thermal contrast functions were smooth, which enabled invariant determination of informative parameters.

The cross sections at the centerline of one of the three-dimensional models that were used for numerical computations is presented in Figure 2.28(a) and the other two defect depth configurations are as shown in Figure 2.28(b). An isotropic plate of composite material (Figure 2.28 (a)) with plan dimensions $100 \mathrm{~mm} \times 100 \mathrm{~mm}$ and $20 \mathrm{~mm}$ thickness, thermal diffusivity $\alpha=1.4 \times 10^{-6} \mathrm{~m}^{2} / \mathrm{s}$, thermal conductivity $\mathrm{K}=2.7 \mathrm{~W} /(\mathrm{mK})$, was used to investigate the parameters of interest. The defect incorporated in the model was a square non-conductive flat bottom void with $20 \mathrm{~mm}$ on a side. The void was located at a depth ' $d$ ' below the surface (Figure 2.28 (a)). An instantaneous uniformly distributed heating pulse was used to excite the upper surface (Figure 2.28(a)). An alternating direction implicit scheme was used to obtain a solution of the $3 \mathrm{D}$ thermal diffusion equation. Boundary conditions were chosen to simulate an adiabatic transient process. Temperature evolution functions were computed at the central point of the plate (above the center of the flaw) and at the corner of the plate (for the reference value). The time 
evolution of the thermal contrast was computed from these two temperature functions using Equation 2.6.1.
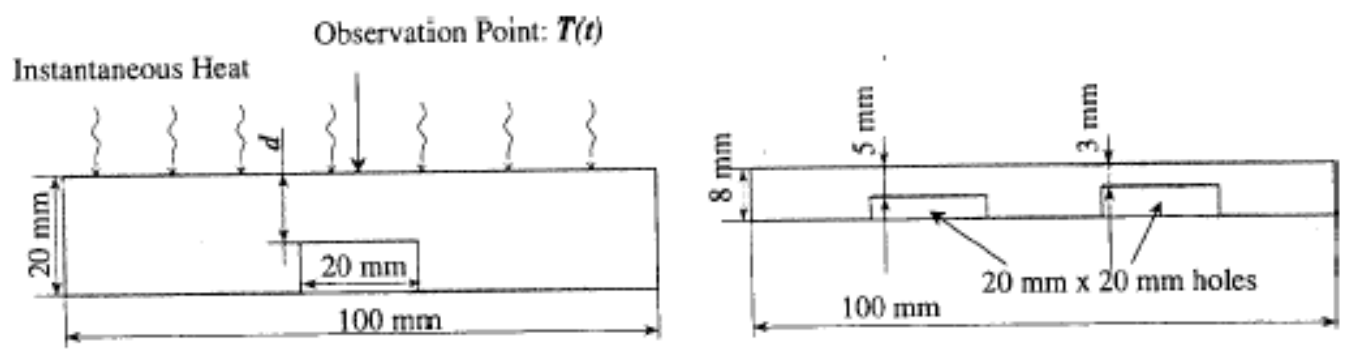

Figure 2.28. Model for simulations (a) isotropic panel with one defect, and (b) anisotropic panel with two defects (Plotnikov and Winfree 1999)

For the model considered $\left(100 \times 100 \times 20 \mathrm{~mm}^{3}\right.$ with $20 \times 20 \mathrm{~mm}^{2}$ defect size), the time related parameters corresponding to the simulated thermal contrast curves were computed with $d$ varying from 1 to $19 \mathrm{~mm}$. The results are shown in the Figure 2.29(a). The parameters were dependent on the defect depth variation and therefore could be used for defect depth estimation. Also, the defect size variations have an impact on the parameters. Figure 2.29(b) shows the same characteristic times for defects of sizes 10x10 $\mathrm{mm}^{2}$ and $40 \times 40 \mathrm{~mm}^{2}$ dimensions. The early time parameters $\left(t_{\mathrm{div}}\right.$ and $\left.\mathrm{t}_{\mathrm{ps}}\right)$ were approximately independent of the flaw sizes for shallow depth defects and differed significantly for deeper defects. The later time parameters $\left(t_{07}\right.$ and $\left.t_{\max }\right)$ had large dependence on flaw size for shallow depths. Since the boundary condition of the model was approximated as an adiabatic transient process the material above the flaw approximated to a thermally insulated material for an initial period after heat application in case of wide defects. For a one-dimensional case, the contrast never achieves a maximum and hence the timing of the maximum is a function of both the size and depth of the flaw. 


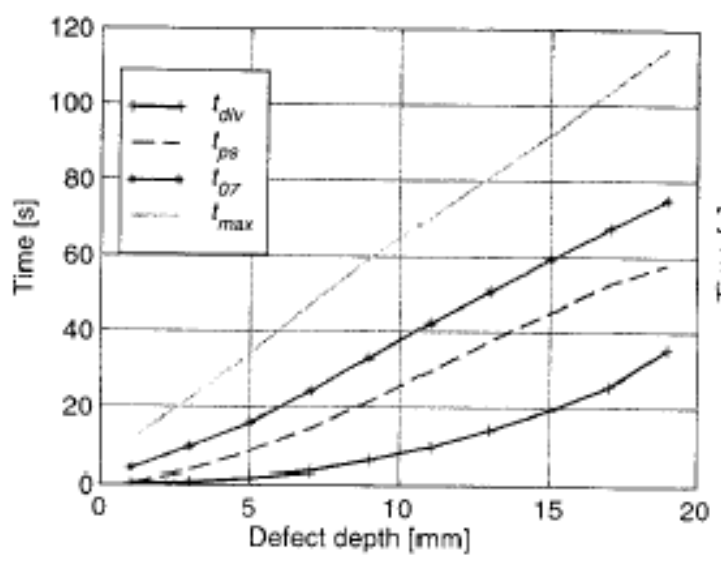

(a)

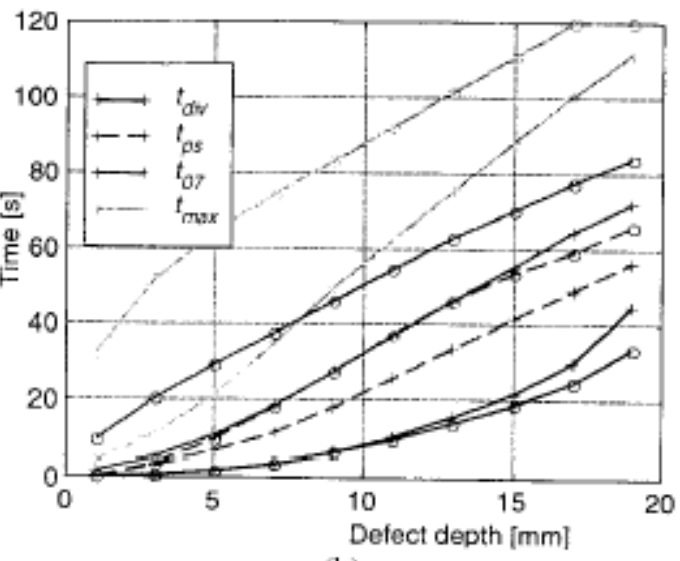

(b)

Figure 2.29. Temporal informative parameters for variable depth of a square non-conductive void (data from simulated thermal contrast evolutions). (a) defect size is $20 \times 20 \mathrm{~mm}^{2}$ (b) defect size is $10 \times 10 \mathrm{~mm}^{2}$ (shown in +-+-+-) and 40x40 $\mathrm{mm}^{2}$ (shown in o-o-o) (Plotnikov and Winfree 1999)

The next phase of the simulation was obtaining the lateral profiles of these timerelated parameters above the defects. It was informative to observe two defects in close proximity (Figure 2.28(b)) Anisotropic media was considered (thermal diffusivity $\alpha=$ $0.7 \times 10^{-6} \mathrm{~m}^{2} / \mathrm{s}$ along the depth and $1.8 \times 10^{-6} \mathrm{~m}^{2} / \mathrm{s}$ in-plane, and $1.4 \times 10^{-6} \mathrm{~m}^{2} / \mathrm{s}$ along and across the defect centerline, respectively).

Two-dimensional distributions were obtained for all informative parameters from the simulated thermal response. The lateral profiles above the two voids located 5 and 3 $\mathrm{mm}$ under the surface are presented in Figure 2.30(a). Presence of the defects is evident in the reduced value regions of the characteristic time curves. The defect-plate boundary for the shallower depth defect (flat part with less visible noise) is much clearer than the deeper defects. A series of simulated thermal images were stored in a binary format with a limited dynamic range to represent the measurement. This resulted in the introduction of noise into the time derivative and hence the tps profile is noisier. It is the case even in experimental results. The late time parameters, $t_{07}$ and $t_{\max }$ provided better lateral separation of the defects because of their better in-depth penetration. 

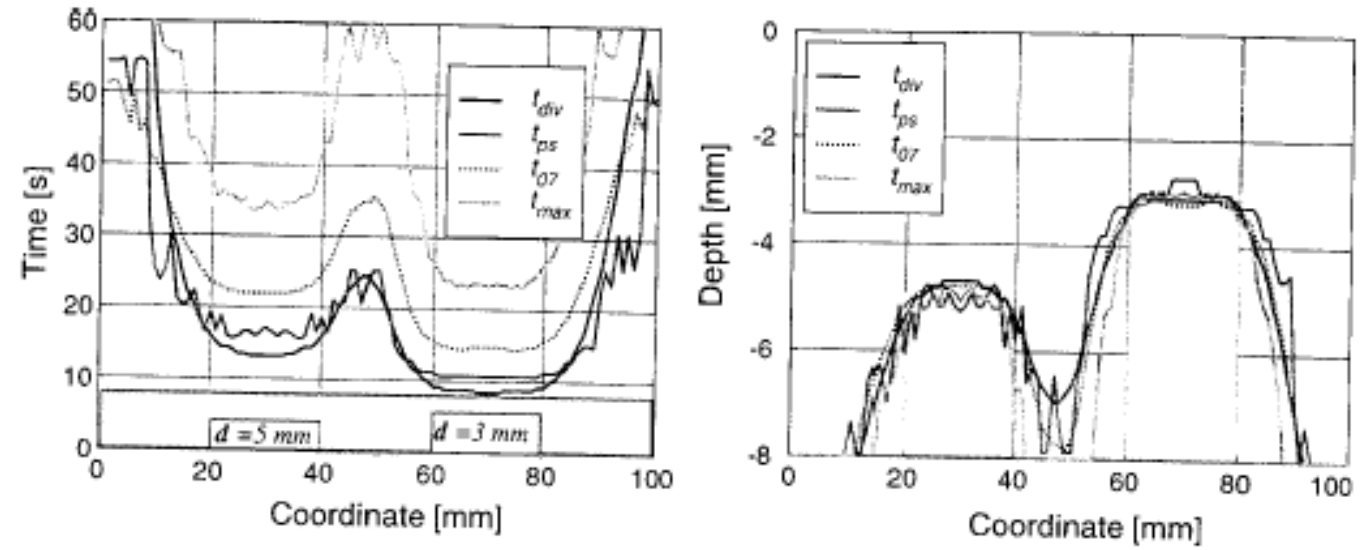

Figure 2.30. (a) Characteristic time profiles and (b) depth profiles, obtained from simulated data set (Plotnikov and Winfree 1999)

To characterize the defect depth a simple data inversion procedure was applied using a polynomial

$$
d=a \cdot \sqrt{t_{\text {char }}}+b \cdot t_{\text {char }}+c
$$

where, $\mathrm{t}_{\text {char }}$ is one of the temporal informative parameters used. The constants $a, b$, and $c$ were determined separately for each parameter. The estimated depths and the actual geometry of the voids are shown in Figure 2.30(b).

Variations of the defect depths over a wide range in the simulated model highlighted some expected limitations of the technique. For example, it was difficult to obtain a depth profile based on tdiv parameter for shallow (less than $2 \mathrm{~mm}$ ) defects. The depth estimations based on tmax parameter had a noticeable crater-like surface for shallow defects. The deeper defects (greater than $6 \mathrm{~mm}$ ) estimated from tps resulted in noisy profiles, but for other parameters deeper defects resulted in more rounded profile estimates.

\subsubsection{Comparison of Algorithms (Experimental Approach)}

The validation of the results of computational approach by experiments was very important. Measurements were performed on a piece of an aircraft wing box structure composed of thick stitched graphite-epoxy composite polymer. The panel had a thickness of $8 \mathrm{~mm}$ with 5 flat bottom 20x20 $\mathrm{mm}^{2}$ holes machined into the backside. A thermal flux pulse lasting 8.5 seconds was applied to the front surface by two quartz lamps with a total 
power of $1.5 \mathrm{~kW}$. A series of 150 thermal images of $256 \times 256$ elements each with a sampling rate of $2.5 \mathrm{~Hz}$ were acquired for post processing.

The thermal contrast, as noted earlier, was computed for the quantitative information of the experimental data. Three commonly used forms of equation for contrast computations are:

$$
\begin{aligned}
& C(t)=\frac{T(t)-T_{r e f}(t)}{T_{r e f}(t)-T_{r e f}(0)} ; \\
& C(t)=\frac{T(t)-T(0)}{T_{r e f}(t)-T_{r e f}(0)} ; \\
& C(t)=\frac{T(t)-T(0)}{T\left(t_{h}\right)-T(0)}-\frac{T_{r e f}(t)-T_{r e f}(0)}{T_{r e f}\left(t_{h}\right)-T_{r e f}(0)},
\end{aligned}
$$

where $t_{h}$ is the time of the heating pulse, when the thermal response has the highest magnitude. Even though all three equations were used, Equation 2.6.3 provided the poorest result while the thermal contrast normalized by the signal peak value (computed using Equation 2.6.5) provided the clearest defect images in the timegrams shown in Figure 2.31. It is worth noting that the time evolution function could be constructed for a segment of several (for instance $3 \times 3$ ) pixels. This furnished a lower noise level and offered more possibilities for contrast computation. However the increase in the possible permutations made it difficult to compare the contrast extraction techniques.

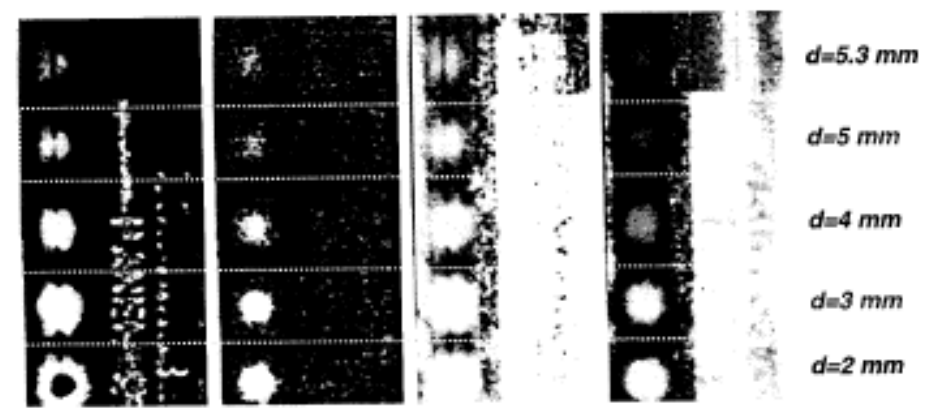

Figure 2.31. Timegrams $t_{\text {char }}(i, j)$ of the $8 \mathrm{~mm}$ composite panel with flat bottom holes of various depths obtained by using different informative parameters. (a) $t_{\text {div }}$; (b) $t_{\mathrm{ps}}$; (c) $t_{07}$; (d) $t_{\max }$

(Plotnikov and Winfree 1999) 
To compute the defect depth, Equation 2.6.2 was applied to the obtained characteristic time distributions (Figure 2.31(a)). The estimated depth from $t_{\text {div }}$, yielded an inaccurate representation of the shallowest defect. A gray scale depth image obtained by averaging the depth profiles estimated from three other timegrams $\left(t_{p s}, t_{07}\right.$, and $\left.t_{\max }\right)$ is shown in the Figure 2.32. The comparison between the estimated and the actual (dotted line) bottom profiles for the centerlines of the defects is also shown. The reconstructed profiles for the defects have round edges. Also, the contrast image indicates that the noise in the defect- free area is noticeable.
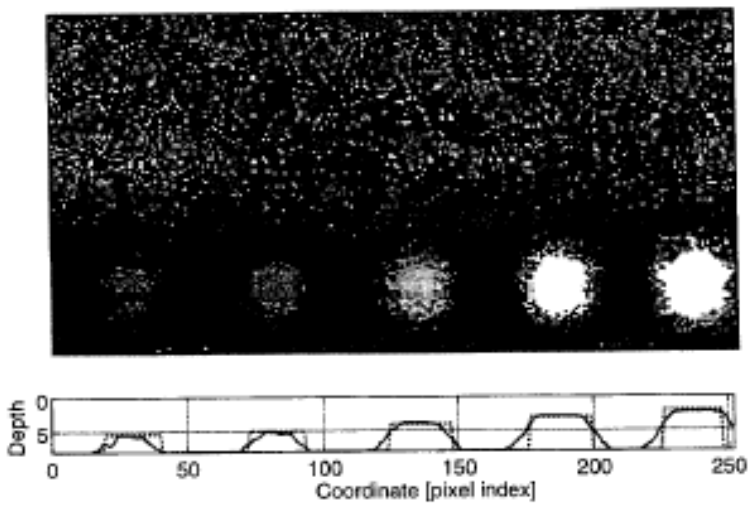

Figure 2.32. 2D contrast image and average depth profile (Plotnikov and Winfree 1999)

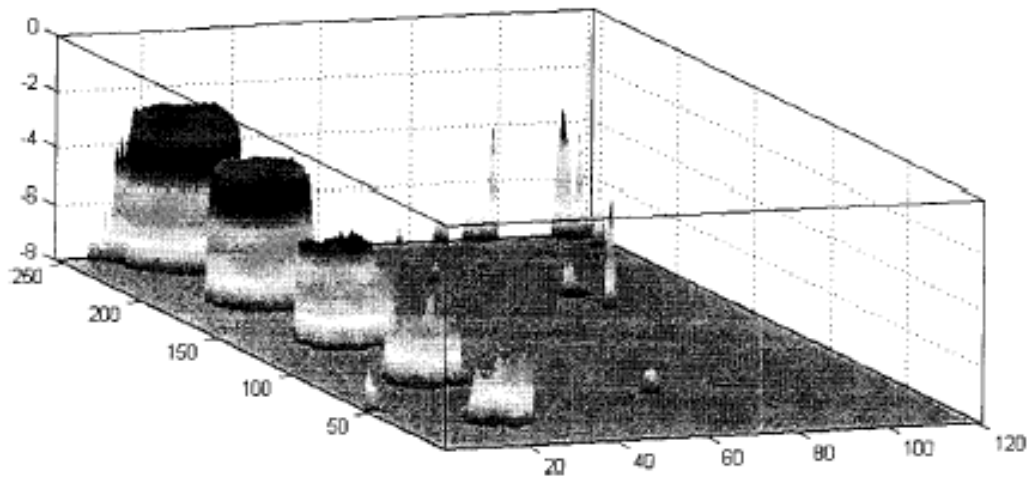

Figure 2.33 3D image of the flat bottom holes in the 8-mm composite panel obtained with the thermal technique. Vertical scale is given in $\mathrm{mm}$, horizontal scales are in pixels (approx. $0.86 \mathrm{pixel} / \mathrm{mm}$ )

(Plotnikov and Winfree 1999)

To overcome the aforementioned limitations, an initial defect free map was constructed using pulse phase technique followed by Laplacian defect shape extraction 
(Plotnikov and Winfree 1999). The defect planar geometry in the resulting defect map provided a much more accurate representation of the real defect geometry. A masking of the depth profile with this binary defect map yielded an accurate representation of the internal structure. The 3D representation of this result is shown in Figure 2.33.

\subsubsection{Conclusions}

All the considered parameters were found to be suitable for the defect depth determination of the large defects (lateral dimensions greater than twice the panel thickness). The best results were obtained by averaging the depth profiles obtained based on several characteristic points on the thermal contrast curves. Care must be exercised when using early time parameters ( $t_{\text {div }}$ and $t_{\mathrm{ps}}$ ) for the estimation of shallower defects. Accurate characterization of these parameters requires a high sampling rate so that the behavior during the initial time period is captured accurately, otherwise the technique yields inaccurate defect depth estimations. The information available in the thermal response over the entire time interval from tdiv to tmax could be used, along with good curve fitting techniques, for future development of a robust method for estimating defect depths. 


\section{Chapter 3 \\ INFRARED MONITORING SYSTEMS AND EQUIPMENT}

The infrared (IR) thermography technique is generally divided into two phases. They are the creation of a thermal gradient on the specimen surface by using a heating or a cooling source and detecting the defects with an infrared imaging system. This chapter describes the details of the infrared monitoring equipment used for the infrared NDT. The various heating and cooling equipment that have been used for the laboratory studies (presented in Chapter 4) are also included.

\subsection{INFRARED CAMERAS}

The infrared (IR) camera detects the surface temperature of the specimen and produces thermal images, which can be directly recorded on a computer or on videotape. The type of the images (digital or non-digital) depends on the type of the camera used. Descriptions of the non-digital and digital infrared cameras that were used in the laboratory studies are given below.

\subsubsection{The FSI Prism Single Point (SP) Infrared Camera}

The non-digital infrared camera that was used for some of the laboratory experiments was the FSI Prism SP infrared camera. This camera can detect radiation in the spectral range of 3 to 5 microns (medium wavelength spectral range). It can also remotely measure and display the absolute temperature of a specific point on the target. The detector type used in the camera is Platinum Silicate (PtSi) IR CCD Array (320 x 240 pixels). The camera's radiometric temperature range is from $-20^{\circ}$ to $250^{\circ} \mathrm{C}\left(-4^{\circ}\right.$ to $\left.482^{\circ} \mathrm{F}\right)$ without filter and up to $1500^{\circ} \mathrm{C}\left(2732^{\circ} \mathrm{F}\right)$ with filter. The infrared images can be displayed in a black and white scale as well as a color scale. A Polarity switch in the camera allows the operator to select between white and black hot display mode which displays hotter regions as white or black, respectively (FSI FLIR Systems 1994). In the experiments conducted in the laboratory it was set to the white hot display mode. Figure 3.1 shows the infrared camera. 


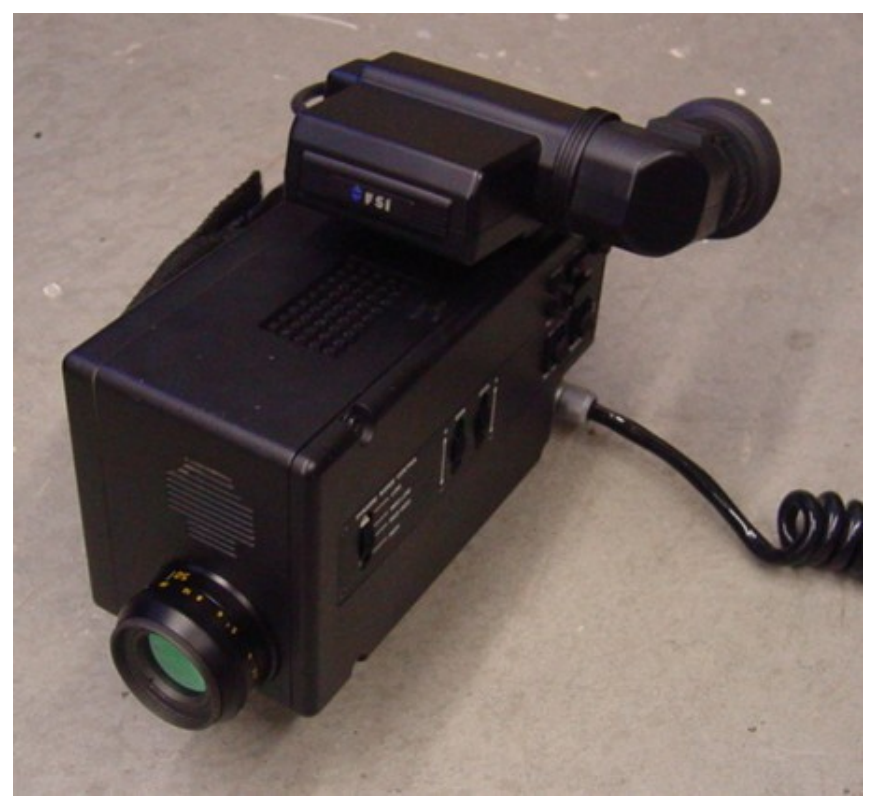

Figure 3.1 FSI Prism Single Point (SP) Infrared Camera

The video output coming from the infrared camera was recorded in a TV with a built-in VCR. The real time thermal images were recorded in a VHS tape over a period of time. The images were then transferred from the VHS tape to the computer with the help of special equipment and software called the Snappy Video Snapshot. This equipment could capture still images from the tape and convert them into jpeg files that could be stored in the computer. However, the disadvantage with the images stored in this format is that they were non-digital images and hence did not provide details of temperature at every pixel. This made the process of image enhancement more difficult when compared to the digital image enhancement techniques. Also, the ability to conduct any type of quantitative analysis was limited with the use of such non-digital images.

\subsubsection{ThermaCAMTM S60}

The ThermaCAM ${ }^{\mathrm{TM}}$ S60 (FLIR Systems) infrared condition monitoring system consists of an advanced digital infrared camera and associated image processing software. The ThermaCAM ${ }^{\mathrm{TM}}$ camera (shown in Figure 3.2) is a handheld, lightweight and a truly portable camera with a built-in $24^{\circ}$ lens. It also contains an integral digital color camera, a laser pointer, a 4” color LCD on a removable remote control, and a range of accessories. This camera can detect radiation in the spectral range of 7.5 to 13 microns. 
The type of detector in the camera is a focal plane array (FPA), uncooled microbolometer. The different temperature ranges available for the measurement are 0 to $+500^{\circ} \mathrm{C}\left(+32\right.$ to $\left.+932{ }^{\circ} \mathrm{F}\right),-40$ to $+120{ }^{\circ} \mathrm{C}\left(-40\right.$ to $\left.+248{ }^{\circ} \mathrm{F}\right)$ and +350 to $1500{ }^{\circ} \mathrm{C}(+662$ to $+2732^{\circ} \mathrm{F}$ ). The measurements can be detected up to an accuracy of $\pm 2{ }^{\circ} \mathrm{C}$ or $\pm 2 \%$ of the temperature reading. The imaging performance for the camera has a spatial resolution of $1.3 \mathrm{mrad}$ and can record images at a frequency of $50 / 60 \mathrm{~Hz}$, non-interlaced. That is, the infrared image capture rate can go as high as 60 frames per second. It is possible to capture and store images on a removable flash card. The camera also features burst recording functionality that allows the user to record sequences of events into the internal RAM memory. Voice and/or text comments could be stored. The built-in digital color camera captures critical details, making reporting and analysis easy. The images can be analyzed either in the field by using the real-time measurement markers built into the camera software, or in a PC using FLIR Systems software (FLIR Systems 2002a).

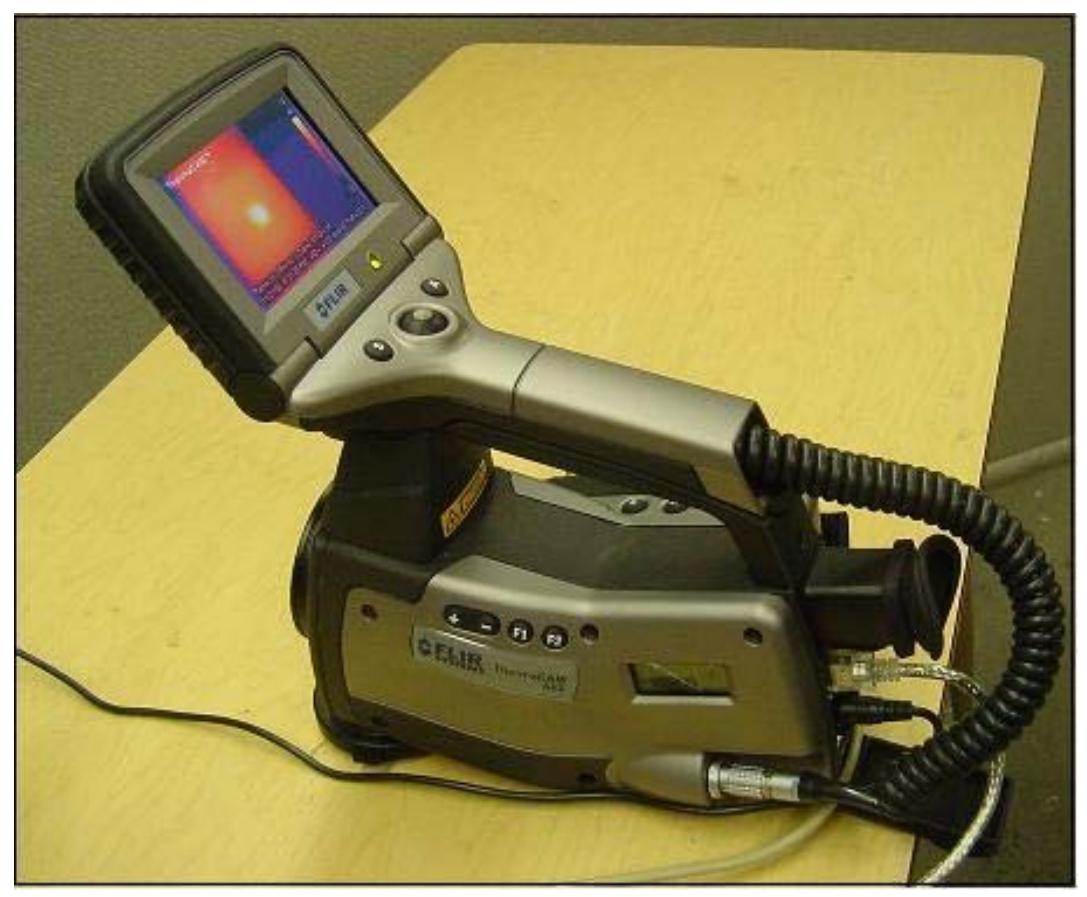

Figure 3.2. ThermaCAM ${ }^{\mathrm{TM}} \mathrm{S} 60$ infrared camera from FLIR Systems

The software that is used along with the camera is called as the ThermaCAM ${ }^{\mathrm{TM}}$ Researcher 2002. It deals with the live IR images arriving through the camera interface and can also receive IR images from other media, such as PC card hard disk from the 
camera. The software can be used to display the IR images, record them on the disk, or analyze them later during the replay. The measurements can be made with the analysis tools like isotherm, spotmeter, area and line. The images can be processed further to enhance their contrast. Since the camera captures fully radiometric digital images, a reference image can be subtracted from the full image sequence to achieve better results in terms of detectability of defects and to conduct a quantitative analysis (FLIR Systems 2002b).

The infrared camera allows the images to be recorded first and then viewed at a later time with a different temperature/color intensity scale to improve the contrast. The temperature corresponding to any point could easily be obtained by simply using the spot temperature measurement option provided by the analysis software. This is one of the major advantages in using the digital infrared images when compared to the non-digital images, which cannot provide such details at every pixel.

\subsection{HEATING SOURCES}

\subsubsection{Quartz Tower Heater}

The quartz tower heater shown in Figure 3.3, was one of the main heating sources used in the laboratory. This heater can be operated in two settings - 750 and 1500 Watts. To impart high energy in a short time the 1500 Watts with maximum level setting was used during the experiments.

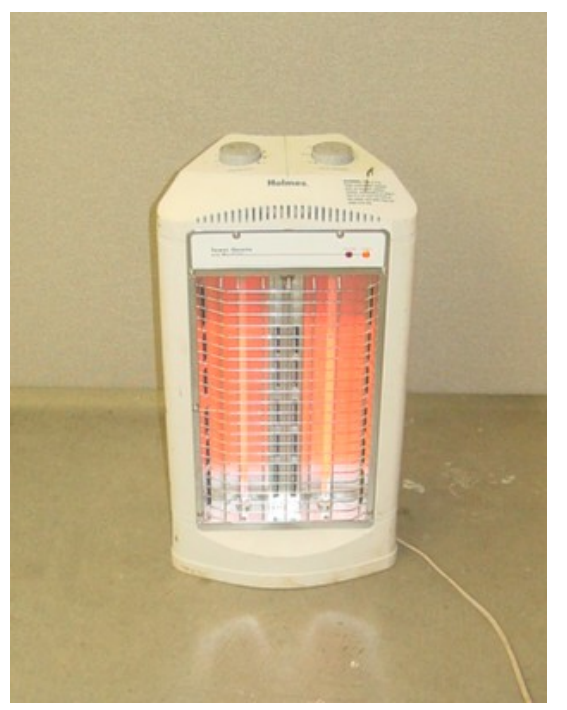

Figure 3.3. Photograph of the quartz tower heater 
Uniform heating of the specimen surface was achieved by placing the heater at a small distance ( 8”) from the specimen surface. The thermal images were observed after heating the specimen for a small duration of time and the images were studied as the specimen cooled down. The heater could heat the specimens kept in a vertical position. However, it could not heat specimens in a horizontal position. This was due to the inbuilt automatic cut-off system that shut down the heater when it was placed facing the horizontal plane.

\subsubsection{Heating Blankets}

The electric heating blanket of plan size 36" x 36" (914mm x 914mm) and 1" (25mm) thickness (shown in Figure 3.4) was the other main heating sources used for the laboratory studies. This heating blanket had a 1500W rating with a built-in temperature control. It could also be connected to an external temperature control box (shown in Figure 3.4) which provided better features.

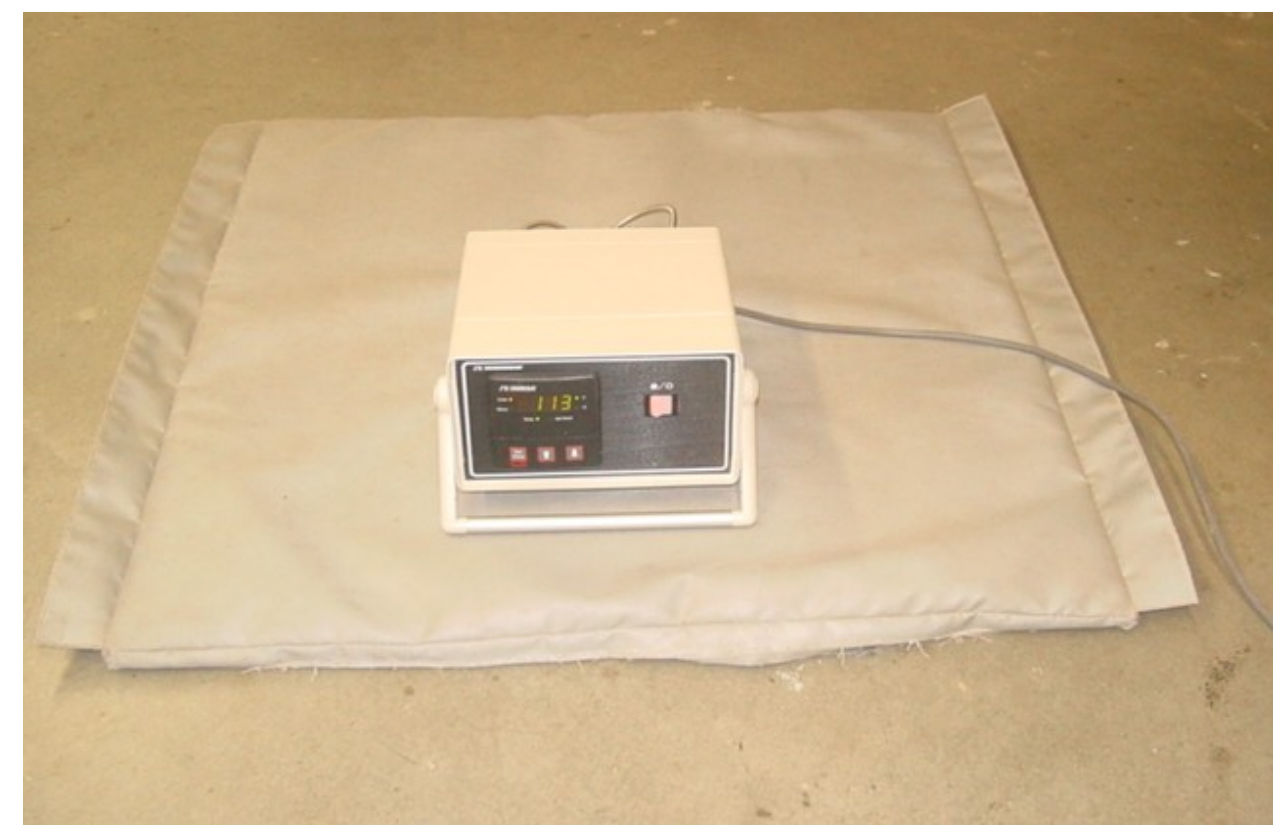

Figure 3.4. Photograph showing a heating blanket with an external temperature control box

The heating element was of multi-stranded, flexible electric knitted tape type, covered with a silicone laminated cover material. A maximum temperature of $163^{\circ} \mathrm{C}$ $\left(325^{\circ} \mathrm{F}\right)$ could be achieved. However the safe operational temperature range was only 
about $32-60{ }^{\circ} \mathrm{C}\left(90-140{ }^{\circ} \mathrm{F}\right)$ as very high temperatures over prolonged periods could burn the heating coils. Hence an external temperature control box was used to ensure and set the temperature range. The heating blanket could be used either in the vertical or horizontal plane and could also be wrapped around the materials. The heating blanket had to be in contact with the specimen for several minutes to heat it efficiently. Hence, the heating time was larger when compared to that of the quartz heater. Uniform heating was a little difficult to achieve because of the placement of the tape type heating elements which resulted in higher temperatures directly beneath the coils. However, this problem was overcome by displacing the blanket slightly during the heating period to ensure even temperature throughout the surface.

\subsubsection{Solar Radiation}

Solar radiation has also been used as a heating source for heating the specimens. Past infrared studies conducted on concrete decks have shown that maximum temperature differentials between the defective and defect-free areas in bridge decks occur during midday, that is, from 10am to 2pm (Maser and Roddis 1990). Using solar radiation as the heating source reduces the cost involved with the use of external heating sources like the heating blankets, quartz heater etc. Though solar radiation is a good heating source for concrete and also composite materials, its intensity depends on the season of the year and the time of the day. It may not be adequate to rely on solar radiation as the heating source on cooler and windy days, since the amount of heat the specimen would receive is usually

not sufficient enough to reach high temperatures. Also the gradually increasing (from morning to noon) heat source may not build up a sufficiently large thermal gradient through the thickness of the deck.

\subsection{COOLING SOURCES}

Cooling a material is equivalent to applying negative heat on the material surface. Some of the sources that have been used as cooling sources for the laboratory studies are described next. 


\subsubsection{Liquid Carbon Dioxide $\left(\mathrm{CO}_{2}\right)$}

Liquid carbon dioxide compressed in a cylindrical tank (fitted with an internal riser or siphon tube) was sprayed on the FRP test specimens to cool the surface. Figure 3.5 shows a $10 \mathrm{lb}$ cylindrical tank containing liquid $\mathrm{CO}_{2}$, which is usually at $-40^{\circ} \mathrm{C}$ temperature. A flexible tube that was fitted to the tank nozzle was used to spray the gas onto the specimen surface for several minutes. The compressed $\mathrm{CO}_{2}$ impinged onto the specimen surface with some pressure. A low surface temperature (around $8-10^{\circ} \mathrm{C}$ ) was achieved by spraying the liquid $\mathrm{CO}_{2}$ for a few minutes on the surface of a bridge deck specimen with the wearing surface material. The $\mathrm{CO}_{2}$ cylinders are relatively expensive and only a small surface area can be cooled at a given time with the current arrangement. If this cooling mechanism is to be used for field testing, then elaborate spray equipment will have to be devised.

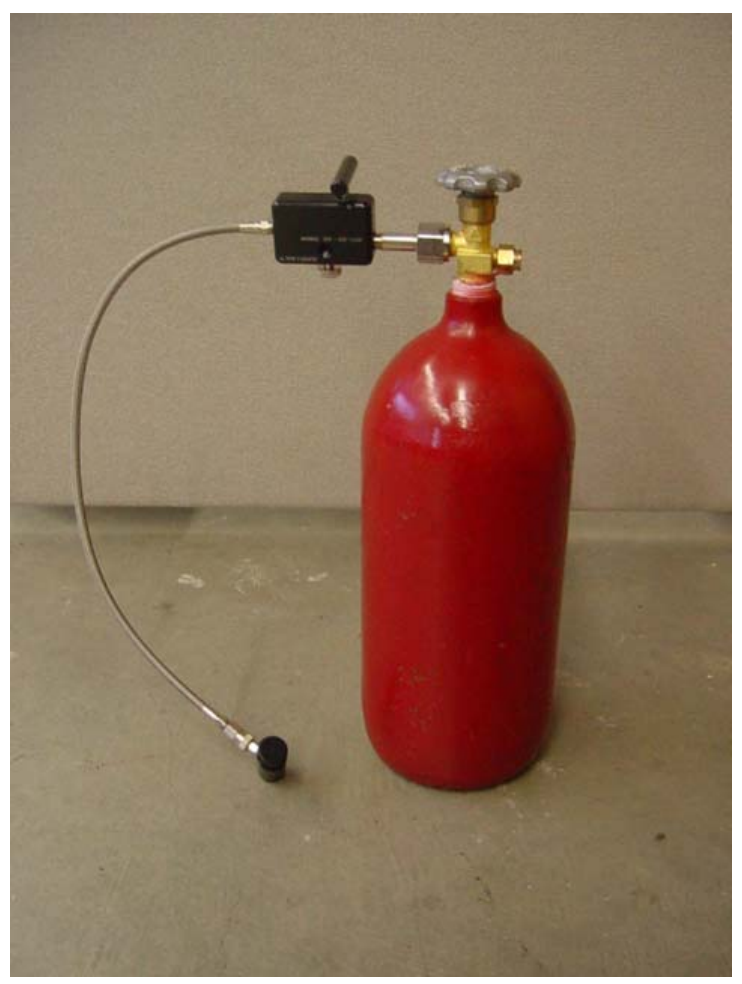

Figure 3.5. Photograph of a $10 \mathrm{lb}$ cylindrical tank containing liquid $\mathrm{CO}_{2}$ 


\subsubsection{Cold Water}

Cold tap water with a temperature of about $4-5^{\circ} \mathrm{C}$ was used as an alternative cooling source for the laboratory experiments conducted on FRP bridge deck specimens. Adequate and uniform cooling of the specimen's surface could not be achieved because water could not remain on the surface and tended to flow out of the small sized specimens. In the field, the sizes of the decks are large and hence this problem would not occur. However, varying thickness of the water layer could result in non-uniform cooling of the surface. 


\section{Chapter 4}

\section{LABORATORY EXPERIMENTS, ANALYSIS AND RESULTS}

\subsection{INTRODUCTION}

Steel and Fiber Reinforced Polymer (FRP) jacketing of existing concrete bridge piers is being used for increasing the bridge's earthquake resistance and for repairing piers that have sustained extensive cracking and spalling due to corrosion or fire during the life of the structure. FRP jackets are also used as wraps for rehabilitating old wooden bridge components. These jackets also provide confinement to the underlying material and increase the load carrying capacity of these components. Also, FRP bridge decks are being considered for replacing old concrete bridge decks. The composite decks are manufactured in a plant using a process called Pultrusion (see Figure 4.1). The FRP composites can be pultruded into different shapes and sizes for various infrastructure applications (e.g., bridge decks, supporting beams).
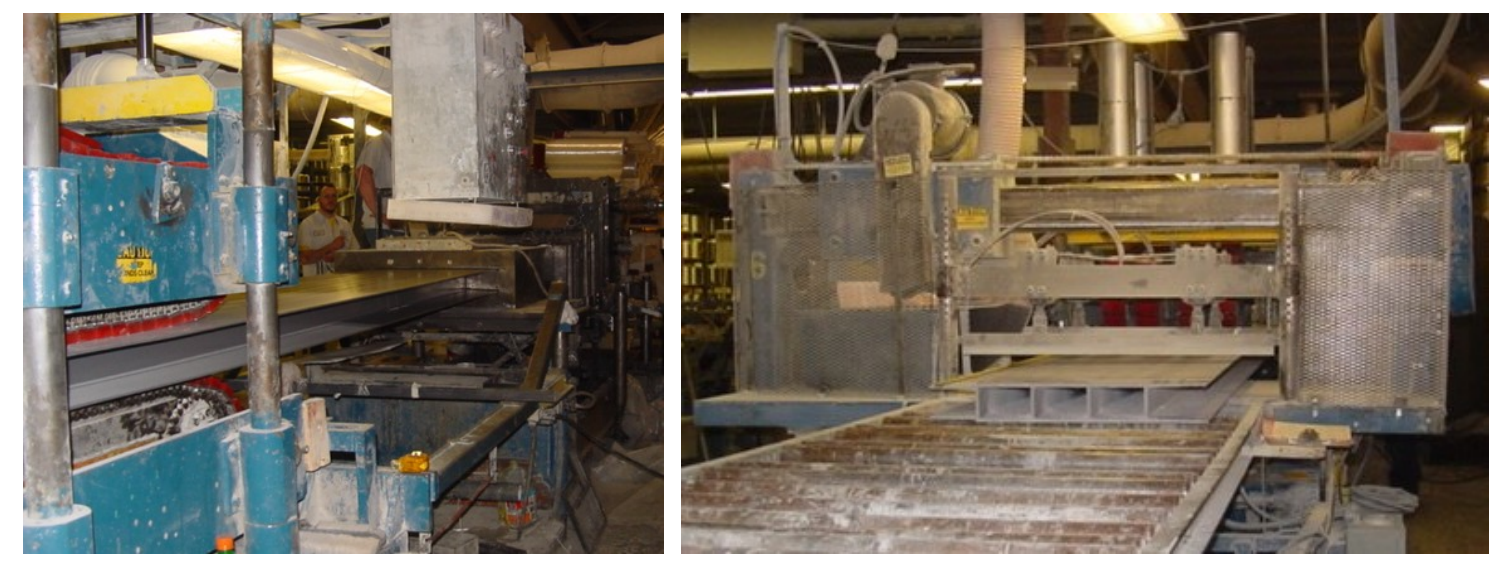

Figure 4.1 Photographs showing manufacturing of an FRP bridge deck in a factory using the Pultrusion process

All of the above mentioned composite bridge components could develop subsurface defects (e.g., cracks, voids, delaminations, debonds) during the manufacturing process, during construction, and/or during the service life of the components. The subsurface defects can adversely affect the structure locally and globally. Since there are only a few FRP decks and beams currently in use in the field environment, and they are 
relatively new, the durability aspects of these composite components in the field environment are not fully understood. Therefore, it has becomes necessary to inspect and evaluate these components at various stages of manufacturing, construction, and service life in order to ensure continued structural integrity. Infrared thermography has proven to be a promising technique for nondestructive testing and evaluation of such materials. The thermal images acquired using an infrared camera can reveal the location and size of subsurface defects in composite members (Halabe et at. 2002, Halabe et at. 2001). Advanced digital infrared cameras and image processing techniques can be used to enhance the quality of the images.

This laboratory study evaluates the applicability of digital infrared thermography system to detect subsurface anomalies such as debonds and delaminations in different types of bridge components. Details of the experimental setup, infrared tests, analysis and results are included in this chapter.

\subsection{PREPARATION OF DEBONDS AND DELAMINATIONS}

Various subsurface defects (debonds and delaminations) were created within these specimens. Debonds refer to the subsurface defects that are present at the interface between the wearing surface layer and the underlying FRP deck or between the composite wrap and underlying component. Delaminations refer to the defect present within the top or bottom flange of the deck material.

The air-filled debonds were made by joining two polypropylene sheets (material used for making microwave safe containers) with an enclosed air pocket in between them. Figure 4.2 shows a photograph of an air-filled debond and materials used for its preparation. Small strips of polypropylene sheet were cut and glued along the boundary as spacers in order to enclose an air pocket in between the two sheets. Additional strips were placed in the central region as stiffeners in case of larger delaminations. Finally, this debond was sealed in between two latex sheets so that the air is fully trapped inside.

The water-filled debonds (shown in Figure 4.3) were made by enclosing water within super-strength plastic sheets. A sheet was first folded and the open edges were fused together by heating them. A small opening was left on one of the edges before fusing it together, for injecting water. This opening was further fused, thereby entrapping 
the water inside the plastic pouch. However one or two small air bubbles inside the pouch could not be avoided while enclosing the water and they remained as air pockets.

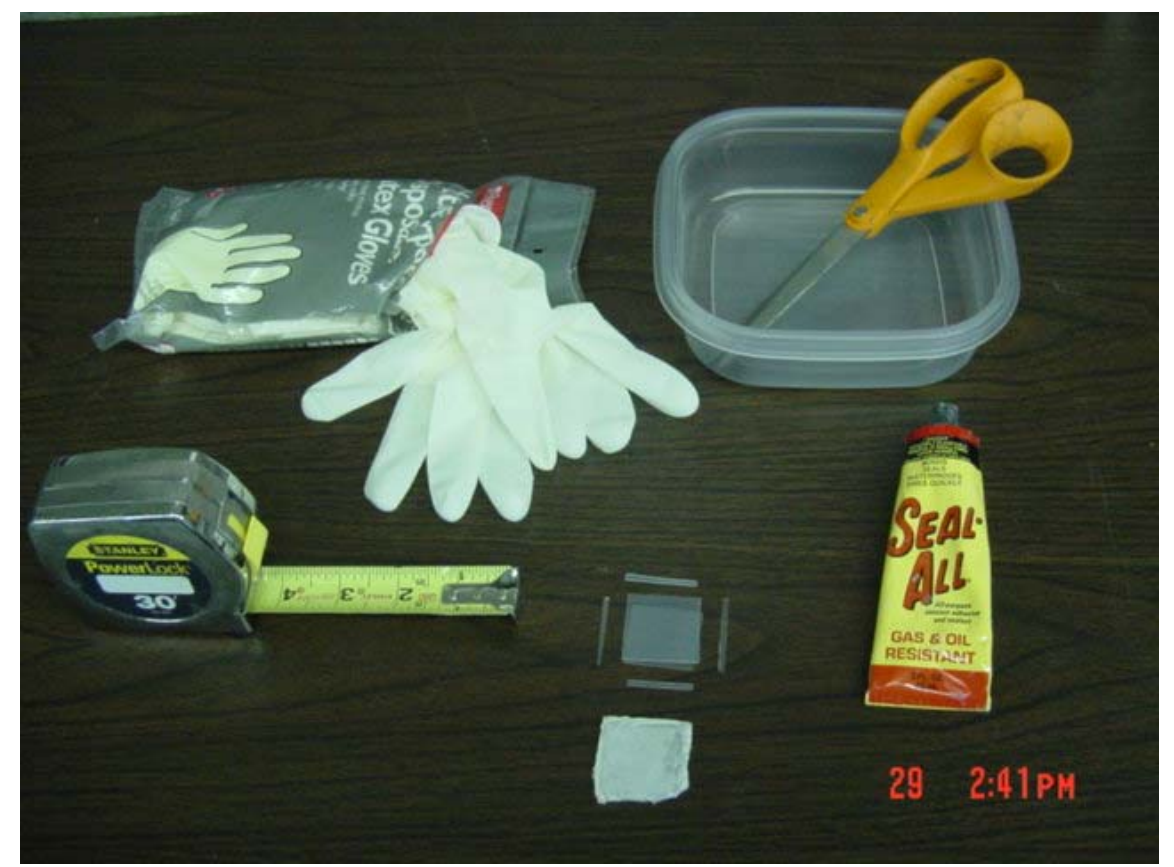

Figure 4.2 Photograph of a debond prepared by enclosing air gap between two polypropylene sheets

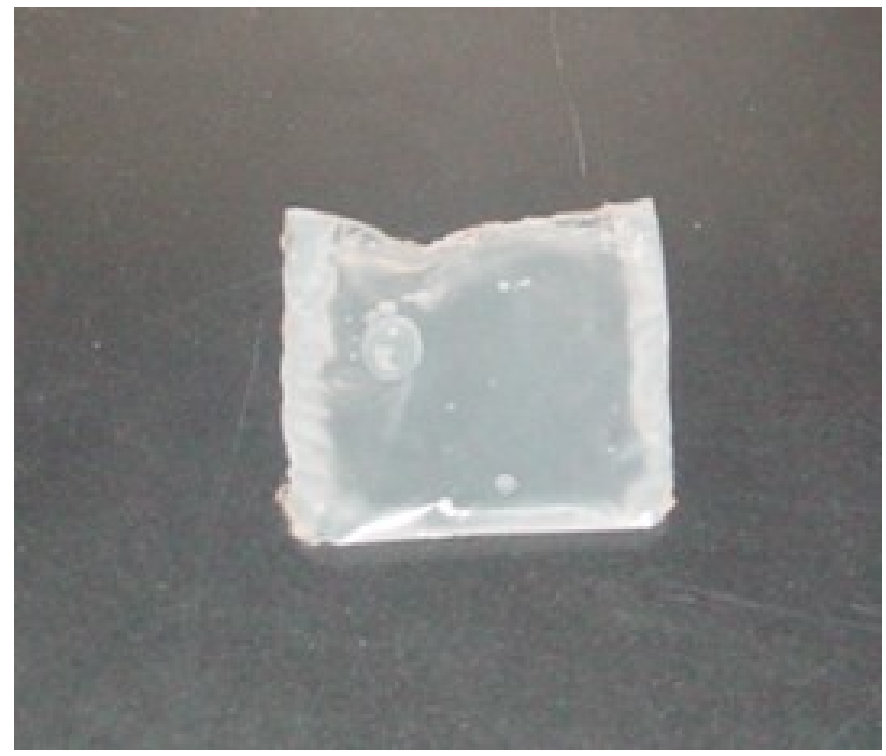

Figure 4.3 Photograph showing a water-filled debond

A Milling machine was used to mill (or cut) rectangular portions of required sizes on the flange joint area of a bridge deck module. These delaminations of various plan 
sizes and thicknesses were created in the middle of the flange joint area (top flange) in one of the modules before joining two modules together. The delamination was covered with wax paper, so that the glue did not get into the delamination and also to leave the air gap intact. The two deck modules were then joined together using a structural adhesive called Pliogrip. The delaminations were thus embedded within the flange-flange junction at an average depth of 0.32 " (8mm) from the top surface. Figures $4.4(\mathrm{a})$ and (b) shows photographic view of the specimens with the embedded delaminations.
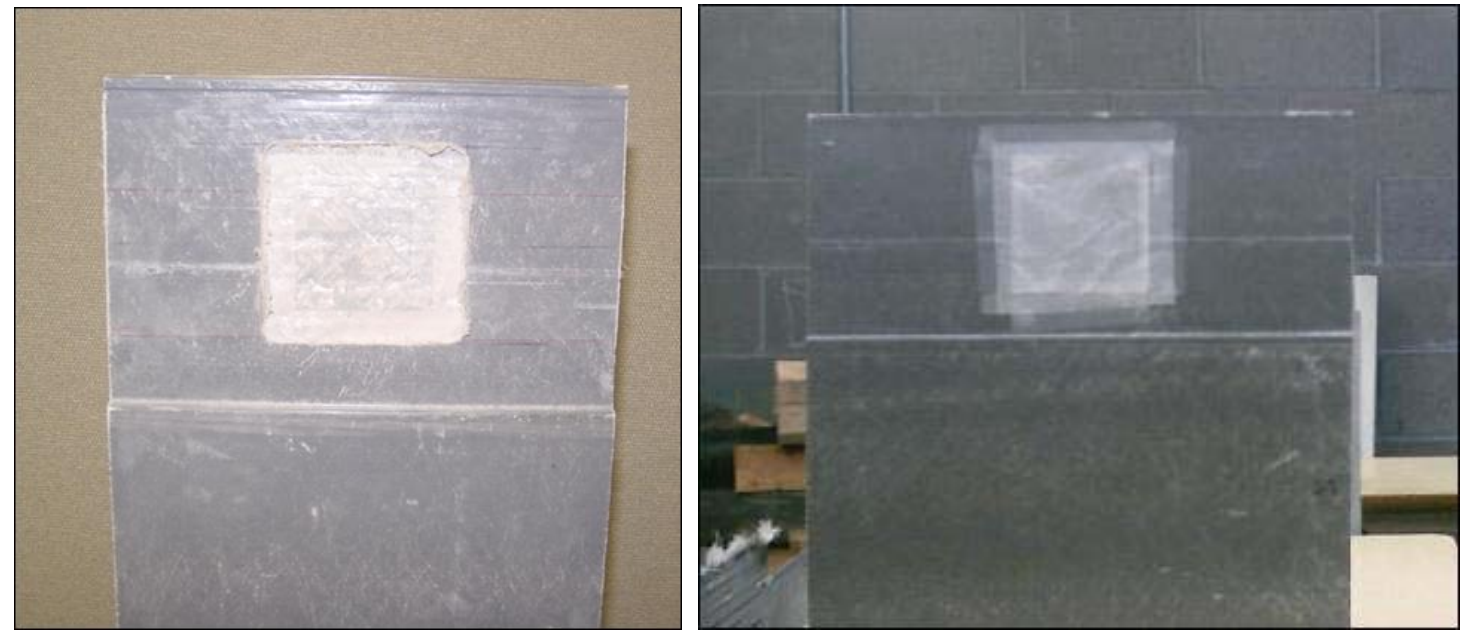

Figure 4.4. Close up view of the 3" x 3" delamination, created at the flange-flange junction of a module

(a) without wax paper (b) with wax paper

\subsection{EXPERIMENTAL SETUP}

The laboratory study using infrared thermography consisted of two steps. The first was to create a thermal gradient through the thickness of the specimen using either a heating or cooling source. Such gradients lead to surface temperature variations since the thermal conductivity and rate of heat transfer through a defect is different from surrounding defect-free areas. The second step in the testing was to detect the defects by recording the surface temperature variations using the infrared monitoring system. Most of the laboratory experiments were conducted using the ThermaCAM ${ }^{\mathrm{TM}}$ S60 digital infrared system for detecting the subsurface defects. The thermal gradient through the specimen was established using one of the heating or cooling sources described in the previous chapter. Figure 4.5 shows a typical infrared setup used for the laboratory study. In this figure the quartz heater is seen heating an FRP deck. A laptop computer connected 
to the infrared camera was used to store the sequence of digital images arriving from the camera interface. The upper and lower limits of the temperature scale in the infrared image could be adjusted so that a good color-contrast between the defective and defectfree areas was achieved.

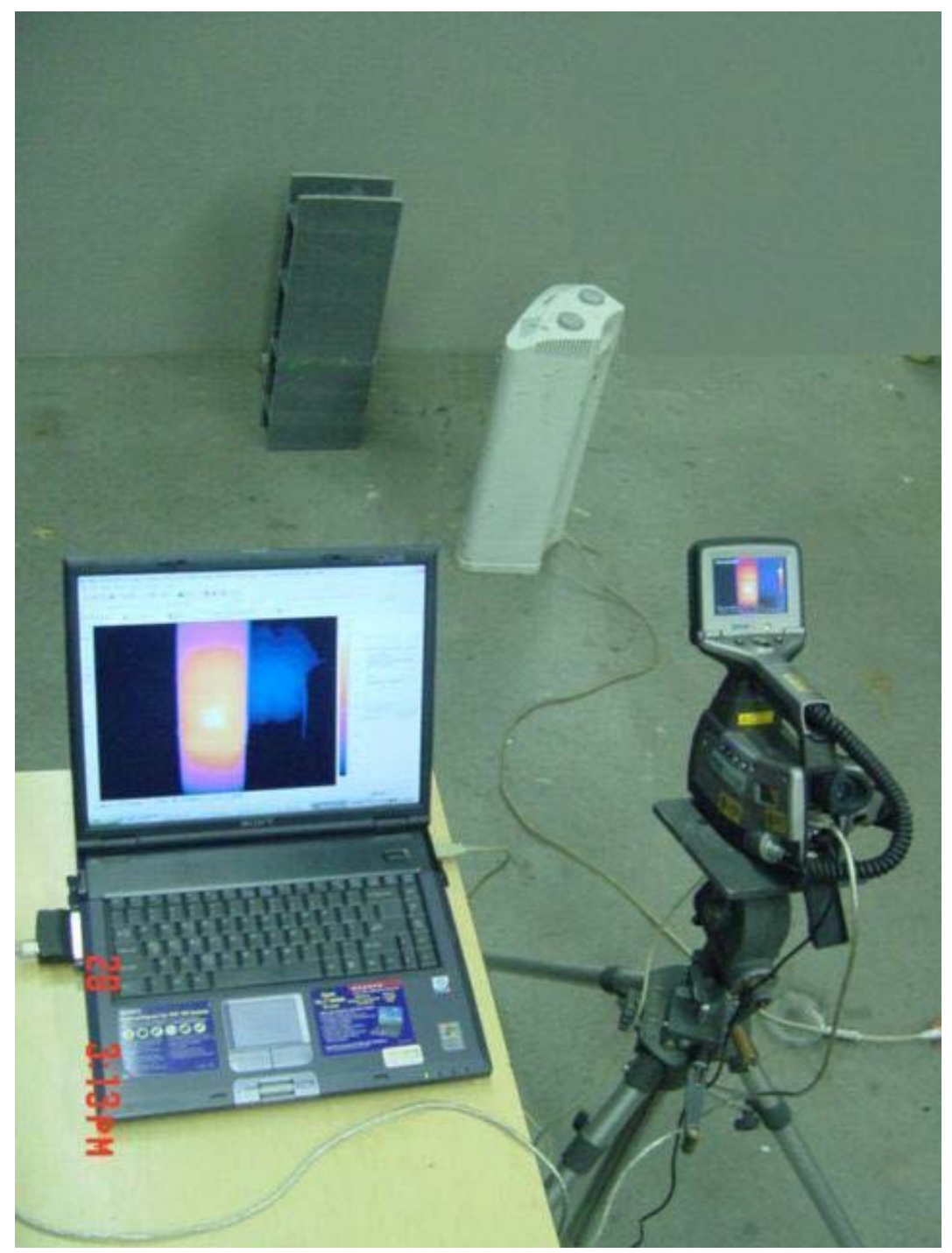

Figure 4.5. Experimental setup using digital infrared camera 


\subsection{DETECTION OF DEBONDS BENEATH THE WEARING SURFACE}

\subsubsection{Description of Specimens}

\section{Bridge deck specimen BD1}

The specimen BD1 (Figure 4.6) used here consisted of Glass Fiber Reinforced Polymer (GFRP) bridge deck module of size 24 " x 12 " $(0.6 \mathrm{~m} \times 0.3 \mathrm{~m})$ and overall depth of 8 " $(0.2 \mathrm{~m})$. The top and the bottom flange thicknesses were $0.5 \%(12.7 \mathrm{~mm})$. The web thickness and the diagonal member thickness were $0.35 "(8.9 \mathrm{~mm})$ and $0.25 "(6.4 \mathrm{~mm})$, respectively. The GFRP deck is composed of E-glass fibers and polyester resin combination. The glass fibers are continuous strand roving and triaxial fabrics. The fiber volume fraction is about 45\%. (pultruded at Bedford Reinforced Plastics, Inc., PA). The deck is overlaid with a wearing surface layer of thickness $3 / 8 "(9.5 \mathrm{~mm})$. The wearing surface consisted of a non-skid, flexible, hybridized, and copolymer overlay system, with a commercial name Mark-163 FLEXOGRID (manufactured by Poly-Carb, Inc., OH). It is made of a specially selected blend of aggregates (Glacial gravel - Basalt, Quartzite, Granite) used along with two-part liquid polymer system (mixed at the job site).

Several debonds were placed in between the wearing surface and the underlying FRP deck. The debonds were placed on the surface of the deck specimen, which was followed by the application of $3 / 8$ " $(9.5 \mathrm{~mm})$ thick wearing surface on the entire top surface. Figure 4.6 (a) shows photographic view of the specimen and Figure 4.6(b) shows the sectional dimensions of the deck.

Figure 4.7 gives the schematic view of the deck showing the location of the debonds underneath the wearing surface layer in BD1a and BD1b. One side of the specimen, BD1a consisted of two debonds of sizes 2"x 2" (51mm x 51mm) and 3"x 3" $(76 \mathrm{~mm} \times 76 \mathrm{~mm})$ and the other side BDlb consisted of two debonds of sizes 1" $\mathrm{x} 1$ " $(25 \mathrm{~mm} \times 25 \mathrm{~mm})$ and $1 / 2 " \times 1 / 2 "(12.7 \mathrm{~mm} \times 12.7 \mathrm{~mm})$ between the wearing surface layer and the deck (for conducting laboratory experiments, the wearing surface was placed on the bottom side as well, which minimized the number of actual specimens required to conduct tests with different debond sizes). All the debonds had thicknesses of 1/16" (1.6mm). 


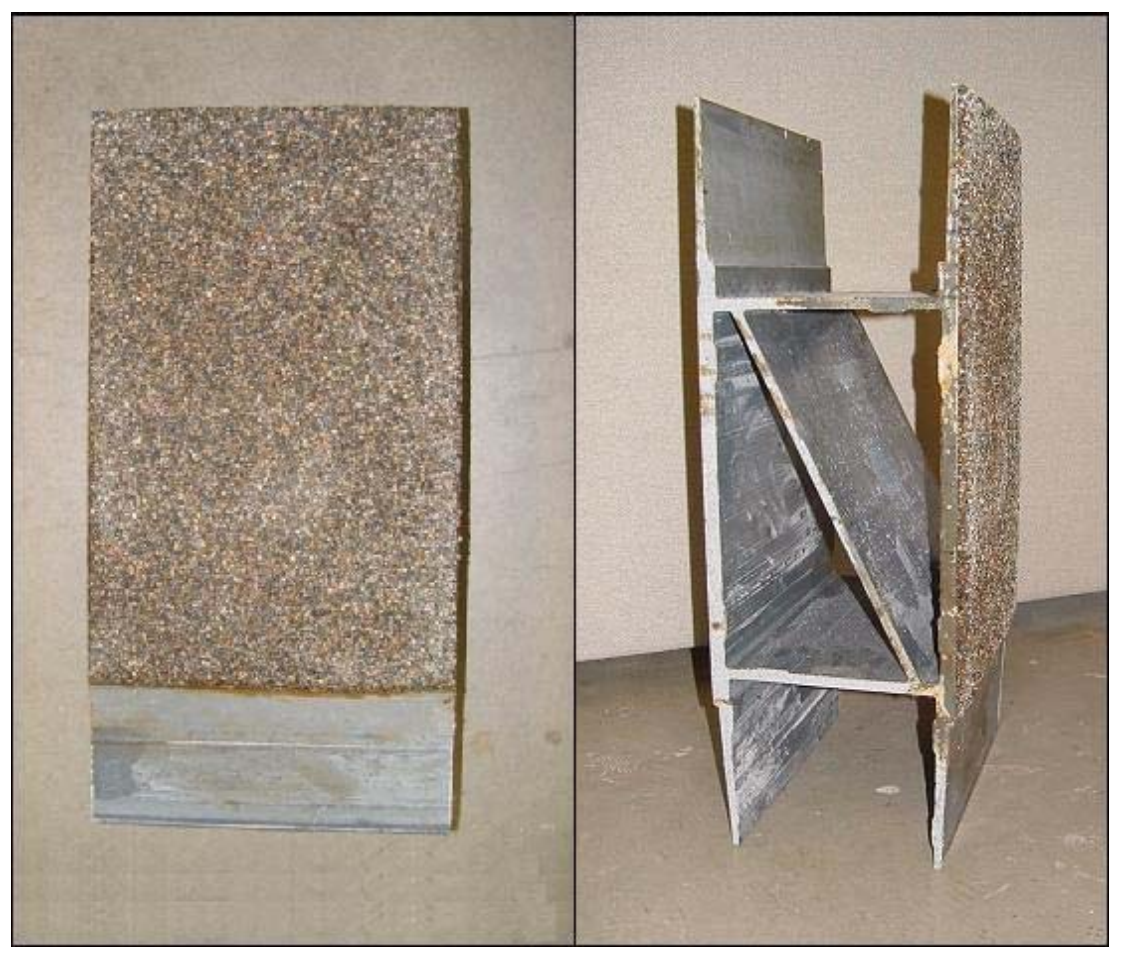

(a)

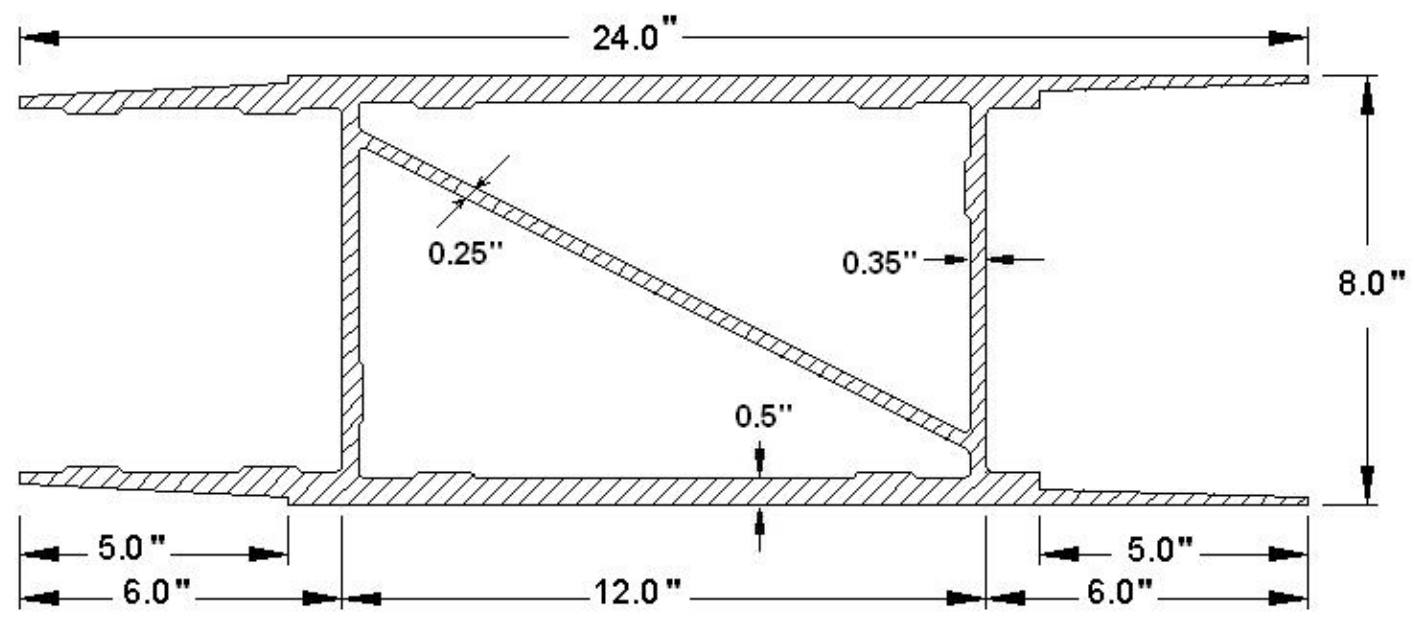

(b)

Figure 4.6. (a) Front view and cross-sectional view of the GFRP bridge deck specimen BD1 with wearing surface (b) schematic view of the deck showing the cross sectional dimensions 


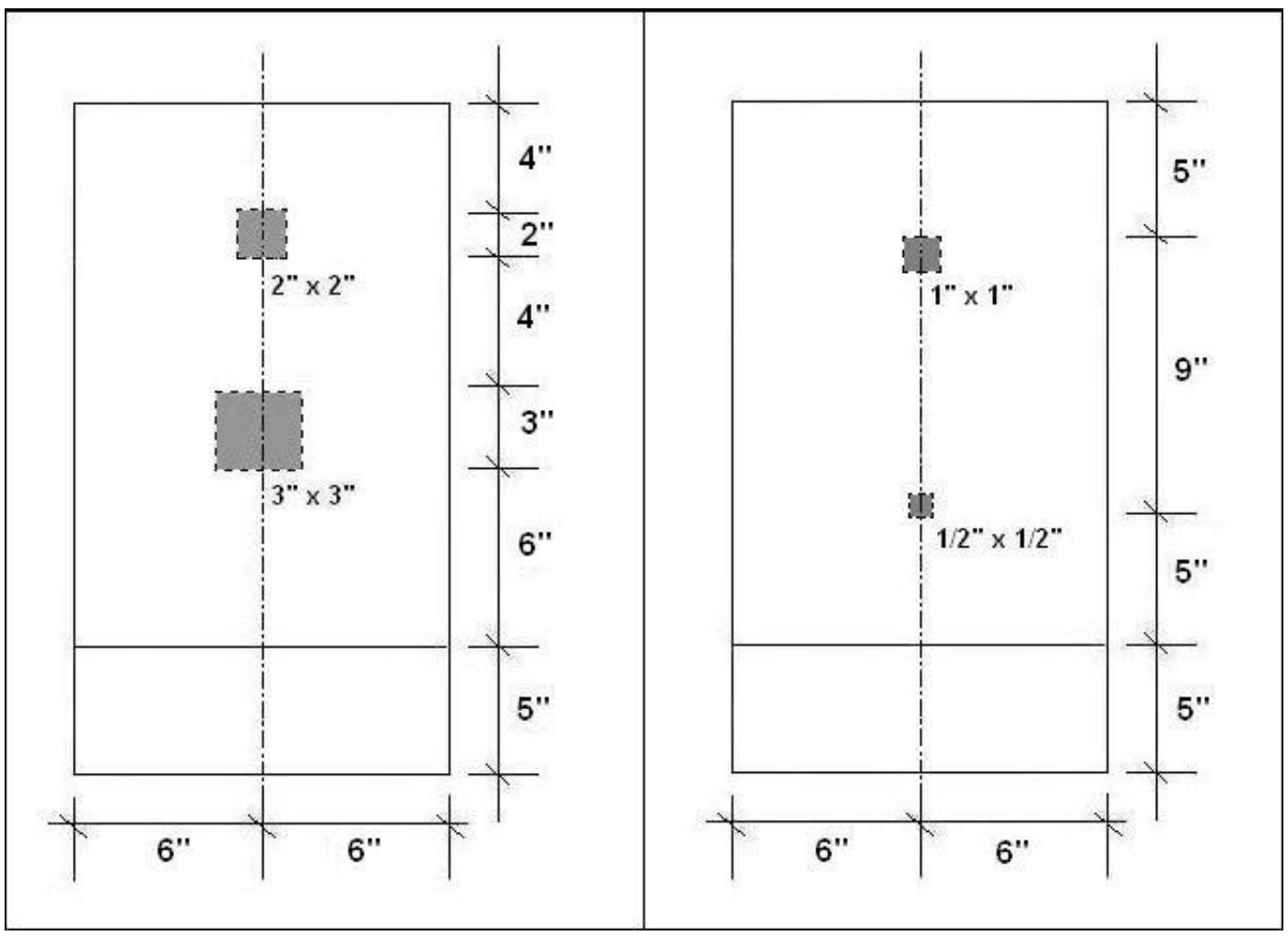

Figure 4.7. Schematic view of location of debonds in bridge deck specimens (a) BD1a (b) BD1b

\section{Bridge deck specimen BD2}

Bridge deck BD2 (Figure 4.8(a)) was a low profile FRP deck with plan size of 24 " x 12 " $(0.6 \mathrm{~m} \times 0.3 \mathrm{~m})$, overall depth of 4 " $(0.1 \mathrm{~m})$, flange thickness of 0.45 " $(11 \mathrm{~mm})$ and web thickness of $0.4 "(10 \mathrm{~mm})$. The component is made of E-glass fiber with vinylester resin. The deck consists of triaxial and quadriaxial fabric layers, mats and rovings. It has a fiber volume fraction of $50 \%$. The top surface of the deck was coated with $3 / 8$ " thick wearing surface. The wearing surface consisted of a premium quality, twocomponent polysulfide epoxy based overlay system, and sold under a commercial name Transpo T-48 (manufactured by Castek, Inc., A Transpo Industries Company., PA). It is made of a specially selected blend of resin, hardener and powder. Basalt aggregates was used as the broadcast along with the T-48.

To determine the detectability of moisture in between the wearing surface layer and underling deck using infrared thermography, water-filled debonds were used. Two water-filled debonds of sizes 2"x 2" (51mm x $51 \mathrm{~mm})$ with thickness of approximately 1/16" (1.6mm) and 3"x 3" (76mm x 76mm) with thickness of 1/8" (3mm), and an air- 
filled debond of size 2" x 2" x 1/16" (51mm x $51 \mathrm{~mm} \times 1.6 \mathrm{~mm})$ were placed on the surface of the deck, prior to the application of the wearing surface layer. Figure 4.8(b) represents the schematic view of the deck showing the location of these debonds. Figure 4.8(c) shows the schematic view of the cross section and its dimensions.
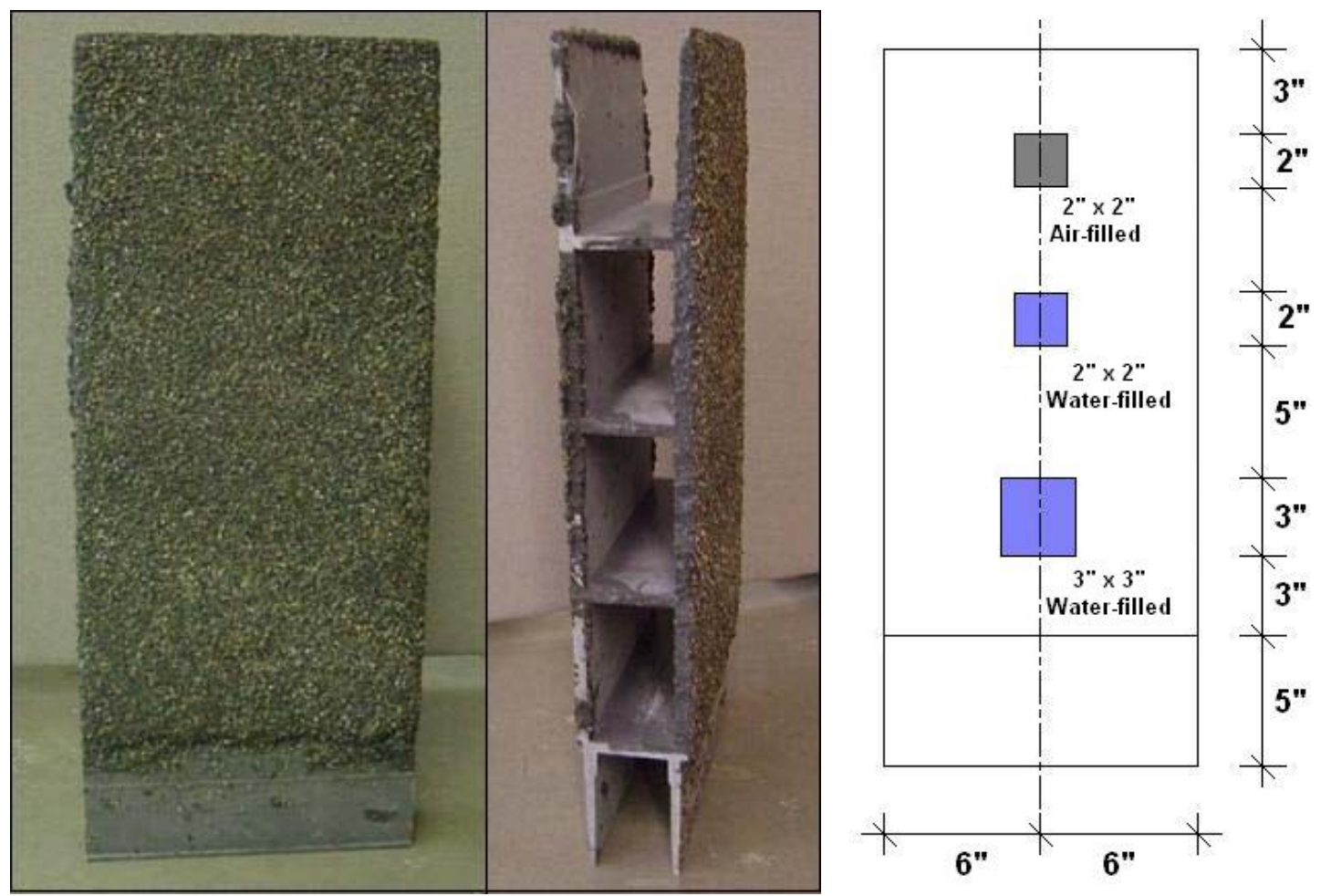

Figure 4.8. (a) Front view and cross-sectional view of the GFRP bridge deck specimen BD2 (b) schematic view of location of debonds in BD2

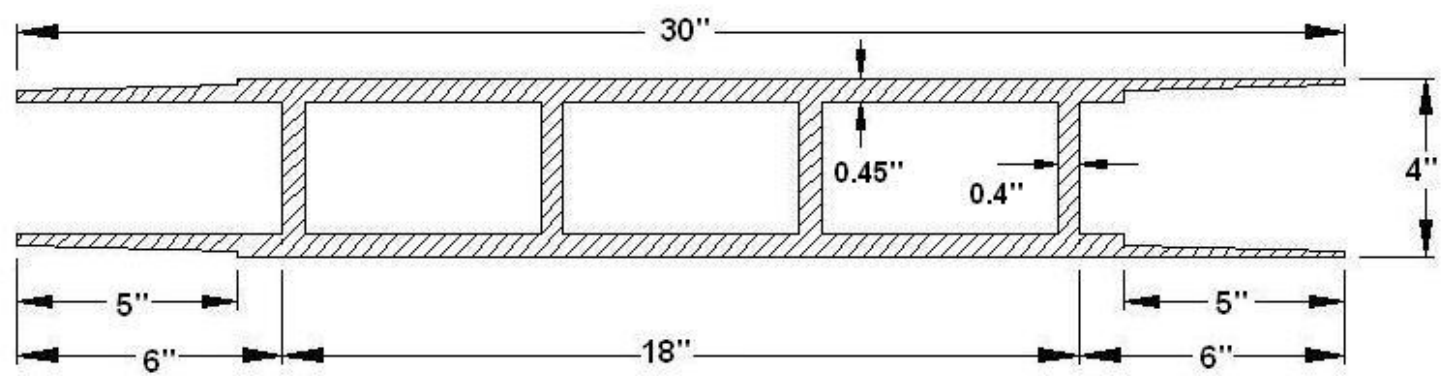

Figure 4.8 (c) Schematic view of the deck module showing the cross sectional dimensions 


\subsubsection{Infrared Tests and Results}

\section{Bridge deck specimen BD1}

Uniform heating was achieved by placing the quartz heater a few inches away from the specimen surface. Heat was applied for about 2-3 minutes. The infrared image of the specimen revealed the location of the debonds as white regions. They were areas with higher temperature when compared to the surrounding defect-free regions. The color scale showing the temperature variability over the deck area is also available with the infrared image.

Figure 4.9 shows the infrared image of the 2 " x 2" $(51 \mathrm{~mm} \times 51 \mathrm{~mm})$ and 3 " x 3 " $(76 \mathrm{~mm} \times 76 \mathrm{~mm})$ debonds in specimen BD1a. The boundaries of both these debonds were well-defined in the image. The difference between the surface temperatures of the 3" x 3" $(76 \mathrm{~mm} \times 76 \mathrm{~mm})$ and $2 " \times 2 "(51 \mathrm{~mm} \times 51 \mathrm{~mm})$ debonded areas compared to the defectfree area were about $11^{\circ} \mathrm{C}$ and $8^{\circ} \mathrm{C}$, respectively.

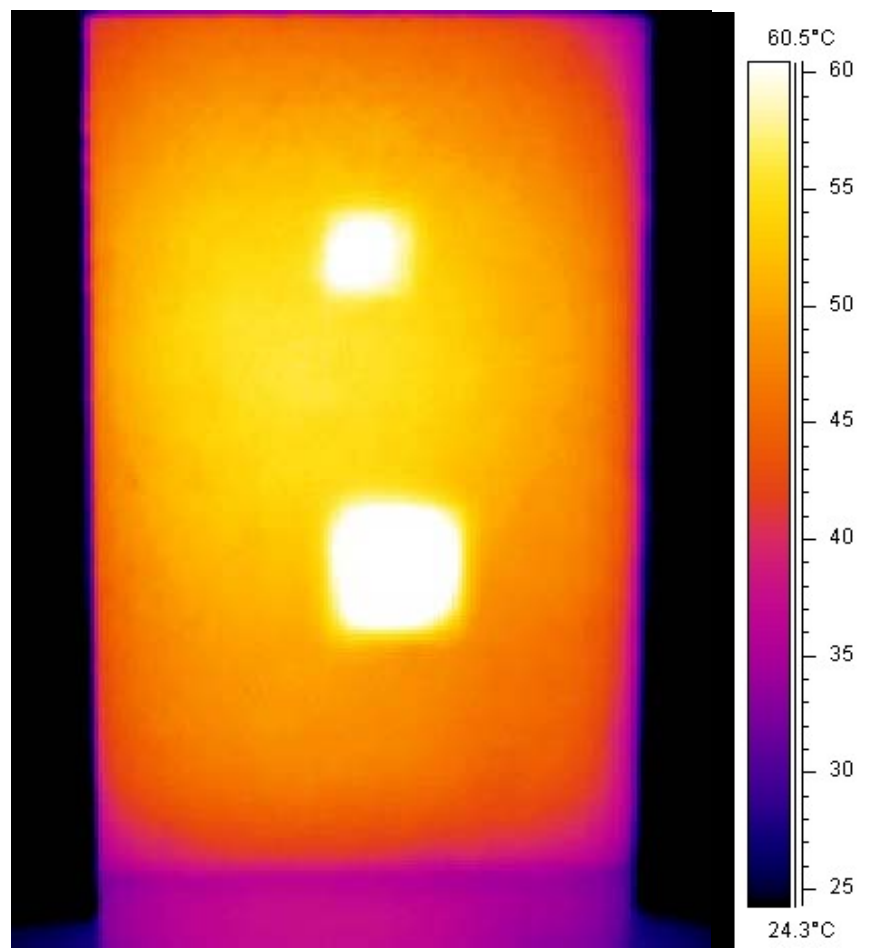

Figure 4.9. Infrared image of BD1a with debonds of sizes 2" x 2" x $1 / 16$ " and 3 " x 3 " x 1/16"

Figure 4.10 shows the location of the 1 " $x 1$ " $(25 \mathrm{~mm} \times 25 \mathrm{~mm})$ and $1 / 2 " x \frac{1}{2}$ " $(12.7 \mathrm{~mm} \times 12.7 \mathrm{~mm})$ debond beneath the wearing surface in specimen BD1b. The boundaries for the 1"x 1" debond was clearly seen. Though a well-defined boundary for 
the $1 / 2 " \times 1 / 2 "(12.7 \mathrm{~mm} \times 12.7 \mathrm{~mm})$ debond was not visible, the area shows sufficient contrast which confirmed the presence of the debond. The difference between the surface temperatures of the 1 " $\times 1 "(25 \mathrm{~mm} \times 25 \mathrm{~mm})$ and $1 / 2$ " $\times 1 / 2$ " $(12.7 \mathrm{~mm} \times 12.7 \mathrm{~mm})$ debonded areas compared to the defect-free area were about $8^{\circ} \mathrm{C}$ and $4^{\circ} \mathrm{C}$, respectively.

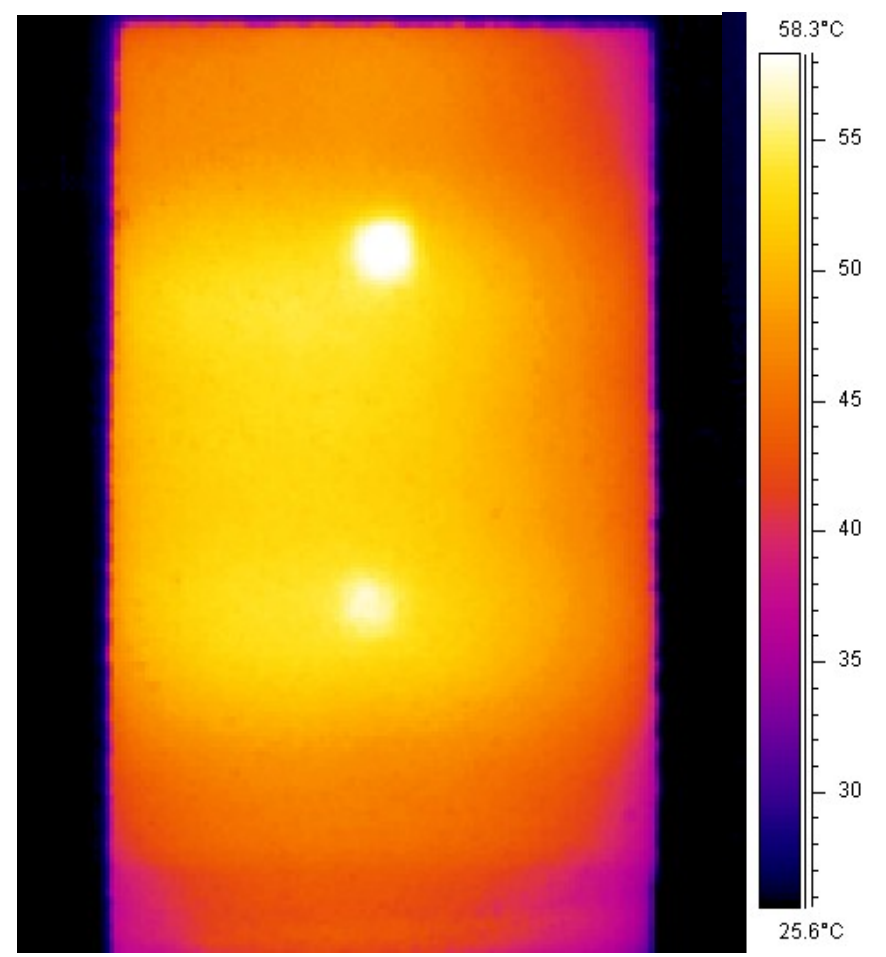

Figure 4.10. Infrared image of BD1b with debonds of sizes 1 " x 1 " x 1/16" and 1/2" x 1/2" x 1/16"

\section{Bridge deck specimen BD2}

Specimen BD2 was also heated using the quartz heater and the infrared images were captured after the heater was taken away. Figure 4.11 shows the infrared image of the bridge deck. The surface temperatures for the 3"x 3" $(76 \mathrm{~mm} \times 76 \mathrm{~mm}), 2$ " 2 " $(51 \mathrm{~mm} \times 51 \mathrm{~mm})$ water-filled debonds, 2" x $2 "(51 \mathrm{~mm}$ x $51 \mathrm{~mm})$ air-filled debond and defect-free areas were about $36.9^{\circ} \mathrm{C}, 38.5^{\circ} \mathrm{C}, 45.7^{\circ} \mathrm{C}$ and $41^{\circ} \mathrm{C}$ respectively. The surface temperature above the air-filled debond (white area in infrared image) is higher than the temperature above defect-free area (temperature difference: $4.7^{\circ} \mathrm{C}$ ). On the other hand, the temperature above water-filled debond is lower when compared to that of defect-free area (temperature difference: $-4.1^{\circ} \mathrm{C}$ for 3 " $\mathrm{x} 3$ " and $-2.5^{\circ} \mathrm{C}$ for $2 " \mathrm{x} 2$ "). This is because the thermal conductivity of water $\left(0.6 \mathrm{Wm}^{-1}{ }^{\circ} \mathrm{C}^{-1}\right)$ is higher than that of the deck $(\sim 0.3$ to $\left.0.38 \mathrm{Wm}^{-10} \mathrm{C}^{-1}\right)$ while air has a lower thermal conductivity $\left(0.024 \mathrm{Wm}^{-10} \mathrm{C}^{-1}\right)$ (values from 
Table 2.1 (Maldague 1993)). This explains why air-filled debonds show as "hot spots" while water-filled debonds show as "cold spots". Also, the conductivity difference between water and the FRP deck is usually smaller compared to air and the deck, which explains why water-filled case results in smaller temperature differentials with respect to surrounding defect-free area compared to the case with air-filled debond of the same size (2" x 2" or $51 \mathrm{~mm} \times 51 \mathrm{~mm}$ in our case). Also, it should be noted that water has a tendency to absorb heat and take a longer time to get heated up when compared to the surrounding FRP material.
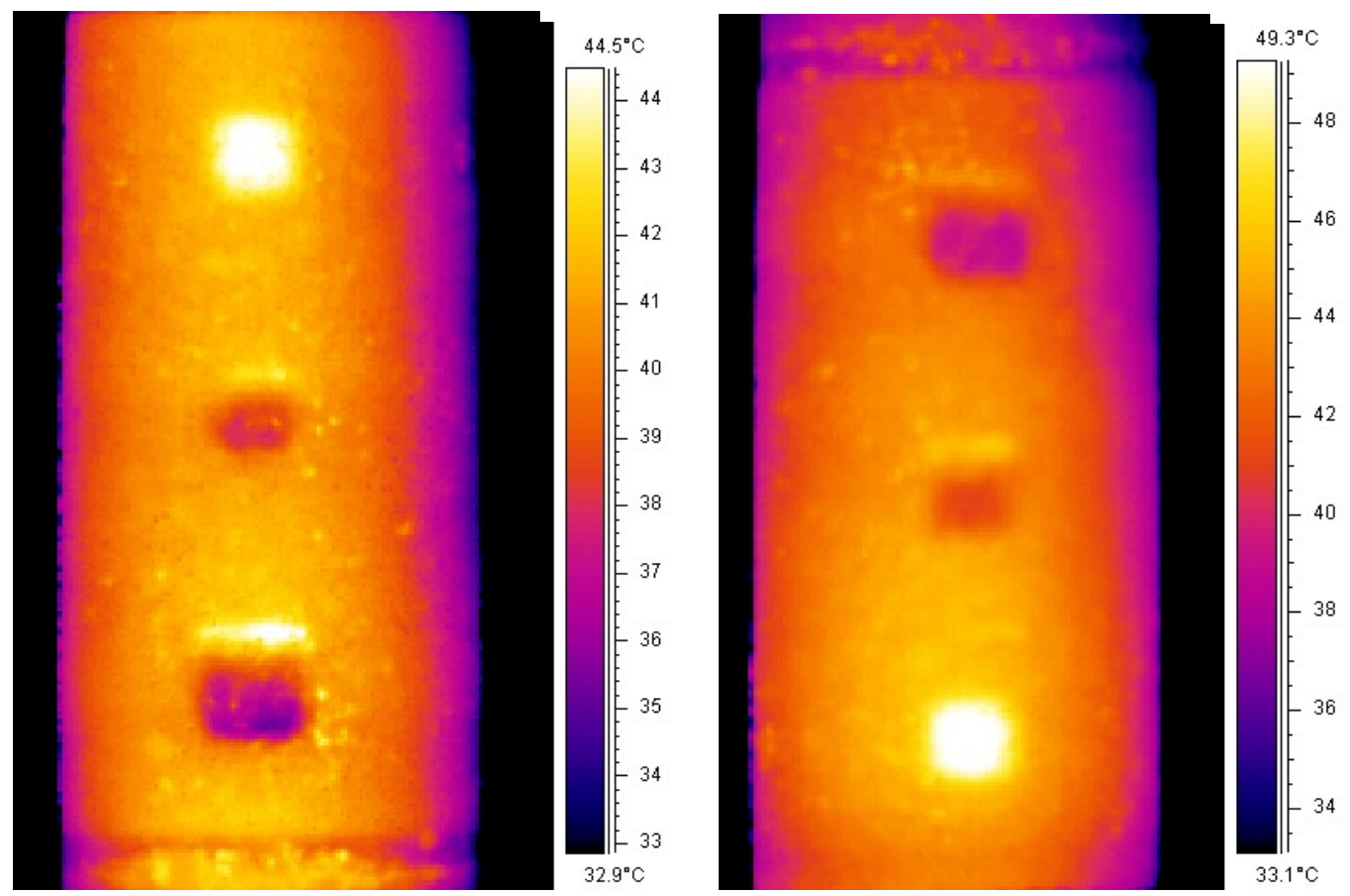

Figure 4.11. Infrared image of (a) deck BD2 (b) deck BD2 placed in inverted position

It was also observed that the top portion $(\sim 0.25 " \mathrm{x} 3 "$ in plan $)$ of the water-filled debonds (both 3" x 3" and 2" x 2") showed a higher temperature as represented by white area just above the water-filled debonds in Figure 4.11 (a). This was due to the presence of small air bubbles inside the plastic pouch that was used to make the water-filled debond (see Figure 4.3). To ascertain this, the deck was placed in the inverted position so that the air pocket moved on the top of the debond. The infrared image of the inverted deck (Figure 4.11(b)) was then captured. The infrared image showed the presence of 
higher temperature on the top portion of the debond, which was due to the movement of air pocket to the top of the debond pouch.

The infrared images revealed that the boundaries of the air-filled debond was more clearly defined when compared to the water-filled debonds. The color scale showing the temperatures profile of the deck (Figure 4.11 (a)) was inversed to observe the water-filled debonds. Figure 4.12 shows the infrared image with the inverted color scale. It was observed that there was not much change in terms of the boundary definition for these debonds. Also, lower values of temperature differences was observed for the water-filled debond, when comparing the temperature difference for the water-filled debond and air-filled debond to that of defect-free area. Hence it was concluded that water-filled debonds are generally more difficult to detect than the air-filled debonds.

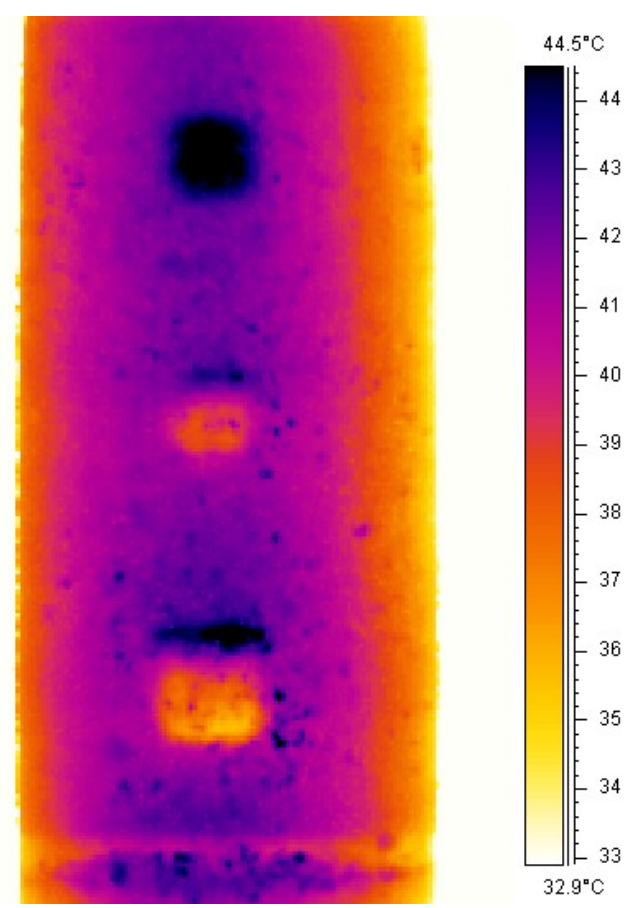

Figure 4.12. Infrared image of bridge deck BD2 with inverted color scale

\subsubsection{Conclusions}

The digital infrared thermography has been successful in detecting air-filled debonds as small as of $1 / 2 " \times 1 / 2 " \times 1 / 16 "(12.7 \mathrm{~mm} \times 12.7 \mathrm{~mm} \times 1.6 \mathrm{~mm})$ between the wearing surface and the underlying FRP deck. It has also detected the presence of moisture (water-filled debonds with size as small as 2" x 2" x 1/16" or 51mm x $51 \mathrm{~mm}$ x 
$1.6 \mathrm{~mm}$ ) between the wearing surface and the underlying deck. However, the air-filled debonds could be more easily detected when compared to the water-filled debonds.

\subsection{DETECTION OF DELAMINATIONS WITHIN THE FLANGE-FLANGE JUNCTION}

\subsubsection{Description of Specimens}

Bridge deck specimen JD1

Specimen JD1 was a low-profile GFRP bridge deck, with material and fiber architecture similar to the deck BD2 described in Section 4.4.1, except that it did not have the wearing surface layer. Specimen JD1 (Figure 4.13(a)) had a plan size of 15" x 8" $(380 \mathrm{~mm} \times 200 \mathrm{~mm})$ and flange thickness of $0.45 "(11 \mathrm{~mm})$. The thickness at the junction area, where two modules were joined was about 0.6 " $(15 \mathrm{~mm})$. Delaminations of various plan sizes and thicknesses were created in the middle of the flange joint area (top flange) in one of the modules before joining two modules together. On one side (JD1a), a delamination of size 3" x 3" $(76 \mathrm{~mm} \times 76 \mathrm{~mm})$ in plan and 1/20" $(1.27 \mathrm{~mm})$ thickness was created in the middle of the flange joint area (top flange). The other side (JD1b) had two delaminations of sizes 2" x 2" $(51 \mathrm{~mm} \times 51 \mathrm{~mm})$ and 1" x 1 " $(25 \mathrm{~mm} \times 25 \mathrm{~mm})$, both with thicknesses of 1/16" $(1.5 \mathrm{~mm})$. The delaminations were located at an average depth of 0.32 " $(8 \mathrm{~mm})$ from the top surface. Figures $4.14(\mathrm{a})$ and (b) shows the close up of the delaminations in the flange. Both the sides (JD1a and JD1b) did not have any wearing surface layer.

\section{Bridge deck specimen JD2 and JD3}

Specimen JD2 was a low-profile GFRP bridge deck, with material, fiber architecture and cross sectional dimensions, similar to the deck BD2 described in section 4.4.1 (i.e., same as JD1). Specimen JD2 (Figure 4.13(b)) had a plan size of 15" x 8" $(380 \mathrm{~mm} \times 200 \mathrm{~mm})$ and flange thickness of $0.45 ”(11 \mathrm{~mm})$ overall and $0.6 "(15 \mathrm{~mm})$ at the junction. The top flange was covered with a wearing surface with a thickness of about $3 / 8$ " $(9.5 \mathrm{~mm})$. It had a delamination of size 3" x 3" $(76 \mathrm{~mm} \times 76 \mathrm{~mm})$ in plan and $1 / 8$ " $(3 \mathrm{~mm})$ thickness (see Figure 4.4) in the middle of the flange joint area (top flange). Bridge deck JD3 was similar to specimen JD2 except that it had a delamination of size 3" 
x 3" $(76 \mathrm{~mm} \times 76 \mathrm{~mm})$ in plan and $1 / 16 "(1.6 \mathrm{~mm})$ thickness. The delaminations were located at an average depth of 0.69 " $(17.5 \mathrm{~mm})$ from the top of the wearing surface.
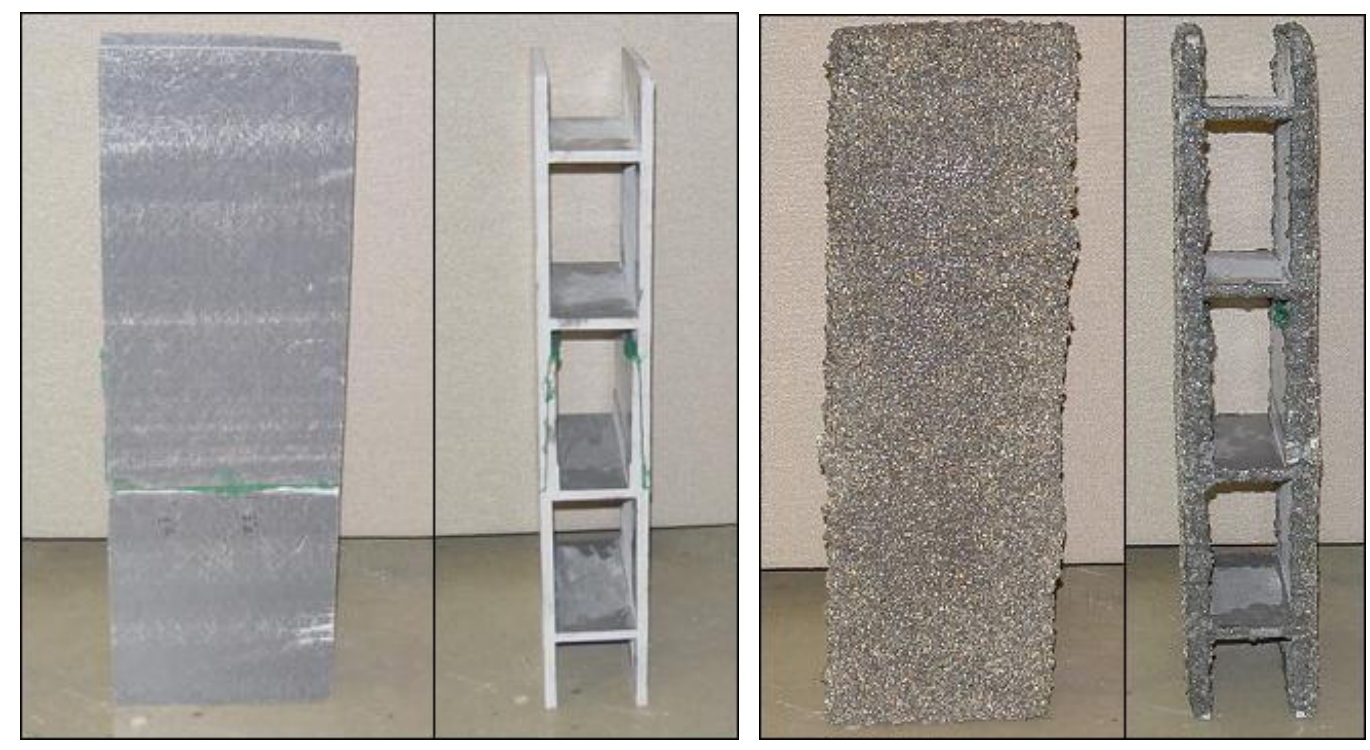

Figure 4.13 Front view and cross-sectional view of the GFRP bridge deck specimens (a) without wearing surface (b) with wearing surface
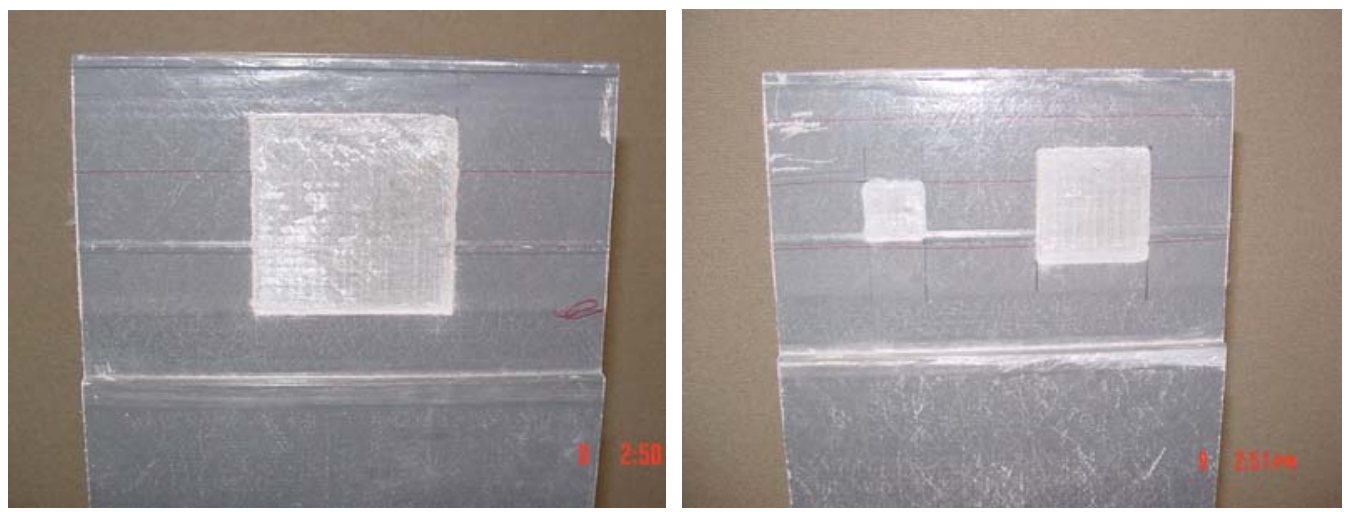

Figure 4.14 Photograph showing the location of the debonds of sizes (a) 3" x 3" x 1/20" (b) 1" x 1"x 1/16" and 2 " $x 2$ 2" $1 / 16 "$, in specimen JD1

\subsubsection{Infrared Tests and Results}

\section{Bridge deck specimen JD1}

The bridge deck specimen JD1 was heated using a quartz tower heater prior to the acquisition of the infrared images. The digital infrared camera was used to capture the sequence of infrared images, which in turn were saved into the laptop computer connected to the camera. Heating was continued for about 3 minutes. 
Figure 4.15(a) shows the infrared image of the deck specimen JD1a which had 3" x 3" x 1/20" (76mm x $76 \mathrm{~mm} \times 1.27 \mathrm{~mm})$ delamination. Surface temperature above the 3"x 3" $(76 \mathrm{~mm} \times 76 \mathrm{~mm})$ delamination and defect-free areas were $61.8^{\circ} \mathrm{C}$ and $51.1^{\circ} \mathrm{C}$, respectively, resulting in a surface temperature differential of $10.7^{\circ} \mathrm{C}$.

Figure 4.15(b) shows specimen JD1b with the 1" x 1" $(25 \mathrm{~mm}$ x 25mm) and 2" $\mathrm{x}$ 2" $(51 \mathrm{~mm} \times 51 \mathrm{~mm})$ delaminations (both $1 / 16$ " or $1.6 \mathrm{~mm}$ thick). Surface temperature above 2"x 2" and 1" x 1" delaminations, and defect-free areas were $61^{\circ} \mathrm{C}, 59^{\circ} \mathrm{C}$ and $55.2^{\circ} \mathrm{C}$. Thus, the surface temperature differentials between the 2 " $\mathrm{x} 2$ " and 1 " $\mathrm{x} 1$ " delaminations with respect to defect-free area were $5.8^{\circ} \mathrm{C}$ and $3.8^{\circ} \mathrm{C}$ respectively. In all the images (Figure 4.15) the delaminations can be seen as bright yellow square regions (areas with higher temperature compared to the surrounding areas).

The thermal conductivity for GFRP is between 0.3 and $0.38 \mathrm{Wm}^{-10} \mathrm{C}^{-1}$, whereas the value is $0.024 \mathrm{Wm}^{-10} \mathrm{C}^{-1}$ for air. Hence, the defect-free area conducts heat at a faster rate through the deck when compared to the delaminated area. Thus, the delaminated result in higher surface temperatures compared to the surrounding defect-free area.
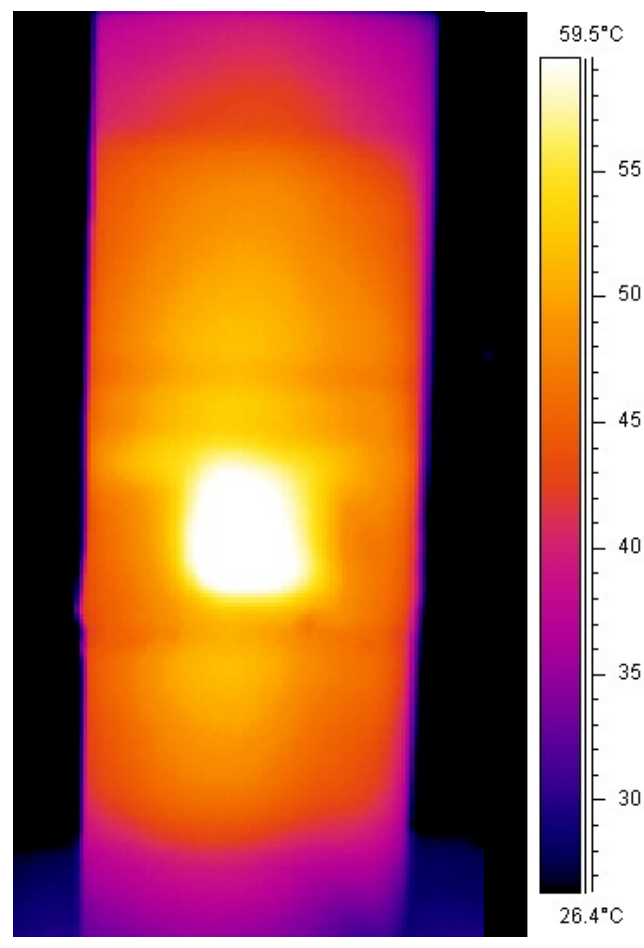

(a) 


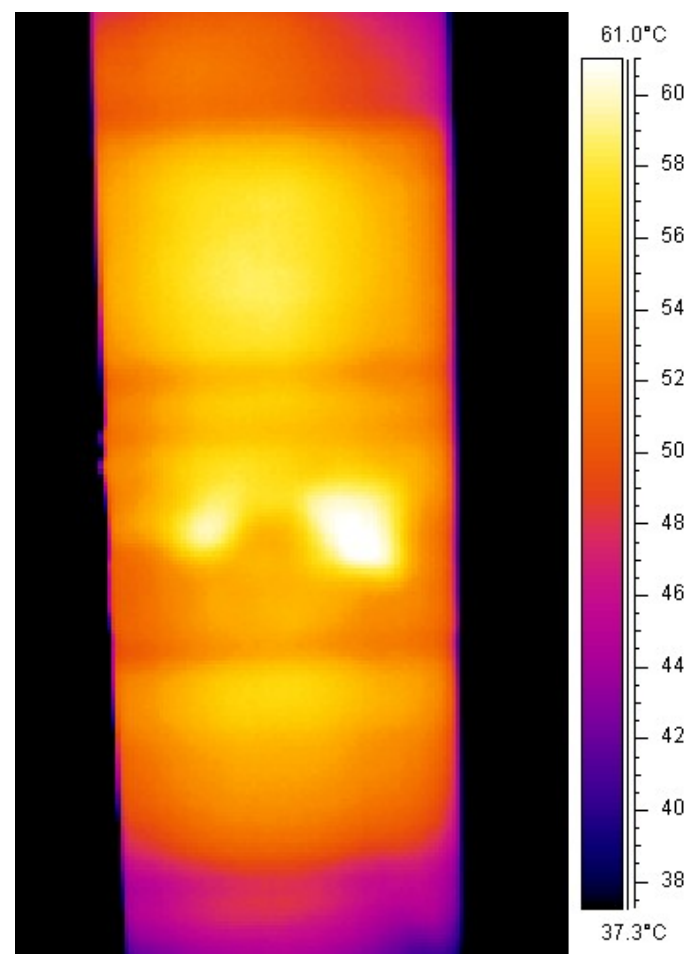

(b)

Figure 4.15. Infrared image of specimens (without wearing surface) with embedded delaminations at the flange-flange junction (a) JD1a with 3" x 3" x 1/20" delamination (b) JD1b with the 1" x 1" x 1/16" and 2" x 2" x 1/16" delaminations

\section{Bridge deck specimen JD2}

For specimen JD2, which had a $3 / 8$ " $(9.5 \mathrm{~mm})$ thick wearing surface covering the flange of the deck containing the embedded delamination, heating was continued for a relatively long time of up to 5 minutes, until the surface temperature of the specimen reached about $70-75^{\circ} \mathrm{C}$. As the delamination was located well beneath the wearing surface layer and the FRP layers, heating it for a smaller duration did not give an image with a good contrast between the sound and the defective areas. It takes a long time for heat to travel in the perpendicular direction through the deck towards the delamination when the FRP deck is covered with the wearing surface. Hence heating had to be continued for a longer duration than for the specimens BD1 and JD1, which had no wearing surface. Figure 4.16 shows the infrared image of deck JD2 before and after the application of the wearing surface overlay. The surface temperature differential in the specimen between delaminated and defect-free areas before the application of the 
wearing surface was around $13^{\circ} \mathrm{C}$. After the application of the wearing surface, the surface temperatures above the 3 " x 3" (76mm x 76mm) delamination and defect-free area were $78.0^{\circ} \mathrm{C}$ and $71.7^{\circ} \mathrm{C}$, respectively, with the temperature difference between the areas being $6.3^{\circ} \mathrm{C}$. Greater the depth of the delamination from the top surface, the more difficult it is to detect it. This is because the contrast between the defective and defectfree areas is inversely proportional to the cube of the depth (Maldague 2000). Though the infrared image (Figure 4.16) did not show a very prominent boundary of the delamination, it could still confirm the presence of a subsurface delamination. It was observed that after some period of time, the surface temperature differential was still high enough to see the delamination in the infrared image. This was because the delaminated area retained heat for a longer time than the defect-free area.
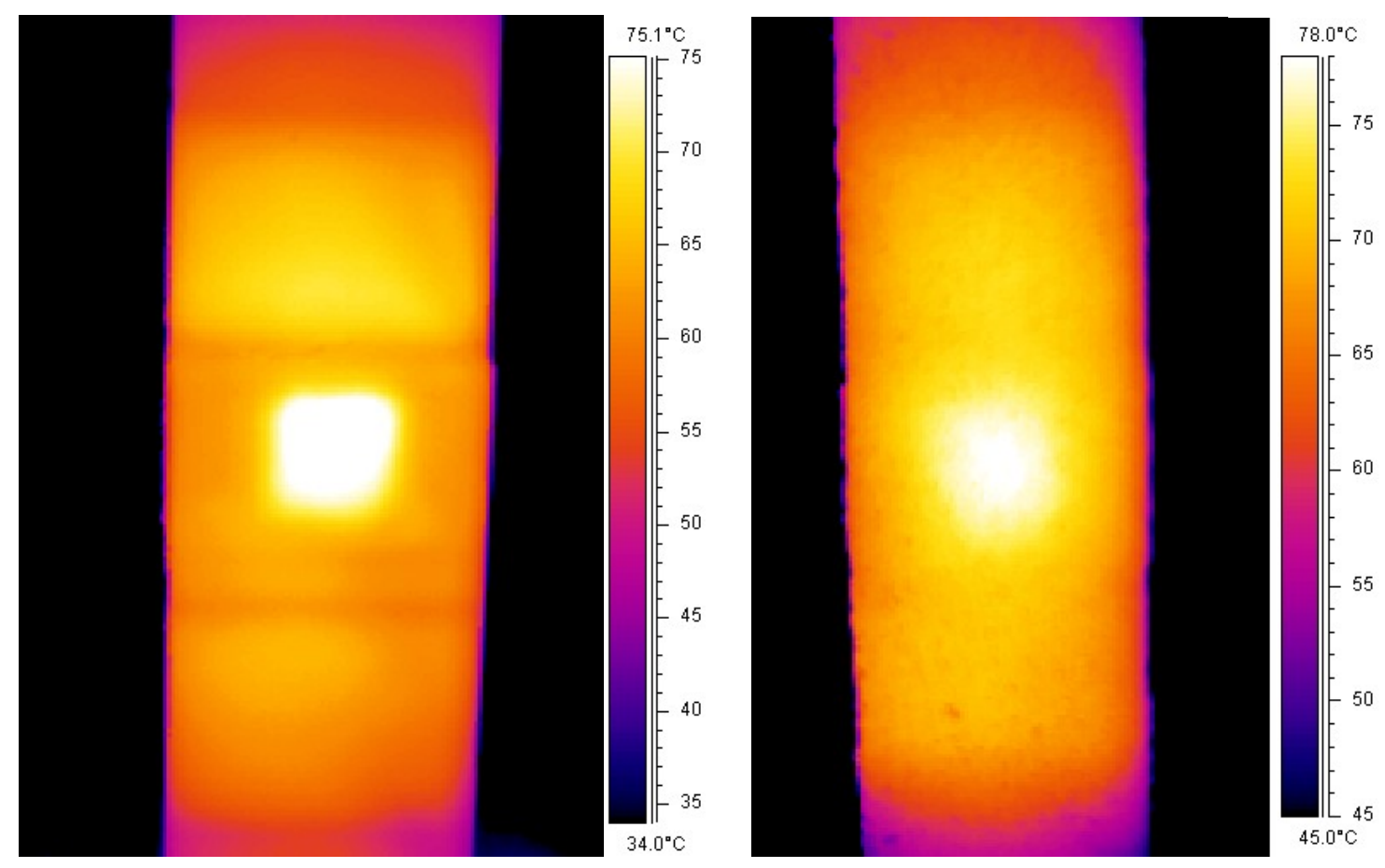

Figure 4.16. Infrared image of bridge deck specimen JD2 with wearing surface and embedded delamination of 3 " x 3 " x $1 / 8$ " at the flange-flange junction (a) before applying the wearing surface overlay (b) after applying the wearing surface overlay

\section{Bridge deck specimen JD3}

Heating for specimen JD3 was continued for a relatively long time of up to 5 minutes (just as in case of JD2), until the surface temperature of the specimen reached 
about $75^{\circ} \mathrm{C}$. Figure 4.17 shows the infrared images from deck JD3. Before application of wearing surface, the surface temperature differential between defective and defect-free areas was about $10^{\circ} \mathrm{C}$. After the application of the overlay, the surface temperature differential between the defective and defect-free areas reduced to $3.7^{\circ} \mathrm{C}$ (surface temperatures above defective and defect-free areas were $62.1^{\circ} \mathrm{C}$ and $58.4^{\circ} \mathrm{C}$, respectively). The infrared image of JD3 (Figure 4.17) did not show a very prominent boundary of the delamination but confirmed the presence of a subsurface delamination.
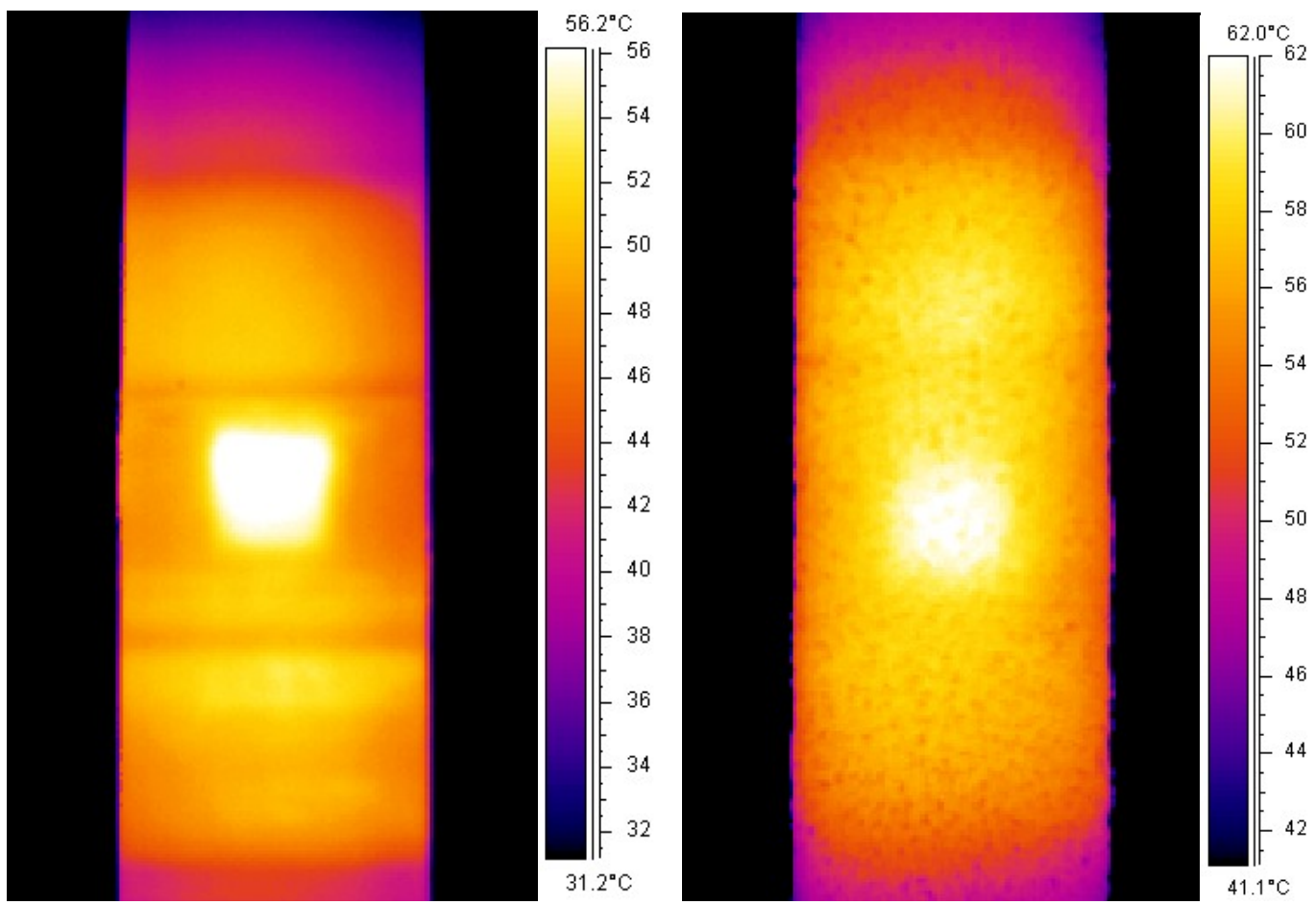

Figure 4.17. Infrared image of bridge deck specimen JD3 with wearing surface and embedded delamination of 3" x 3" x 1/16" at the flange-flange junction (a) before applying the wearing surface overlay (b) after applying the wearing surface overlay

\subsubsection{Conclusions}

The digital infrared thermographic system was successful in detecting the embedded delaminations as small as 1 " x 1 " x 1/16" $(25 \mathrm{~mm}$ x $25 \mathrm{~mm} \times 1.6 \mathrm{~mm})$ present at the flange-flange junction of an FRP deck, without wearing surface. The specimens JD2 and JD3, which had wearing surface overlay, had to be heated to a comparatively higher temperature in order to produce an image with good contrast corresponding to the 
location of the delamination. Though the boundary of the 3" x 3" x 1/16" (76mm x $76 \mathrm{~mm}$ $\mathrm{x} 1.6 \mathrm{~mm}$ ) delaminations in JD2 and JD3 were not very clear, their presence was still detected. Thus, the digital infrared camera was able to detect one of the most difficult defects, the one embedded inside the flange which was overlaid with a wearing surface.

From all the tests conducted to detect both debonds and delaminations, the digital infrared thermography has satisfied the standards specified in ACI 440.2R. Section 6.2.3 of ACI 440.2R states that, for inspection method used for detecting delaminations in FRP systems, the testing method should be capable of detecting delamination of size $2 \mathrm{in}^{2}$ $\left(1300 \mathrm{~mm}^{2}\right)$ or greater. It should be noted that this ACI standard is actually developed for FRP wrapped concrete components, and no such standards currently exist for FRP bridge decks.

\subsection{SURFACE TEMPERATURE-TIME CURVES AND ANALYSIS FOR DEBONDS AND DELAMINATIONS}

\subsubsection{Bridge Deck Specimens}

The bridge deck specimens that were used to study the surface temperature-time curves were BD1 (both sides BD1a and BD1b), JD1 (both sides JD1a and JD1b) and JD2. The type and sizes of these specimens and the embedded subsurface defects in each of them are already described in Sections 4.4.1 and 4.5.1.

\subsubsection{Infrared Testing and Results}

The bridge deck specimens were heated using a quartz tower heater and the infrared images were recorded over a period of time. The first infrared image was captured immediately after removing the heating source from the specimen's surface, and subsequent images were captured after every 10 -second intervals.

The temperatures of the defective and defect free areas at 10 -second time intervals were tabulated and the corresponding temperature differences were calculated. Graphs were plotted with time along the $\mathrm{X}$-axis and temperatures of the defective and defect-free areas along the $\mathrm{Y}$-axis. An infrared image showing a prominent boundary of the delamination was obtained when the temperature difference between the defective and the defect-free area was maximum. 


\section{Bridge deck specimen BD1}

Table 4.1 gives the surface temperature values for the 3 " $\mathrm{x} 3$ " $\mathrm{x} 1 / 16$ " $(76 \mathrm{~mm} \mathrm{x}$ $76 \mathrm{~mm} \times 1.6 \mathrm{~mm}), 2 "$ x 2" x 1/16" (51 $\mathrm{mm}$ x $51 \mathrm{~mm}$ x $1.6 \mathrm{~mm})$ debonds and defect-free area in the specimen BD1a. The first column in the table gives the time. The second through fourth columns give the surface temperatures above the debonded and defect-free areas respectively, at 10-second time intervals. The fifth and sixth columns give the corresponding surface temperature differentials between the debonded and defect-free areas for the 3"x3" and 2"x2" debonds.

Figure 4.18 shows the surface temperature-time curves for the 3 " x 3 " $(76 \mathrm{~mm} \times$ $76 \mathrm{~mm})$ and 2" x 2" (51mm x 51mm) debonds and the defect-free area. It was observed that the maximum temperature difference between the debonded (both for the 3" $\mathrm{x} 3$ " and 2" x 2") and defect-free area was obtained after 20 to 30 seconds after the heating source was taken away from the surface of the specimen. Since the values of temperature differences for both the debonds at $0^{\text {th }}$ second (immediately after removing the heating source) are very close to that at $30^{\text {th }}$ second (time of maximum temperature difference), it can be said that the image with the best contrast was obtained almost immediately after the heating source was taken away. Figure 4.19 shows the infrared image with the most prominent boundary of the debonds (represented by white regions) in deck specimen BD1a. The graph (Figure 4.18) shows that the curves for the debonded and defect-free areas converges. The decrease in the temperature difference is very slow for the first few minutes, after which it becomes more rapid. Hence images with good contrast between the defective and defect-free areas are available for only about 4-5 minutes after the heating source has been removed. After this period of time the deck moves towards thermal equilibrium. 
Table 4.1. Surface temperatures of 3"x 3", 2" x 2" debonds and defect-free area in deck BD1a

\begin{tabular}{|c|c|c|c|c|c|}
\hline $\begin{array}{l}\text { Time } \\
\text { (sec) }\end{array}$ & $\begin{array}{c}3 " \times 3 " \\
\left({ }^{\circ} \mathrm{C}\right)\end{array}$ & $\begin{array}{l}2 " \times 2 " \\
\left({ }^{\circ} \mathrm{C}\right)\end{array}$ & $\begin{array}{c}\text { Defect-free area } \\
\left({ }^{\circ} \mathrm{C}\right)\end{array}$ & $\begin{array}{c}\text { Difference for } \\
3^{\prime \prime} \times 3 "\left({ }^{\circ} \mathrm{C}\right) \\
\end{array}$ & $\begin{array}{c}\text { Difference for } \\
2 " \times 2 "\left({ }^{\circ} \mathrm{C}\right)\end{array}$ \\
\hline 0 & 54.4 & 48.4 & \begin{tabular}{|l|}
43.1 \\
\end{tabular} & 11.3 & 5.3 \\
\hline 10 & 53.3 & 47.0 & 41.4 & 11.9 & 5.6 \\
\hline 20 & 52.4 & 45.8 & 40.1 & 12.3 & 5.7 \\
\hline 30 & 51.4 & 44.9 & 39.1 & 12.3 & 5.8 \\
\hline 40 & 50.6 & 44.1 & 38.4 & 12.2 & 5.7 \\
\hline 50 & 49.8 & 43.3 & 37.7 & 12.1 & 5.6 \\
\hline 60 & 48.9 & 42.7 & 37.1 & 11.8 & 5.6 \\
\hline 70 & 48.1 & 42.0 & 36.6 & 11.5 & 5.4 \\
\hline 80 & 47.3 & 41.4 & 36.2 & 11.1 & 5.2 \\
\hline 90 & 46.5 & 40.9 & 35.8 & 10.7 & 5.1 \\
\hline 100 & 45.9 & 40.3 & 35.4 & 10.5 & 4.9 \\
\hline 110 & 45.3 & 39.9 & 35.2 & 10.1 & 4.7 \\
\hline 120 & 44.7 & 39.5 & 34.9 & 9.8 & 4.6 \\
\hline 130 & 43.9 & 39.0 & 34.5 & 9.4 & 4.5 \\
\hline 140 & 43.3 & 38.6 & 34.3 & 9.0 & 4.3 \\
\hline 150 & 42.8 & 38.2 & 34.1 & 8.7 & 4.1 \\
\hline 160 & 42.3 & 37.9 & 34.0 & 8.3 & 3.9 \\
\hline 170 & 41.7 & 37.5 & 33.7 & 8.0 & 3.8 \\
\hline 180 & 41.1 & 37.1 & 33.5 & 7.6 & 3.6 \\
\hline 190 & 40.7 & 36.8 & 33.4 & 7.3 & 3.4 \\
\hline 200 & 40.2 & 36.5 & 33.2 & 7.0 & 3.3 \\
\hline 210 & 39.6 & 36.0 & 32.9 & 6.7 & 3.1 \\
\hline 220 & 39.2 & 35.8 & 32.8 & 6.4 & 3.0 \\
\hline 230 & 38.8 & 35.5 & 32.7 & 6.1 & 2.8 \\
\hline 240 & 38.3 & 35.3 & 32.4 & 5.9 & 2.9 \\
\hline 250 & 37.9 & 35.0 & 32.3 & 5.6 & 2.7 \\
\hline 260 & 37.5 & 34.8 & 32.2 & 5.3 & 2.6 \\
\hline 270 & 37.1 & 34.5 & 32.1 & 5.0 & 2.4 \\
\hline 280 & 36.8 & 34.3 & 32.0 & 4.8 & 2.3 \\
\hline 290 & 36.5 & 34.1 & 31.9 & 4.6 & 2.2 \\
\hline 300 & 36.1 & 33.9 & 31.8 & 4.3 & 2.1 \\
\hline 310 & 35.8 & 33.8 & 31.7 & 4.1 & 2.1 \\
\hline 320 & 35.5 & 33.6 & 31.7 & 3.8 & 1.9 \\
\hline
\end{tabular}




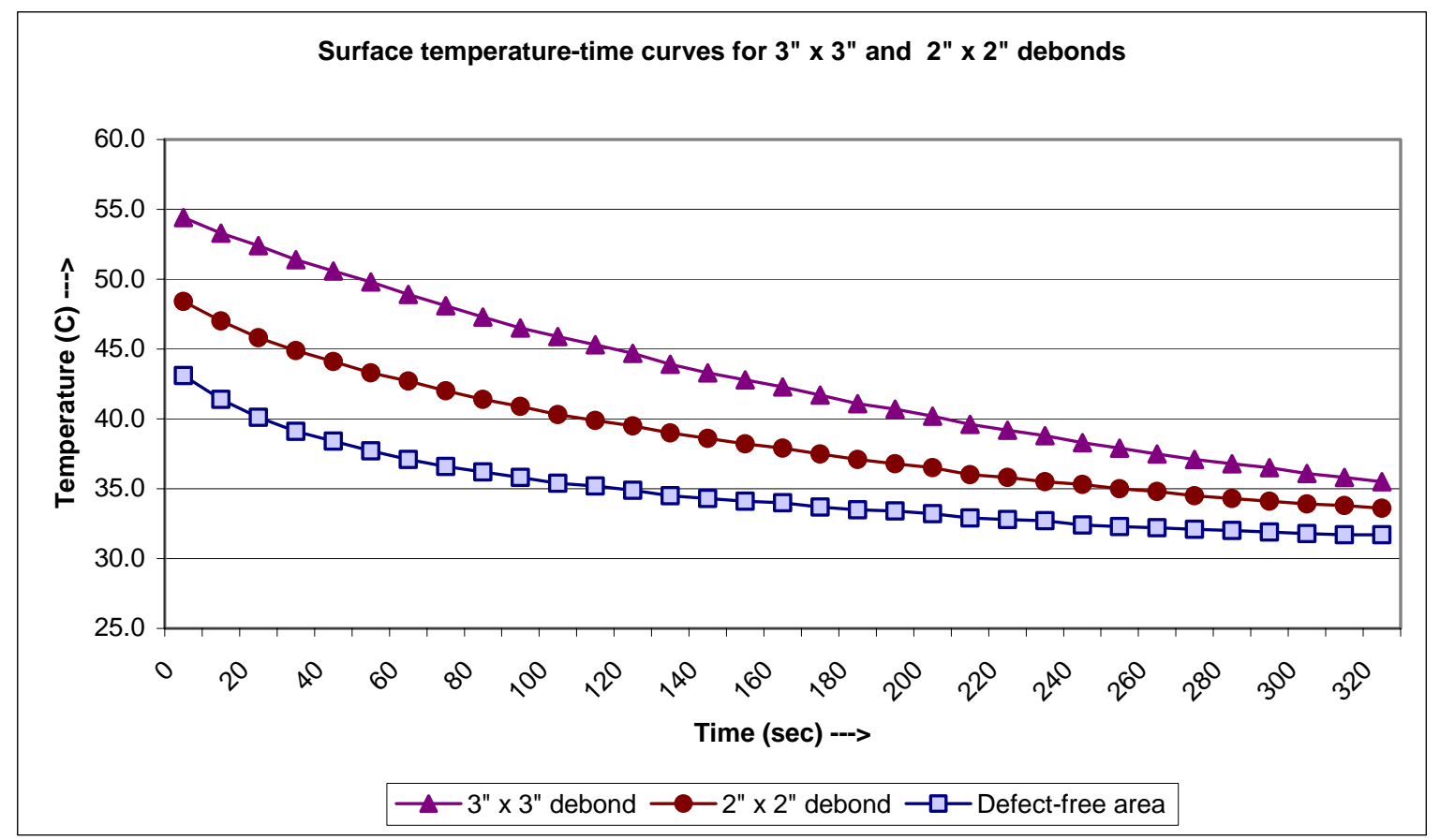

Figure 4.18. Surface temperature-time curves for 3"x 3" x 1/16" and 2"x 2" x 1/16" debonds in deck BD1a

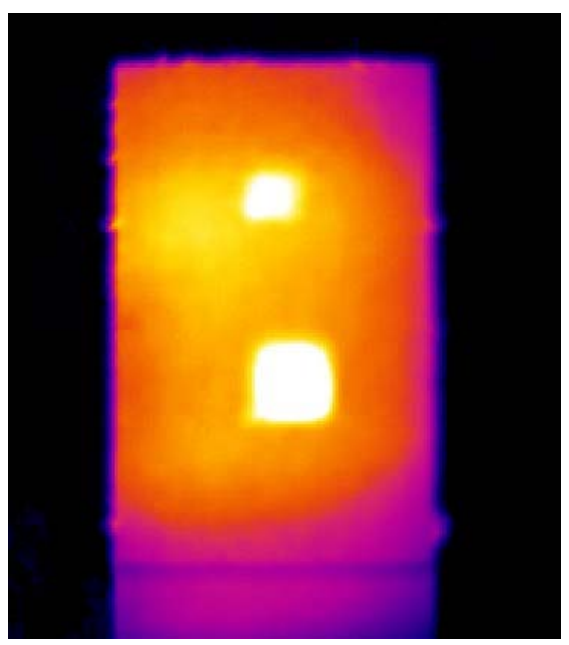

Figure 4.19. Infrared image of 2" x 2" x 1/16" and 3" x 3" x 1/16"debonds in deck BD1a, taken 30 seconds after removing the heat source

Table 4.2 gives the surface temperature values for the 1 " $\mathrm{x} 1$ " $\mathrm{x} 1 / 16$ " $(25 \mathrm{~mm} \mathrm{x}$ $25 \mathrm{~mm} \times 1.6 \mathrm{~mm}), 1 / 2 " \times 1 / 2 " \times 1 / 16 "(12.7 \mathrm{~mm} \times 12.7 \mathrm{~mm} \times 1.6 \mathrm{~mm})$ debonds and defect-free area in the specimen BD1b. Figure 4.20 shows the surface temperature-time curves for the 1 " x 1" x 1/16" (25mm x 25mm x 1.6mm), 1/2" x 1/2" x 1/16" (12.7mm x 12.7mm x $1.6 \mathrm{~mm})$ debonds. The infrared image with best contrast was obtained immediately (0 to 30 seconds) after the heating source was taken away. Images with good contrast between 
the defective and defect-free areas are available for about 3 minutes after the heating source has been removed. The time available for getting good contrasts in the infrared image reduces with the size of the defect.

Table 4.2. Surface temperatures of 1"x 1", $1 / 2$ " $x \frac{1}{2} 2$ " debonds and defect-free area in deck BD1b

\begin{tabular}{|c|c|c|c|c|c|}
\hline $\begin{array}{l}\text { Time } \\
\text { (sec) }\end{array}$ & $\begin{array}{c}1 " \times 1 " \\
\left({ }^{\circ} \mathrm{C}\right)\end{array}$ & $\begin{array}{c}1 / 2 " \times 1 / 2 " \\
\left({ }^{\circ} \mathrm{C}\right)\end{array}$ & $\begin{array}{c}\text { Defect-free area } \\
\left({ }^{\circ} \mathrm{C}\right)\end{array}$ & $\begin{array}{c}\text { Difference for } \\
1 " \times 1 "\left({ }^{\circ} \mathrm{C}\right)\end{array}$ & $\begin{array}{l}\text { Difference for } \\
1 / 2 " \times 1 / 2 "\left({ }^{\circ} \mathrm{C}\right)\end{array}$ \\
\hline 0 & 60.4 & 57.4 & 53.4 & 7.0 & 4.0 \\
\hline 10 & 57.5 & 53.6 & 50.0 & 7.5 & 3.6 \\
\hline 20 & 55.9 & 51.7 & 48.1 & 7.8 & 3.6 \\
\hline 30 & 54.8 & 50.5 & 46.8 & 8.0 & 3.7 \\
\hline 40 & 53.8 & 49.6 & 46.0 & 7.8 & 3.6 \\
\hline 50 & 52.9 & 48.9 & 45.2 & 7.7 & 3.7 \\
\hline 60 & 52.2 & 48.2 & 44.7 & 7.5 & 3.5 \\
\hline 70 & 51.5 & 47.6 & 44.2 & 7.3 & 3.4 \\
\hline 80 & 50.8 & 47.0 & 43.7 & 7.1 & 3.3 \\
\hline 90 & 49.0 & 45.6 & 42.4 & 6.6 & 3.2 \\
\hline 100 & 48.3 & 45.1 & 42.0 & 6.3 & 3.1 \\
\hline 110 & 47.7 & 44.6 & 41.7 & 6.0 & 2.9 \\
\hline 120 & 47.1 & 44.2 & 41.3 & 5.8 & 2.9 \\
\hline 130 & 46.6 & 43.8 & 41.1 & 5.5 & 2.7 \\
\hline 140 & 46.0 & 43.4 & 40.8 & 5.2 & 2.6 \\
\hline 150 & 45.6 & 43.0 & 40.6 & 5.0 & 2.4 \\
\hline 160 & 45.0 & 42.6 & 40.3 & 4.7 & 2.3 \\
\hline 170 & 44.5 & 42.2 & 40.0 & 4.5 & 2.2 \\
\hline 180 & 44.1 & 41.9 & 39.8 & 4.3 & 2.1 \\
\hline 190 & 43.7 & 41.5 & 39.6 & 4.1 & 1.9 \\
\hline 200 & 42.9 & 41.0 & 39.1 & 3.8 & 1.9 \\
\hline 210 & 42.5 & 40.8 & 39.0 & 3.5 & 1.8 \\
\hline 220 & 41.9 & 40.3 & 38.7 & 3.2 & 1.6 \\
\hline 230 & 41.6 & 40.1 & 38.5 & 3.1 & 1.6 \\
\hline 240 & 41.3 & 39.9 & 38.4 & 2.9 & 1.5 \\
\hline 250 & 40.8 & 39.5 & 38.2 & 2.6 & 1.3 \\
\hline
\end{tabular}




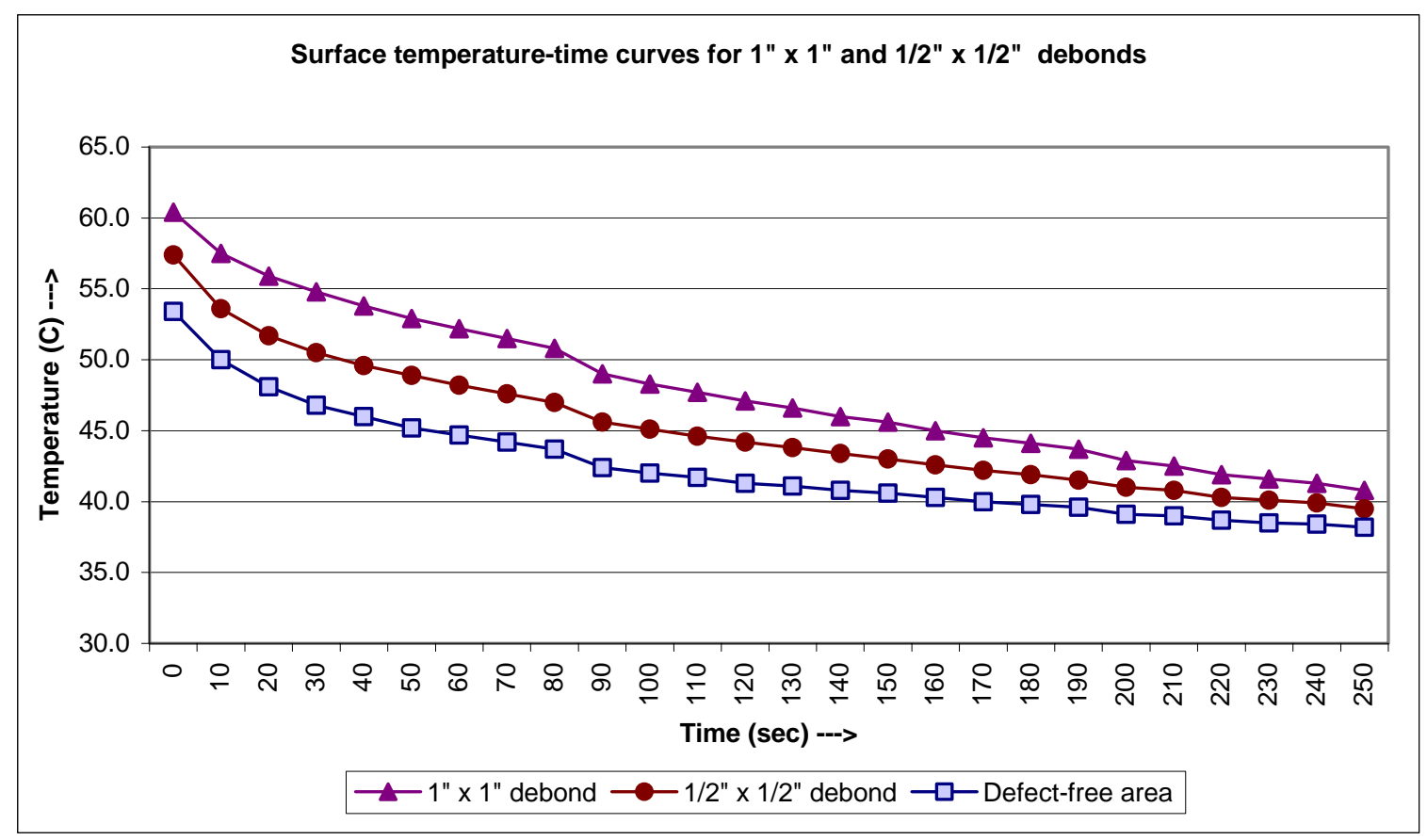

Figure 4.20. Surface temperature-time curves for 1"x 1 " x $1 / 16$ " and $1 \frac{1}{2}$ " $\mathrm{x} 1 / 2$ " $1 / 16$ " debonds in BD1b

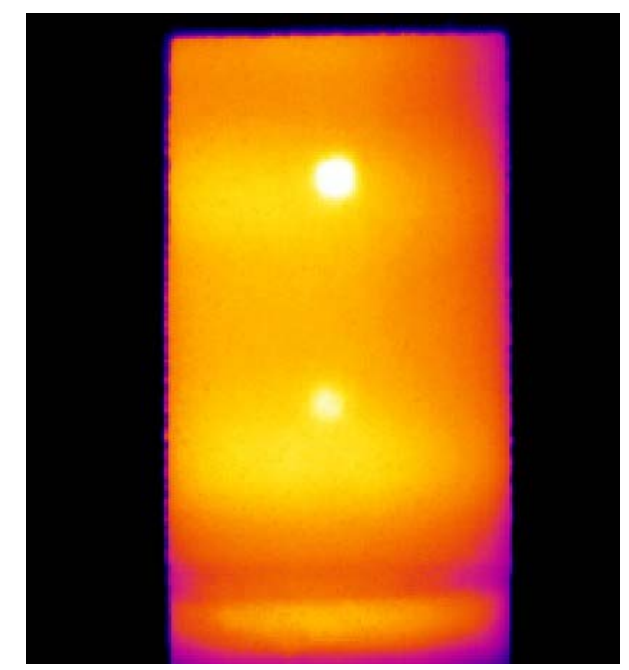

Figure 4.21 Infrared of 1"x 1" x 1/16" and 1/2" x 1/2" x 1/16" debonds in deck BD1b, taken 30 seconds after removing the heat source

Bridge deck specimen JD1

Table 4.3 and Figure 4.22 establishes surface-temperature values and curves for the 3" x 3" x 0.05 " (76mm x 76mm x $1.27 \mathrm{~mm})$ delamination in specimen JD1a. Table 4.4 and Figure 4.24 shows the values and curves for both the 2" x 2" x 1/16" $(51 \mathrm{~mm} \times$ $51 \mathrm{~mm} \times 1.5 \mathrm{~mm})$ and 1 " x 1 " x $1 / 16 "(25 \mathrm{~mm} \times 25 \mathrm{~mm} \times 1.5 \mathrm{~mm})$ delaminations in 
specimen JD1b. The results from the tables and graphs for the 3" x 3" (76mm x 76mm) delamination, showed that the maximum temperature difference between the delaminated and defect-free area was obtained after 140 seconds from the moment the heat source was removed (Table 4.3). The maximum temperature differential between the delaminated areas for both the 2" x 2" $(51 \mathrm{~mm} \times 51 \mathrm{~mm}), 1$ " x 1 " $(25 \mathrm{~mm} \times 25 \mathrm{~mm})$ delaminations and defect-free area were obtained after 120 seconds and 110 seconds respectively, after the heating source was removed (Table 4.4). This time is longer that observed in the previous debonded case, because the FRP deck's flange conducts heat at a smaller rate than the wearing surface in the previous specimen (BD1). Figure 4.23 shows the infrared image with best contrast for the deck specimen JD1a which had 3" x 3" x 0.05 " $(76 \mathrm{~mm}$ x 76mm $\mathrm{x} 1.27 \mathrm{~mm}$ ) delamination. Figure 4.25 shows the image with most prominent boundary of the 1 " x 1 " $(25 \mathrm{~mm} \times 25 \mathrm{~mm})$ and 2" x 2 " $(51 \mathrm{~mm} \times 51 \mathrm{~mm})$ delaminations (both $1 / 16$ " or $1.6 \mathrm{~mm}$ thick) in specimen JD1b. In all the images the delaminations are seen as bright white square regions (areas with higher temperature when compared to the surrounding areas).

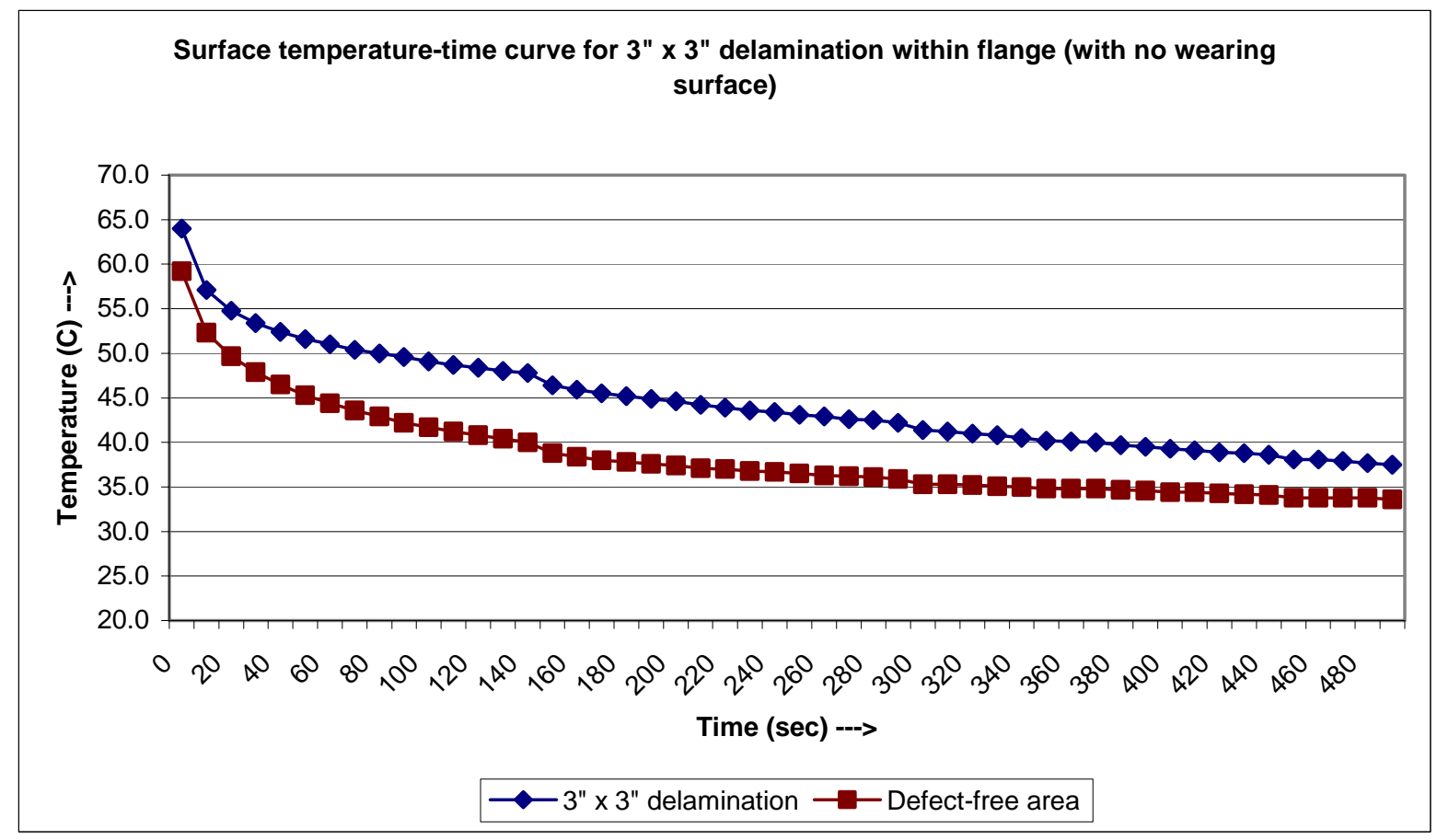

Figure 4.22. Surface temperature-time curves for 3"x 3" x 1/20" delamination located at the flange-flange junction of deck JD1a 
Table 4.3. Surface temperatures of 3"x 3" x 1/20" delamination and defect-free area in deck JD1a

\begin{tabular}{|c|c|c|c|}
\hline $\begin{array}{l}\text { Time } \\
\text { (sec) }\end{array}$ & $\begin{array}{c}3 " \times 3 " \\
\left({ }^{\circ} \mathrm{C}\right)\end{array}$ & $\begin{array}{c}\text { Defect-free area } \\
\left({ }^{\circ} \mathrm{C}\right)\end{array}$ & $\begin{array}{c}\text { Difference } \\
\left({ }^{\circ} \mathrm{C}\right) \\
\end{array}$ \\
\hline 0 & 64.0 & 59.2 & 4.8 \\
\hline 10 & 57.1 & 52.3 & 4.8 \\
\hline 20 & 54.8 & 49.7 & 5.1 \\
\hline 30 & 53.4 & 47.9 & 5.5 \\
\hline 40 & 52.4 & 46.5 & 5.9 \\
\hline 50 & 51.6 & 45.3 & 6.3 \\
\hline 60 & 51.0 & 44.4 & 6.6 \\
\hline 70 & 50.4 & 43.6 & 6.8 \\
\hline 80 & 50.0 & 42.9 & 7.1 \\
\hline 90 & 49.6 & 42.2 & 7.4 \\
\hline 100 & 49.1 & 41.7 & 7.4 \\
\hline 110 & 48.7 & 41.2 & 7.5 \\
\hline 120 & 48.4 & 40.8 & 7.6 \\
\hline 130 & 48.0 & 40.4 & 7.6 \\
\hline 140 & 47.8 & 40.0 & 7.8 \\
\hline 150 & 46.4 & 38.8 & 7.6 \\
\hline 160 & 45.9 & 38.4 & 7.5 \\
\hline 170 & 45.5 & 38.0 & 7.5 \\
\hline 180 & 45.2 & 37.8 & 7.4 \\
\hline 190 & 44.9 & 37.6 & 7.3 \\
\hline 200 & 44.6 & 37.4 & 7.2 \\
\hline 210 & 44.2 & 37.1 & 7.1 \\
\hline 220 & 43.9 & 37.0 & 6.9 \\
\hline 230 & 43.6 & 36.8 & 6.8 \\
\hline 240 & 43.4 & 36.7 & 6.7 \\
\hline 260 & 42.9 & 36.3 & 6.6 \\
\hline 280 & 42.5 & 36.1 & 6.4 \\
\hline 300 & 41.4 & 35.3 & 6.1 \\
\hline 320 & 41.0 & 35.2 & 5.8 \\
\hline 340 & 40.5 & 35.0 & 5.5 \\
\hline 360 & 40.1 & 34.8 & 5.3 \\
\hline 380 & 39.7 & 34.7 & 5.0 \\
\hline 400 & 39.3 & 34.4 & 4.9 \\
\hline 420 & 38.9 & 34.3 & 4.6 \\
\hline 440 & 38.6 & 34.1 & 4.5 \\
\hline 460 & 38.1 & 33.8 & 4.3 \\
\hline 480 & 37.7 & 33.8 & 3.9 \\
\hline 500 & 37.4 & 33.6 & 3.8 \\
\hline
\end{tabular}




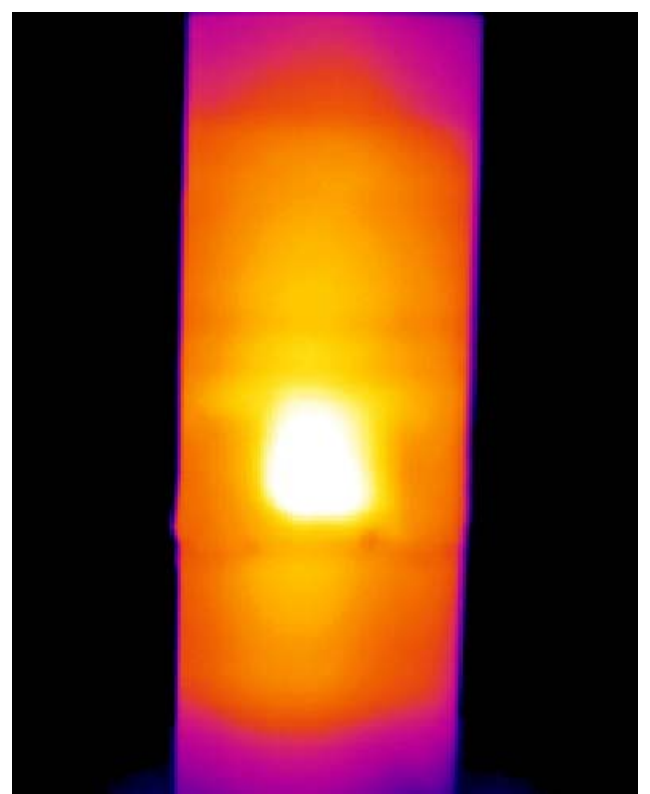

Figure 4.23. Infrared image of 3" x 3 " x 1/20" delamination at the flange-flange junction of deck JD1a, captured at the $140^{\text {th }}$ second after removing the heat source

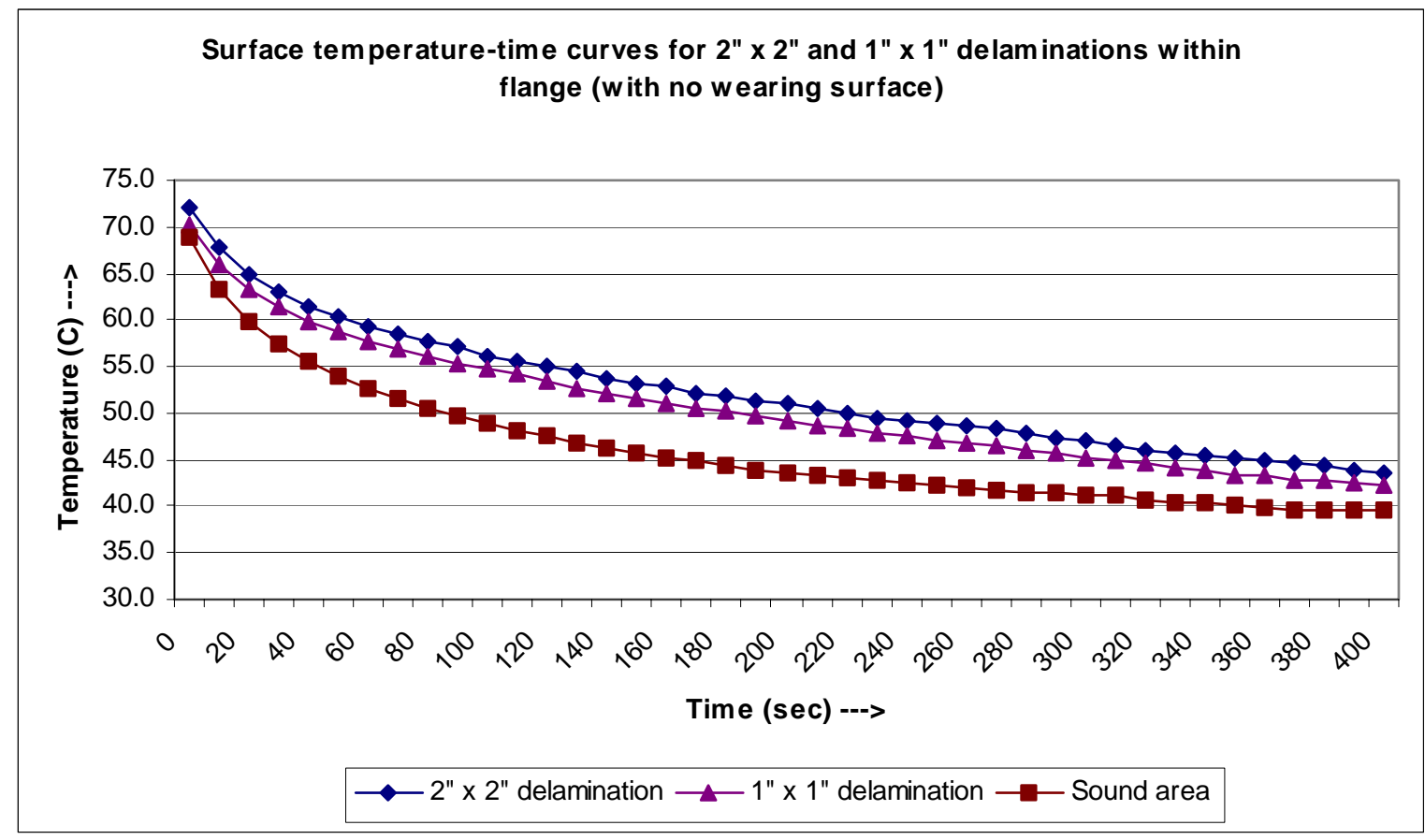

Figure 4.24. Surface temperature-time curves for 2" x 2" x 1/16" and 1" x 1" x 1/16" delaminations located at the flange-flange junction of deck JD1b 
Table 4.4 Surface temperatures of 1" x 1" and 2" x 2" delaminations and defect-free area in JD1b

\begin{tabular}{|c|c|c|c|c|c|}
\hline $\begin{array}{l}\text { Time } \\
(\mathrm{sec})\end{array}$ & $\begin{array}{c}2 " \times 2 " \\
\left({ }^{\circ} \mathrm{C}\right)\end{array}$ & $\begin{array}{c}1 " \times 1 " \\
\left({ }^{\circ} \mathrm{C}\right)\end{array}$ & $\begin{array}{c}\text { Defect-free area } \\
\left({ }^{\circ} \mathrm{C}\right)\end{array}$ & \begin{tabular}{|c|} 
Difference for \\
$2 " \times 2 "\left({ }^{\circ} \mathrm{C}\right)$ \\
\end{tabular} & $\begin{array}{l}\text { Difference for } \\
1 " \times 1 "\left({ }^{\circ} \mathrm{C}\right)\end{array}$ \\
\hline 0 & 72.0 & 70.3 & 69.0 & 3.0 & 1.3 \\
\hline 10 & 67.9 & 65.9 & 63.4 & 4.5 & 2.5 \\
\hline 20 & 64.8 & 63.2 & 59.8 & 5.0 & 3.4 \\
\hline 30 & 62.9 & 61.3 & 57.4 & 5.5 & 3.9 \\
\hline 40 & 61.4 & 59.9 & 55.5 & 5.9 & 4.4 \\
\hline 50 & 60.3 & 58.7 & 53.9 & 6.4 & 4.8 \\
\hline 60 & 59.3 & 57.8 & 52.7 & 6.6 & 5.1 \\
\hline 70 & 58.6 & 56.9 & 51.6 & 7.0 & 5.3 \\
\hline 80 & 57.7 & 56.1 & 50.6 & 7.1 & 5.5 \\
\hline 90 & 57 & 55.4 & 49.6 & 7.4 & 5.8 \\
\hline 100 & 56.2 & 54.8 & 48.9 & 7.3 & 5.9 \\
\hline 110 & 55.5 & 54.2 & 48.2 & 7.3 & 6.0 \\
\hline 120 & 55.0 & 53.4 & 47.5 & 7.5 & 5.9 \\
\hline 130 & 54.4 & 52.7 & 46.9 & 7.5 & 5.8 \\
\hline 140 & 53.8 & 52.1 & 46.3 & 7.5 & 5.8 \\
\hline 150 & 53.2 & 51.6 & 45.8 & 7.4 & 5.8 \\
\hline 160 & 52.8 & 51.0 & 45.2 & 7.6 & 5.8 \\
\hline 170 & 52.2 & 50.5 & 44.8 & 7.4 & 5.7 \\
\hline 180 & 51.8 & 50.3 & 44.5 & 7.3 & 5.8 \\
\hline 190 & 51.4 & 49.7 & 43.9 & 7.5 & 5.8 \\
\hline 200 & 51.1 & 49.2 & 43.5 & 7.6 & 5.7 \\
\hline 210 & 50.4 & 48.7 & 43.2 & 7.2 & 5.5 \\
\hline 220 & 50.0 & 48.3 & 43.0 & 7.0 & 5.3 \\
\hline 230 & 49.5 & 47.9 & 42.7 & 6.8 & 5.2 \\
\hline 240 & 49.3 & 47.5 & 42.5 & 6.8 & 5.0 \\
\hline 250 & 48.8 & 47.1 & 42.3 & 6.5 & 4.8 \\
\hline 260 & 48.6 & 46.8 & 42.1 & 6.5 & 4.7 \\
\hline 270 & 48.3 & 46.4 & 41.8 & 6.5 & 4.6 \\
\hline 280 & 47.8 & 46.0 & 41.5 & 6.3 & 4.5 \\
\hline 290 & 47.3 & 45.6 & 41.4 & 5.9 & 4.2 \\
\hline 300 & 47.0 & 45.3 & 41.1 & 5.9 & 4.2 \\
\hline 310 & 46.6 & 45.0 & 41.1 & 5.5 & 3.9 \\
\hline 320 & 46.1 & 44.6 & 40.7 & 5.4 & 3.9 \\
\hline 330 & 45.8 & 44.1 & 40.5 & 5.3 & 3.6 \\
\hline 340 & 45.5 & 43.8 & 40.3 & 5.2 & 3.5 \\
\hline 350 & 45.2 & 43.4 & 40.1 & 5.1 & 3.3 \\
\hline 360 & 45.0 & 43.2 & 39.9 & 5.1 & 3.3 \\
\hline 370 & 44.6 & 42.9 & 39.7 & 4.9 & 3.2 \\
\hline 380 & 44.3 & 42.8 & 39.7 & 4.6 & 3.1 \\
\hline 390 & 43.9 & 42.6 & 39.6 & 4.3 & 3.0 \\
\hline 400 & 43.5 & 42.3 & 39.5 & 4.0 & 2.8 \\
\hline
\end{tabular}




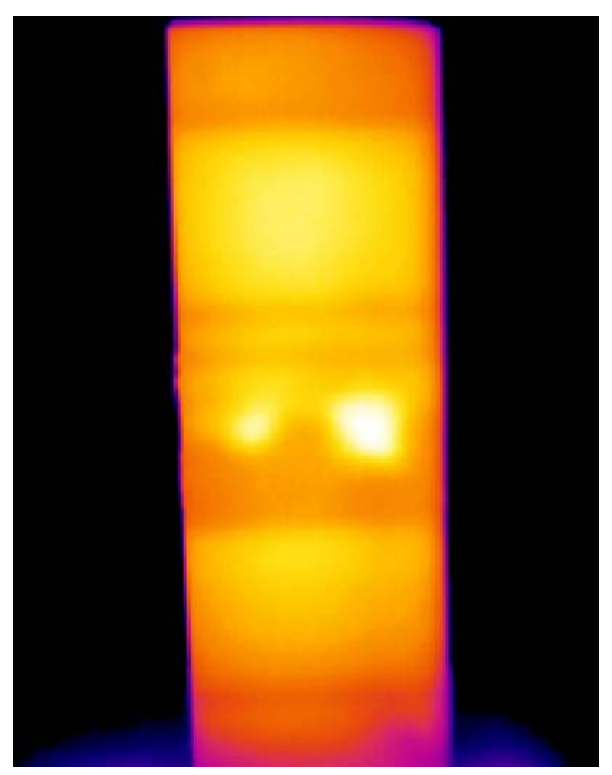

Figure 4.25. Infrared image of 1 " 1 1" x 1/16" and 2" x 2" x $1 / 16$ " delaminations at the flange-flange junction of deck JD1b, captured at the $120^{\text {th }}$ second after removing the heat source

\section{Bridge deck specimen JD2}

Table 4.5 and Figure 4.26 establishes values and curves for the 3 " $\mathrm{x} 3$ " x $1 / 8$ " $(76 \mathrm{~mm} \times 76 \mathrm{~mm} \times 3 \mathrm{~mm})$ delamination. Heating for specimen JD2, which had a $3 / 8$ " $(9.5 \mathrm{~mm})$ thick wearing surface, was continued for a relatively longer time of about 4-5 minutes, until the surface temperature of the specimen reached about $75-80^{\circ} \mathrm{C}$. As the delamination was located well beneath the wearing surface layer and the FRP layers, it took a longer time for the heat to travel into the deck towards the delamination.

The infrared image with maximum surface temperature difference (Figure 4.27) was obtained immediately after the heating source was taken away. The values of temperature differences obtained from the $20^{\text {th }}$ second time period up to 10 minutes, were very close to each other. Hence the infrared image with good contrast could be obtained up to 10 minutes after the heating source has been removed. This implies that the presence of the delamination (that lies underneath the wearing surface and FRP layers) can still be detected even after 10 minutes after the heating source was taken away. This is because more amount of heat was applied to the specimen and the surface temperature above the delamination was as high as $82.7^{\circ} \mathrm{C}$. Also, since the location of the delamination was well beneath the surface of the deck (about 13mm), the trapped heat 
energy above the delamination takes time to get conducted through the thickness of the deck towards the surface.

Table 4.5 Surface temperatures of 3"x 3" x 1/8" delamination and defect-free area in deck JD2

\begin{tabular}{|c|c|c|c|}
\hline $\begin{array}{l}\text { Time } \\
\text { (sec) }\end{array}$ & $\begin{array}{c}3 " \times 3 " \\
\left({ }^{\circ} \mathrm{C}\right)\end{array}$ & $\begin{array}{c}\text { Defect-free area } \\
\left({ }^{\circ} \mathrm{C}\right) \\
\end{array}$ & $\begin{array}{c}\text { Difference } \\
\left({ }^{\circ} \mathrm{C}\right)\end{array}$ \\
\hline 0 & 82.7 & 75.2 & 7.5 \\
\hline 10 & 80.4 & 73.5 & 6.9 \\
\hline 20 & 78.9 & 72.4 & 6.5 \\
\hline 40 & 76.9 & 70.6 & 6.3 \\
\hline 60 & 75.6 & 69.4 & 6.2 \\
\hline 80 & 74.3 & 68.1 & 6.2 \\
\hline 100 & 73.3 & 67.1 & 6.2 \\
\hline 120 & 72.4 & 66.3 & 6.1 \\
\hline 140 & 71.6 & 65.4 & 6.2 \\
\hline 160 & 71.0 & 64.7 & 6.3 \\
\hline 180 & 70.2 & 63.9 & 6.3 \\
\hline 200 & 69.6 & 63.4 & 6.2 \\
\hline 220 & 68.9 & 62.6 & 6.3 \\
\hline 240 & 68.3 & 62.2 & 6.1 \\
\hline 260 & 67.6 & 61.5 & 6.1 \\
\hline 280 & 67.1 & 60.9 & 6.2 \\
\hline 300 & 66.5 & 60.4 & 6.1 \\
\hline 320 & 65.9 & 59.8 & 6.1 \\
\hline 340 & 65.4 & 59.3 & 6.1 \\
\hline 360 & 64.9 & 58.9 & 6.0 \\
\hline 380 & 64.3 & 58.5 & 5.8 \\
\hline 400 & 63.8 & 58.0 & 5.8 \\
\hline 420 & 63.3 & 57.5 & 5.8 \\
\hline 440 & 62.7 & 57.1 & 5.6 \\
\hline 460 & 62.3 & 56.7 & 5.6 \\
\hline 480 & 61.8 & 56.1 & 5.7 \\
\hline 500 & 61.4 & 56.0 & 5.4 \\
\hline 520 & 61.0 & 55.7 & 5.3 \\
\hline 540 & 60.6 & 55.3 & 5.3 \\
\hline 560 & 60.2 & 55.0 & 5.2 \\
\hline 580 & 59.4 & 54.4 & 5.0 \\
\hline 600 & 59.0 & 54.0 & 5.0 \\
\hline
\end{tabular}




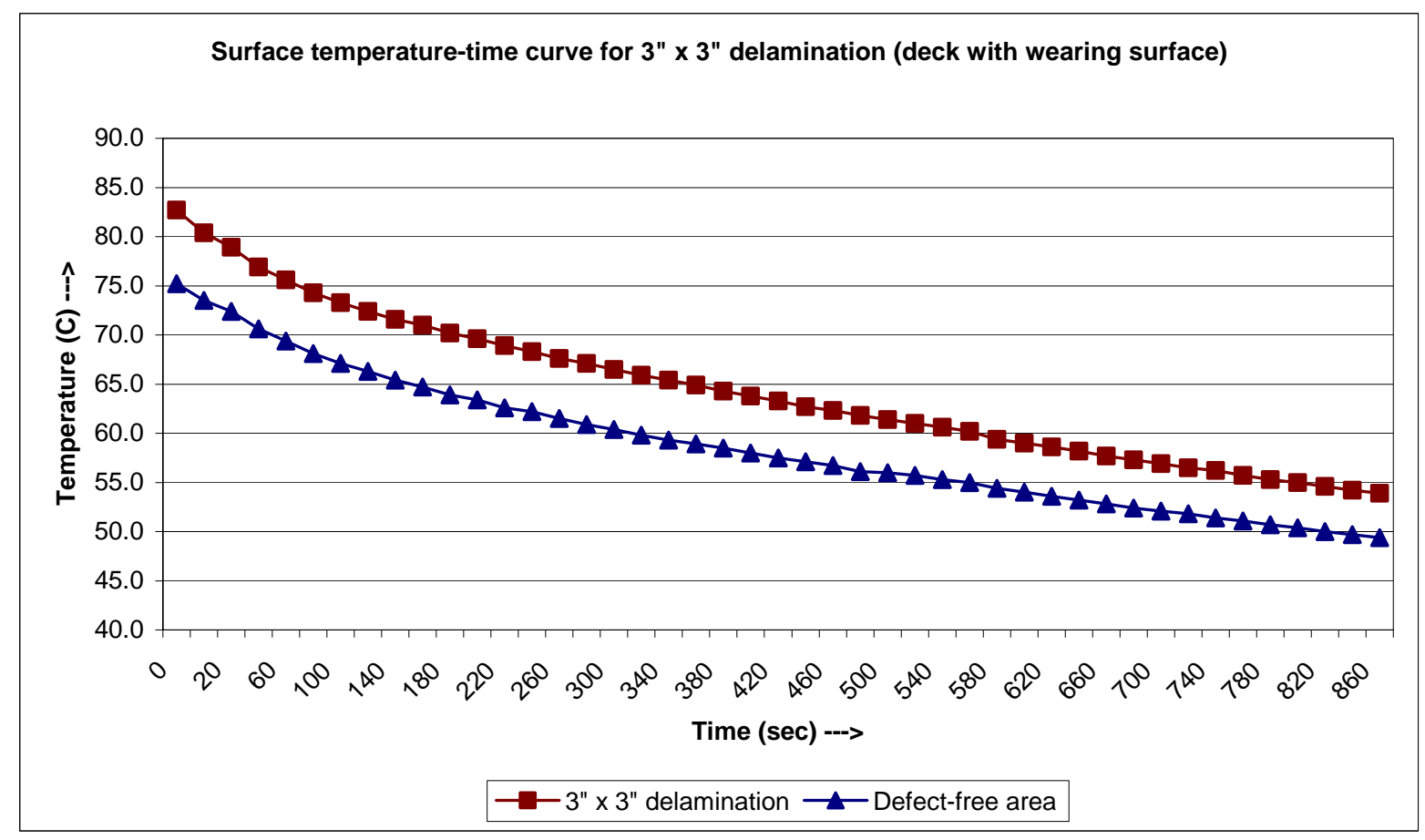

Figure 4.26. Surface temperature-time curves for 3"x 3" x 1/8" delamination in deck deck JD2

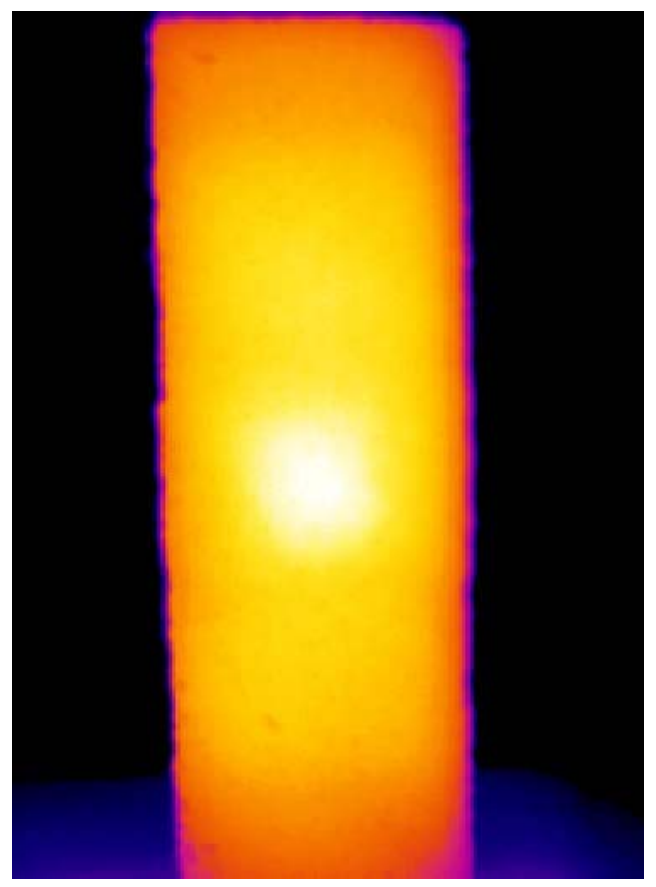

Figure 4.27. Infrared image of bridge deck specimen JD2 with wearing surface and embedded delamination of size 3" x 3 " x $1 / 8$ " at the flange-flange junction 


\subsubsection{Conclusions}

The surface temperature-time tables and graphs for the different sizes of debonds and delaminations were established. These tables and graphs indicate times at which the best contrast image for each of these defects are available. For the debonds present between the wearing surface and the underlying FRP deck (specimen BD1), the image with best contrast was available almost immediately after the heat source was removed away from the surface. The image with best contrast between defective and defect-free areas for the specimens with delaminations embedded within the flange area and with no wearing surface overlay (specimen JD1) was detected only 2 minutes after the heat source was removed. The surface temperature differentials for debonds in BD1 reduced more rapidly when compared to those of the delaminations in JD1. One of the reasons for this was that time for which the heat was applied on the deck BD1 was less when compared to the time of heat application on deck JD1. Another reason is the differences in thermal conductivity in case of the two specimens. The thermal conductivity of the GFRP deck material $\left(0.3 \mathrm{Wm}^{-10} \mathrm{C}^{-1}\right.$ for $\_$_ _ fibers and $0.38 \mathrm{Wm}^{-10} \mathrm{C}^{-1}$ for $\|$ fibers [values available in Table 2.1]) is comparatively smaller than the wearing surface material used in BD1. Also, the void ratio of a material affects its thermal conductivity, and FRP decks have more voids compared to the wearing surface, thus leading to lower thermal conductivity. Hence the wearing surface in BD1 (under which the debonds were present) conducts heat at a very fast rate when compared to the GFRP material (under which the delaminations were present in specimen JD1).

For the delamination present at the flange-flange junction of the FRP deck with $3 / 8$ " thick wearing surface (specimen JD2), the image with best contrast was available immediately after the heating source was removed. Infrared images with good surface temperature differences between the delaminated area at the flange-flange junction and defect-free area in case of this deck specimen with wearing surface were available for a considerable period of time (7-10 minutes) after the heating source was removed. This is because of the larger amount of entrapped heat which takes considerable time to travel to the surface due to conduction through the flange of the deck and the wearing surface overlay. 


\subsection{INFRARED TESTS ON DECKS SUBJECTED TO FATIGUE LOADING}

The development of debonds or cracks in a composite member due to fatigue loads applied during the service life of the structure may adversely affect its structural integrity. Therefore, continuous monitoring of the structural member becomes necessary. Laboratory experiments were conducted to demonstrate the use of infrared thermography to record the infrared images of the debonds before and after the application of fatigue loads on composite bridge deck specimens, hence serving as a method to monitor the development of cracks or debonds and their subsequent growth.

\subsubsection{Bridge Deck Specimens}

\section{Bridge deck specimen FS1}

The specimen was a 12' x 8' (3.66m x 2.44m) GFRP composite bridge deck with 8 " thickness $(0.2 \mathrm{~m})$ with a $3 / 8$ " $(9.5 \mathrm{~mm})$ thick wearing surface overlay. Several modules of dimensions 24 " x 12 " x 8 " $(0.61 \mathrm{~m} \times 0.3 \mathrm{~m} \times 0.2 \mathrm{~m})$ were connected to make the 12 ' $\mathrm{x}$ $8^{\prime}(3.66 \mathrm{~m} \times 2.44 \mathrm{~m})$ deck specimen. Each of these modules were similar in cross-section and material to specimen BD1 as described in Section 4.4.1. Debonds with sizes of $1 / 2$ " $\mathrm{x}$ $1 / 2$ " (12.7mm x 12.7mm), 2" x 2" (51 mm x 51mm), 3" x 3" (76mm x 76mm), and 4" x 4" $(102 \mathrm{~mm} \times 102 \mathrm{~mm})$ were inserted in between the wearing surface and the composite deck. All the debonds had 1/16" $(1.6 \mathrm{~mm})$ thickness. Figure 4.28 shows the location of the debonds inserted between the bridge deck and the wearing surface overlay.

\section{Bridge deck specimen FS2}

The specimen was a 12' x 8' (3.66m x 2.44m) GFRP composite bridge deck with 8 " thickness $(0.2 \mathrm{~m})$ with a $3 / 8$ " $(9 \mathrm{~mm})$ thick wearing surface overlay. Several modules of dimensions 24 " × 12 " × 8 " $(0.61 \mathrm{~m} \times 0.3 \mathrm{~m} \times 0.2 \mathrm{~m})$ were connected to make this deck specimen. Each of these modules were similar in cross-section and material to specimen BD1 as described in Section 4.4.1, except that this bridge deck component was made with a combination of vinyl-ester resin instead of polyester resin. The portion of the surface of the vinyl-ester deck (about 3' x 3') at the loading areas under the patch loads was strengthened by applying 8 layers of glass fabric of size 3'x 3' (914mm x 914mm). This was done to prevent the punching shear failure that was observed (described in later 
sections) in the previous FRP deck specimen, FS1. Four debonds sizes of $1 / 2$ " $x 1 / 2$ " $(12.7 \mathrm{~mm} \times 12.7 \mathrm{~mm}), 1$ x 1" $(25 \mathrm{~mm}$ x $25 \mathrm{~mm}), 2$ x 2 " $(51 \mathrm{~mm}$ x $51 \mathrm{~mm})$ and 3 x 3 " $(76 \mathrm{~mm} \times 76 \mathrm{~mm})$ were placed between the top surface of the deck and the wearing surface overlay. All the debonds had 1/16" $(1.6 \mathrm{~mm})$ thickness. The location of the debonds are shown in the schematic view in Figure 4.29.

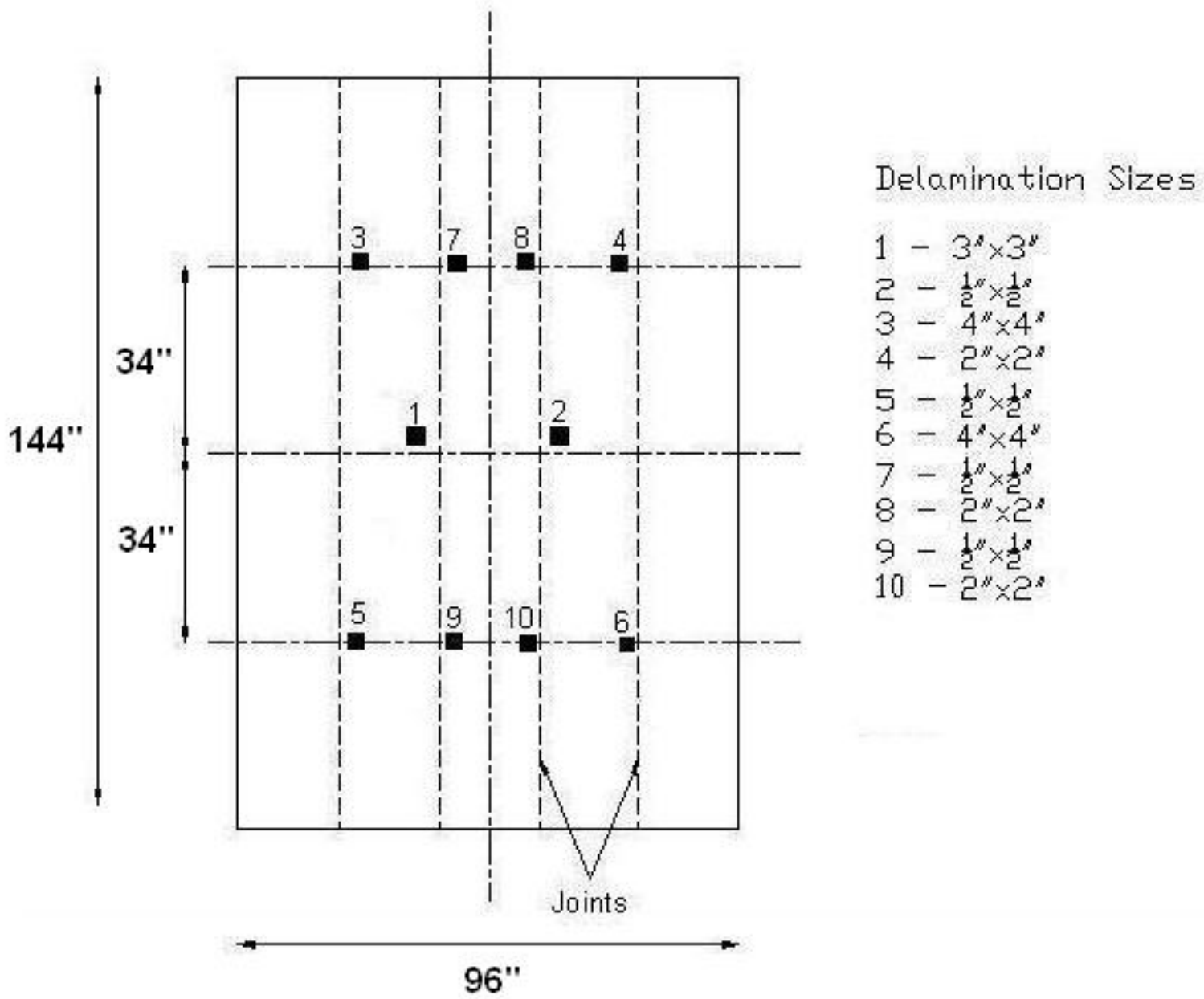

Figure 4.28 Schematic view of bridge deck FS1, showing location of the debonds 


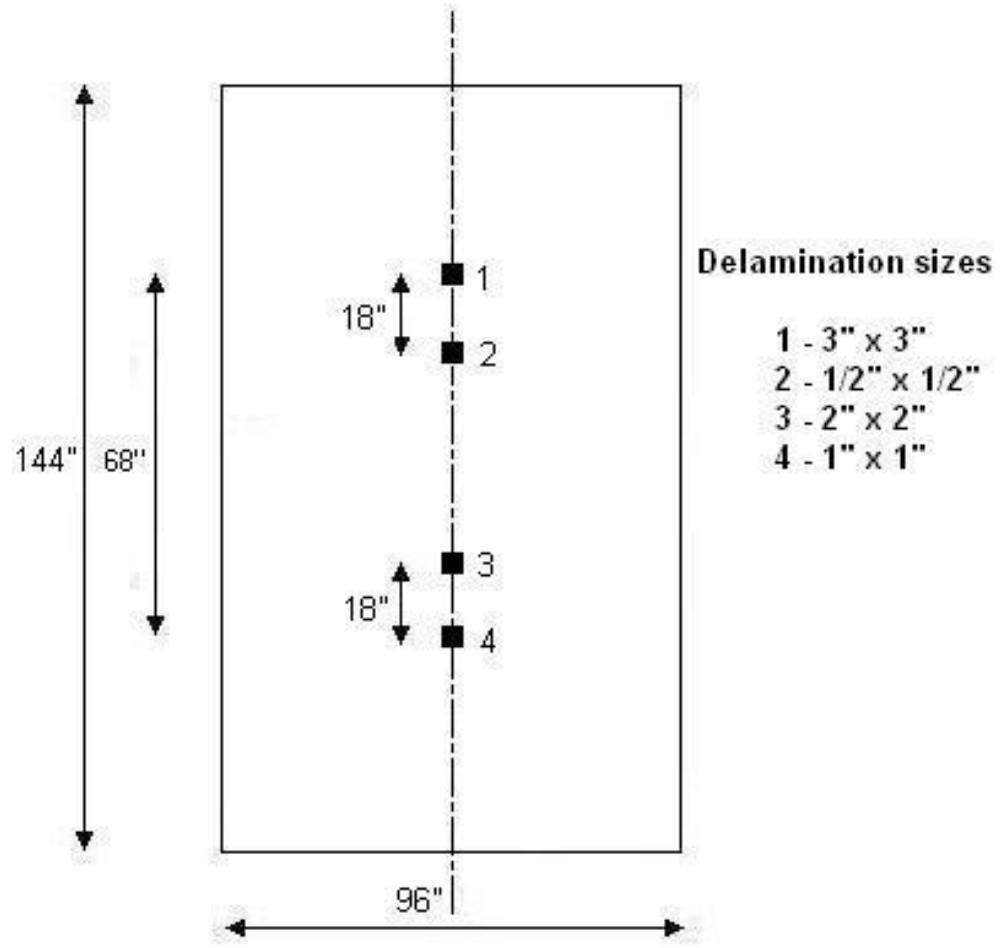

Figure 4.29 Schematic view of bridge deck FS2, showing location of the debonds

\subsubsection{Fatigue Loading Setup}

Figure 4.30 shows the fatigue loading setup used in this study. The FRP bridge deck system (both FS1 and FS2) was supported on three W10x39 steel stringers placed at 68 " $(1.73 \mathrm{~m})$ center to center as shown in the plan view in Figure 4.31. The stringers were placed on rigid, 14 " $(0.36 \mathrm{~m})$ deep, steel supports to provide a firm base for fatigue testing. Steel rollers were welded to the top of these supports to simulate simply supported conditions for the deck/stringer systems. The center-to-center span between the rollers was maintained at 88 " $(2.24 \mathrm{~m})$. The FRP composite bridge deck system was tested under sinusoidal loading with a loading range of 1 kip to 50 kips, applied at a frequency of $1 \mathrm{~Hz}$. The patch load consisted of two standard steel plate 10 " x 20 " $(0.25 \mathrm{~m} \times 0.51 \mathrm{~m})$, spaced at $68 \%(1.73 \mathrm{~m})$ center to center and placed over elastometric bearing pad (so as to apply a uniform pressure on deck surface). The load was applied on the structural system through a hydraulic jack and was monitored using a load cell. The patch load was chosen, 
so as to simulate the application of a truck wheel load. Figure 4.31 shows the plan view of the deck indicating the location of the patch loads.

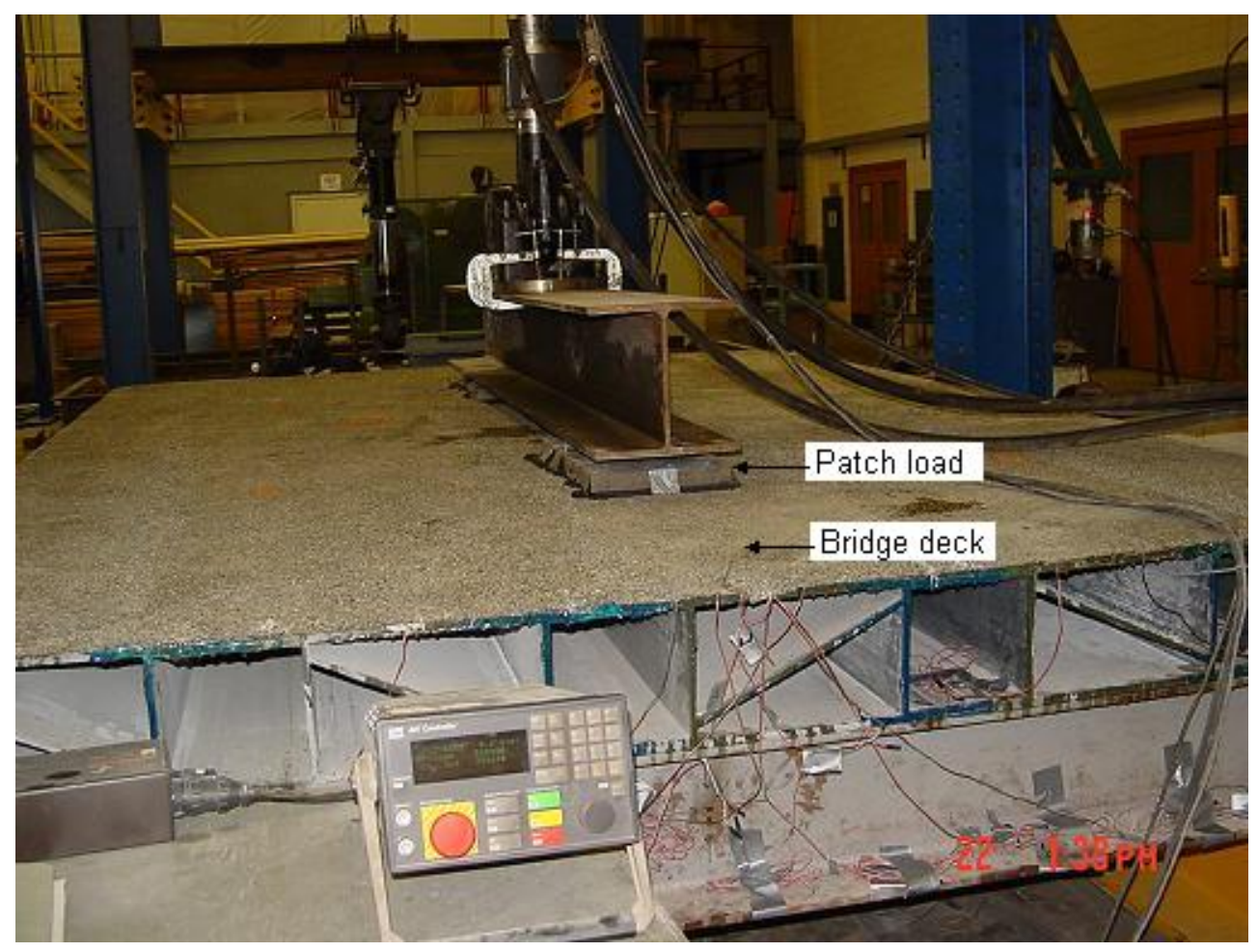

Figure 4.30 Photograph of the bridge deck module and setup for fatigue load testing

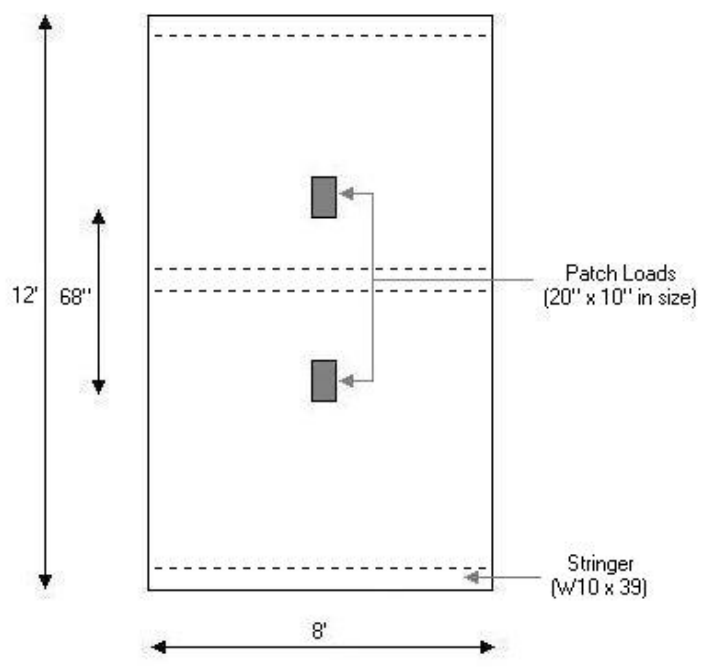

Figure 4.31 Schematic view of location of patch loads on deck surface 


\subsubsection{Infrared Tests and Results}

\section{Bridge deck specimen FS1}

The infrared camera used for the detection of defects was the FSI Prism Single Point (SP) non-digital camera (described in Chapter 3, Section 3.1.1), since the digital infrared camera was not available at the time of this testing. The real time thermal images were first recorded on a VHS tape and then transferred to a personal computer in the form of still images. The specimen was heated using two 3' x 3' (914mm x 914mm) heating blankets prior to the acquisition of the infrared images. Under application of fatigue loads (see loading details in the previous section), the specimen failed at about 230,000 cycles due to the local punching shear. The infrared images were acquired before and after the application of the fatigue loads. The "before" and "after" images were then compared to determine if any new debonds or cracks had developed and if the existing debonds had grown in size.

The location, shape and size of the debonds were marked on the deck surface by viewing the infrared image and simultaneously marking the debonds on the deck surface. It was found that 8 out of 10 debonds did not grow in size. Figures 4.32 to 4.45 show the photographic views and the infrared images of the debonds that did not grow in size. The orange and white marking in the photographic views represent the shape of the debond, before and after the application of fatigue loads, respectively.

In the infrared images, the bright yellow spots represent the debonds. In some of the infrared images the debonds are marked by black circles. The infrared images of all the debonds no. 1 to no. 6 and no.9, revealed that they did not grow in size, even after the application of the fatigue loads. 


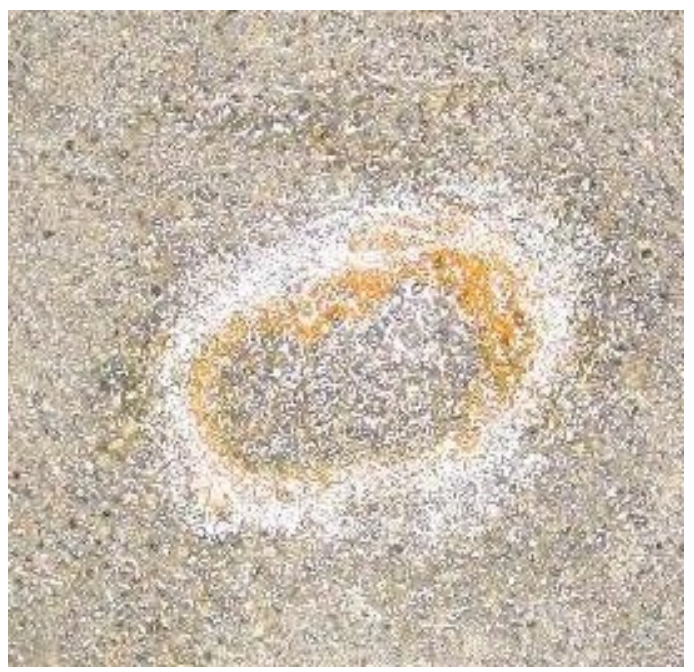

Figure 4.32 Photographic view of debond no.1
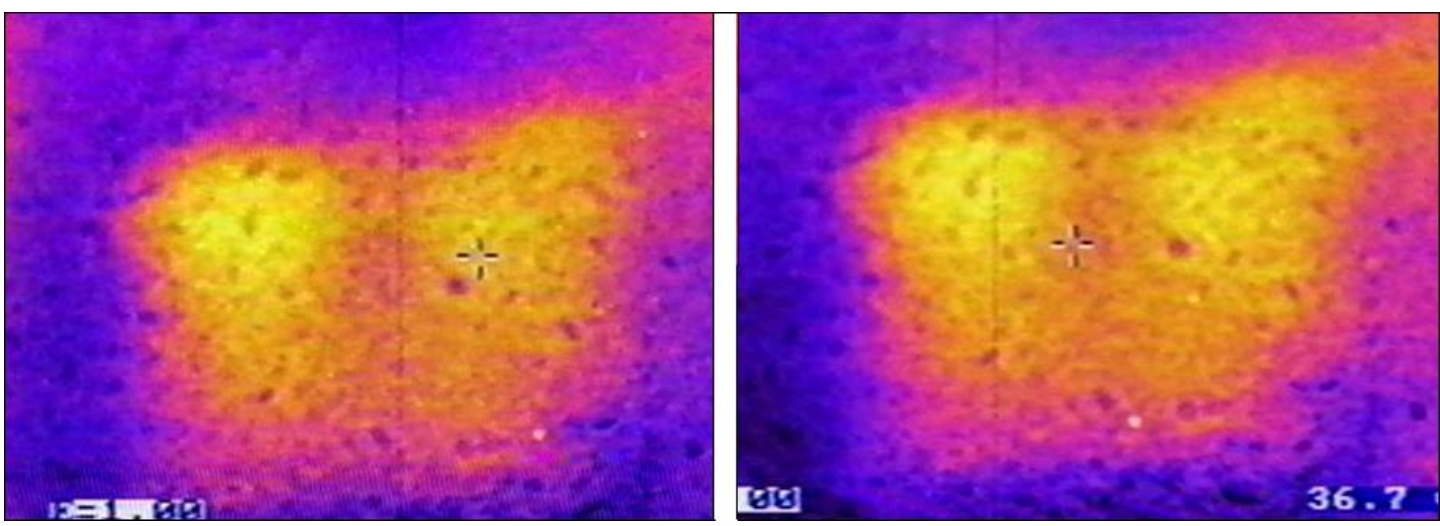

Figure 4.33 Infrared image of debond no.1 (a) before application of fatigue loads

(b) after application of fatigue loads

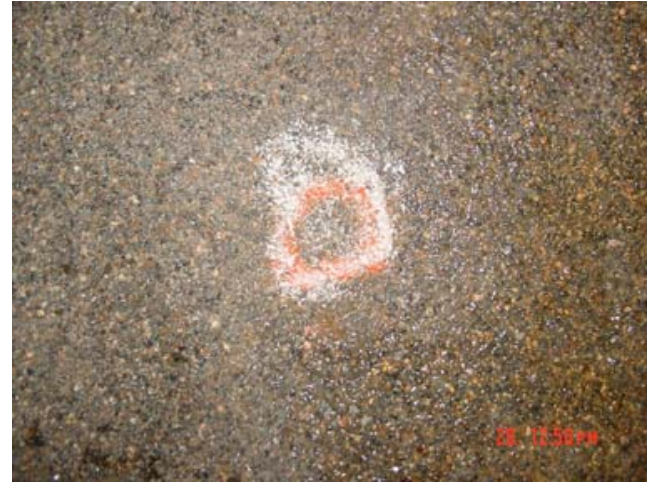

Figure 4.34 Photographic view of debond no.2 


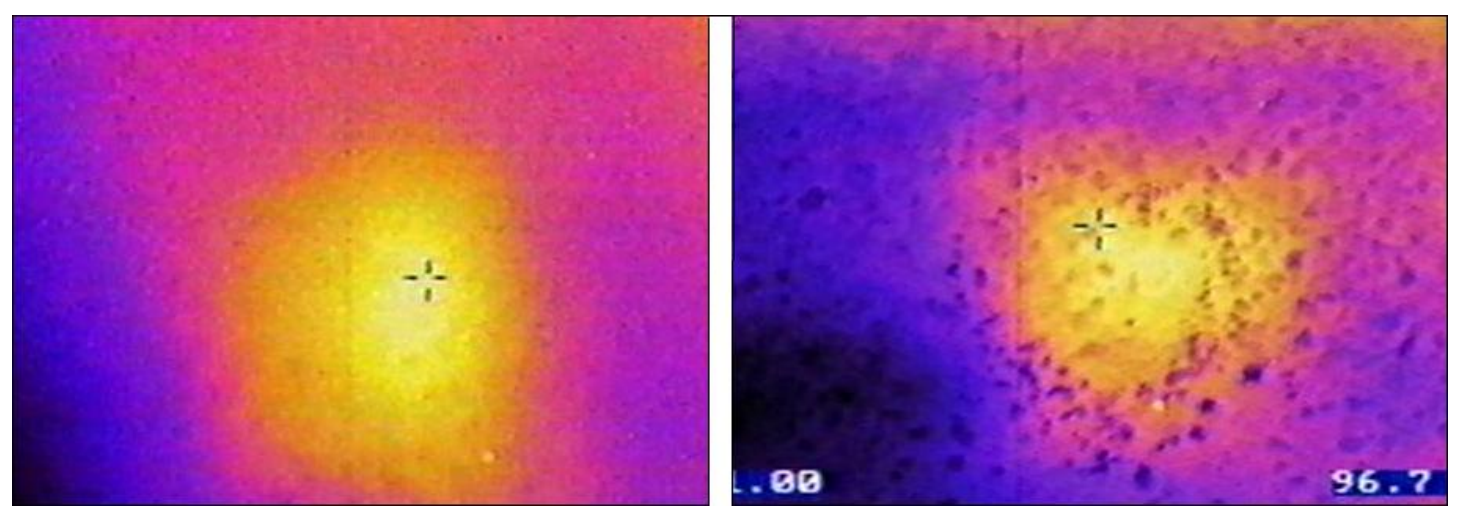

Figure 4.35 Infrared image of debond no.2 (a) before application of fatigue loads

(b) after application of fatigue loads

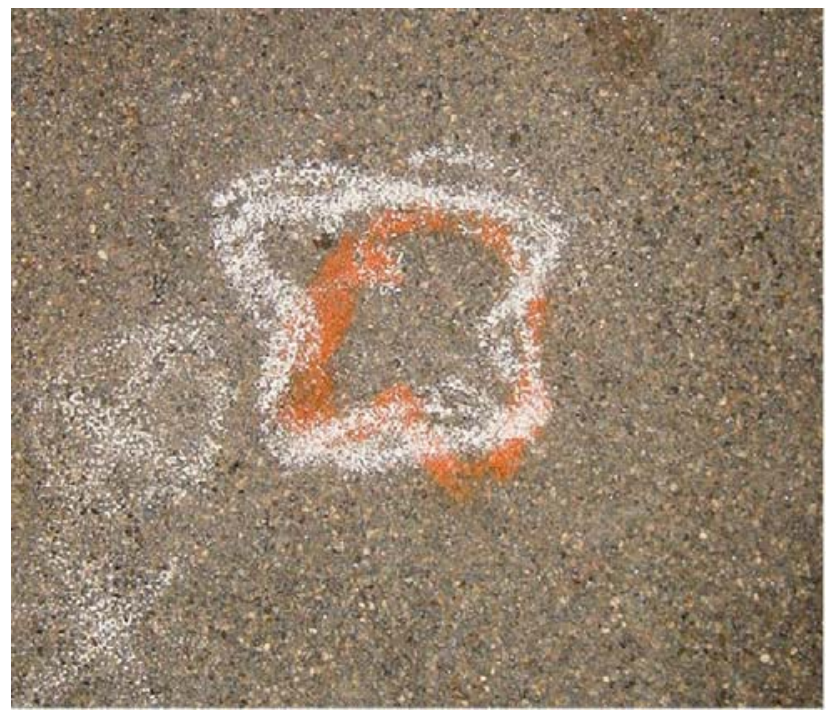

Figure 4.36 Photographic view of debond no.3

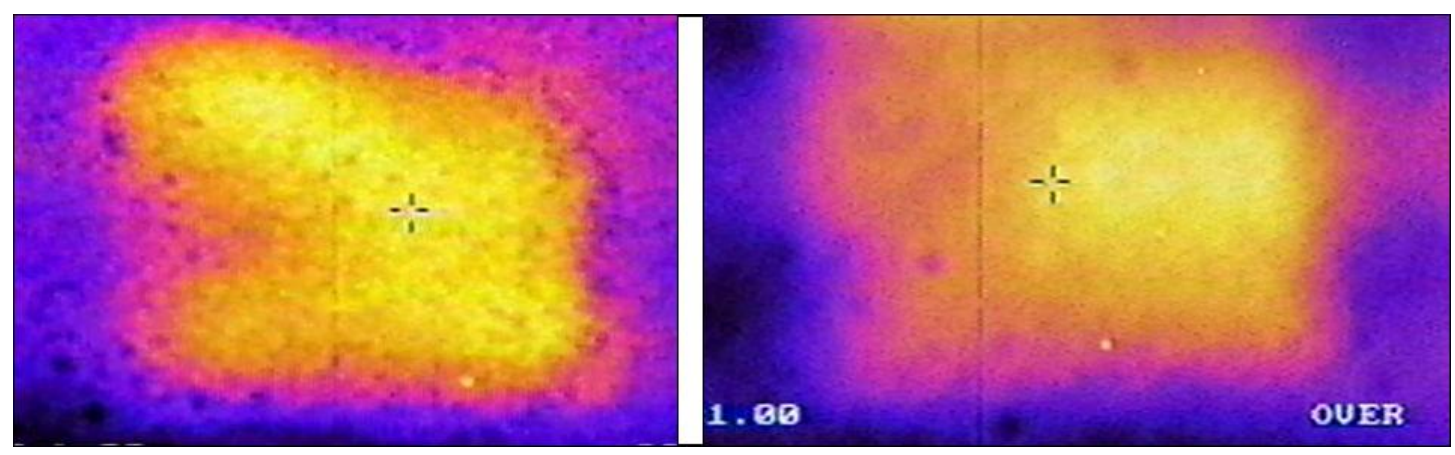

Figure 4.37 Infrared image of debond no.3 (a) before application of fatigue loads

(b) after application of fatigue loads 


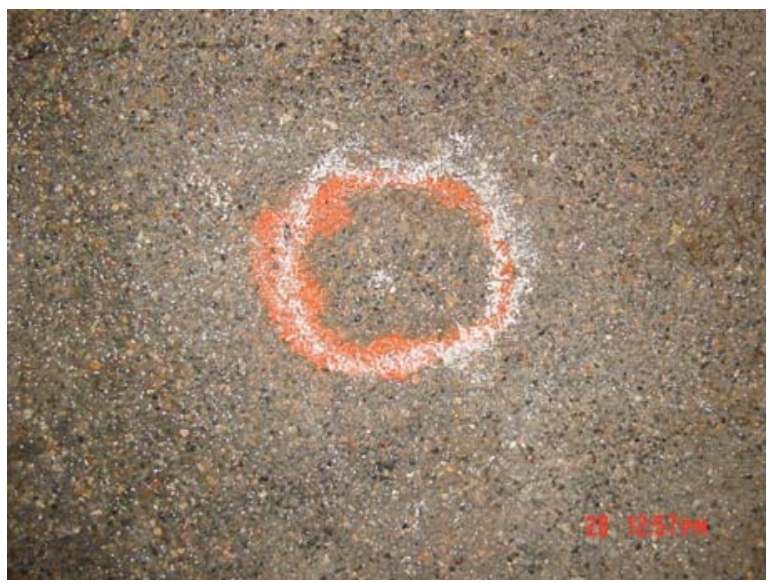

Figure 4.38 Photographic view of debond no.4

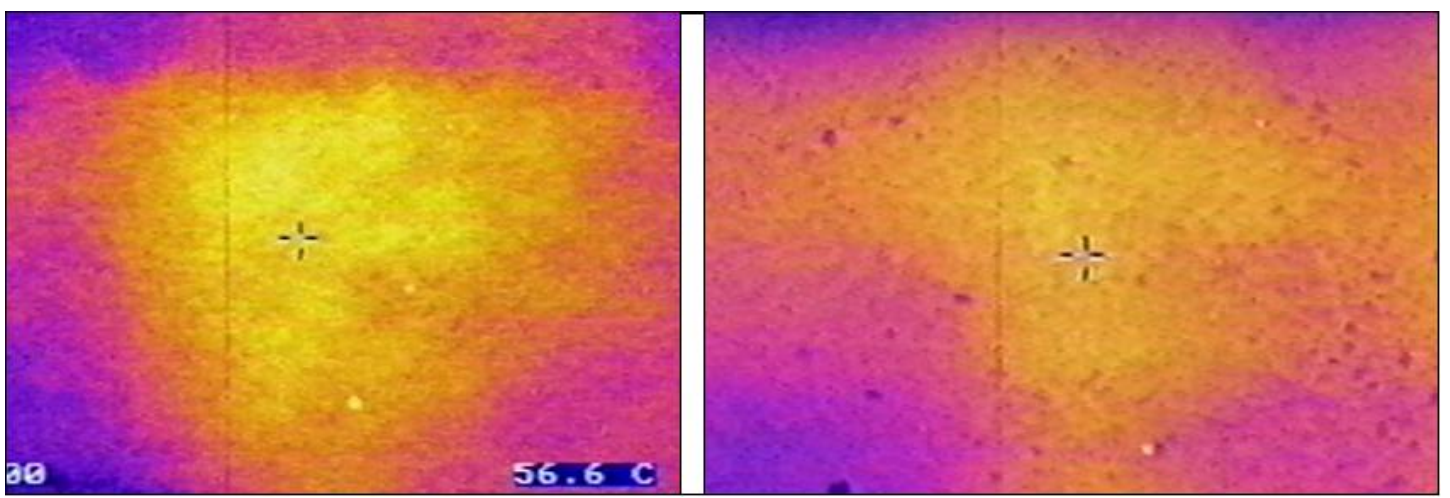

Figure 4.39 Infrared image of debond no.4 (a) before application of fatigue loads

(b) after application of fatigue loads

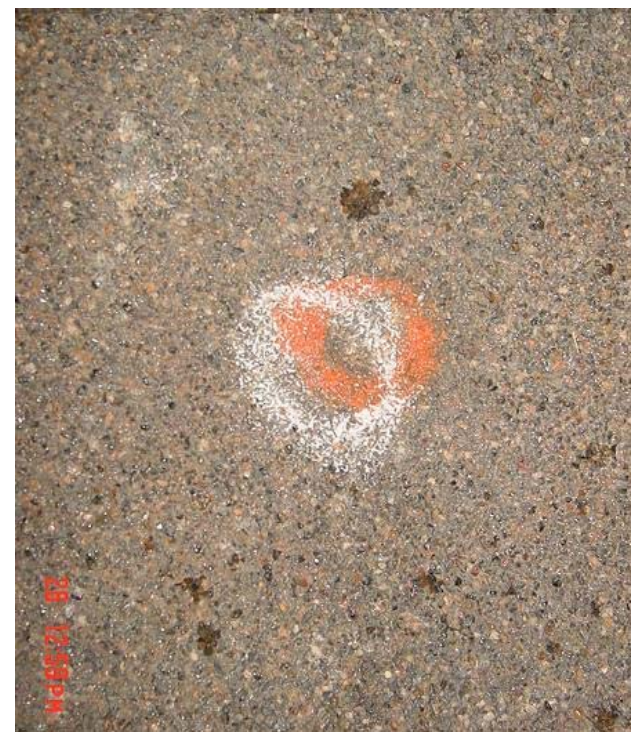

Figure 4.40 Photographic view of debond no.5 


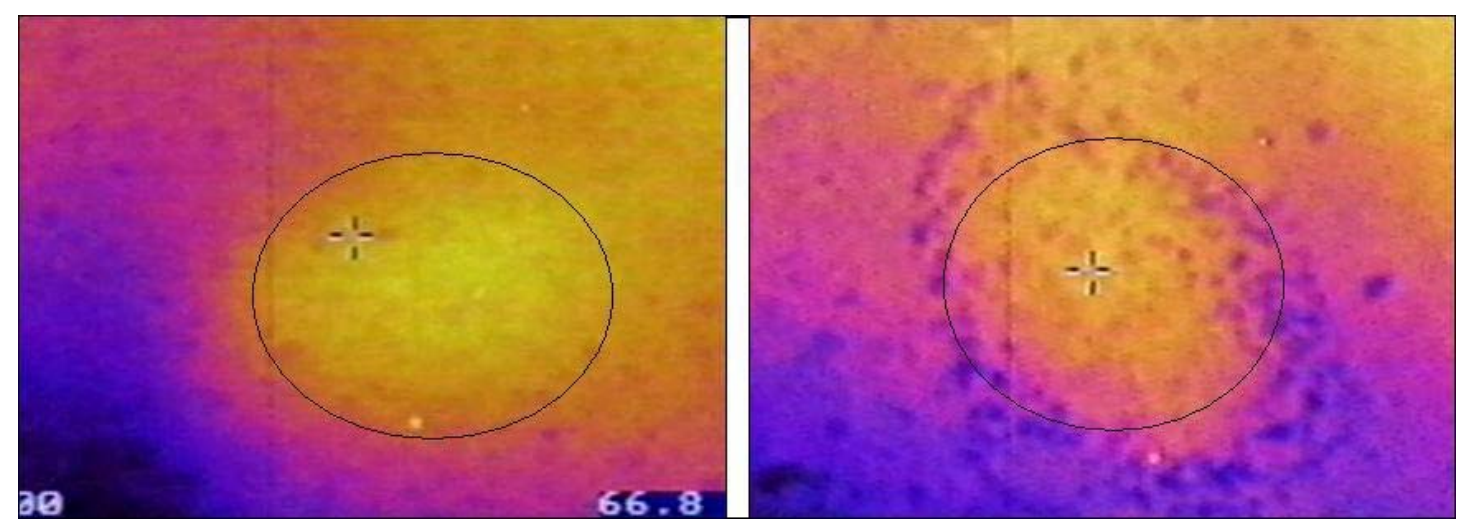

Figure 4.41 Infrared image of debond no.5 (a) before application of fatigue loads

(b) after application of fatigue loads

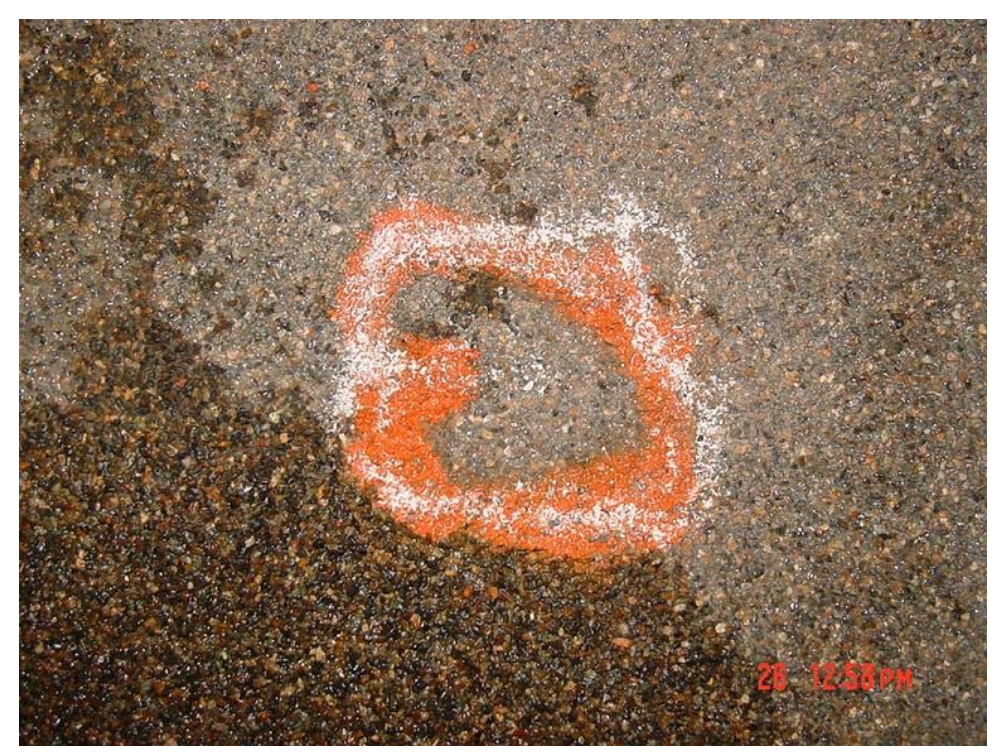

Figure 4.42 Photographic view of debond no.6.

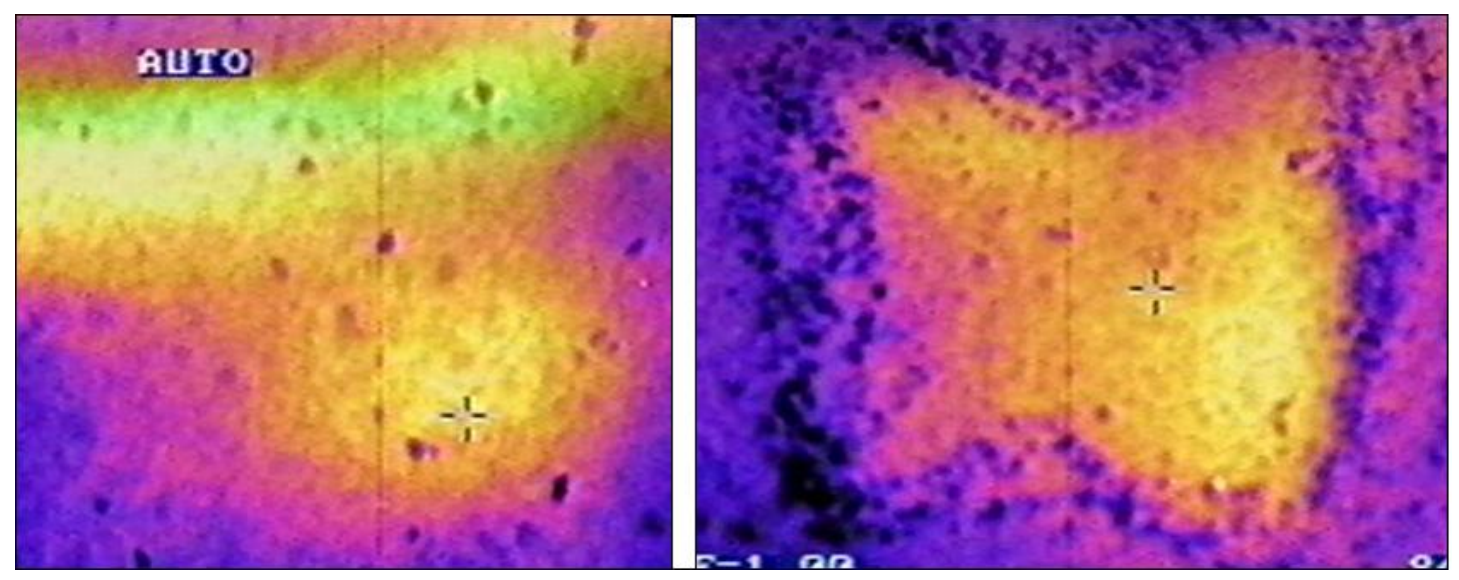

Figure 4.43 Infrared image of debond no.6 (a) before application of fatigue loads

(b) after application of fatigue loads 


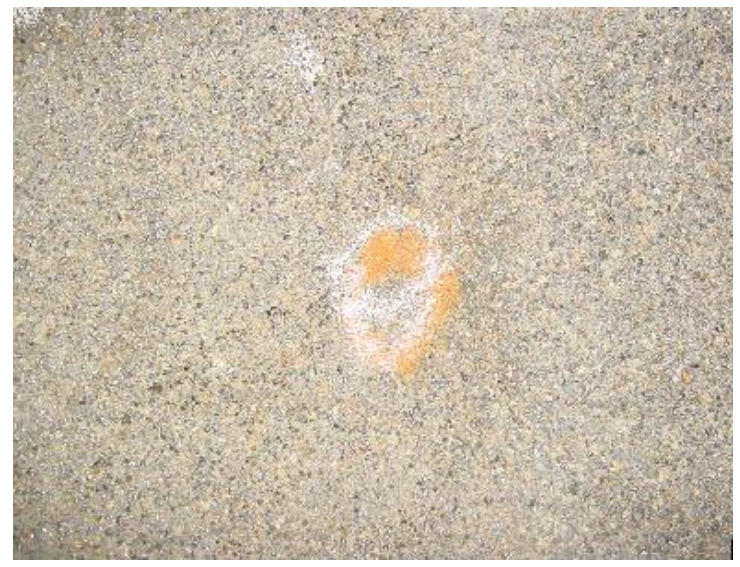

Figure 4.44 Photographic view of debond no.9
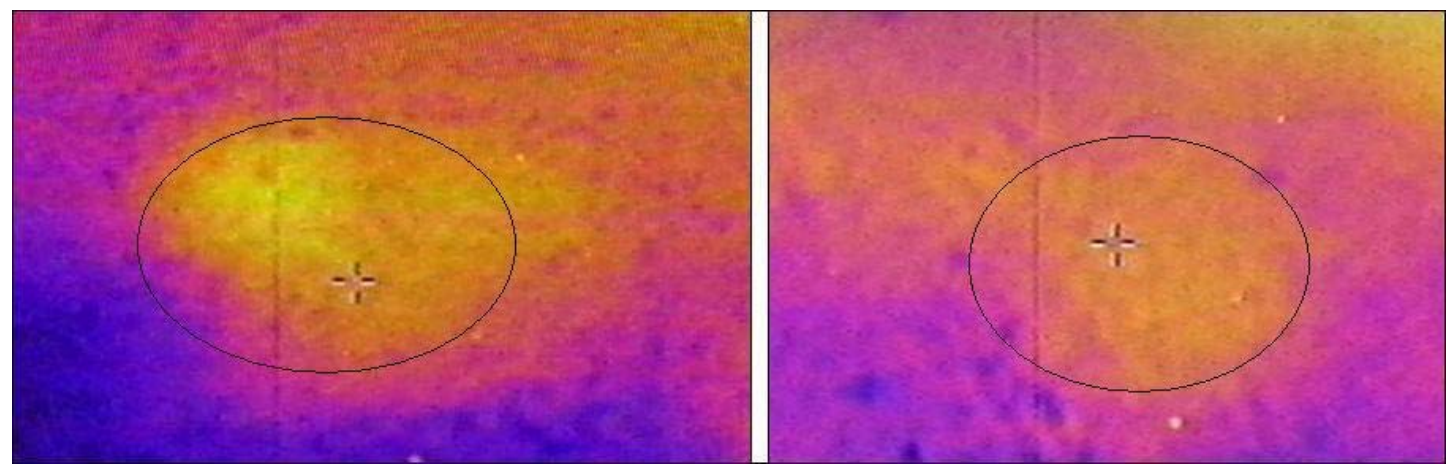

Figure 4.45 Infrared image of debond no.9 (a) before application of fatigue loads

(b) after application of fatigue loads

Debond no.7 (Figure 4.46) did not grow in size but another new debond and some cracks were detected near it. Figure 4.47 shows the infrared image of the debond no. 7 $(1 / 2 " \times 1 / 2$ " or $12.7 \mathrm{~mm} \times 12.7 \mathrm{~mm}$ in size) and the cracks propagating from it. Another debond of size approximately $1 / 4 " \times 1 / 4 "(6 \mathrm{~mm} \times 6 \mathrm{~mm})$ near the debond no.7 is also visible in the infrared image.

The infrared images of debonds no. 8 and no. 10 revealed that they grew in size after the application of fatigue loads. These debonds were located directly below the steel plates (patch loads). The debond no.8 (Figures 4.48 and 4.49) which was 2" x 2" (51mm x $51 \mathrm{~mm})$, had grown into $21 / 2 "$ x 3" $(63 \mathrm{~mm} \times 76 \mathrm{~mm})$ in size, after being loaded. The debond no.10 (Figures 4.50 and 4.51) which was also 2" x 2" (51mm x $51 \mathrm{~mm})$ in size, had grown into approximately a $2 \frac{1}{2}$ " x $3 \frac{1}{2} 2 "(63 \mathrm{~mm} \times 89 \mathrm{~mm})$ debond. 


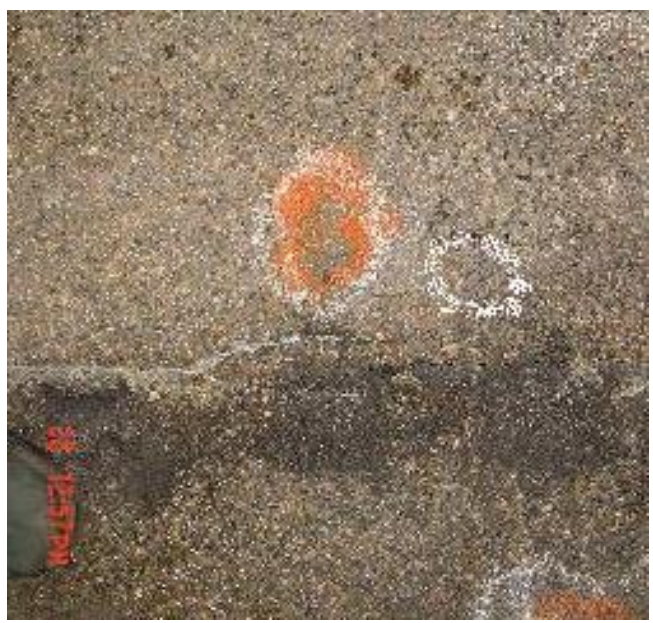

Figure 4.46 Photographic view of debond no.7 and the newly developed debond
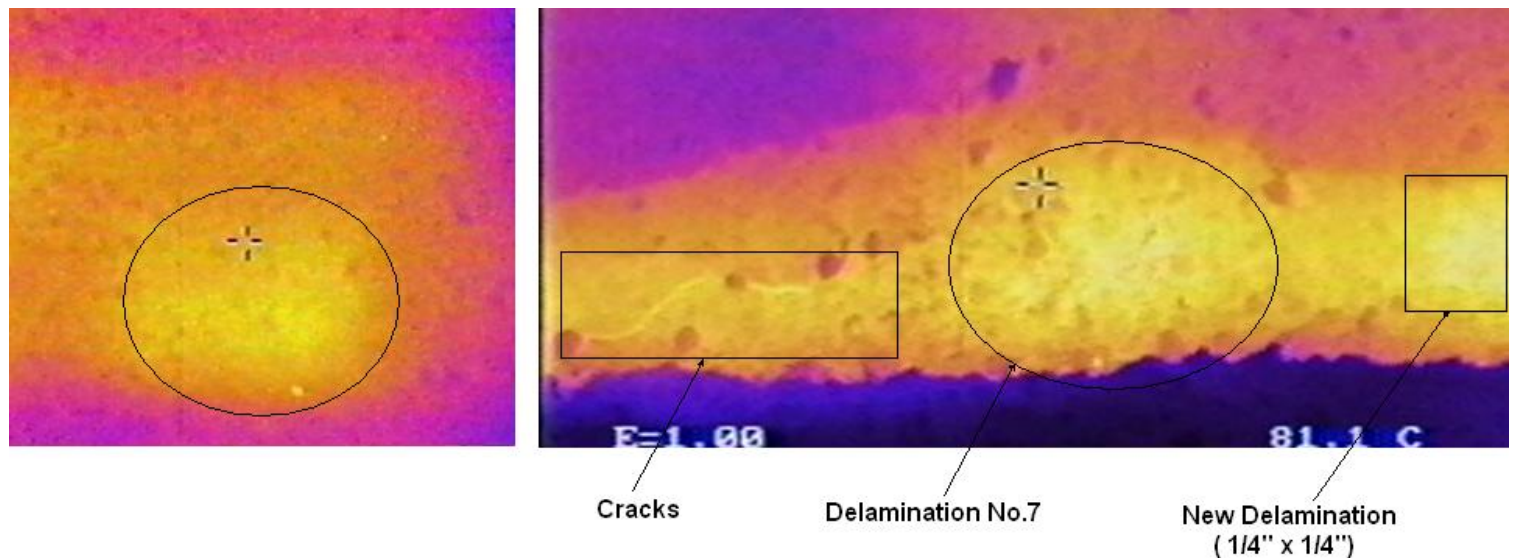

Figure 4.47 Infrared image of debond no.7 (a) before application of fatigue loads

(b) after application of fatigue loads

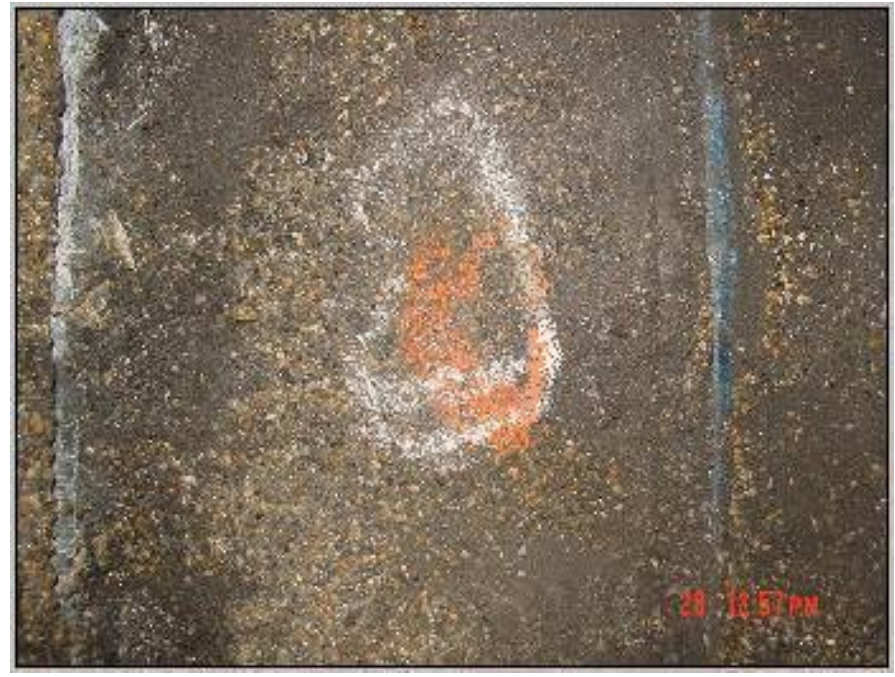

Figure 4.48 Photographic view of debond no.8 

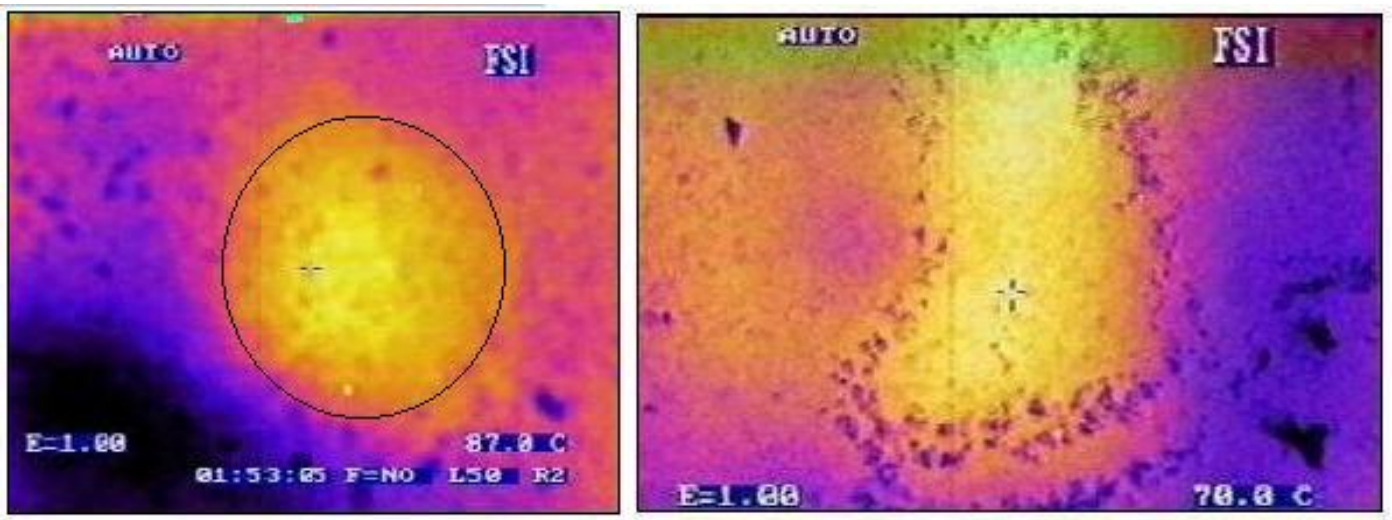

Figure 4.49 Infrared image of debond no.8 (a) before application of fatigue loads

(b) after application of fatigue loads

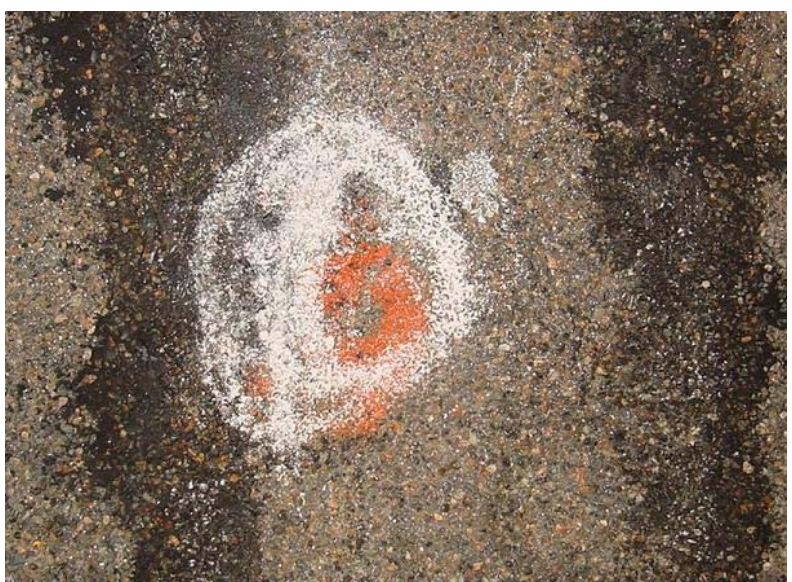

Figure 4.50 Photographic view of debond no.10

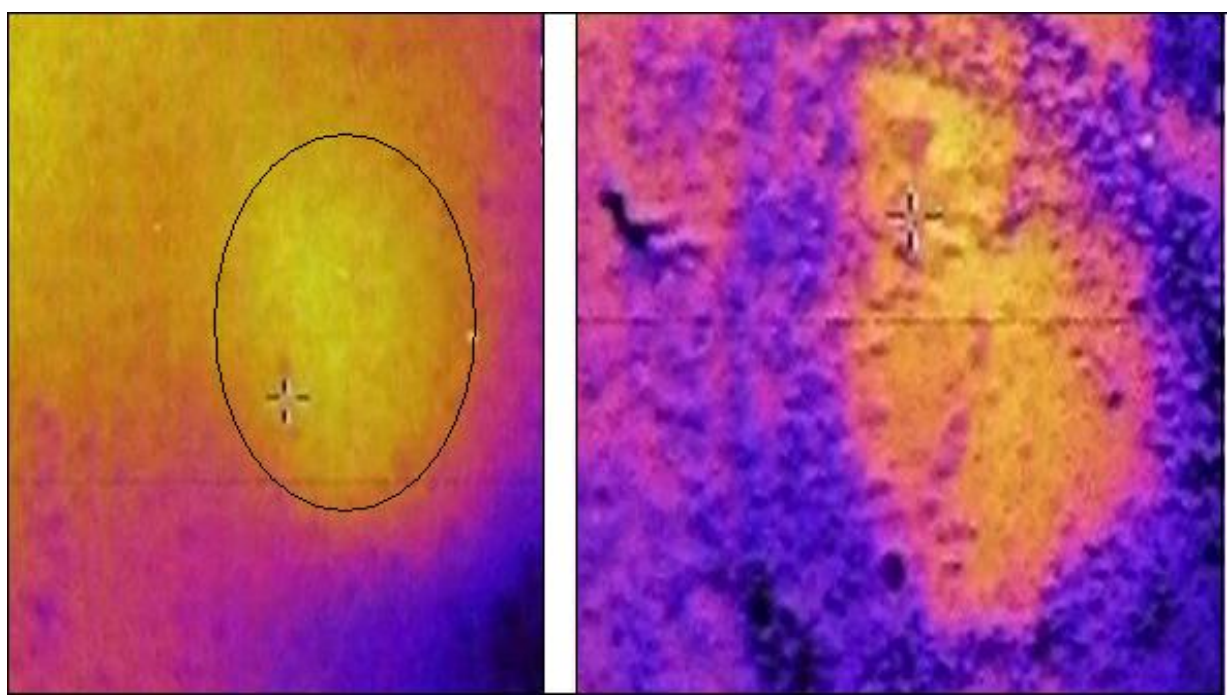

Figure 4.51 Infrared image of debond no.10 (a) before application of fatigue loads

(b) after application of fatigue loads 


\section{Bridge deck specimen FS2}

This specimen did not fail even after 2 million cycles of fatigue loading. The infrared images of the debonds were taken before and after the application of 2,000,000 cycles of fatigue loading. The specimen was heated using the 3' x 3' (914mm x 914mm) heating blanket prior to acquisition of the infrared images. The $1 / 2$ " $\times 1 / 2$ " $\times 1 / 16 "(12.7 \mathrm{~mm}$ x $12.7 \mathrm{~mm} \times 1.6 \mathrm{~mm}$ ) debond could not be detected at all by the infrared camera. This could have been due to the slightly thicker wearing surface layer (thickness greater than the usual $3 / 8$ " or $9 \mathrm{~mm}$ ), in the area underneath the patch loads, that was applied to prevent the local punching shear failure caused in the previous deck, FS1. The photograph and the infrared images (before and after loading) of the debonds of sizes 3" x 3" (76mm x 76mm), 2" x 2" (51 mm x 51mm) and 1" x 1" (25mm x 25mm), are shown in Figures 4.52 to 4.57 . The orange and white marking in the photographic views represent the shape of the debond, before and after the application of fatigue loads, respectively.

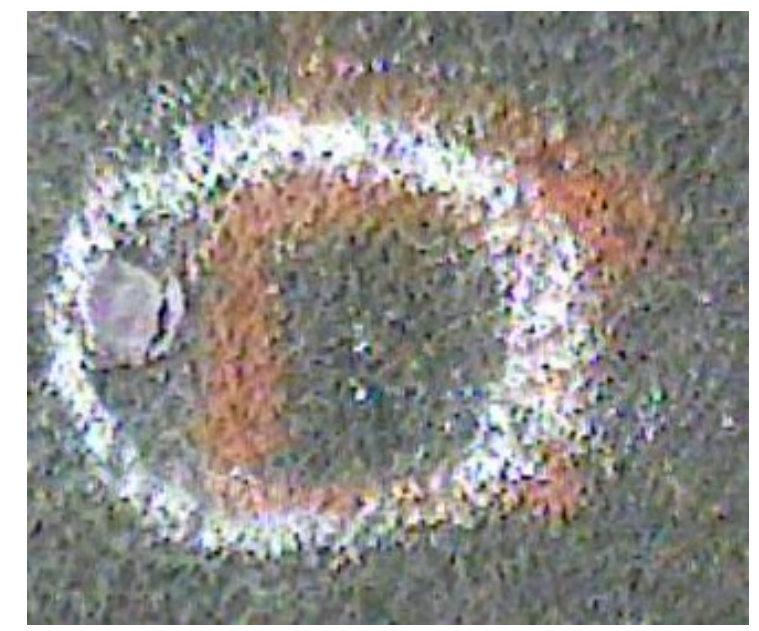

Figure 4.52 Photographic view of debond of size 3" x 3" x 1/16" 

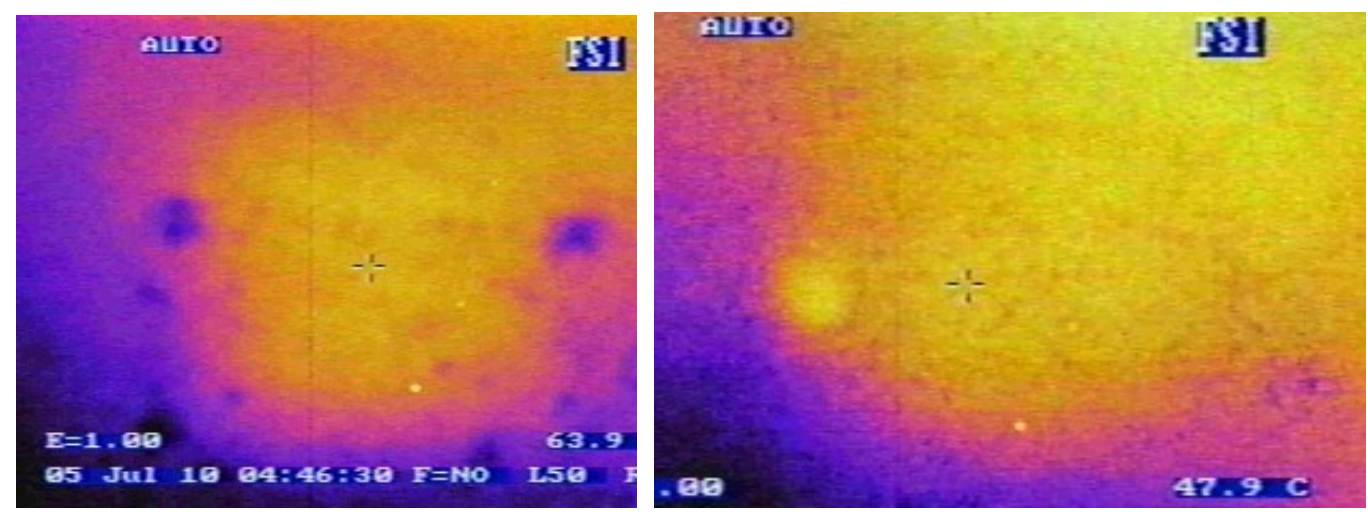

Figure 4.53 Infrared image of debond of size 3" x 3 " x 1/16" (a) before application of fatigue loads (b) after application of fatigue loads

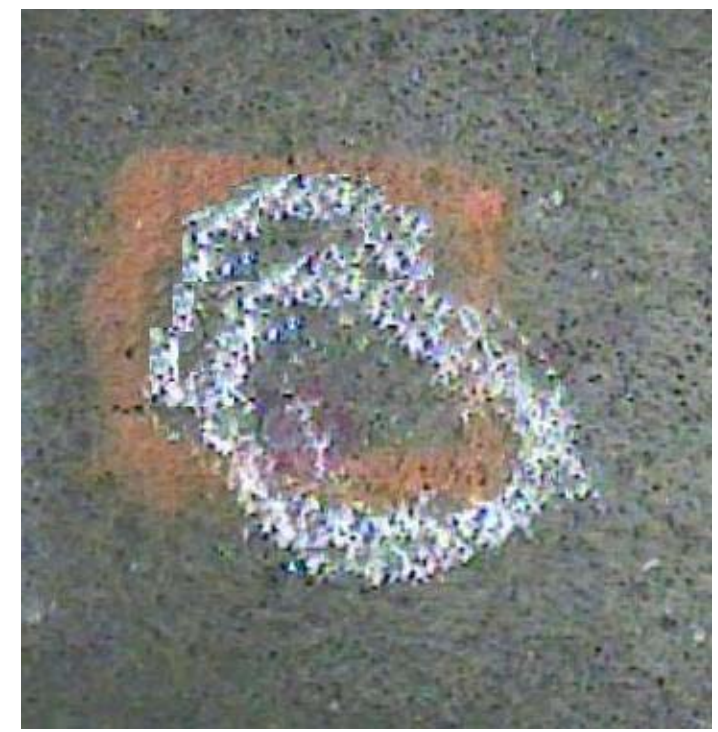

Figure 4.54 Photographic view of debond of size 2" x 2" x 1/16"

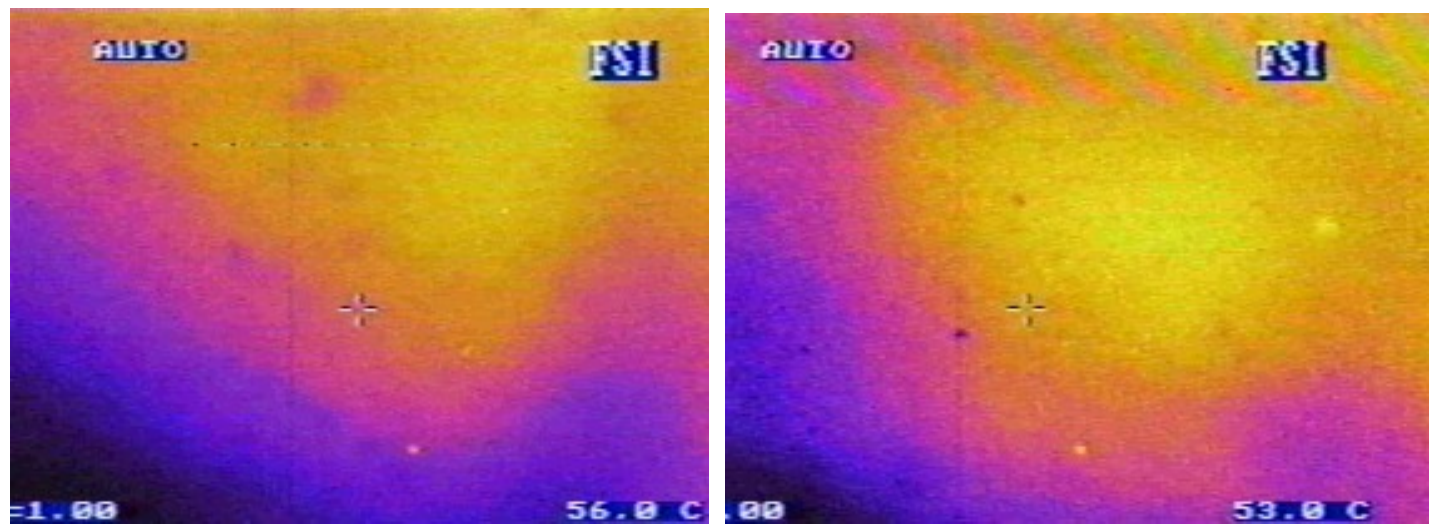

Figure 4.55 Infrared image of debond of size 2" x 2" x 1/16" (a) before application of fatigue loads

(b) after application of fatigue loads 


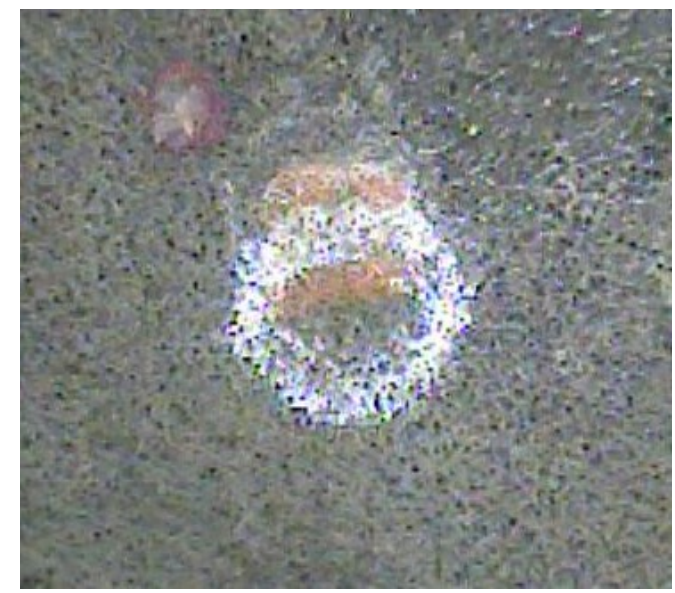

Figure 4.56 Photographic view of debond of size 1" x 1" x 1/16"
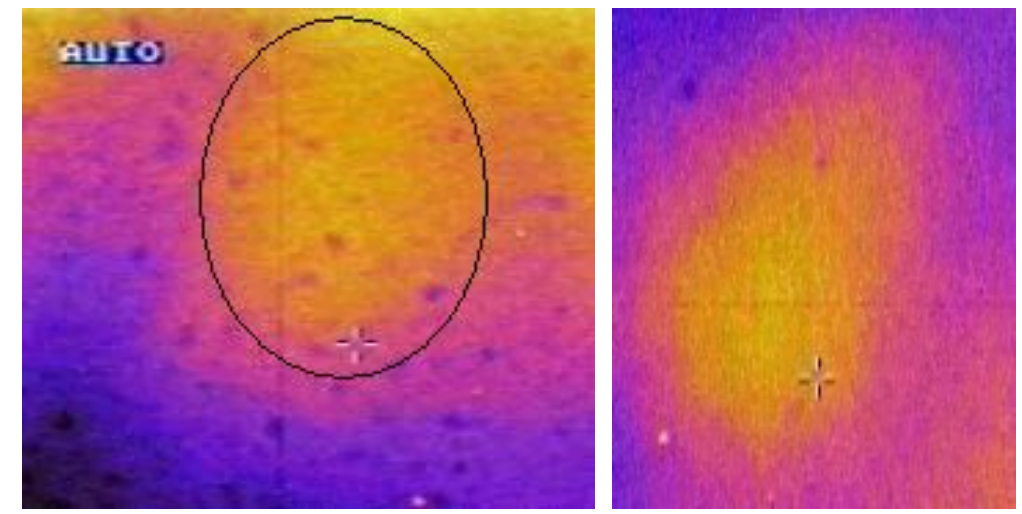

Figure 4.57 Infrared image of debond of size 1" x 1" x 1/16" (a) before application of fatigue loads

(b) after application of fatigue loads

The infrared images of the debonds, before and after loading showed that none of the debonds grew in size. The thickness of the wearing surface over a 3' x 3' (914 $\mathrm{mm} x$ $914 \mathrm{~mm}$ ) portion of the deck (underneath the patch loads) was greater than in case of the previous deck specimen, FS1. Hence the deck FS2 did not have any failure due to local punching shear. Hence these debonds which were located under the 3' x 3' $(914 \mathrm{~mm} \times$ $914 \mathrm{~mm}$ ) area did not grow in size.

\subsubsection{Conclusions}

The infrared technique can be successfully used to monitor debond growth before and after the application of fatigue loads. Some of the debonds (in FS1), that were located in the areas underneath the patch loads, grew in size and another small debond had also developed next to one of the existing debonds. None of the debonds that were located in 
deck FS2 grew in size before and after the application of the fatigue loads. This is because the wearing surface layer was made thicker under the patch loads in deck FS2 in order to avoid punching shear failure. Certain difficulties were encountered while marking the exact shape of the debonds, since the boundaries of the debonds were not clearly defined in the non-digital images. It should be noted that the fatigue tests were conducted before the acquisition of the new digital infrared camera. Use of the digital infrared camera could have enhanced the quality of the infrared images and provided better contrast between the defective and defect-free areas.

\subsection{INFRARED TESTS ON DECKS SUBJECTED TO ACCELERATED AGING}

Six specimens were subjected to accelerated aging effect. Infrared images of the debonds and delaminations were recorded before and after the specimens were subjected to accelerated aging. The infrared technique served as a method to monitor the growth of the debonds and the development of other cracks or debonds.

The decks were subjected to two types of aging conditions: Acidic immersion and Freeze-thaw conditioning. Each of the six bridge deck modules were subjected to either (or both) of the aging condition. Some of the specimens were immersed in $\mathrm{pH} 3$ (acidic) solution at room temperature (about $72^{\circ} \mathrm{F}$ or $22.2^{\circ} \mathrm{C}$ ) for a period of 6 months. The other specimens were subjected to the freeze-thaw conditioning inside the Thermotron environmental chamber (Figure 4.58a) and were placed either in dry condition or immersed in a solution (either water or acidic solution). The temperature and humidity cycle in the conditioning chamber was preset to particular cycle (as shown in Figure 4.58b). One complete cycle in the environmental chamber consisted for 5 days and 9 hours of conditioning, between different temperatures varying from $-29^{\circ} \mathrm{C}$ to $+49^{\circ} \mathrm{C}$ $\left(-20.2^{\circ} \mathrm{F}\right.$ to $\left.+120.2^{\circ} \mathrm{F}\right)$ and relative humidity between $20 \%$ and $70 \%$, as shown in figure $4.58 \mathrm{~b}$.

Aging studies were conducted by researchers at West Virginia University (Vijay and GangaRao 1999) which included experimental studies on GFRP bars, that could be used as reinforcement in concrete structures, that were subjected to the freeze-thaw conditioning in the same Thermotron environmental chamber with temperatures varying between $-11^{\circ} \mathrm{C}$ to $+49^{\circ} \mathrm{C}\left(12.2^{\circ} \mathrm{F}\right.$ to $\left.120.2^{\circ} \mathrm{F}\right)$. Based on the experimental studies, it was 
concluded that one day of chamber conditioning was equivalent to 18 days in natural U.K. weather or 17 days of natural weathering in Morgantown, WV (mean annual temperature over past 30 years is cited as $52.5^{\circ} \mathrm{F}$ ). However, if the glass fibers in GFRP bars are protected by better quality resin, then a conservative time scale factor of 2 is specified (Vijay and GangaRao 1999). This means one day of chamber conditioning for GFRP bars with good quality resin is approximately equivalent to 34 days of natural weathering in Morgantown, WV or 36 days under U.K. weather (Vijay and GangaRao 1999). Previous study by Litherland et al. (1981) has compared the effect of weather in different parts of the world for GFRP strands embedded in cement representative and suggested that the guiding parameter in freeze-thaw aging is the weighted average temperature (T). Based on this principle, an exponential equation of the form shown in Equation 4.1 has been proposed (Litherland et al. 1981). For a weighted average temperature of $93.68^{\circ} \mathrm{F}\left(34.27^{\circ} \mathrm{C}\right)$ in the chamber, Equation 4.1 predicts that one day of chamber conditioning is equivalent to 18 days of natural U.K. weathering, which is considered same as 17 days of Morgantown, WV weather.

Age in Natural Days/Day of Chamber Conditioning $=y=0.098 \mathrm{e}^{0.0558 \mathrm{~T}}$......(4.1) where, $\mathrm{T}=$ weighted average temperature over the entire cycle in ${ }^{\circ} \mathrm{F}$.

Past accelerated aging studies (Vijay and GangaRao 1999) using submerged solution for GFRP bars in concrete used alkaline solution (as opposed to acidic solution used here) since concrete provides an alkaline environment. Studies have also shown that acid reacts slower with glass when compared to reaction of glass with alkali (that is, alkaline attack is more severe). There is not much difference between the effect of low acidic $\mathrm{pH}$ and that of $\mathrm{pH} 5$ to 6 (Adams 1984). 


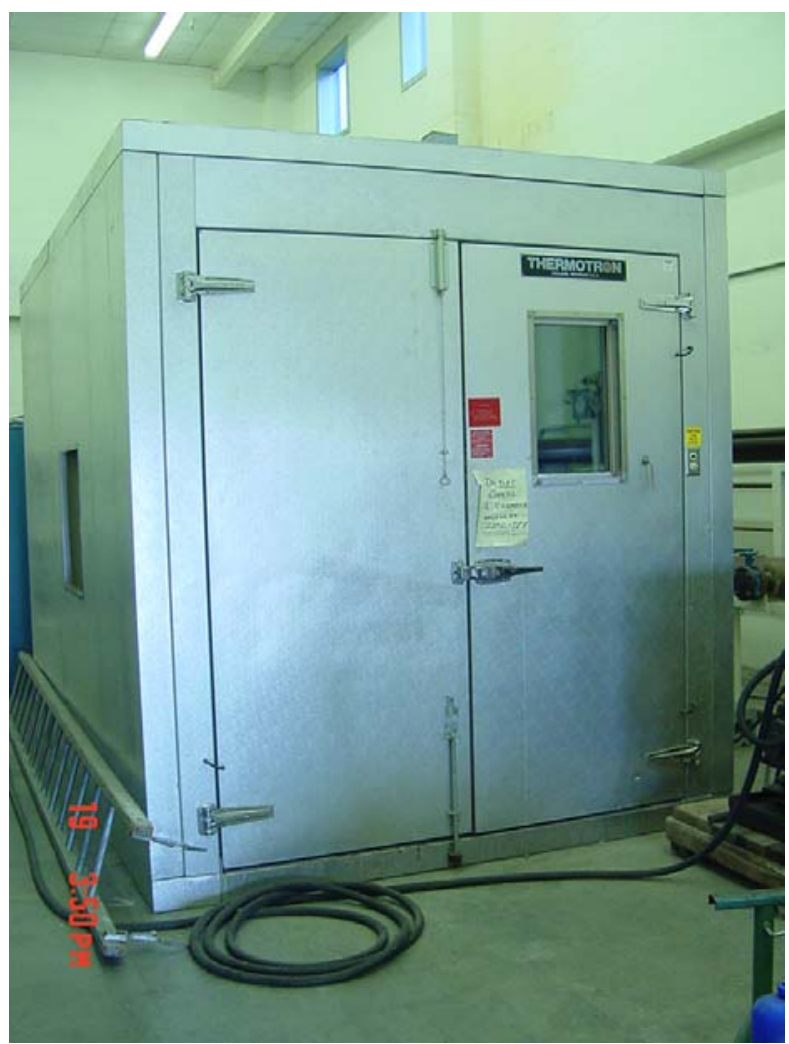

Figure 4.58(a). Thermotron environmental chamber

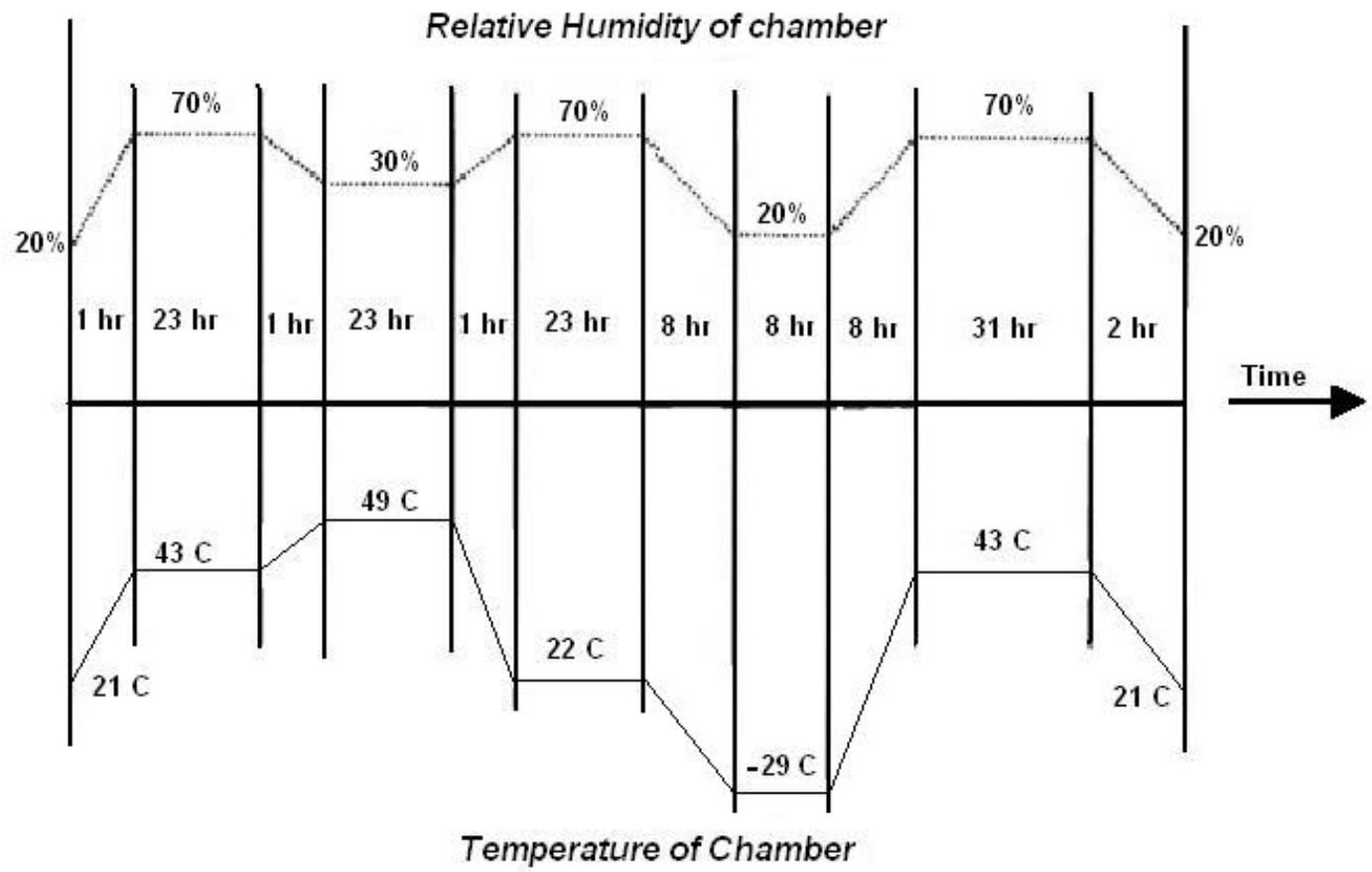

Figure 4.58(b). Temperature and humidity cycle inside the environmental chamber 


\subsubsection{Description of Specimens and their Conditioning}

The specimens that were subjected to accelerated aging tests had embedded debonds and delaminations of different plan sizes, as described below. A summary of the specimen configurations and the corresponding accelerated aging conditions are given in Table 4.6.

\section{Bridge deck specimen AS1}

Specimen AS1 was a GFRP bridge deck module of plan size 12" x 24" (0.3m x $0.6 \mathrm{~m})$ and $3 / 8 "(9.5 \mathrm{~mm})$ thick wearing surface layer on both the sides (AS1a and AS1b). This specimen has material properties similar to specimen BD1 (described in Section 4.4.1). Side AS1a had two debonds of sizes 3" x 3" x 1/16" (76mm x 76mm x 1.6mm) and 2" x 2" x 1/16" (51mm x 51mm x 1.6mm), placed between the wearing surface and the underlying deck. Side AS1b did not have any debonds and was used as a control specimen. This specimen was subjected to 6 cycles of freeze-thaw conditioning by placing it inside the environmental chamber.

\section{Bridge deck specimen AS2}

Specimen AS2 was a GFRP bridge deck module of plan size 12" x 24" (0.3m x $0.6 \mathrm{~m}$ ) with material properties similar to deck JD1, as described in Section 4.5.1. This deck did not have wearing surface overlay on either side. Side AS2a had two delaminations of sizes 1" x 1" x 1/16" (25mm x $25 \mathrm{~mm}$ x 1.6mm) and 2" x 2" x 1/16" $(51 \mathrm{~mm} \times 51 \mathrm{~mm} \times 1.6 \mathrm{~mm})$, created at the flange-flange junction between two modules using the method described in Section 4.2. Side AS2b did not have any delaminations and was used as control specimen. This specimen was subjected to 6 cycles of freeze-thaw conditioning by placing it inside the environmental chamber.

\section{Bridge deck specimen AS3}

Specimen AS3 was a GFRP bridge deck module of plan size 12 x 24 " $(0.3 \mathrm{~m}$ x $0.6 \mathrm{~m}$ ) with material properties similar to deck BD2, described in Section 4.4.1. Side AS3a had one delamination of size 3" x 3" x 1/16" (76mm x 76mm x 1.6mm) created at

the flange-flange junction between two modules and did not have any wearing surface 
overlay. The other side AS3b had a debond of size 3" x 3" x 1/16" (76mm x 76mm x $1.6 \mathrm{~mm}$ ) between the wearing surface layer and underlying deck. This specimen was immersed in tap water and the container was then placed inside the environmental chamber for the freeze-thaw conditioning.

\section{Bridge deck specimen AS4}

Specimen AS4 was a GFRP bridge deck module of plan size 12 " x 24 " $(0.3 \mathrm{~m}$ x $0.6 \mathrm{~m}$ ) with $3 / 8$ " (9.5mm) thick wearing surface layer on both the sides (AS4a and AS4b). This specimen has material properties similar to specimen BD1 (described in Section 4.4.1). Side AS4a had two debonds of sizes 3" x 3" x 1/16" (76mm x 76mm x 1.6mm) and 1" x 1" x 1/16" (25mm x 25mm x 1.6mm), placed between the wearing surface and the underlying deck. The other side AS4b did not have any debonds. This specimen was kept immersed in a Hydrochloric acid $(\mathrm{HCl})$ solution of $\mathrm{pH} 3$ strength, inside a container. The specimen was left for a period of 6 months, at room temperature $\left(72^{\circ} \mathrm{F}\right.$ or $\left.22.2^{\circ} \mathrm{C}\right)$.

\section{Bridge deck specimen AS5}

Specimen AS5 was a GFRP bridge deck module of plan size 8" x 24 " $(0.2 \mathrm{~m}$ x $0.6 \mathrm{~m}$ ) with material properties similar to deck JD1, described in Section 4.5.1. Side AS5a had one delamination of size $3 "$ × $3 "$ x 1/16" (76mm x 76mm x $1.6 \mathrm{~mm})$ created at the flange-flange junction of two modules, created using the method described in Section 4.2. The other side AS5b did not have any delaminations. This specimen was also kept immersed in the acidic solution of $\mathrm{pH} 3$ strength, at room temperature $\left(72^{\circ} \mathrm{F}\right.$ or $\left.22.2^{\circ} \mathrm{C}\right)$, for a period of 6 months.

\section{Bridge deck specimen AS6}

Specimen AS6 was a GFRP bridge deck module of plan size 8" x $24 "(0.2 \mathrm{~m}$ x $0.6 \mathrm{~m}$ ) with material properties similar to deck BD2, described in Section 4.4.1. Side AS6a had one delamination of size 2" x 2" x 1/16" (51mm x $51 \mathrm{~mm} \times 1.6 \mathrm{~mm})$ created at the flange-flange junction between two modules and without any wearing surface overlay. The other side AS6b had one debond of size 2" x 2" x 1/16" $(51 \mathrm{~mm}$ x $51 \mathrm{~mm}$ x $1.6 \mathrm{~mm})$ underneath a $3 / 8 "(9.5 \mathrm{~mm})$ thick wearing surface overlay. This specimen was 
Table 4.6. Accelerated aging test specimens and aging conditions

\begin{tabular}{|c|c|c|c|c|c|c|c|}
\hline \multicolumn{8}{|c|}{ Specimens for the Freeze-Thaw cycle } \\
\hline \multirow{2}{*}{$\begin{array}{c}\text { Spec } \\
\# \\
\end{array}$} & \multirow{2}{*}{$\begin{array}{c}\text { Material } \\
\text { Type }\end{array}$} & \multirow{2}{*}{\begin{tabular}{|c} 
Module \\
Size \\
\end{tabular}} & \multicolumn{2}{|r|}{ Side 1} & \multicolumn{2}{|r|}{ Side 2} & \multirow[t]{2}{*}{ Condition } \\
\hline & & & Surface & Defect size and type & Surface & Defect size and type & \\
\hline AS 1 & GFRP & $12^{\prime \prime} \times 24 "$ & with WS & 3" x 3" x 1/16" \& 2" x 2" x 1/16" (debonds) & with WS & none & Dry \\
\hline AS2 & GFRP & $12^{\prime \prime} \times 24^{\prime \prime}$ & no WS & 2" x 2" x 1/16" \& 1" x 1" x 1/16"(delaminations) & no WS & none & Dry \\
\hline AS3 & GFRP & $12^{\prime \prime} \times 24^{\prime \prime}$ & no WS & 3" x 3" x 1/16" (delamination) & with WS3 & " x 3" x 1/16"(debond) & Under Tap Water \\
\hline \multicolumn{8}{|c|}{ Specimens kept submerged in ph 3 solution } \\
\hline \multirow{2}{*}{$\begin{array}{c}\text { Spec } \\
\# \\
\end{array}$} & \multirow{2}{*}{$\begin{array}{c}\text { Material } \\
\text { Type }\end{array}$} & \multirow{2}{*}{\begin{tabular}{|c} 
Module \\
Size \\
\end{tabular}} & \multicolumn{2}{|r|}{ Side 1} & \multicolumn{2}{|r|}{ Side 2} & \multirow[t]{2}{*}{ Condition } \\
\hline & & & Surface & Defect size and type & Surface & Defect size and type & \\
\hline AS4 & GFRP & $12^{\prime \prime} \times 24 "$ & with WS & 3" x 3"x1/16" \& 1" x 1"x1/16" (debonds) & with WS & none & Room Temp \\
\hline AS5 & GFRP & $8 " \times 24 "$ & no WS & 3" x 3" x 1/16" (delamination) & no WS & none & Room Temp \\
\hline AS6 & GFRP & $8 " \times 24 "$ & no WS & 2" x 2" x 1/16" (delamination) & with WS 2 & " x 2" x 1/16"(debond) & Freeze-Thaw cycle \\
\hline
\end{tabular}


kept immersed in $\mathrm{pH} 3$ solution and then placed inside the environmental chamber for 6 cycles of the freeze-thaw conditioning.

\subsubsection{Infrared Tests and Results}

The infrared tests for all the specimens were conducted before and after aging to monitor the growth of any debonds or delaminations. Tests on specimens AS1, AS2, AS3 and AS6 were conducted before and after the decks were subjected to 6 cycles of freezethaw conditioning. Monitoring for the specimens AS4 and AS5 were done after periods of 1 month, 3 months and 6 months. Figures 4.59 to 4.69 shows the infrared images of these specimens (both sides) with the embedded debonds or delaminations before and after aging.
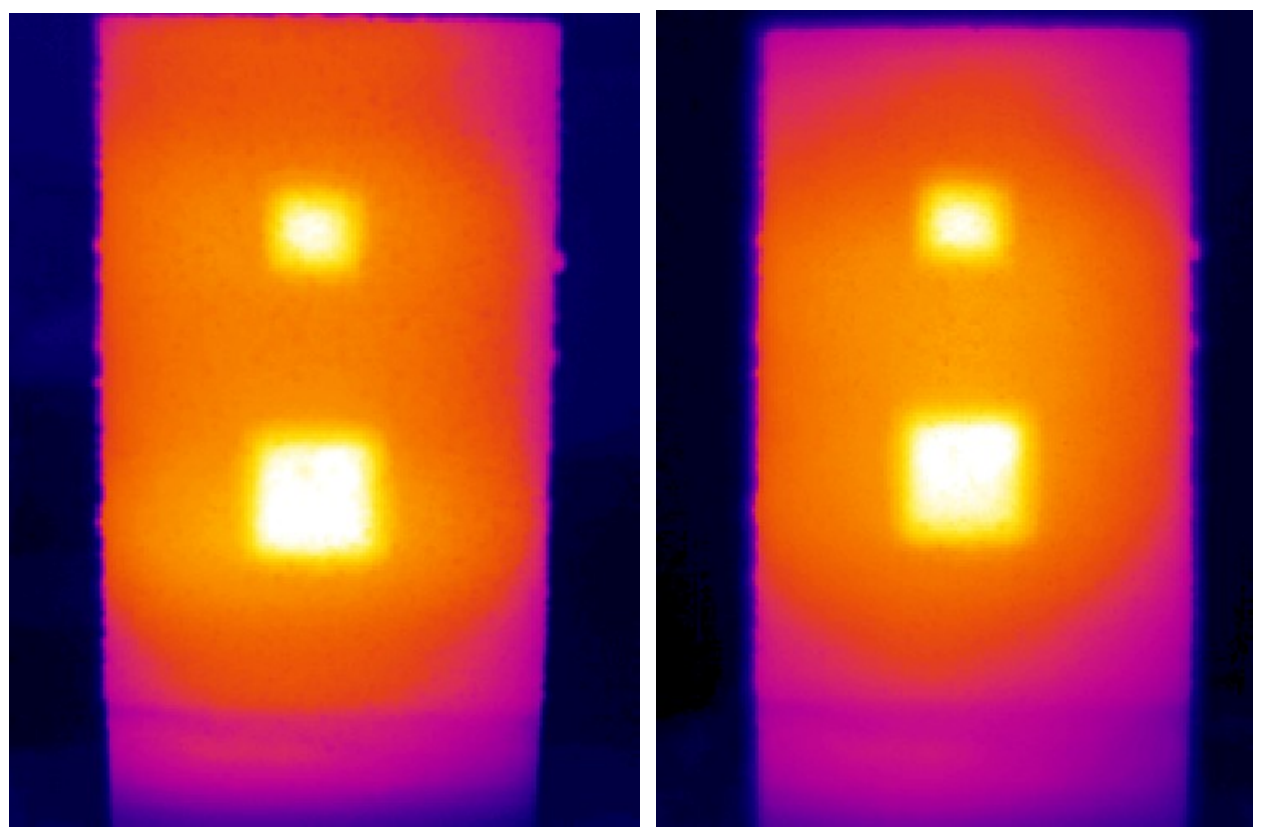

Figure 4.59 Infrared image of specimen AS1-side 1 (a) before freeze-thaw conditioning (b) after 6 cycles of freeze-thaw conditioning aging 


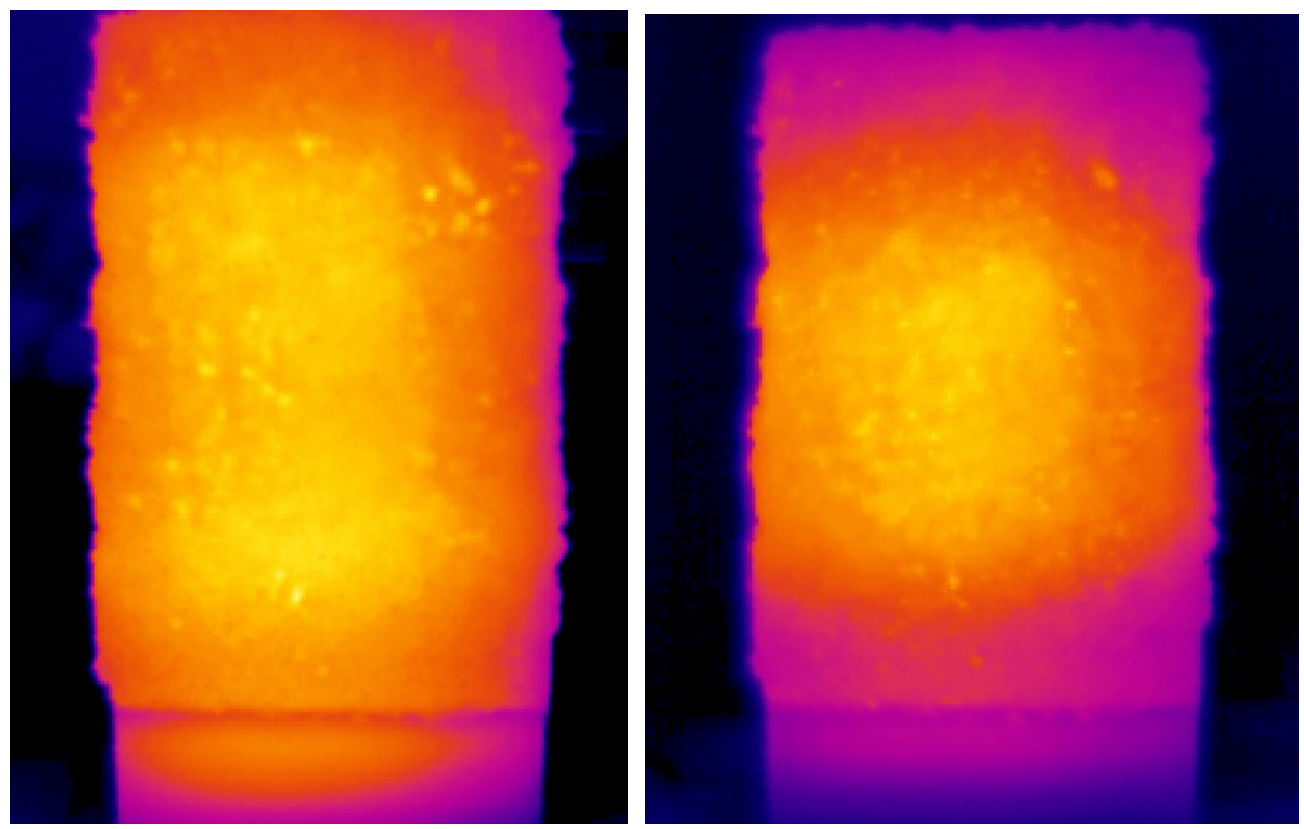

Figure 4.59 Infrared image of specimen AS1-side 2 (c) before freeze-thaw conditioning (d) after 6 cycles of freeze-thaw conditioning aging
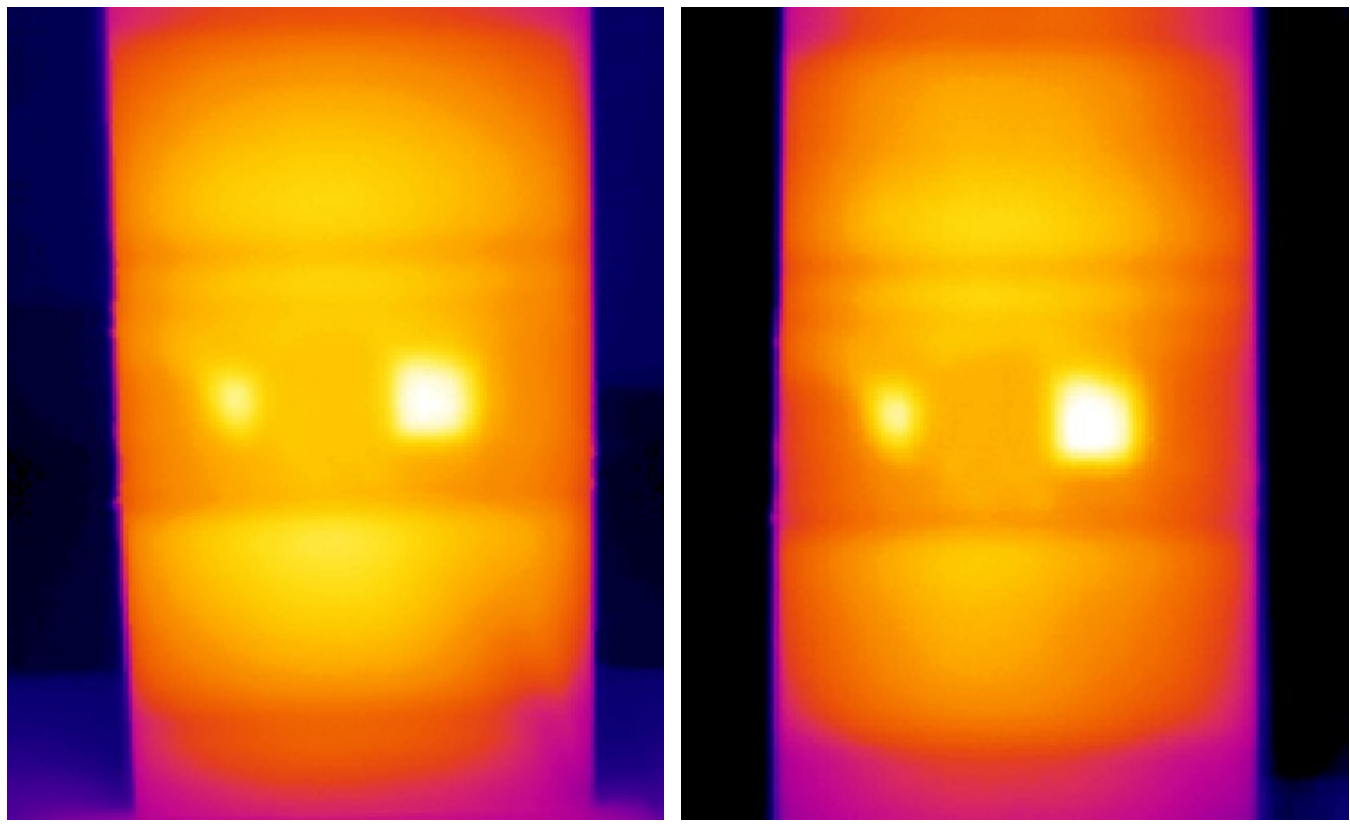

Figure 4.60 Infrared image of specimen AS2-side 1 (a) before freeze-thaw conditioning (b) after 6 cycles of freeze-thaw conditioning aging 


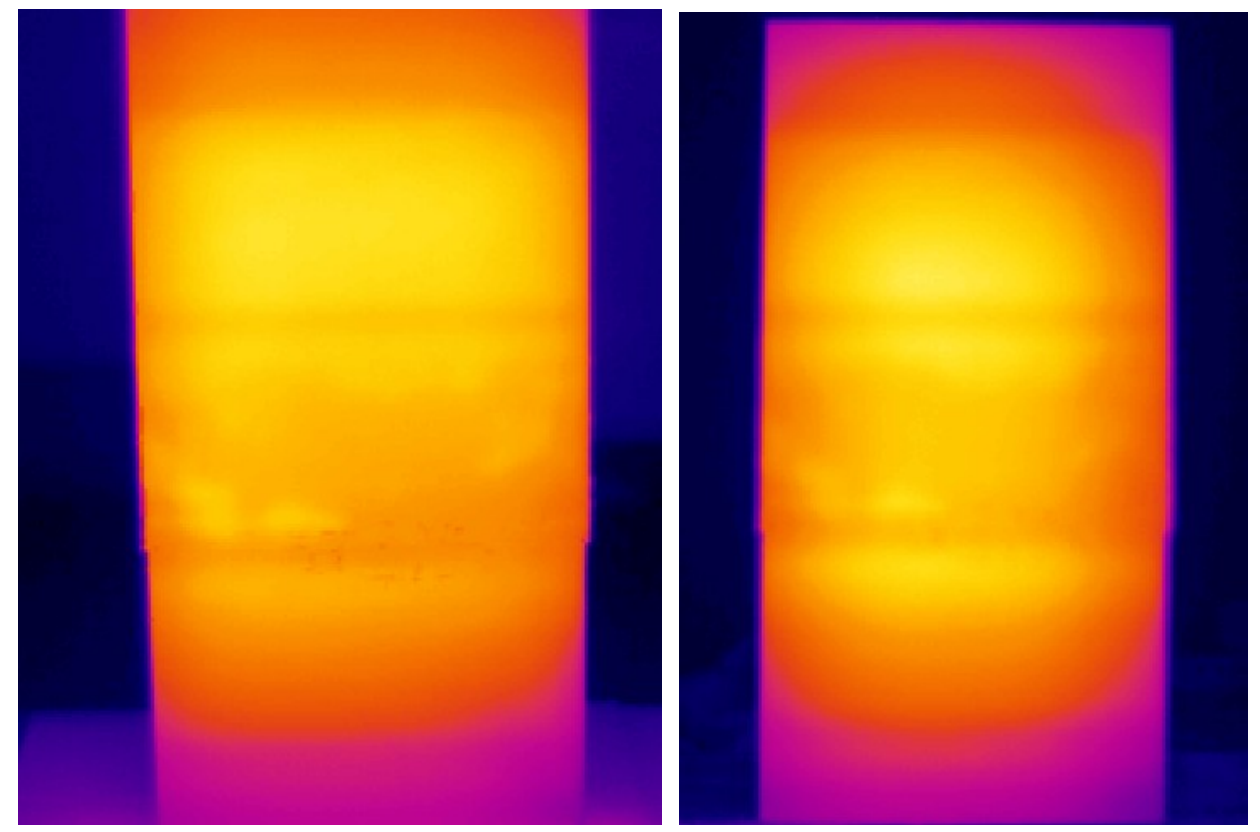

Figure 4.61 Infrared image of specimen AS2-side 2 (a) before freeze-thaw conditioning (b) after 6 cycles of freeze-thaw conditioning aging

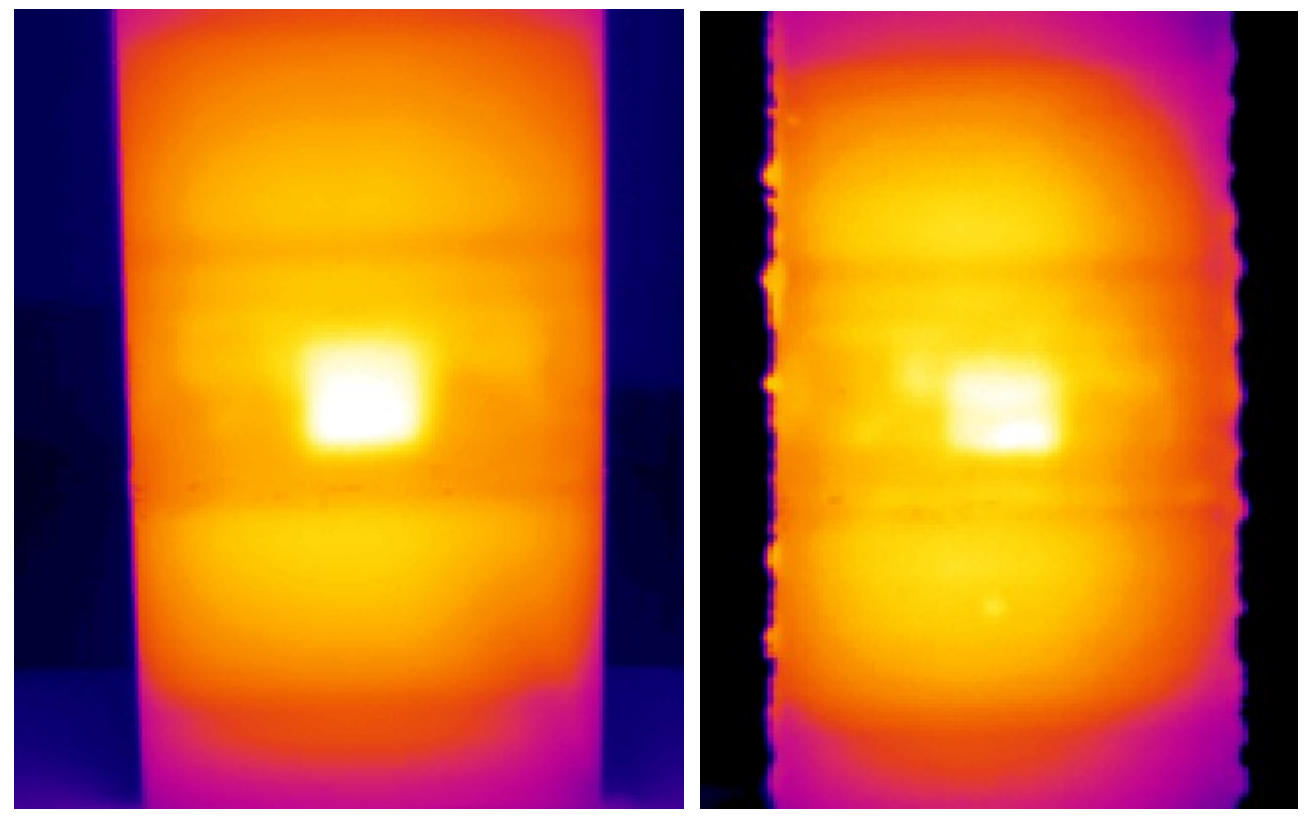

Figure 4.62 Infrared image of specimen AS3-side 1 (a) before freeze-thaw conditioning (b) after 6 cycles of freeze-thaw conditioning aging 


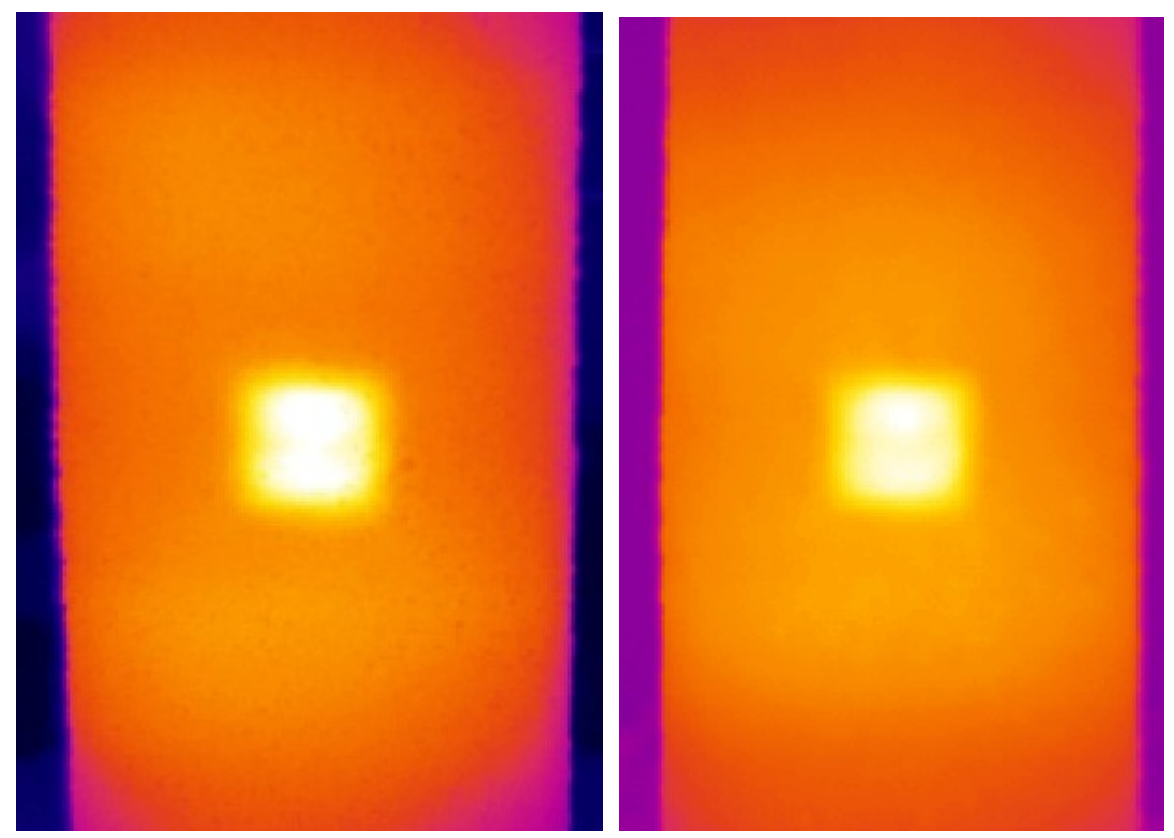

Figure 4.63 Infrared image of specimen AS3-side 2 (a) before freeze-thaw conditioning (b) after 6 cycles of freeze-thaw conditioning aging

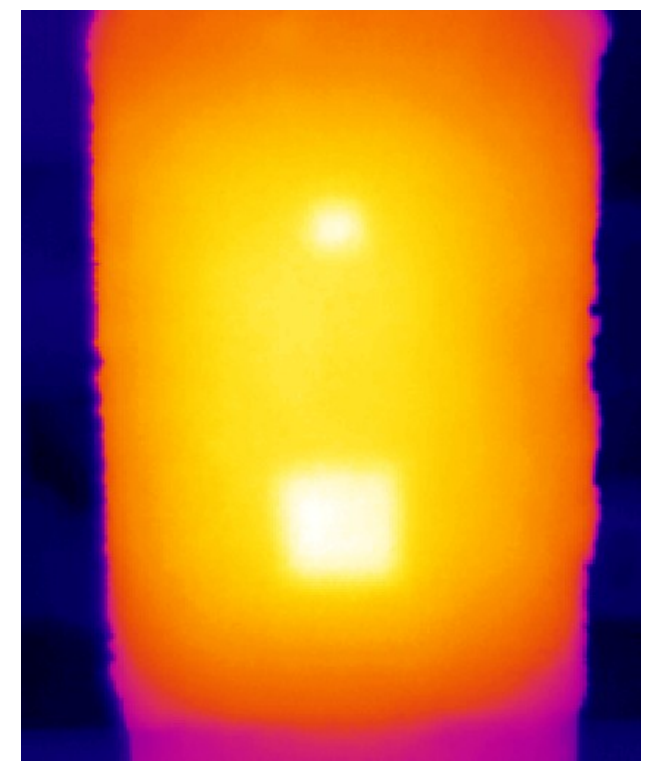

(a)

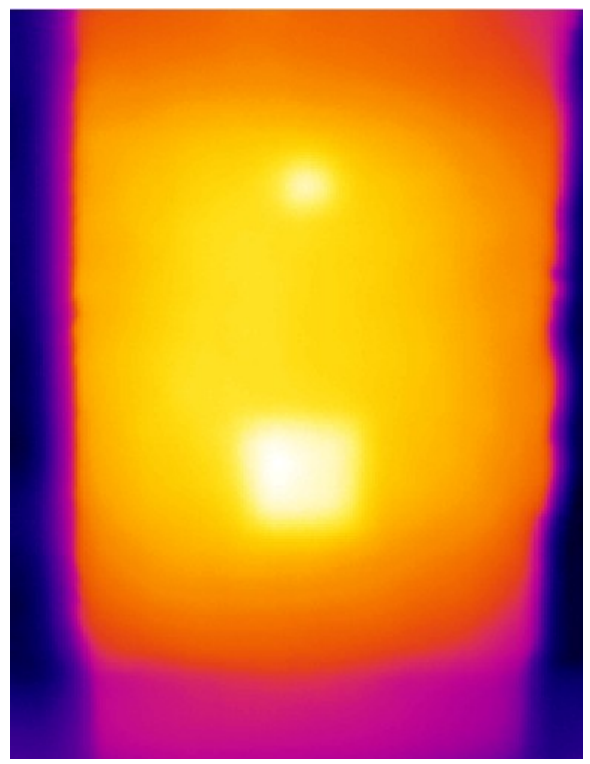

(b) 


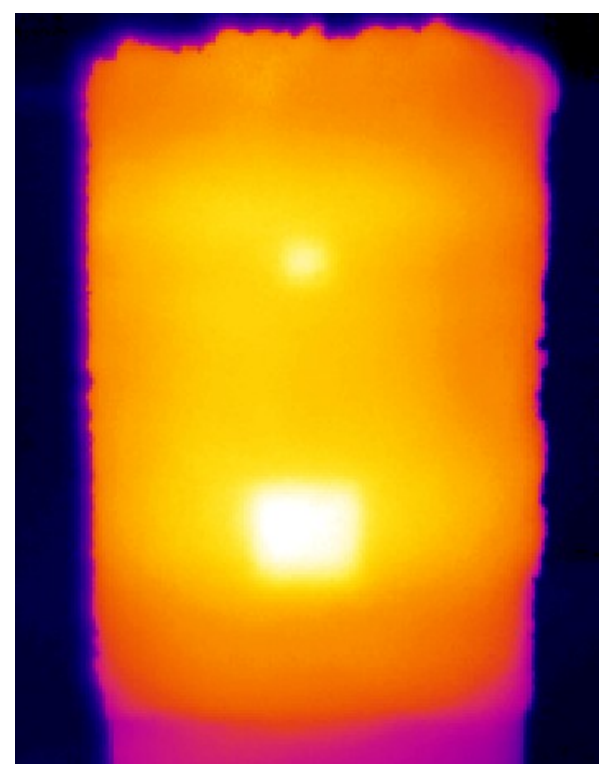

(c)

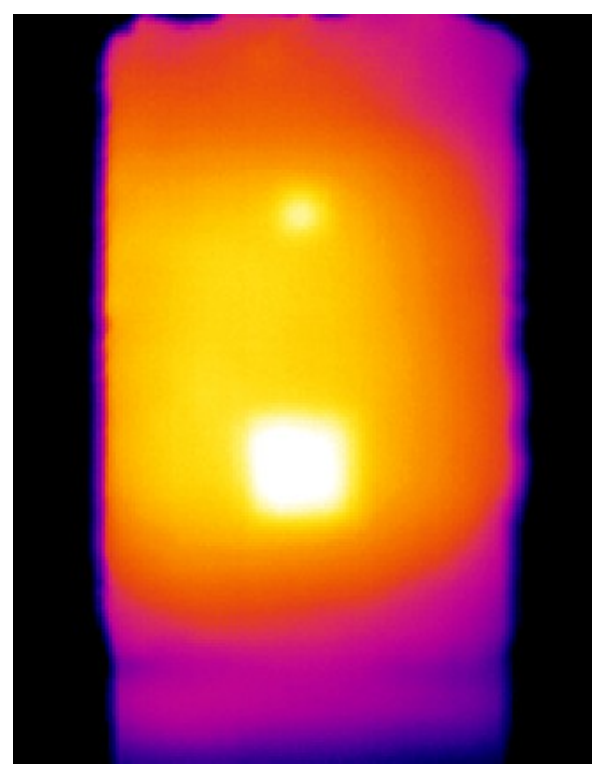

(d)

Figure 4.64 Infrared image of specimen AS4-side 1 (a) before immersion (b) after 1 month (c) after 3 months (d) after 6 months

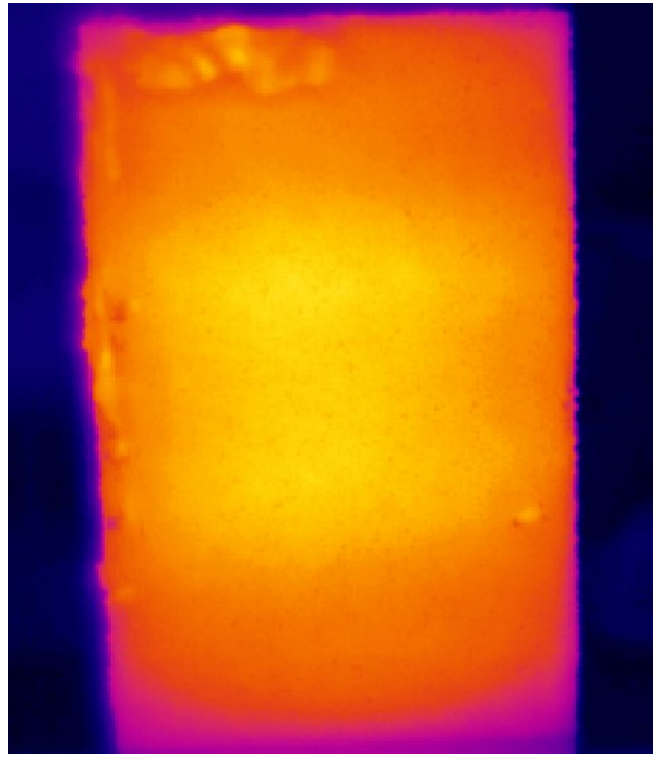

(a)

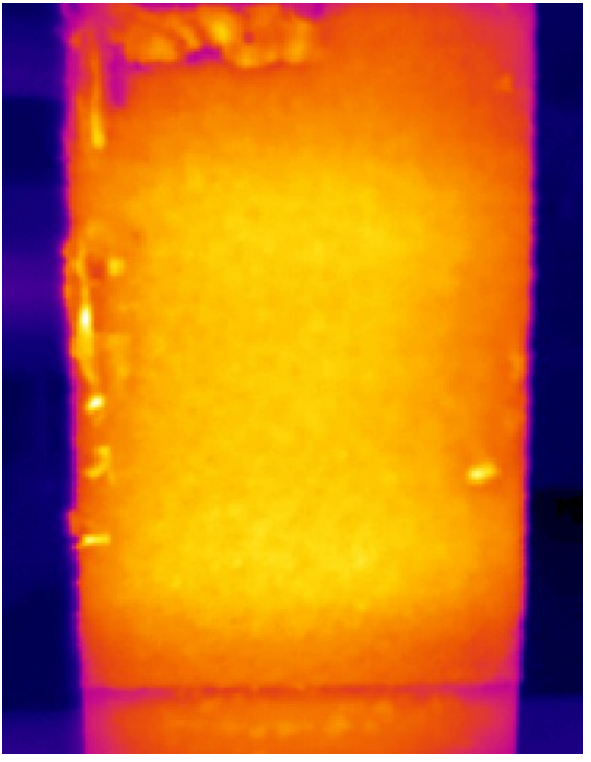

(b) 


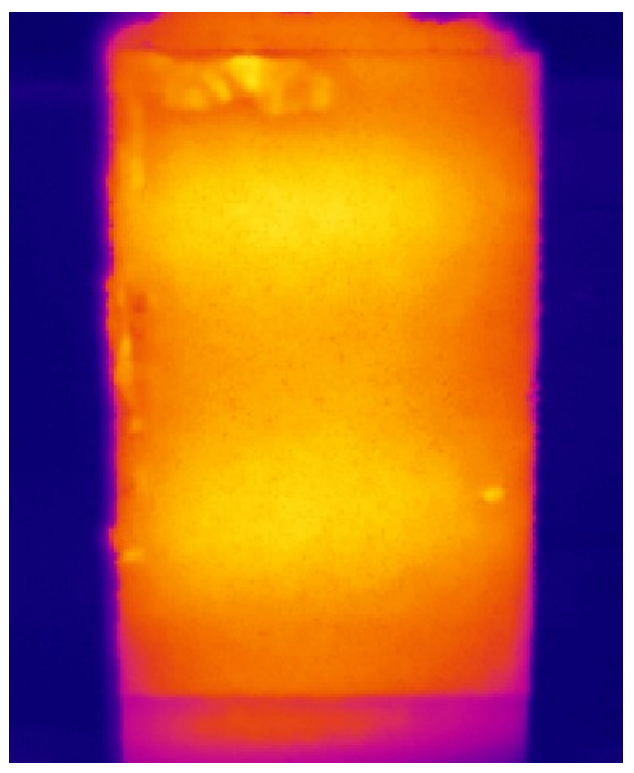

(c)

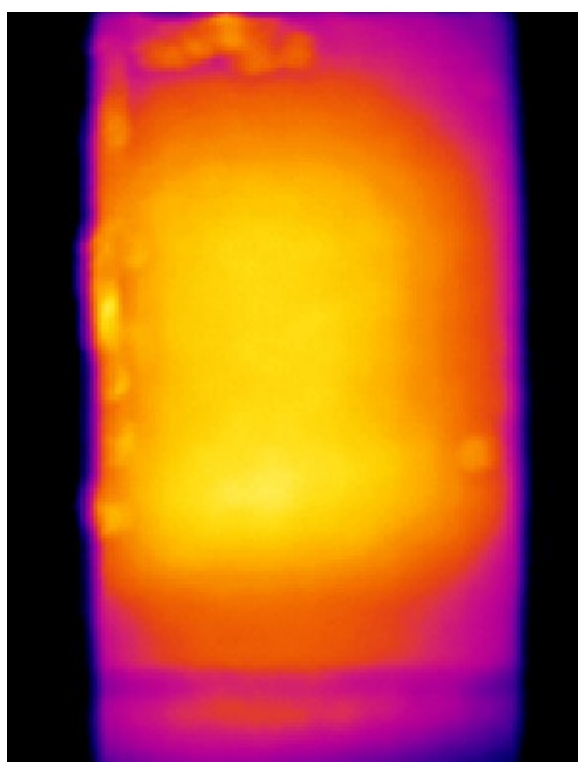

(d)

Figure 4.65 Infrared image of specimen AS4-side 2 (a) before immersion (b) after 1 month (c) after 3 months (d) after 6 months
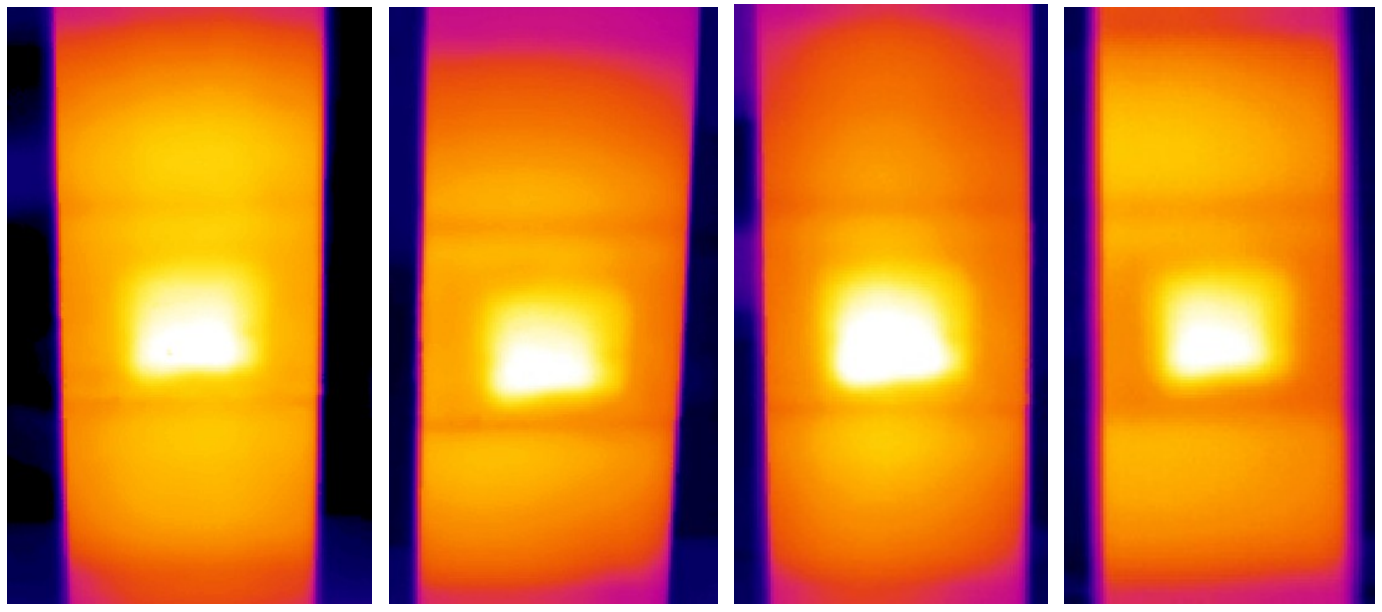

Figure 4.66 Infrared image of specimen AS5-side 1 (a) before immersion (b) after 1 month (c) after 3 months (d) after 6 months 

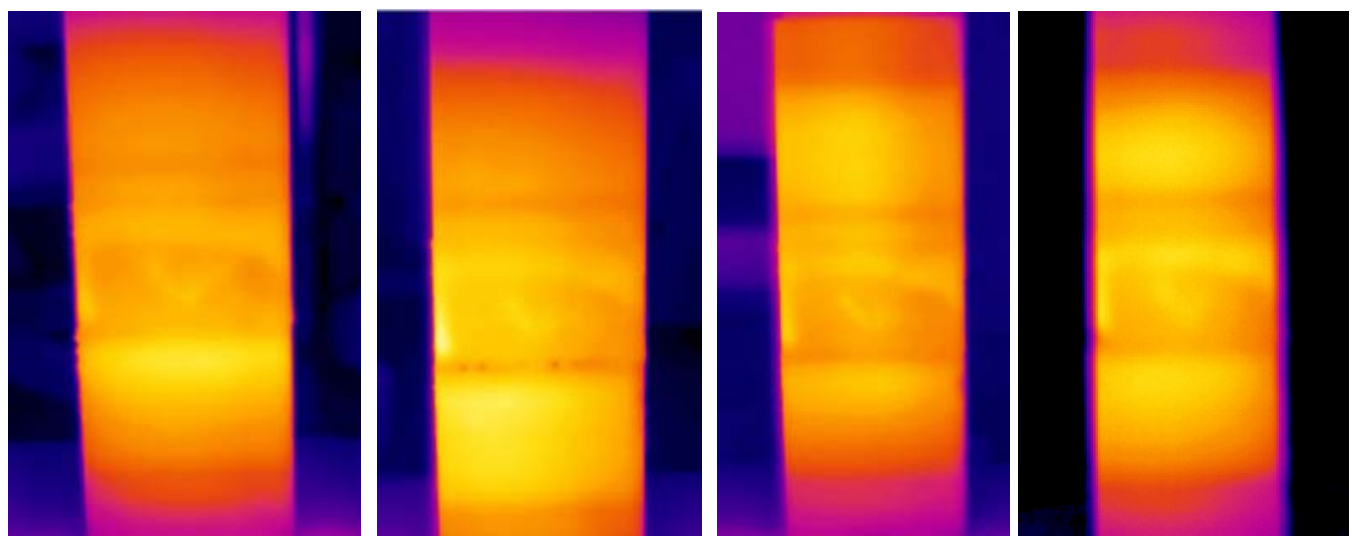

Figure 4.67 Infrared image of specimen AS5-side 2 (a) before immersion (b) after 1 month (c) after 3 months (d) after 6 months

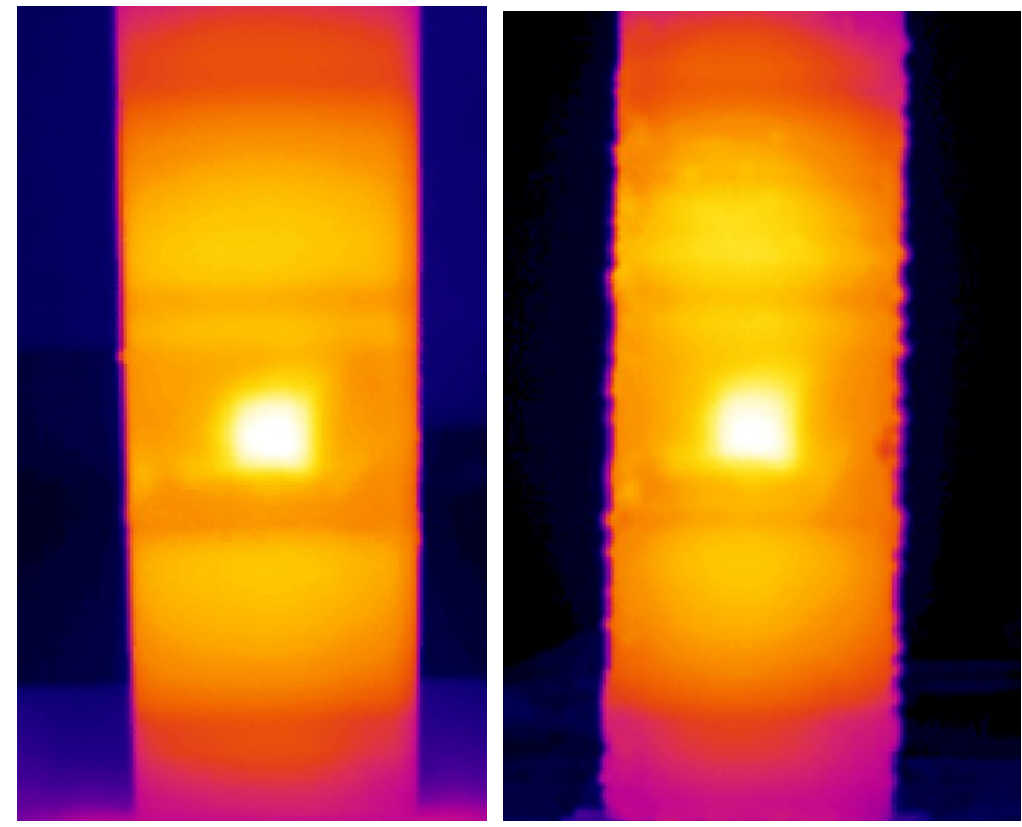

Figure 4.68 Infrared image of specimen AS6-side 1 (a) before freeze-thaw conditioning (b) after 6 cycles of freeze-thaw conditioning aging 

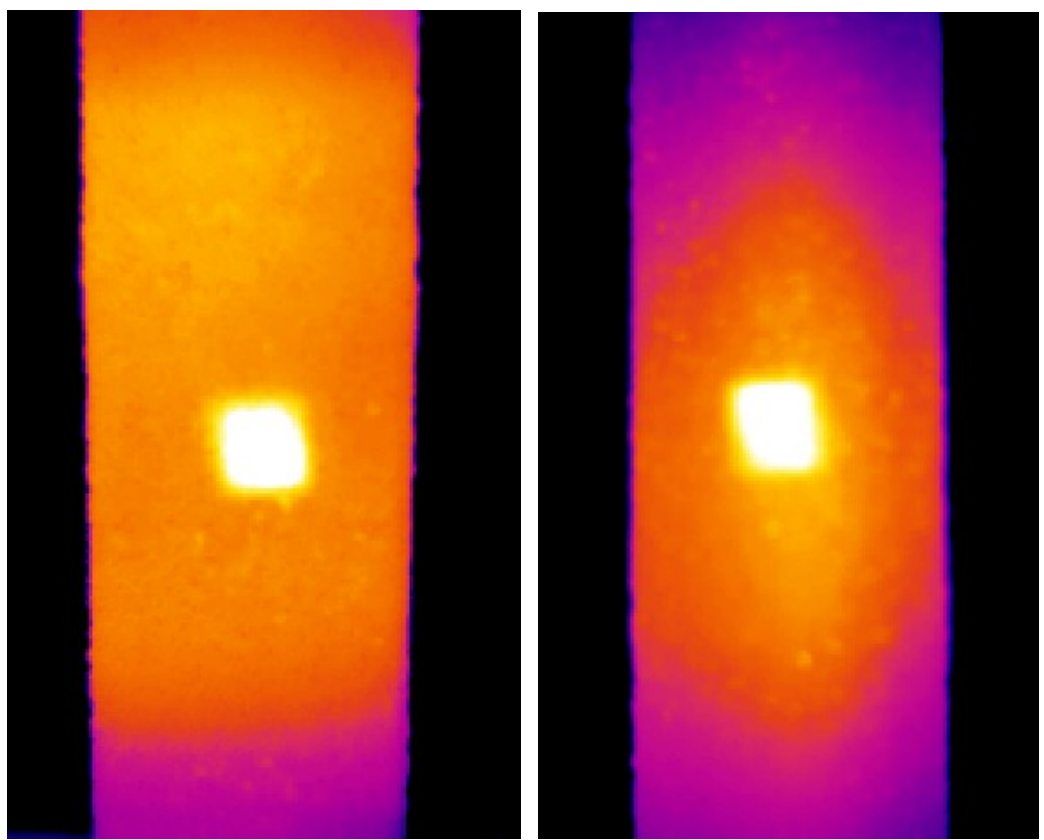

Figure 4.69 Infrared image of specimen AS6-side 2 (a) before freeze-thaw conditioning (b) after 6 cycles of freeze-thaw conditioning aging

\subsubsection{Conclusions}

From the infrared images of the specimens, taken before and after the aging period, it was concluded that there was no change in the sizes of the debonds and delaminations. Based on the previous studies (Vijay and GangaRao 1999) conducted on GFRP bars, it is possible that the GFRP decks that were subjected to 6 cycles (each cycle lasting for 5 days and 9 hours) of conditioning in the freeze-thaw chamber had undergone an equivalent 1096 days (36.5 months) of aging under natural weathering conditions. This duration did not result in growth of the subsurface debonds and delaminations.

\subsection{EFFECT OF DISTANCE ON DETECTABILITY OF DEFECTS}

When conducting infrared tests on field decks, it is possible to mount the infrared camera on a tripod or metallic boom attached to the vehicle, which increases the distance from the camera to the deck surface, thereby increasing the camera's field of view. This allows a large area to be covered in each infrared image and enables rapid scanning of the bridge deck. However, larger distances are associated with reduced pixel resolution. Beyond certain distances (between the infrared camera and the deck surface), the infrared 
images may not reveal subsurface defects with small sizes. The minimum detectable defect size depends on the pixel resolution of the infrared camera at the given distance. Hence one of the objectives of this study was to evaluate the detectability of debonds and delaminations at different distances using digital infrared thermography.

\subsubsection{Description of Specimens}

Two GFRP bridge deck specimens BD1 (both sides) and JD1 (both sides) were used for this test. The description of the material properties and cross-sectional views for these deck specimens are available in Sections 4.4.1 and 4.5.1. BD1a had two debonds of sizes 3" x 3" x 1/16" (76mm x 76mm x 1.6mm) and 2" x 2" x 1/16" (51mm x 51mm x $1.6 \mathrm{~mm})$ placed between the $3 / 8 "(9.5 \mathrm{~mm})$ thick wearing surface overlay and the underlying FRP deck. JD1a had a 3" x 3" x 1/20" (76mm x 76mm x 1.27mm) delamination and the other side (JD1b) had two with delaminations of sizes 1 " x 1 " $\mathrm{x}$ $1 / 16$ " (25mm x $25 \mathrm{~mm} \times 1.6 \mathrm{~mm})$ and 2" x 2" x $1 / 16 "(51 \mathrm{~mm}$ x $51 \mathrm{~mm}$ x $1.6 \mathrm{~mm})$. These delaminations were embedded at the flange-flange junction of the deck. This deck did not have any wearing surface overlay.

\subsubsection{Infrared Tests and Results}

The ThermaCAM ${ }^{\mathrm{TM}}$ infrared camera was used to detect the subsurface defects in both the specimens. The specimens were heated using the quartz heater prior to the acquisition of the infrared images. The specimens were placed at distances of 9.8' $(3 \mathrm{~m})$, 13.1' $(4 \mathrm{~m}), 16.4^{\prime}(5 \mathrm{~m})$ and $19.7^{\prime}(6 \mathrm{~m})$ from the infrared camera and the infrared images were captured at these different distances. The total area of view covered by the infrared image corresponding to each of these distances was noted. This information was used to compute the area covered by each pixel in the infrared image and the results are presented in Table 4.7. It should be noted that each digital infrared image for the given camera consisted of $320 \times 240$ pixels. Figures 4.70 to 4.73 shows the infrared images of specimens BD1a, BD1b, JD1a and JD1b, captured at distances of 3m, 4m, 5m and $6 \mathrm{~m}$. 


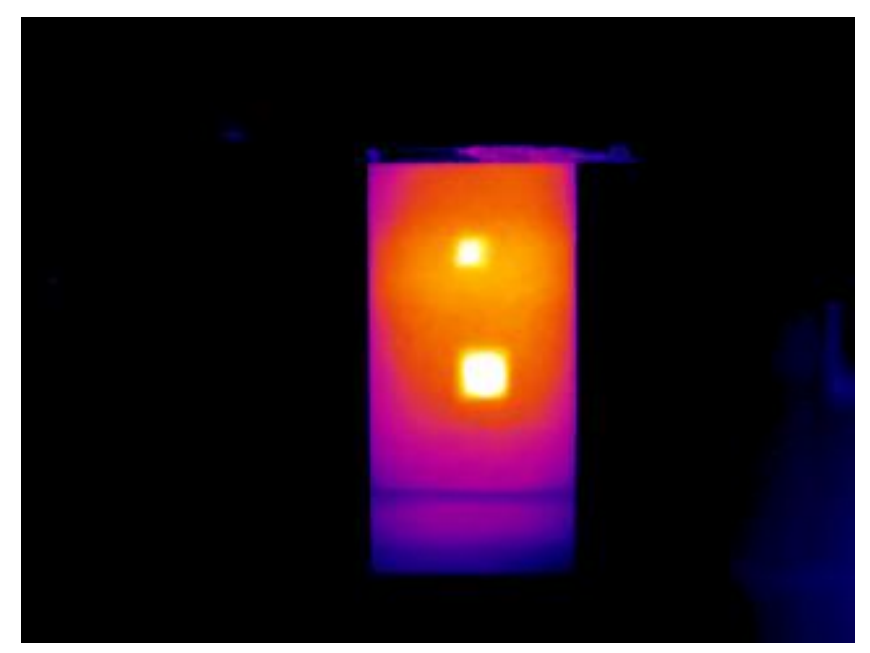

(a)

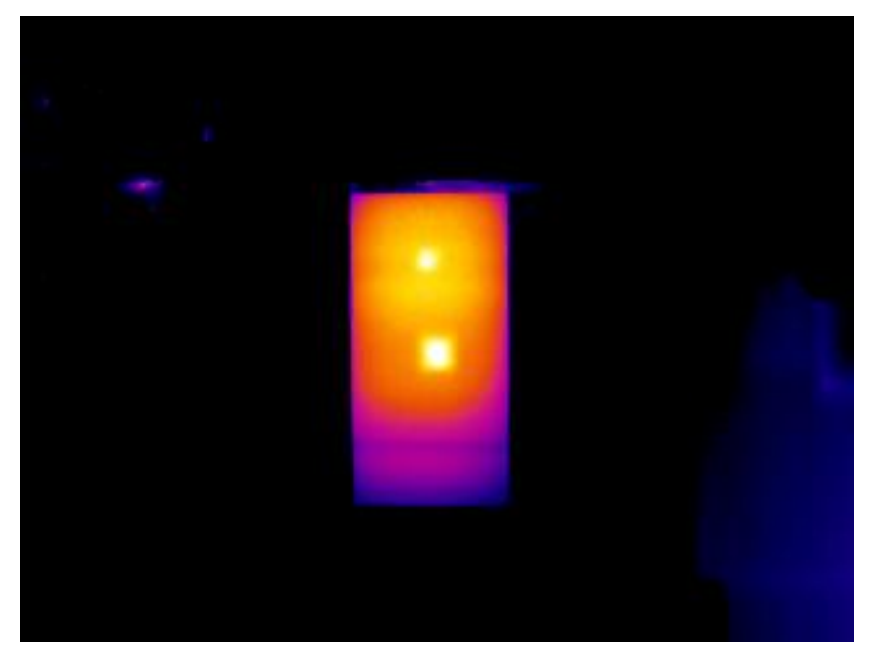

(b)

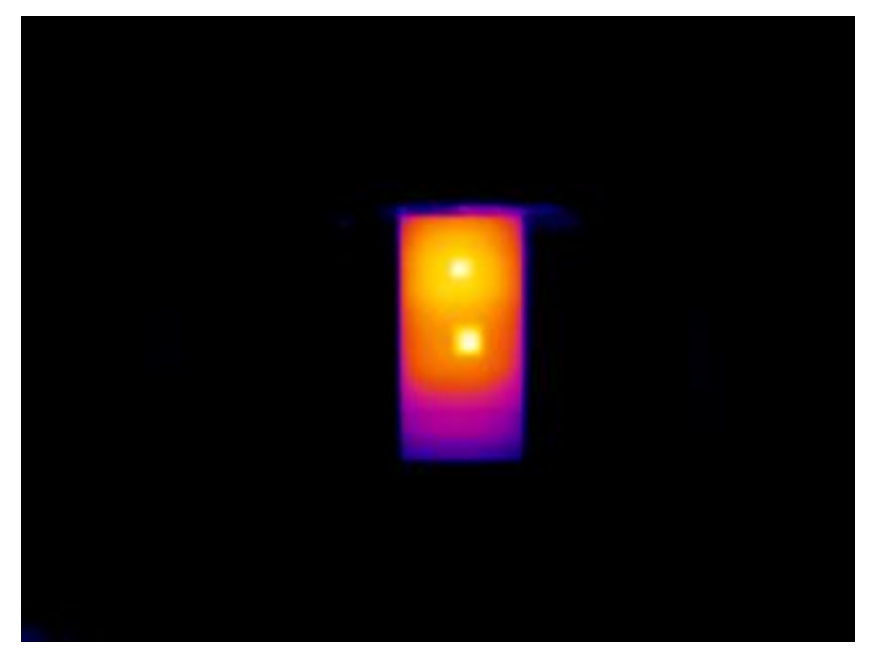

(c) 


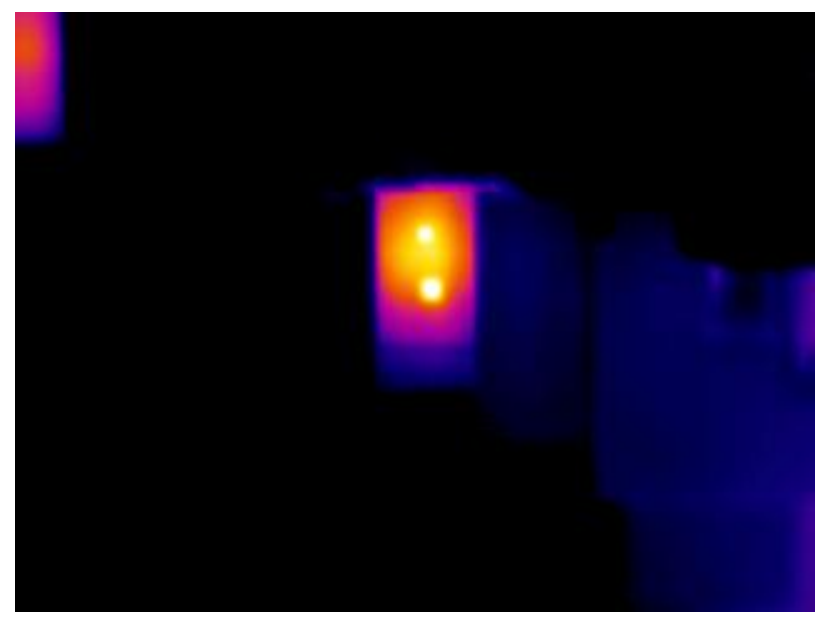

(d)

Figure 4.70. Infrared images of deck BD1a with debonds of sizes 2" x 2" x 1/16" and 3" x 3" x 1/16" detected at a distance of (a) $3 \mathrm{~m}$ (b) $4 \mathrm{~m}$ (c) $5 \mathrm{~m}$ (d) $6 \mathrm{~m}$

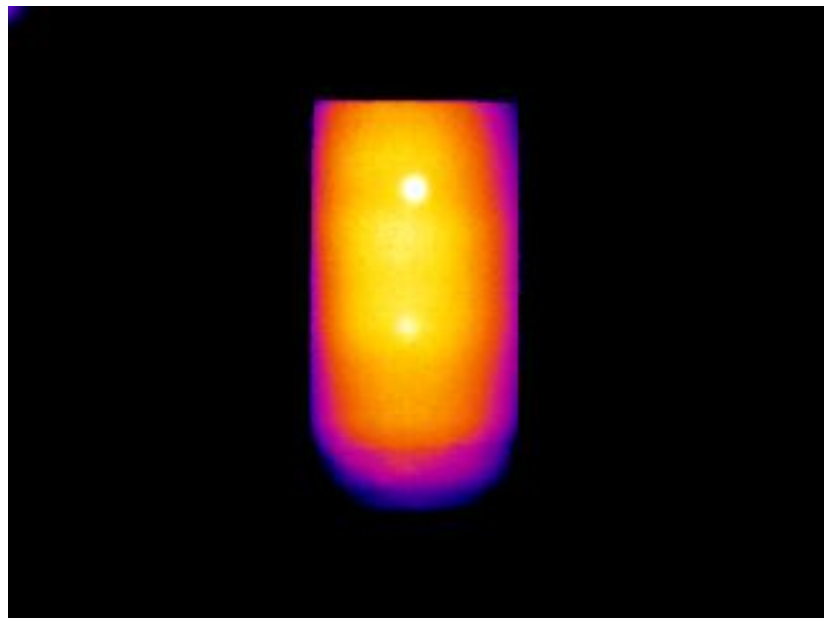

(a)

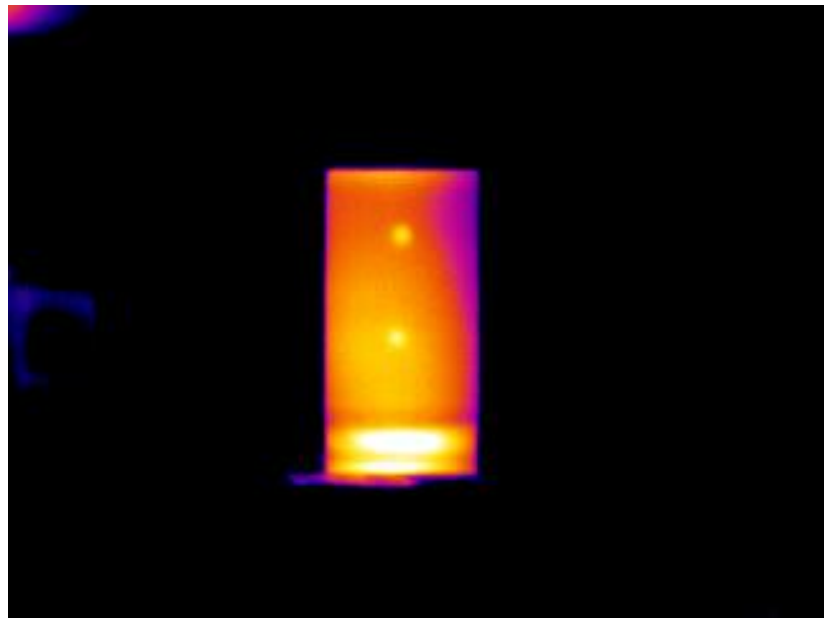

(b) 


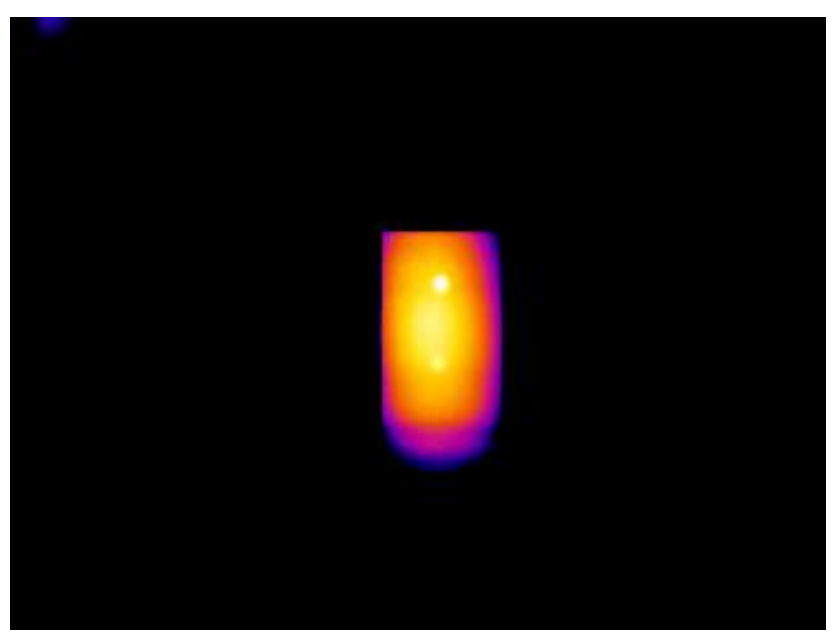

(c)

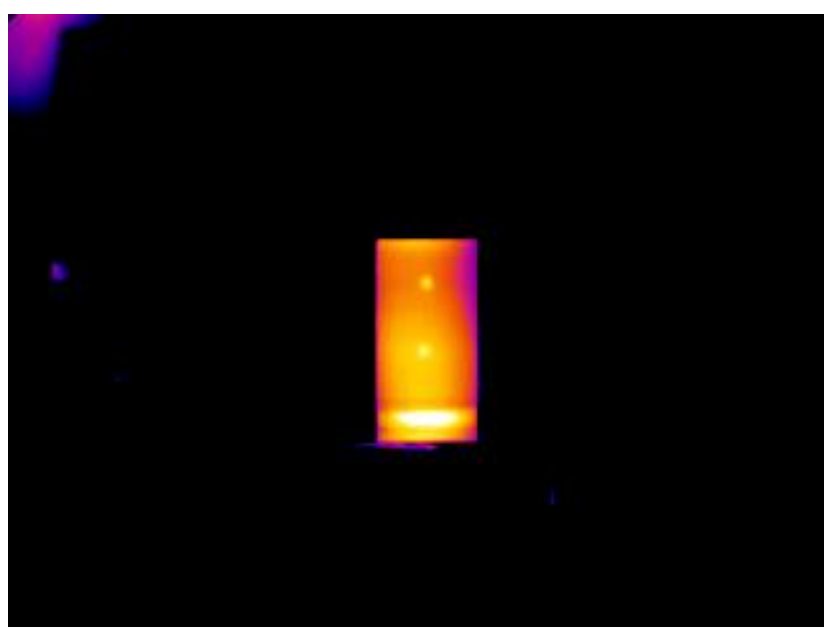

(d)

Figure 4.71. Infrared images of deck BD1b with debonds of sizes 1 " x 1 " x $1 / 16$ " and 1/2" x $1 / 2$ " x 1/16" detected at a distance of (a) $3 \mathrm{~m}$ (b) $4 \mathrm{~m}$ (c) $5 \mathrm{~m}$ (d) $6 \mathrm{~m}$

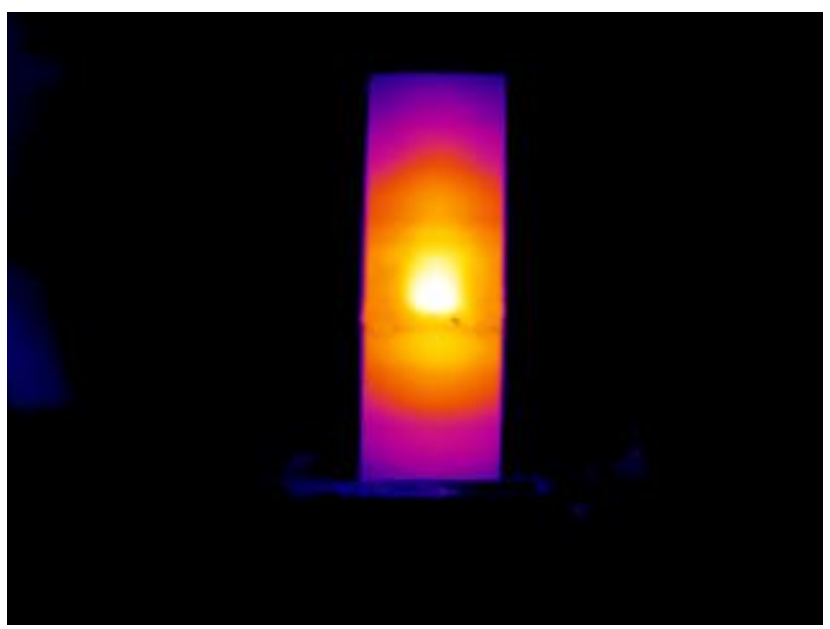

(a) 


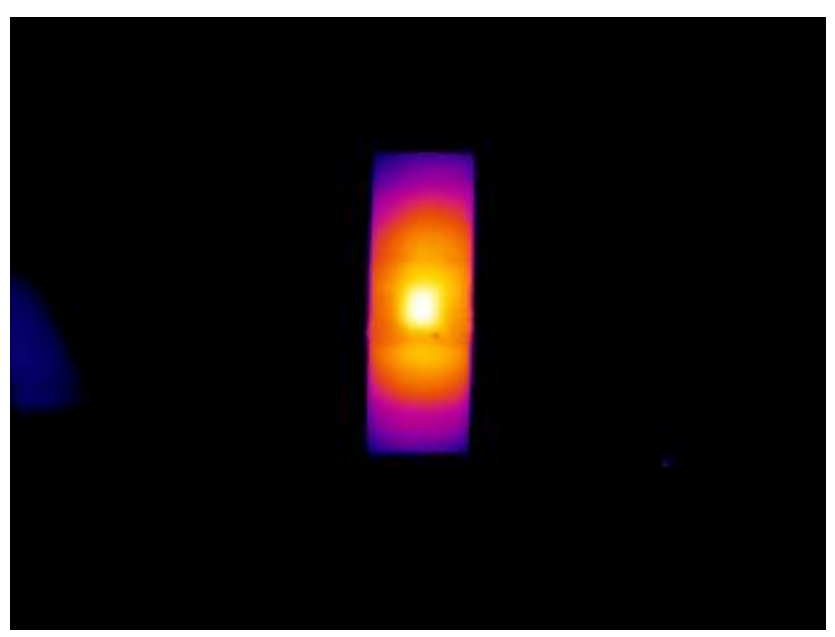

(b)

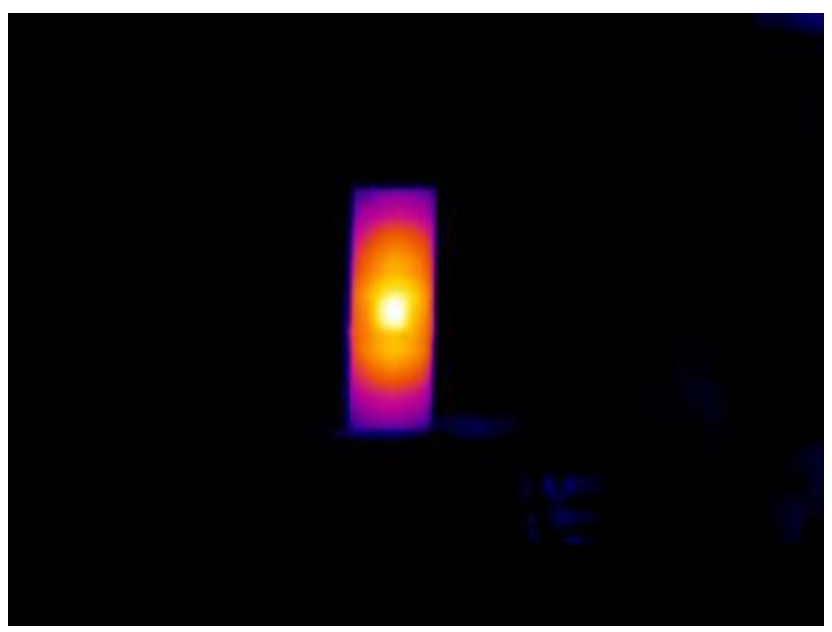

(c)

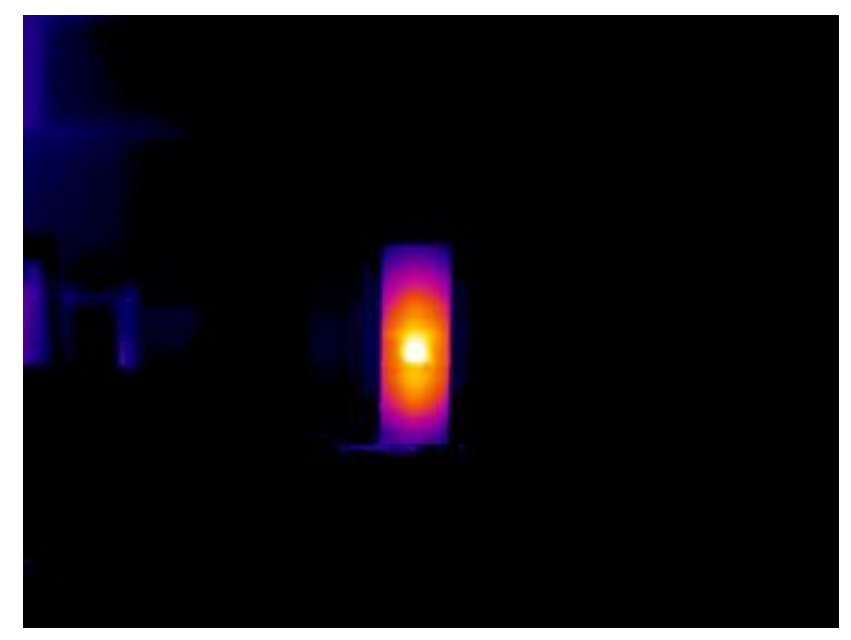

(d)

Figure 4.72. Infrared images of deck JD1a (without wearing surface) with 3" x 3" x 1/20" delamination detected at distance of (a) $3 \mathrm{~m}$ (b) $4 \mathrm{~m}$ (c) $5 \mathrm{~m}$ (d) $6 \mathrm{~m}$ 


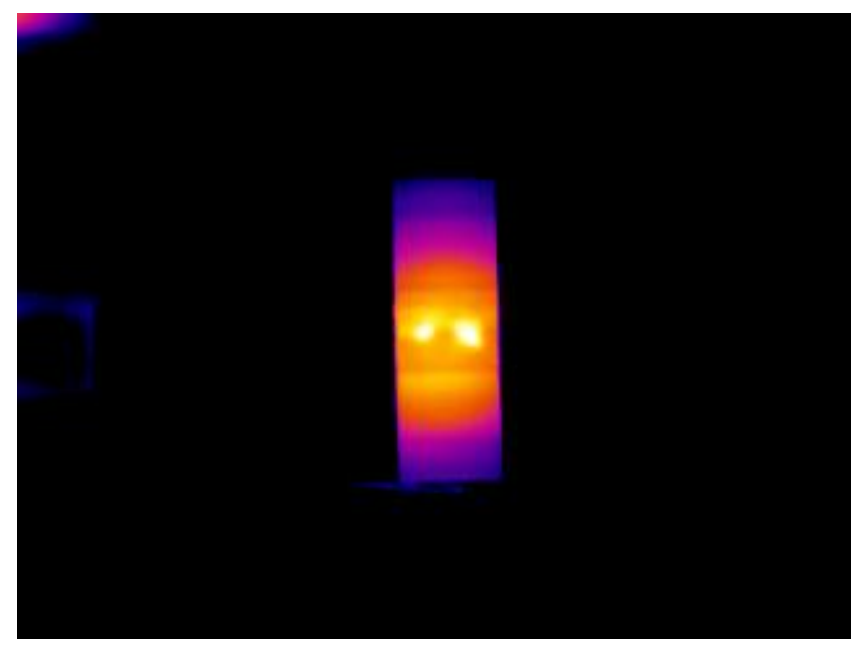

(b)

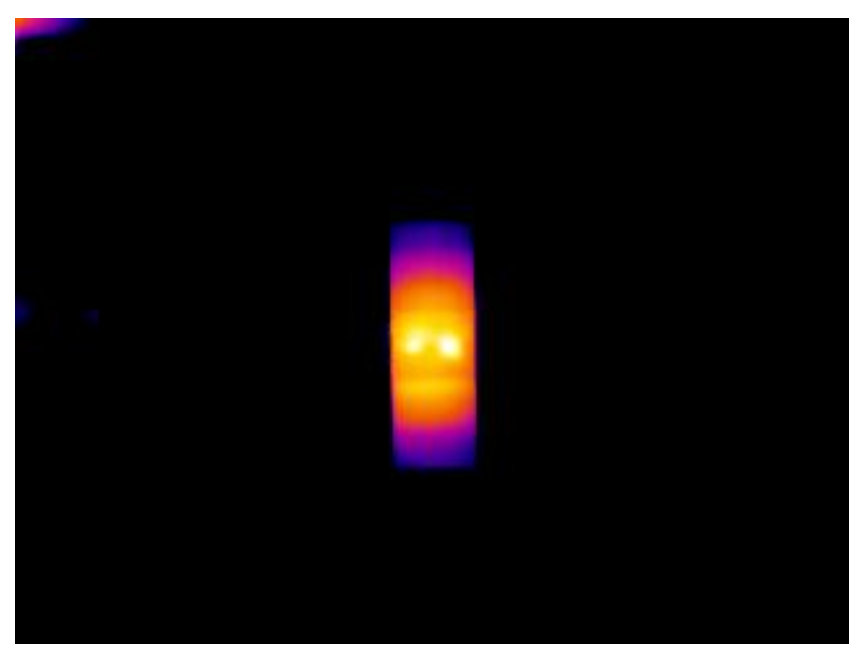

(c) 


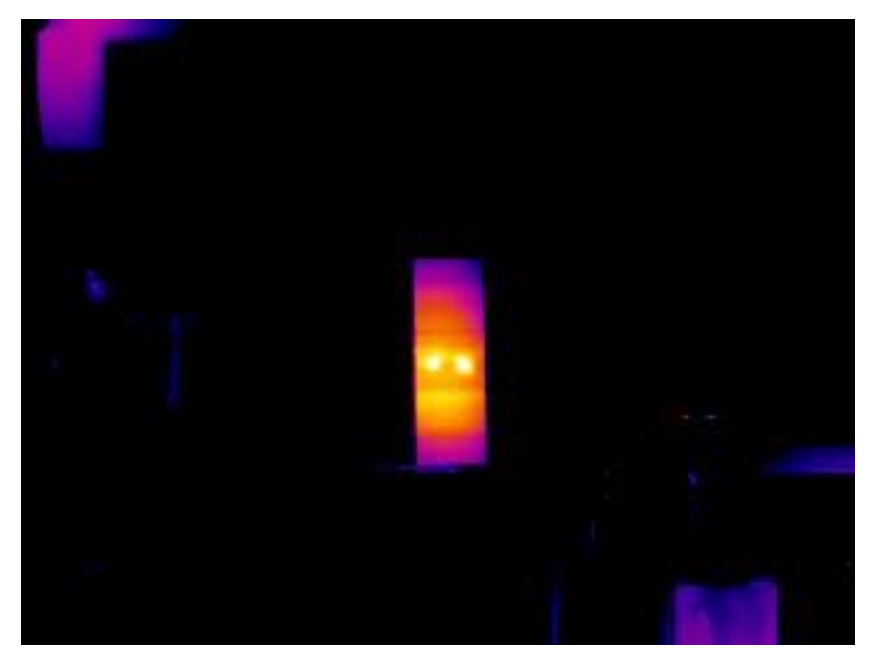

(d)

Figure 4.73. Infrared images of deck JD1b (without wearing surface) with delaminations of sizes 1 " x 1" x 1/16" and 2" x 2" x 1/16" detected at distance of (a) $3 \mathrm{~m}$ (b) $4 \mathrm{~m}$ (c) $5 \mathrm{~m}$ (d) $6 \mathrm{~m}$

Table 4.7 Viewing Area per Pixel in the infrared camera versus Viewing Distance (Camera's view has $320 \times 240$ pixels)

\begin{tabular}{|c|c|c|}
\hline $\begin{array}{c}\text { Viewing Distance } \\
\text { from Camera }\end{array}$ & $\begin{array}{c}\text { Measured } \\
\text { Area of View }\end{array}$ & $\begin{array}{c}\text { Computed Area } \\
\text { per Pixel }\end{array}$ \\
\hline $9^{\prime} 10^{\prime \prime}(3 \mathrm{~m})$ & $3^{\prime} 9^{\prime \prime} \times 2^{\prime} 8^{\prime \prime}(1143 \mathrm{~mm} \times 813 \mathrm{~mm})$ & $3.6 \mathrm{~mm} \times 3.6 \mathrm{~mm}$ \\
\hline $13^{\prime} 1^{\prime \prime}(4 \mathrm{~m})$ & $5^{\prime} 2^{\prime \prime} \times 3^{\prime} 10^{\prime \prime}(1575 \mathrm{~mm} \times 1168 \mathrm{~mm})$ & $4.9 \mathrm{~mm} \times 4.9 \mathrm{~mm}$ \\
\hline $16^{\prime} 5^{\prime \prime}(5 \mathrm{~m})$ & $6^{\prime} 8^{\prime \prime} \times 4^{\prime} 10^{\prime \prime}(2032 \mathrm{~mm} \times 1473 \mathrm{~mm})$ & $6.3 \mathrm{~mm} \times 6.3 \mathrm{~mm}$ \\
\hline $19^{\prime} 8^{\prime \prime}(6 \mathrm{~m})$ & $7^{\prime} 11^{\prime \prime} \times 5^{\prime} 8^{\prime \prime}(2413 \mathrm{~mm} \times 1727 \mathrm{~mm})$ & $7.5 \mathrm{~mm} \times 7.5 \mathrm{~mm}$ \\
\hline
\end{tabular}

The infrared images of the deck BD1a (Figure 4.70) with two debonds, revealed clear boundaries of both the debonds even from a distance of 19' $8^{\prime \prime}(6 \mathrm{~m})$. The plan sizes of the debonds (3" x 3 " and 2" x 2") were greater than the pixel dimension at this distance. Based on Table 4.7 (last row), the 3" x 3" (76mm x 76mm) debond at a distance of $6 \mathrm{~m}$ was represented by $100(10 \times 10)$ pixels and the 2 " 2 " $(50 \mathrm{~mm} \times 50 \mathrm{~mm})$ debond was represented by about 49 ( 7 x 7) pixels. The number of pixels representing the debonds in the infrared image was adequate to show sufficient contrast between the debonded and defect-free area at this distance. At this same distance of $6 \mathrm{~m}$, the 1 " $\mathrm{x} 1$ " $(25 \mathrm{~mm} \times 25 \mathrm{~mm})$ and $1 / 2 "$ x $1 / 2 "(12.7 \mathrm{~mm} \times 12.7 \mathrm{~mm})$ debonds in deck BD1b (shown in Figure 4.71) were represented by 9 pixels $(3 \times 3)$ and 3 pixels $(1.7 \times 1.7)$ respectively. 
The number of pixels representing the $1 / 2 " \times 1 / 2 "(12.7 \mathrm{~mm} \times 12.7 \mathrm{~mm})$ debond is very low to give an image with a good contrast showing the boundary of the debond.

The infrared images of deck JD1a (Figure 4.72) revealed the boundaries of the 3" x 3" x 1/20" (76mm x 76mm x 1.27mm) debond very clearly from a distance of 19' 8" (6m). This delamination was also represented by $100(10 \times 10)$ pixels and hence was clearly detected. The infrared image of deck JD1b (Figure 4.73) also showed clear boundaries of the 2 " x 2" (51mm x $51 \mathrm{~mm})$ delamination (represented by $7 \times 7$ pixels) and 1 " x 1" (25mm x $25 \mathrm{~mm})$ delamination (represented by $3 \times 3$ pixels) at a distance of $6 \mathrm{~m}$. Based on these results, the threshold value for the number of pixels that is required to establish a good contrast would be 9 ( $3 \times 3$ ) pixels. This represents about $0.012 \%$ of the total area in the infrared image. It is important to note that this percentage corresponds to laboratory experiments using a heater. The contrast in the field environment under solar radiation is expected to be less than what is achieved using a heater. This is discussed in more detail in Sections 4.14 and 4.15.

\subsubsection{Conclusions}

The effect of distance on the detectability of the debonds and delaminations was investigated. The maximum distance that can be used between the infrared camera and the deck surface is tied to the pixel dimensions of the infrared camera showing the subsurface defect. Debond as small as 1 " x 1" x 1/16" (25mm x 25mm x 1.6mm) as well as delamination as small as 1 " x 1 " x 1/16" (25mm x $25 \mathrm{~mm} \times 1.6 \mathrm{~mm})$ could be detected at a distance of 19 ' 8 " or $6 \mathrm{~m}$ successfully by the digital infrared camera. However, the boundaries of the $1 / 2 " \times 1 / 2 " \times 1 / 16 "(12.7 \mathrm{~mm} \times 12.7 \mathrm{~mm} \times 1.6 \mathrm{~mm})$ debond could not be clearly identified in the infrared image taken from a distance of $6 \mathrm{~m}$. The number of pixels representing this small delamination at $6 \mathrm{~m}$ distance is not adequate to show a clear contrast between the defective and defect-free areas.

\subsection{INFRARED TESTS CONDUCTED UNDER SOLAR RADIATION}

Solar radiation can be considered as the heating source for field testing of decks. In the field, the deck area is usually large, and hence heating sources like the heating blanket or quartz heater would take a long time to sequentially heat portions of the large 
area. In order to study the applicability of solar radiation (a heat source that gradually increases in intensity from morning to mid-day and then decreases), infrared tests were conducted on bridge deck specimens kept under the sun. The detectability of debonds and delaminations were evaluated using infrared thermography.

\subsubsection{Description of Specimens}

The GFRP bridge deck specimens that were tested under solar radiation were specimen BD1 (side a), JD1 (side a) and JD2 (material properties and details of cross section are available in Sections 4.4.1 and 4.5.1). BD1a consisted of two debonds of sizes 3 " x 3" x 1/16" (76mm x $76 \mathrm{~mm}$ x 1.6mm) and 2" x 2" x 1/16" $(51 \mathrm{~mm}$ x $51 \mathrm{~mm}$ x $1.6 \mathrm{~mm})$ placed between the $3 / 8$ " $(9.5 \mathrm{~mm})$ thick wearing surface and the underlying FRP deck. JD1a had a 3" x 3" x 1/20" (76mm x $76 \mathrm{~mm}$ x 1.27mm) delamination embedded within the flange-flange junction of the deck (with no wearing surface). JD2 consisted of a 3" x 3" x 1/8" (76mm x $76 \mathrm{~mm}$ x 3mm) delamination within the flange-flange junction of the deck overlaid with $3 / 8 "(9.5 \mathrm{~mm})$ thick wearing surface.

\subsubsection{Infrared Tests and Results}

The bridge deck specimens were kept outside under sunlight at around 8.30 A.M. in the morning (on September $17^{\text {th }}, 2003$ ). The decks were left under solar radiation throughout the day. Figure 4.74 shows the deck specimens kept under sunlight. Care was taken to avoid the shadows from the neighboring trees and buildings from falling on the bridge deck specimens. 


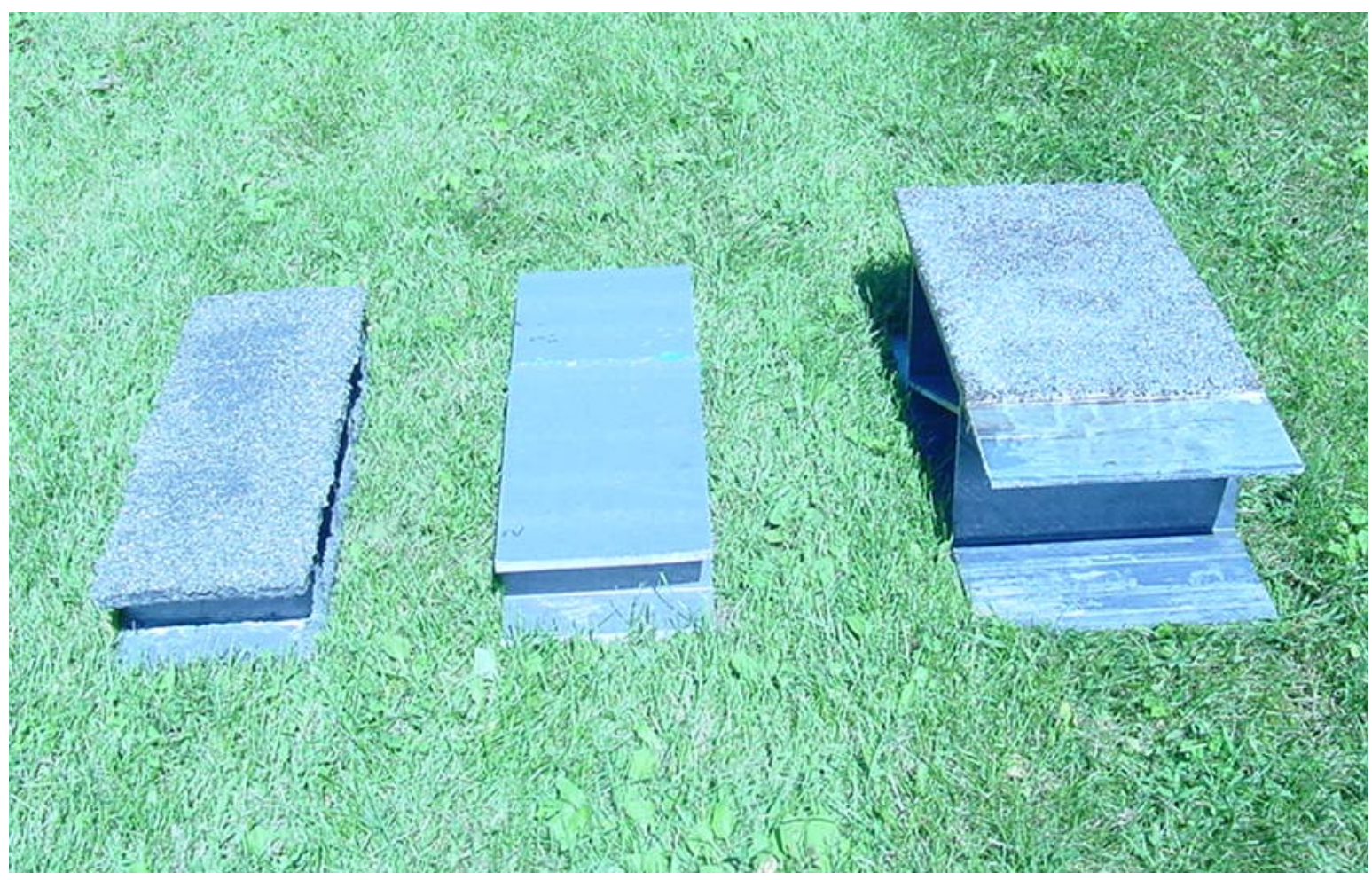

Figure 4.74. Bridge deck specimens (JD2, JD1a, and BD1a) kept under solar radiation

At the beginning of the experiment (8:30 A.M.) the outside atmosphere was misty and the deck began receiving solar radiation at around 9 A.M. Though the day was bright and sunny, it was windy at times during the day. The infrared images of the decks were taken at every half-hour interval, and care was taken not to acquire images while the wind was blowing. The images were captured by focusing the camera on the deck with an angle of incidence of about $45^{\circ}$. Also, it was found that the temperature measurements were not dependent on this angle. The surface temperatures over the defective and defectfree areas at every interval were tabulated and the corresponding temperature differences were calculated. The ambient air temperatures were also noted at the end of each halfhour interval. Graphs were plotted with time along the X-axis and surface temperatures of the defective and defect-free areas along the Y-axis.

\section{Bridge deck specimen BD1a}

Table 4.8 gives the surface temperature values for the 3 " x 3 " x 1/16" (76mm x 76 $\mathrm{mm} \times 1.6 \mathrm{~mm}), 2$ x 2 " x 1/16" (51mm x $51 \mathrm{~mm}$ x 1.6mm) debonds and the defect-free area in the specimen BD1a. The first column in the table gives the time of the day. The 
second through fourth columns give the surface temperatures above the debonded and defect-free areas respectively. The fifth and sixth columns gives the corresponding surface temperature differences between the debonded and defect-free areas. The last column shows the ambient air temperature. Figure 4.75 shows the surface temperaturetime curves for the 3" x 3" x 1/16" (76mm x $76 \mathrm{~mm} \times 1.6 \mathrm{~mm})$ and 2" x 2 " x $1 / 16$ " $(51 \mathrm{~mm} \times 51 \mathrm{~mm} \times 1.6 \mathrm{~mm})$ debonds. The curves were plotted for the surface temperatures of both the defective and defect-free areas along the $\mathrm{Y}$-axis and time over the $\mathrm{X}$-axis.

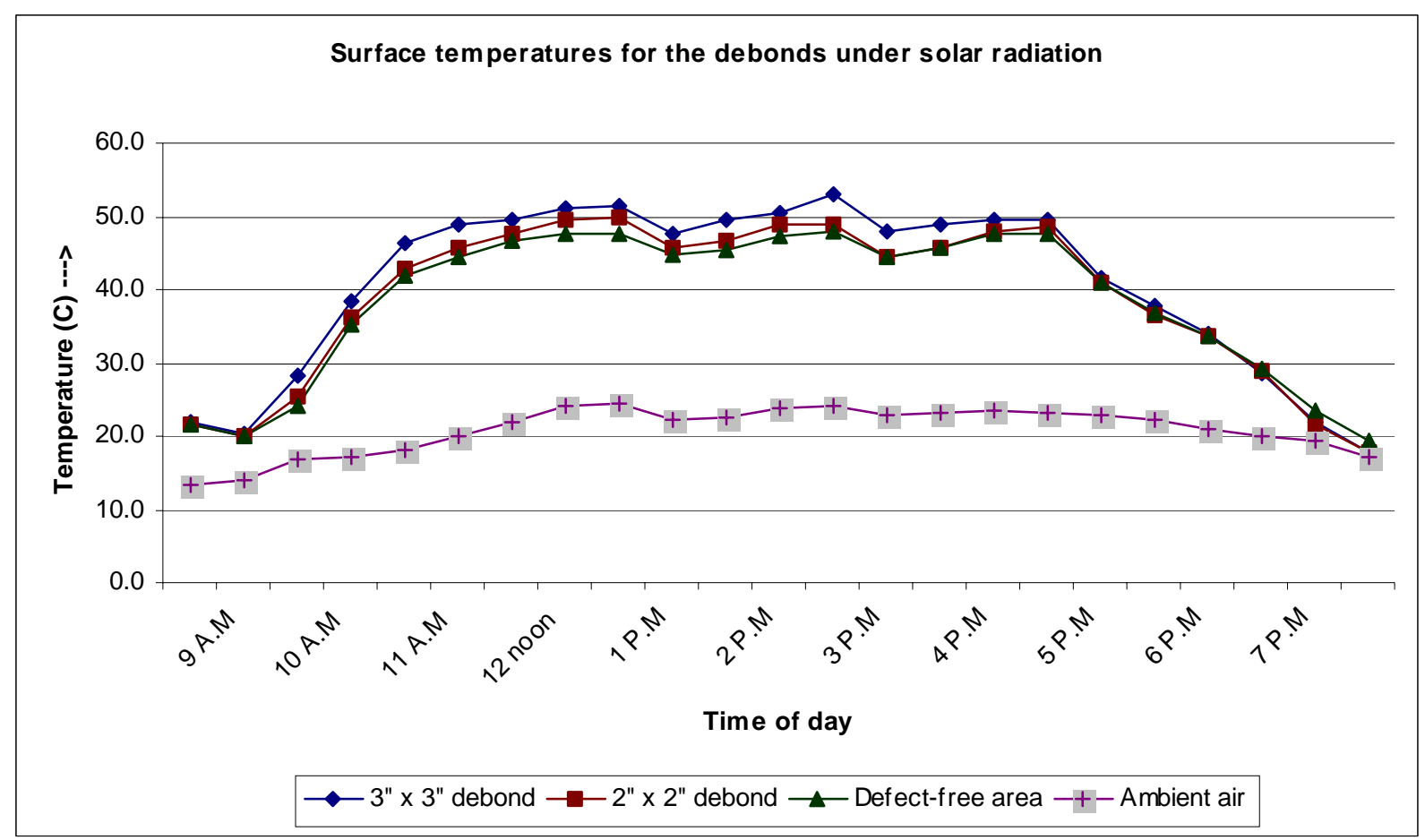

Figure 4.75 Surface temperature-time curves for 3"x 3" x 1/16" and 2"x 2" x 1/16" debonds in BD1a 
Table 4.8 Surface temperatures of 3"x 3", 2" x 2" debonds and defect-free area in specimen BD1a

\begin{tabular}{|c|c|c|c|c|c|c|}
\hline $\begin{array}{l}\text { Time } \\
\text { of day }\end{array}$ & $\begin{array}{c}3 " \times 3 " \\
\text { debond }(C)\end{array}$ & $\begin{array}{c}2 " \times 2 " \\
\text { debond }(\mathrm{C})\end{array}$ & $\begin{array}{c}\text { Defect-free } \\
\text { area (C) }\end{array}$ & $\begin{array}{c}\text { Difference for } \\
3 " \times 3 " \text { debond }(C)\end{array}$ & $\begin{array}{c}\text { Difference for } \\
2 " \times 2 " \text { debond }(C)\end{array}$ & $\begin{array}{l}\text { Ambient Air } \\
\text { (C) }\end{array}$ \\
\hline 8.30 A.M. & 21.9 & 21.5 & \begin{tabular}{|l|}
21.5 \\
\end{tabular} & 0.4 & \begin{tabular}{|l|}
0.0 \\
\end{tabular} & 13.3 \\
\hline 9.00 A.M. & 20.3 & 20.0 & 20.0 & 0.3 & 0.0 & 14.0 \\
\hline 9.30 A.M. & 28.2 & 25.3 & 24.2 & 4.0 & 1.1 & 16.7 \\
\hline 10.00 A.M. & 38.5 & 36.1 & 35.1 & 3.4 & 1.0 & 17.0 \\
\hline 10.30 A.M. & 46.2 & 42.8 & 41.9 & 4.3 & 0.9 & 18.0 \\
\hline 11.00 A.M. & 48.8 & 45.7 & 44.6 & 4.2 & 1.1 & 20.0 \\
\hline 11.30 A.M. & 49.5 & 47.7 & 46.7 & 2.8 & 1.0 & 22.0 \\
\hline 12 Noon & 51.2 & 49.4 & 47.6 & 3.6 & 1.8 & 24.0 \\
\hline 12.30 P.M. & 51.4 & 50.0 & 47.7 & 3.7 & 2.3 & 24.4 \\
\hline 1.00 P.M. & 47.5 & 45.8 & 44.7 & 2.8 & 1.1 & 22.3 \\
\hline 1.30 P.M. & 49.4 & 46.7 & 45.3 & 4.1 & 1.4 & 22.5 \\
\hline 2.00 P.M. & 50.5 & 48.8 & 47.4 & 3.1 & 1.4 & 23.7 \\
\hline 2.30 P.M. & 53.0 & 48.9 & 47.9 & 5.1 & 1.0 & 24.1 \\
\hline 3.00 P.M. & 48.0 & 44.6 & 44.5 & 3.5 & 0.1 & 22.8 \\
\hline 3.30 P.M. & 49.0 & 45.8 & 45.6 & 3.4 & 0.2 & 23.1 \\
\hline 4.00 P.M. & 49.5 & 48.0 & 47.6 & 1.9 & 0.4 & 23.4 \\
\hline 4.30 P.M. & 49.6 & 48.7 & 47.5 & 2.1 & 1.2 & 23.2 \\
\hline 5.00 P.M. & 41.7 & 41.1 & 41.0 & 0.7 & 0.1 & 22.9 \\
\hline 5.30 P.M. & 37.7 & 36.5 & 36.7 & 1.0 & -0.2 & 22.1 \\
\hline 6.00 P.M. & 34.1 & 33.5 & 33.5 & 0.6 & 0.0 & 21.0 \\
\hline 6.30 P.M. & 28.5 & 29.0 & 29.2 & -0.7 & -0.2 & 20.1 \\
\hline 7.00 P.M. & 21.8 & 21.5 & 23.5 & -1.7 & -2.0 & 19.4 \\
\hline 7.30 P.M. & 17.7 & 17.7 & 19.5 & -1.8 & -1.8 & 17.1 \\
\hline
\end{tabular}

It was observed that significant values of surface temperature differences between the 3" x 3" debonded and defect-free area were obtained between 10 A.M. to 4 P.M. Temperature differences between the 2" x 2" $(51 \mathrm{~mm}$ x $51 \mathrm{~mm})$ debond and defect-free area were detectable between 10 A.M. to 2.30 P.M. Figures 4.76 (a), (b), (c) and (d) show the infrared images of the bridge deck BDla taken during different times of the day. Debond with 3" x 3" (76mm x 76mm) size could be detected in the infrared images (as white areas) over the entire duration from 9.30 A.M. to 4.30 P.M. Slight drop in the temperature differentials was observed during the times when the surface was cooled by wind. The temperature difference for this $3 " \times 3 "(76 \mathrm{~mm} \times 76 \mathrm{~mm})$ debond was $5.1^{\circ} \mathrm{C}$ at 2.30 P.M. and is clearly seen (represented by white regions) in Figure 4.76(c). By adjusting the contrast scale in the infrared images, the boundary of the debond can be seen more prominently. This ability to adjust the contrast in the recorded images is one of the major advantages of using the digital infrared system when compared to the non- 
digital infrared system. In Figure 4.76(d), the areas with higher temperatures towards the edge are due to the solar radiation falling on the deck at an angle and heating the edges. The surface temperature difference for the 2" x 2" (51mm x 51mm) debond was only about 1 to $2.3^{\circ} \mathrm{C}$ (see Table 4.8), hence the infrared images do not show the debond very clearly. The graph and table show drops in the deck temperatures at some times around 1 P.M. and 3 P.M.. At around 6.30 P.M. and later, the temperature above the debonds appear to be colder than the surrounding defect-free areas. At this time the deck is undergoing a cooling cycle and hence the debonds show up as lower temperature areas.

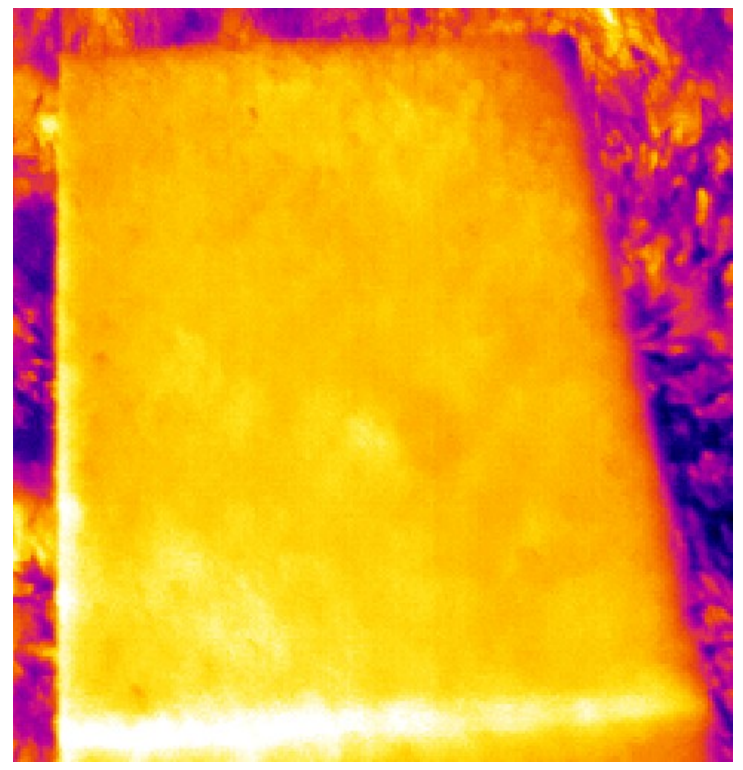

(a)

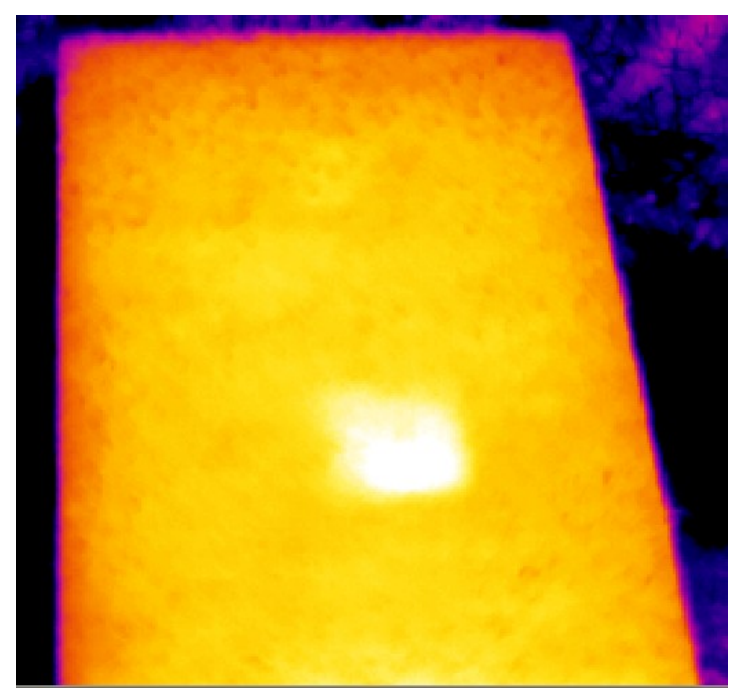

(c)

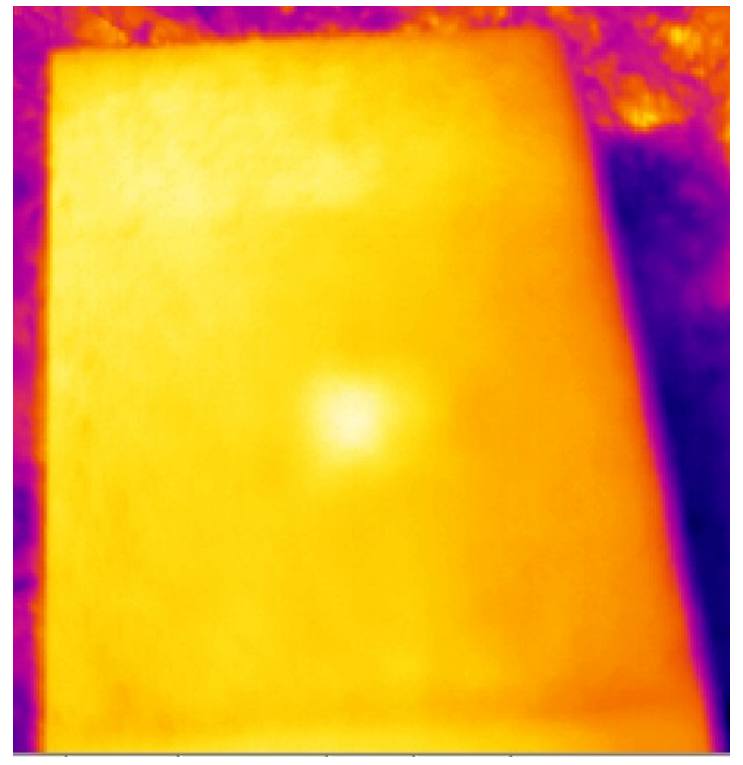

(b)

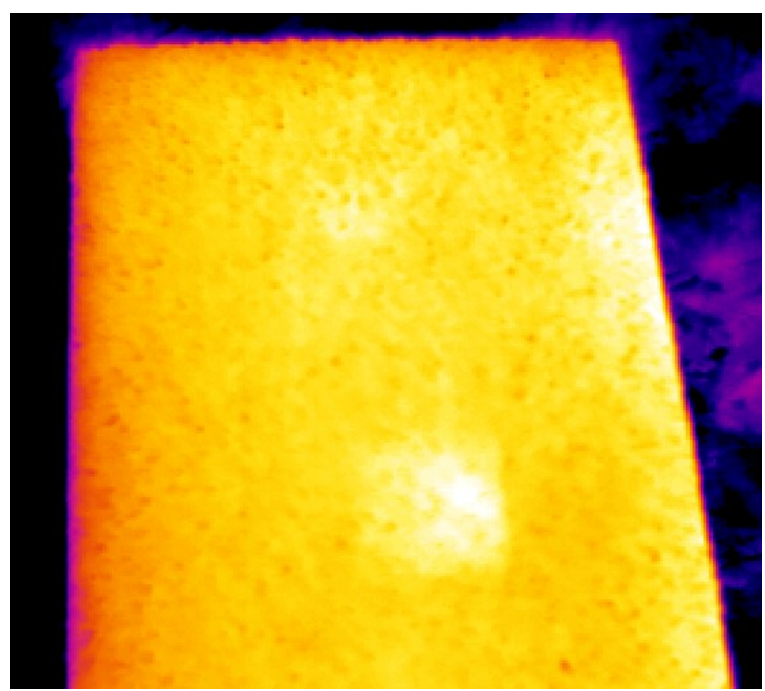

(d)

Figure 4.76 Infrared image of bridge deck specimen BD1a with debonds of sizes 2" x 2" x 1/16" and 3" x 3" x 1/16" at (a) 9 A.M. (b) 12.30 P.M. (c) 2.30 P.M. (d) 4.30 P.M. 


\section{Bridge deck specimen JD1a}

Table 4.9 and Figure 4.77 establishes values and curves for the 3 " x 3" x 1/20" $(76 \mathrm{~mm} \times 76 \mathrm{~mm} \times 1.27 \mathrm{~mm})$ delamination in specimen JD1a. The delaminated flange did not have any wearing surface in this specimen. Surface temperature differences between the delaminated and defect-free areas ranged from 2 to $4^{\circ} \mathrm{C}$ from 9.30 A.M. to 4.30 P.M. The delamination with 3" x 3" (76mm x 76mm) size could be clearly detected in the infrared images at most of the times from 11.30 A.M. to 4.30 P.M., except during the times when the surface was cooled by the wind. Figures 4.78 (a), (b), (c) and (d) shows the infrared images of the bridge deck JD1a taken during different times of the day. The temperature difference for this delamination was about $4^{\circ} \mathrm{C}$ at 2.30 P.M. and is clearly seen in Figure 4.78 (c) as a white square region.

Table 4.9 Surface temperatures of 3"x 3" delamination and defect-free areas in specimen JD1a

\begin{tabular}{|c|c|c|c|c|}
\hline $\begin{array}{c}\text { Time } \\
\text { of day }\end{array}$ & $\begin{array}{c}\text { 3" } \times \text { 3" } \\
\text { delamination (C) }\end{array}$ & $\begin{array}{c}\text { Defect-free } \\
\text { Area (C) }\end{array}$ & $\begin{array}{c}\text { Difference for 3" } \times \text { 3" } \\
\text { delamination (C) }\end{array}$ & $\begin{array}{c}\text { Ambient Air } \\
(C)\end{array}$ \\
\hline 8.30 A.M. & 21.3 & 21.3 & 0.0 & 13.3 \\
\hline 9.00 A.M. & 20.8 & 20.7 & 0.1 & 14.0 \\
\hline 9.30 A.M. & 26.2 & 23.8 & 2.4 & 16.7 \\
\hline 10.00 A.M. & 36.2 & 34.9 & 1.3 & 17.0 \\
\hline 10.30 A.M. & 42.3 & 40.7 & 1.6 & 18.0 \\
\hline 11.00 A.M. & 47.9 & 45.0 & 2.9 & 20.0 \\
\hline 11.30 A.M. & 48.6 & 44.9 & 3.7 & 22.0 \\
\hline 12 Noon & 49.1 & 45.4 & 3.7 & 24.0 \\
\hline 12.30 P.M. & 49.2 & 45.3 & 3.9 & 24.4 \\
\hline 1.00 P.M. & 48.2 & 44.4 & 3.8 & 22.3 \\
\hline 1.30 P.M. & 49.4 & 46.9 & 2.5 & 22.5 \\
\hline 2.00 P.M. & 51.3 & 48.4 & 2.9 & 23.7 \\
\hline 2.30 P.M. & 49.5 & 45.5 & 4.0 & 24.1 \\
\hline 3.00 P.M. & 46.1 & 42.5 & 3.6 & 22.8 \\
\hline 3.30 P.M. & 46.5 & 44.6 & 1.9 & 23.1 \\
\hline 4.00 P.M. & 46.6 & 44.5 & 2.1 & 23.4 \\
\hline 4.30 P.M. & 46.1 & 44.1 & 2.0 & 23.2 \\
\hline 5.00 P.M. & 40.3 & 38.8 & 1.5 & 22.9 \\
\hline 5.30 P.M. & 34.1 & 33.9 & 0.2 & 22.1 \\
\hline 6.00 P.M. & 30.6 & 30.5 & 0.1 & 21.0 \\
\hline 6.30 P.M. & 26.6 & 26.8 & -0.2 & 20.1 \\
\hline 7.00 P.M. & 22.1 & 22.4 & -0.3 & 19.4 \\
\hline 7.30 P.M. & 18.4 & 18.8 & -0.4 & 17.1 \\
\hline
\end{tabular}




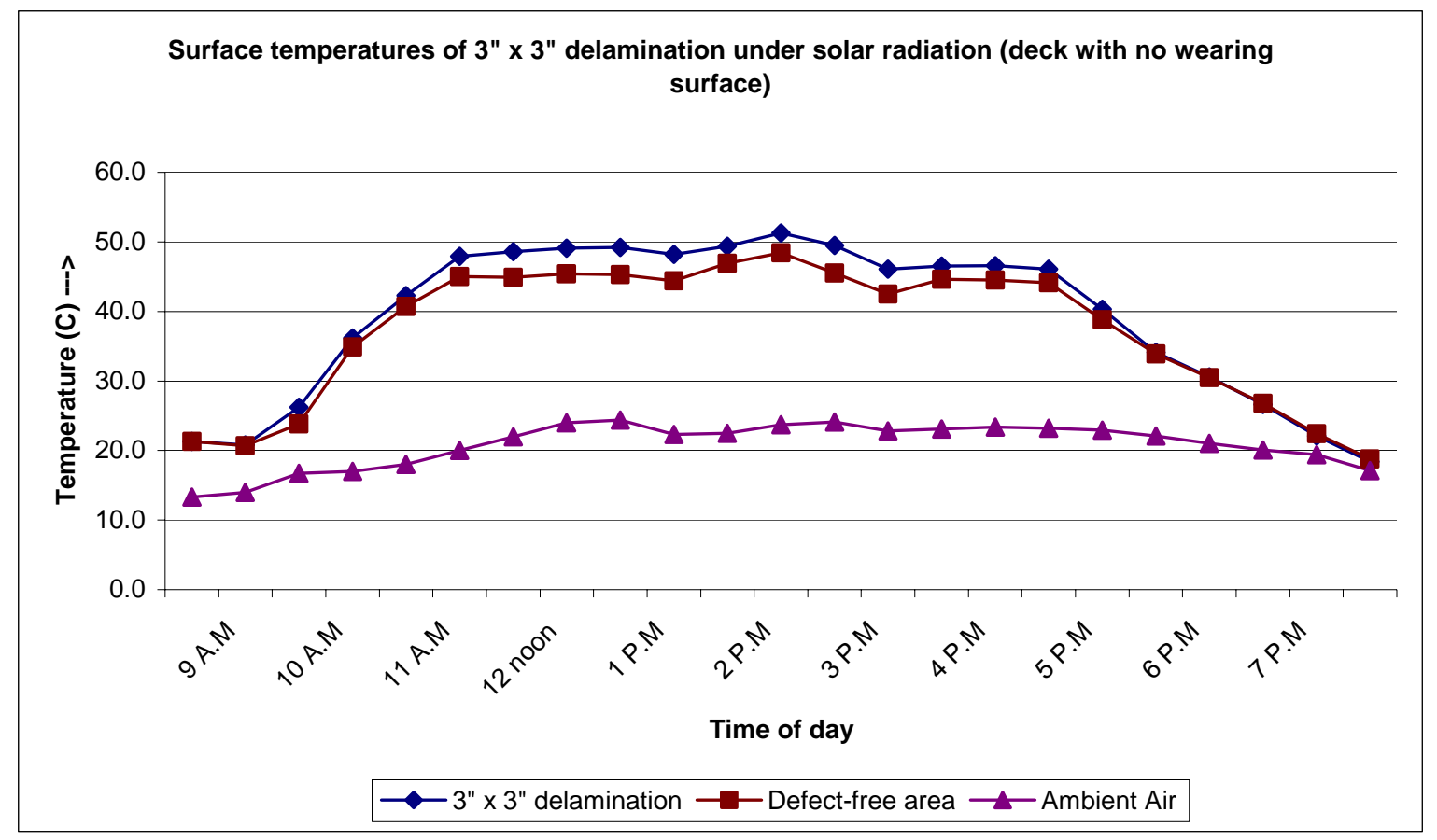

Figure 4.77 Surface temperature-time curves for 3"x 3" x 1/20" delamination in specimen JD1a (no wearing surface overlay)

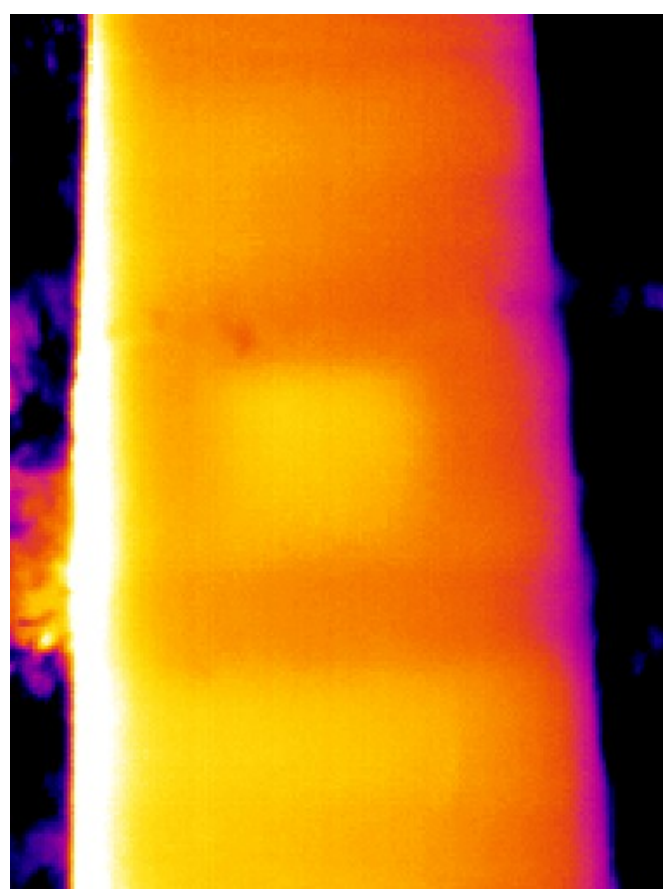

(a)

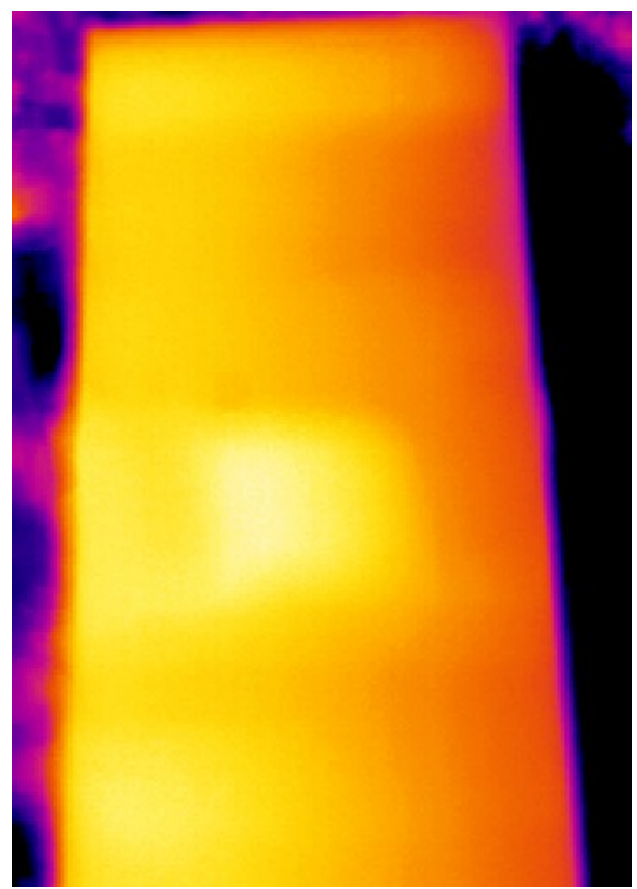

(b) 


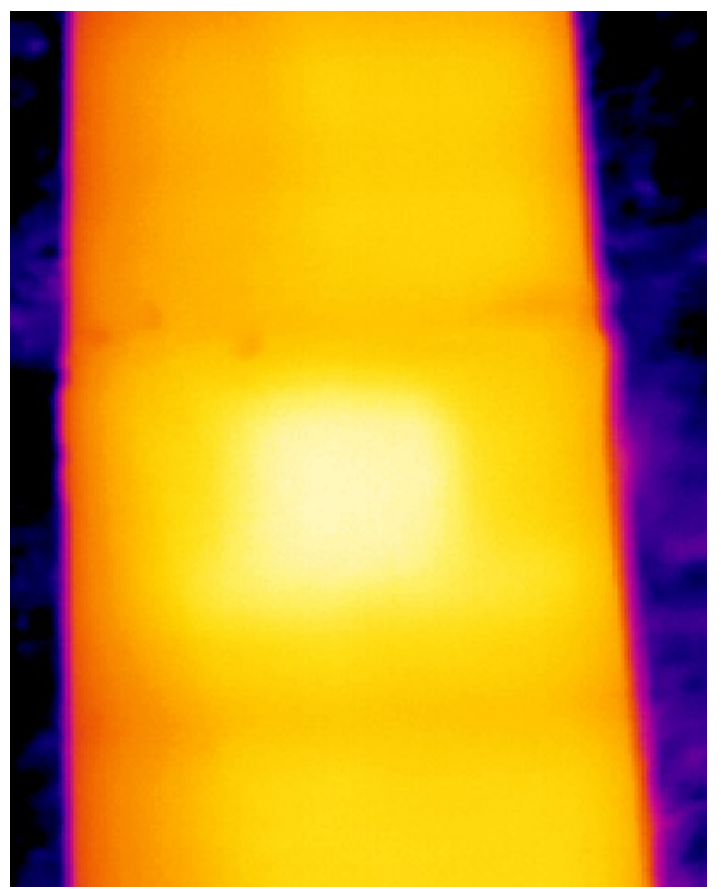

(c)

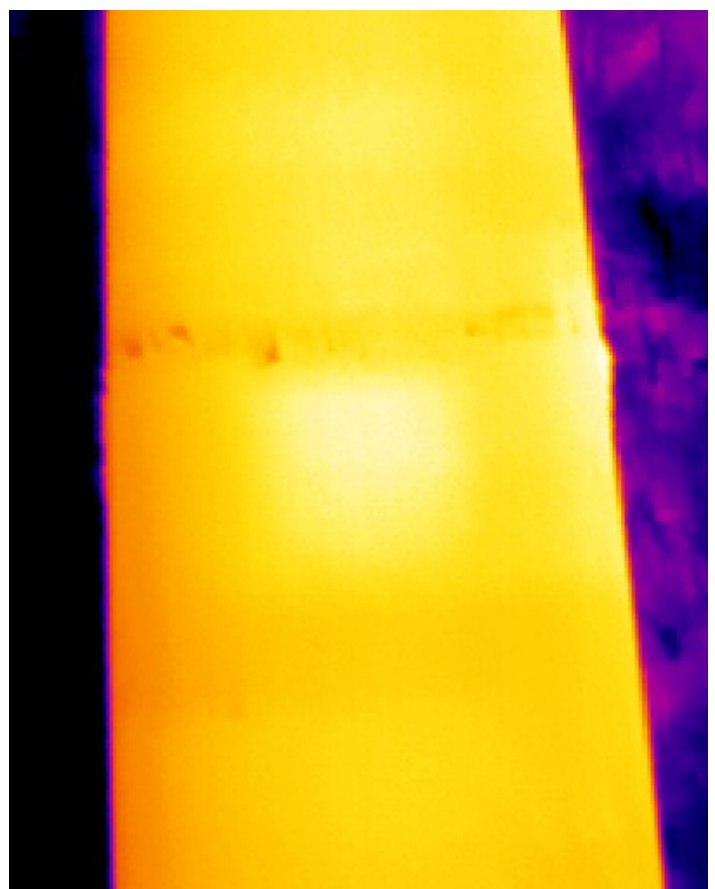

(d)

Figure 4.78 Infrared image of bridge deck specimen JD1a with delamination of size 3" x 3" x 1/20" at (a) 9.30 A.M. (b) 12.30 P.M. (c) 2.30 P.M. (d) 4.30 P.M.

\section{Bridge deck specimen JD2}

Table 4.10 and Figure 4.79 establishes values and curves for the 3 " x 3 " x $1 / 8$ " $(76 \mathrm{~mm} \times 76 \mathrm{~mm} \times 3 \mathrm{~mm})$ delamination in specimen JD2. The flange with the embedded delamination was covered with a $3 / 8$ " $(9.5 \mathrm{~mm})$ thick wearing surface. The delamination was located at an average depth of $0.69 "(17.5 \mathrm{~mm})$ from the top surface.

The surface temperature difference between the delaminated and defect-free areas was not high enough to establish an infrared image showing clear boundaries of the delamination. Figures 4.80 (a), (b), (c) and (d) shows the infrared images of the 3 " x 3 " x $1 / 8 "(76 \mathrm{~mm} \times 76 \mathrm{~mm} \times 3 \mathrm{~mm})$ delamination in the deck specimen JD2. It was observed that the boundary of the delamination could not be clearly detected. Temperature differences of about 2 to $2.9^{\circ} \mathrm{C}$ were detected between noon and around 3 P.M. However, with an adjustment of the contrast of the image by narrowing the difference between the upper and lower limits in the temperature scale, the delamination could be fairly seen in the infrared image. The Figures 4.80 (c) and (d) show surface temperature differentials caused by the presence of the delamination which is seen as a white region, whereas in 
Figure 4.80(b) the delamination is overshadowed by the heated edge (due to solar rays incident on the deck at an angle).

Table 4.10 Surface temperatures of 3"x 3" delamination and defect-free areas in specimen JD2

\begin{tabular}{|c|c|c|c|c|}
\hline $\begin{array}{c}\text { Time } \\
\text { of day }\end{array}$ & $\begin{array}{c}\text { 3" } \times \text { 3" } \\
\text { delamination (C) }\end{array}$ & $\begin{array}{c}\text { Defect-free } \\
\text { area (C) }\end{array}$ & $\begin{array}{c}\text { Difference for 3" } \times \text { 3" } \\
\text { delamination (C) }\end{array}$ & $\begin{array}{c}\text { Ambient Air } \\
(\text { C) }\end{array}$ \\
\hline 8.30 A.M. & 21.0 & 21.0 & 0.0 & 13.3 \\
\hline 9.00 A.M. & 20.9 & 20.9 & 0.0 & 14.0 \\
\hline 9.30 A.M. & 24.7 & 24.5 & 0.2 & 16.7 \\
\hline 10.00 A.M. & 34.2 & 33.9 & 0.3 & 17.0 \\
\hline 10.30 A.M. & 39.5 & 39.2 & 0.3 & 18.0 \\
\hline 11.00 A.M. & 45.4 & 44.3 & 1.1 & 20.0 \\
\hline 11.30 A.M. & 48.4 & 46.7 & 1.7 & 22.0 \\
\hline 12 Noon & 48.6 & 46.2 & 2.4 & 24.0 \\
\hline 12.30 P.M. & 50.5 & 48.1 & 2.4 & 24.4 \\
\hline 1.00 P.M. & 50.6 & 48.3 & 2.3 & 22.3 \\
\hline 1.30 P.M. & 51.6 & 49.7 & 1.9 & 22.5 \\
\hline 2.00 P.M. & 52.2 & 50.2 & 2.0 & 23.7 \\
\hline 2.30 P.M. & 51.1 & 48.8 & 2.3 & 24.1 \\
\hline 3.00 P.M. & 47.1 & 44.2 & 2.9 & 22.8 \\
\hline 3.30 P.M. & 45.3 & 43.7 & 1.6 & 23.1 \\
\hline 4.00 P.M. & 46.3 & 45.5 & 0.8 & 23.4 \\
\hline 4.30 P.M. & 44.8 & 44.1 & 0.7 & 23.2 \\
\hline 5.00 P.M. & 42.2 & 41.1 & 1.1 & 22.9 \\
\hline 5.30 P.M. & 37.8 & 37.5 & 0.3 & 22.1 \\
\hline 6.00 P.M. & 33.7 & 33.7 & 0.0 & 21.0 \\
\hline 6.30 P.M. & 29.5 & 29.4 & 0.1 & 20.1 \\
\hline 7.00 P.M. & 24.7 & 24.1 & 0.6 & 19.4 \\
\hline 7.30 P.M. & 20.6 & 20.4 & 0.2 & 17.1 \\
\hline
\end{tabular}




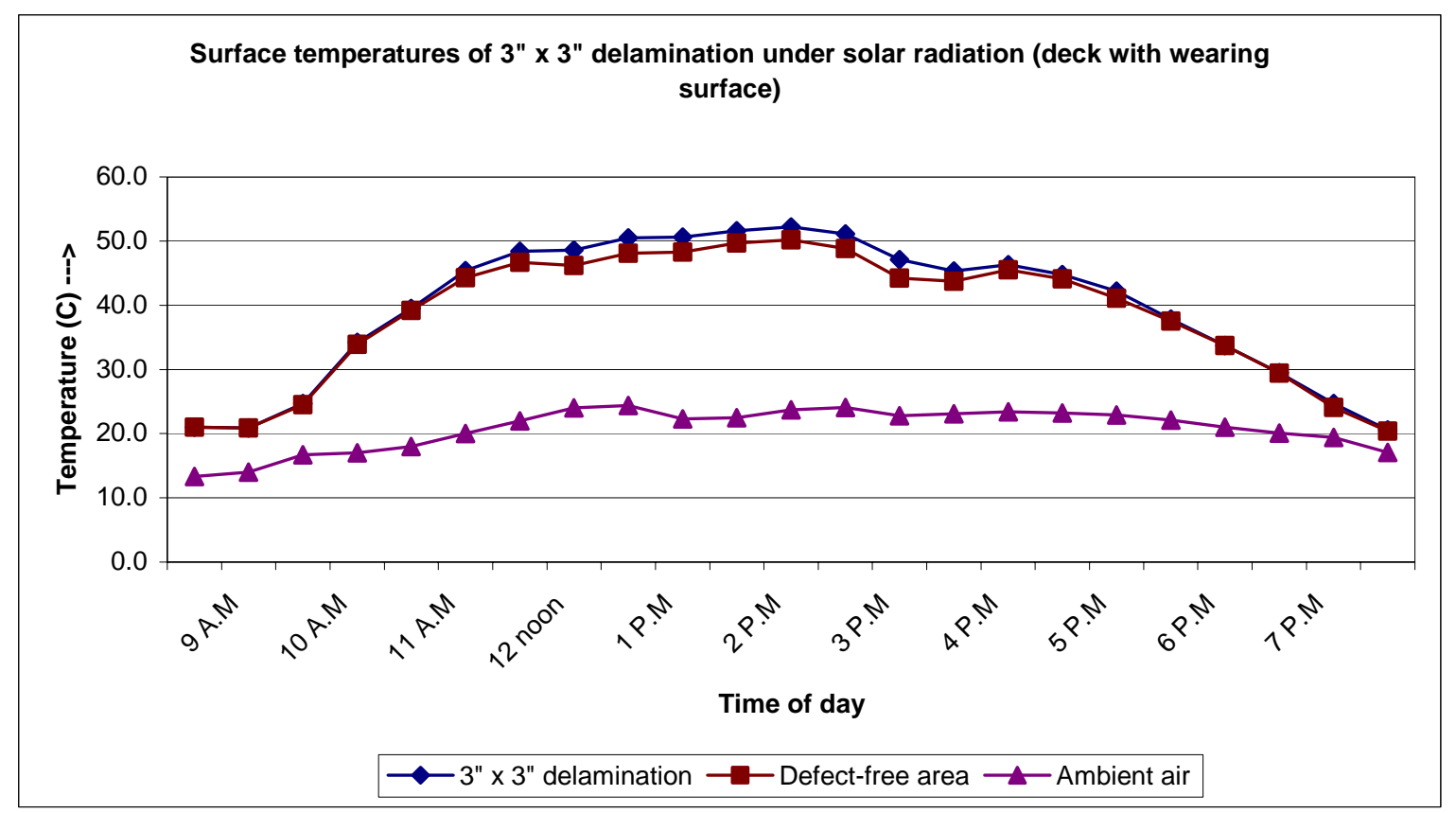

Figure 4.79 Surface temperature-time curves for 3"x 3" x 1/8" delamination in specimen JD2

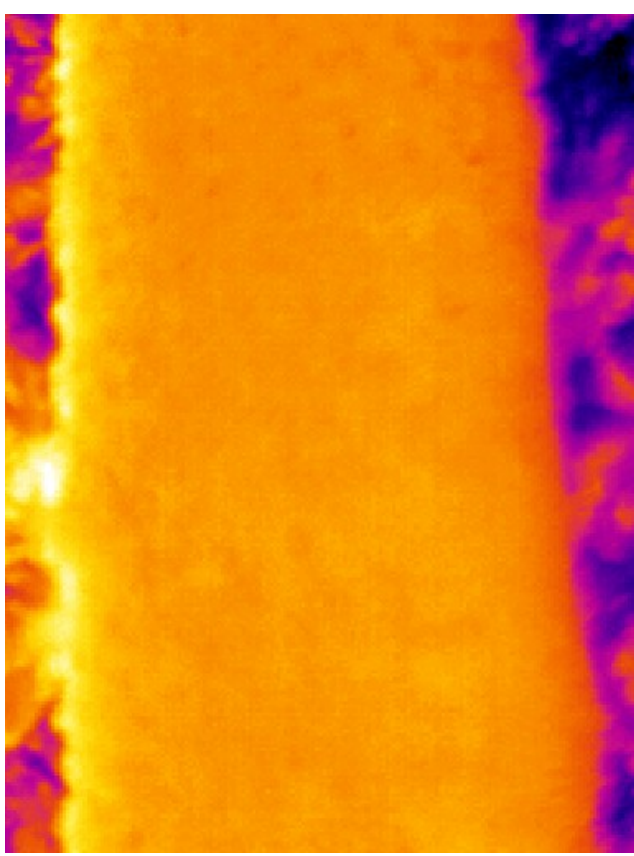

(a)

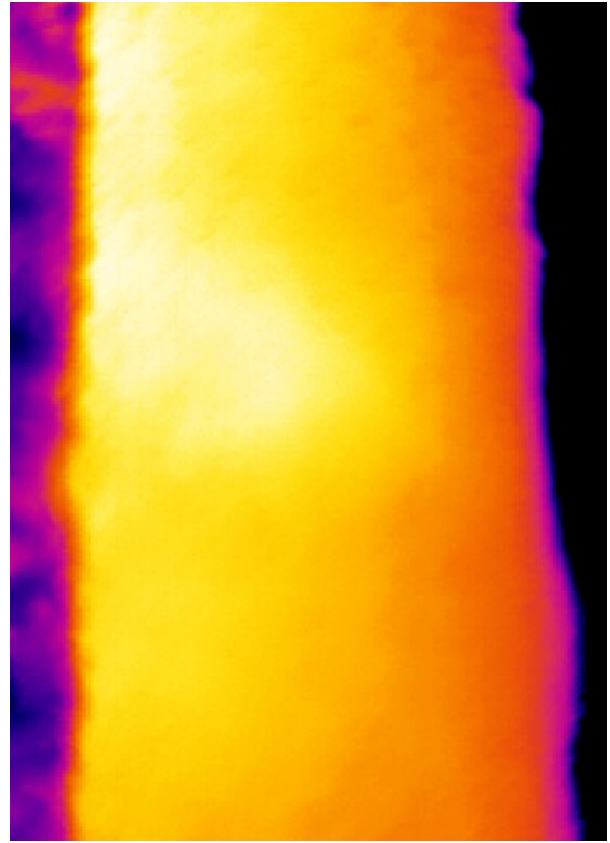

(b) 


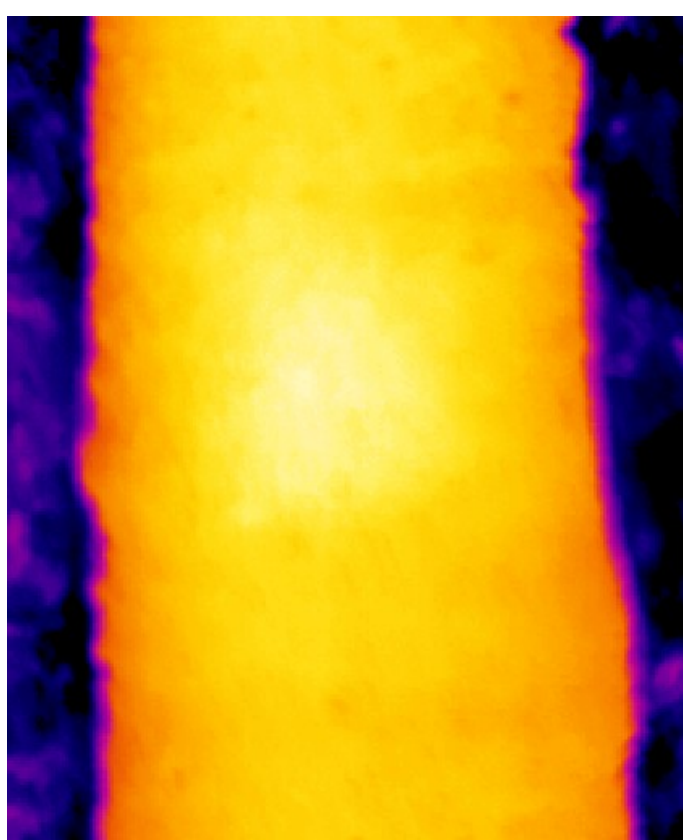

(c)

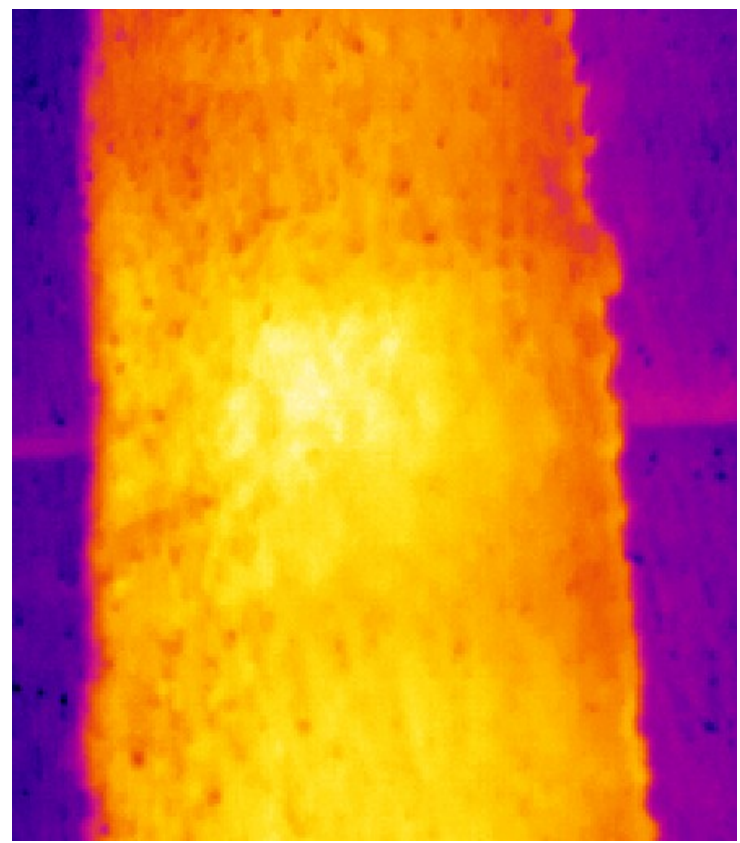

(d)

Figure 4.80 Infrared image of bridge deck specimen JD2 with delamination of size 3" x 3" x 1/8" at (a) 9.30 A.M. (b) 12 P.M. (c) 2.30 P.M. (d) 5 P.M.

\subsubsection{Conclusions}

Solar radiation can be used as a heating source to detect debonds between the wearing surface and the underlying FRP deck and delaminations within flanges of FRP deck without the wearing surface. However, solar radiation is not a very effective heating source for the detection of the delaminations within the FRP deck with a wearing surface overlay. Also, external wind forces could affect the surface temperature of the deck and contaminate the infrared image. Use of solar radiation as the heating source reduces the cost and time involved in using external heating sources like the heating blankets, quartz heater etc., specially in the field. However, when conducting field tests on FRP bridge decks, it may not be adequate to fully rely on solar radiation as the source of heating, since some portions of the deck may be under shadows of trees or adjacent buildings. Also, during colder days and even during evenings of hotter days, the amount of solar radiation received by the deck may not be sufficient enough to generate adequate surface temperature differentials. In such cases other heating sources like the quartz heater or heating blankets would be required. 


\subsection{INFRARED TESTS USING COOLING SOURCES}

Applying a cooling source is equivalent to applying a negative heat over the surface of the specimen. In the tests that were conducted using a heat source, the infrared images were captured after removing the heat source when the specimen's surface was cooling down. For the tests conducted using the cooling source, the infrared images were captured when the temperature of the specimen's surface gradually increased. The two sources that were used for this purpose were liquid carbon dioxide and cold tap water. The infrared tests and results are discussed.

\subsubsection{Liquid Carbon Dioxide $\left(\mathrm{CO}_{2}\right)$}

The bridge deck specimen BDla was used for the infrared tests conducted using liquid carbon dioxide as the cooling source. The deck consisted of two debonds of sizes 3" x 3" x 1/16" (76mm x 76mm x 1.6mm) and 2" x 2" x 1/16" (51 mm x 51mm x 1.6mm) placed between the $3 / 8$ " $(9.5 \mathrm{~mm})$ thick wearing surface and the underlying FRP deck. Pressurized liquid $\mathrm{CO}_{2}$ from a tank was sprayed through a nozzle on the surface of deck (BD1a) continuously for a period of 2 to 3 minutes. Infrared images of the deck were captured immediately after the cooling source was removed. Figures 4.81 and 4.82 shows the infrared image of the deck BDla, where the debonds are clearly seen.

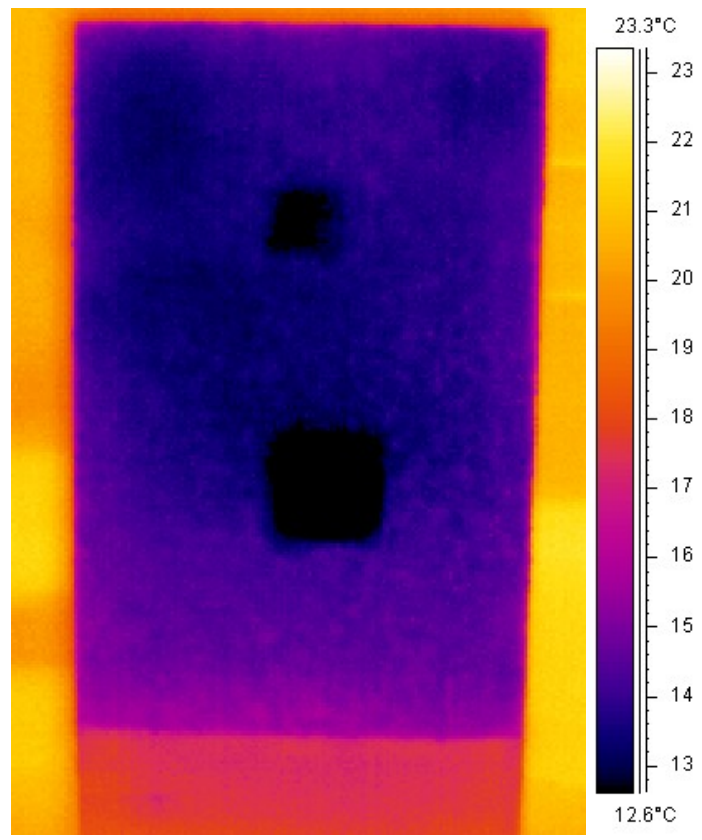

Figure 4.81. Infrared image of bridge deck specimen BDla with debonds of sizes 2" x 2" x 1/16" and 3" x 3" x 1/16", cooled using liquid $\mathrm{CO}_{2}$ 


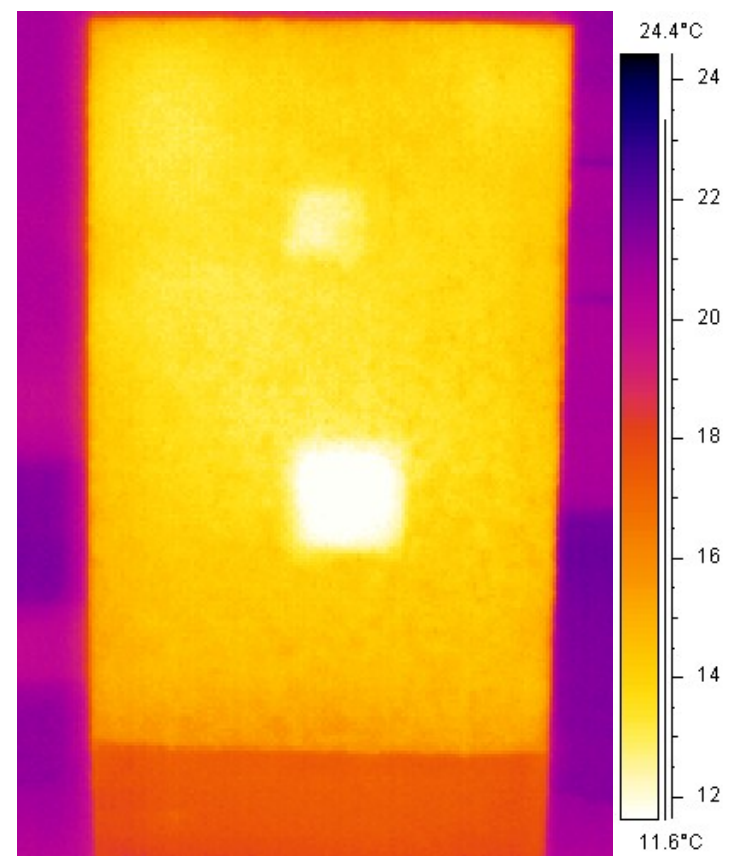

Figure 4.82. Infrared image of bridge deck specimen BD1a with debonds of sizes 2" x 2" x 1/16" and 3" x 3" x 1/16", cooled using liquid $\mathrm{CO}_{2}$, with an inverted color scale for the temperature

Figure 4.82 shows the infrared image with an inverted temperature scale, where the debonded (colder) areas are seen as bright areas. In both the images (Figures 4.81 and $4.82)$ the 3 " x 3 " (76mm x 76mm) debond was more clearly seen than the 2 " x 2 " (51mm x $51 \mathrm{~mm}$ ) debond. The surface temperatures above the 3" x 3", 2" x 2" debonds, and defect-free areas were $11.2^{\circ} \mathrm{C}, 12.4{ }^{\circ} \mathrm{C}$ and $13.8{ }^{\circ} \mathrm{C}$, respectively. This means the temperature differential between the 3 " x 3 " debond and defect-free area was $-2.6{ }^{\circ} \mathrm{C}$ and the differential between 2 " x 2 " and defect-free was only $-1.4{ }^{\circ} \mathrm{C}$. Though the temperature difference between the debonded and defect-free areas were not very high enough, contrast of both the areas were seen clearly in the infrared image. This is because the contrast of the image was adjusted by narrowing the difference between the upper and lower limits in the temperature scale, so that the debonds could be clearly seen in the infrared image. This is the main advantage of the digital infrared images as this feature is not available in case of non-digital cameras. Also, it should be noted that the background (defect-free) temperature is low in this case, hence even a smaller temperature differential leads to a good contrast. This aspect is explained in detail in Section 4.14. 


\subsubsection{Cold Water}

Cold water with a temperature of about $4-5^{\circ} \mathrm{C}\left(39-41^{\circ} \mathrm{F}\right)$, was used as another cooling source and was used for cooling the specimens BD1a, JD1a and JD2 (described in Sections 4.4.1 and 4.5.1). The bridge decks were left under solar radiation from morning to afternoon, prior to pouring cold tap water over the surface. The infrared images of the decks were captured immediately after the deck had been cooled with water.

The specimen BDla consisted of two debonds of sizes 3" x 3" x 1/16" (76mm x $76 \mathrm{~mm} \times 1.6 \mathrm{~mm})$ and $2 " \times 2 " \times 1 / 16 "(51 \mathrm{~mm} \times 51 \mathrm{~mm} \times 1.6 \mathrm{~mm})$ between the $3 / 8$ " $(9.5 \mathrm{~mm})$ thick wearing surface and FRP deck. The surface temperatures above the 3 " $\mathrm{x}$ 3", 2" x 2" debonds, and defect-free areas, before prior to pouring water were $52.5^{\circ} \mathrm{C}$, $50.1^{\circ} \mathrm{C}$ and $48.4^{\circ} \mathrm{C}$ respectively. The difference between the 3 " x 3 " $(76 \mathrm{~mm} \times 76 \mathrm{~mm})$ debond and defect-free area was about $4.1^{\circ} \mathrm{C}$ and the differential between $2 " \mathrm{x} 2$ " $(51 \mathrm{~mm}$ x $51 \mathrm{~mm}$ ) debond and defect-free area was only about $1.7^{\circ} \mathrm{C}$. After the deck was cooled by pouring cold water on its surface, the temperatures above the 3 " x 3 ", 2" x 2 " debonds, and defect-free areas were $27.5^{\circ} \mathrm{C}, 31.8^{\circ} \mathrm{C}$ and $32.9^{\circ} \mathrm{C}$ respectively. The temperature differential between the 3" $\mathrm{x} 3$ " $(76 \mathrm{~mm} \times 76 \mathrm{~mm})$ debond and defect-free area was $-5.4^{\circ} \mathrm{C}$ and the differential between 2" x 2" (51mm x 51mm) debond and defect-free area was only $-1.1^{\circ} \mathrm{C}$. The infrared image of this deck (Figure 4.83$)$ revealed the 3 " x 3 " $(76 \mathrm{~mm} \mathrm{x}$ $76 \mathrm{~mm})$ debond clearly. But the 2" x 2" (51mm x 51mm) debond could not be detected though there was a very small temperature differential between this debond and defectfree area. The cooler temperature in the deck did not sustain for very long. As the deck was left under solar radiation (same condition as for a field deck), the surface temperature started rising immediately and after about 2 minutes the surface temperature above the 3 " x 3" (76mm x 76mm) debond and defect-free area were almost the same. 


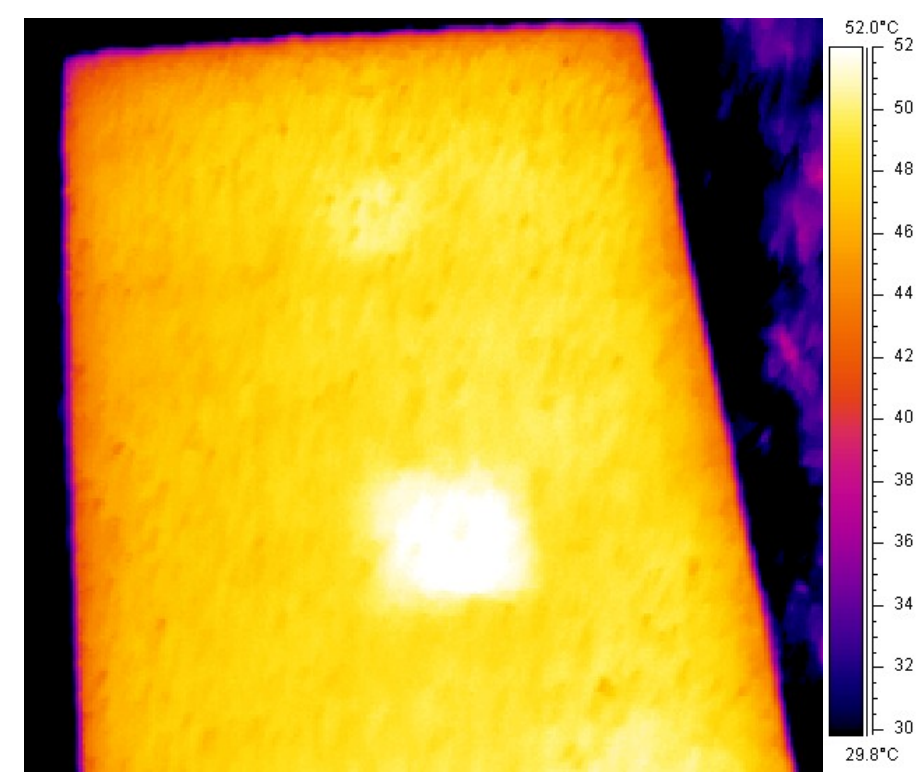

(a)

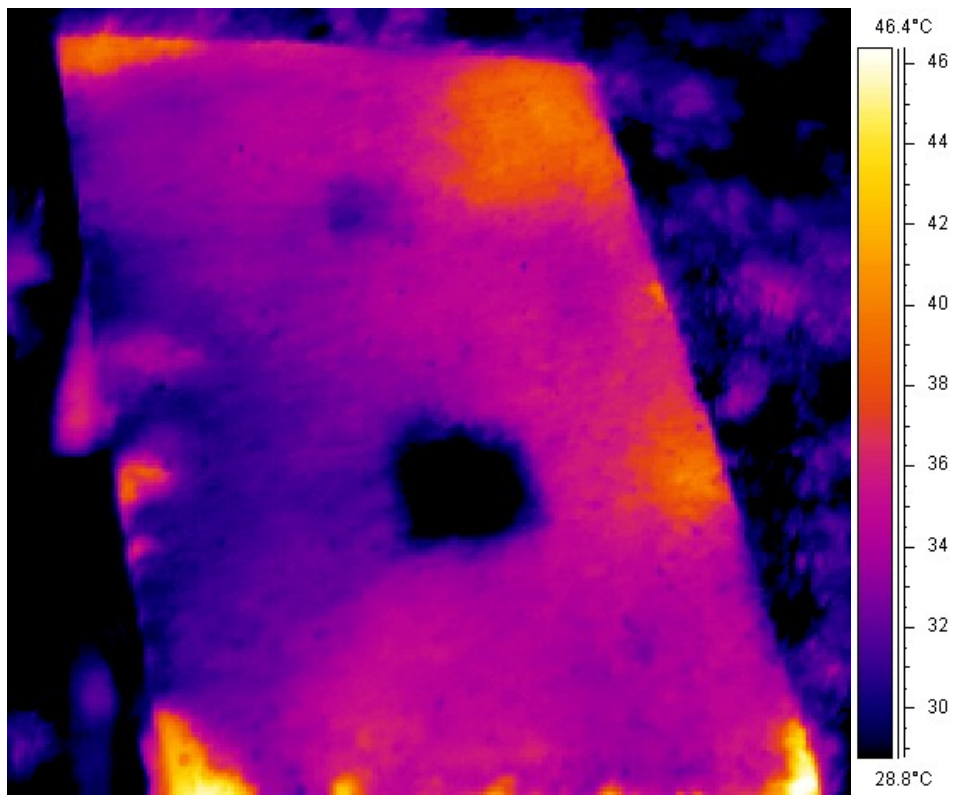

(b)

Figure 4.83. Infrared image of bridge deck specimen BD1a with debonds of sizes 2" x 2" x 1/16" and 3" x 3" x 1/16" (a) before application of cold water (b) after application of cold water

The infrared images of specimens JD1a (with no wearing surface) and JD2 (with wearing surface layer) with delaminations in the flange-flange junction (Figures 4.84 (a) and (b)) did not show any surface temperature differentials corresponding to the delaminations before and after pouring water. The surface temperature differentials seen in the infrared image of JD1a was due to the uneven layer of water on its surface. 

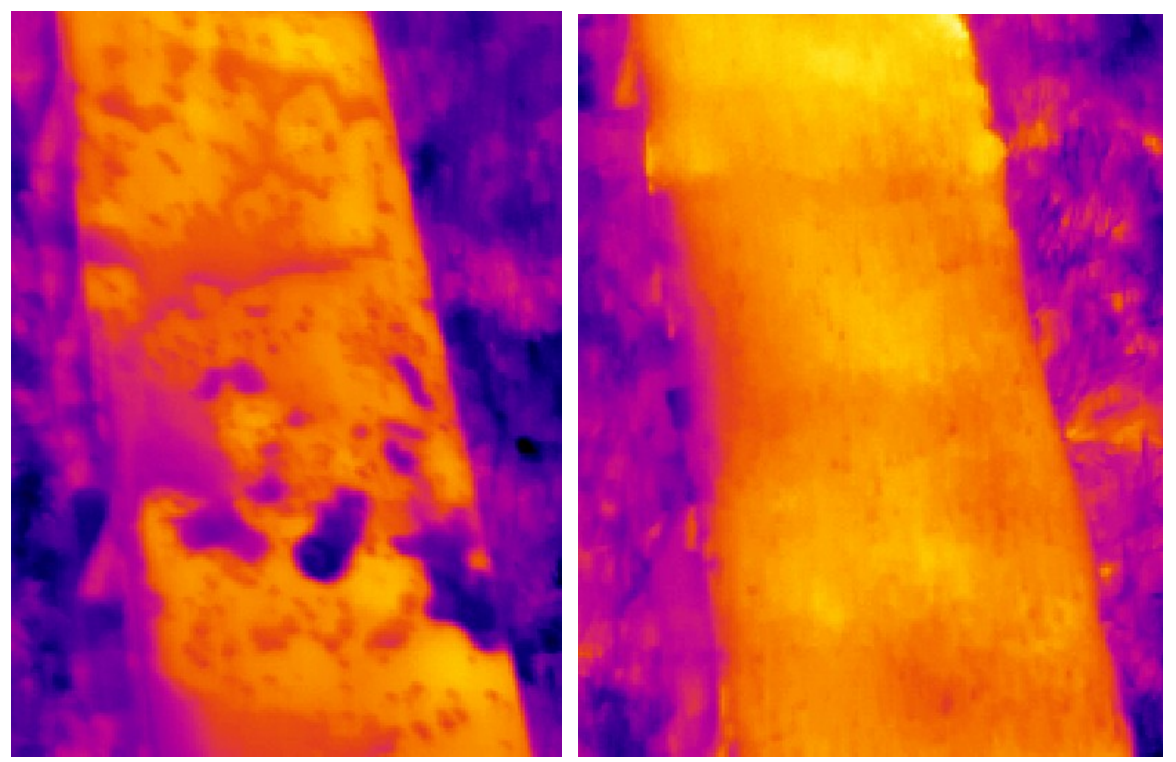

Figure 4.84. Infrared images of bridge deck specimens (a) JD1a (b) JD2, both cooled using tap water

\subsubsection{Conclusions}

Infrared tests conducted using liquid carbon dioxide as the cooling source detected debonds as small as 2" x 2" x $1 / 16$ " $(51 \mathrm{~mm}$ x $51 \mathrm{~mm} \times 1.6 \mathrm{~mm})$. However the temperature differentials for the debonded and defect-free area were not very high. When cold water was used as the cooling source, debond of size 3" x 3" x 1/16" (76mm x $76 \mathrm{~mm} \times 1.6 \mathrm{~mm}$ ) present between the wearing surface layer and underlying FRP deck layer in deck BD1a, was detected. But the cooling was not sustained for a longer time and hence the temperature of both the areas reached the same value in a short time. The 2" $\mathrm{x}$ 2" x 1/16" $(51 \mathrm{~mm} \times 51 \mathrm{~mm} \times 1.6 \mathrm{~mm})$ debond could not be detected. The delaminations present at the flange-flange junction of decks JD1a and JD2 could not be detected with water cooling. Also, the area was small and the water flowed down through the edges. The effective cooling period was not long enough to establish a good thermal differential on the surface of the deck.

\subsection{INFRARED TESTS ON STEEL-CONCRETE COMPOSITE COLUMNS}

Steel jacketing (wrapping) of existing concrete bridge piers is one of the techniques used for increasing the bridge's earthquake resistance and for repairing piers that have sustained extensive cracking and spalling due to corrosion or fire during the life 
of the structure. These jackets (wraps) provide confinement to the underlying concrete and increase the load carrying capacity of the piers. Laboratory experiments were conducted on steel-concrete bridge columns created with embedded simulated defects. Details on the experimental study and the results from infrared testing are given below.

\subsubsection{Description of Specimens}

Three steel-concrete column specimens were cast by pouring concrete (with no rebars) into steel cylinder of external diameter of 8.25 " (210mm), length of 12 " (305mm) and a thickness of $1 / 2 "(13 \mathrm{~mm})$. The concrete was prepared at a Ready Mix company site and the specified compressive strength of this concrete was 4000 psi. Air-filled debonds of various sizes were placed on the inner surface of the steel cylindrical jacket prior to pouring of concrete (see Figure 4.85). Concrete was then poured, compacted and left to cure.

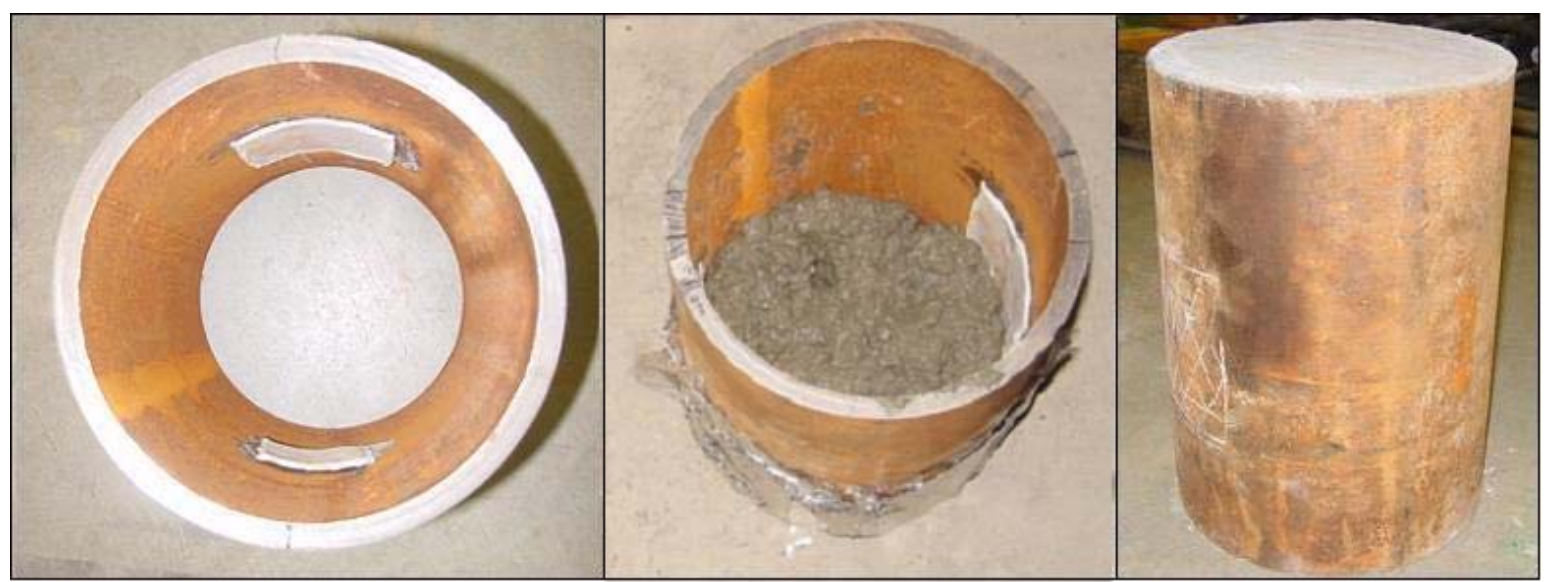

Figure 4.85. Photographs showing a steel-concrete column specimen (a) location of debonds on the inner surface of the steel cylindrical jacket (b) pouring of concrete into the steel cylinder (c) finished steelconcrete column specimen

Specimen SC1 had 2" x 2" $(50 \mathrm{~mm} \times 50 \mathrm{~mm})$ and 3" x 3" $(76 \mathrm{~mm} \times 76 \mathrm{~mm})$ debonds on the opposite sides. Specimen SC2 had 4" x 4" (100mm x 100mm) debond on one side and two other debonds of sizes 1" x 1" ( $25 \mathrm{~mm}$ x 25mm) and 1/2" x 1/2" (13mm x $13 \mathrm{~mm})$ on the opposite side. All these debonds were air-filled with $1 / 16$ " (1.6mm) thickness. Specimen SC3 had no debonds and was used as a control specimen. Although 
these column specimens have smaller diameter than actual bridge piers $(\sim 1$ to $2 \mathrm{~m}$ in diameter), the thickness of the steel jacket used here $(1 / 2$ " or $13 \mathrm{~mm})$ is typical of what is used in the field bridges. Therefore, these specimens are adequate for establishing the detectability of subsurface debonds at the steel-concrete interface using infrared thermography.

\subsubsection{Infrared Testing and Results}

The steel-concrete composite cylinders were heated using a quartz heater. Uniform heating of the specimen was carried out for about 5 minutes, so that the temperature was high enough $\left(\sim 75^{\circ} \mathrm{C}\right)$ to produce an infrared image with a good contrast between the sound and defective areas. Steel is a good conductor of heat, thus it has a tendency to equilibrate the surface temperature with lateral heat transfer. Therefore, a longer heating duration is required to establish a significant thermal gradient through the thickness, especially because of the relatively high thickness of the steel jacket (1/2").

In this experimental study, debonds of sizes 2" x 2", 3" x 3" and 4" x 4" were detected by the digital infrared camera. The smaller debonds of sizes 1 " x 1 " and $1 / 2$ " $\mathrm{x} 1 / 2$ " could not be detected even after heating the specimen to a higher temperature (up to $85^{\circ} \mathrm{C}$ ). This is because the debonds were too small and were located at a considerable depth of $1 / 2 "(13 \mathrm{~mm})$ underneath the steel jacket.

Figures 4.86, 4.87 and 4.88 show the infrared images of the steel-concrete cylinders with the simulated 4" x 4", 3" x 3" and 2" x 2" debonds between the steel and underlying concrete material. The temperature differences between the defective (4" x 4", $3 " x 3$ " and 2" x 2") and defect-free areas were about $11^{\circ} \mathrm{C}, 10^{\circ} \mathrm{C}$ and $9^{\circ} \mathrm{C}$ respectively. In the figures the debonds are seen as the bright square regions (areas with higher temperature when compared to the surrounding areas). 


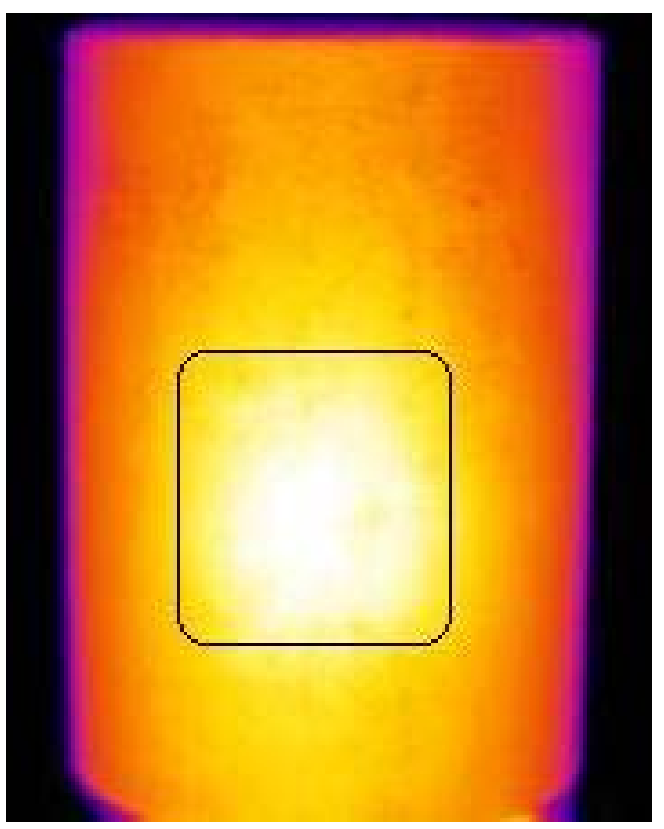

Figure 4.86. Infrared image of the steel-concrete specimen SC2 showing debond of size 4" x 4"

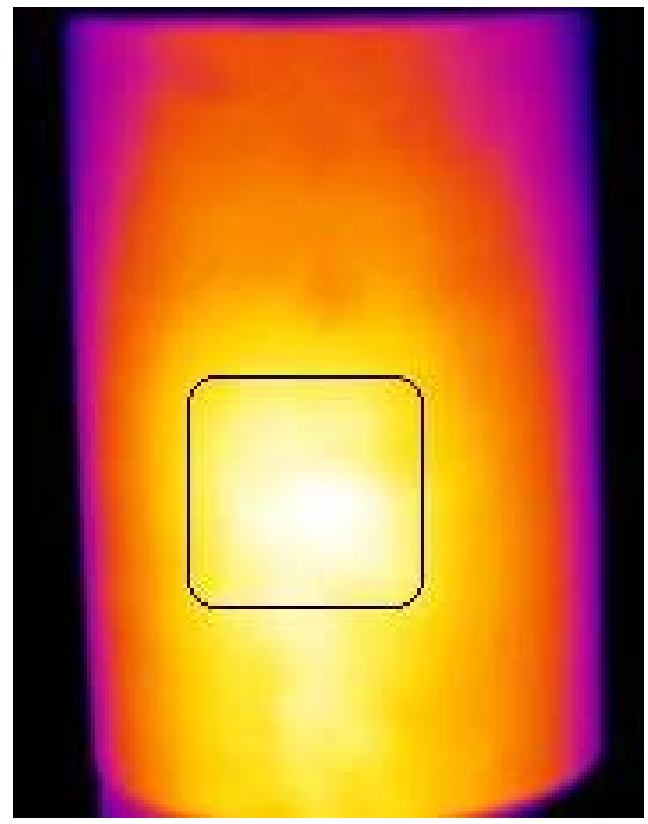

Figure 4.87. Infrared image of the steel-concrete specimen SC1 showing debond of size 3" x 3" 


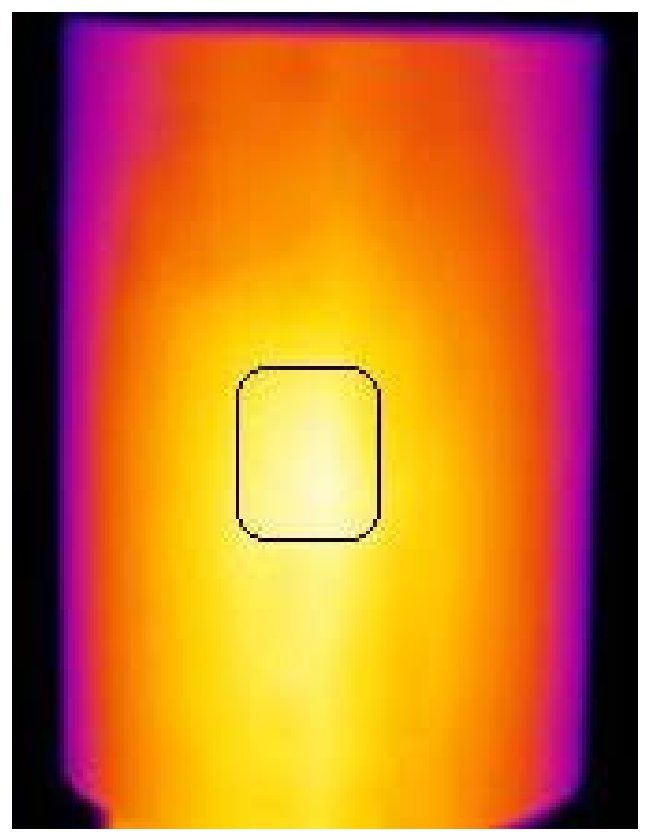

Figure 4.88. Infrared image of the steel-concrete specimen SC1 showing debond of size 2" x 2"

\subsubsection{Conclusions}

Infrared thermography has been successful in detecting the debonds in a steelconcrete column specimen. The debonds of sizes 2" x 2", 3" x 3" and 4" x 4" (all with thicknesses of $1 / 16 "(1.6 \mathrm{~mm})$ and located underneath the $1 / 2 "(13 \mathrm{~mm})$ thick steel jacket, could be detected using the digital infrared camera. Debonds of sizes 1 " x 1 " and $1 / 2$ " x $1 / 2$ " could not be detected even after heating the specimen for a very high temperature. The sizes of these debonds were too small to be located underneath a $1 / 2$ " thick steel jacket. Hence it was not possible to detect these defects.

\subsection{INFRARED TESTS ON FRP WRAPPED TIES}

Wooden ties are used as a base for the railroad tracks. Portions of the ties (underneath the location of rails where the deterioration is the most severe) were rehabilitated with FRP wraps and tested to determine the increase in load carrying capacity as a part of another study. Infrared tests were conducted on these FRP wrapped railroad ties to detect the presence of any debonds between the FRP wraps and underlying wooden member, and the results are presented here. 


\subsubsection{Description of Specimens}

Two railroad ties $\mathrm{A}$ and $\mathrm{B}$, with some portions wrapped with FRP wrap were tested using infrared thermography. Figure 4.89 shows the photograph of these specimens.

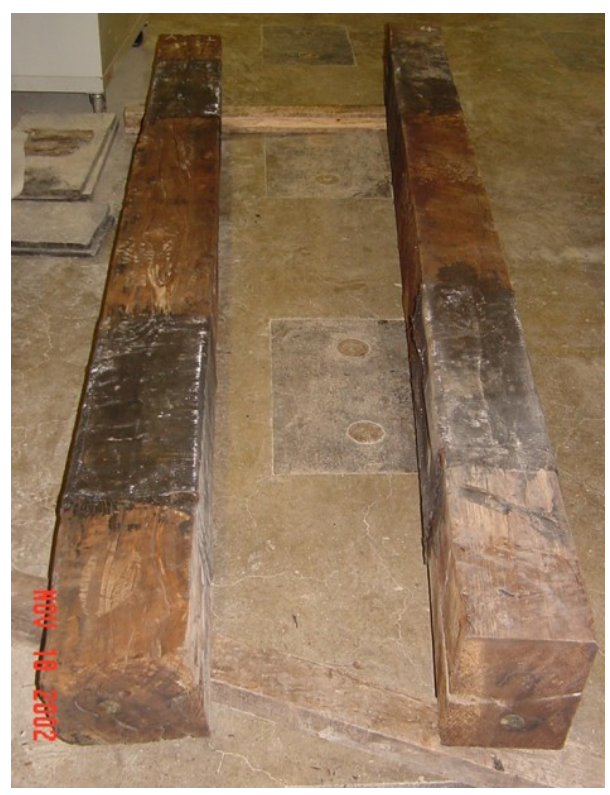

Figure 4.89. Photograph of FRP wrapped railroad tie specimens A and B

The portions that lied directly underneath the railroad tracks were wrapped with the FRP wraps (on all four surfaces). Wrapped portions on all the four surface of the rectangular member (named A1 to A4, B1 to B4) were tested using infrared thermography in order to detect any subsurface debonds. Since each tie had two rail locations, they were named side 1 and side 2 .

\subsubsection{Infrared Testing and Results}

The portions that were wrapped with FRP were heated using the quartz heater. The infrared images were acquired from all the four surfaces of the wrapped portions of the rectangular specimens $\mathrm{A}$ and B. Figures 4.90 to 4.97 shows the photographs and the corresponding infrared images of these wrapped portions, where sides 1 and 2 refer to the two rail locations for each tie. 

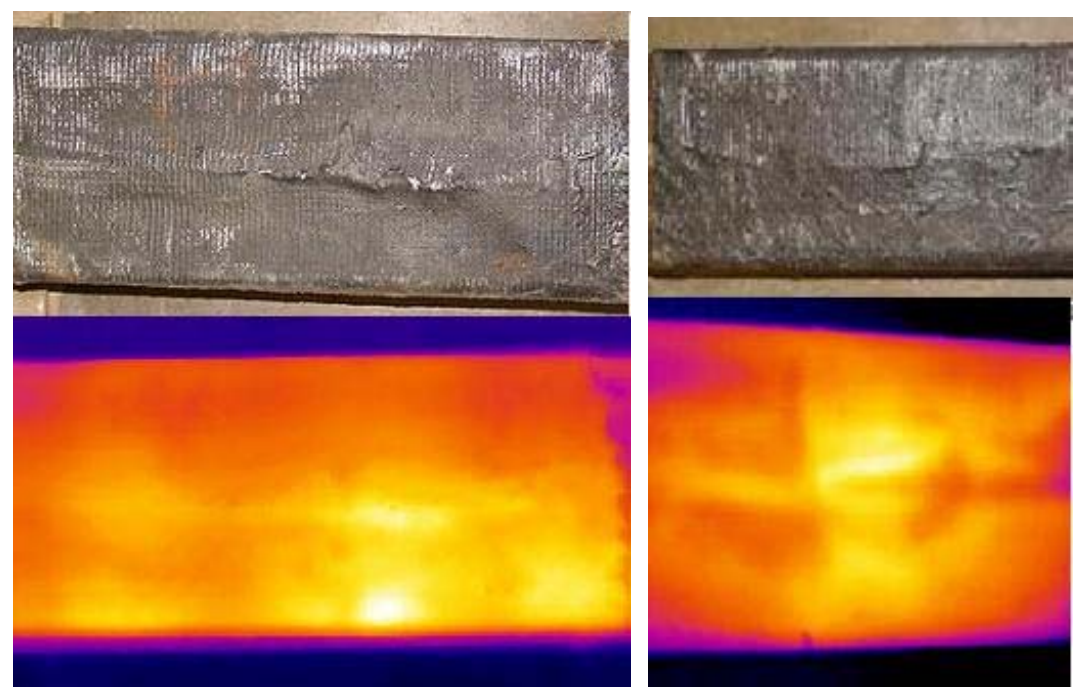

Figure 4.90. Photograph and infrared image of (a) A1-side1 (b) A1-side 2
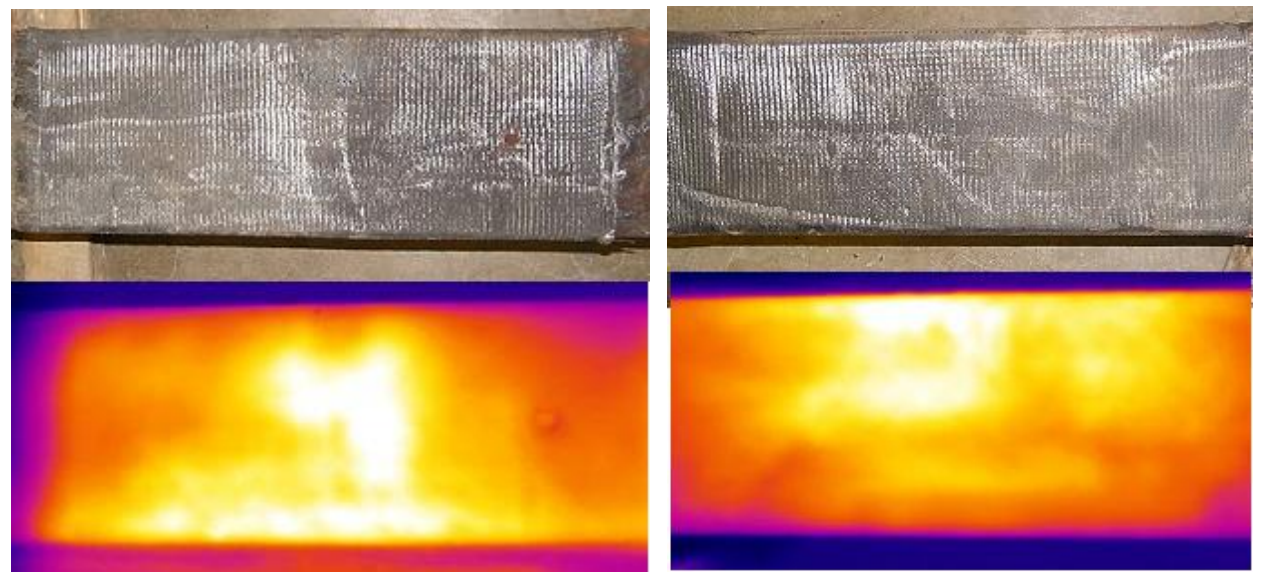

Figure 4.91. Photograph and infrared image of (a) A2-side1 (b) A2-side 2
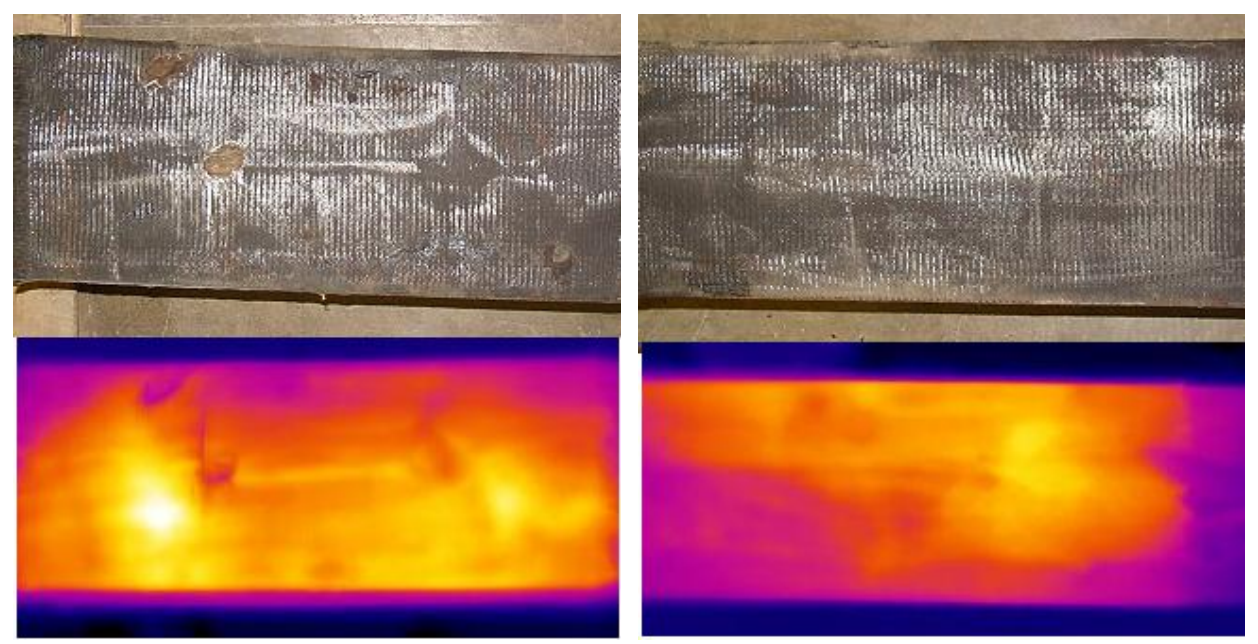

Figure 4.92. Photograph and infrared image of (a) A3-side1 (b) A3-side 2 

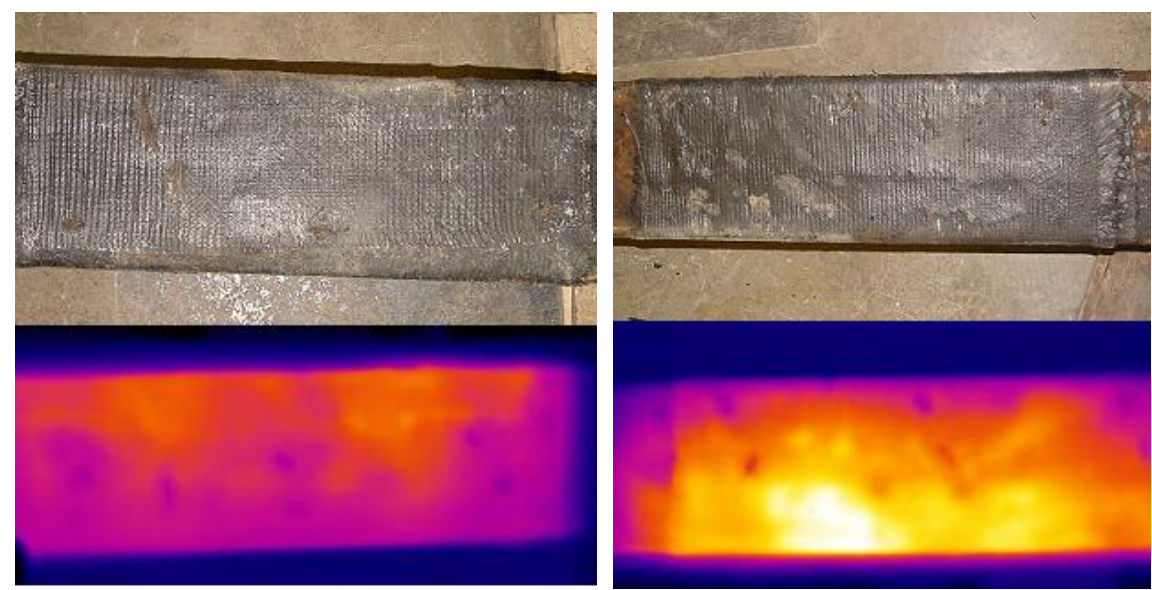

Figure 4.93. Photograph and infrared image of (a) A4-side1 (b) A4-side 2
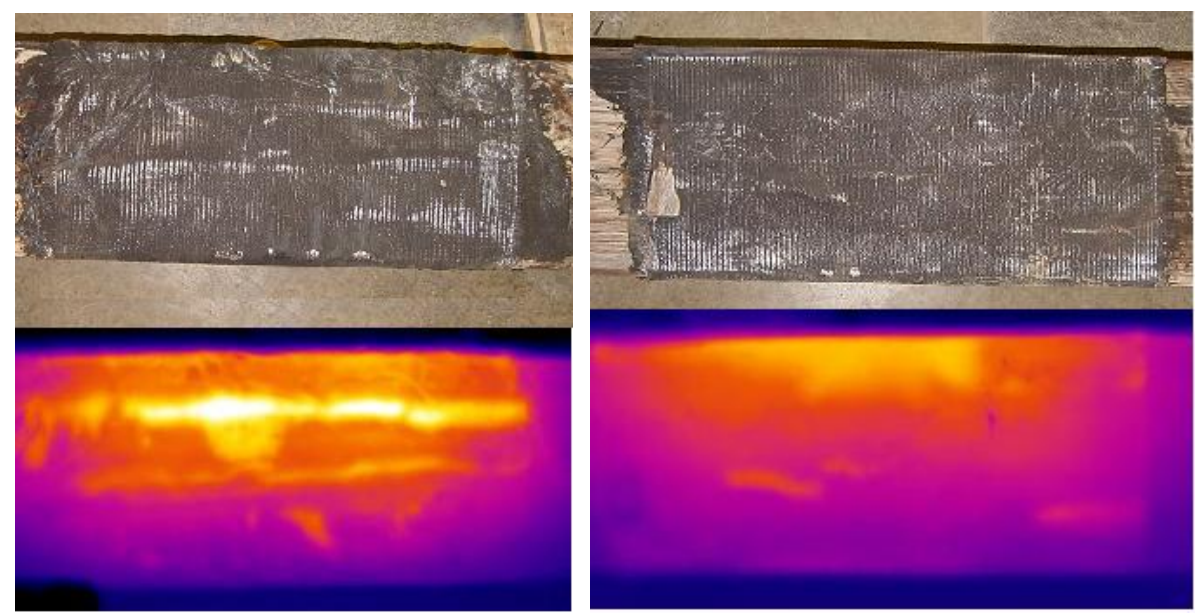

Figure 4.94. Photograph and infrared image of (a) B1-side1 (b) B1-side 2
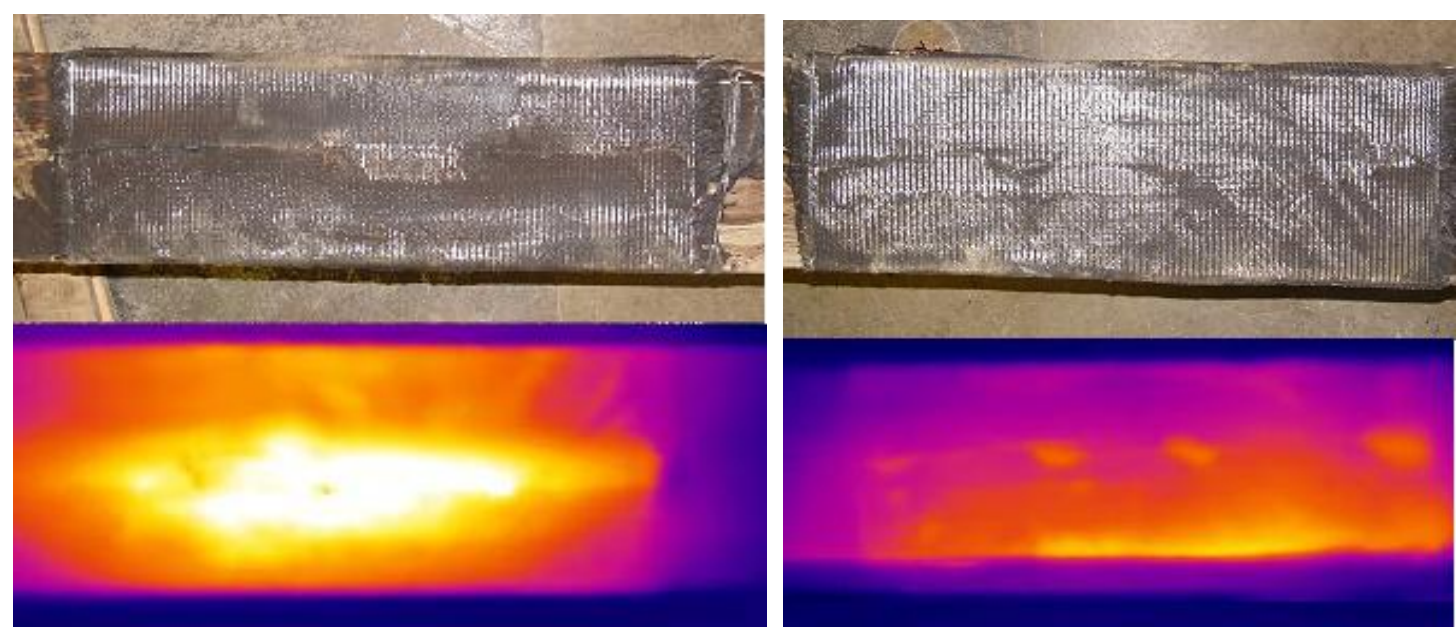

Figure 4.95. Photograph and infrared image of (a) B2-side1 (b) B2-side 2 

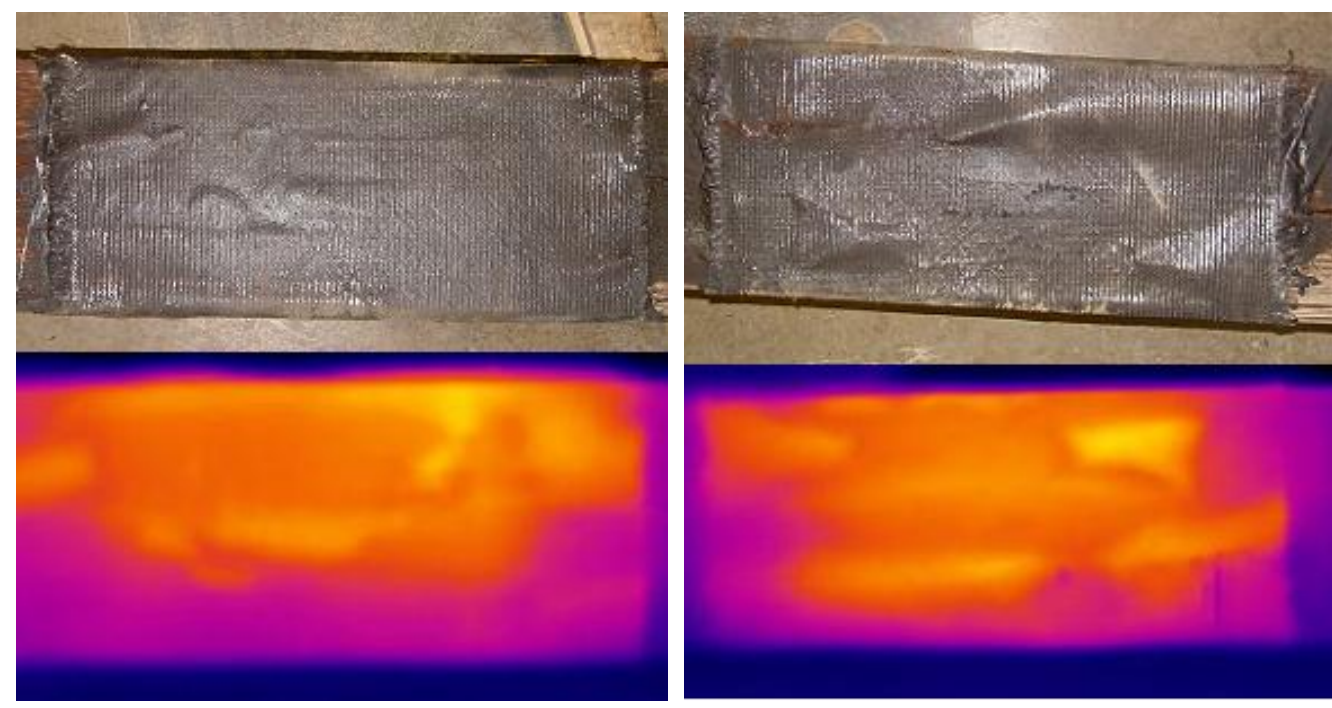

Figure 4.96. Photograph and infrared image of (a) B3-side1 (b) B3-side 2
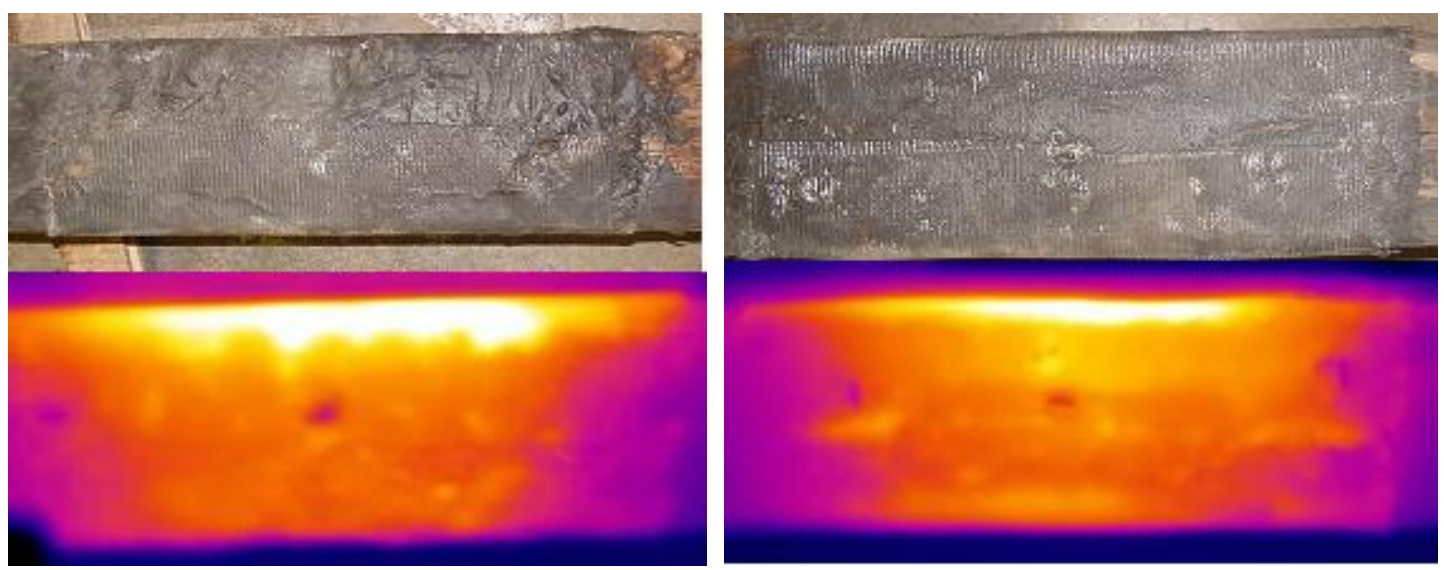

Figure 4.97. Photograph and infrared image of (a) B4-side1 (b) B4-side 2

The infrared images revealed small areas of debondings between the FRP wrap and the underlying wood. The defective areas stood out as bright white areas in the infrared images. For example, the infrared image in 4.94(a) shows some of the cracks in the underlying wooden tie. The FRP was wrapped around this tie to arrest the crack growth.

\subsubsection{Conclusions}

Infrared technique detected debonds present in-between FRP layer and the underlying wood in the wrapped wooden ties. It was also able to detect the some of the cracks that were present in the wooden members, underneath the FRP wrap. 


\subsection{CONTRAST PARAMETER}

The detectability of the subsurface defects in the digital infrared image mainly depends on the temperature contrast between the defective and defect-free areas. Equation 4.1 is one of the common thermal contrast parameter equations, which has been previously established by researchers (Plotnikov and Winfree 1999). Chapter 2, section 2.6 contains a detailed description of the contrast parameter.

The contrast parameter used here is given by the following expression:

$$
\mathrm{C}=\Delta \mathrm{T} / \mathrm{T}_{\text {defect-free }}
$$

where $\Delta \mathrm{T}$ is the temperature difference between the defective and defect-free areas and $\mathrm{T}_{\text {defect-free }}$ is the surface temperature of the defect-free area.

The contrast values for most of the laboratory cases were computed and the values are given in Table 4.11. The first and the second columns in the table give the type and the size of the subsurface defects. The third and the fourth columns give the surface temperatures of the defective and defect-free areas. The fifth column gives the temperature difference between these two areas. The sixth column shows the absolute value of the computed contrast parameter, which is defined in Equation 4.1. The last column comments on the detectability of the defects as observed in the corresponding infrared images.

It was observed that the boundaries of the subsurface defects were clearly visible in the infrared image when the contrast parameter $(C)$ was greater than or equal to the value of $1 / 10$. In most of the cases, where the contrast value was less than $1 / 10$, the infrared images did not show a very clear boundary of the defective area. Hence it could be concluded that a value of $1 / 10$ or greater is required to confirm the presence of the subsurface defect in the infrared images captured using the ThermaCAM $^{\mathrm{TM}}$ digital infrared camera. 
Table 4.11 Values for the Contrast parameter in different experimental setup cases

\begin{tabular}{|c|c|c|c|c|c|c|}
\hline Type & Size & $\begin{array}{c}\mathbf{T}_{\text {defect }} \\
{ }^{0} \mathrm{C} \\
\end{array}$ & $\begin{array}{c}\mathbf{T}_{\text {defect-free }} \\
{ }^{0} \mathrm{C} \\
\end{array}$ & $\begin{array}{c}\text { Difference } \\
(\Delta \mathrm{T})^{\circ} \mathrm{C}\end{array}$ & $\begin{array}{c}\text { Contrast } \\
\Delta \mathrm{T} / \mathrm{T} \text { defect-free } \\
\end{array}$ & Comments \\
\hline \multicolumn{7}{|l|}{ Laboratory Exp } \\
\hline \multicolumn{7}{|l|}{ Debond } \\
\hline \multirow[t]{4}{*}{ Air-filled } & $3 " \times 3 " \times 1 / 16 "$ & 61 & 52 & 9 & $1 / 5.8$ & Easily detectable \\
\hline & $2 " \times 2 " \times 1 / 16 "$ & 59.5 & 52 & 7.5 & $1 / 6.9$ & Easily detectable \\
\hline & $1 " \times 1 " \times 1 / 16 "$ & 56 & 48 & 8 & $1 / 6.0$ & Easily detectable \\
\hline & $1 / 2 " \times 1 / 2 " \times 1 / 16 "$ & 52 & 48 & 4 & $1 / 12.0$ & Detectable \\
\hline \multirow[t]{2}{*}{ Water-filled } & $3 " \times 3 " \times 1 / 16$ & 36.9 & 41 & -4.1 & $1 / 10.0$ & Detectable \\
\hline & $2 " \times 2 " \times 1 / 16 "$ & 38.5 & 41 & -2.5 & $1 / 16.4$ & Detectable but boundary not prominent \\
\hline \multicolumn{7}{|l|}{ Delamination } \\
\hline (no wearing surface) & $3 " x$ 3" x 1/20" & 61.8 & 51.1 & 10.7 & $1 / 4.78$ & Easily detectable \\
\hline (no wearing surface) & $2 " \times 2 " \times 1 / 16 "$ & 61 & 55.2 & 5.8 & $1 / 9.5$ & \begin{tabular}{|c|} 
Easily detectable \\
\end{tabular} \\
\hline (no wearing surface) & $1 " \times 1 " \times 1 / 16 "$ & 59 & 55.2 & 3.8 & $1 / 14.53$ & Detectable but boundary not prominent \\
\hline (with wearing surface) & $3 " \times 3 " \times 1 / 8 "$ & 78 & 71.7 & 6.3 & $1 / 11.38$ & Detectable but boundary not prominent \\
\hline (with wearing surface) & $3 "$ x 3" x 1/16" & 62.1 & 58.4 & 3.7 & $1 / 15.78$ & Detectable but boundary not prominent \\
\hline \multicolumn{7}{|l|}{$\underline{\text { Solar Radiation }}$} \\
\hline \multicolumn{7}{|l|}{ Debond } \\
\hline at 2.30 P.M. & $3 " \times 3 " \times 1 / 16$ & 53 & 47.9 & 5.1 & $1 / 9.4$ & Easily detectable \\
\hline at 12.30 P.M. & $2 " \times 2 " \times 1 / 16^{\prime \prime}$ & 50 & 47.7 & 2.3 & $1 / 20.7$ & Difficult to detect \\
\hline \multicolumn{7}{|l|}{ Delamination } \\
\hline at 2.30 P.M. (no WS) & $3 " x 3 " x 1 / 20 "$ & 49.5 & 45.5 & 4 & $1 / 11.38$ & Detectable \\
\hline at 2.30 P.M. (with WS) & $3 " \times 3 " \times 1 / 8 "$ & 51.1 & 48.8 & 2.3 & $1 / 21.2$ & Difficult to detect \\
\hline \multicolumn{7}{|l|}{$\underline{\text { Liquid } \mathrm{CO}_{2}}$} \\
\hline \multicolumn{7}{|l|}{ Debond } \\
\hline & $3 " \times 3 " \times 1 / 16$ & 11.2 & 13.8 & -2.6 & $1 / 5.3$ & Easily detectable \\
\hline & $2 " \times 2 " \times 1 / 16 "$ & 12.4 & 13.8 & -1.4 & $1 / 9.9$ & Detectable \\
\hline \multicolumn{7}{|l|}{$\underline{\text { Cold water }}$} \\
\hline \multicolumn{7}{|l|}{ Debond } \\
\hline & $3 " \times 3 " \times 1 / 16$ & 27.5 & 32.9 & -5.4 & $1 / 6.1$ & Easily detectable \\
\hline & $2 " \times 2 " \times 1 / 16 "$ & 31.8 & 32.9 & -1.1 & $1 / 29.9$ & Difficult to detect \\
\hline
\end{tabular}




\subsection{OVERALL CONCLUSIONS}

In the laboratory, since the specimens are heated (or cooled) under controlled conditions and the location of the defects are previously known, the detection of the defects are easier. In actual field conditions this is not the case. Hence it was concluded that the minimum detectable sizes for the field conditions would be as follows:

- 1 " x 1 " x 1/16" (25mm x $25 \mathrm{~mm}$ x $1.6 \mathrm{~mm})$ debond located between the wearing surface and the underlying deck

- 1 " x 1 " x 1/16" (25mm x 25mm x 1.6mm) delamination located within the flange of an FRP deck with no wearing surface. For decks with wearing surface, delamination within the underlying deck's flange is difficult to detect conclusively.

- Distance less than $6 \mathrm{~m}$ between the camera and the deck is recommended

Based on Section 4.14 it can be concluded that good contrast between the defectfree and defective areas can be achieved when the value of the temperature difference is at least $1 / 10$ th of the background defect-free temperature.

The heating source should be able to supply intense heat at a fast rate to provide a strong thermal perturbation. The amount of heat energy form the 1500 watt quartz heater to heat an area of 1' $x 2^{\prime}\left(0.186 \mathrm{~m}^{2}\right)$ would be around $8075 \mathrm{~W} / \mathrm{m}^{2}$. Assuming that twothirds of the heat energy would be transmitted onto the surface of the specimen (loss to outside areas is assumed to be one-third) and further applying a reduction factor of 0.5 to account for the loss in the electrical circuit (ratio of output to input power of the heater), the heat energy incident on the specimen was calculated to be $2700 \mathrm{~W} / \mathrm{m}^{2}$. In comparison, the value of total solar radiation, taken from one of the previously established solar intensity data shown in Figure 4.98 (Threlkeld 1970) is typically about $1000 \mathrm{~W} / \mathrm{m}^{2}$ $\left[\sim 300 \mathrm{Btu} /\left(\mathrm{hr} . \mathrm{ft}^{2}\right)\right]$ on a peak summer day at a location of $42^{\circ}$ North latitude (close to New York city). 


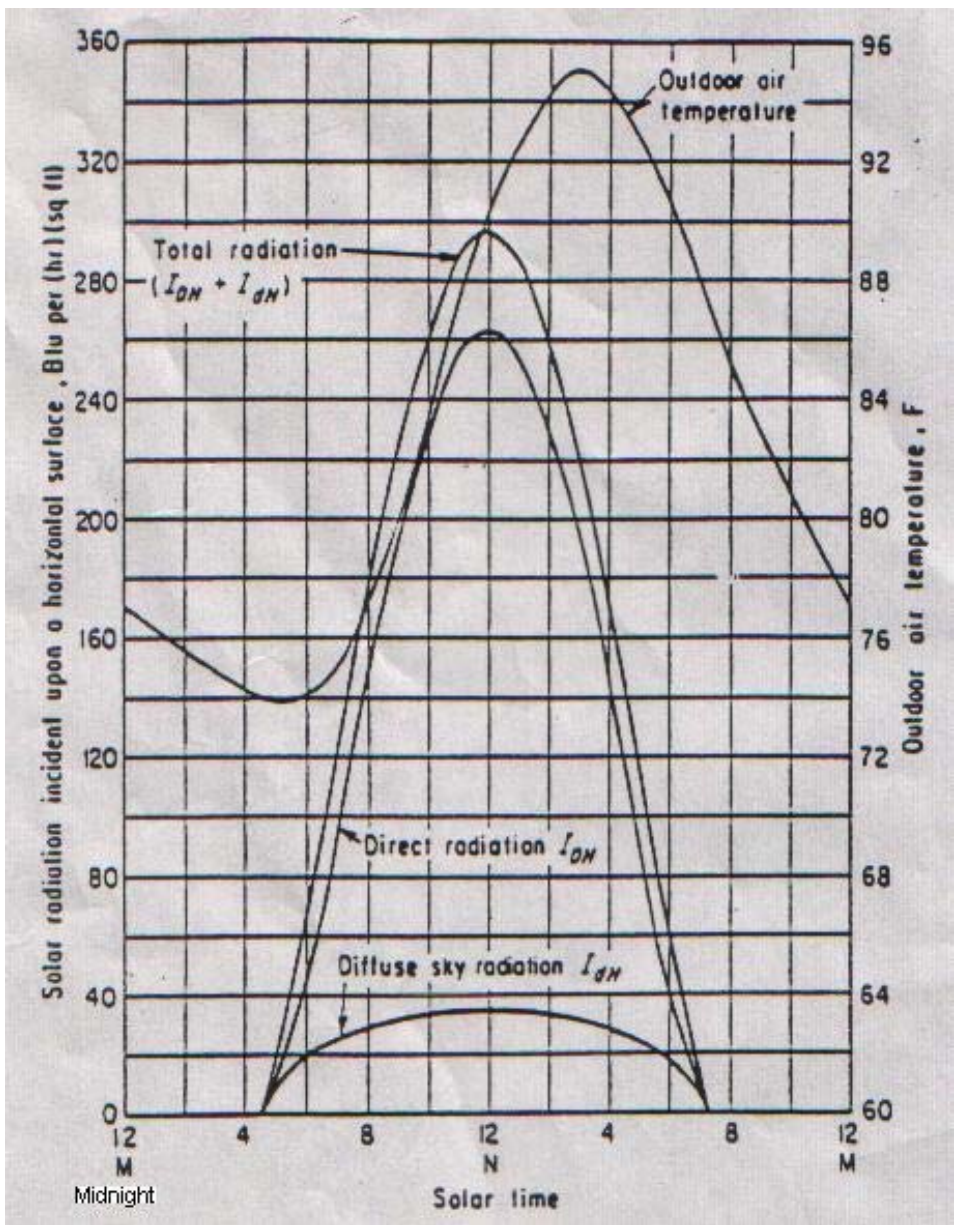

Figure 4.98. Typical variations of outdoor air temperature and intensity of solar radiation incident upon a horizontal surface for a location at $42^{\circ}$ north latitude on July 1 for a clearness number of unity

(Threlkeld 1970)

It should be noted that the heat buildup on the specimen using quartz heater takes only a few minutes when compared to the solar radiation where the heat is built up slowly over a period of few hours ( 8 A.M. to 2 P.M.). Hence the quartz heater produces a much stronger transient effect which leads to higher contrast between the defective and defect-free areas. Hence the quartz heater is a better heating source when compared to solar radiation. It may also be possible to generate strong transient effect in the field using an effective cooling source (e.g., liquid $\mathrm{CO}_{2}$ ) instead of a heating source. The threshold value for the input power that is required to generate a significant contrast in the infrared images can possibly be established through heat transfer models using Finite Element Method, which is a topic for future research. 


\section{Chapter 5 \\ FIELD TESTING AND EVALUATION OF TIMBER RAILROAD BRIDGE COMPONENTS}

\subsection{INTRODUCTION}

Many of the timber railroad bridges in the US are over 100 years old and the degradation is visible in some of its components like piles, joints and pile caps. Fiber Reinforced Polymer (FRP) composite wraps are now widely being used in rehabilitating such deteriorating timber bridge components. The timber components are being wrapped with these composite materials to increase their strength, load carrying capacity and serviceability. The structural integrity of such components relies on proper bonding between wraps and the underlying timber components. As the bridges age and the freight car weights increases, the need for rapid bridge inspection and strength evaluation methods increases as well. Infrared thermography is one of the promising nondestructive evaluation techniques used for the inspection of such deteriorating railroad bridge components.

This chapter presents the field experiments conducted on the wrapped timber railroad bridges located in Moorefield, West Virginia. Some of the components of the bridges were previously rehabilitated with Glass Fiber Reinforced Polymer (GFRP) composite wraps. Infrared Thermographic tests were conducted to detect any debonds present at the interface between the GFRP composite wrap and the underlying timber component. Discussions on the location of the bridges, laboratory experiments conducted on wrapped timber components, field setup, infrared tests and results, and difficulties encountered during the field study are included.

\subsection{DESCRIPTION OF THE BRIDGES}

The three timber railroad bridges were located on the South Branch Valley Railroad (SBVR). The railroad is owned and operated by the West Virginia State DOTState Railway Authority (SRA). The line provides freight and passenger service to the state’s eastern panhandle. The bridges were referred to as Bridge \#568, Bridge \#570, and 
Bridge \#583. These timber bridges were rehabilitated using Glass Fiber Reinforced Polymer (GFRP) composite wraps. All three bridges were located in Moorefield, West Virginia. The location of Moorefield, WV is shown in the Figure.5.1 and the three bridges are shown in Figures 5.2, 5.3, and 5.4

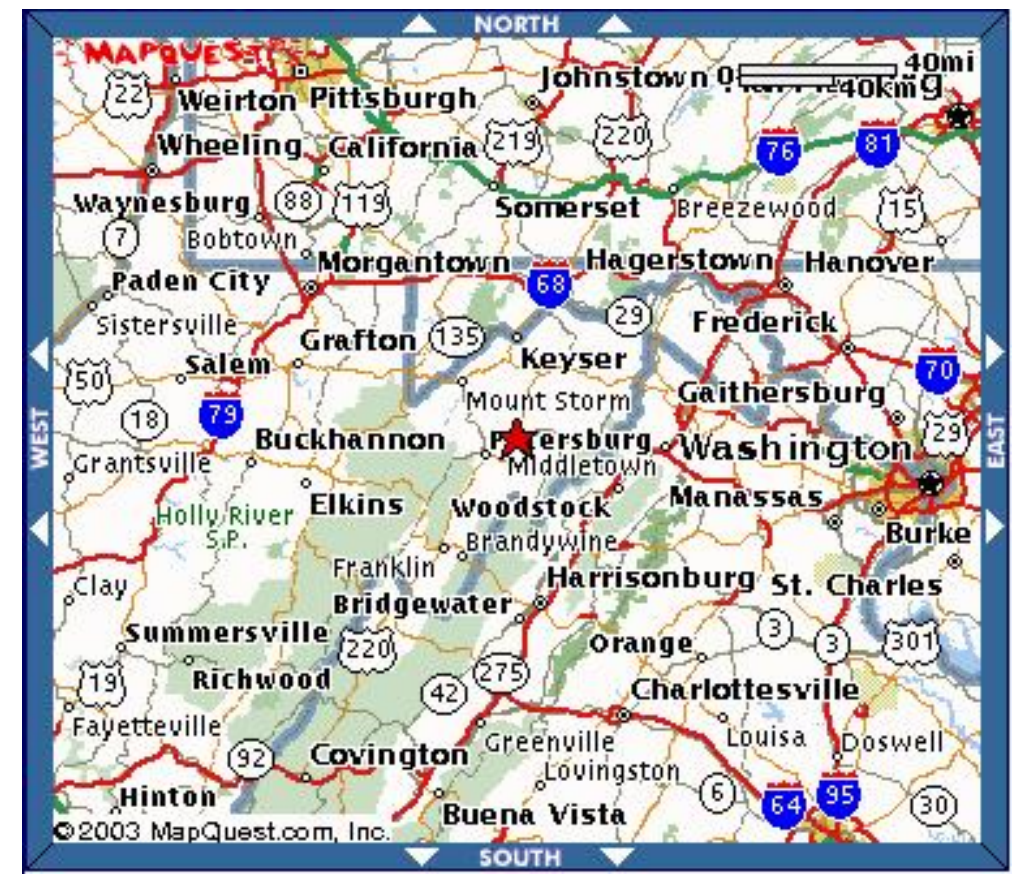

Figure 5.1. Location of Moorefield, WV

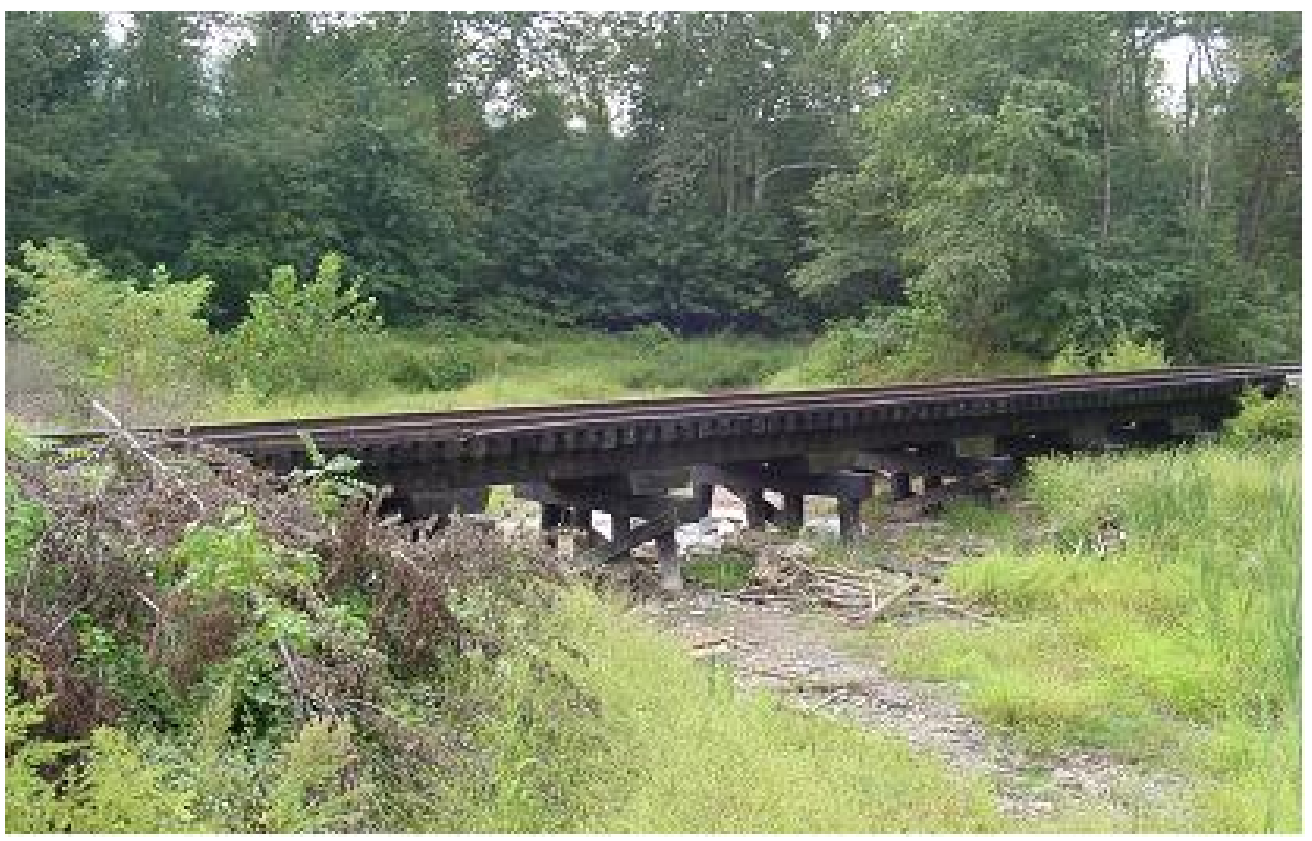

Figure 5.2. Photograph of Bridge \# 568 taken in Summer 2002 


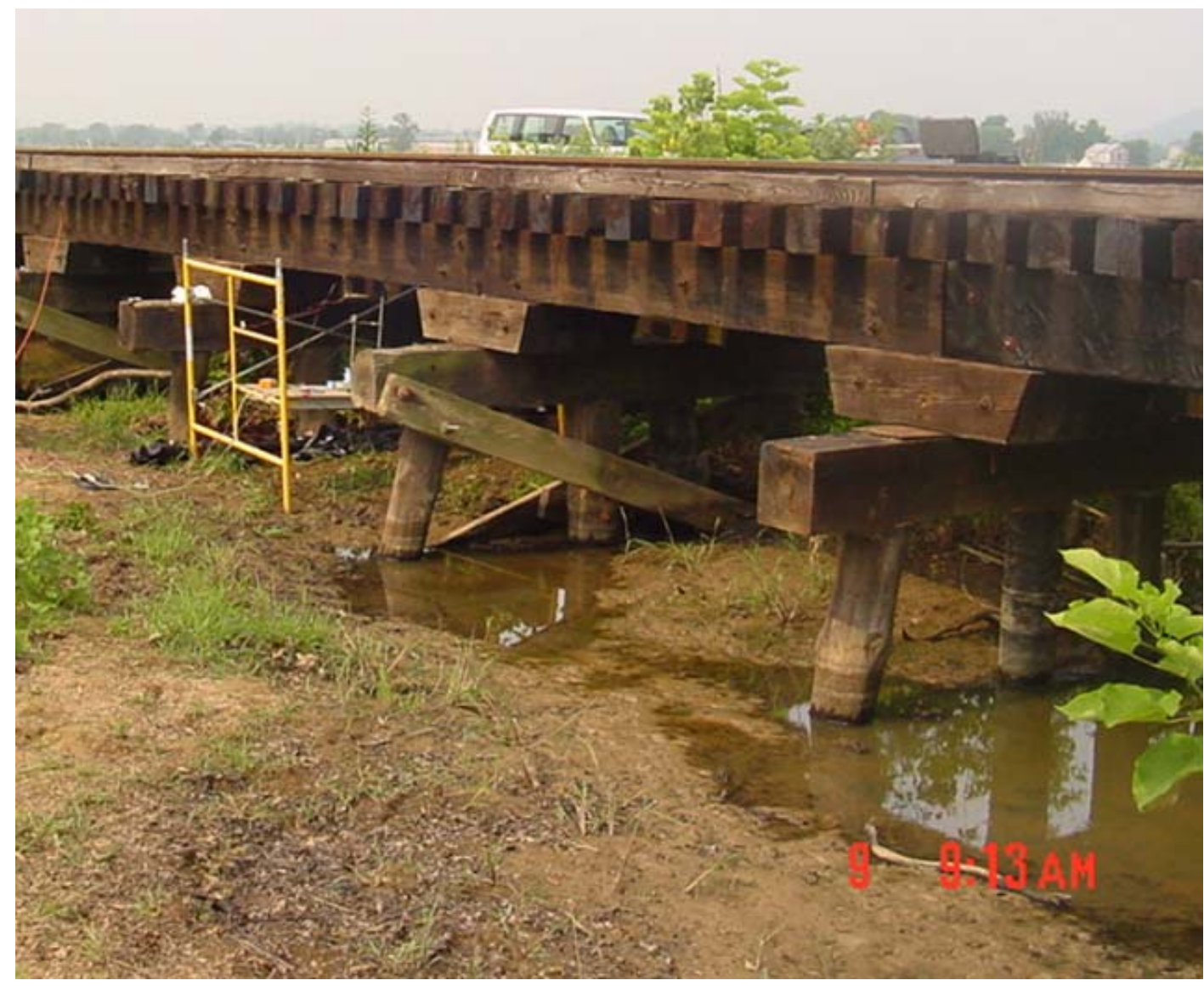

Figure 5.3. Photograph of Bridge \# 570 taken in Summer 2002

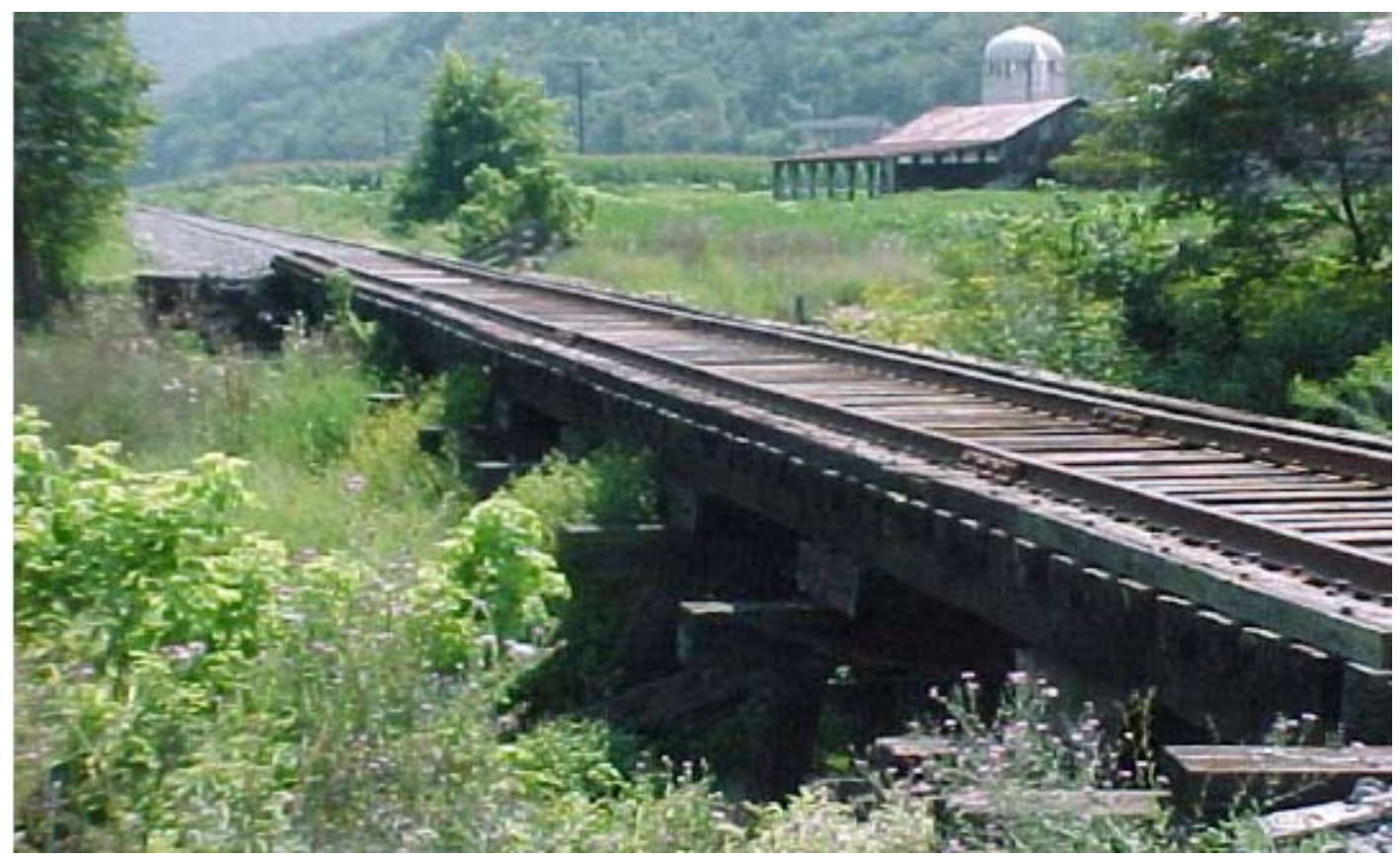

Figure 5.4. Photograph of Bridge \# 583 taken in Summer 2001 (Steele 2001) 


\subsection{LABORATORY EXPERIMENTS}

This section presents the laboratory experiments conducted on wrapped timber specimens by Steele (2001) at West Virginia University. The objective of these laboratory experiments were to evaluate the detectability of subsurface debonds in the laboratory setting before employing infrared testing for field evaluation of FRP wrapped timber members.

\subsubsection{Experimental Setup}

The experiments consisted of two steps. The first step was the creation of debonds of known shapes and sizes in the specimens and the second was to locate them using infrared thermography. The infrared camera that was used for testing was the FLIR's FSI Prism SP (Single Point), which can detect the radiation in the medium wavelength (3 to 5 $\mu \mathrm{m})$ spectral-range (FSI FLIR SYSTEMS 1994). The infrared images were continuously recorded on videotape. A 9-inch TV monitor with built-in VCR was used to view and record the real time thermal images captured by the camera. The real time thermal images were first recorded on a VHS tape and then transferred to a personal computer in the form of still images using special equipment (Snappy Video Snapshot).

The main heating source used in the laboratory was a $1500 \mathrm{~W}$ quartz tower heater (Figure. 5.5). It was found that heating the specimens by placing the heater at a distance of about 8 inches from the specimen surface helped in achieving more uniform heating. It was also observed that studying the thermal images by heating the specimen for a small duration of time and then observing the images during the cooling cycle was much more effective than heating the specimen for a long duration and studying the images as the specimen cools down. Other heating sources that were considered in this study included the use of solar radiation (Figure. 5.6) and simulated greenhouse (Figure. 5.7). 


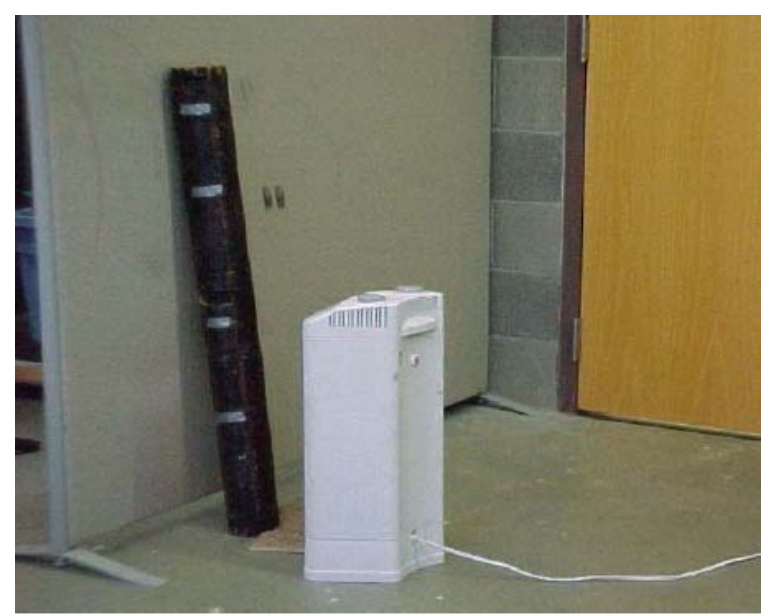

Figure 5.5. Specimens 1 heated by quartz heater (Steele 2001)

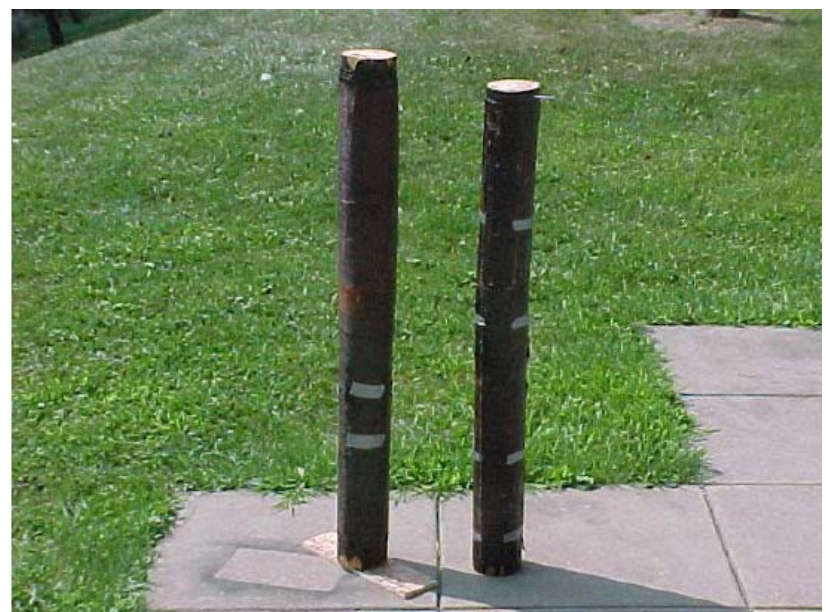

Figure 5.6. Specimens 1 and 2 heated by solar radiation (Steele 2001)

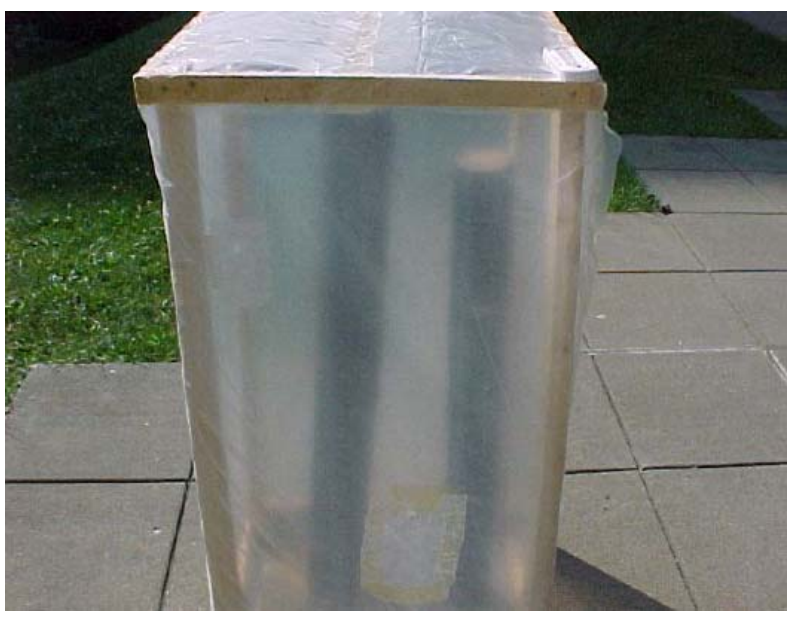

Figure 5.7. Simulated greenhouse effect (Steele 2001) 


\subsubsection{Test Specimens}

Three timber pile specimens (acquired from an old railroad bridge) reinforced with Glass Fiber Reinforced Polymer (GFRP) composite wraps were tested in the laboratory. The timber piles were approximately 4” in diameter. The composite wrap was approximately 1/8” thick and made of glass reinforced fabrics and phenolic resin composites. Simulated debonds were inserted in two of the timber pile specimens by either sawing or prying open a portion of the wrap and gluing the cracked edges back with resin to create a trapped air pocket (debond). Specimen 1 had four debonds ranging in sizes from 1.5” in diameter (circular debond) to 3” x 1.5” (rectangular debond). The thicknesses of these debonds varied from 1/8” to 3/8”. Specimen 2 had one 3”x3” debond with 1/8” thickness. The third specimen had no known defect and was used as a control specimen.

\subsubsection{Experimental Results}

\subsubsection{Results with Quartz Tower Heater}

Figure 5.8(a) shows the location of the first debond in specimen 1. The infrared image in Figure 5.8(b) shows this debond (3” x 1.5” with 3/8” thickness) as well as the smaller sized second debond (1.5” diameter and 1/8” thickness). The bright yellow/white regions is representative of the areas with the debonds. This infrared image was captured during the cooling cycle after heating the specimen with the quartz tower heater for some time (about five minutes). Figures 5.9(a) and (b) shows the location and infrared image of the third and fourth debond in specimen 1. The simulated debond in specimen 2 also showed a clear temperature differential. Figures 5.10(a) and (b) shows the photograph and the infrared image of the specimen 2. Figures 5.11(a) and (b) shows the photograph and infrared image of specimen 3 (control specimen) that had no debonds or defects. This infrared image shows a more or less uniform temperature distribution with no prominent anomalies. 

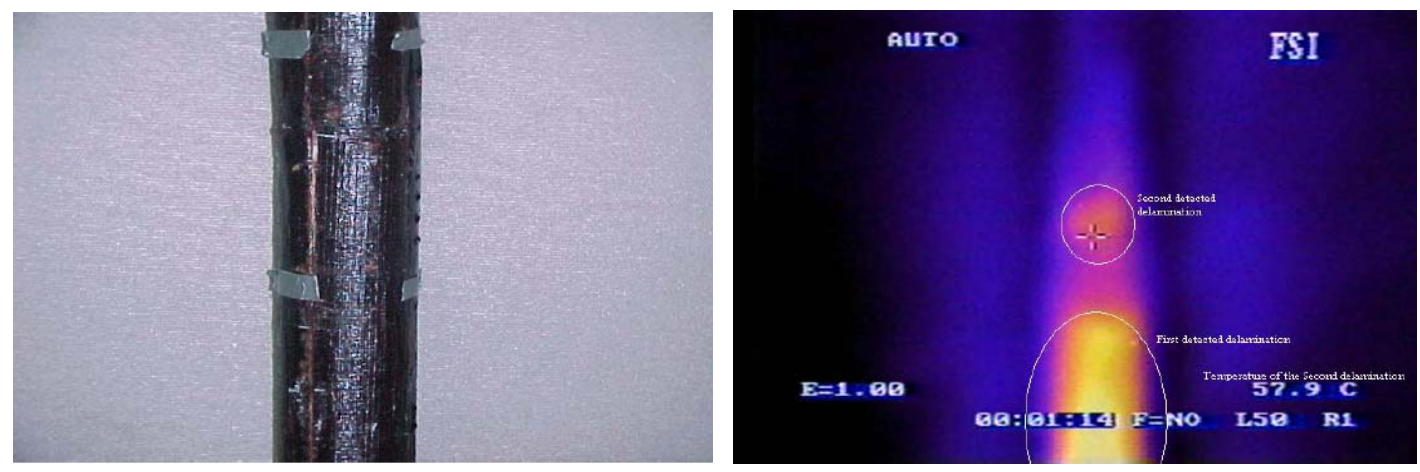

Figure 5.8. (a) Photograph showing first debond in specimen 1 (b) infrared image showing first and second debonds in specimen 1 (Steele 2001)
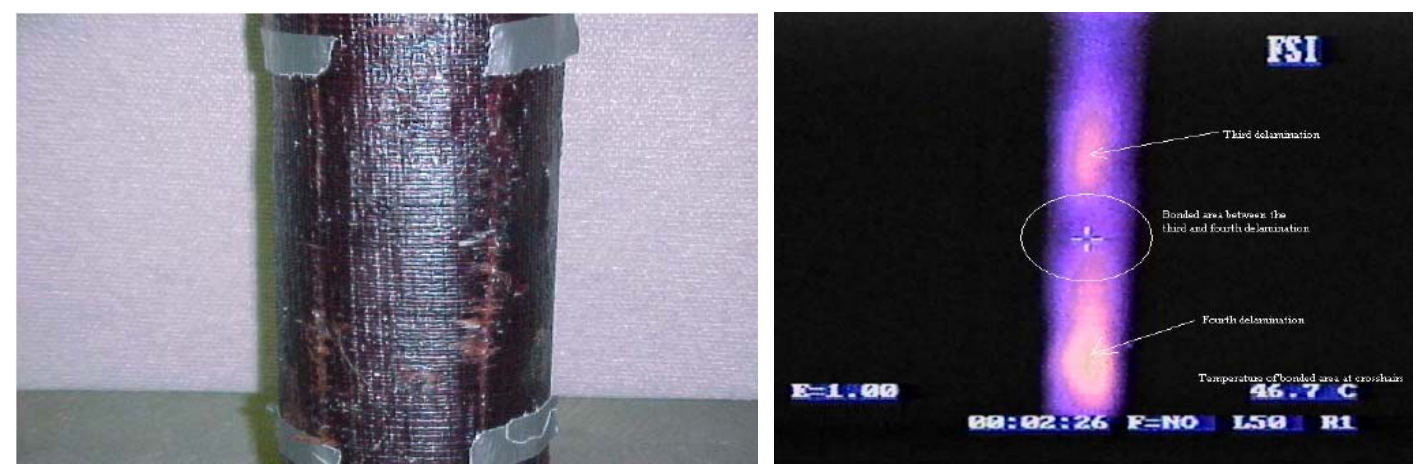

Figure 5.9. (a) Photograph of surface between the third and fourth debonds in specimen 1 (b) infrared image showing third and fourth debonds in specimen 1 (Steele 2001)
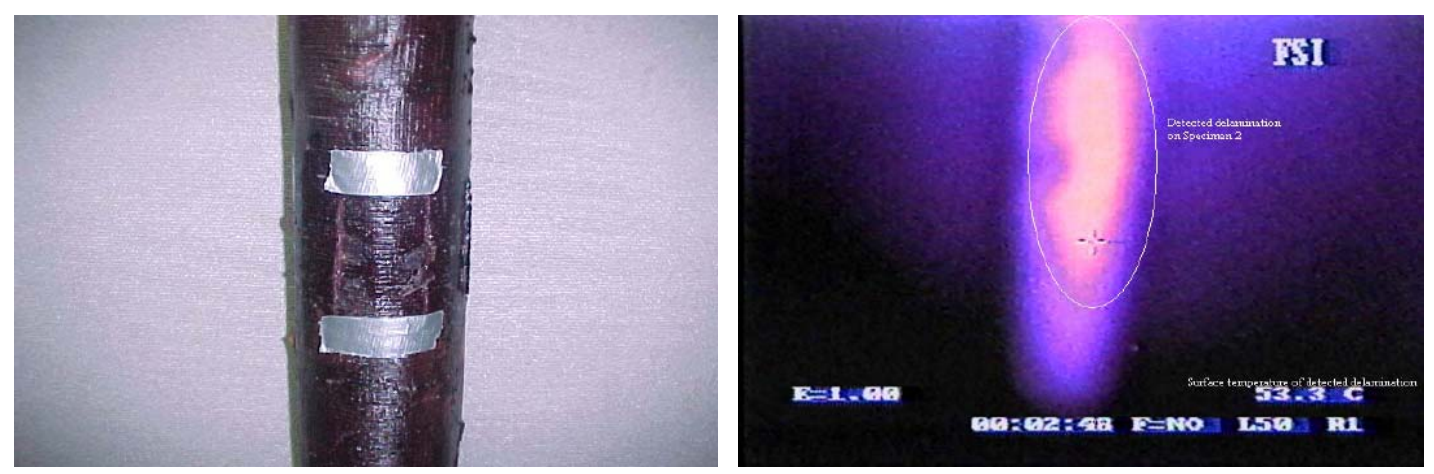

Figure 5.10. (a) Photograph showing simulated debond in specimen 2 (b) infrared image showing simulated debond in specimen 2 (Steele 2001) 

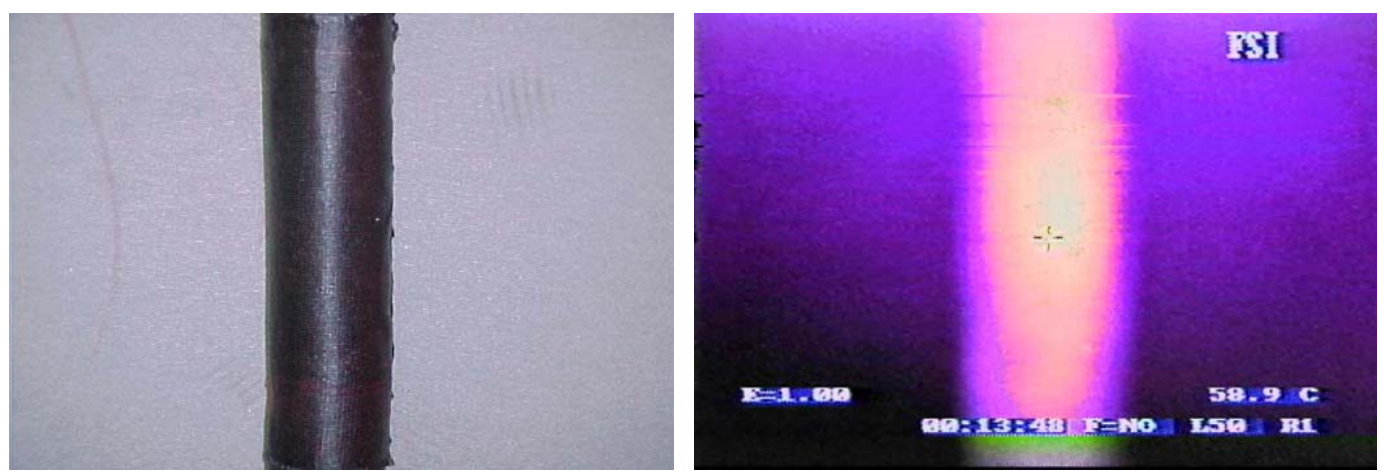

Figure 5.11. (a) Photograph of surface where no debonds were detected (specimen 3) (b) thermal image of bonded area with no defects or debonds (Steele 2001)

\subsubsection{Results with Solar Radiation}

Figure 5.12 shows the infrared image for specimens 1 and 2 under the influence of solar radiation. As one moves from the top of the specimens to the bottom, the colors change from yellow to orange to pink and blue, which represents a continuous decrease in temperature from top to bottom. This is indicative of the atmospheric temperature gradient due to convection (hotter air moving up and colder air moving down) which completely masked the effect due to subsurface debonds. Thus, it was concluded that solar radiation could not be relied upon as a heat source for infrared testing of vertical members, although it is commonly used as a heat source for testing horizontal members like bridge decks.

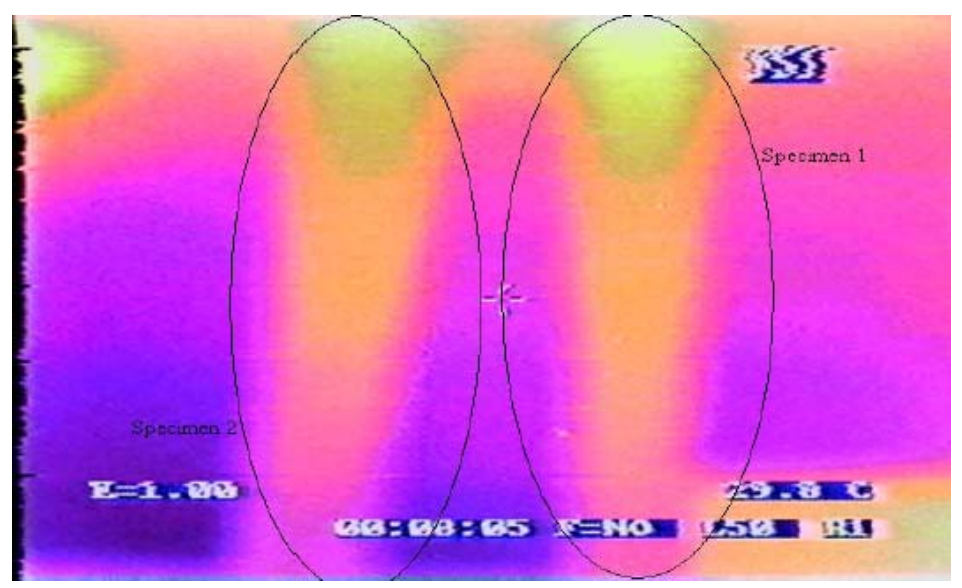

Figure 5.12. Infrared image of specimens 1 and 2 using solar radiation as heat source (Steele 2001)

\subsubsection{Results with Greenhouse effect}

Figure 5.13 shows the infrared image for the same set of specimens under the 
influence of simulated greenhouse effect. While the greenhouse effect resulted in higher temperatures (air temperature between the specimens being $35.2^{\circ} \mathrm{C}$ in Figure 5.13 versus $29.8^{\circ} \mathrm{C}$ in Figure 5.12), the effect of air convection is present in this case as well. Therefore, this type of heat source is not useful for detection of subsurface debonds in vertical components using infrared thermography.

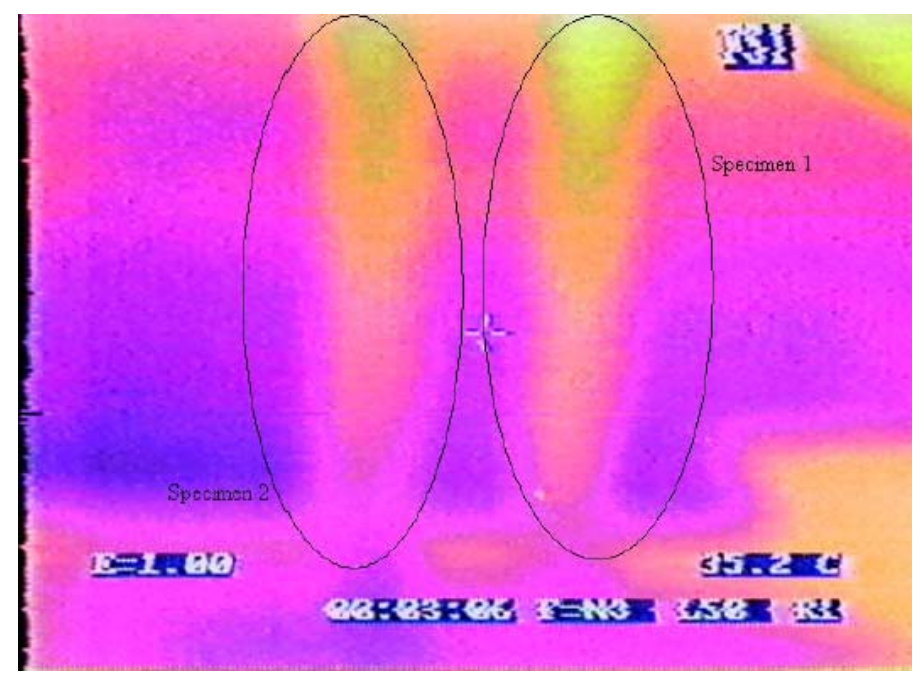

Figure 5.13. Infrared image of specimens 1 and 2 under the greenhouse effect (Steele 2001)

\subsection{FIELD TESTS}

This section describes the field tests and inspections that were conducted on the three railroad bridges (Bridge \#568, Bridge \#570, and Bridge \#583). The field tests were conducted during the summer of 2001, summer of 2002 and summer of 2003. The field setup, infrared tests and results for each of the summer sessions are presented below.

\subsubsection{Summer 2001 Testing}

During Phase I study by Steele (2001), components of the three timber railroad bridges were tested using infrared thermography. These tests were conducted during Summer 2001.

\subsubsection{Experimental Setup}

The field equipment was the same equipment used in the laboratory. The three heat sources that were used in the field were the quartz tower heater, solar radiation, and 
a simulated greenhouse effect (the latter two for horizontal members only). When the quartz tower heater was used as the heat source, different distances between the heater and the timber components, and different time periods of heating were considered. Clear plastic wrap was glued around some horizontal timber components to simulate greenhouse effect as a method of heating the components. Solar radiation was also used as a heat source for the GFRP wrapped timber components exposed to sunlight.

The FLIR Prism Single Point Infrared Camera was used for the field tests. Figure 5.14 shows a basic testing situation. Due to the small space under the bridges, the infrared camera could not be mounted on a tripod. A microphone was used to record sound and correlate thermal images recorded by the VCR with the photographs taken using a digital camera.

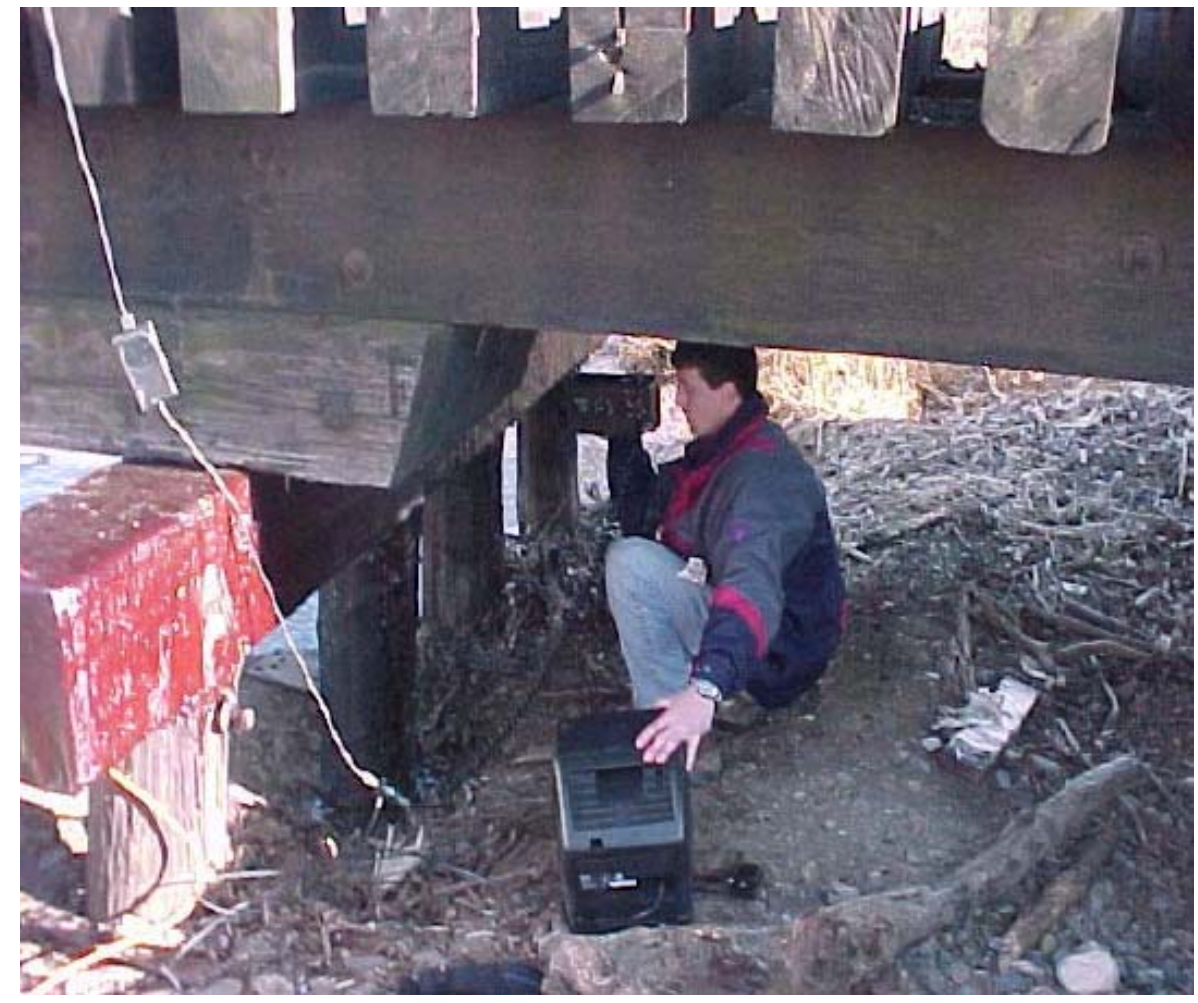

Figure 5.14. Infrared test setup in the field (Steele 2001)

\subsubsection{Infrared Testing and Results}

In Bridge \#568 a pile cap and a pile were tested. Figure 5.15(a) shows a picture of a pile cap section before being wrapped in plastic wrap. The pile cap section was subsequently wrapped with plastic to simulate greenhouse effect. Then the plastic wrap 
was removed and the infrared picture shown in Figure 5.15(b) was recorded. The surface temperature measured by the infrared camera was $50.3^{\circ} \mathrm{C}$. Figure $5.16(\mathrm{~b})$ shows another thermal image of a different pile cap section (shown in Figure 5.16(a)) that was also wrapped in plastic wrap. The surface temperature of this section reads $52.2^{\circ} \mathrm{C}$. A black spot was observed in this thermal image, which represents a cooler region compared to the surrounding area. This could have been caused by a metal nail or bolt (acting as a heat conductor) under the GFRP composite wrap. Since metal transfers heat faster than timber, the surface temperature of the nail or bolt would be cooler than the surface temperature of the surrounding timber area.
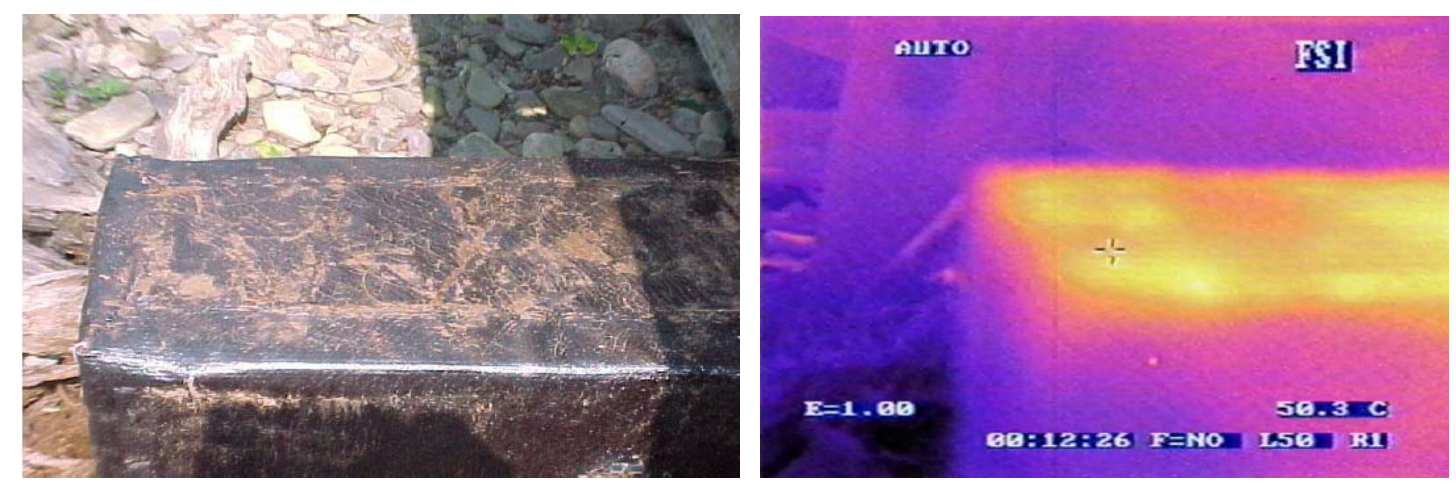

Figure 5.15. (a) Photograph of the pile cap section before being wrapped in plastic wrap (b) thermal image of the pile cap section after the plastic wrap was removed (Steele 2001)
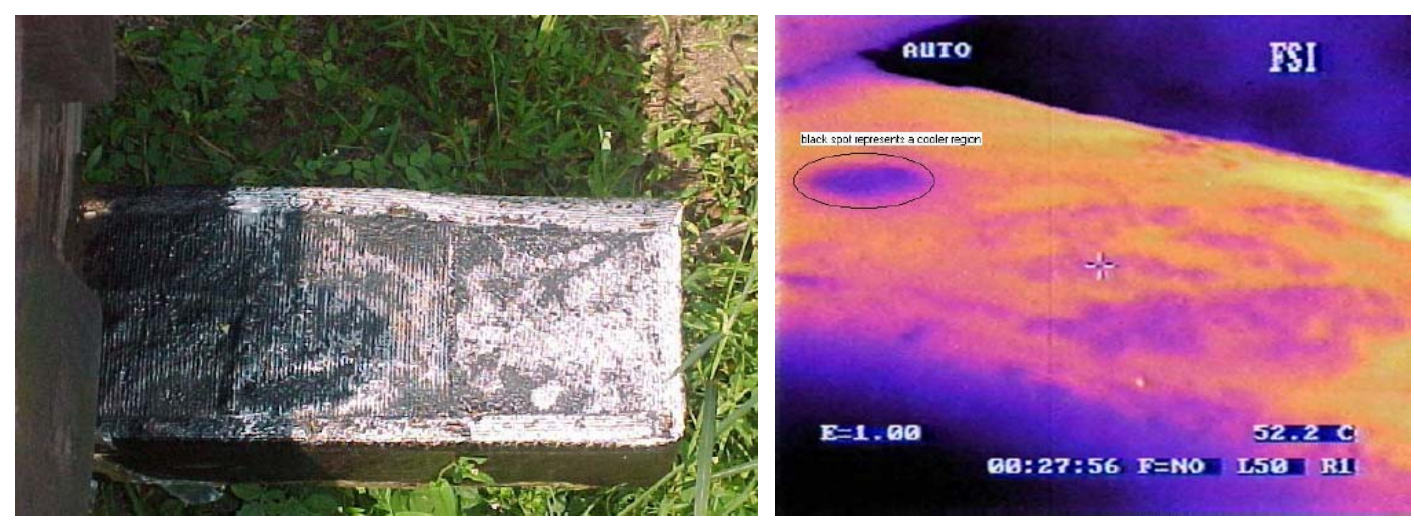

Figure 5.16. (a) Photograph of the pile cap section with the observed black spot, and (b) thermal image of the pile cap section that was wrapped in plastic wrap. The black spot could be caused by a metal nail or bolt under the GFRP wrap (Steele 2001) 
Figure 5.17 is a thermal image of a GFRP wrapped timber stringer that had a known bolt going throw the stringer. Again, the darker region represents the bolt, which indicates a cooler region compared to the surrounding areas.
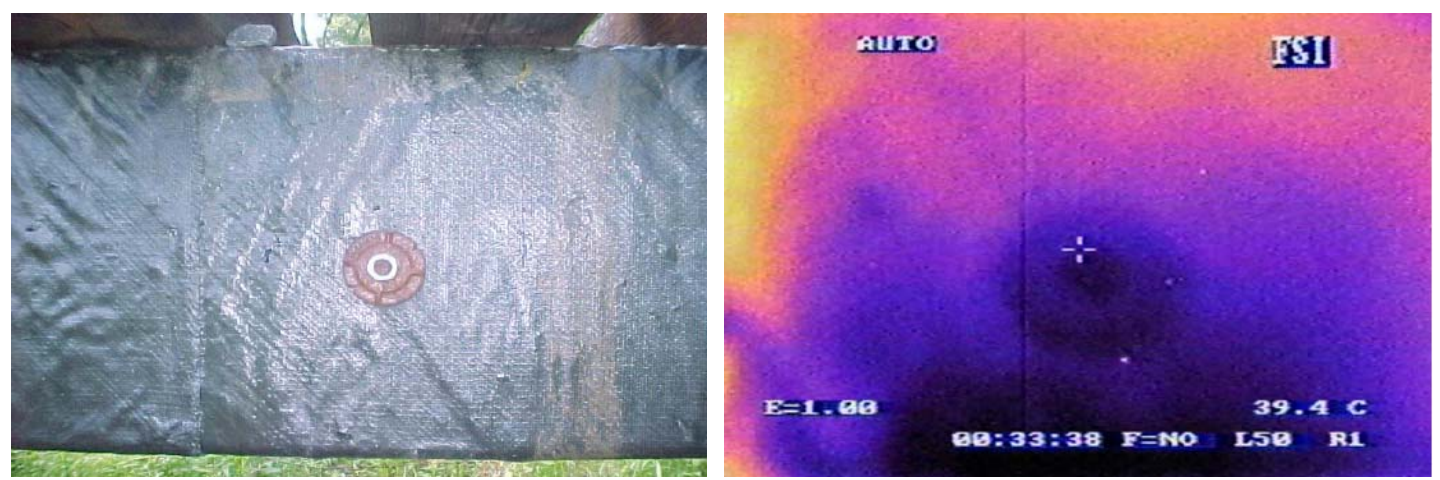

Figure 5.17. (a) Photograph of a stringer with a bolt going through it (b) thermal image of the stringer. The dark area by the cross hairs represents the bolt (Steele 2001)

In Bridge \#570, a section of the stringer was wrapped in plastic wrap to create simulated greenhouse effect as shown in Figure 5.18. However, the thermal images obtained after the plastic wrap was removed did not show significant surface temperature differentials that would have indicated a delamination or defect. A section of the stringer was also tested using the quartz tower heater as the heat source. Different distances between the heater and the stringer were experimented with in order to establish the effect of varying distances. The heater was placed at a distance of 2 inches, 4 inches and 8 inches from the surface of the stringer. Figure 5.19 shows the photograph and the thermal images obtained when the heater was placed at different distances from the stringer. The most uniform heating occurred when the heater was placed approximately 8 inches away from the surface of the stringer (Figure 5.19(d)). The plastic wrap and quartz tower heater were also used to heat a pile on Bridge \#570. However, no delaminations or other defects were detected. 


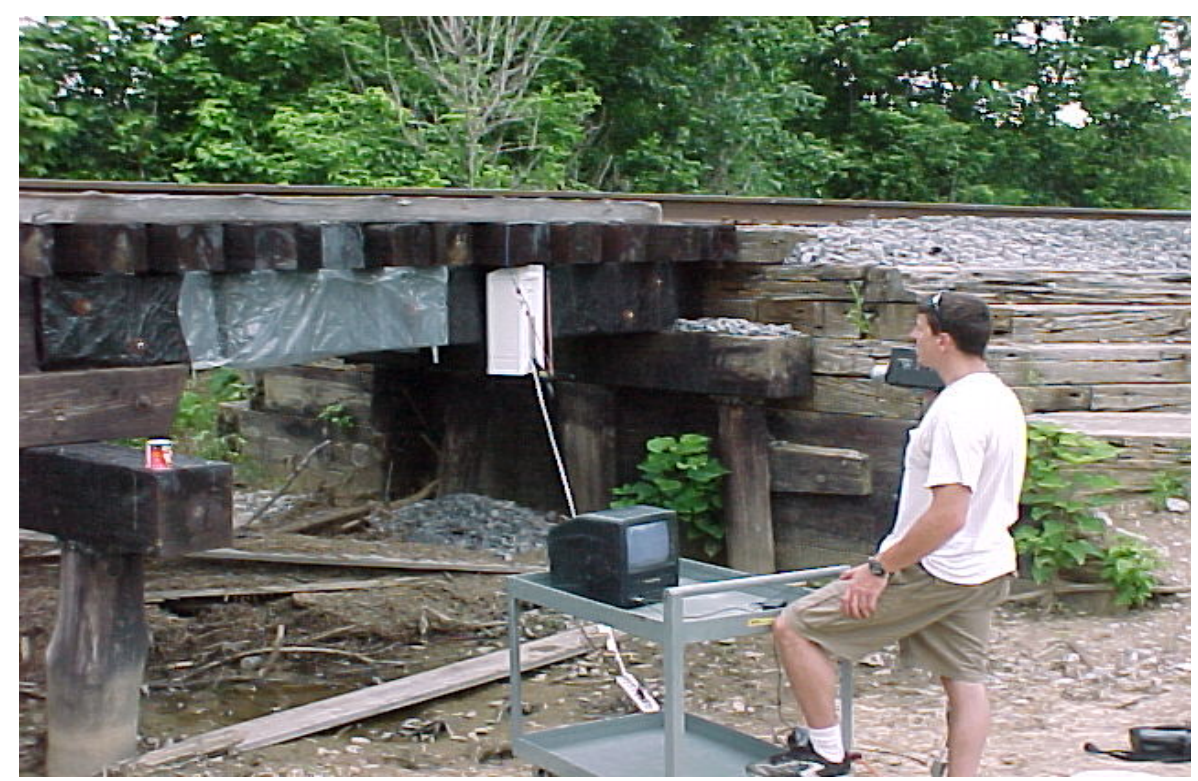

Figure 5.18. A section of the stringer heated by plastic wrap and a quartz tower heater (Steele 2001)

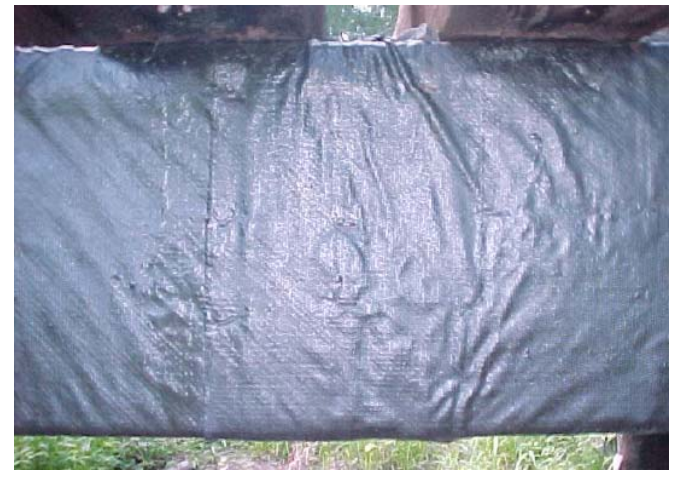

(a)

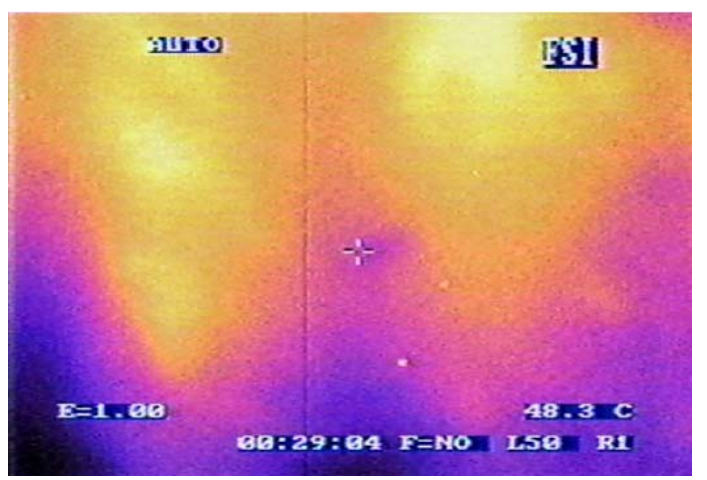

(b)

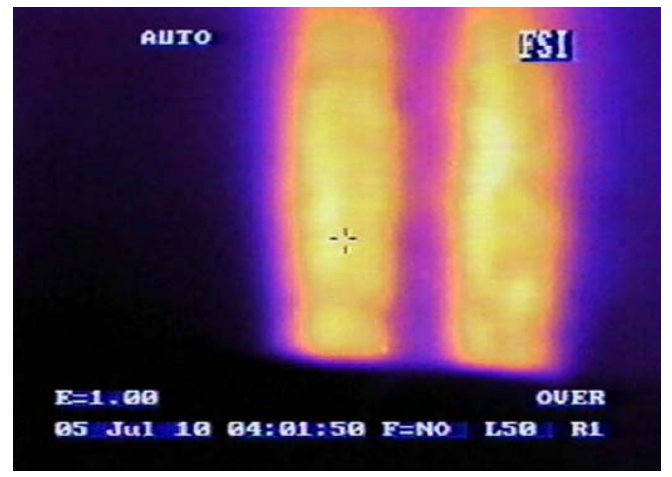

(b)

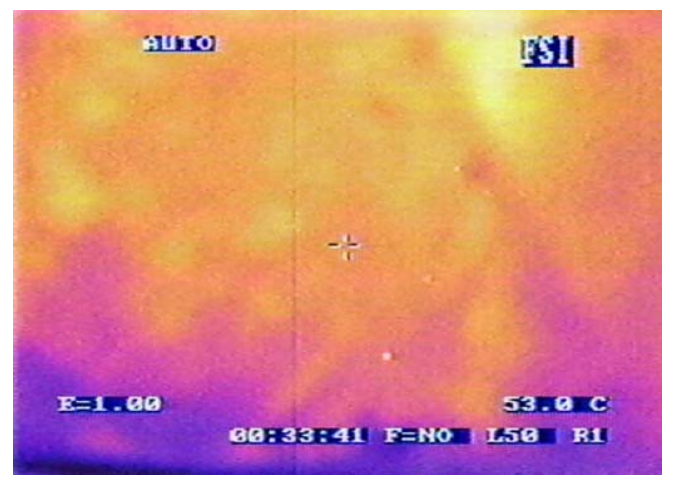

(d)

Figure 5.19. (a) Photograph of the stringer section heated with the quartz tower heater, (b) thermal image of the stringer with the quartz tower heater placed 2 inches away, (c) 4 inches away, and (d) 8 inches away from the stringer surface (Steele 2001) 
Bridge \#583 was tested using the same infrared camera. The thermal images obtained after heating the stringer using solar radiation and the plastic wrap to simulate greenhouse effect did not show any significant surface temperature differentials that would have indicated delaminations or defects.

\subsubsection{Summer 2002 Testing}

Testing the wrapped timber components from time to time helps to monitor the growth of existing debonds and also to detect newer debonds that may have developed over time. Infrared tests were conducted on a wrapped timber components in Bridge \# 568 (see Figure 5.2) in July 2002. One of the pile caps (the first pile bent from the west end of Bridge 568) was tested using infrared thermography and the debonded portions were marked with a chalk. However, some of the piles under this bridge were flooded with water and only some portions were above the water level. This made them inaccessible for testing. Testing also could not be continued on Bridge \# 570 as water had flooded underneath the bridge (see Figure 5.3). This made it impossible to access the pile caps and the piles under the bridge and to heat them for the infrared tests. Solar radiation could not be used as heating source since these components were located underneath the rail tracks where solar rays did not reach. Sufficient heating of the components is required to establish a thermal gradient with adequate temperature difference between the defect-free and the debonded areas.

\subsubsection{Experimental Setup}

The infrared camera that was used for testing was the FLIR's FSI Prism SP (Single Point), which can detect the radiation in the medium wavelength (3 to $5 \mu \mathrm{m}$ ) spectral-range (FSI FLIR SYSTEMS 1994). A 9-inch TV monitor with built-in VCR was used to view and record the real time thermal images captured by the camera. The real time thermal images were first recorded on a VHS tape and then transferred to a personal computer in the form of still images using special equipment (Snappy Video Snapshot).

Solar radiation was used as the heating source for the exposed portion of the pile cap. Other portions that were not directly exposed to the sun were heated using the 1500 
watt capacity quartz tower heater and 1500 watt capacity heating blankets (each of size 3' $x$ 3’). Figure 5.20 shows the field setup for the infrared testing.

\subsubsection{Infrared Testing and Results}

The beam was initially tested by tamping it with a rod and then marking the debonded locations with a chalk. Figure 5.21 shows the location and infrared image of debond D1 on one side of the beam. Figure 5.22 shows the location of the debonds D2 and D3, and D14. Figures 5.23 and 5.24 shows the infrared images of these debonds. In all the infrared images, the debonds are represented by the bright yellow/white regions. The debond D1 was detected by tap testing. The debonds D2 and D3 could be detected only by the infrared camera and were also comparatively smaller sized debonds. Though debond D14 was larger in size, it was detected only by the infrared testing. This may have been due to a smaller thickness of the air gap between the wrap and the underlying timber.

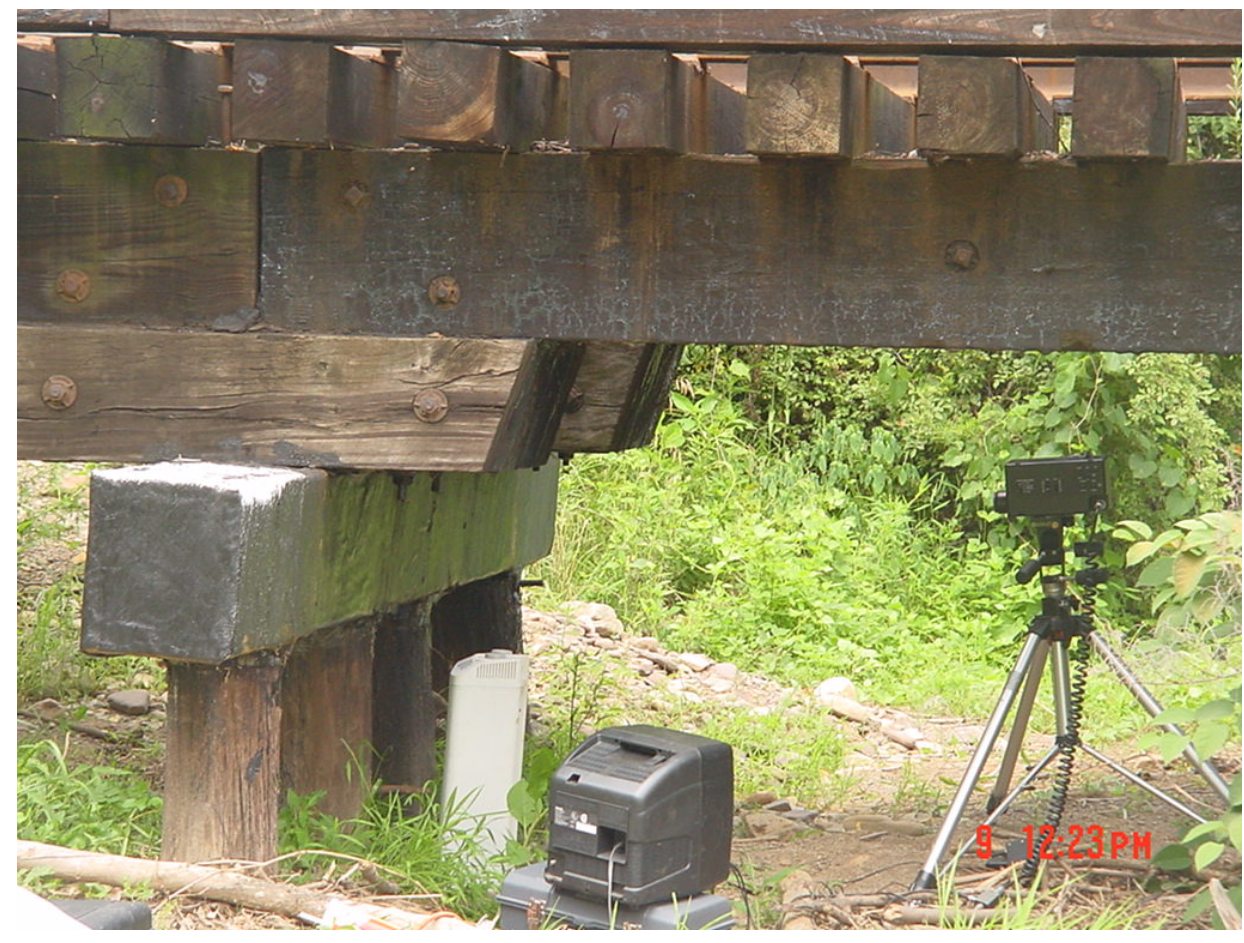

(a) 


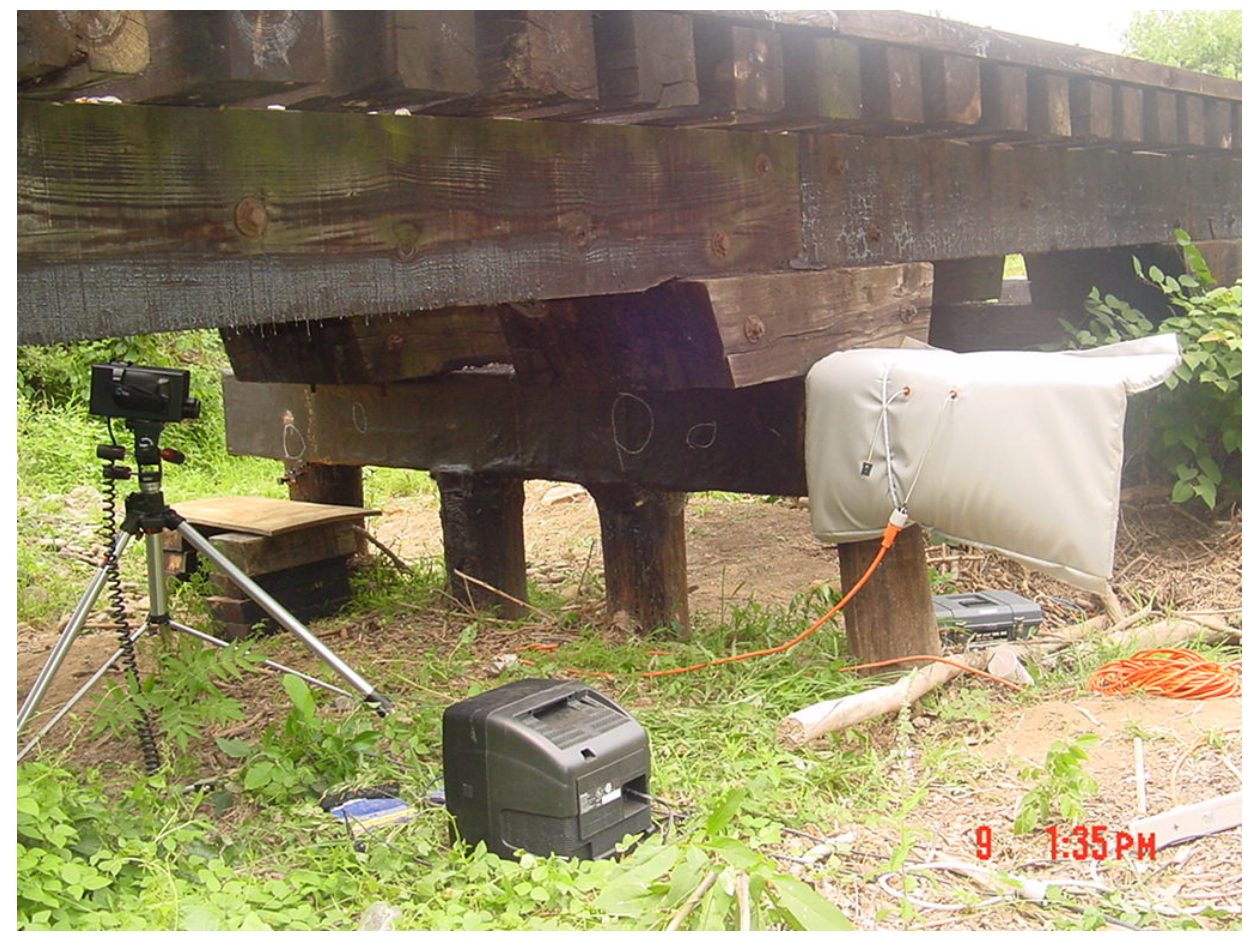

(b)

Figure 5.20. Field testing setup (a) using quartz heater as the heating source (b) using heating blanket as the heating source
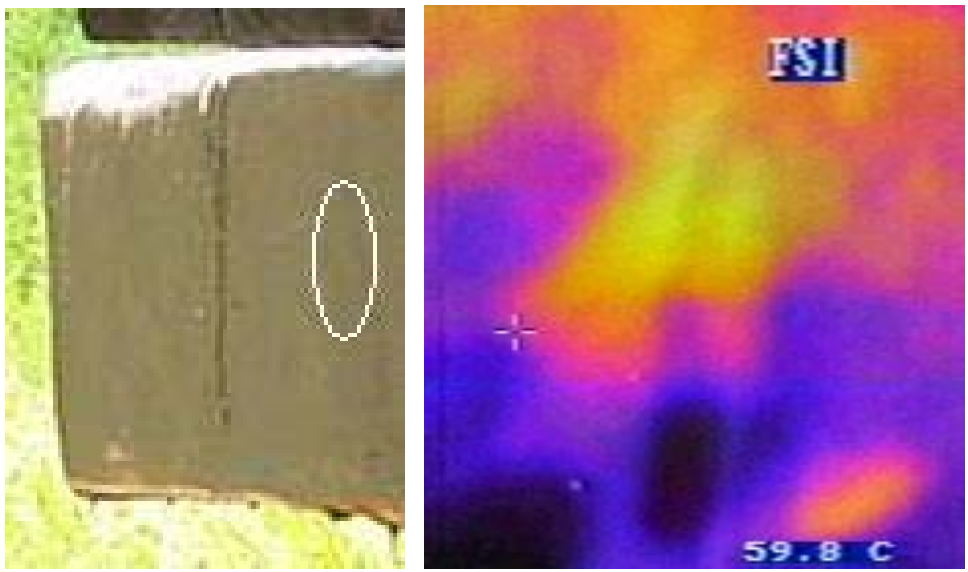

Figure 5.21. (a) Location of debonds D1 (b) infrared image of debond D1 


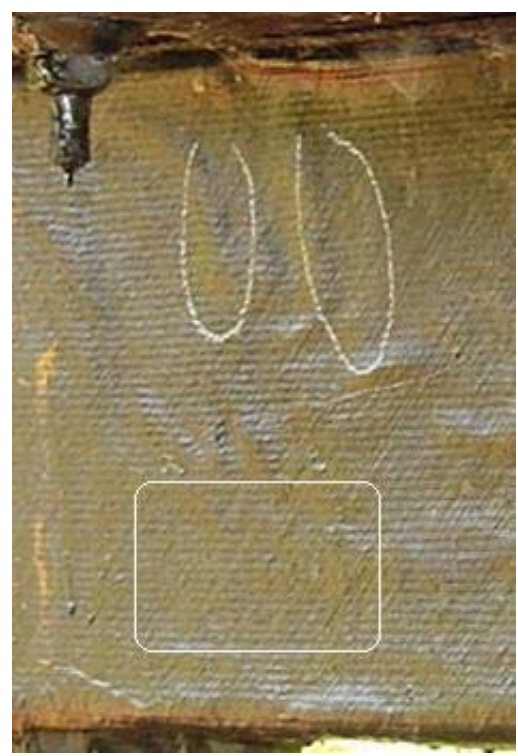

Figure 5.22. Location of debonds D2 and D3 on the top and debond D14 at the bottom
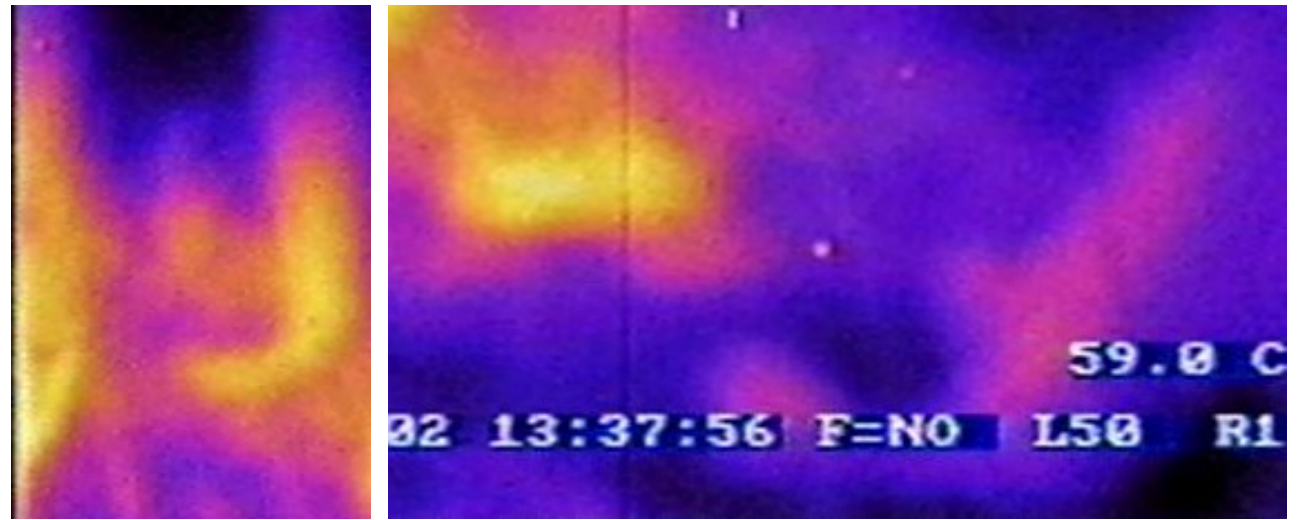

Figure 5.23. Infrared images showing a close up of debonds D2 and D3

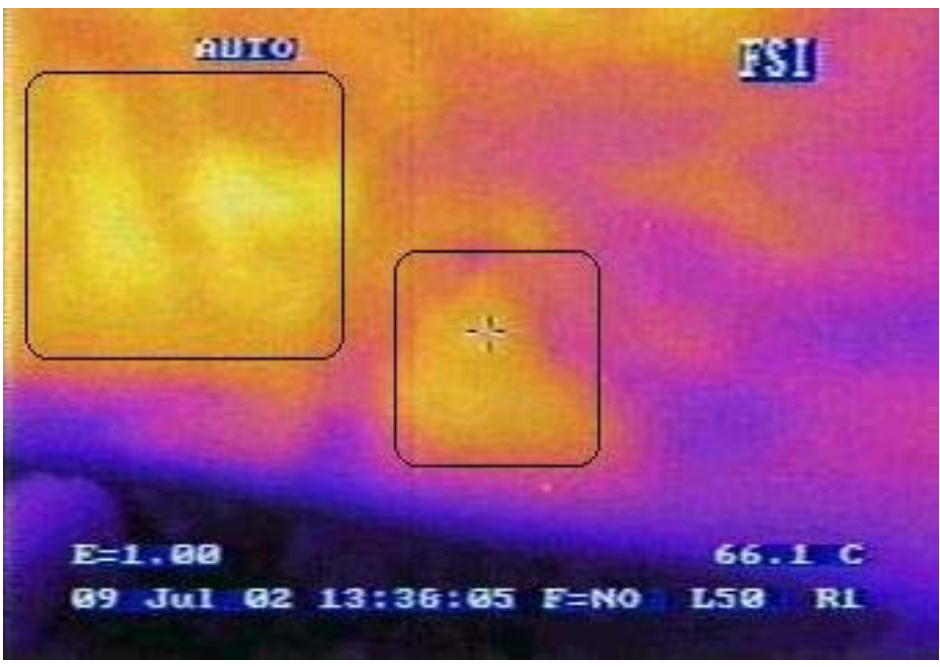

Figure 5.24. Infrared image showing a close up of debond D14 
Figure 5.25 shows the location and infrared image of debond D4 on the same side of the beam. D4 consisted of many air gaps. Since D4 consisted of larger sized debonds it was detected by tap testing as well as by infrared testing. The infrared image shows the air gaps are as yellow and white regions.
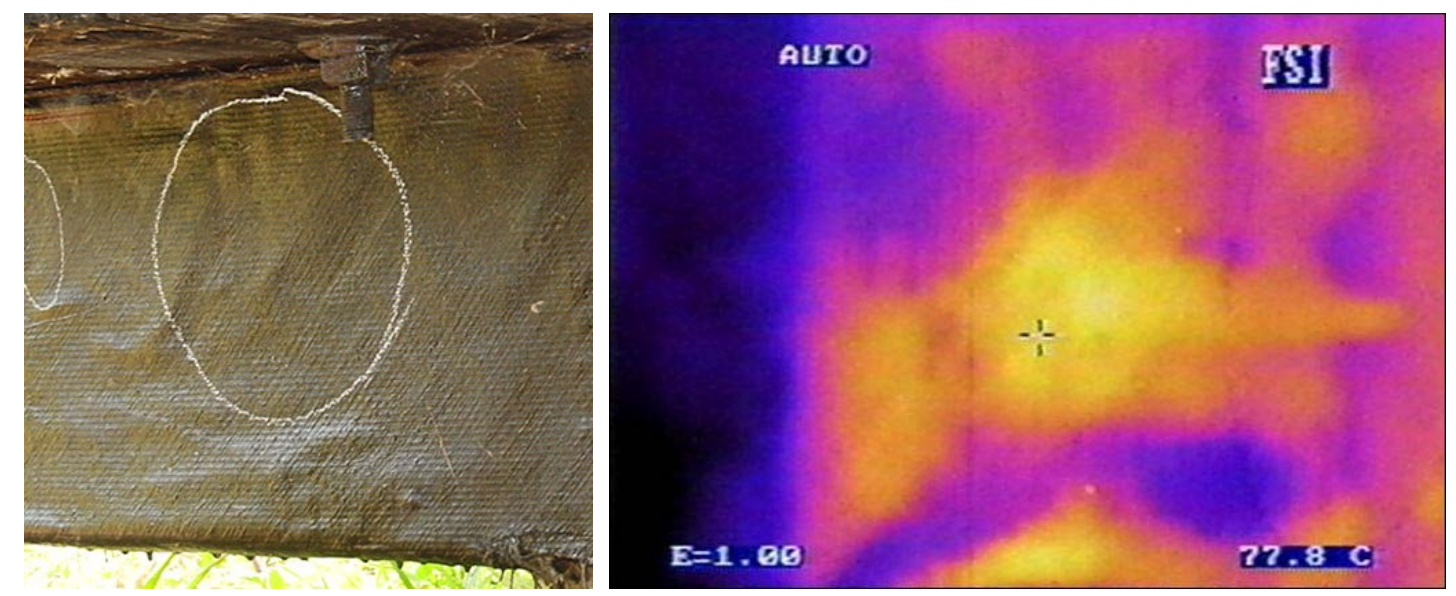

Figure 5.25. (a) Location of debond D4 (b) Infrared image of debond D4

Debond D5 was located in the center portion of the pile cap and was detected by the infrared testing only. Figures 5.26 (a) and (b) shows the location and the infrared image of the debond D5. When the infrared tests were being conducted, the bridge was simultaneously loaded with a General Electric 80-ton locomotive (provided by South Branch Valley Railroad (SBVR)). Dynamic load tests were performed by other researchers, using the locomotive at four different speeds: $3 \mathrm{mph}, 5 \mathrm{mph}, 10 \mathrm{mph}$, and 15 mph. Infrared images of the debond D5 were taped simultaneously, when the locomotive passed over the bridge. The images were later viewed to see if there was any development of cracks, and/or if the debonds grew in size during the loading period. But there were no such changes in the images during loading period. The tests also implied that, other tests could be carried on simultaneously without being interrupted by the infrared testing. Also the infrared tests do not require closing the bridge for the locomotive traffic. 

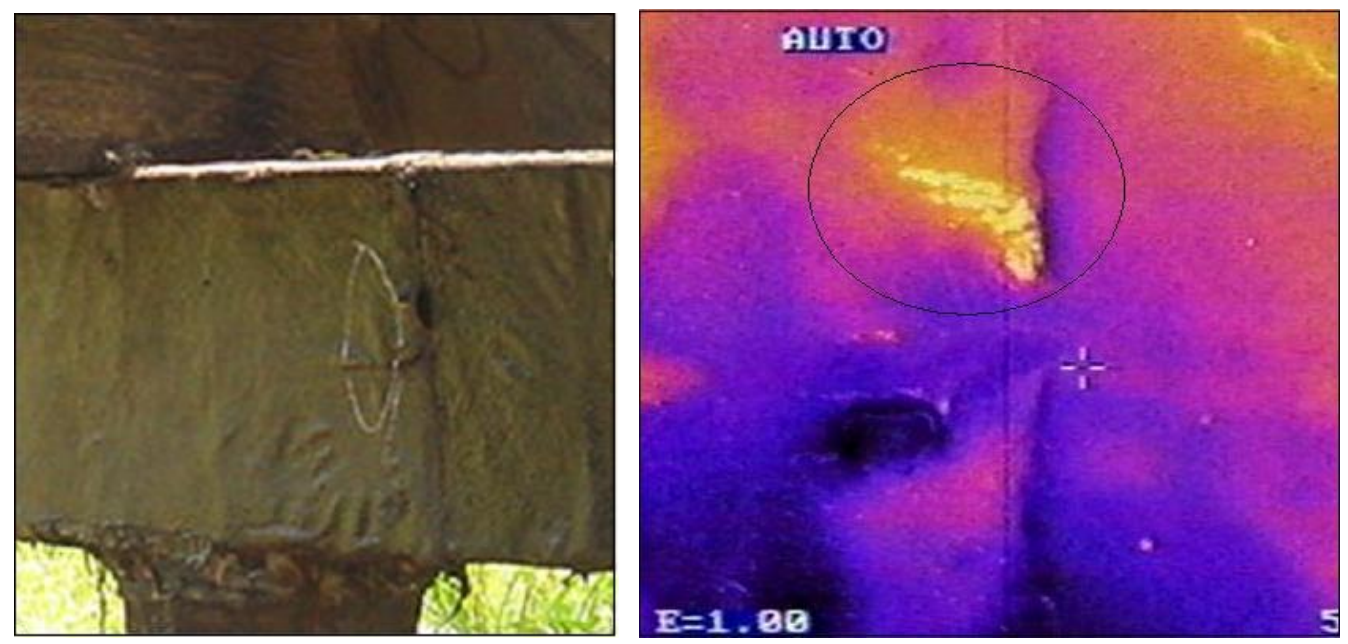

Figure 5.26. (a) Location of debond D5 in the middle of the beam (b) infrared image of debond D5

Many other debonds were detected on the same side of the pile cap. Debonds D6 and D7 were visible as air bulges on the surface (see Figure. 5.27). These debonds were detected by tap testing and infrared thermography as well. However the debond D10, close to debond D6 was detected only by the infrared camera. Figures 5.27 to 5.29 shows the digital and the infrared images of these defects. The debonds' shapes and sizes can be observed (represented by the yellow regions) in the infrared images.

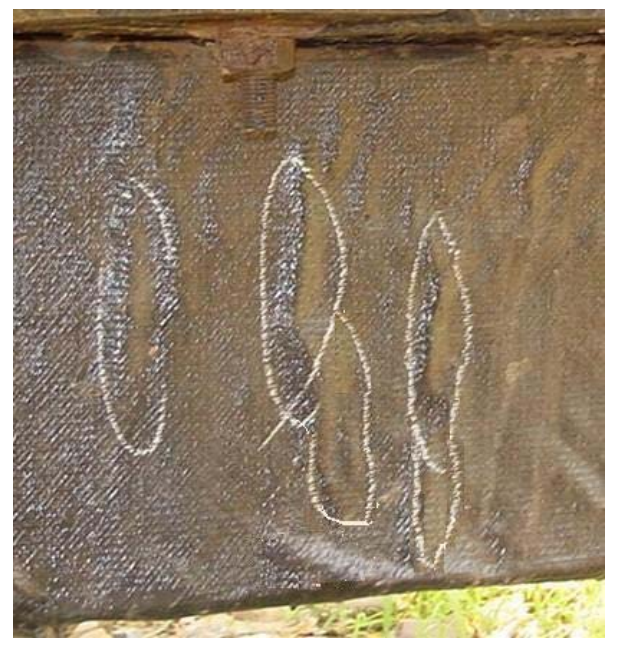

Figure 5.27. Picture of debonds D10, D6 and D7 


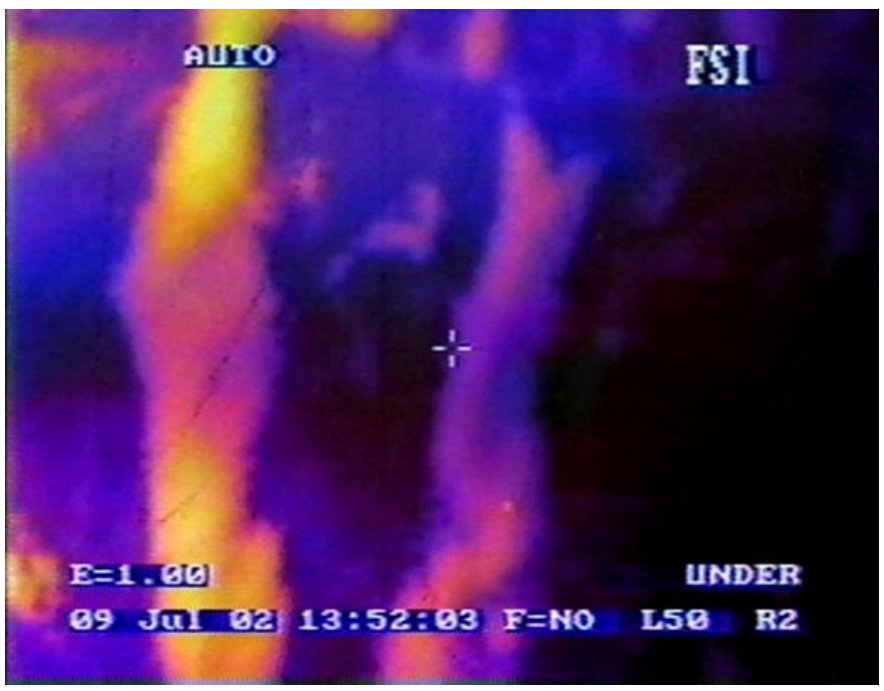

Figure 5.28. Infrared image showing the close up of debonds D6 and D7

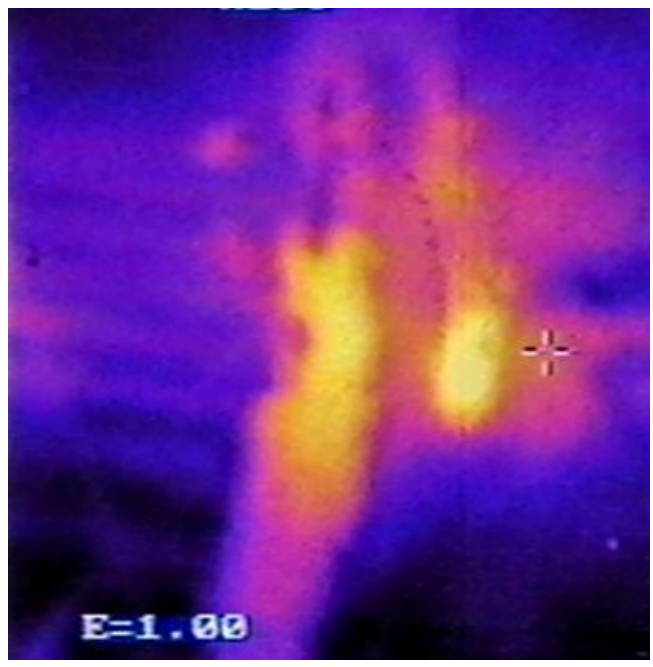

Figure 5.29. Infrared image of debond D10

Debonds in D8 consisted of many air pockets. They could be detected only by infrared testing and not by tap testing. Figure 5.30 shows the location and infrared image of these debonds. 

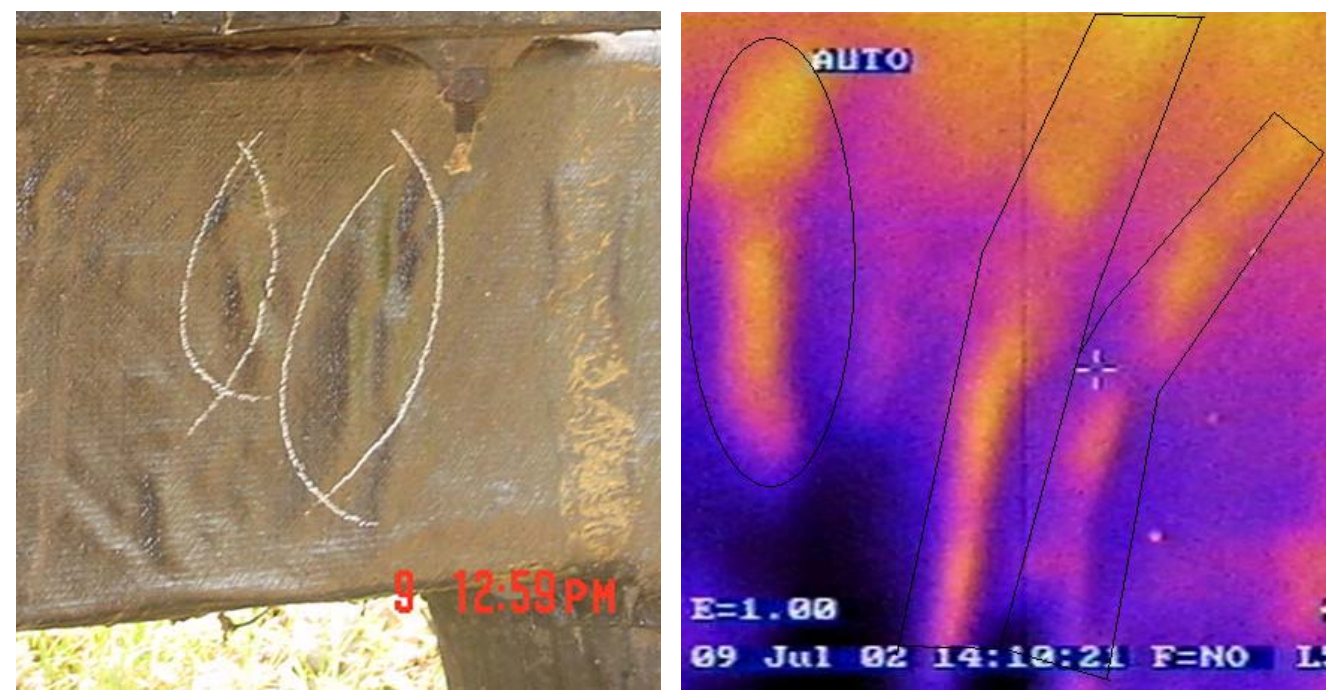

Figure 5.30. (a) Picture of debonds D8 (b) infrared image of the debonds

Debond D9 consisted of a few small air pockets. They could be detected only by infrared testing. Figure 5.31 shows the location and infrared image of the debonds D9.
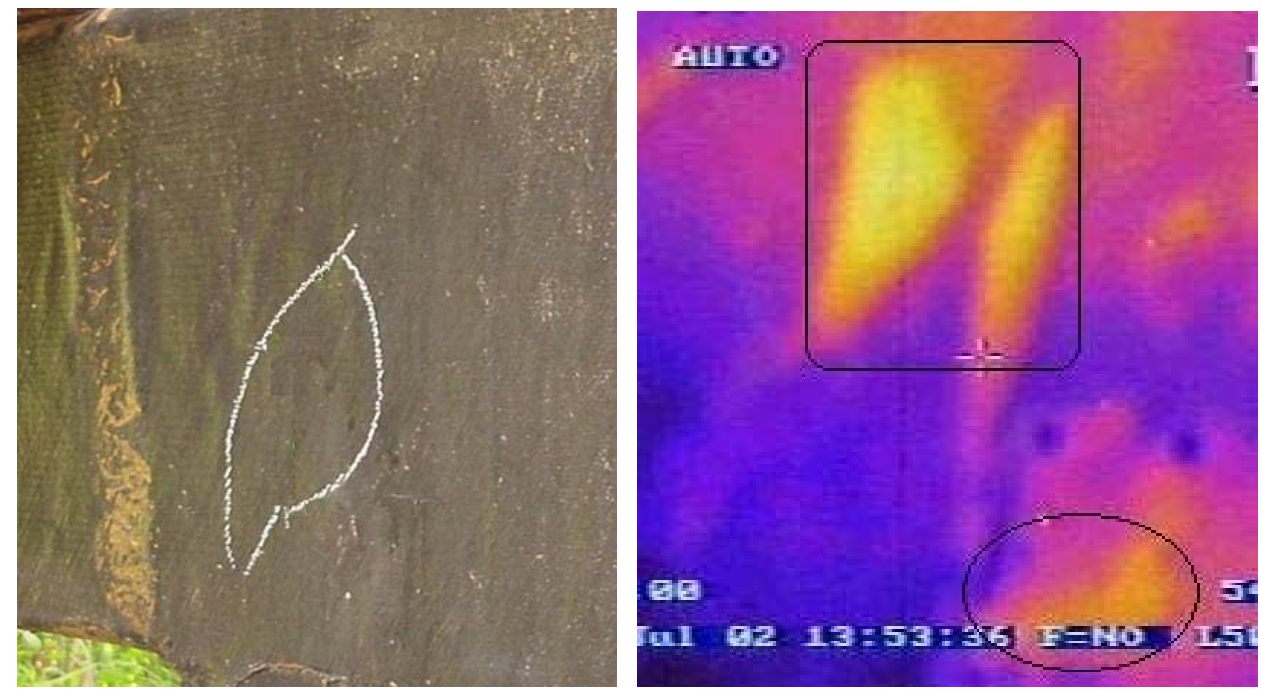

Figure 5.31. (a). Picture of debonds D9 (b) infrared image showing close up of debonds D9

At the middle-top portion of the pile cap, the FRP wrap had worn out and portions of the timber were visible (see Figure.5.32(a)). Infrared tests revealed air pockets in this portion of the pile cap. Figure 5.32(b) shows the infrared image of a small debond that was not visible on the surface. 

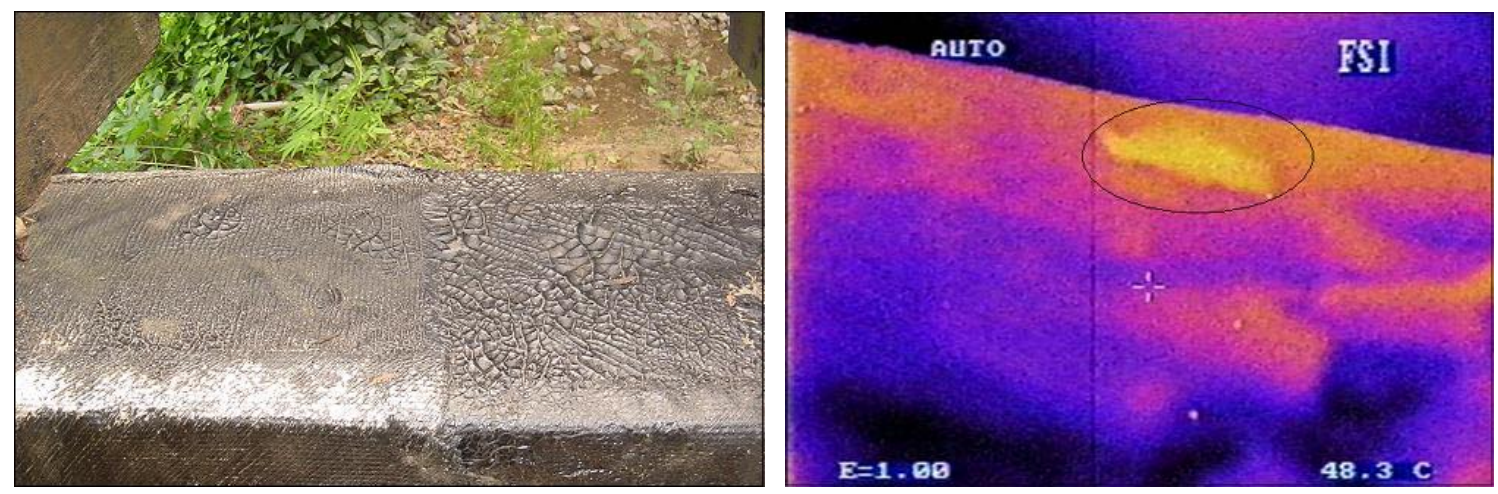

Figure 5.32. (a) Picture showing the middle top of the beam (b) infrared image of debond

The other side of the pile cap was tested using infrared thermography. It was found that there were not many debonds on this side of the pile cap. Infrared testing revealed one debond (D11) close to its edge. The location and the infrared image of the debond D11 is shown in Figure. 5.33 (a) and (b).
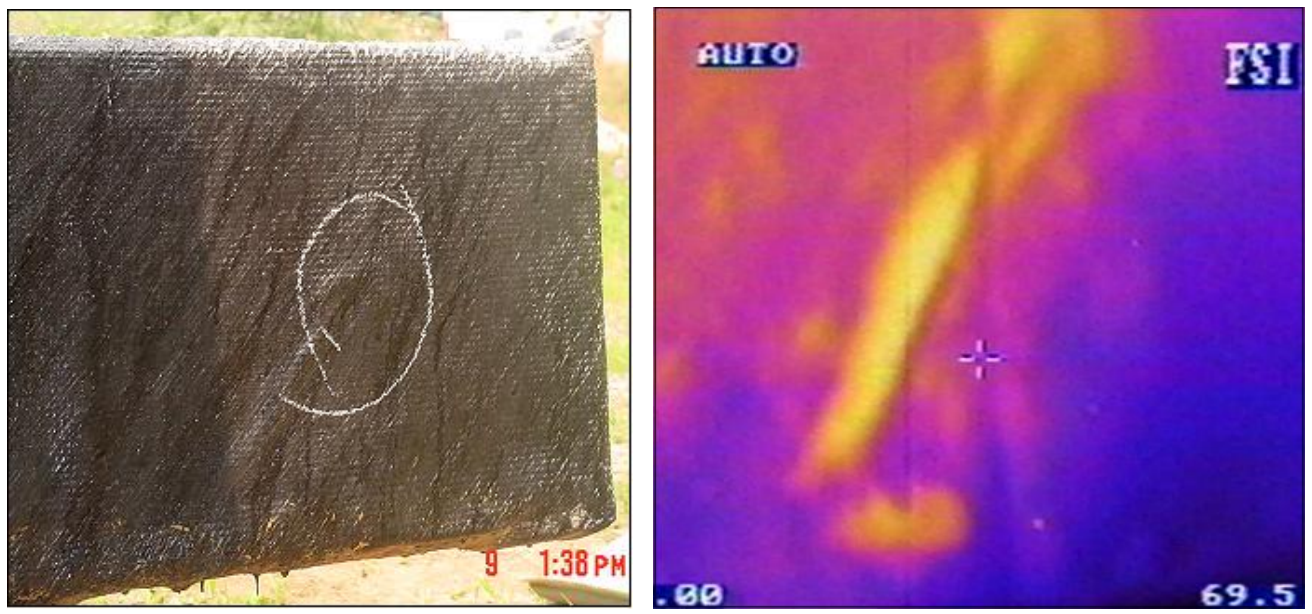

Figure 5.33. (a) Picture showing debond D11 on other side of the beam (b) infrared image of debond D11

Few small sized debonds were detected only by infrared thermography. D12 was a small sized debond close to the center of the pile cap. Figure 5.34 shows the location and infrared image of D12. Debonds in D18 were small air pockets located on the same side of the beam. Figure 5.35 shows the location and infrared image of D18. 

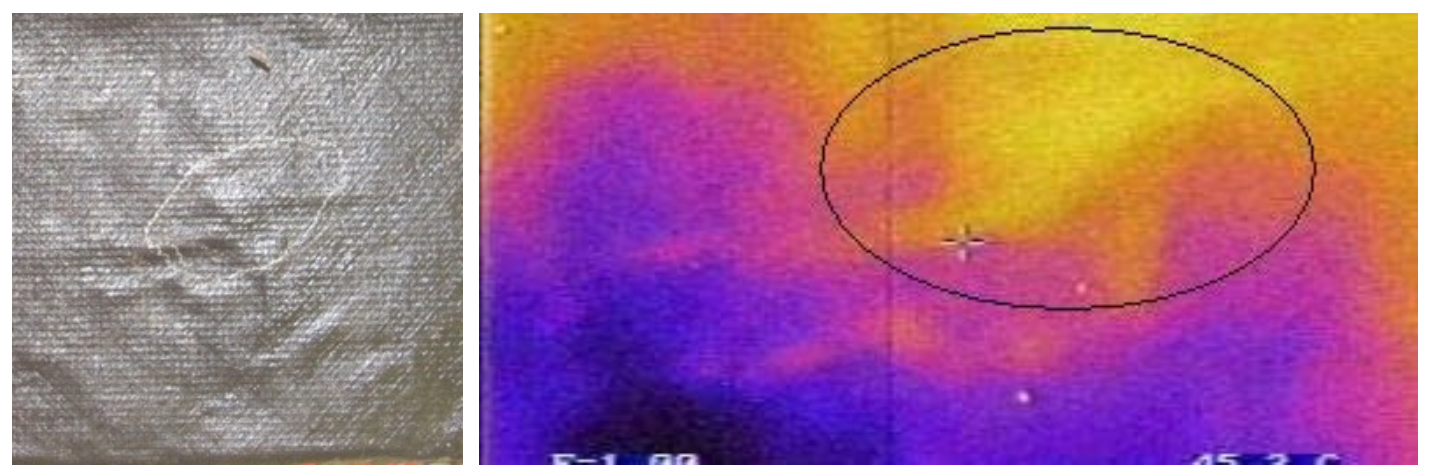

Figure 5.34. (a) Picture showing D12 on other side of the beam (b) infrared image of debond D12
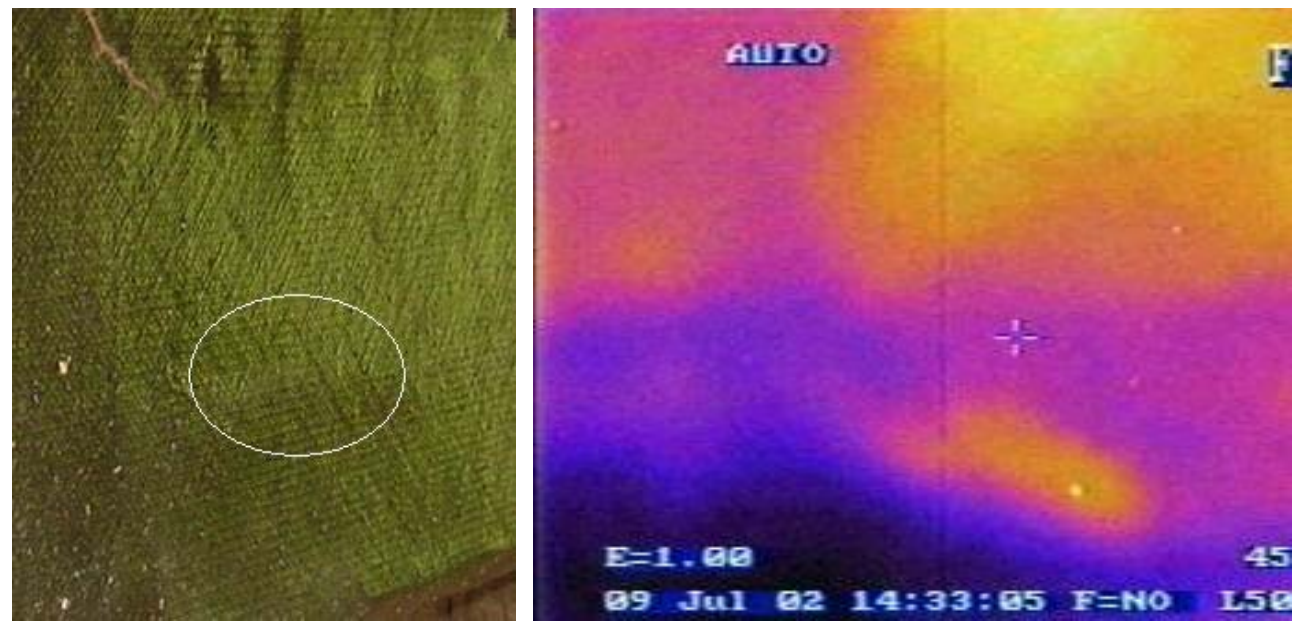

Figure 5.35. (a) Picture showing D18 on other side of the beam (b) infrared image showing close up of debond D18

The FRP wrap on the edge of the pile cap had worn out since it was directly exposed to the atmosphere. This pile cap had been previously tested during the summer of 2001 (refer to Section 5.4.1). The glass fibers in the wrap were visible on the surface (Figure. 5.36). Though the pile cap did not require any further testing, infrared tests were conducted on the pile cap to examine if there were any air gaps between the wrap and the timber. Figure 5.37 shows the infrared images of the pile cap. The infrared images revealed that there were no debonds between the wrap and the timber. 


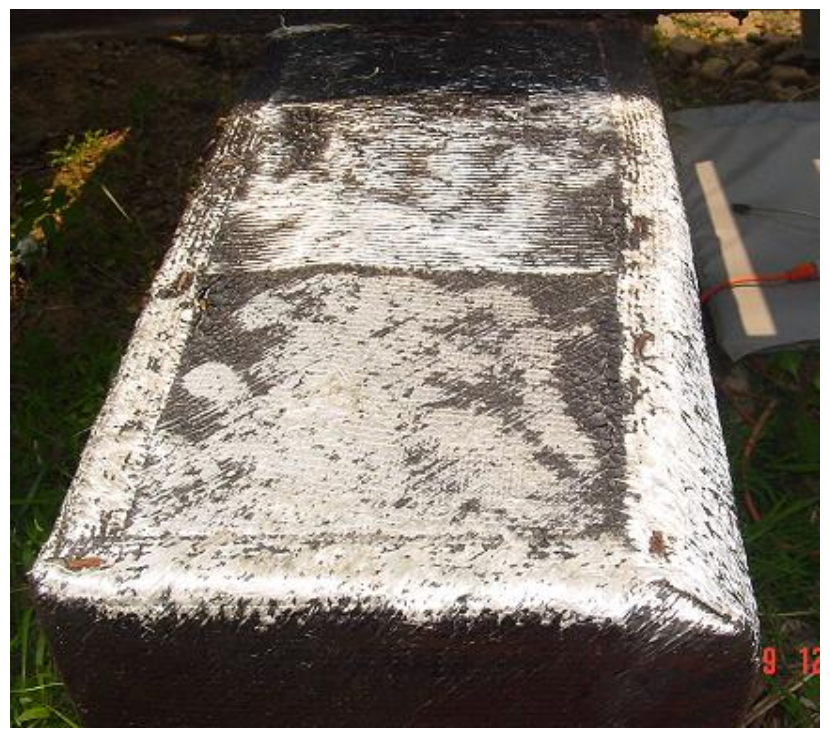

Figure 5.36. Picture showing the top surface of the edge of pile cap

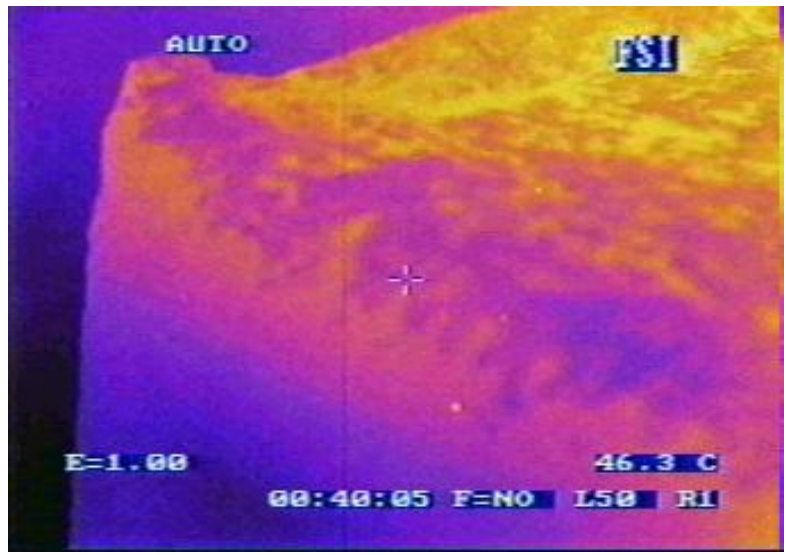

(a)

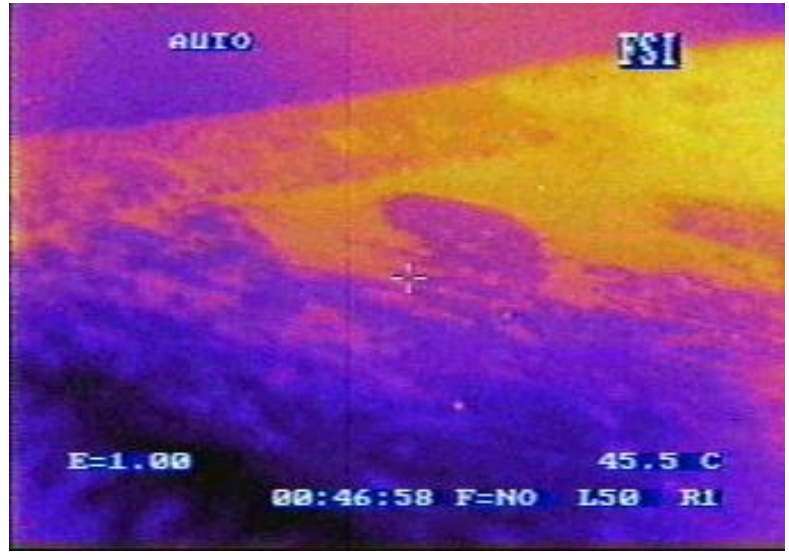

(b)

Figure 5.37. Infrared images showing the top surface of the pile cap (a) edge portion (b) away from edge 


\subsubsection{Summer 2003 Testing}

Periodic monitoring of wrapped composite members is necessary to ensure the structural integrity and also for the Quality and Maintenance type issues. Infrared tests conducted during summer 2003 were a continuation of tests that were conducted during summer 2002. Two pile caps and two piles were tested using the digital infrared camera. One of the pile caps (the first pile bent from the west end of Bridge \#568) was the same FRP wrapped timber component that was tested during summer 2002. The pile cap was tested to examine if the previously existing debonds grew in size and/or if any other additional debonds had developed during the span of one year. The other timber components that were tested had been rehabilitated with FRP wraps during October 2002. In coordination with the South Branch Valley Railroad (SBVR), the Bridge \#568 was inspected by a team of researchers and it was determined that the fifth pile bent from the west end of Bridge \#568's “pile cap/pile” joint of span four needed rehabilitation. The insitu rehabilitation and strengthening of this "pile cap/pile" joint and the pile was completed between the months of August and October 2002. Glass Fiber Reinforced Polymer (GFRP) fabric in combination with phenolic-based adhesives was used to repair the pile bent. The phenolic resin was mixed with a formaldehyde hardener at a 5:1 ratio by weight. The GFRP wrap was then coated with the adhesive. This was done to provide sufficient bond between the GFRP and the substrate (FRA Progress report 2002). Infrared tests were conducted to determine if the rehabilitated portions of the pile/pile cap developed any debonds.

\subsubsection{Experimental Setup}

During Summer 2003, infrared tests were conducted on the timber components using the ThermaCAM ${ }^{\mathrm{TM}}$ S60 (FLIR Systems) infrared condition monitoring system. The system consisted of a digital infrared camera connected to a laptop computer with associated data acquisition and image processing software (detailed description of the camera and the software is available in Chapter 3 of this thesis). The 1500 watts quartz heater was used to heat the piles and pile caps. Figure 5.38 shows the field setup for the infrared testing. 


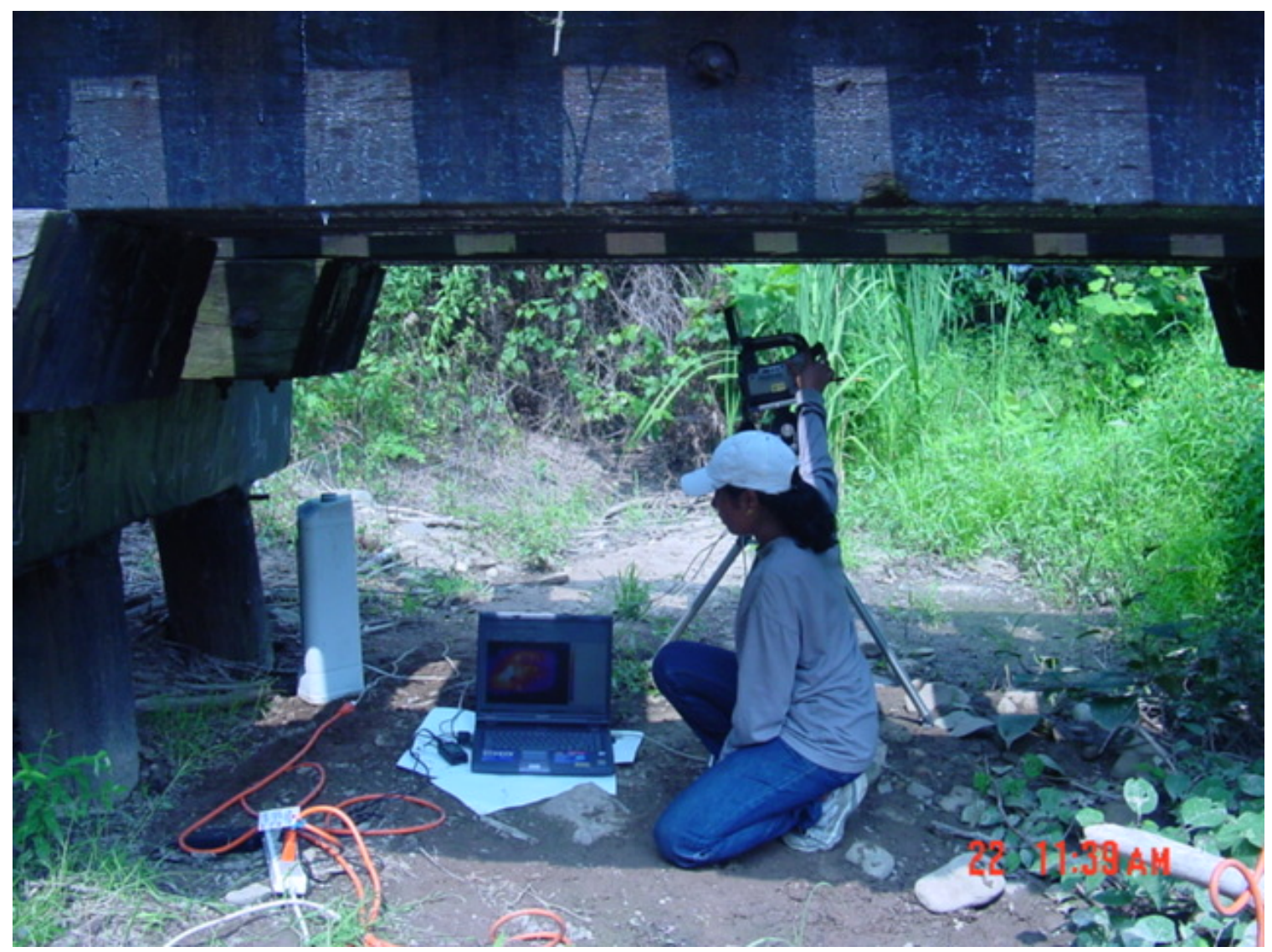

Figure 5.38. Field setup for infrared testing using the digital infrared camera

\subsubsection{Infrared Testing and Results}

The pile cap that was tested during summer 2002 was tested using the digital infrared camera and the debonded areas were marked with a chalk. The quartz heater was used to heat the pile cap. The marked debonds were compared to the ones marked during summer 2002. Some of the debonds had grown in size. New debonds had also developed over time.

Figure 5.39 shows the location of the debond D1 and another new debond named as D13. The infrared image of debond D1 (shown as the white regions in Figure 5.40) revealed that it had grown in size. The image was compared with the infrared image of debond D1 taken in the previous year (compare Figure 5.40 and Figure 5.21). D13 was a new debond that had developed in this portion of the pile cap as shown in Figure 5.39. Figure 5.41 shows the infrared image of the debond D13. 


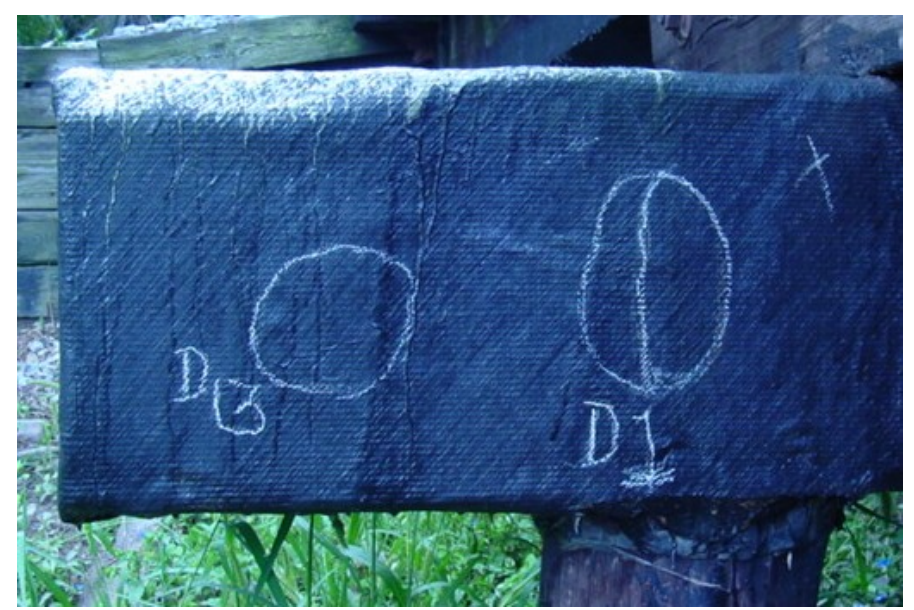

Figure 5.39. Picture showing the top surface of the pile cap

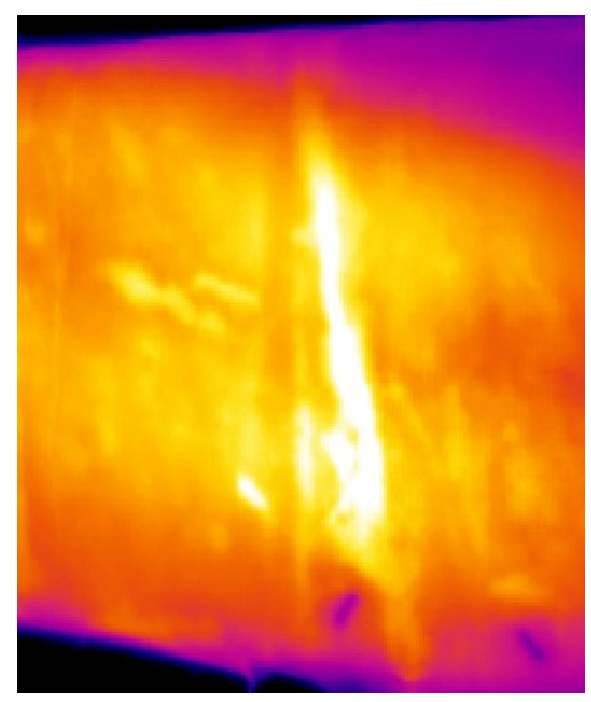

Figure 5.40. Infrared image of debond D1

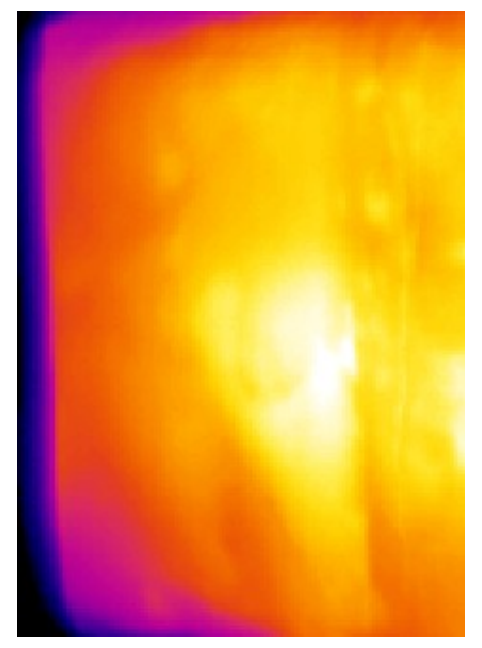

Figure 5.41. Infrared image of debond D13 
Figure 5.42 shows the location of the debonds D2, D3 and D14. The infrared images of debonds D2 and D3 (Figure 5.43), when compared to previous years' infrared results (see Figure 5.23) revealed that the sizes of the debonds D2 and D3 remained the same. The black region (area with lower temperature) in Figure 5.43 is caused due to the bolt and the nut fixed to the timber component above the pile cap (shown in Figure.5.42). The infrared image of debond D14 is shown as white areas in Figure 5.44. Compared to the previous years' tests (see Figure 5.24), the debond had slightly grown in size. This is obvious from comparing both the years’ infrared images.

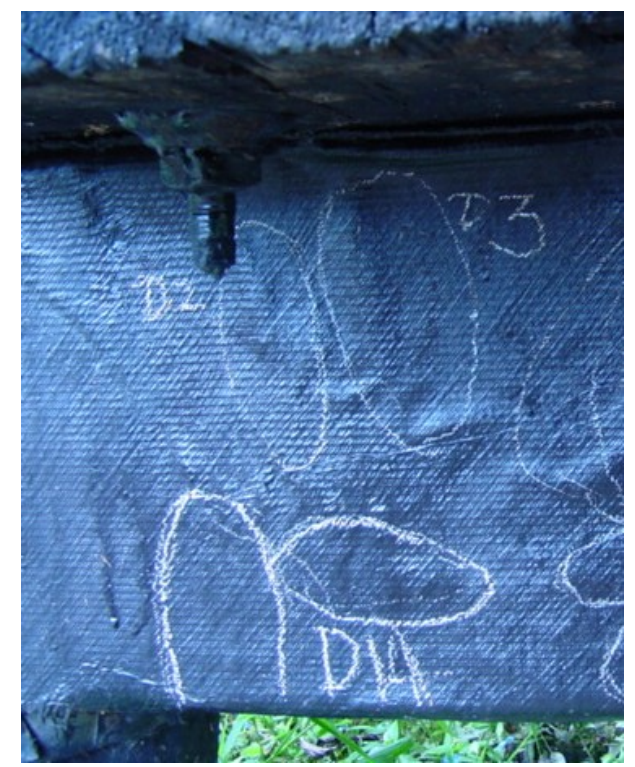

Figure 5.42. Picture showing debonds D2, D3 and D14
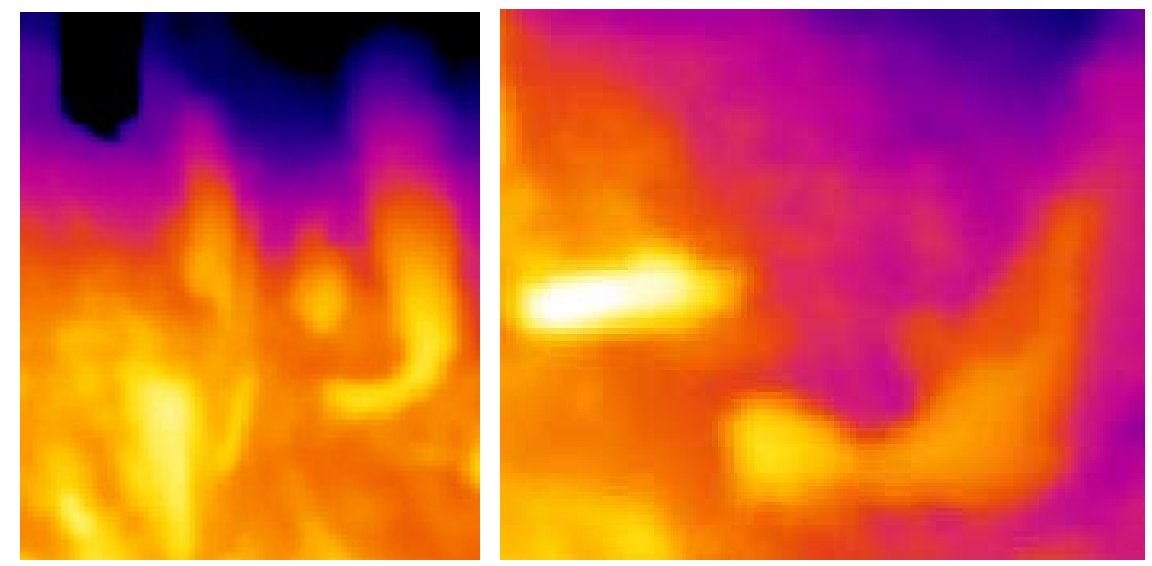

Figure 5.43. Infrared images showing close up of debonds D2 and D3 


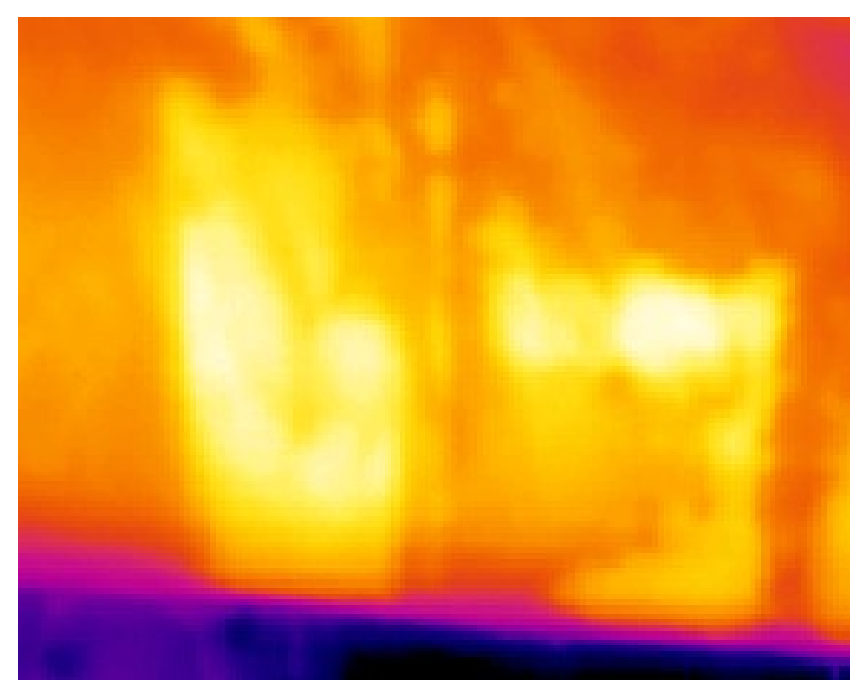

Figure 5.44. Infrared image of debond D14

Figure 5.45 shows the location of the debonds D4 and D15. Figure 5.46 shows the infrared image of debond D4 (shown as bright white and yellow regions). When compared to its previous years' infrared images, (see Figure 5.25) it was concluded that the size of the debond remained the same. The newly developed debond D15 consisted of many small air pockets and had formed below the debond D4. Figure 5.47 shows the infrared image of these debonds (D15) (shown as white areas).

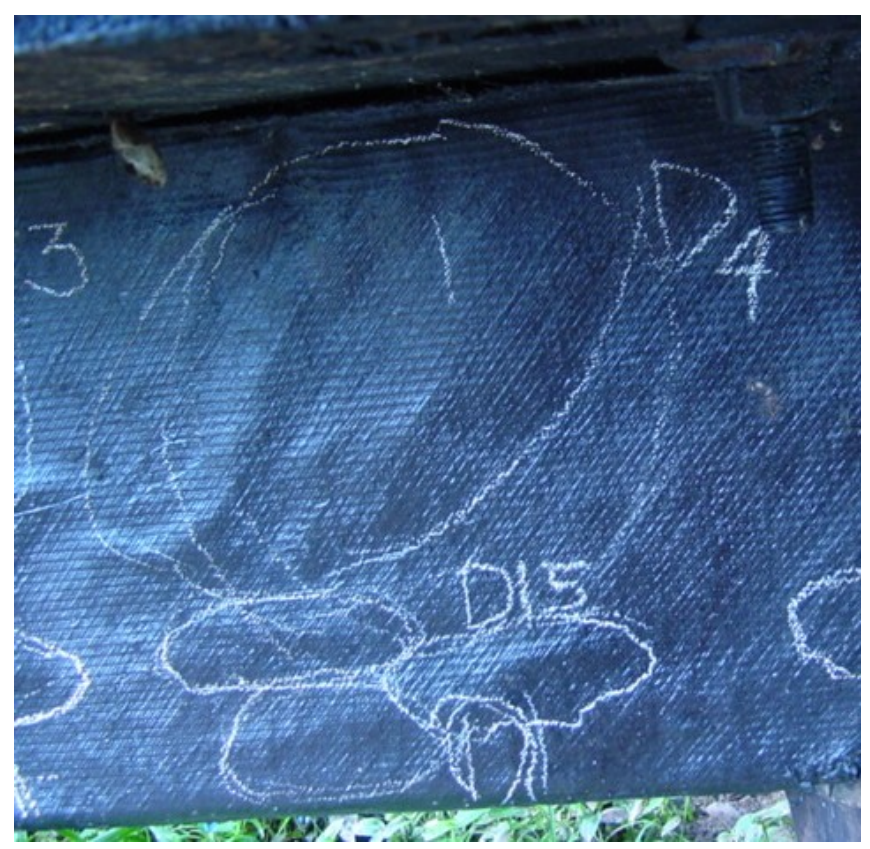

Figure 5.45. Picture showing debonds D4 and D15 


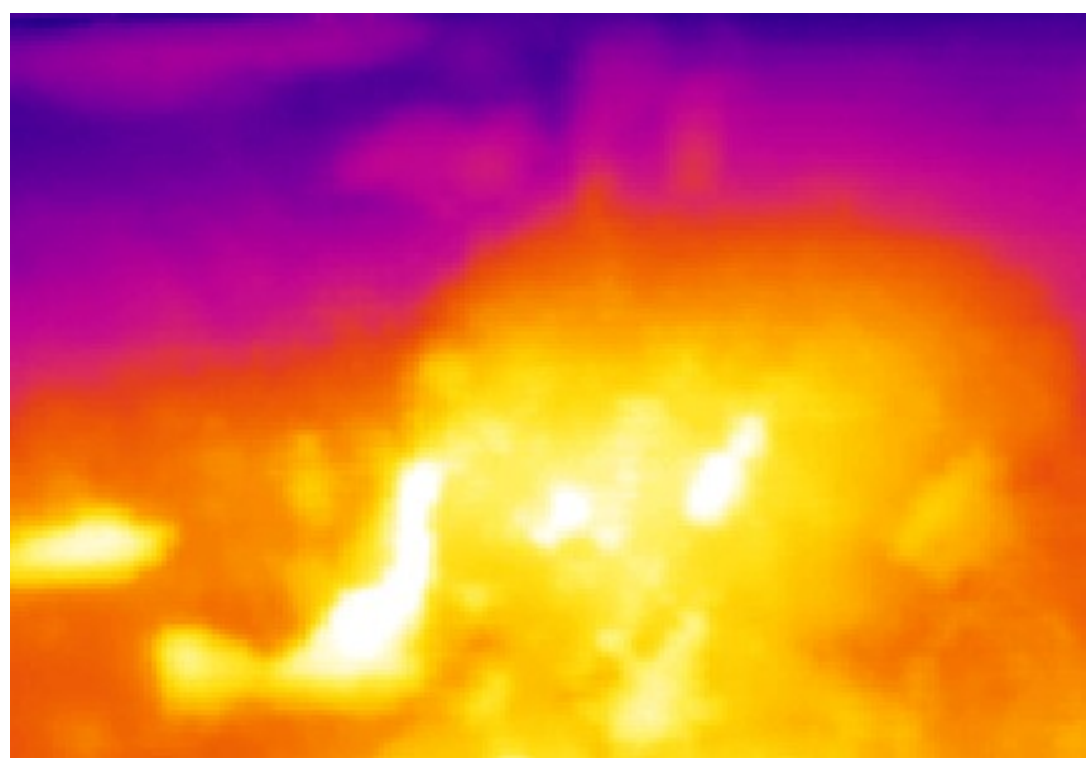

Figure 5.46. Infrared image of debond D4

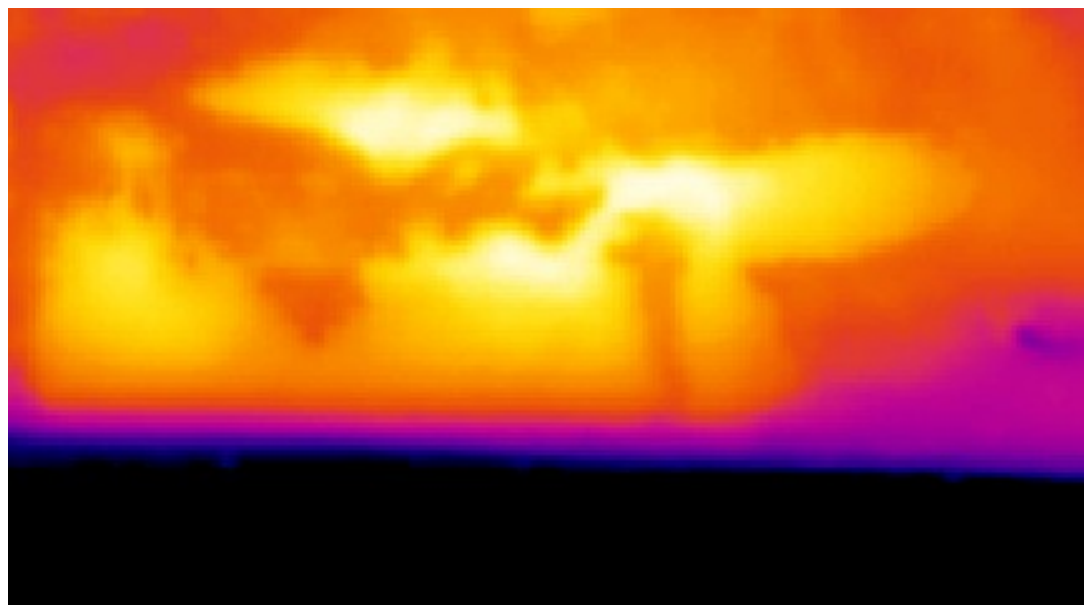

Figure 5.47. Infrared image of debond D15

Figure 5.48(a) shows the location of debond D5. The infrared image shown in Figure 5.48(b) revealed many small air pockets in the portion. The infrared image of D5 taken during summer 2002 (see Figure 5.26), showed only one small air pocket. When compared to previous years' infrared images, it was found that many other small debonds had formed around the old debond. In the infrared image (Figure 5.48(b)) these debonds are indicated by the white regions inside the marked circles. 

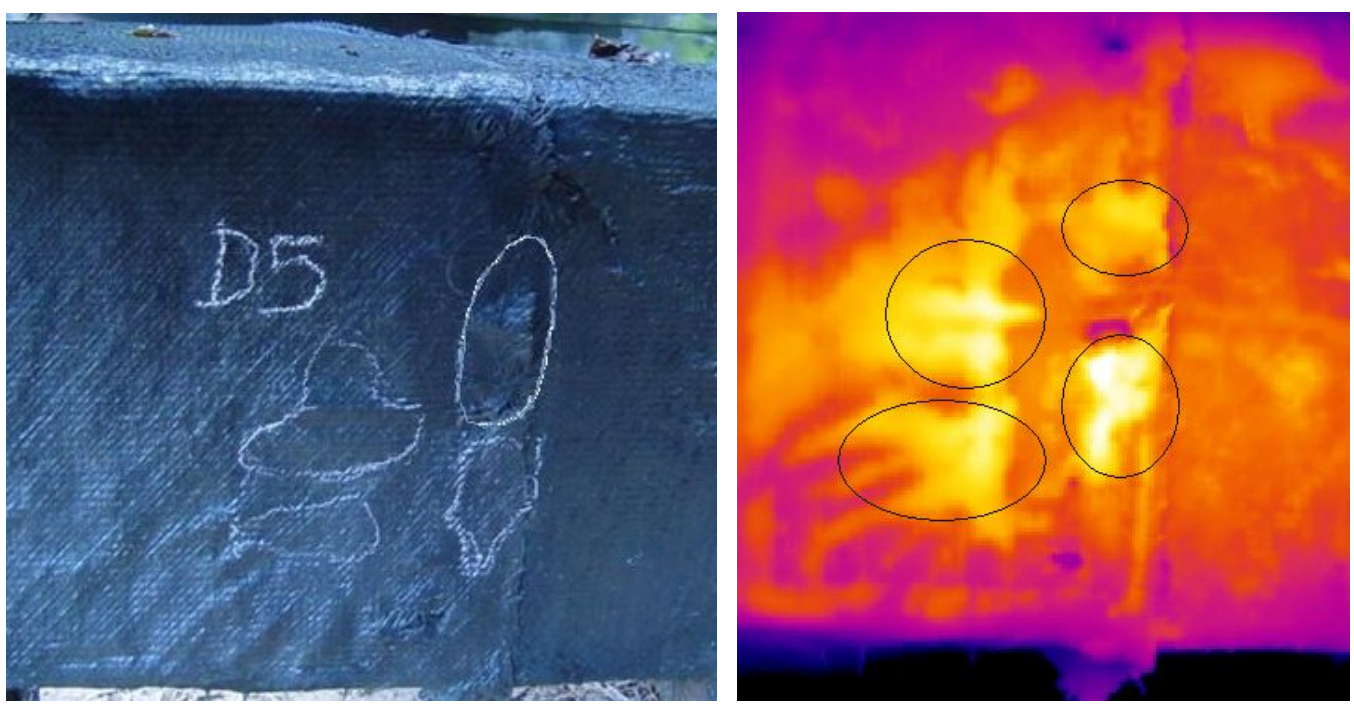

Figure 5.48. (a) Picture showing debond D5 (b) infrared image of debond D5

Figure 5.49 shows the location of the debonds D10, D6 and D7. The infrared images of debonds D6, D7 and D10 (shown as bright white and yellow regions) are shown in Figures 5.50 and 5.51. When compared to previous years' infrared results (see Figures 5.28 and 5.29), it was concluded that none of the debonds grew in size. The dark region seen on the top right corner in Figure 5.51 is due to the presence of the screw attached to the timber component lying above it. The temperature of the screw was colder than the other parts, as it was not heated.

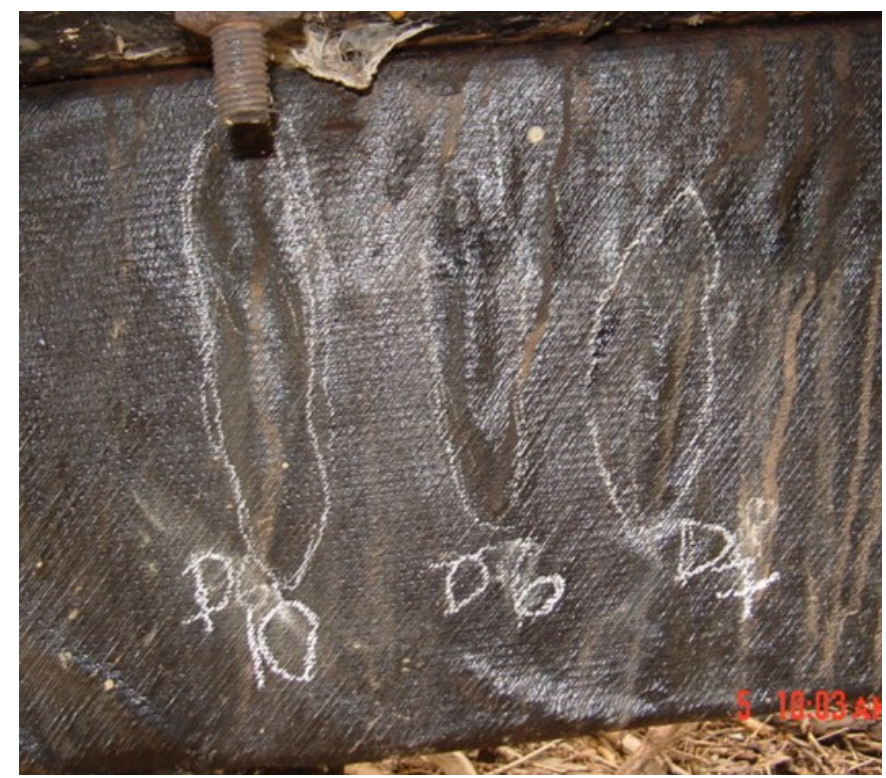

Figure 5.49. Picture showing debonds D10, D6 and D7 


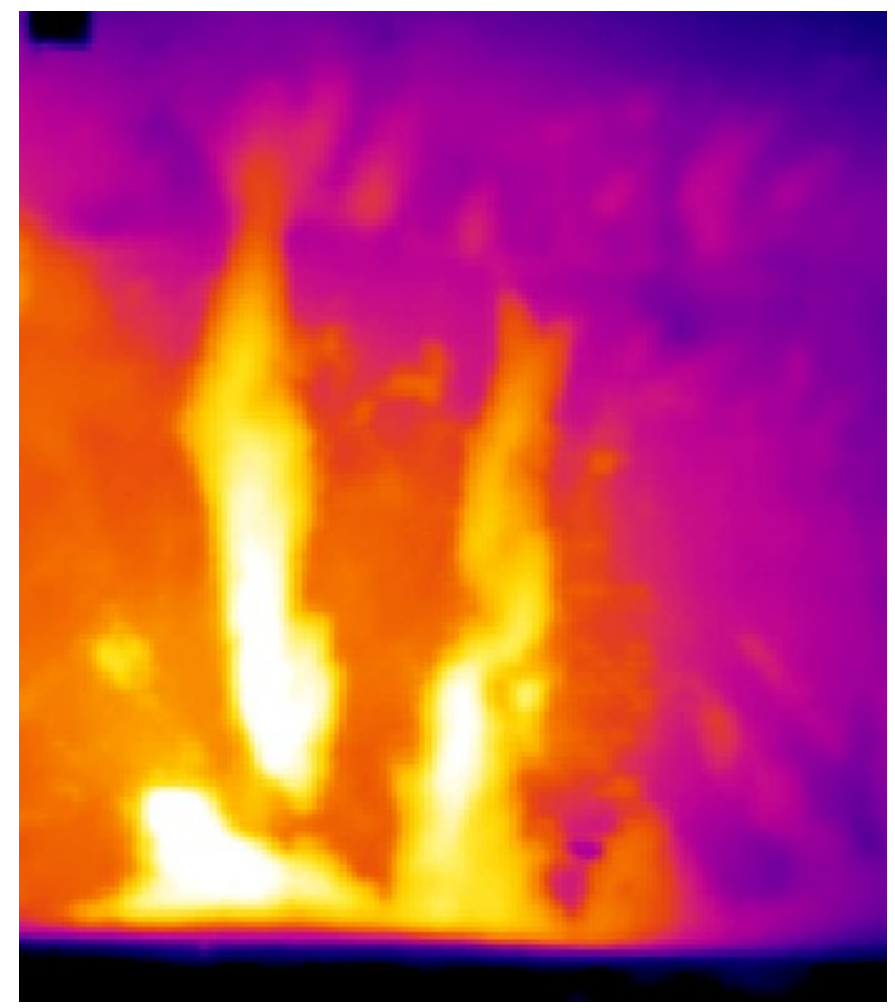

Figure 5.50. Infrared image of debonds D6 and D7

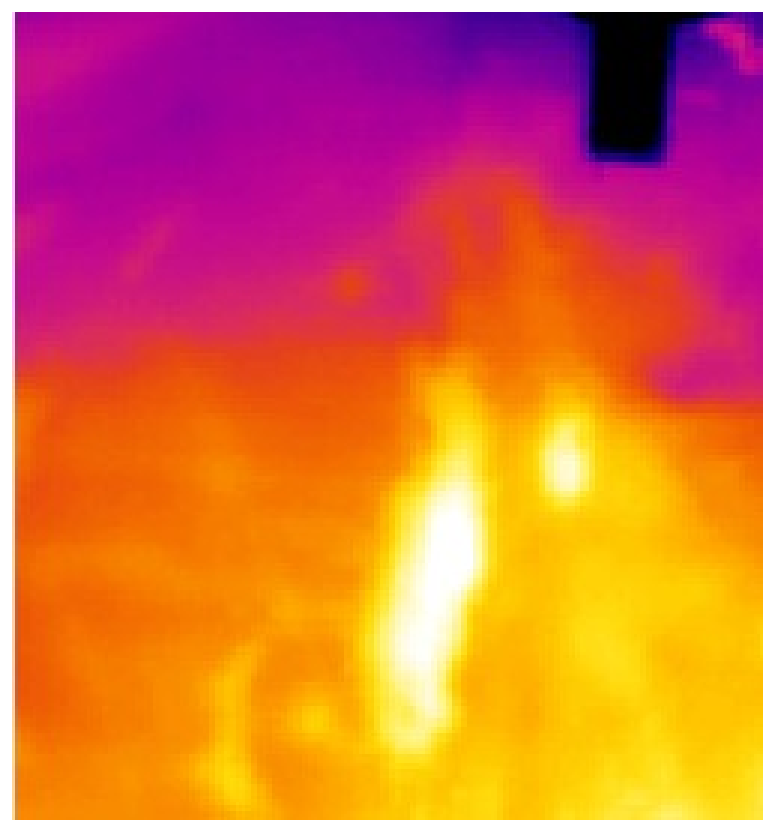

Figure 5.51. Infrared image of debond D10 
Figure 5.52 (a) shows the location of debond D8. It consisted of many small air pockets close to each other. Figure 5.52 (b) shows the infrared image of these air gaps. They are shown as white regions (areas with higher temperature). Compared to the previous years' infrared results (Figure 5.30(b)), it was observed that the sizes remained the same. It was also observed that the digital infrared images more clearly defined the shape and size of the debonds compared to the non-digitized images acquired during the pervious years' tests. This can be observed by comparing the two respective infrared images of debond D8.
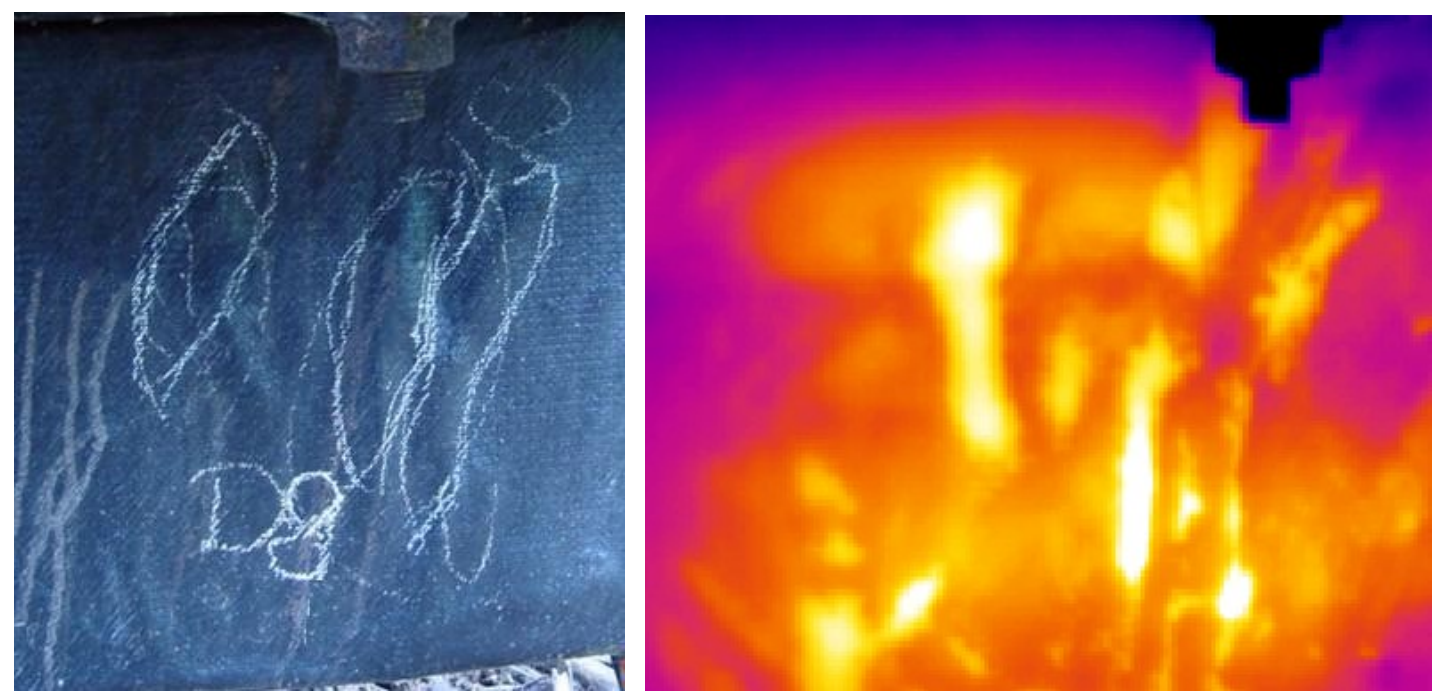

Figure 5.52. (a) Picture of debond D8 (b) Infrared image of debond D8 and other debonds in its vicinity

Figure 5.53(a) shows the location of debond D9. It consisted of one big air pocket and another small one close to it. Figure 5.53(b) shows the infrared image of these air gaps. They are shown as white regions (areas with higher temperature). Compared to the previous years' infrared results (Figure 5.31(b)), it was observed that the sizes remained the same. 

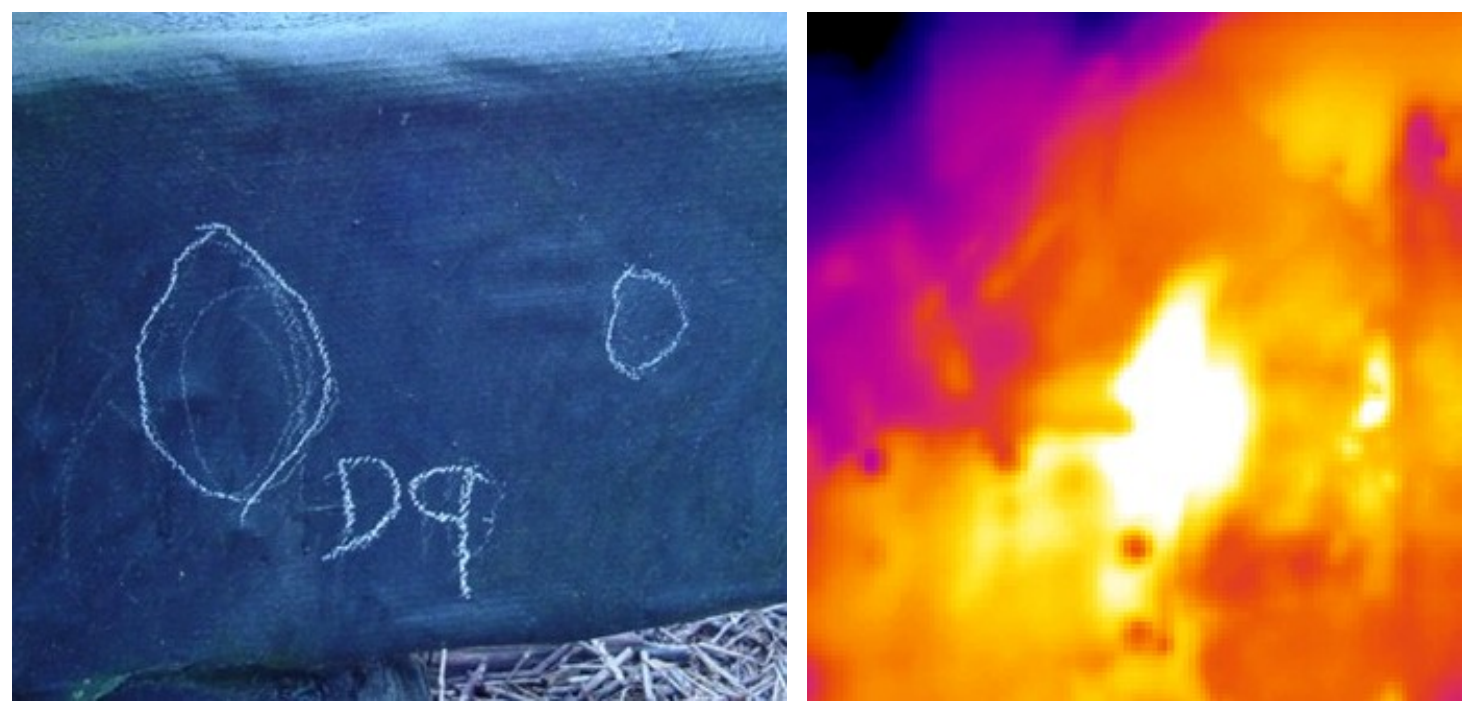

Figure 5.53. (a) Picture of debond D9 (b) infrared image of debond D9

Figure 5.54 (a) shows the location of a newly developed debond D16, on the same side of the pile cap. Figure 5.54 (b) shows the infrared image of these air gaps which consisted of many small air pockets that were located close to each other. They are shown as bright white regions (areas with higher temperature when compared to the surrounding areas).
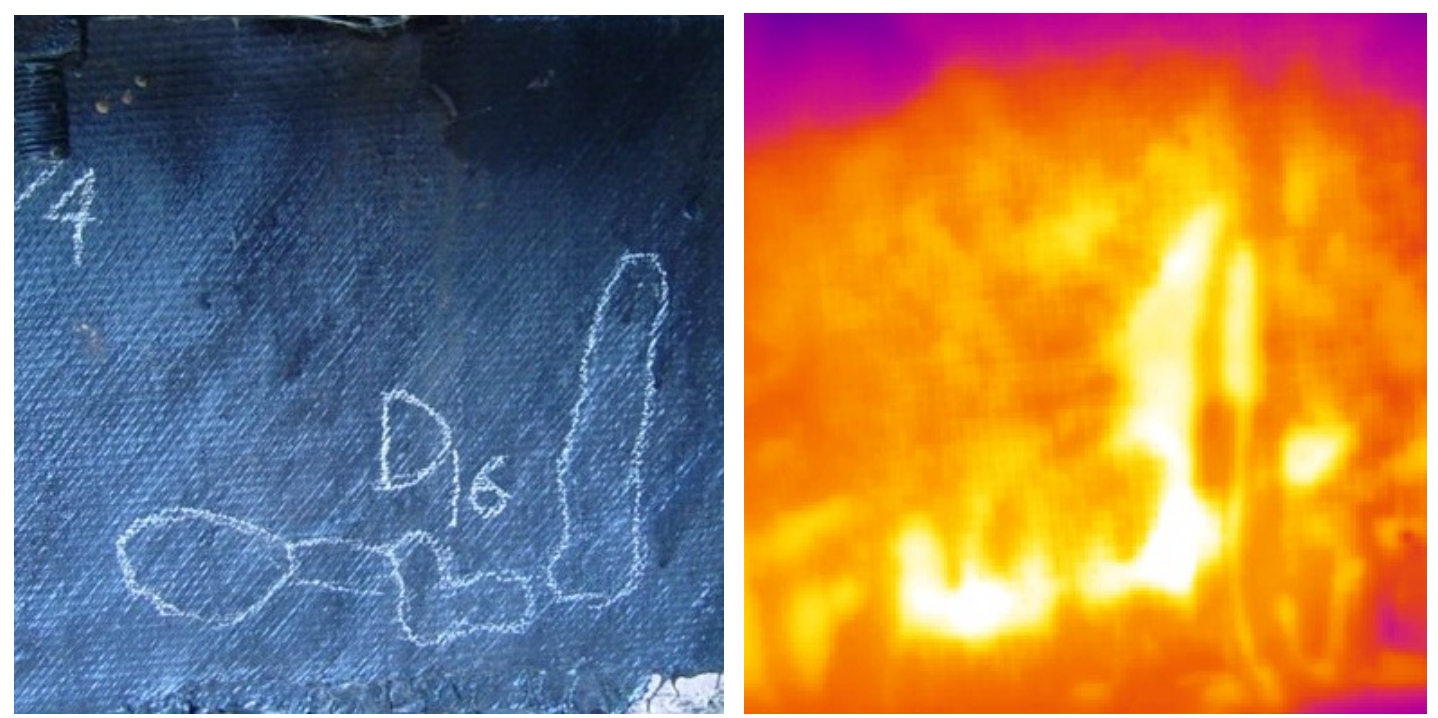

Figure 5.54. (a) Picture of debond D16 (b) Infrared image of debond D16 
The other side of the same pile cap seemed to have developed many debonds when compared to the previous years' tests. Figure 5.55 (a) and (b) shows the location and the infrared image of the debond D11. This debond located towards the end of the beam did not grow in size when compared to the previous year (see Figure 5.33(b)). Figure 5.56 shows the location and infrared image of debond D12. The infrared image of D12 reveals a cluster of small sized debonds. When compared to the previous years infrared image (see Figure 5.34(b)), it was found that debond D12 had developed several other smaller sized air pockets around the vicinity of the already existing debond.
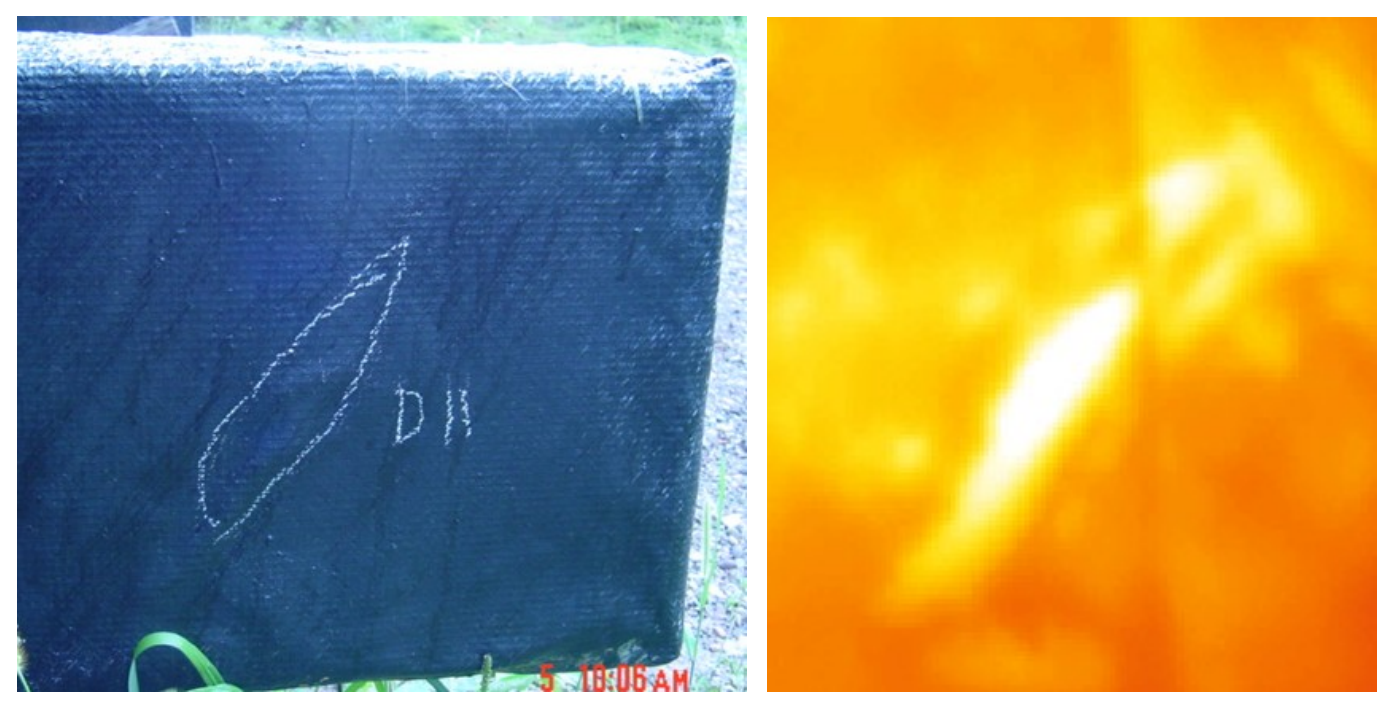

Figure 5.55. (a) Picture of debond D11 (b) infrared image of debond D11
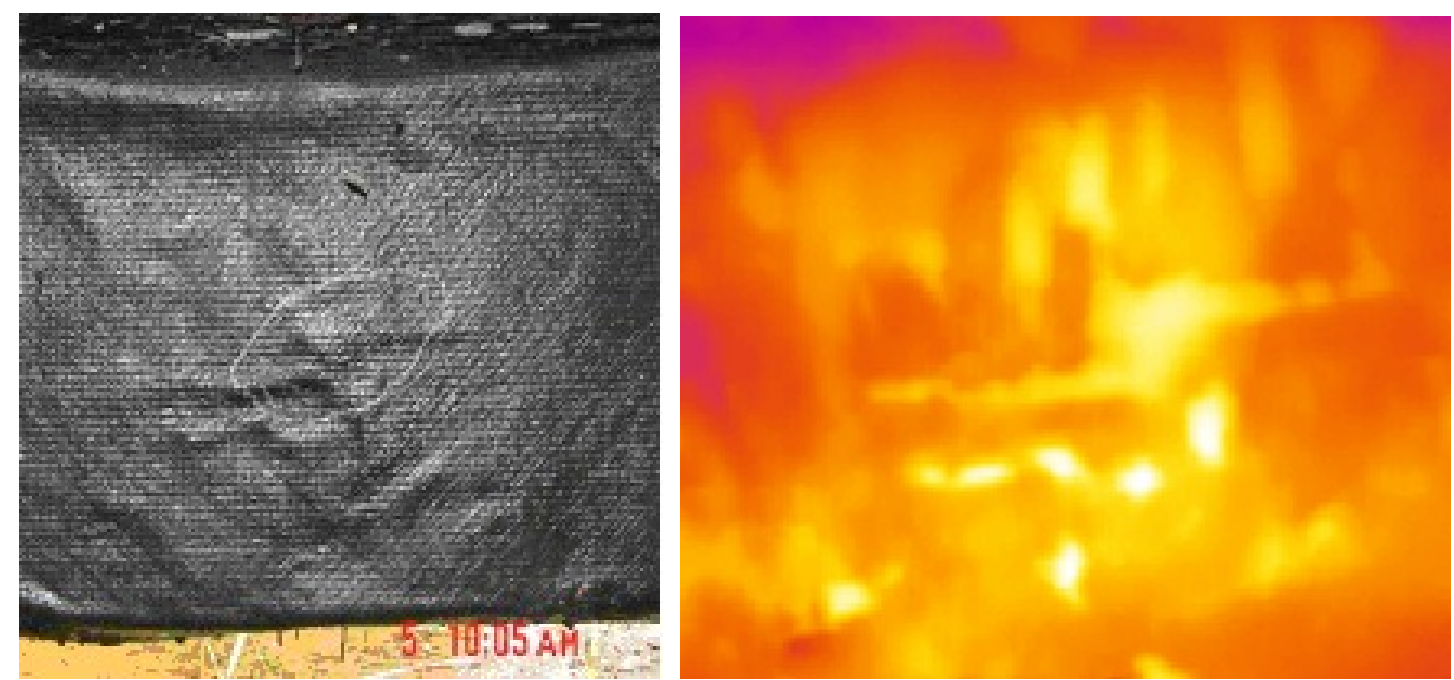

Figure 5.56. (a) Picture of debond D12 (b) infrared image of debond D12 
Figures 5.57 to 5.59 show the locations and infrared images of all the other newly developed debonds. The debonds D17, D18 and D19 did not exist during the previous years' tests. All these debond were small air pockets located on the other side of the beam. The shape and sizes of the debonds are shown as bright white regions (areas with higher temperature when compared to the surrounding defect-free areas) in their respective infrared images.
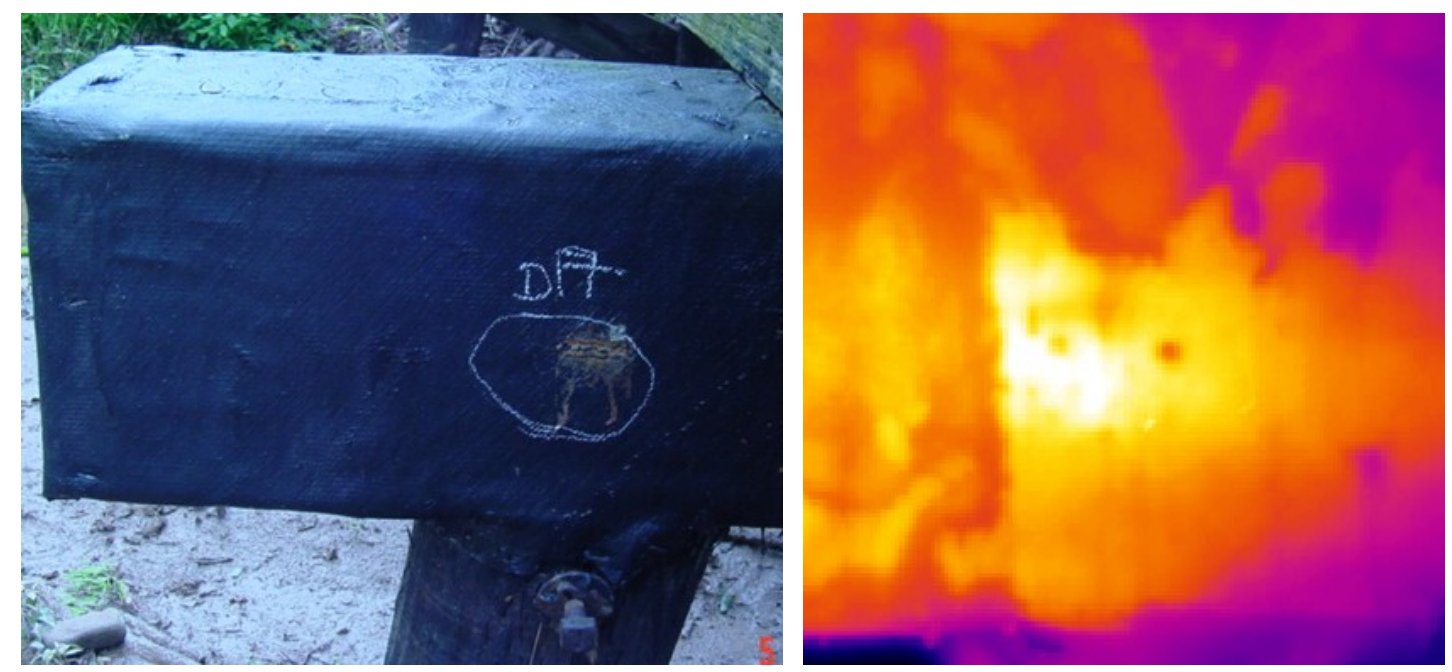

Figure 5.57. (a) Picture of debond D17 (b) infrared image of debond D17

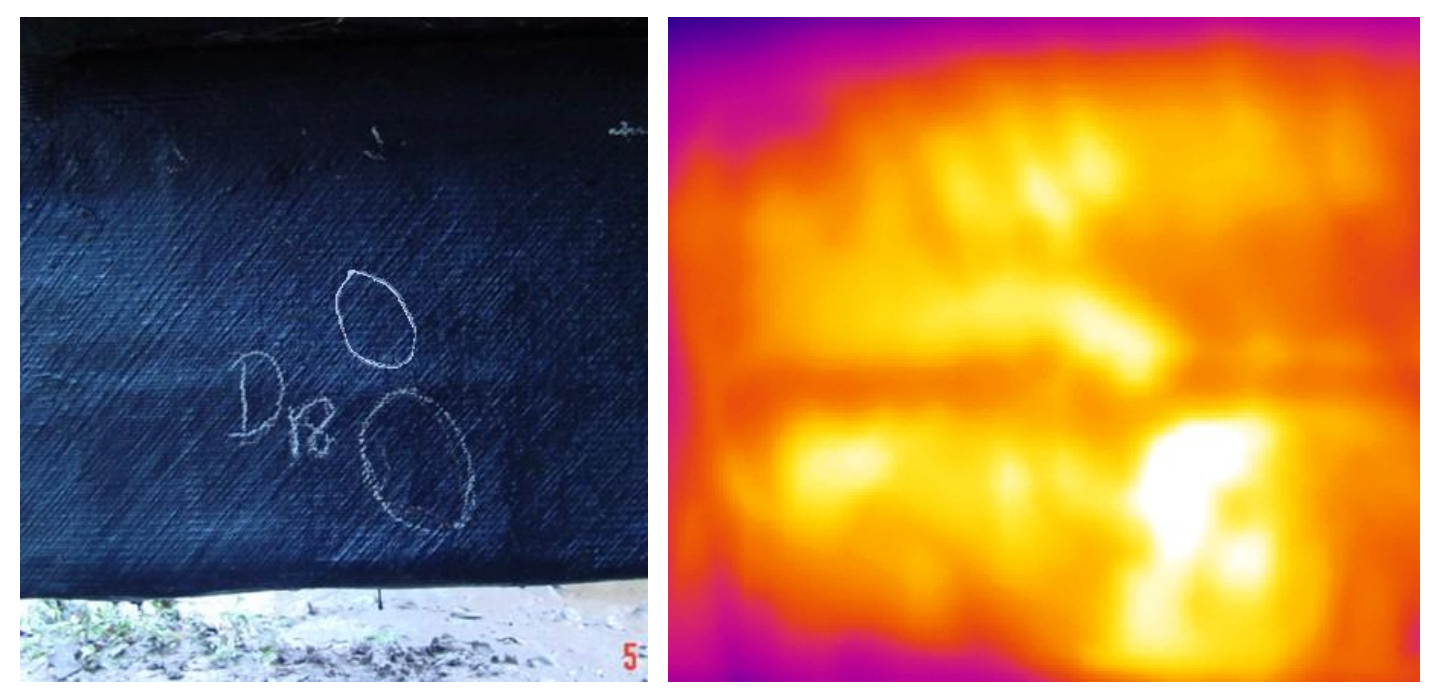

Figure 5.58. (a) Picture of debond D18 (b) infrared image of debond D18 

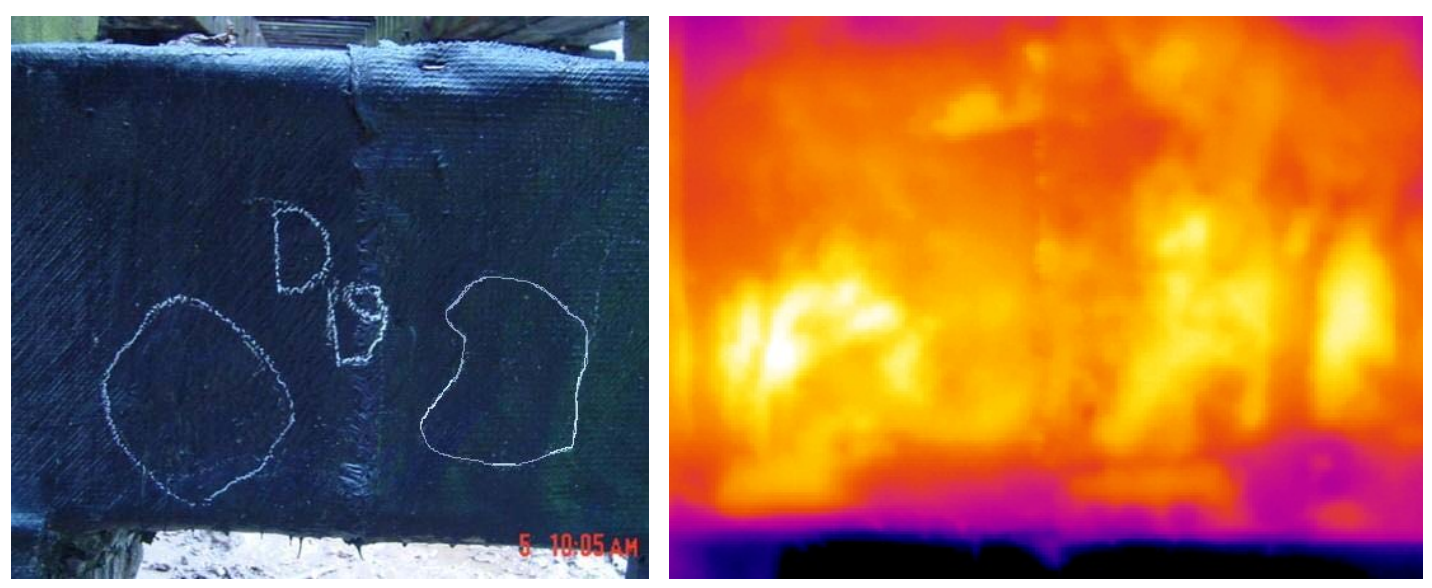

Figure 5.59. (a) Picture of debond D19 (b) Infrared image of debond D19

Figure 5.60 shows the portion of the pile cap that had been previously tested during the summer of 2001 (refer to section 5.4.1) and summer of 2002 (refer to section 5.4.2). The glass fibers in the wrap were visible on the surface. The picture of this portion seemed to be the same as that taken during the previous years. There was not much difference in the amount of deterioration.

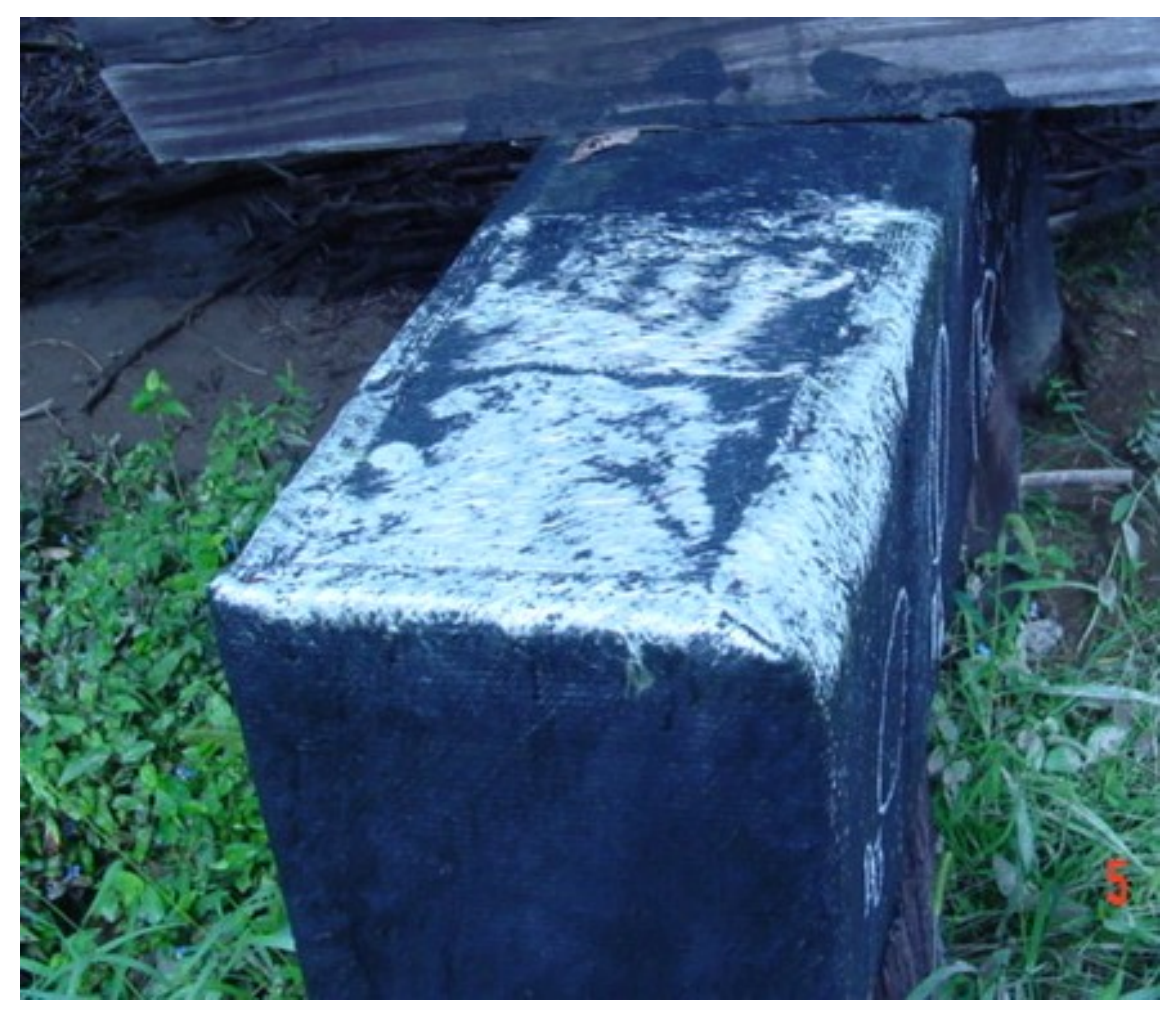

Figure 5.60. Picture showing the top surface of the edge of pile cap 
The "pile cap/ pile” joint and the pile that were rehabilitated during October 2002 were inspected during Summer 2003. Infrared tests were conducted to detect the presence of any debonds. Two other piles and a pile cap were heated using the quartz heater prior to taking the infrared images. Only a portion of the pile cap (pile/pile cap joint) and the two piles were wrapped using the GFRP wraps. Figure 5.61 shows the picture of these timber components and the portion that had been wrapped with the GFRP wraps.

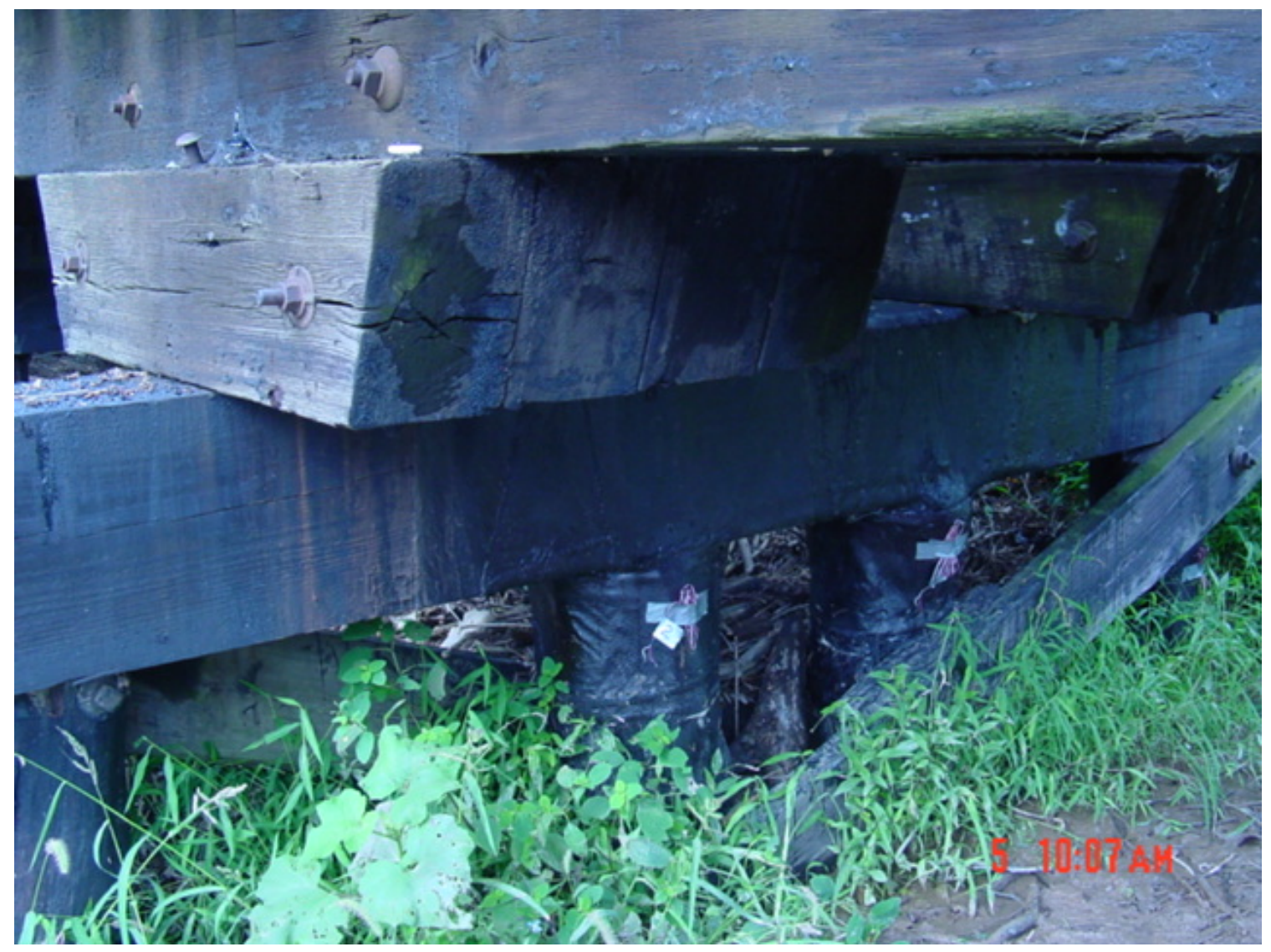

Figure 5.61. Picture of pile cap and piles

Figure 5.62 and 5.64 shows the picture of the portion of the pile cap that had very small debonds (marked by white circle). Figure 5.63 and 5.65 shows the infrared images of these debonds (represented by the white region). Both the debonds were relatively small in size. No other portion of the pile cap seemed to have any debonds. The other portions of the pile cap seemed to have proper bond between the GFRP layers and the underlying timber. 


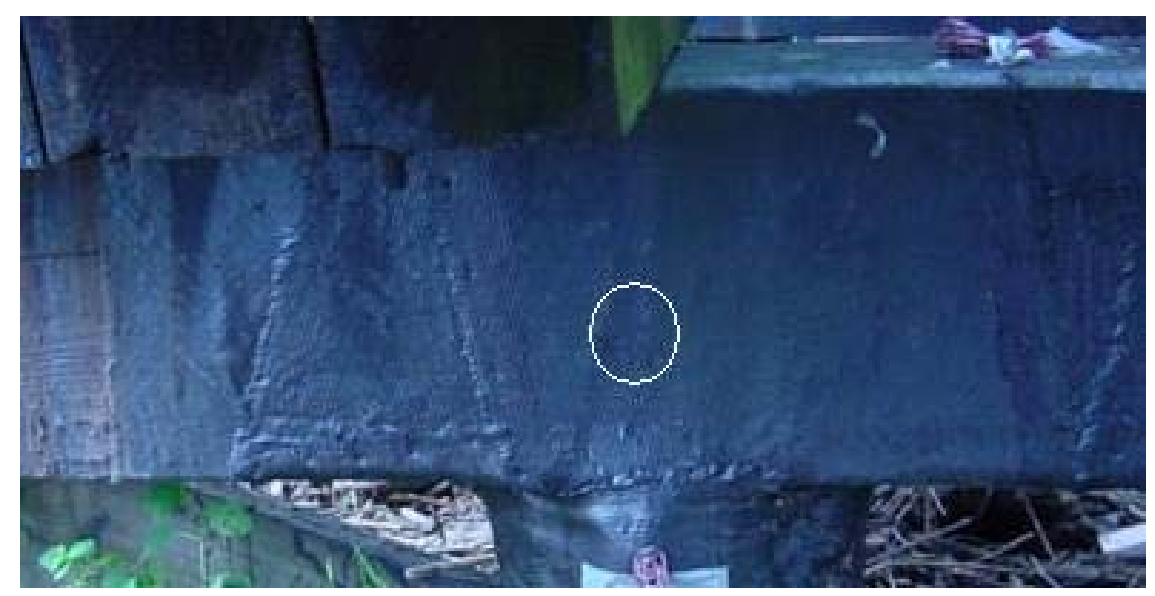

Figure 5.62. Picture of a portion of the pile cap above the first pile

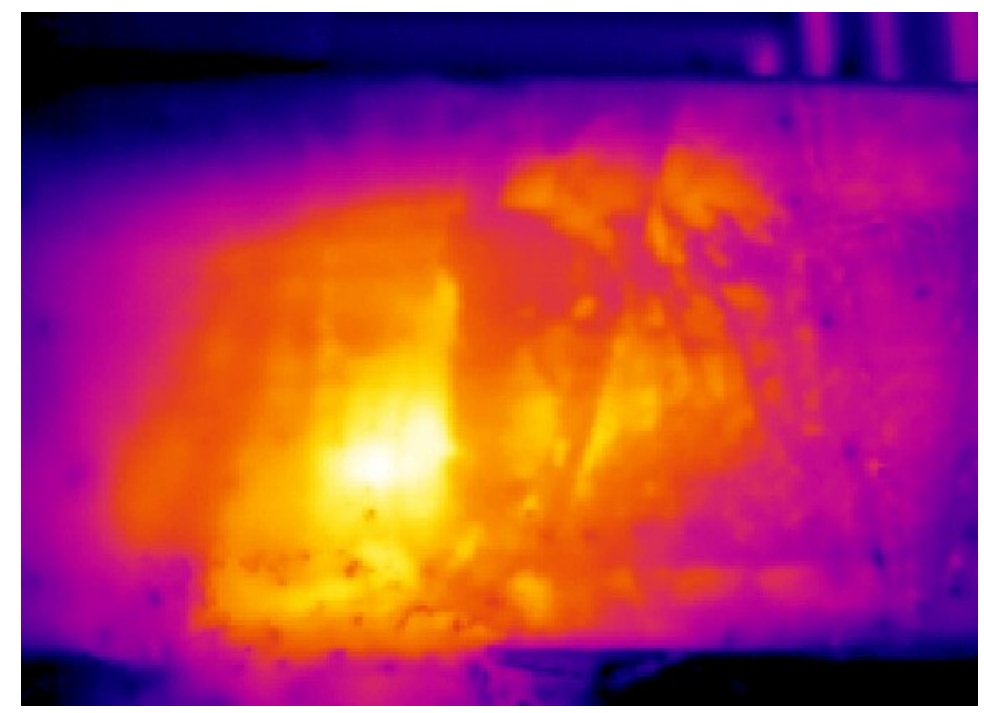

Figure 5.63. Infrared image of the pile cap

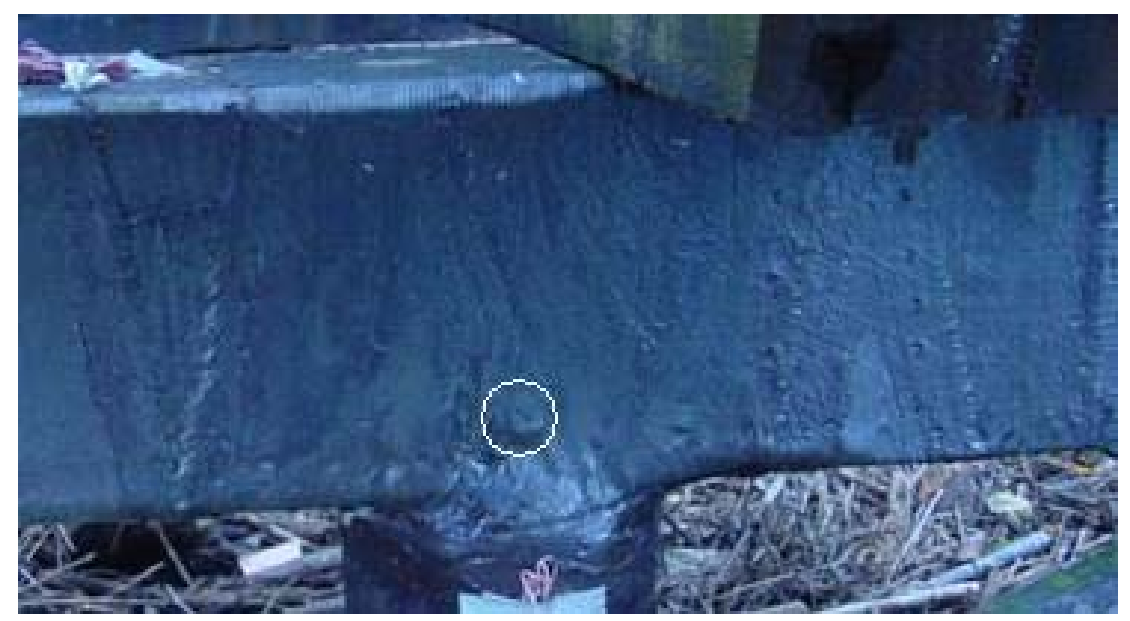

Figure 5.64. Picture of a portion of the pile cap above the second pile 


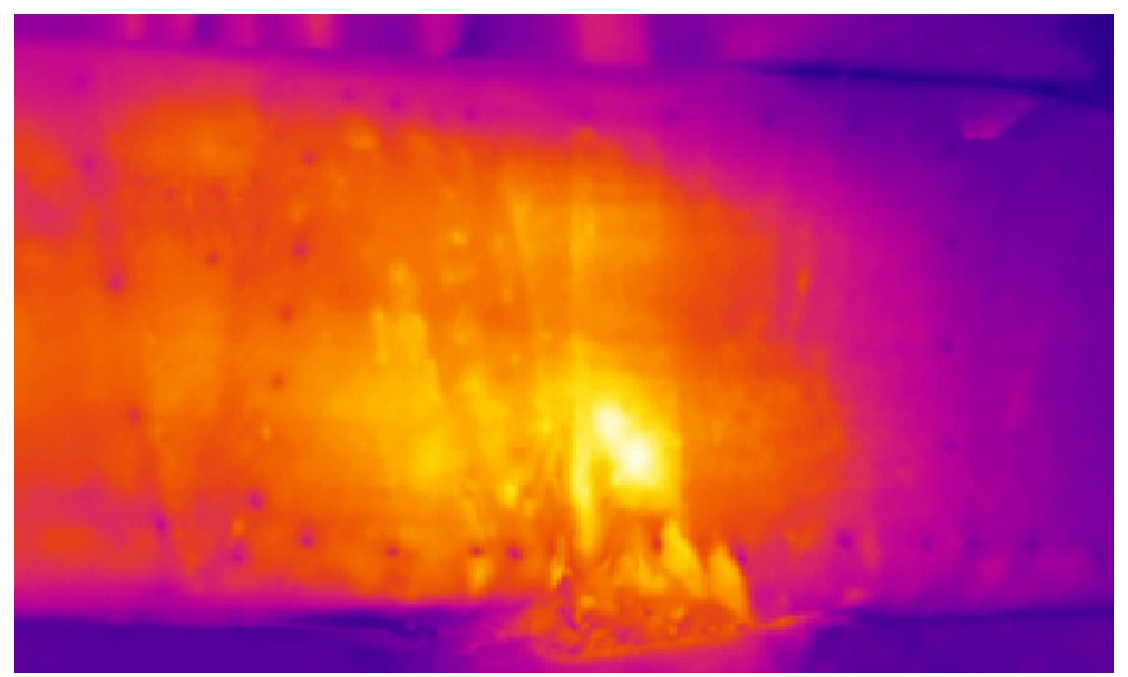

Figure 5.65. Infrared image of the pile cap

Figure 5.66 and 5.67 shows the picture and infrared images of the two piles. The white colored regions shown in both the infrared images (5.66 (b) and 5.67 (b)) are caused due to the air gap between the masking tape and the wood (see picture 5.66 (a) and 5.67 (a)). Load tests were conducted by other researchers who used the tapes and wires for their experiments. There were no debonded areas in the pile and the wrap seemed to be sufficiently bonded to the underlying timber. It was concluded that both the piles did not have any air gaps underneath the GFRP wrap.
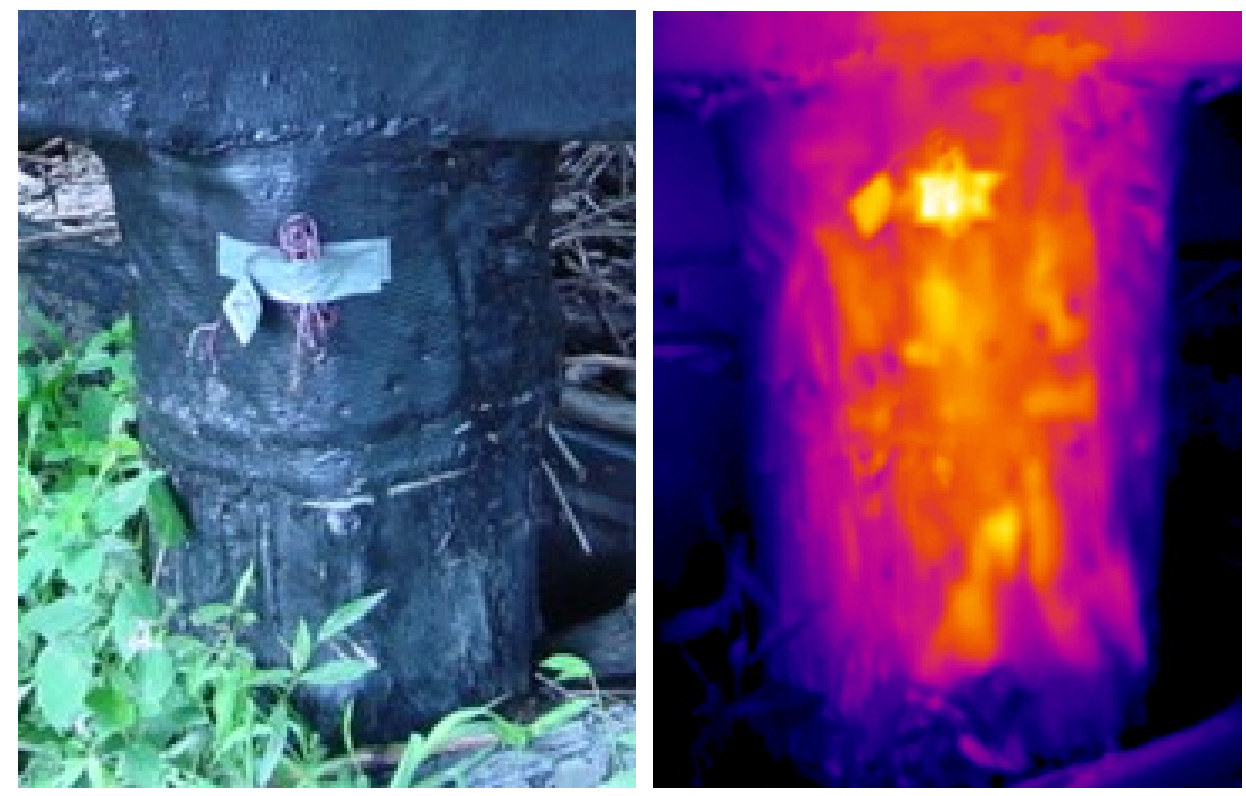

Figure 5.66. (a) Picture of pile cap and piles (b) Infrared image of the pile cap 

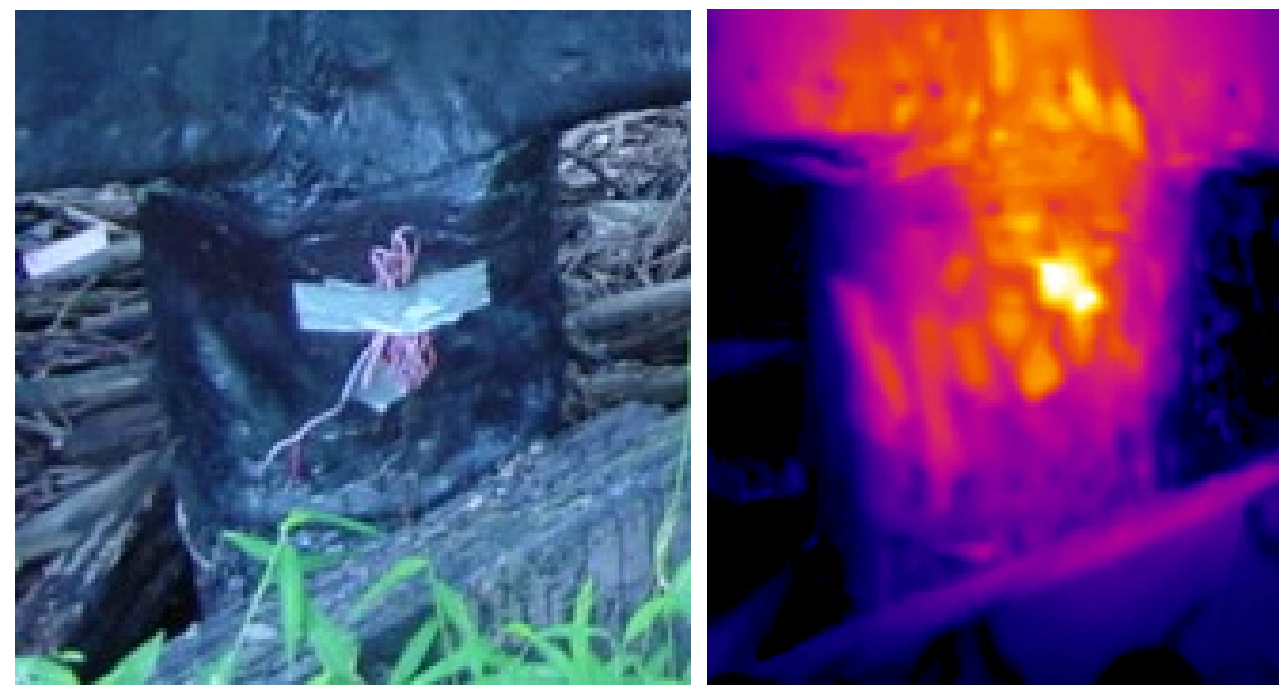

Figure 5.67. (a) Picture of pile cap and piles (b) Infrared image of the pile cap

\subsubsection{Conclusions}

The laboratory experiments on the timber pile specimens wrapped with GFRP composite wrap have proven that the infrared thermography technique is able to detect subsurface delaminations at the composite-timber interface. The infrared camera detected delaminations as small as 1.5 " in diameter and 0.125 " thick. Solar radiation could possibly be used to detect delaminations for horizontal members with the use of an advanced (digital) infrared camera.

From the field tests conducted during Summer 2001 it was determined that the GFRP wrapped timber components did not have any debonds. However, the infrared camera detected some surface temperature differentials not caused by debonds. Also, it was found that if a quartz tower heater was used, it had to be placed at least 8 inches away from the timber components in order to provide uniform heating over the surface.

From the field tests conducted during Summer 2002, it was concluded that the pile cap (the first pile bent from the west end of Bridge \#568) had several small and large sized debonds. Though tap testing could detect a few large debonds with larger thickness, it was found that the smaller sized debonds or those with lesser thickness could be detected only by using infrared thermography technique. Debonds were monitored during the loading of the bridge using a locomotive and it was concluded that they did not grow in size during the loading period. Most of the debonds were located on one side of the 
pile cap. The other side did not have many debonds. The edge of the pile cap that was exposed directly to the sun and rain had worn out and the glass fibers from the GFRP wrap were clearly visible on the top surface. The Bridge \#570 could not be tested using infrared thermography because it was flooded with water and was inaccessible. Hence the timber components could not be heated for the infrared testing.

From the field tests conducted during Summer 2003, it was concluded that some of the debonds in one of the pile cap components (the first pile bent from the west end of Bridge \#568) grew in size while some of the other debonds did not grow in size. Apart from the previously existing debonds, other new debonds had also developed during the span of one year. The acquired digital infrared images gave clearer and well-defined shapes of the debonds when compared with the previously acquired non-digital infrared images using an older infrared camera. The edge of the pile cap had worn out and the glass fibers from the GFRP wrap were clearly visible on the top surface. There was not much difference in the deterioration in this portion of the pile when compared to the Summer 2002 and Summer 2003 test results. This portion of the beam requires rehabilitation using new set of GFRP wraps. The pile cap/pile (the fifth pile bent from the west end of Bridge \#568) that were rehabilitated using FRP wraps during October 2002 had a couple of very small sized debonds. The other rehabilitated portions were sufficiently bonded.

The above tests conducted over a period of three years have shown that infrared thermography has been successful in monitoring progressive growth of debonds and providing useful information for maintaining quality control of the GFRP wrapping. 


\section{Chapter 6 \\ FIELD TESTING OF FRP BRIDGE DECK}

\subsection{INTRODUCTION}

Fiber Reinforced Polymer (FRP) bridge decks are being considered for replacing old concrete bridge decks because of the higher strength-to-weight ratio, good fatigue resistance and better corrosion resistance properties offered by FRP deck systems. The FRP bridge decks are susceptible to subsurface defects, which can adversely affect their load carrying capacity. Therefore, periodic monitoring of the bridge components is necessary for timely detection of subsurface defects such as debonds and delaminations. Infrared thermography is emerging as one of the promising nondestructive techniques for subsurface defect detection. Chapter 4 of this thesis report has demonstrated its ability to detect subsurface defects in various types of composite specimens. Details of the infrared monitoring system and the interpretation method are available in Chapters 3 and 4.

This chapter presents the infrared field tests conducted on the La Chein FRP bridge deck on September 10, 2003. Infrared thermographic tests were conducted to detect debonds between the wearing surface and the underlying FRP deck. This chapter provides details on the bridge, infrared test setup and field results showing the debonded areas, and the difficulties encountered during the field study.

\subsection{DESCRIPTION OF THE BRIDGE}

The bridge is located in Monroe County, near Peterstown in West Virginia. This is a single span bridge and is owned and operated by the West Virginia Division of Highways. The construction of the bridge was completed in April 2003. The bridge has two lanes for traffic (one lane in each direction). The bridge deck is made of FRP material and has a 3/8” thick polymer concrete overlay. The deck has a skew angle of $25^{\circ}$ with an out-to-out length of 41' and a center-to-center bearing length of 38', supported on 6 steel girders spaced at 4' 4’'. The wearing surface overlay covered an area of 26’ x 41' in plan. The location and the photograph of the bridge are shown in the Figures 6.1 and 6.2 , respectively. 


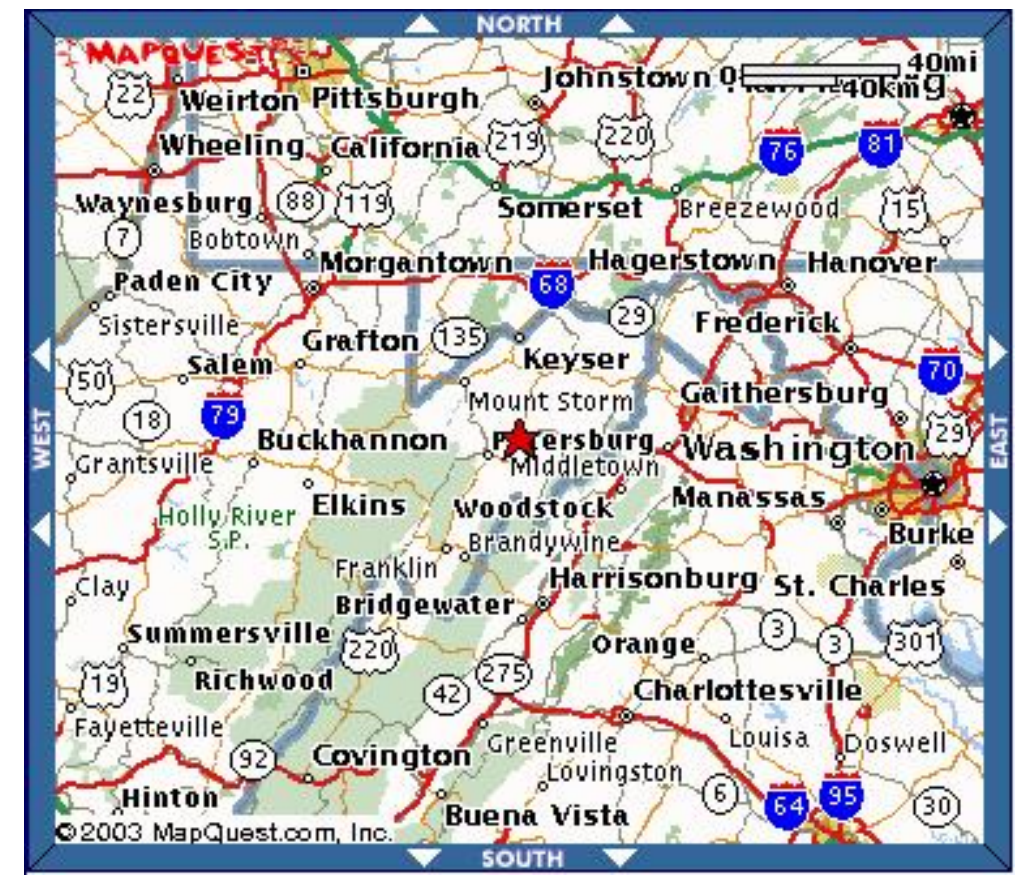

Figure 6.1 Location of La Chein bridge in Monroe County, WV

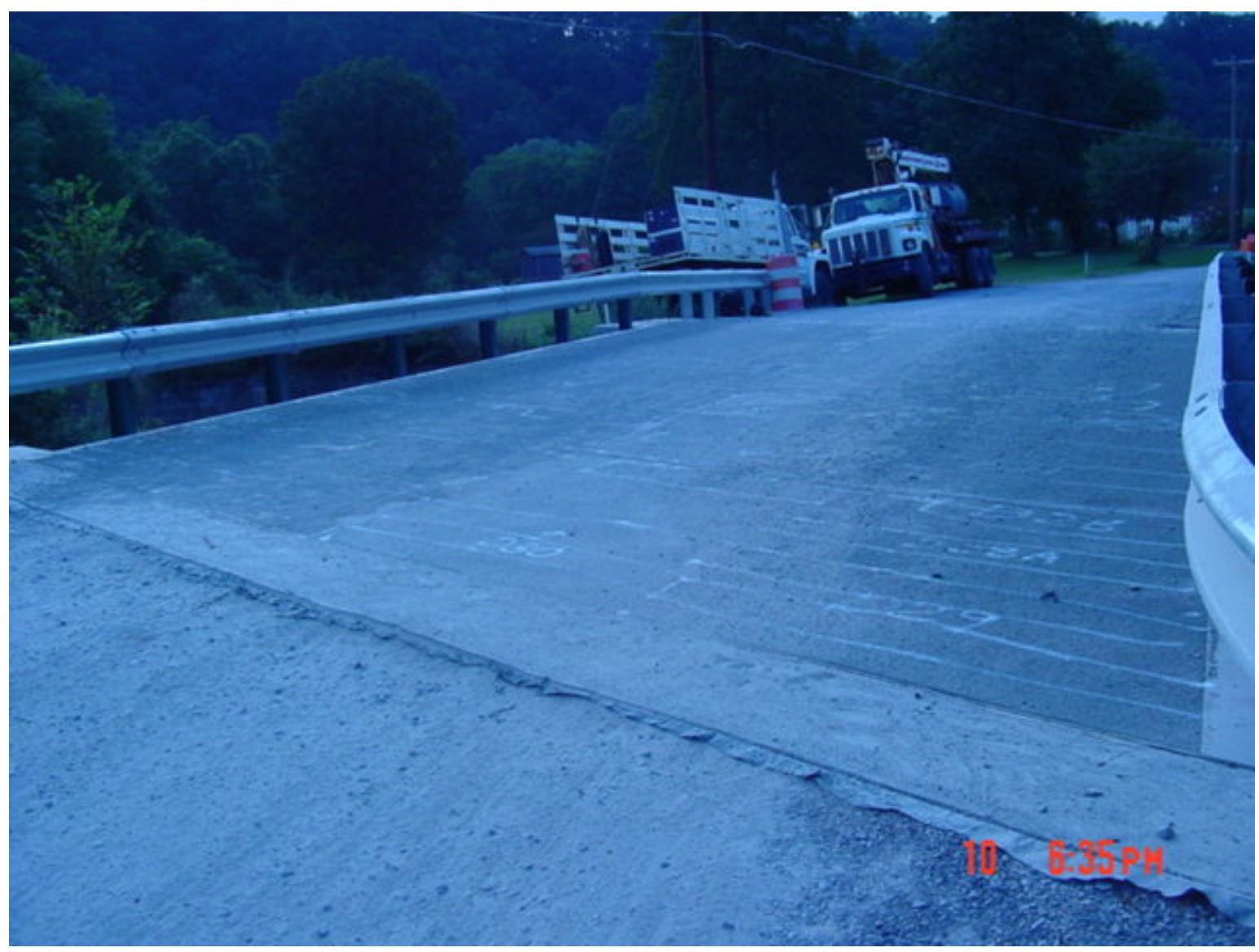

Figure 6.2 Photograph of La Chein FRP bridge 


\subsection{EXPERIMENTAL SETUP}

The infrared monitoring system used for the field test was the ThermaCAM ${ }^{\mathrm{TM}}$ S60 that consists of a digital infrared camera (see Figure 3.2 in Chapter 3), a laptop computer and associated data acquisition and image processing software. The description of the camera and the associated software is available in Chapter 3, Section 3.1.2. The bridge deck has to be heated prior to the acquisition of the infrared images in order to produce images with a good thermal contrast (differences in surface temperatures) between the sound and defective areas. For most part of the day, solar radiation was used as the heating source. The temperature of the deck was as high as $120-125{ }^{\circ} \mathrm{F}$ and the ambient air temperature was around $80-85{ }^{\circ} \mathrm{F}$ for most part of the day. During late afternoon, when the sun could not heat the deck efficiently, two 1500 watt heating blankets of size 3' x 3' each (described in Section 3.2.2), were used as the heating source. Figure 6.3 shows the infrared field setup including the heating blankets.

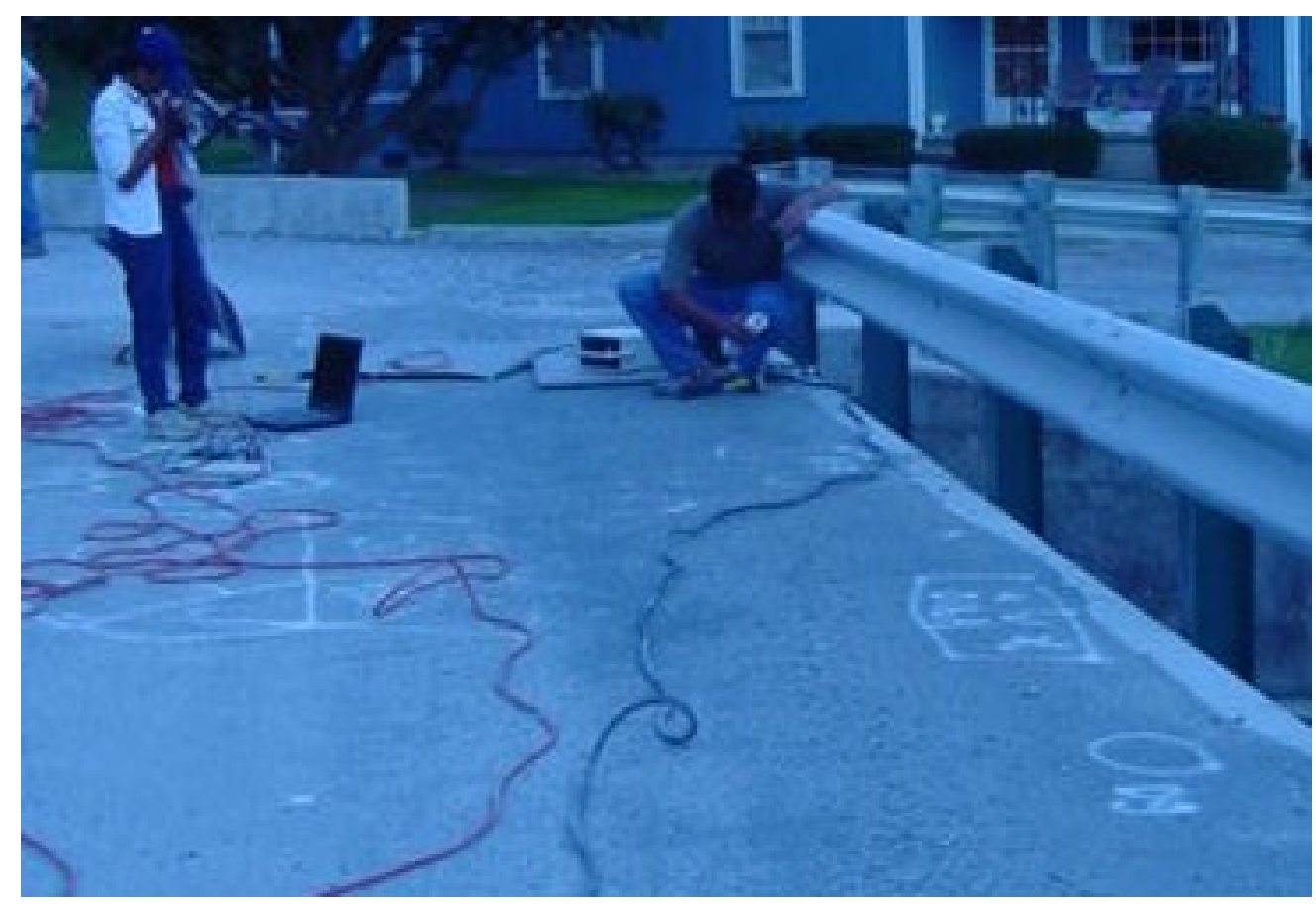

Figure 6.3 Infrared field setup

\subsection{INFRARED TESTING AND RESULTS}

The bridge deck was divided into thirty two grids numbered from 1 to 32. The grids 1 to 28 had size of 5' x 6'-6”' each and the last four grids (number 29 to 32) had size 
of 6' x 6'-6’. Figure 6.4 shows a schematic view of the plan showing all the grids. Each of these grids was tested using infrared thermography. The grid was first scanned with the infrared camera to identify the location of the debonds. A second infrared scan was made focusing on the debonded areas and their overall shapes and sizes were marked on the surface of the deck using white spray paint. The infrared images were enhanced by adjusting the color scale and the contrast, to identify the debonds more clearly. The infrared images were simultaneously recorded into the laptop connected to the infrared camera for permanent storage.

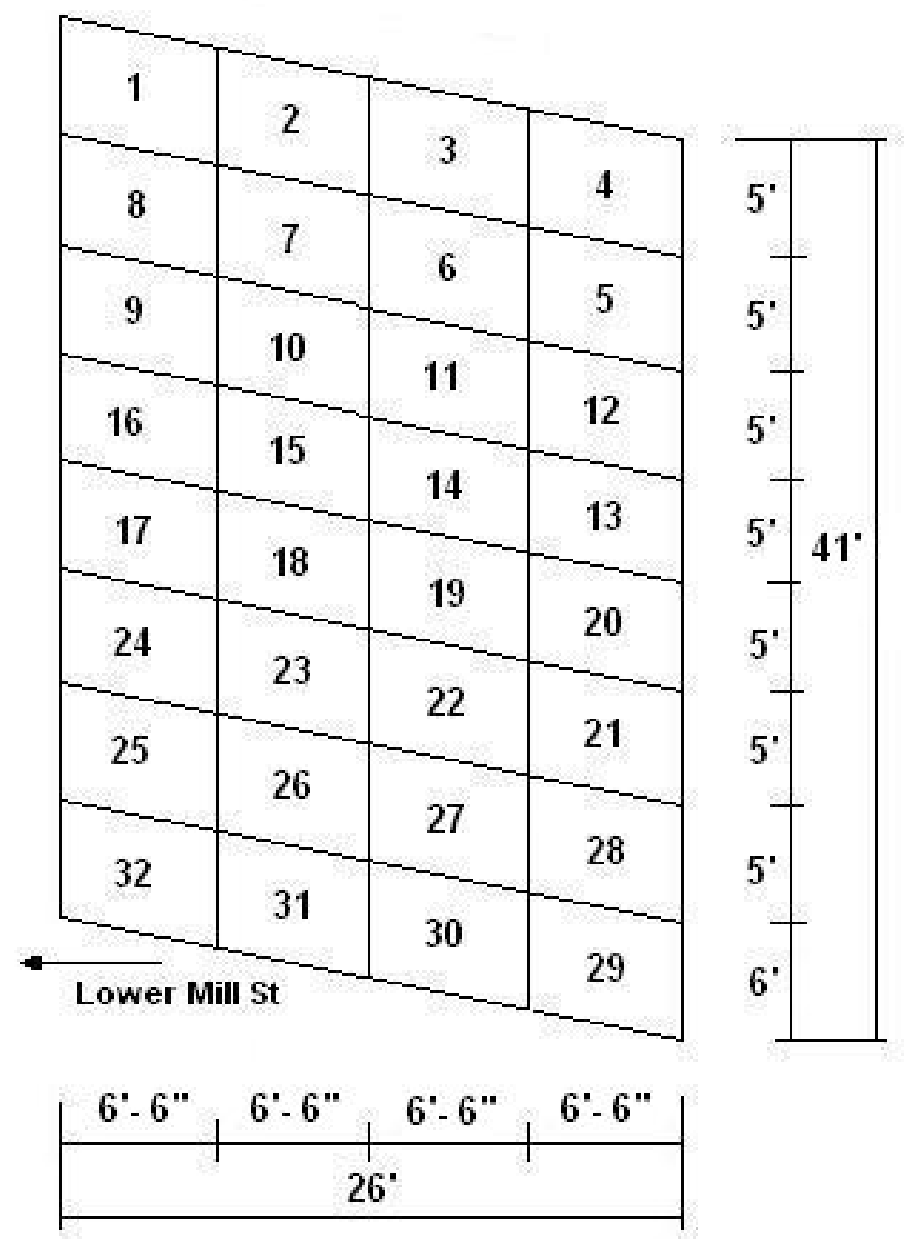

Figure 6.4 Schematic view of the grids

The test was started around noon and the sun had already heated the deck to a sufficiently high temperature to conduct the infrared testing. The bridge contained many 
small and large debonds. Figures 6.5 to 6.17 show the photographs and infrared images of these debonds. These debonds are air gaps formed between the wearing surface (polymer concrete) layer and the underlying FRP deck. In all the infrared images the white colored portions represent areas with higher temperature and the remaining portions represent areas with lower temperature. The debonds are represented by the white colored areas. The sound areas in the deck would conduct heat through the thickness of the deck more efficiently than the areas that have the air gaps. Hence there is build up of heat above the debonds which results in higher surface temperature when compared to the neighboring defect-free areas. The shape and the size of the debonds are clearly seen in the infrared images.

Figures 6.6(a) and 6.7(a) shows the middle portions of the deck along the center line between the two lanes of traffic moving in opposite directions. This center line is not marked on the deck. However, cracks and undulations are visible at several places along this unmarked center line. Figures 6.6(b) and 6.7(b) show the infrared images of this middle portion.
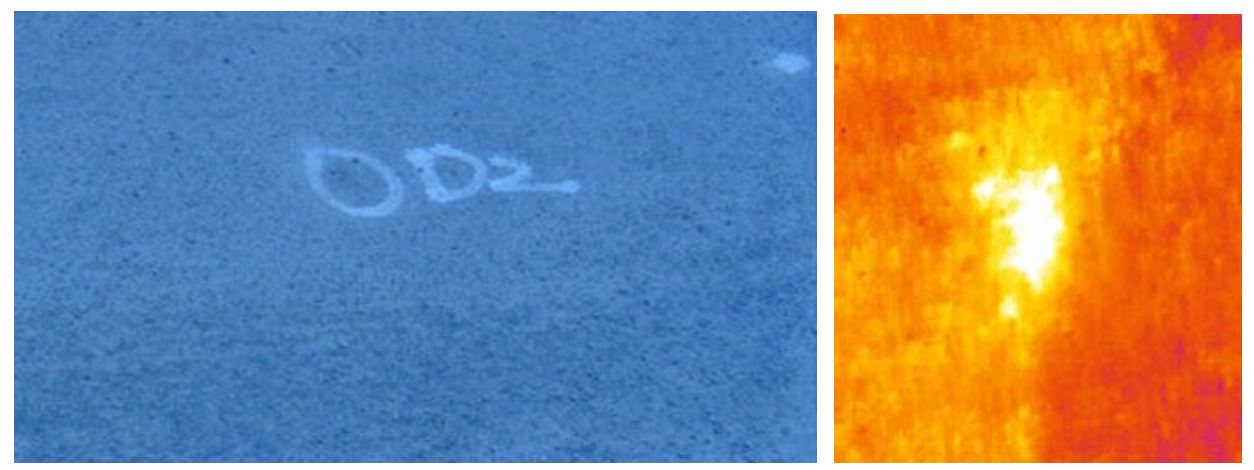

Figure 6.5. Photograph and infrared image of a small debond in grid 2

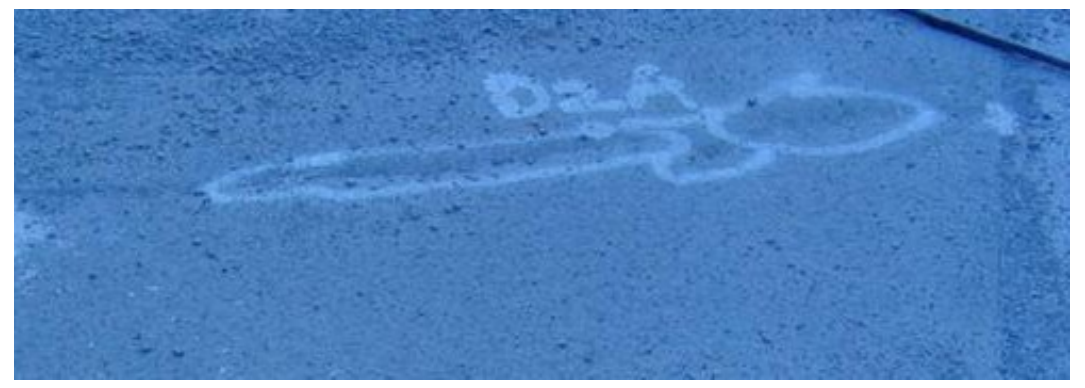

Figure 6.6(a). Photograph showing another debond in grid 2 

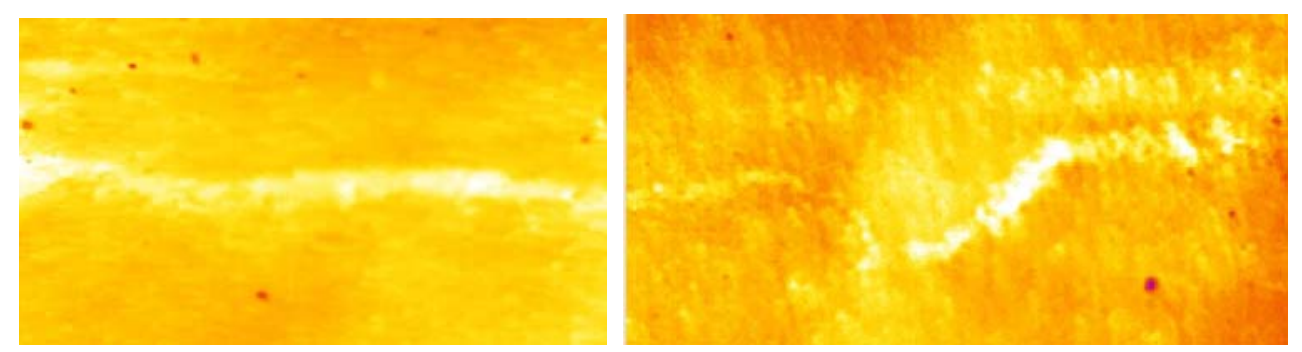

Figure 6.6(b). Infrared images of the debond in grid 2

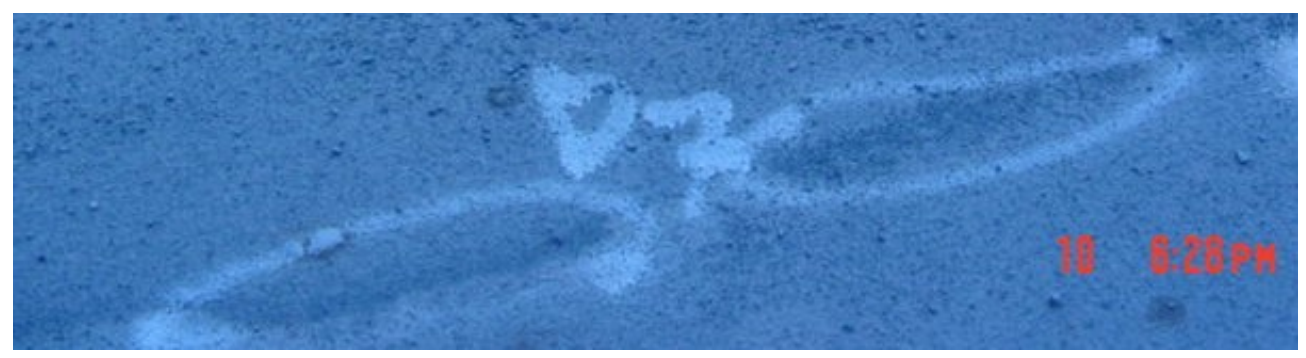

Figure 6.7(a). Photograph of the debonds in grid 7
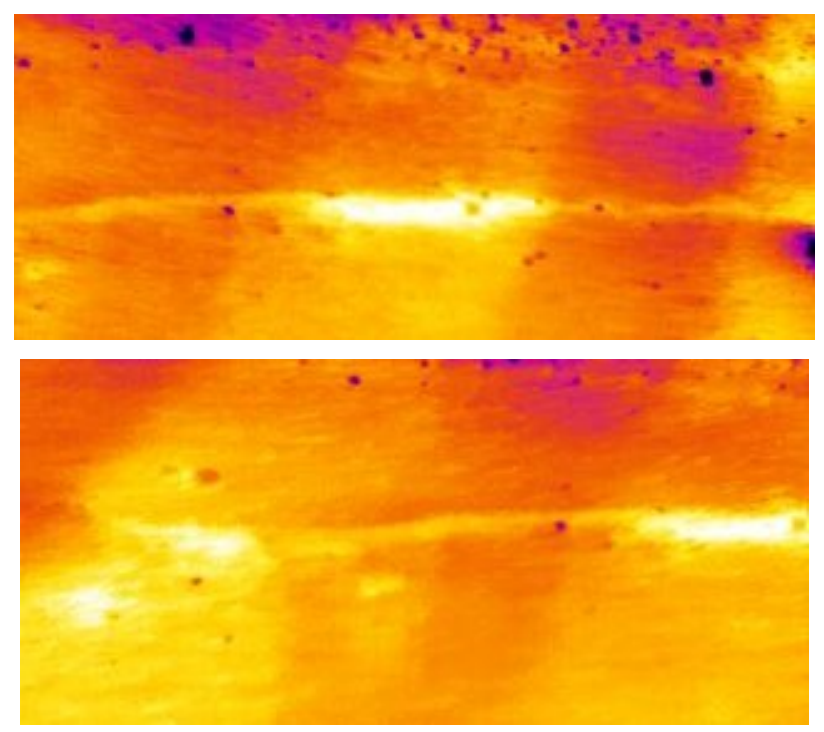

Figure 6.7(b). Infrared images of the debonds in grid 7

Most of the above field testing relied on solar radiation as the heat source with ambient air temperature of around $80-85^{\circ} \mathrm{F}$. It should be noted that sufficient heating of the deck is required to establish an adequate thermal gradient for producing an infrared image with better thermal contrast between the sound and defective areas. Thus, field testing can only be conducted during bright sunny days between 10:00 A.M. and 4:00 P.M. or so unless external heating source is used. During the later period (late in the afternoon and early in the evening) when the heat from the sun was not adequate to 
establish a significant thermal gradient through the thickness of the deck, portions of the deck were heated using the heating blankets mentioned in the previous section.

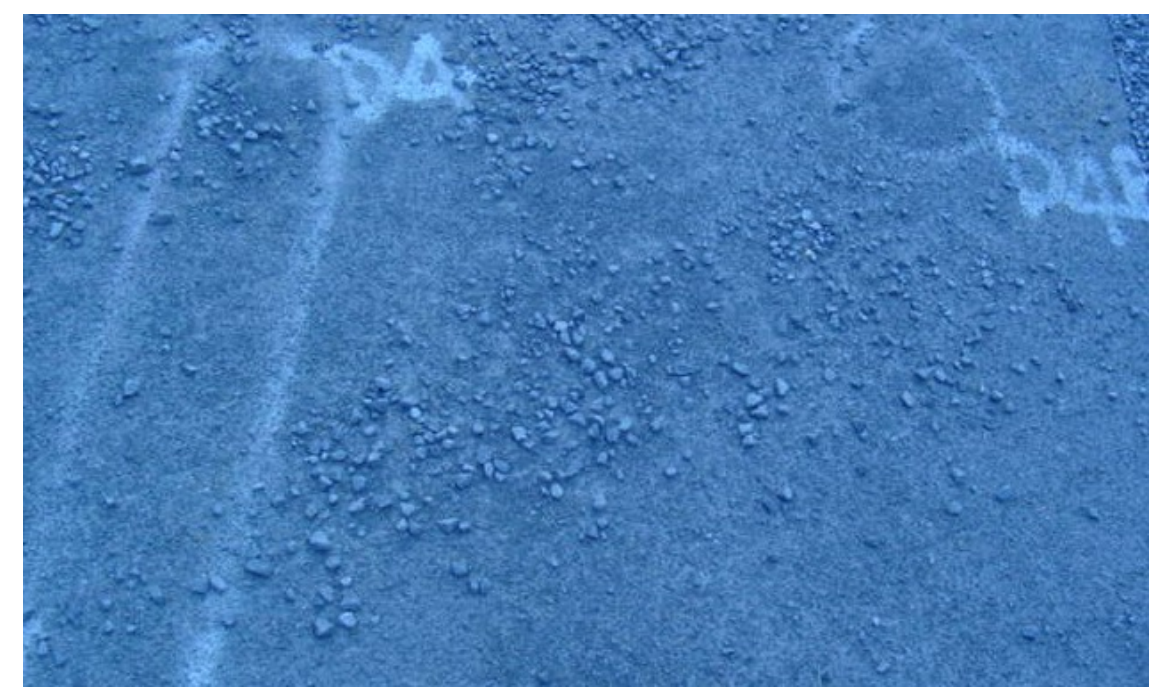

Figure 6.8. (a) Photograph of a two debonds in grid 4
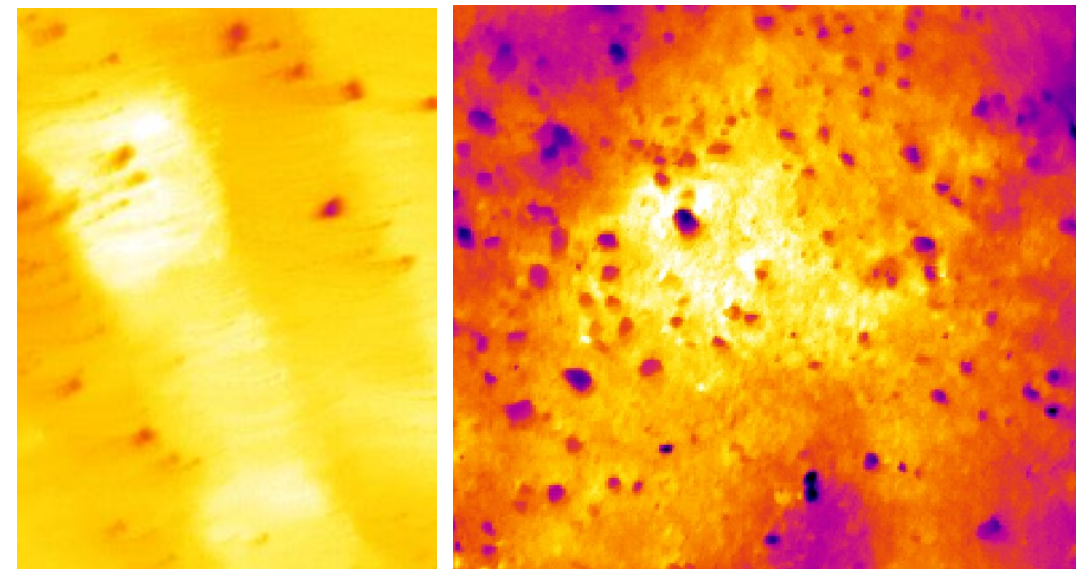

Figure 6.8. (b) Infrared image of a two debonds in grid 4
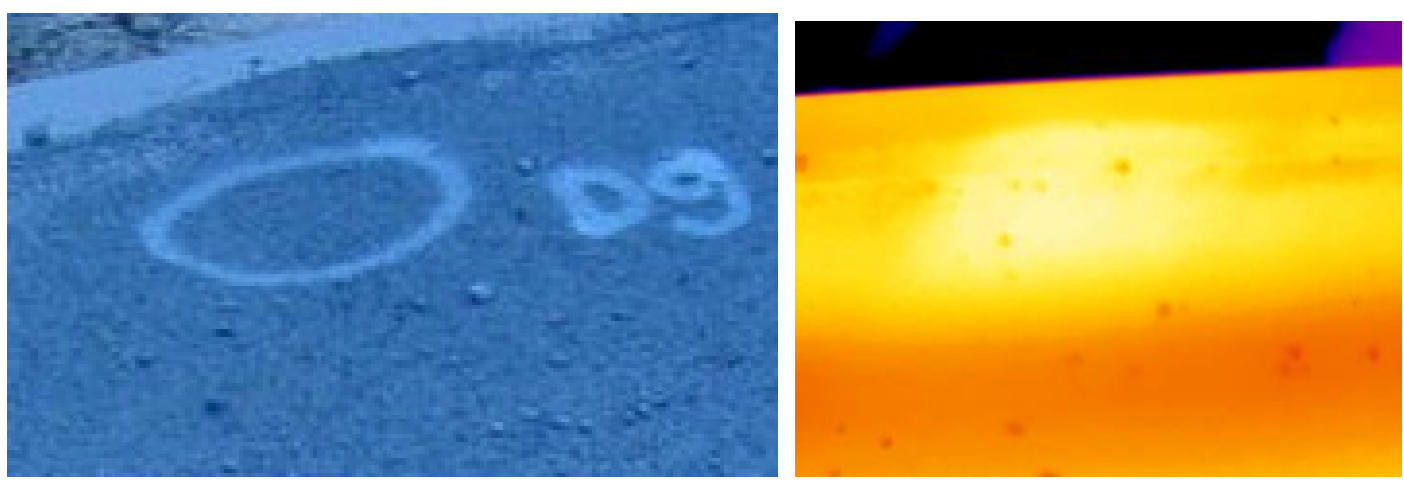

Figure 6.9. Photograph and infrared image of a small debond in grid 9 


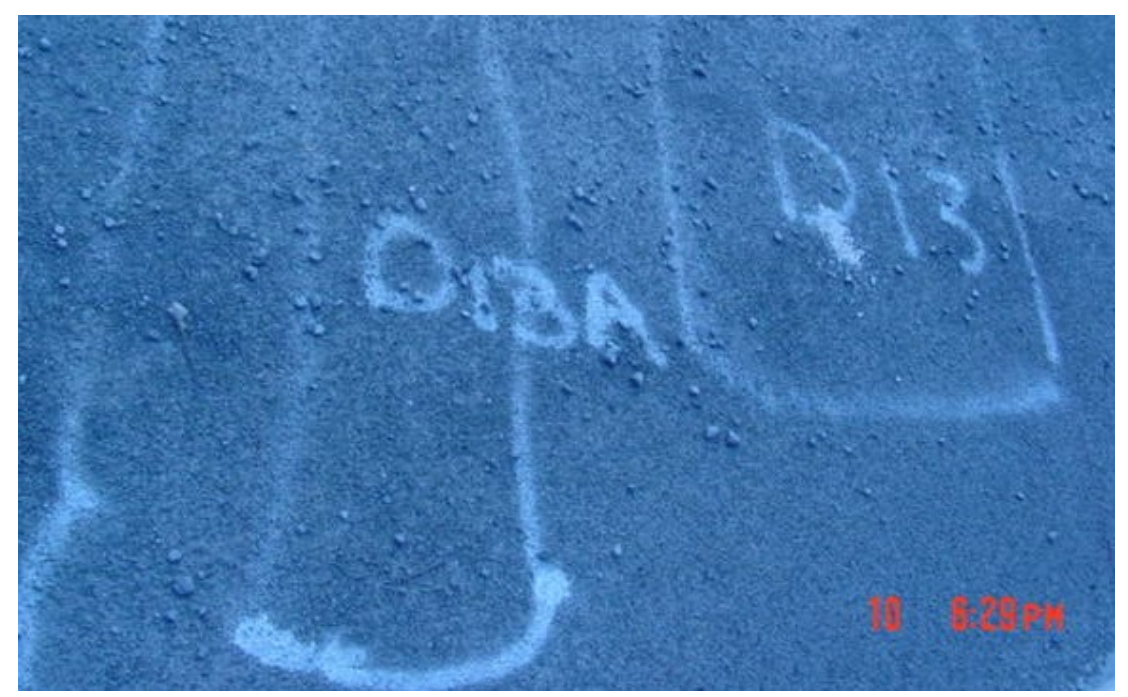

Figure 6.10. (a) Photograph of a two debonds in grid 13
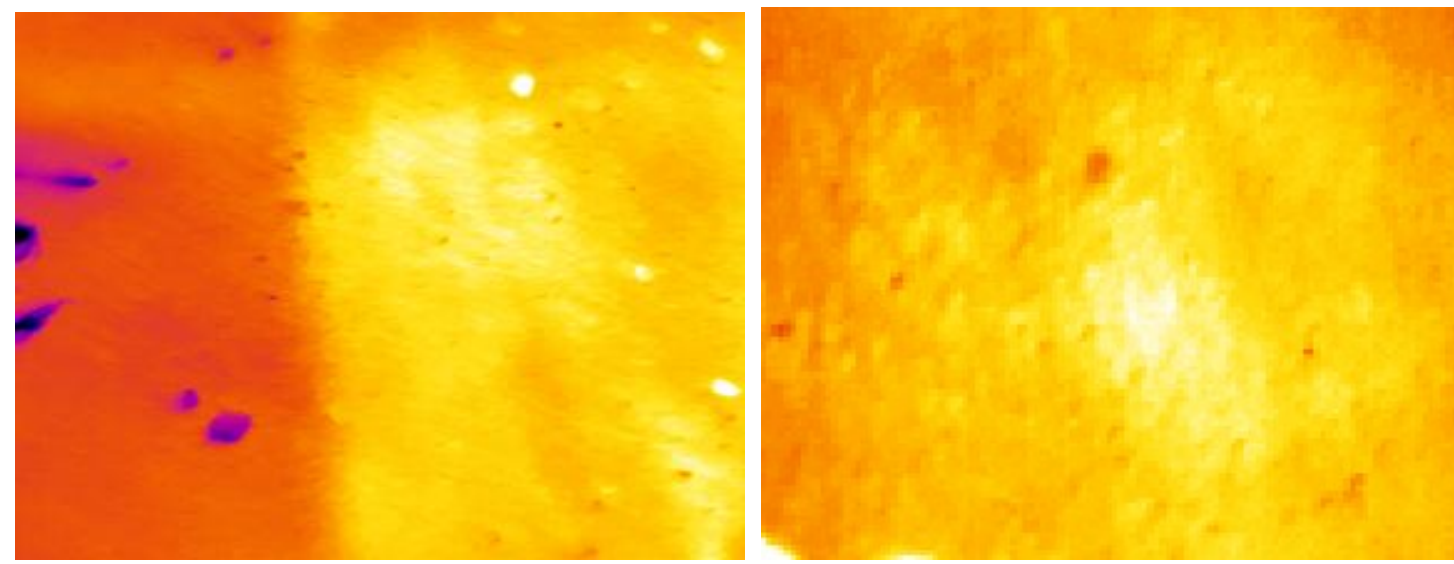

Figure 6.10. (b) Infrared image of a two debonds in grid 13
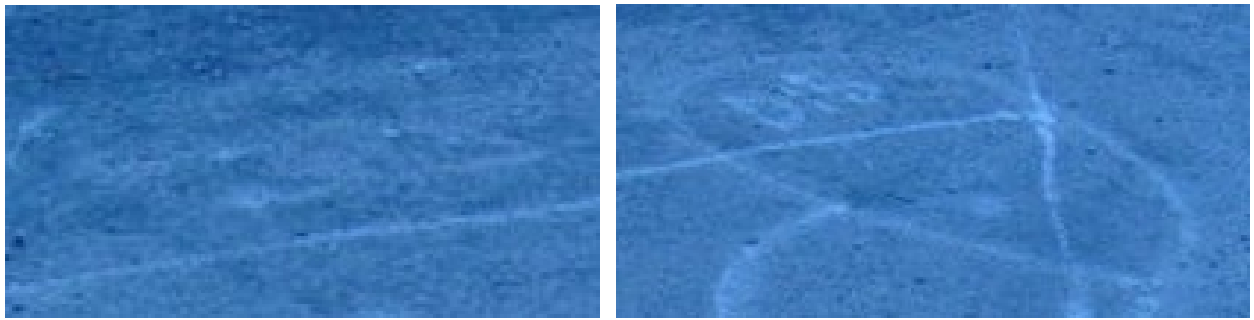

Figure 6.11(a). Photograph of the debonds in grid 15
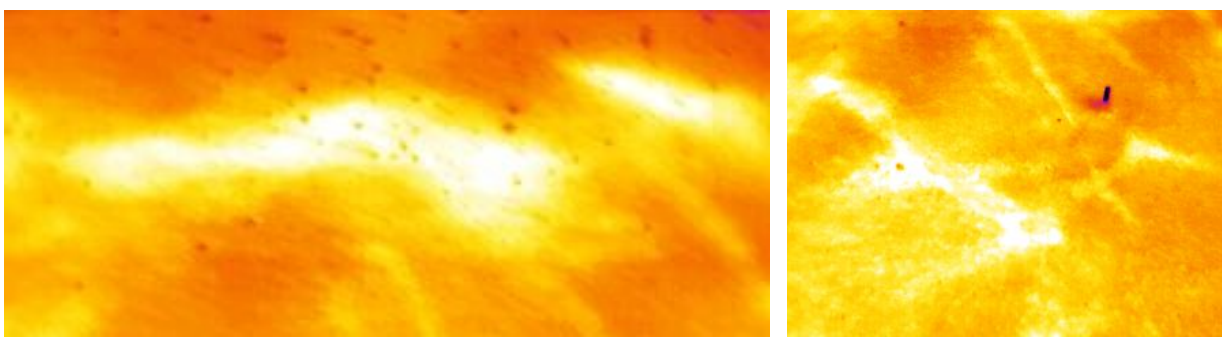

Figure 6.11(b). Infrared images of the debonds in grid 15 

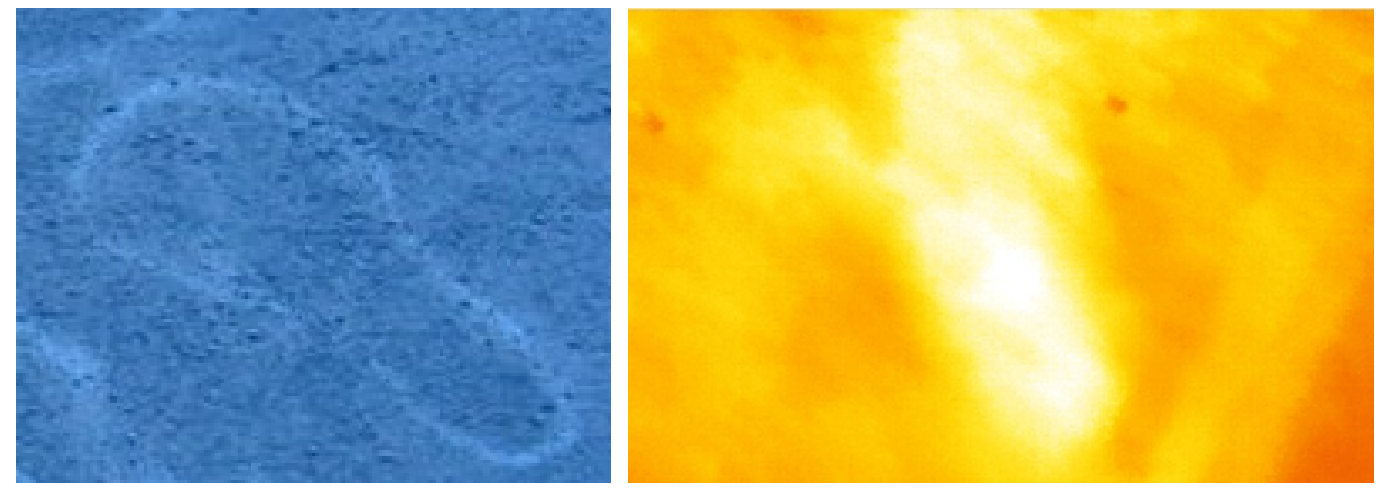

Figure 6.12. Photograph and infrared image of a bigger sized debond in grid 15
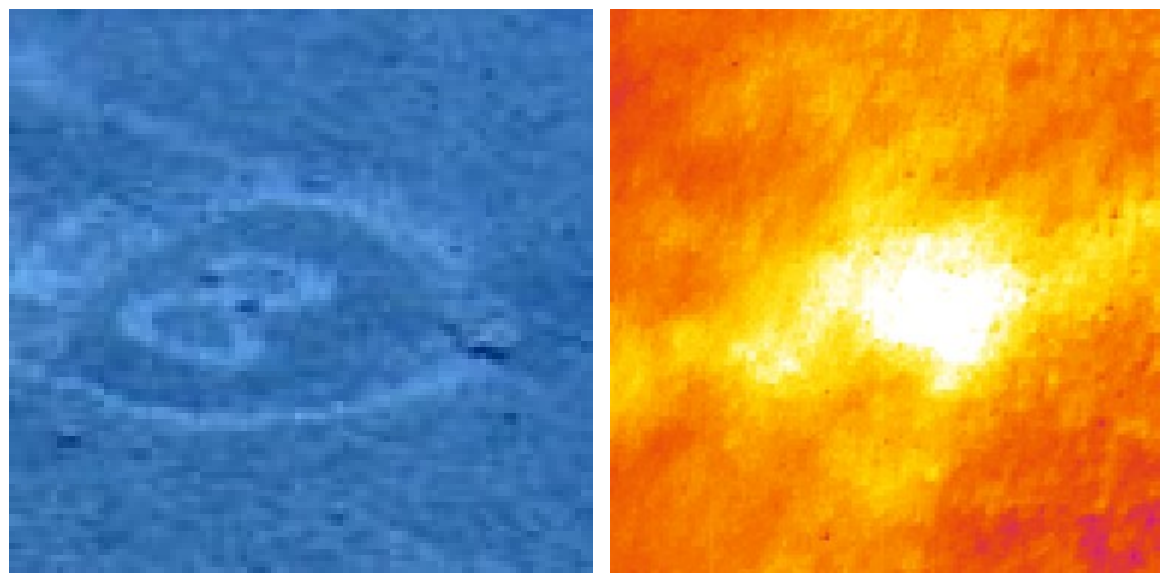

Figure 6.13. Photograph and infrared image of a bigger sized debond in grid 18

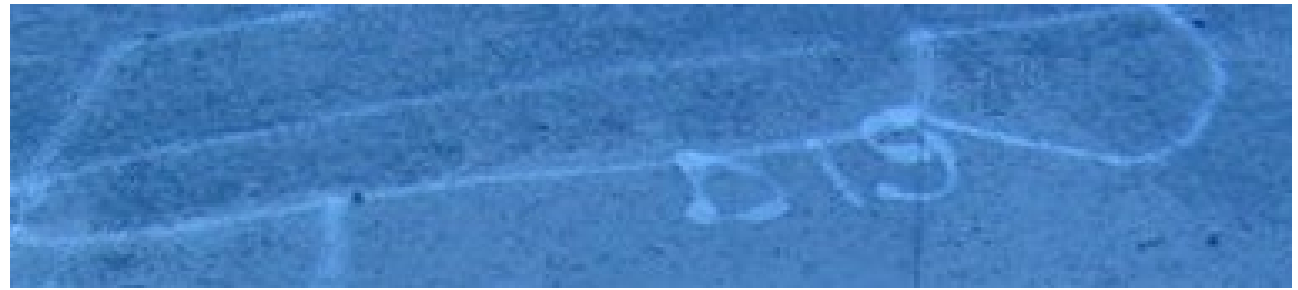

Figure 6.14 (a). Photograph of the debonds in grid 19

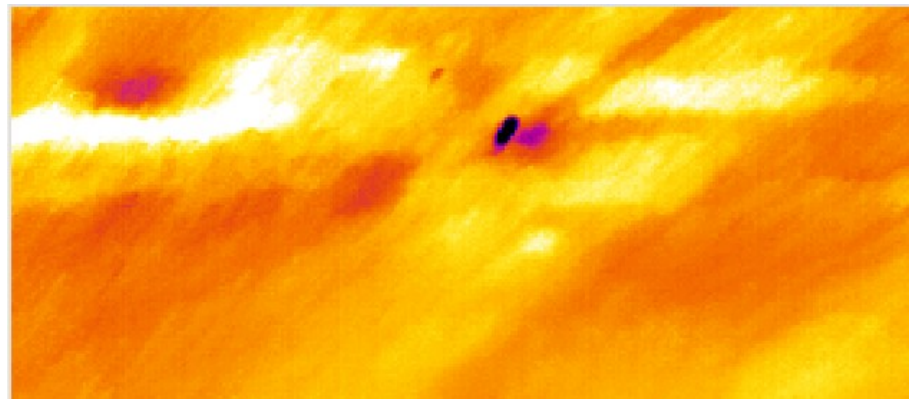

Figure 6.14 (b). Infrared images of the debonds in grid 19 

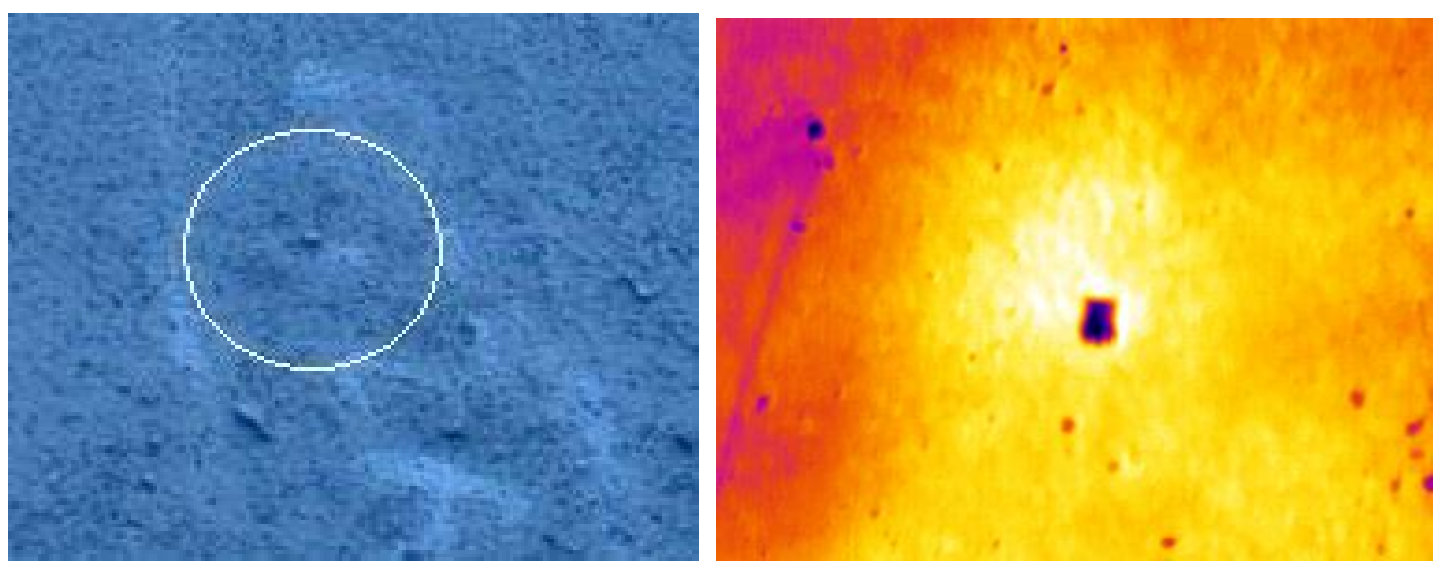

Figure 6.15. Photograph and infrared image of a debond in grid 22

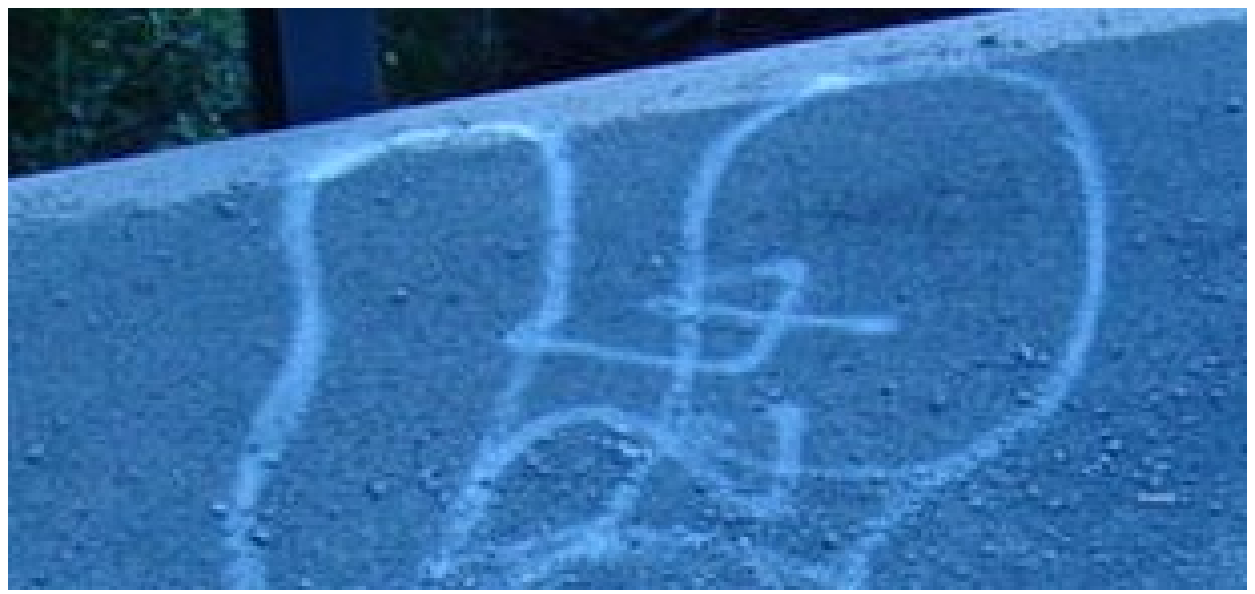

Figure 6.16. (a) Photograph of a debond in grid 24

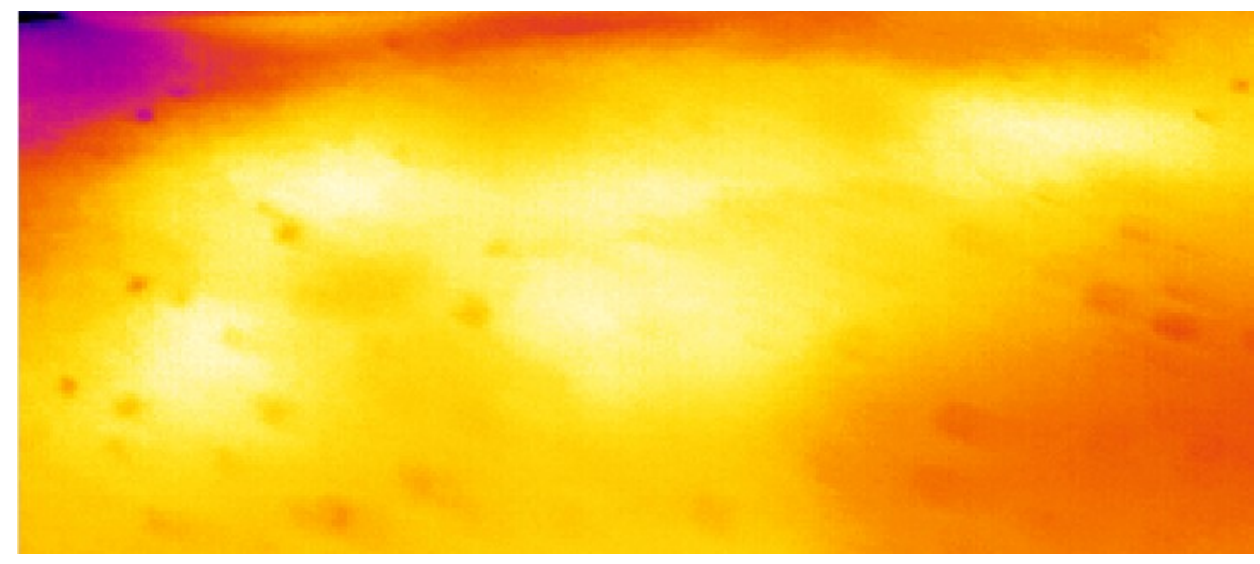

Figure 6.16. (b) Infrared image of a debond in grid 24 

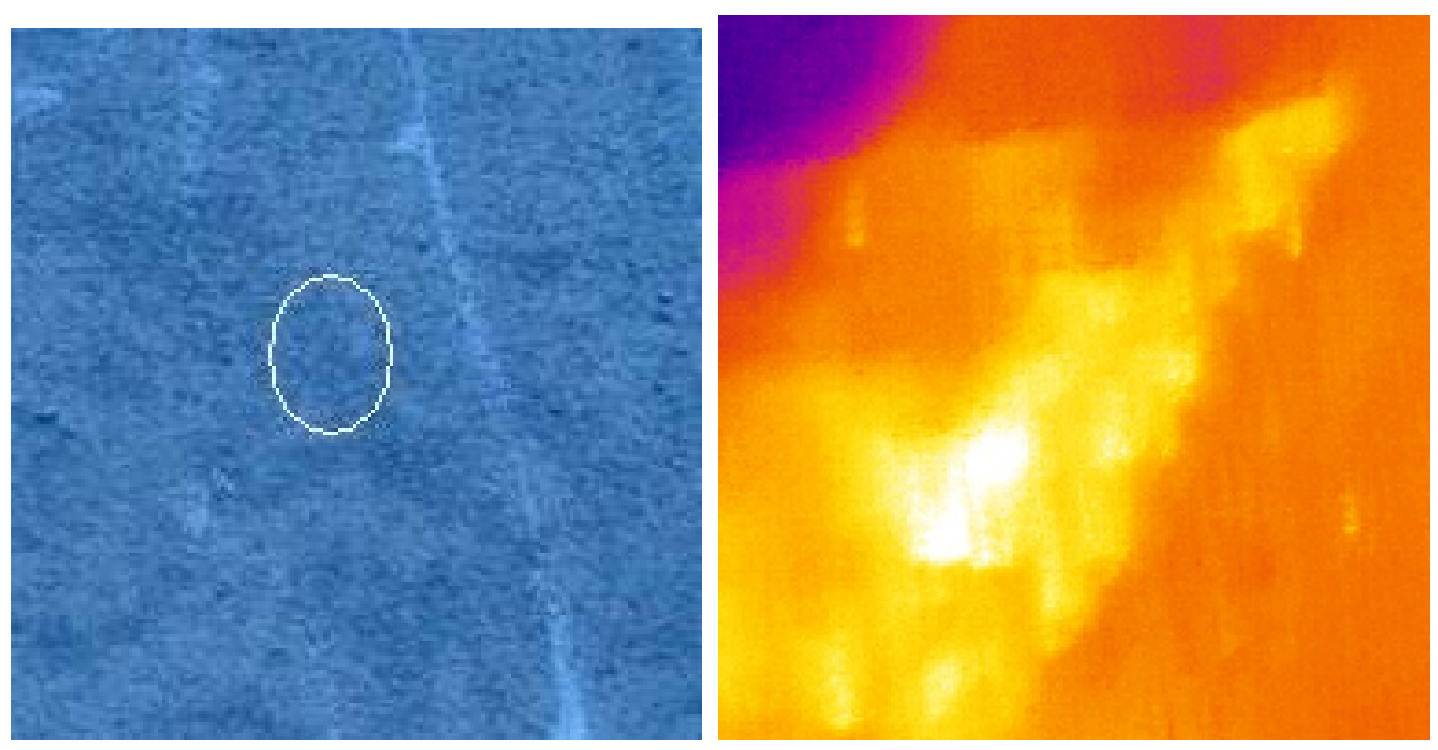

Figure 6.17. Photograph and infrared image of a small debond in grid 31

Tap testing was also conducted throughout the deck with the help of a hammer and the areas that gave distinct sound were identified. Infrared testing of some of these areas marked by tap testing revealed that they were not debonds, but were actually defect-free areas. This shows that tap testing is not a reliable technique for detecting the debonds. For example, Figure 6.18 shows a debond marked by white paint as identified by tap testing. The infrared image of the grid showed that the size of the actual debond (marked by the black circle) was smaller than the portion marked by the tap testing. Figure 6.19 shows a portion of grid 30 that was first marked by tap testing. The infrared image of the grid revealed that there were no debonds in that area.
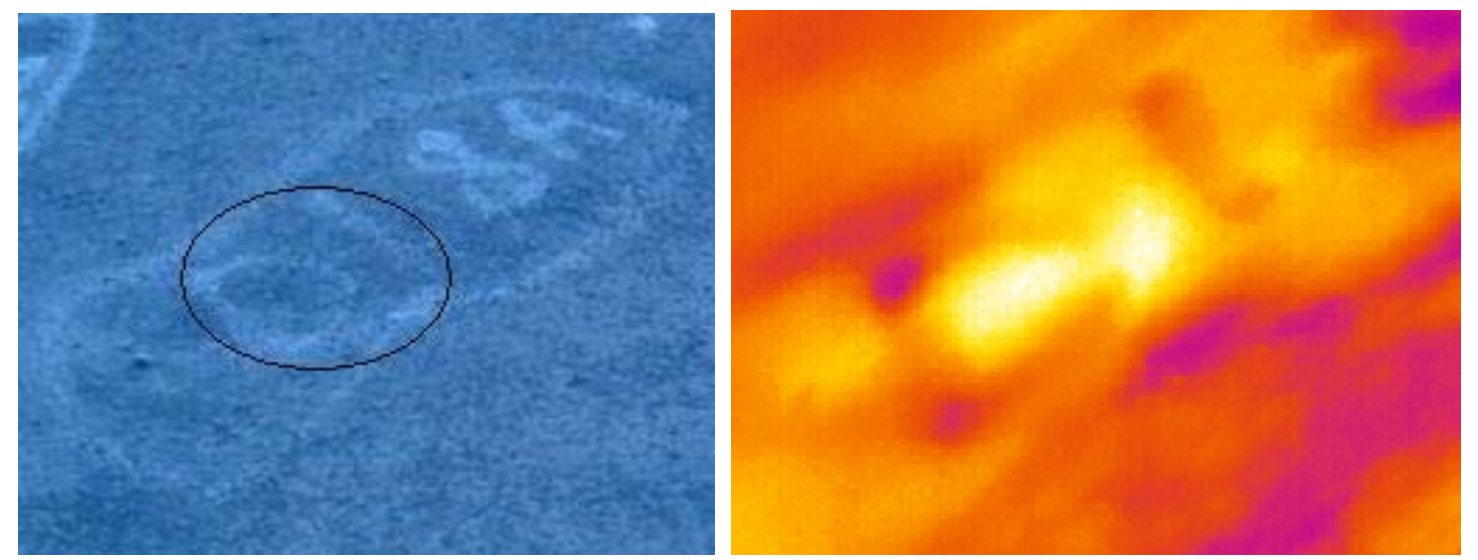

Figure 6.18. Photograph and infrared image of a small debond in grid 18 

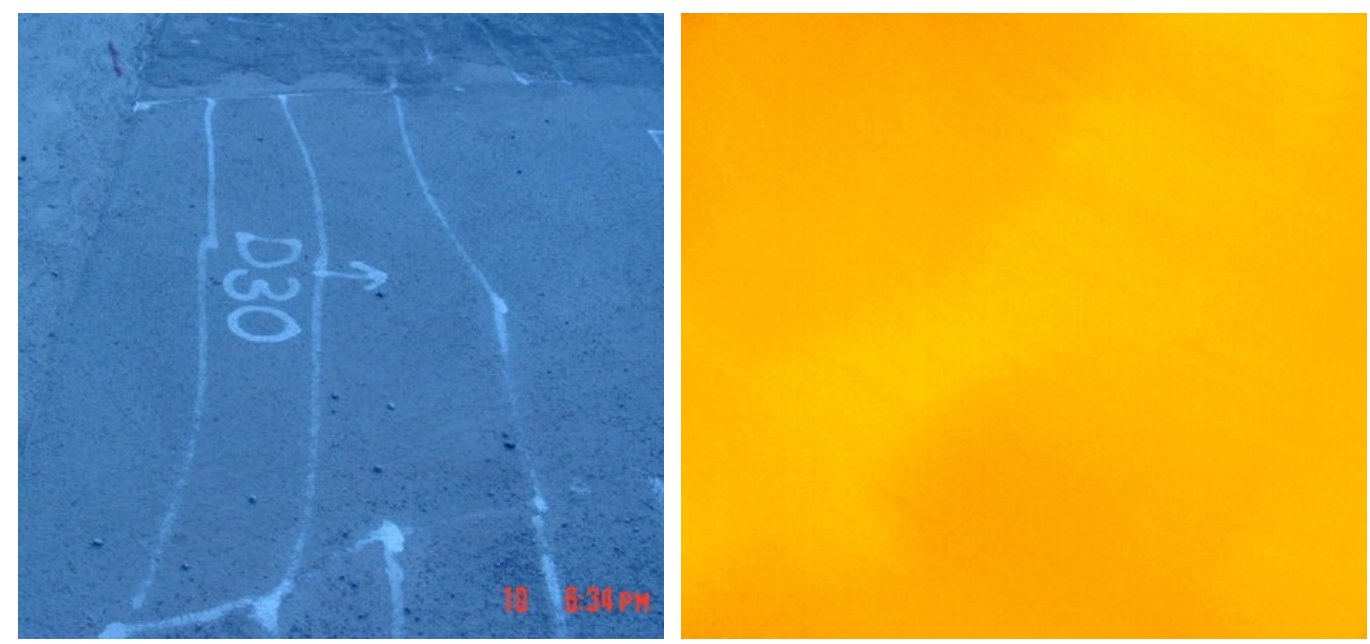

Figure 6.19. Photograph and infrared image of a portion of grid 30 where there was no debond

In some portions of the grid the debonded wearing surface layer had completely peeled off and the resulting surface depression was clearly visible. The photograph and infrared image of one of these areas is shown in Figure 6.20. A number of other grids also had debonded portions of the wearing surface peeled off, which led to depressions on the surface. These areas could be easily seen in the visual pictures as well as the infrared color images. The photographs of these areas are shown in Figures 6.21 to 6.25. There were many visible cracks on the surface as a result of the debonding, and these could also be easily seen in the visual pictures as well as the infrared color images. Some of these cracks are shown in Figures 6.26 (a), (b) and (c).

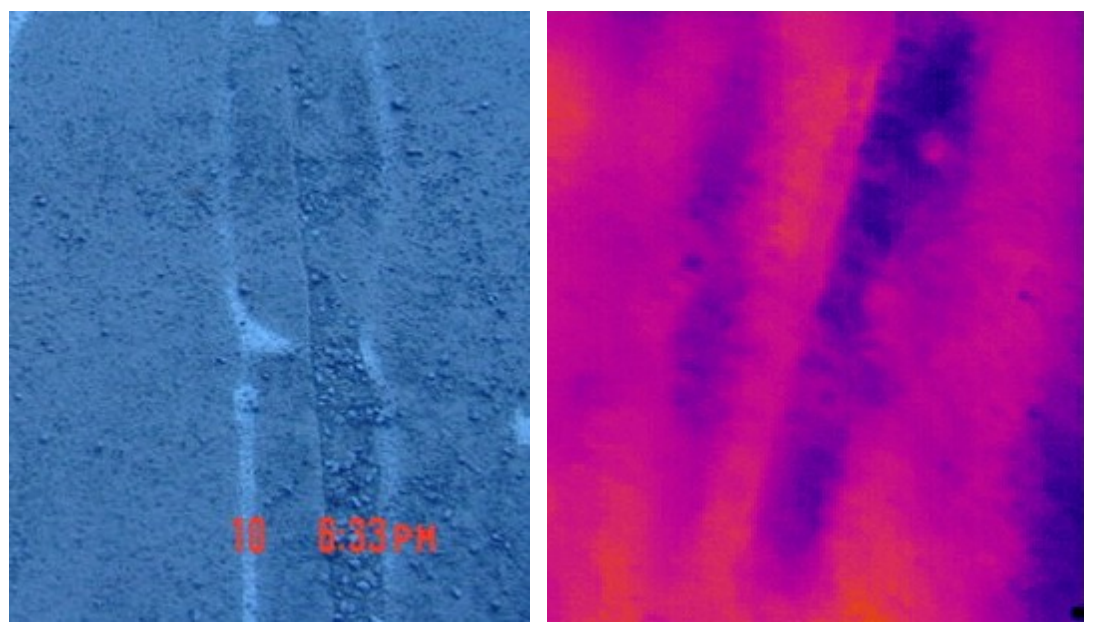

Figure 6.20. Photograph and infrared image of grid 27 where a large debonded portion of the wearing surface had peeled off and the surface depression is clearly visible 


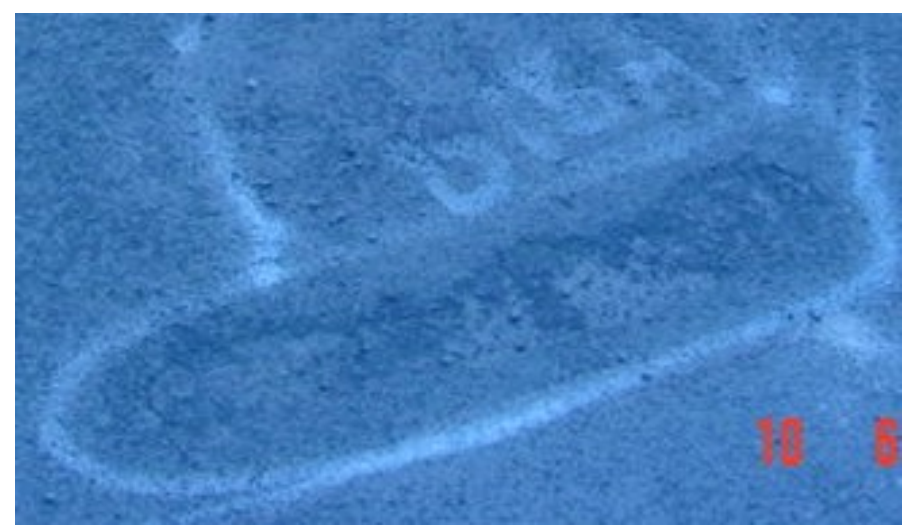

Figure 6.21. Photograph of grid 15 where a large debonded portion of the wearing surface had peeled off and the surface depression is clearly visible

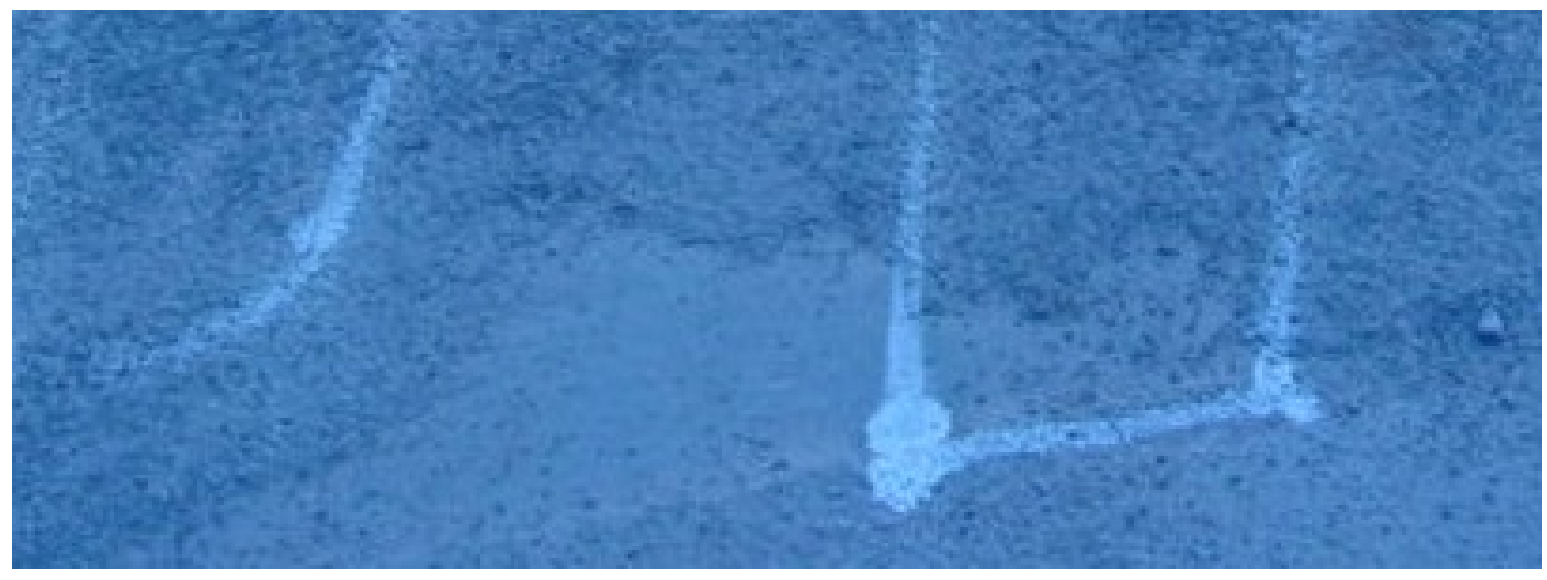

Figure 6.22. Photograph of grid 26 where a large debonded portion of the wearing surface had peeled off and the surface depression is clearly visible

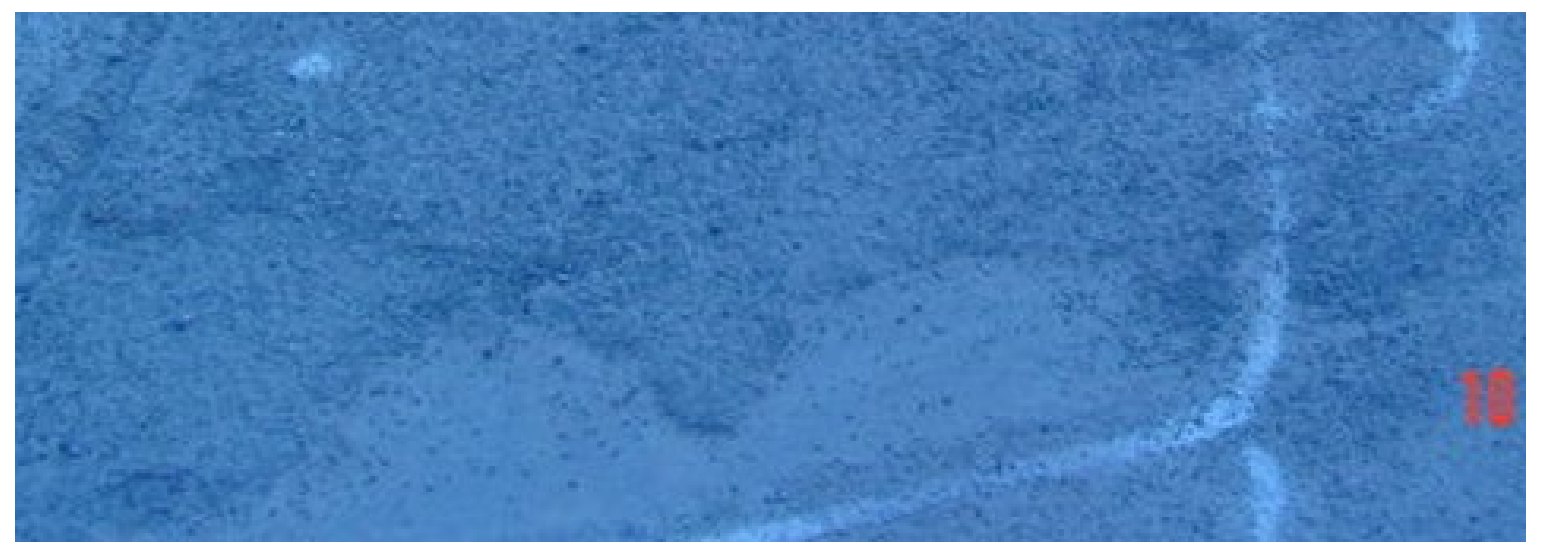

Figure 6.23. Photograph of grid 31 where a large debonded portion of the wearing surface had peeled off and the surface depression is clearly visible 

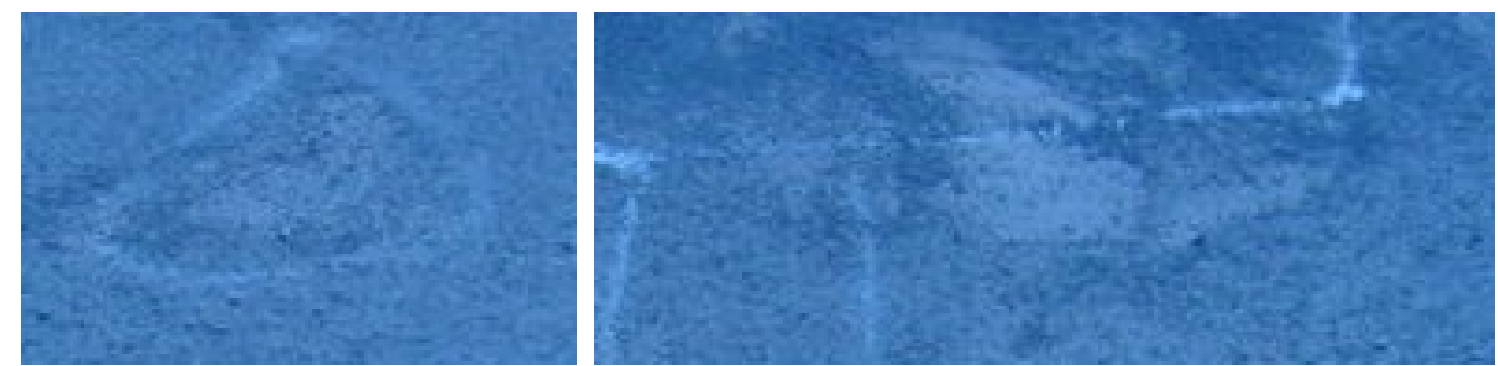

Figure 6.24. Photograph of grids 15 and 26 where relatively smaller debonded portions of the wearing surface had peeled off
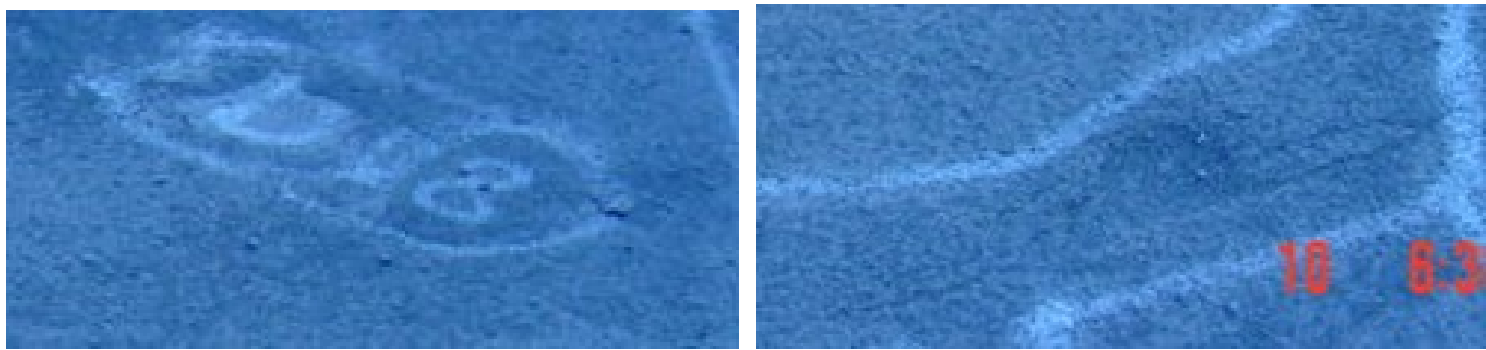

Figure 6.25. Photograph of grid 18 where relatively smaller debonded portions of the wearing surface had peeled off
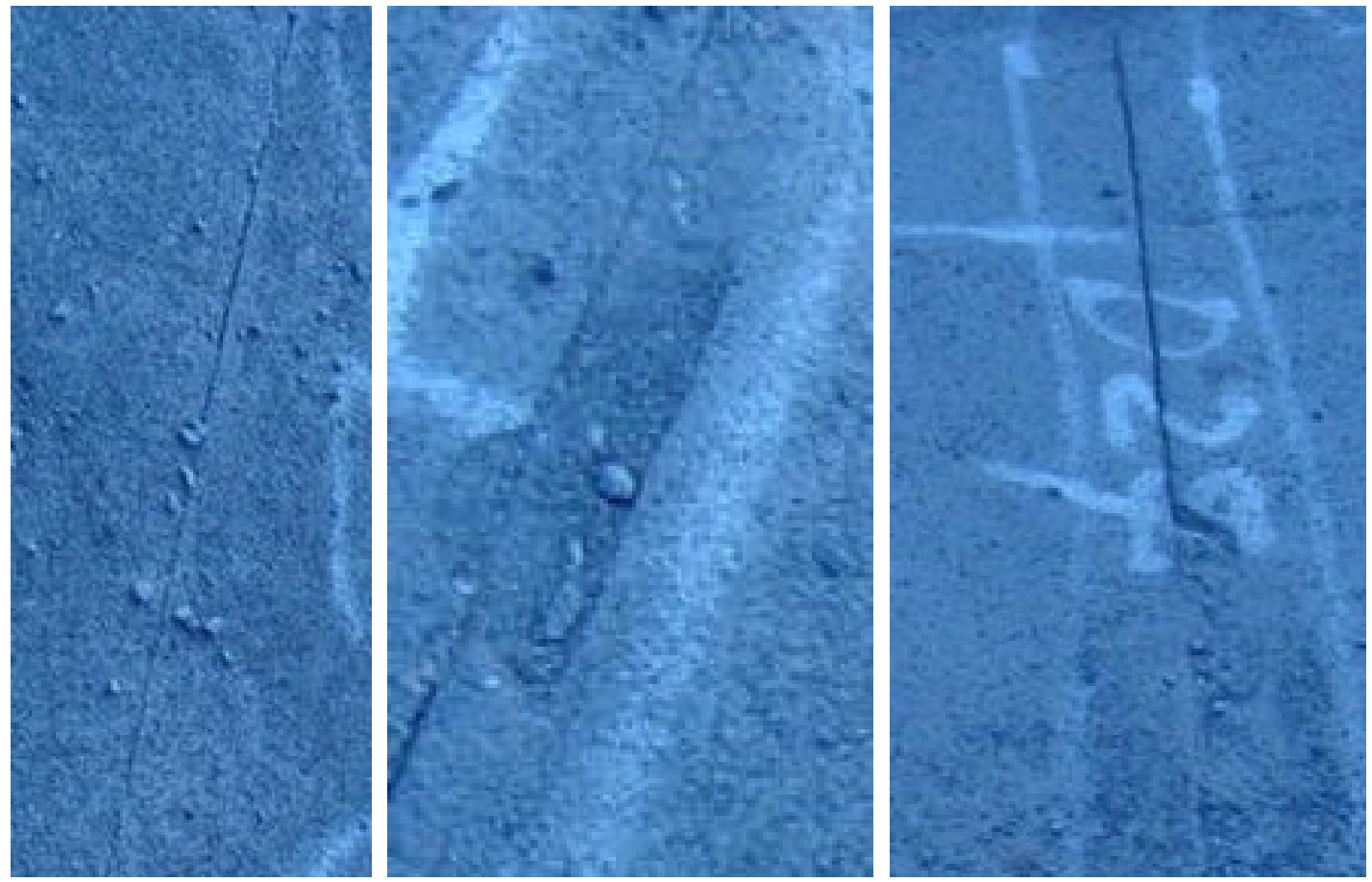

Figure 6.26. Photograph showing surface cracks resulting from debonds in portions of

(a) grid 20 (b) grid 22 (c) grid 27 
Portions of the grids $(1,8,9,16,17,24,25$ and 32) that were located adjacent to the guard rail (on the same lane) were under shadows of the guard rail. The infrared images of these grids revealed areas with lower temperature that were caused due to the shadow. Figure 6.27 shows the infrared image of one of these grids. The shadow of the guard rail is seen as an area with lower temperature (represented by the darker red-violet areas). These areas should not be misinterpreted as debonded areas. Many grids had loose gravel on the surface that had separated from the polymer concrete overlay. There were also many dirt particles on the surface of the deck. The infrared images of such loose gravels and dirt particles are shown in Figures 6.28 (a) and (b). Proper care was taken when analyzing the infrared images to avoid erroneous classification of the areas under the shadows of guard rail and areas with loose gravel/dirt as debonded areas.
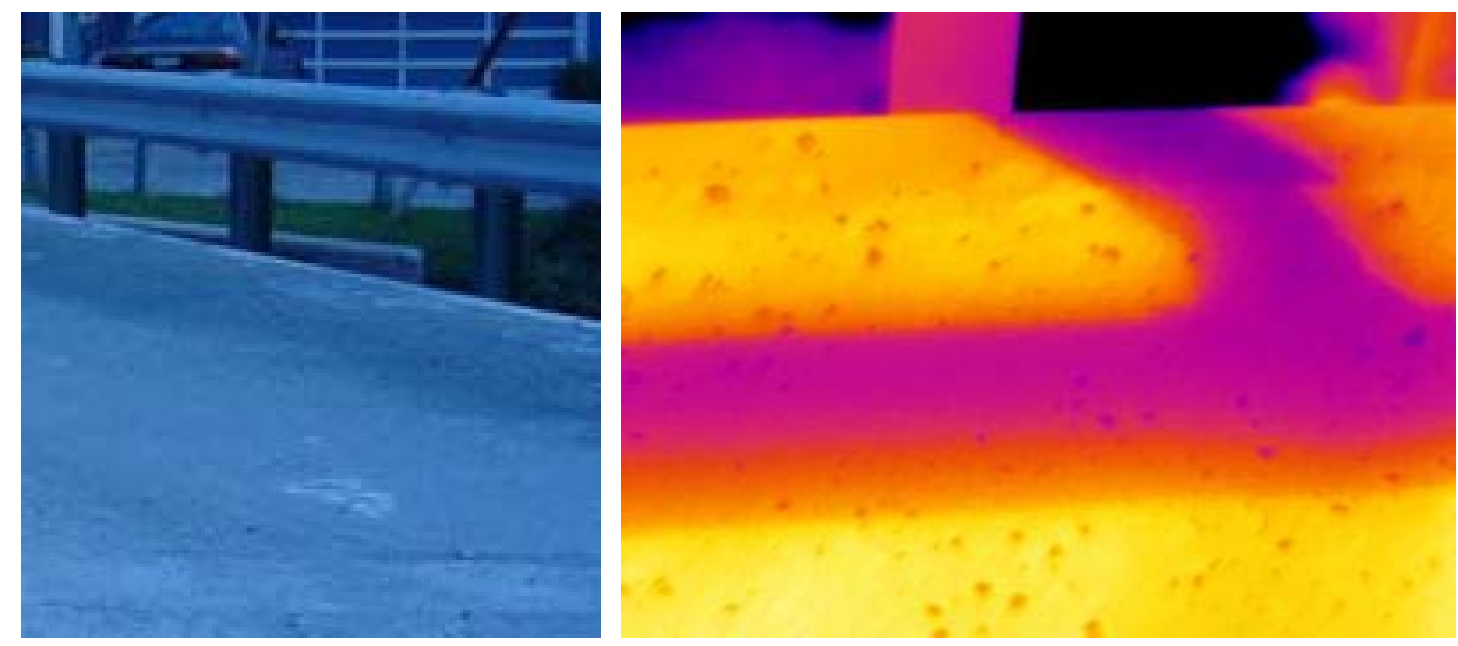

Figure 6.27. (a) Photograph of the guard rail area (b) Infrared image showing the shadow of the guard rail
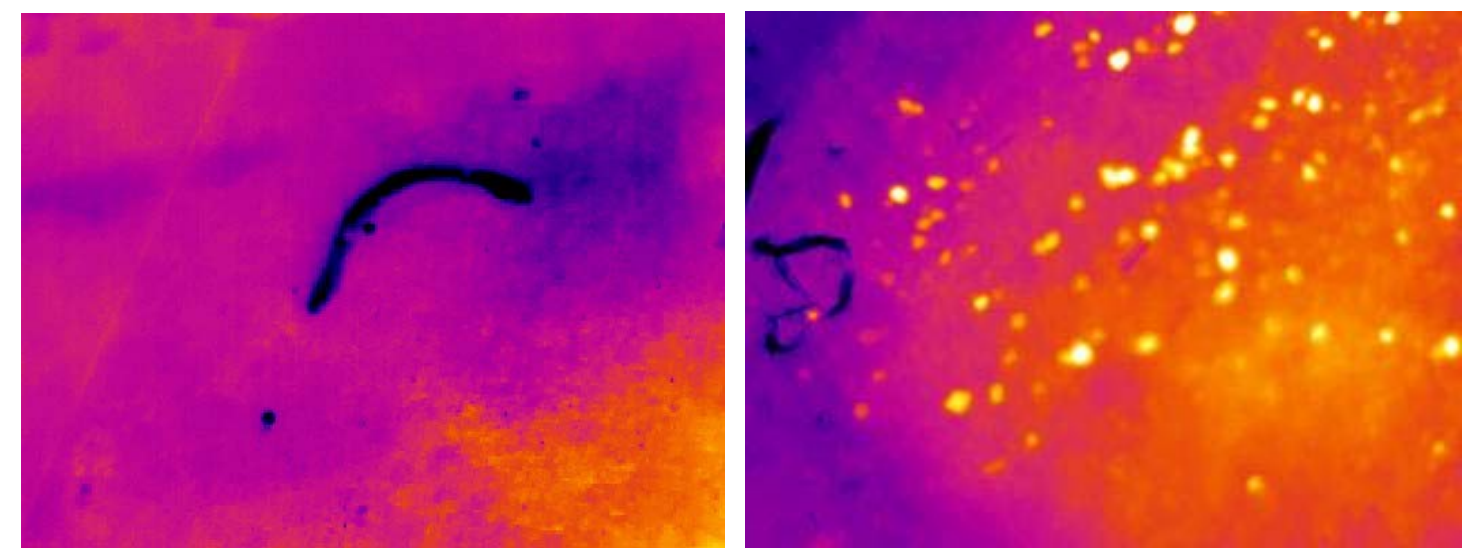

Figure 6.28. (a) Infrared image showing dirt on the surface (b) Infrared image showing dirt and loose gravel 


\subsection{CONCLUSIONS}

The infrared technique has been successful in detecting the subsurface debonds (air gaps) between the wearing surface and the underlying deck. By analyzing the infrared images obtained from the FRP bridge deck surface, it was concluded that grids 15 to 32 had many debonds, which also appeared as peeled off surface areas and cracks at several locations. The grids 1 to 14 had relatively few debonds. Based on the size and location of the subsurface and surface defects, it could be concluded that approximately two-thirds of the deck had defective areas. 


\section{Chapter 7 \\ CONCLUSIONS AND RECOMMENDATIONS}

\subsection{CONCLUSIONS}

\subsubsection{Literature Review}

From the literature review in Chapter 2, the following observations were made:

- Infrared thermography technique has detected air-filled delaminations in concrete bridge decks and also in concrete decks overlaid with asphalt (Section 2.2). But the presence of subsurface moisture and asphalt overlay (> 2” or 51mm thickness) adversely affected the infrared images. On the other hand, Ground Penetrating Radar (GPR) technique could detect the presence of moisture and chloride content in such decks. Therefore, best predictions of a deteriorated deck area can be obtained by combining the results of both GPR and infrared thermography techniques.

- Subsurface delaminations (plan sizes 2" x 2" and 3” x 3”) in both the unpainted and painted FRP box-sections were clearly visible in the thermal images. Delaminations present between the flanges of two adjacent bridge deck sections could not be detected. However, debonds with plan sizes of 3" x 3” (76mm x 76mm) and 2” x 2" (51mm x 51mm) with 1/16” (1.6mm) thickness placed between the 3/8” (9.5mm) thick wearing surface and the FRP bridge deck surface were easily detectable (Section 2.3).

- Laboratory tests conducted on the FRP bridge deck specimens (Section 2.4) showed that infrared thermography could not detect the duct tape in between the wearing surface and the bridge deck. Air-filled debond of 0.05” $(1.27 \mathrm{~mm})$ thickness under a 3/8” (9.5mm) thick wearing surface was detectable by infrared thermography. From the field tests conducted on two FRP bridge decks, it was concluded that thermal contrasts could also result from surface anomalies, shadows and oil spills. Care must be exercised while interpreting such results.

- Infrared imaging can be used for monitoring the health of FRP decks with disbonds. Surface anomalies caused due to stains and non-uniform wear can complicate image interpretation. Presence of moisture in a disbond can cause its size to be underestimated (Section 2.5). 
- The defect depth from the surface of the structure could be determined in aerospace composites using its thermal response and data inversion procedure (Section 2.6).

\subsubsection{Laboratory Experiments and Analysis}

Based on the laboratory experiments, the following conclusions were drawn:

- From the laboratory experiments conducted on FRP bridge decks with 3/8" thick wearing surface, it was concluded that debond as small as $1 / 2$ " $\times 1 / 2$ " $(12.7 \mathrm{~mm} \times$ $12.7 \mathrm{~mm})$ and thickness $1 / 16$ ” $(1.6 \mathrm{~mm})$ could be detected using the digital infrared technique. The debond could be detected with both the quartz heater and heating blanket as heat sources.

- Delaminations as small as 1" x 1" (25mm x 25mm) and thickness of 1/16" (1.6mm) that were embedded at the flange-flange junction of the FRP deck (with no wearing surface) were detected using digital infrared thermography by using the quartz heater as the heating source.

- The infrared image for a 3" x 3" x 1/16" (76mm x 76mm x 1.6mm) delamination created at the flange-flange junction of an FRP deck with 3/8” (9.5mm) thick wearing surface did not show a very prominent boundary of the delamination. However the infrared image could still confirm the presence of a subsurface delamination.

- It is clear from the above mentioned experimental conclusions, that the digital infrared thermographic method has satisfied the available standards for inspection method used for detecting delaminations in FRP systems, which states that the method should be capable of detecting delamination of $2 \mathrm{in}^{2}\left(1300 \mathrm{~mm}^{2}\right)$ or greater (as per ACI 440.2R 2002). The infrared images can be used to estimate the spatial extent of the subsurface defects, which is important for the rehabilitation decisions. For example, Section 6.2.3 of ACI 440.2R 2002, states acceptance guidelines as: delaminations less than $2 \mathrm{in}^{2}\left(1300 \mathrm{~mm}^{2}\right)$ are permissible as long as the delaminated area is less than $5 \%$ of the total laminate area and there are no more than 10 such delaminations per $10 \mathrm{ft}^{2}\left(1 \mathrm{~m}^{2}\right)$; and larger delaminations, greater than $25 \mathrm{in}^{2}$ $\left(16,000 \mathrm{~mm}^{2}\right)$, should be repaired. It should be noted that the above guidelines are for concrete structures strengthened using externally bonded FRP systems, and currently no guidelines exist for FRP decks. 
- The effect of water-filled debonds on the infrared images was investigated. The infrared technique could detect the presence of water between the wearing surface layer and the underlying deck. These water-filled debonds were found to result in lower surface temperatures compared to the surrounding defect-free areas, whereas air-filled debonds resulted in higher surface temperature as mentioned earlier. This is because water has a higher thermal conductivity value when compared to air. Also, water has a tendency to absorb more heat during the heating cycle and the heating process is slower for water than for air or composite. This is because water has a higher specific heat value.

- From the infrared tests conducted using solar radiation as the heat source, it was concluded that the debonds between the wearing surface and the underlying FRP deck, and delaminations at the flange-flange junction of an FRP deck without wearing surface, could be detected. Though the delamination within the flange of an FRP deck overlaid with wearing surface showed some temperature differentials in the infrared images, its boundary could not be very clearly detected.

- Surface temperature-time curves were established for debonds and delaminations of different sizes and thicknesses. When quartz heater was used, the image with best contrast between the defective and defect-free areas was obtained almost immediately after removing the heat source. This was the case for the debonds under the wearing surface and also for the delaminations within the flange-flange junction of an FRP deck with wearing surface.

- The effect of distance on the detectability of the debonds (between wearing surface and FRP deck) and delaminations (at flange-flange junction of FRP deck without wearing surface) was explored. A 1" x 1" x 1/16" (25mm x 25mm x 1.6mm) debond and 1" x 1" x 1/16" (25mm x 25mm x 1.6mm) delamination could be detected at a distance of $6 \mathrm{~m}$ successfully by the digital infrared camera. However, a $1 / 2$ ” $\mathrm{x} 1 / 2$ ” $\mathrm{x}$ $1 / 16$ " $(12.7 \mathrm{~mm} \times 12.7 \mathrm{~mm} \times 1.6 \mathrm{~mm})$ debond could not be very clearly seen in the infrared image taken from a distance of $6 \mathrm{~m}$. These limits are tied to the pixel dimensions of the infrared camera (Section 4.9).

- From the fatigue tests conducted on FRP decks with wearing surface and with embedded debonds of various sizes, it was observed through infrared thermography 
that some of the debonds that were located directly below the loading plates grew in size. The other debonds (away from the loading plate) did not grow in size.

- Infrared images of debonds and delaminations present in FRP decks subjected to accelerated aging (kept immersed in acidic solution for 6 months and kept under freeze-thaw conditions for six cycles) did not show any difference in the defect sizes before and after aging. These aging tests will be continued for the next several months as a part of another extended study.

- Use of negative heat sources (cooling) was explored. Infrared images detected the temperature differentials for the 2" x 2" x 1/16” (51mm x 51mm x 1.6mm) debond when liquid $\mathrm{CO}_{2}$ was used as the cooling source. Cold water (subsequent to solar heating) when used as the cooling source resulted in infrared images showing measurable surface temperature differentials for the 3" x 3" x 1/16” (76mm x 76mm x $1.6 \mathrm{~mm}$ ) debond.

- Infrared thermography could detect debonds as small as 2” x 2” and 1/16” (51mm x $51 \mathrm{~mm} \times 1.6 \mathrm{~mm}$ ) thickness present at the steel-concrete interface (under $1 / 2$ " thick steel jacket). Debonds of sizes 1" x 1" and 1/2” x 1/2” (both of thickness 1/16”) could not be detected even after heating the specimen for a very high temperature. The sizes of these debonds were too small to be located underneath a 1/2” thick steel jacket.

- Infrared technique detected debonds present in-between FRP layer and underlying wood in the wrapped wooden ties.

- The threshold value for the thermal contrast parameter (temperature difference between defective and defect-free areas divided by the temperature of the defect-free area) was established to be $1 / 10$. Defects with contrast value greater than $1 / 10$ are easily detectable by looking at the infrared images.

\subsubsection{Field Testing and Evaluation}

From the field testing and evaluation of the FRP wrapped timber railroad components the following observations were made:

- Digital infrared images gave more obvious and well defined location of the debonds when compared to the non digital images. Also, tap testing did not reveal many debonds that were detected using infrared thermography. 
- Summer 2001 infrared tests, conducted during a prior study, had revealed that the GFRP wrapped timber components did not have any debonds. However, this study revealed some new debonds during summer 2002 testing and the number had increased in summer 2003.

- The pile cap that had been rehabilitated during summer 2002 did not have significant debonds and the FRP wrap was properly bonded to the underlying timber member.

- The above tests conducted over a period of three years have shown that infrared thermography has been successful in monitoring progressive growth of debonds and providing useful information for maintaining quality control of the GFRP wrapping.

From the field testing of the La Chein FRP bridge deck the following observations were made:

- The infrared technique has been successful in detecting the subsurface debonds or air gaps between the wearing surface and the underlying deck.

- Tap testing is not a reliable technique for detecting debonds.

- Based on the size and location of the subsurface and surface defects, it could be concluded that approximately two-thirds of the deck had defective areas.

- Proper care should be taken when analyzing the infrared images to avoid erroneous classification of the areas under the shadows of guardrail and areas with loose gravel/dirt to avoid misclassifying them as debonded areas.

\subsection{RECOMMENDATIONS FOR FUTURE RESEARCH}

Several recommendations can be made for the detection of subsurface defects in bridge components using digital infrared thermography.

- Detectability of delaminations with smaller sizes and thickness present in the flangeflange junction of an FRP deck with wearing surface layer on the top surface need to be investigated.

- The detectability of water-filled delaminations within the flange-flange junction of an FRP deck should be evaluated. 
- Use of other cooling sources like dry ice need to explored, as it may provide sustained cooling over longer duration (when compared to liquid $\mathrm{CO}_{2}$ and cold water) in order to generate significant thermal gradient through the thickness of the FRP deck.

- The application of heat underneath the top flanges (or bottom flanges) so that heat flows in the reverse direction (towards the top surface) could be carried out by blowing steam or hot air. The detectability of debonds and delaminations using this technique should be studied.

- Advanced image processing techniques (including background noise filtering and neural-fuzzy algorithms) should be studied and used to produce infrared images with prominent boundaries in case of delaminations that are difficult to detect such as the one at the flange-flange junction of an FRP deck with 3/8” $(9.5 \mathrm{~mm})$ wearing surface layer. Use of such advanced techniques could pave the way for automated defect identification in FRP bridge decks using digital infrared thermography.

- Heat transfer finite element modeling should be used to study the effect of varying debond/delamination thicknesses at different depths, and determine the effect of applied heat transfer rate so as to establish minimum thresholds for heat transfer rate and thermal gradient for defect detection using infrared thermography. 


\section{REFERENCES}

ACI 440.2R-02 (2002). Guide for the Design and Construction of Externally Bonded FRP Systems for Strengthening Concrete Structures, American Concrete Institute, Farmington Hills, MI.

Adams, P.B. (1984), "Glass Corrosion, A Record of the Past? A Predictor of the Future?.” Journal of non-crystalline solids, 67, 193-205.

Alqennah, H. (2000). "Detection of subsurface anomalies in composite bridge decks using infrared thermography.” MS Thesis, Department of Civil and Environmental Engineering, West Virginia University, Morgantown, WV.

Bangalore, G. S. (2002). “Nondestructive evaluation of FRP composite members using infrared thermography." MS Thesis, Department of Civil and Environmental Engineering, West Virginia University, Morgantown, WV.

Bridge technology 2003 - http://www.fhwa.dot.gov/bridge/index.htm

Dunker, K. F., and Rabbat B. G. (1990). “Highway Bridge Type And Performance Patterns.” Journal of Performance of Constructed Facilities”, 4 (3), 161-173.

Favro, L. D., Xiaoyan, H., Kuo, P. K., and Thomas, R. L. (1996). Thermosense XVIII, Proceedings of SPIE, 2766, D.D. Burleigh, J. W. M. Spicer eds., SPIE, Bellingham, 236.

FRA Progress report $-2^{\text {nd }}$ and $3^{\text {rd }}$ Quarterly Progress Reports for the Fiber Reinforced Polymer Composites Used to Repair and Rehabilitate Wood Rail Road Bridges - Phase II project for the period July 16 - December 15, 2002

FSI FLIR SYSTEMS (1994). Prism Single Point INFRARED CAMERA OPERATOR'S MANUAL, Revision 0, May. 
FLIR SYSTEMS (2002a). ThermaCAMTM S60 Operator's Manual, Revision A, 14 June.

FLIR SYSTEMS (2002b). ThermaCAM ${ }^{\mathrm{TM}}$ Researcher Operating Manual, Version A.

Halabe, U. B., Bangalore, G., GangaRao, H. V. S., and Klinkhachorn, P. (2002). "Infrared Scanning of FRP Composite Bridge Members," Proceedings of the TwentyNinth Annual Review of Progress in Quantitative Nondestructive Evaluation, 22, Bellingham, WA, July 14-19, 1003-1010.

Halabe, U. B., AlQennah, H., G., GangaRao, H. V. S., and Klinkhachorn, P., and Sazonov, E. S. (2001). "Nondestructive evaluation of FRP composite bridge components using infrared thermography," Proceedings of the Twenty-Eighth Annual Review of Progress in Quantitative Nondestructive Evaluation, 21B, Brunswick, Maine, July 29 August 3, 1303-1309.

Halabe, U. B., Petro, S. H., and GangaRao, H. V. S. (1995). Nondestructive Evaluation Methods for Highway Bridge Supestructures. Report No. CFC 95-215, Constructed Facilities Center, West Virginia University, Morgantown, WV, July, 161-176.

Halabe, U. B., and Maser, K. R. (1986). Thermal Modelling of a Leaky Roof. MIT CCRE Technical Note 86-4, Center for Construction Research and Education, Department of Civil and Environmental Engineering, Massachusetts Institute of Technology, Cambridge, MA.

Hawkins, G. F., Johnson, E. C., and Nokes, J. P. (1999). “Detecting Manufacturing Flaws in Composite Retrofits.” Nondestructive Evaluation of Bridges and Highways III, Proceedings of SPIE, 3578, Newport Beach, CA, March 3-5, 97-104. 
Kaplan, H. (1999). Practical Applications of Infrared Thermal Sensors and Imaging Equipment, SPIE -The International Society for Optical Engineering, Bellingham, Washington, U.S.A.

Karpez, J. C., Balages, D., Doem, A., and Lepoutre, F. (1994). Advances in Signal Processing for NDE of Materials, X. Maldague ed., NATO ASI Series, Series E, 303.

Litherland, K. L., Oakley, D. R., and Proctor, B. A. (1981). "The Use of Accelerated Ageing Procedures to Predict the Long Term Strength of GRC Composites." Cement and Concrete Research, 11, 455-466.

Maldague, X. (1993). Nondestructive Evaluation of Materials by Infrared Thermography, Springer-Verlag, London.

Maldague, X. (2000). "Applications of infrared thermography in nondestructive evaluation.” Trends in Optical Nondestructive Testing (invited chapter), Pramod Rastogi ed., 591- 609. (paper also available at http://www.ndt.net/v06n04.htm).

Maldague, X. P. V., and Moore, P. O. (2001). "Infrared and Thermal Testing." Nondestructive Testing Handbook. American Society for Nondestructive Testing, 3.

Manning, D. G., and Holt, F. B. (1980). "Detecting deterioration in concrete bridge decks," Concrete International, 34-41.

Manning, D. G., and Holt, F. B. (1983). "Detecting deterioration in asphalt-covered bridge decks," Transportation Research Records, 899, 10-20.

Maser, K. R., and Roddis, W. M. K. (1990). "Principles of Thermography and Radar For Bridge Deck Assessment.” Journal of Transportation Engineering, 116(5), SeptemberOctober. 
Miceli, M., Horne, M. R., and Duke, J. C. (2001). "Health monitoring of FRP bridge decks.” Advanced Nondestructive Evaluation for Structural and Biological Health Monitoring, Proceedings of SPIE, 4335, March 6-8, 100-105.

National Bridge Inventory 2003 - http://www.fhwa.dot.gov/bridge/nbi.htm

Plotnikov, Y.A., and Winfree, W.P. (1999). “Temporal treatment of thermal response for defect depth estimation.” Review of Progress in Quantitative Nondestructive Evaluation, , AIP Conference Proceedings 509, 19A, Montréal, Canada, 587-594.

Reynolds, W.N., and Wells, G.M. (1984). Video-compatible thermography. British Journal of NDT, January, 40-44.

Shekar, V., Petro, S, H., and GangaRao, H. V. S. (2002). "Construction of FiberReinforced Plastic Modular Decks for Highway Bridges.” Transportation Research Record, 1813, Washington, D.C.

Steele III, W. E. (2001). "Detection Of Subsurface Anomalies In Fiber Reinforced Polymer (FRP) Wrapped Timber Bridge Components Using Infrared Thermography.” MS Thesis, Department of Civil and Environmental Engineering, West Virginia University, Morgantown, WV.

Therkeld, J. L. (1970). Thermal Environmental Engineering, Second edition, PrenticeHall., Englewood Cliffs, NJ.

Touloukian, Y. S., and DeWitt, D. P. (1970). Thermal Radiative Properties. Thermophysical Properties of Matter, 7, IFI/Plenum, New York, Washington.

Tretout, H. (1987). “Applications industrielle de la thermographie infrarouge au controle non destructif de pieces en materiaux composites.” Rev. Gen. Therm. Fr., 301, 47-53 (in French). 
Vavilov (1980). "Infra-red non-destructive testing of bonded structures: aspects of theory and practice.” British Journal of NDT, July, 175-183.

Vijay, P. V., and GangaRao, H. V. S. (1999). “Accelerated and Natural Weathering of Glass Fiber Reinforced Plastic Bars.” Fourth International Symposium on Fiber Reinforced Polymer Reniforcement for Reinforced Concrete Structures, SP-188, ACI, Farmington Hills, MI, 605-614.

Weil, G.J. (1991). Infrared Thermographic techniques. CRC Handbook on Nondestructive Testing edited by Malhotra, V.M., and Carino, N.J. Boca Raton, FL. pp.305-316. 